LBL --32515

DE92 041173

\title{
REACTION DYNAMICS AND PHOTOCHEMISTRY OF DIVALENT SYSTEMS
}

\author{
H. Floyd Davis \\ Department of Chemistry \\ University of California \\ and \\ Chemical Sciences Division \\ Lawrence Berkeley Laboratory \\ Berkeley, CA 94720 USA
}

May 1992

This work was supported by the Director, Office of Energy Research, Office of Basic Energy Sciences, Chemical Sciences Division, of the U.S. Department of Energy under Contrast No. DE-AC03-76SF00098. 


\section{TABLE OF CONTENTS}

\section{Chapter 1: Reactions of Ground State and Electronically}

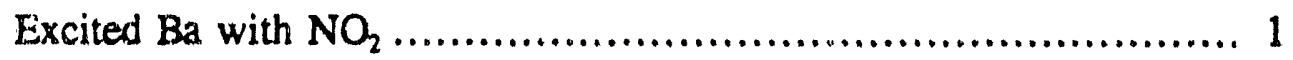

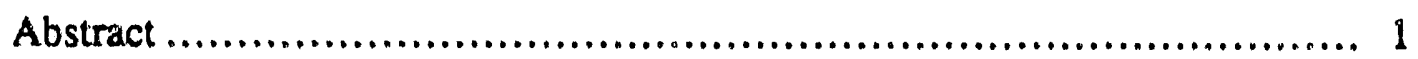

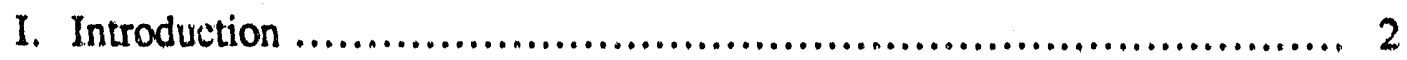

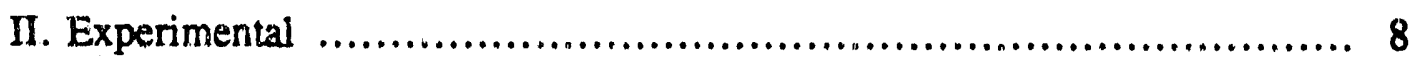

iII. Results and Analysis

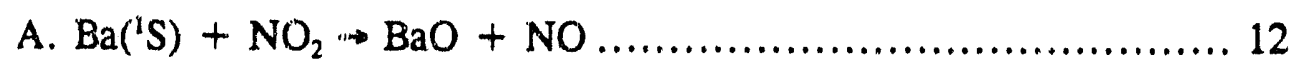

B. $\mathrm{Ba}\left({ }^{1,3} \mathrm{D},{ }^{\mathrm{j}} \mathrm{P}\right)+\mathrm{NO}_{2} \rightarrow \mathrm{BaO}+\mathrm{NO} \ldots \ldots \ldots \ldots \ldots \ldots \ldots \ldots \ldots \ldots \ldots . \ldots . \ldots \ldots$

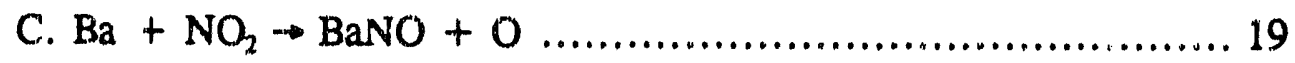

IV. Discussion

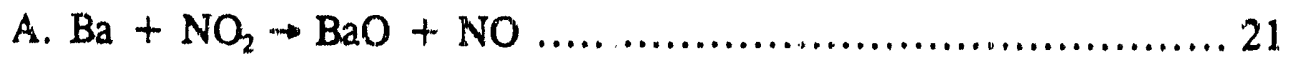

i. Comparison to Past Work ................................ 21

ii. Mechanism for $\mathrm{Ba}+\mathrm{NO}_{2} \rightarrow \mathrm{BaO}+\mathrm{NO} \ldots \ldots \ldots \ldots \ldots \ldots . . . . .23$

B. Source of the Forward Scattered $\mathrm{BaO}$ Channel .................... 27

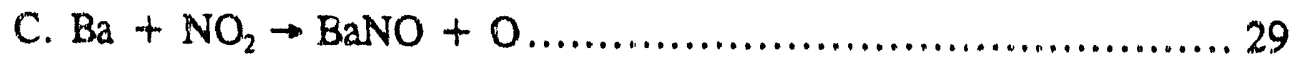

i. The $\mathrm{Ba}\left({ }^{1} \mathrm{~S}\right)$ Reaction Mechanism ........................ 29

ii. The Effect of Electronic Excitation ..................... 31

iii. The Dissociation Energy of BaNO .................... 22

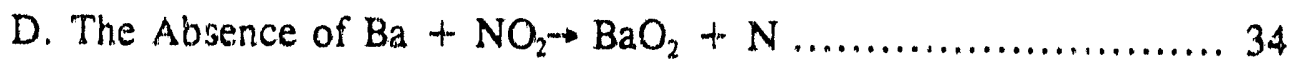

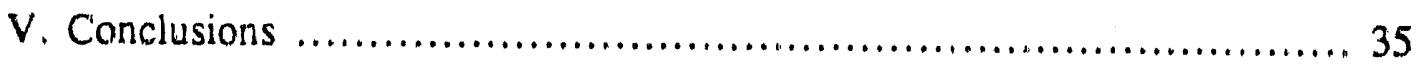




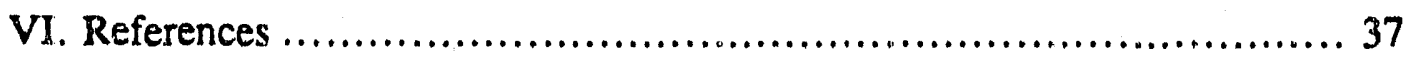

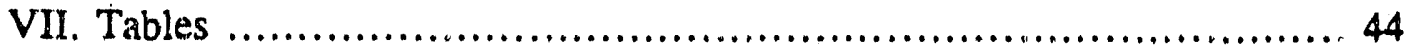

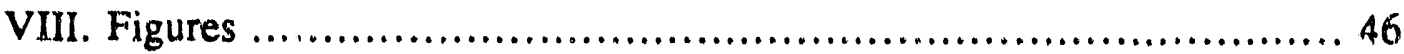

Chapter 2: State Specific Reactions of $\mathrm{Ba}\left({ }^{1} \mathrm{~S}_{\mathrm{a}}\right)$ and $\mathrm{Ba}\left({ }^{1} \mathrm{D}_{2}\right)$

With Water and its Alkyl Derivatives ............................... 66

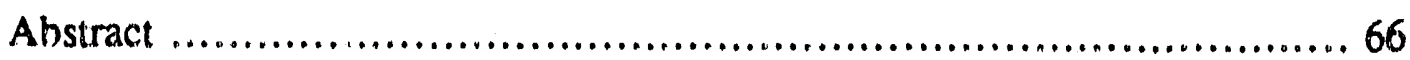

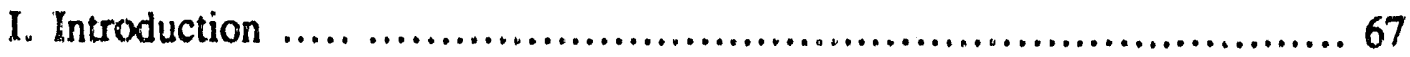

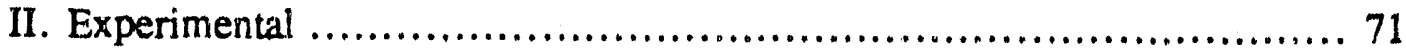

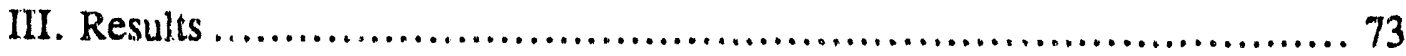

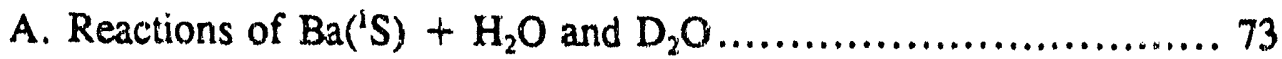

B. Reactions of $\mathrm{Ba}\left({ }^{\prime} \mathrm{D}\right)+\mathrm{H}_{2} \mathrm{O}$ and $\mathrm{D}_{2} \mathrm{O} \ldots \ldots \ldots \ldots \ldots \ldots \ldots \ldots \ldots . \ldots 77$

C. Reactions of $\mathrm{Ba}\left({ }^{\prime} \mathrm{S}\right), \mathrm{Ba}\left({ }^{\prime} \mathrm{D}\right)$

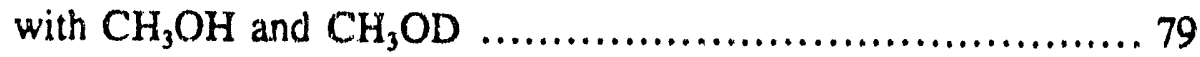

D. Collisions of $\mathrm{Ea}\left({ }^{\mathrm{l}} \mathrm{S}\right)$, ('D) with $\mathrm{CH}_{3} \mathrm{OCH}_{3} \ldots \ldots \ldots \ldots \ldots \ldots \ldots . \ldots 1$

E. Collisions with Allyl Alcohol and

t-Butyl Hydroperoxide ......................................... 81

IV. Discussion ........................................................ 82

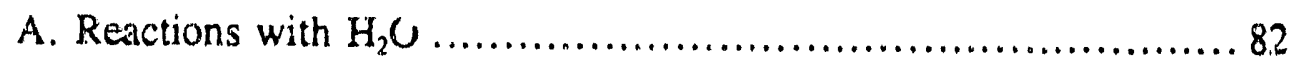

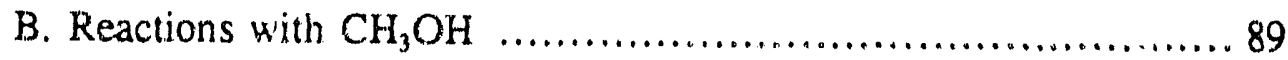

C. The effut of deuterium substitution and

collision energy on $\mathrm{Ba}\left({ }^{\prime} \mathrm{D}\right)$ Reactions 
D. Product Angular Distributions for the

radical channels

E. Comparison with dissociative electron

attachment experiments ........................................ 94

F. The Role of the Excited State in H-atom migration ............... 97

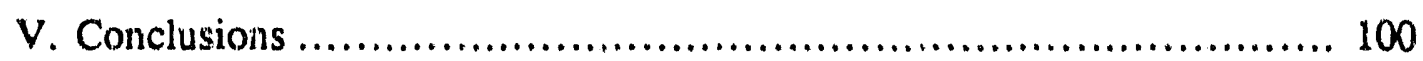

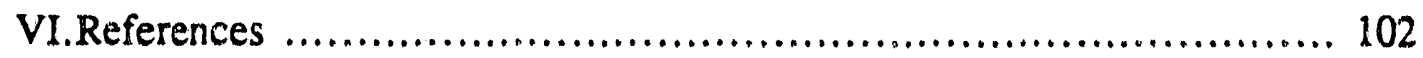

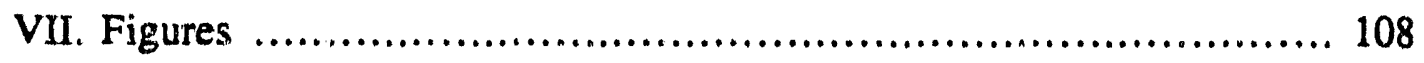

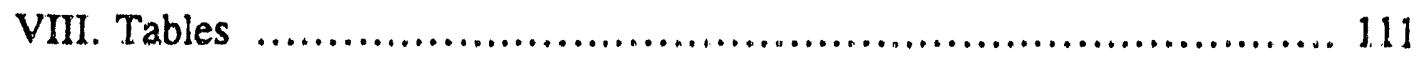

Chapter 3: Reactions of $\mathrm{Ba}$ atoms with Triatomic Oxidants:

$\mathrm{Ba}+\mathrm{ClO}_{2}$ and $\mathrm{O}_{3}$

Abstract

1. Introduction

II. Experimental

III. Results and Analysis

A. $\mathrm{Ba}+\mathrm{ClO}_{2} \rightarrow \mathrm{BaO}+\mathrm{ClO}$

B. $\mathrm{Ba}+\mathrm{ClO}_{2} \rightarrow \mathrm{BaCl}+\mathrm{O}_{2}$ 144

C. $\mathrm{Ba}+\mathrm{O}_{3} \rightarrow \mathrm{BaO}+\mathrm{O}_{2}$ 146

D. $\mathrm{Ba}+\mathrm{O}_{3} \rightarrow \mathrm{BaO}_{2}+\mathrm{O}$ 148

IV. Discussion 149

A. $\mathrm{Ba}+\mathrm{ClO}_{2}$ 149

b. $\mathrm{Ba}+\mathrm{O}_{3} \rightarrow \mathrm{BaO}+\mathrm{O}_{2}$ 154 


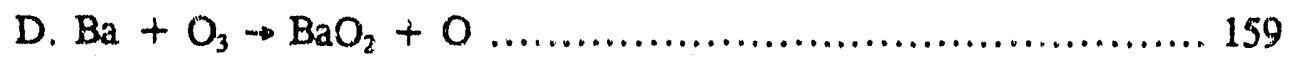

V. Conclusions .................................................... 166

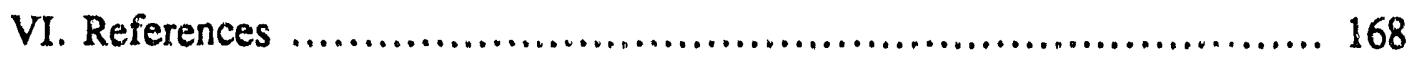

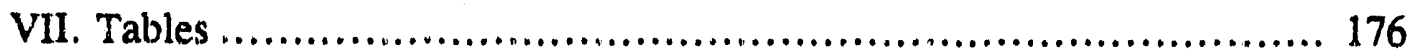

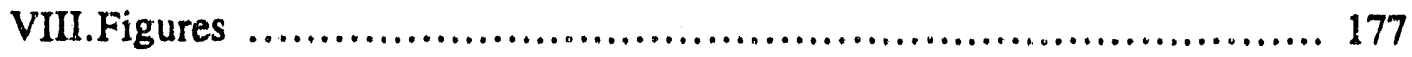

Chapter 4: Photodissociation Dynamics of the $\mathrm{NO}_{3}$ Radical ....................... 193

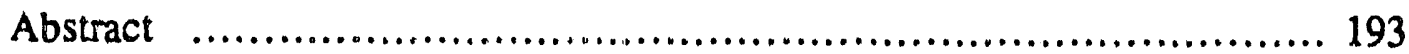

I. Introduction ..................................................... 194

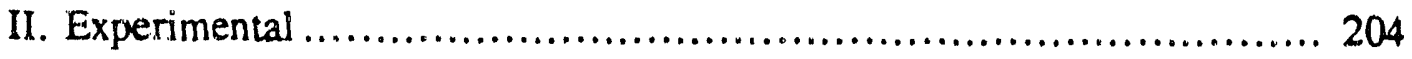

III. Results and Analysis .......................................... 212

A. Photodissociation at $590 \mathrm{~nm}$

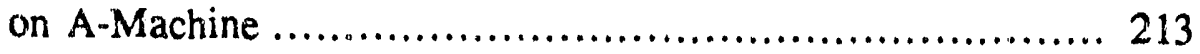

B. Wavelength Dependence

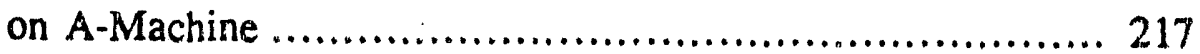

C. High Resolution Studies on

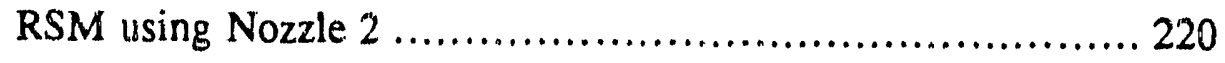

D. The $\mathrm{NO}_{2}+\mathrm{O}$ Translational Energy

Distributions above Threshold ................................. 221

E. Wavelength dependence of the

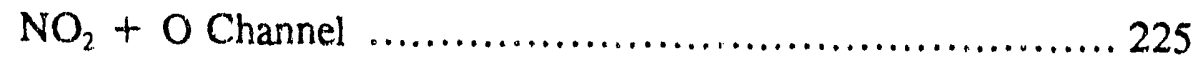

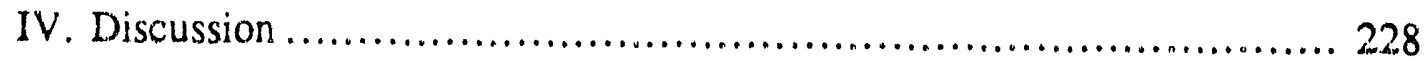

A. $\mathrm{NO}_{3}$ Photodissociation Wavelength Dependence ................ 228 


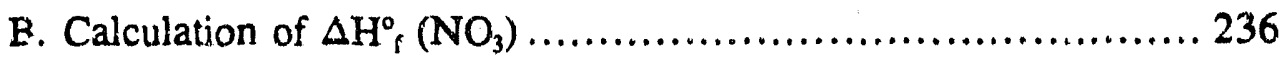

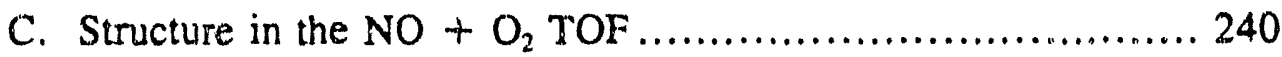

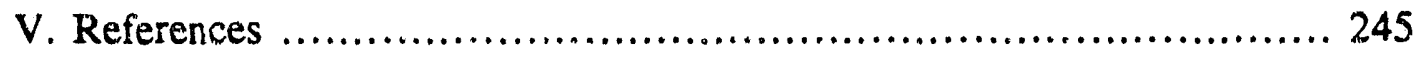

VI. Tabies ........................................................... 248

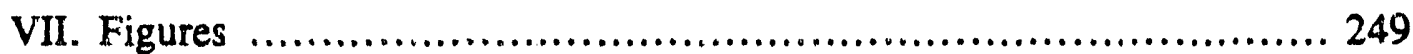

Chapter 5: Dynamics and Mode Specificity in OClO Photodissociation ............ 284

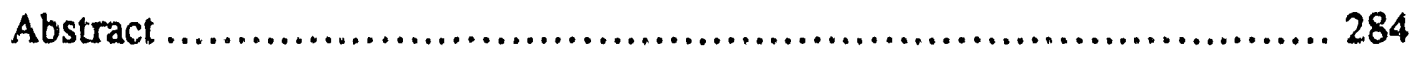

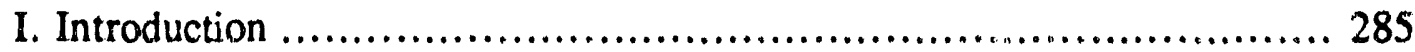

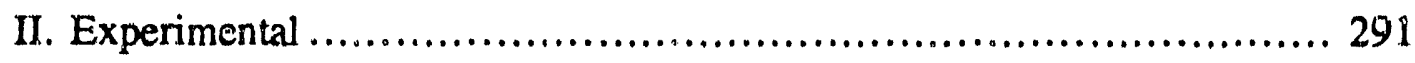

III. Results and Discussion ................................................ 292

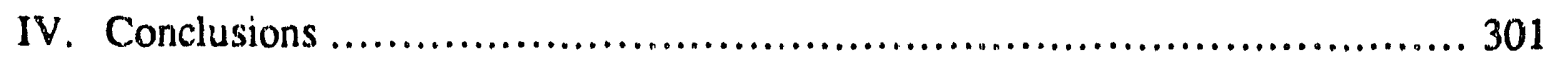

V. References............................................................. 302

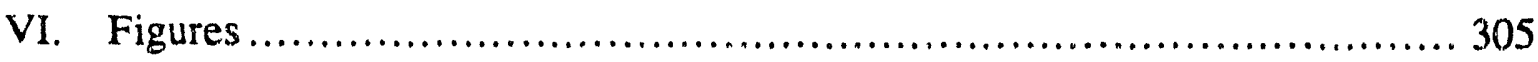




\section{ACKNOWLEDGEMENTS}

I am deeply indebted to Prof. Yuan T. Lee for giving me the freedom and inspiration to pursue a wide range of exciting experiments. His enthusiasm and devotion to science rubs off on everyone who works with him. He is one who has the remarkable gift to somehow always know just what atoms and molecules are doing.

I am grateful to Prof. John Hepburn for introducing me to the field of chemical dynamics. I not only benefitted tremendously from my year in his lab at Waterloo, but it was he who first suggested that the mighty group of Y.T. Lee might be a good place for me to do a Ph.D. My first taste of basic research came at the Notre Dame Radiation Laboratory as a University of Waterloo Co-op student. Dr. P.K. Das, and Profs. R.W. Fessenden, R.H. Schuler, and M.V. George all gave me scientific opportunities that undergraduates rarely get. It is their confidence in me that got me started, and I will always be grateful to them.

During my stay at Berkeley, Arthur Suits has been an outstanding collaborator as well as a good friend. His ability to see things through from beginning to completion is something 1 am only now beginning to grasp. His cool manner and rational way of thinking is something that I have certainly learned to appreciate. The work on $\mathrm{NO}_{3}$ was conducted in collaboration with Prof. H. S. Johnston and Bongsoo Kim. Although this project turned out to be considerably more difficult than originally planned, Prof. Johnston's patience, enthusiasm, and dedication to finding out the truth has been a great 
inspiration to me. Bongsoc Kim and I conducted the early series of experiments on the A-machine. His knowledge about $\mathrm{NO}_{3}$, both from an experimental and theoretical standpoint, was instrumental to our early successes. Mike Covinsky and I formulated the original ideas for the "next generation" atomic beam source. It was hearing about his earlier trials and tribulations with the old sodium source that led to the new design which was brought to fruition in collaboration with Arthur. In retrospect, it seems that nothing as complex as the Ba source should ever work so well from the start. It was the early discussions with Mike that led to a great design, and this helped pave our way to success. Mike's interest and amazing body of knowledge really helped me understand the intricacies of metal atoms and their reactions. Hongtou Hou is the newest member of the A-Team. He is certain to continue the productive pace during his tenure at Berkeley.

I am greatly indebted to James Chesko who was always able to keep the microvax going, even when all forces seem to be acting against it. Much of the contents of this thesis would not be where it is today if it weren't for James. In an earlier era, Pam Chu was in charge of the computers in the lab, and it was her hard work that kept things going. I thank her for her efforts. Albert Stolow's amazing body of knowledge from both a theoretical and experimental standpoint is quite an inspiration to me. I have always benefitted greatly from discussions with him and wish him good fortune at NRC in Ottawa. Marcus J.J. Vrakking has always provided an alternative and probably more rational way of looking at things. Discussions with Marc have always been profitable. He has also cheerfully and generously loaned me equipment from his lab, and has helped 
me out on a number of occasions. Although he doesn't always appreciate my humor, somehow I appreciate his. Jim Myers has also been a useful source of knowledge for me, particularly when it comes to computers. He has really excelled in computer programming. Everyone involved with CMLAB2 is truly grateful for his efforts in rewriting the program. This was a major effort and his contributions will benefit the group for many years to come. We expect that further efforts from both Jim Myers and John Price will allow us to keep pace with the rapidly advancing possibilities in the area of graphical user interface software. I am grateful to Evan Cromwell for his expert advice and assistance on the use of the 699 ring laser. His help was instrumental in our early efforts on the excited state $\mathrm{Ba}$ atom reactions.

In my earlier years in the group, I witnessed the dedicated efforts of some extremely talented people, and to this day and I have tried to follow their lead. Gil Nathanson and Bob Continetti exemplified the "Lee group dedication" that is so important when trying to get difficult experiments to work. I see that same spark in the newer students in the group. My advice to them is that even when things seem impossible, there is always a way, but in this business only careful planning and hard work will pay off in the end. I have always enjoyed talking with Jingsong Zhang and am impressed by his endless efforts to keep things going on the $35^{\prime \prime}$ machine-- the Lee group tradition lives on!

Ann Lawhead somehow keeps the group running smoothly, no doubt due to i.er vast experience with the LBL bureaucracy and amazingly efficient way of getting things done. She has shown me great kindness, and I am grateful to her. There are many 
other people, too numerous to list, both within the department, and at LBL who have been instrumental to our experimental successes over the years. In particular, the expert technical assistance from Harry Chiladakis is greatly appreciated, especially at 4:00 am. Bob Conroy in the sheet metal shop at LBL has proven that it is indeed possible to do some amazing things with molybdenum. I am grateful to him for many of his Herculean efforts in the early days of the $\mathrm{Ba}$ experiments. I also wish to thank everyone in the Chemistry machine shop for their expert assistance over the years. Above all, Hans is truly a "master machinist" and we are all thankful to him. George and Ron always managed to get those "rush" jobs done, even when it seemed like everyone else was trying to do the same.

It has truly been a pleasure helping Laura Smoliar get her machine up and running. Although she might not realize it, I too have learned a lot from this. I am also grateful to Laura for her kindness and thank her for her proofreading efforts. Kim Prather showed me some of the subtleties of the RSM, and has also proven to be a good friend. I wish her success at U.C. Riverside.

Finally, I wish to thank NSERC (Canada) for a 1967 Science and Engineering Fellowship. This work was supported by the Director, Office of Energy Research, Office of Basic Energy Sciences, Chemical Sciences Division of the U.S. Department of Energy under Contract No. DE-AC03-76SF00098. 


\title{
REACTION DYNAMICS AND PHOTOCHEMISTRY OF DIVALENT SYSTEMS
}

\author{
H. Floyd Davis
}

\begin{abstract}
This thesis presents the results of molecular beams studies of bimolecular and unimolecular reactions. The rich chemistry seen in these systems is a direct consequence of the divalent nature of barium and oxygen atoms.

Chapter 1 discusses the reaction $\mathrm{Ba}+\mathrm{NO}_{2}$. Formation of the dominant $\mathrm{BaO}\left({ }^{1} \Sigma\right)$ + NO products resulted primarily from decay of long-lived $\mathrm{Ba}^{+} \mathrm{NO}_{2}^{-}$collision complexes. Secondary mechanisms led to formation of forward scattered, internally excited $\mathrm{BaO}$, and $\mathrm{BaNO}+\mathrm{O}$. Our results indicate that $\mathrm{D}_{\mathrm{o}}(\mathrm{Ba}-\mathrm{NO})=65 \pm 20$ $\mathrm{kcal} / \mathrm{mol}$.

The reactions of ground state and electronically excited $\mathrm{Ba}$ with water and alcohols are examined in Chapter 2. Reaction of $\mathrm{Ba}\left({ }^{\prime} \mathrm{S}\right)+\mathrm{H}_{2} \mathrm{O}$ led to $\mathrm{BaO}+\mathrm{H}_{2}$, whereas excited state $\mathrm{Ba}\left({ }^{\mathrm{I}} \mathrm{D}\right)+\mathrm{H}_{2} \mathrm{O}$ reacted to form $\mathrm{BaOH}+\mathrm{H}$. Collisions between $\mathrm{Ba}$ and $\mathrm{CH}_{3} \mathrm{OH}$ led to $\mathrm{BaOCH}_{3}+\mathrm{H}$. The radical channels involve $\mathrm{H}$-atom migration, and are promoted by electronic excitation of the incident $\mathrm{Ba}$ atom.
\end{abstract}


In Chapter 3, the reactions of $\mathrm{Ba}(' \mathrm{~S})$ with $\mathrm{ClO}_{2}$ and $\mathrm{O}_{3}$ are discussed. Again, direct and complex mechanisms were observed. Formation of $\mathrm{BaCl}+\mathrm{O}_{2}$ from concerted decomposition of long-lived $\mathrm{Ba}^{+} \mathrm{ClO}_{2}{ }^{-}$collision complexes accounted for $-10 \%$ of the total reaction cross section. Although $\mathrm{Ba}+\mathrm{O}_{3} \rightarrow \mathrm{BaO}+\mathrm{O}_{2}$ occurs primarily by direct reaction mechanisms, the secondary channel $\mathrm{Ba}+\mathrm{O}_{3} \rightarrow \mathrm{BaO}_{2}+$ $\mathrm{O}$ involved decay of long lived $\mathrm{Ba}^{+} \mathrm{O}_{3}{ }^{-}$intermediates. We find that $\mathrm{D}_{0}\left(\mathrm{Ba}-\mathrm{O}_{2}\right)=120 \pm$ $20 \mathrm{kcal} / \mathrm{mol}$.

The photodissociation dynamics of $\mathrm{NO}_{3}$ is explored in chapter 4 . We confirm that visible excitation leads to formation of $\mathrm{NO}+\mathrm{O}_{2}$ and $\mathrm{NO}_{2}+0$. The wavelength dependence of the branching ratios is investigated. We find that $\mathrm{D}_{0}\left(\mathrm{O}-\mathrm{NO}_{2}\right)=48.55$ $\pm 0.16 \mathrm{kcal} / \mathrm{mole}$ and calculate $\Delta \mathrm{H}_{\mathrm{r}}\left(\mathrm{NO}_{3}\right)=17.75 \pm 0.24 \mathrm{kcal} / \mathrm{mole}(298 \mathrm{~K})$.

Chapter 5 discusses the photodissociation of OClO in a molecular beam. Although $\mathrm{ClO}\left({ }^{2} \mathrm{II}\right)+\mathrm{O}\left({ }^{3} \mathrm{P}\right)$ is dominant, we also observed formation of $\mathrm{Cl}\left({ }^{2} \mathrm{P}\right)+\mathrm{O}_{2}$. The yield reaches a maximum of $3.9 \pm 0.8 \%$ near $404 \mathrm{~nm}$. Mode specificity was seen in these branching ratios. The $\mathrm{Cl}+\mathrm{O}_{2}$ results from concerted unimolecular decomposition with a large release of product translational energy. 


\title{
CHAPTER 1
}

\section{Reactions of Ground State and Electronically Excited $\mathrm{Ba}$ with $\mathrm{NO}_{2}$}

\begin{abstract}
Angular and velocity distributions of the neutral products resulting from the reaction $\mathrm{Ba}+\mathrm{NO}_{2}$ were measured using the crossed molecular beams method. Despite a large reaction exosigicity ( $\Delta \mathrm{H}=-61 \mathrm{kcal} / \mathrm{mole})$, formation of the dominant ground state $\mathrm{BaO}\left({ }^{\prime} \Sigma\right)+\mathrm{NO}$ products results primarily from decay of long-lived $\mathrm{Ba}^{+} \mathrm{NO}_{2}$ collision complexes, even at incident collision energies as high as $59 \mathrm{kcai} /$ mole or with electronic excitation of the $\mathrm{Ba}$ atom. A large fraction of the reaction exoergicity is channeled into product translational energy. This rather unusual behavior results from a large exit potential energy barrier for decay of the initially formed singly ionic $\mathrm{Ba}^{+} \mathrm{NHO}_{2}$ intermediate to ground state doubly ionic $\mathrm{Ba}^{2+} \mathrm{O}^{2-}$. A secondary source of forward scattered, internally excited $\mathrm{BaO}$ results from a direct reaction without the involvernent of long-lived intermediates. An additional minor channel, formation of $\mathrm{BaNO}+\mathrm{O}$ is observed from ground state $\mathrm{Ba}+\mathrm{NO}_{2}$ at high collision energies by a direct reaction mechanism. Unlike the dominant $\mathrm{BaO}+\mathrm{NO}$ channel which involves harpooning at the first ionic-covalent curve crossing, formation of BaNO from reaction of ground state $\mathrm{Ba}$ likely results from the small range of collision geometries which are able to avoid long range electron transfer. The BaNO + O channel was enhanced substantially by electronic excitation of the incident barium atom. However, BaNO from reactions of electronically
\end{abstract}


excited Ba primarily resulted from decay of collision complexes, rather than from a direct mechanism.

\section{INTRODUCTION}

The early studies by Michael Poianyi and coworkers ${ }^{1,2}$ on the reactions of alkali metal atoms with halogen containing moiecules in diffusion flames initiated a field of research that has led to profound insight into the reactions of moriovalent species. The early observation that reaction rates were larger than those expected by gas kinetic theory led to the now famous "harpoon mechanism"1-6 used to describe the general class of reactions initiated by long range electron transfer. ${ }^{4}$ In the 60 's the advancement of crossed molecular beams techniques confirmed these early ideas and led to a detailed understanding of the reaction dynamics of monovalent atoms. ${ }^{5,6}$ In the reaction $\mathrm{K}+\mathrm{Br}_{2}$ $\rightarrow \mathrm{KBr}+\mathrm{Br}$, the facile dissociation of newly formed diatomic halogen anions ${ }^{7}$ under the influence of alkali cations led to the "spectator stripping" meshanism with the product salt molecule forward scattered with respect to the incoming alkali atom. On the other hand, the pronounced backscattering of the $\mathrm{KI}$ product from the reaction $\mathrm{K}+\mathrm{CH}_{3} \mathrm{I}^{\mathrm{B}}$ resulted from the need for approach of the alkali atom towards the halogen end of the molecule, followed by strorig repulsive forces in the exit channel. These two prototype reactions illustrated two extremes in chemical dynamics.

Although most early studies were restricted to alkali atoms due to the ease of product detection using surface ionization, ${ }^{9}$ the development of the "universal" crossed molecular beams apparatus ${ }^{10}$ and optical techniques such as laser induced fluorescence ${ }^{11}$ 
and chemiluminescence detection ${ }^{12}$ permitted studies of a variety of other neutral atommolecule reactions. More than two decades ago, $\mathrm{BaO}$ chemiluminescence was first observed from single collisions between $\mathrm{Ba}$ atoms and oxygen- containing triatomic molecules. ${ }^{13.15}$ Due to the potential applications of these systems in the development of electronic transition chemical lasers, these and many subsequent studies focussert on the identification and relative yields of rascent chemiluminescent species. Although hopes for practical laser applications soon faded, fascination with the reactions continued primarily because the origin of the $\mathrm{BaO}$ emission spectrum was not well understood. ${ }^{16,17}$ In most cases, the chemiluminescence yield was found to be pressure dependent: increasing pressure led to increased chemiluminescence. More than 50 fapers $^{16}$ were devoted to these studies but most focussed on $\mathrm{Ba}+\mathrm{N}_{2} \mathrm{O}$ since the effect in that case was particularly dramatic--the chemiluminescence yield increased from $2.5 \%$ to $20 \%$ upon increasing the pressure from $1 \times 10^{-4}$ Torr to 10 Torr.

There has been considerably less work devoted to the reaction $\mathrm{Ba}+\mathrm{NO}_{2}$, primarily because of the small photon yield. It was found that more than $98 \%$ of all $\mathrm{BaO}$ was formed in non-chemiluminescent states. ${ }^{16,17}$ Careful measurements by several groups showed that the collision free yield of chemiluminescent $\mathrm{BaO}\left(\mathrm{A}^{1} \Sigma^{+}\right)$molecules was only $0.2 \%$, with the value reaching a maximum of $\leq 2 \%$ at high pressure. According to Hsu and Pruet ${ }^{17}$, the very low high pressure yield could be attributed to the fact that the nascent $\mathrm{BaO}$ from $\mathrm{Ba}+\mathrm{NO}_{2}$ are almost all formed in the $\mathrm{X}^{\prime} \Sigma$ ground state with only a small amount of vibrational energy. This dominant ground state $\mathrm{BaO}$ possessed insufficient internal energy for electronic excitation by secondary collisions. 
Angular distributions of the $\mathrm{BaO}$ resulting from $\mathrm{Ba}+\mathrm{NO}_{2}$ were measured by Haberman, et al. ${ }^{38}$ These experiments were rather primitive by present standards, employing effusive beans with broad beam velocity distributions, and no product velocity distributions could be obtained. They concluded that the $\mathrm{BaO}$ product was forward scattered with respect to the Ba beam with only a small fraction of the available energy appearing in $\mathrm{BaO}-\mathrm{NO}$ transiational recoil. Herm and' coworkers, ${ }^{19}$ using a similar apparatus studied the reactions of $\mathrm{Sr}$ and $\mathrm{Ca}$ (but not $\mathrm{Ba}$ ) with $\mathrm{NO}_{2}$. Their results on the lighter alkaline earth species were consistent with the results of Haberman on $\mathrm{Ba}+\mathrm{NO}_{2}$. Based on the work from these two laboratories, it was concluded that the reactions of alkaline earth atoms with $\mathrm{NO}_{2}$ were analogous to the well-studied alkali-halogen systems. ${ }^{7,20}$ Due to the low ionization potential of $\mathrm{Ba}(5.2 \mathrm{eV})^{21}$ and large electron affinity of $\mathrm{NO}_{2}(2.3 \mathrm{eV})^{22}$, the reaction is initiated by long range electron transfer, ${ }^{4,13-15}$ consistent with a very large experimentally determined reaction cross section $\left(>150 \AA^{2}\right){ }^{13}$ By analogy with the alkahi-halogen systems, it was argued that after long range electron transfer, the strong field of the approaching $\mathrm{Ba}^{+}$led to immediate dissociation of $\mathrm{NO}_{2}$. The incoming $\mathrm{Ba}^{+}$"picked up" the $\mathrm{O}^{\circ}$ ion with the newly formed $\mathrm{BaO}$ molecule continuing in nearly the same center-of-mass $(\mathrm{CM})$ direction as the incident $\mathrm{Ba}$ atom. ${ }^{18,19}$

This direct reaction mechanism contrasted the general behavior seen earlier by Ham and $\mathrm{Kinsey}^{23}$ in scattering of alkali atoms such as $\mathrm{Cs}$ with $\mathrm{SO}_{2}, \mathrm{CO}_{2}$ and $\mathrm{NO}_{2}$. Angular distributions measured using a surface ionization detector provided \&'sod evidence that collisions between alkali atoms and these triatomic oxidants led to formation of strongly bound ionic collision complexes (e.g. $\mathrm{Cs}^{+} \mathrm{SO}_{2}{ }^{\circ}$ ). The center-of-mars 
angular distributions of the ronreactively scattered Cs showwd forward-backward symmetry, indicating that the lifetime of the ionic intermediate exceeded several rotational periods. ${ }^{24}$ Decay of a long-lived prolate collision complex is expected to result in a cester-of-mass product angular distribution peaking at $\theta_{C M}=0^{\circ}$ and $180^{\circ}$; this often leads to a characteristic laboratory angular distribution exhibiting two peaks. In the case of $\mathrm{SO}_{2}$ and $\mathrm{CO}_{2}$, chemical reaction was too endoergic to be possiole; the observed $\mathrm{Cs}$ signal could only result from decay of complexes back to reactants. Altiough the reaction $\mathrm{Cs}+\mathrm{NO}_{2} \rightarrow \mathrm{CsO}+\mathrm{NO}$ was thoughr to be slightly excergic, it was not clear from that work whether or not a reaction actually occurred. Subsequently, Herm and Herschbach ${ }^{25}$ observed formation of $\mathrm{CsO}$ with a large cross section from $\mathrm{Cs}+\mathrm{NO}_{2}$. The bimodal character of the observed $\mathrm{CsO}$ laboratory angular distribution was again strongly suggestive of the participation of long-lived $\mathrm{Cs}^{+} \mathrm{NO}_{2}^{-}$reaction intermediates. However, they resisted drawing any definite conclusions because uncertainties remained in the analysis of the data for the reactive channel since the product translational energy distributions were not recorded. We have recently measured angular and velocity distributions for the reaction $\mathrm{Na}+\mathrm{NO}_{2} \rightarrow \mathrm{NaO}+\mathrm{NO}$ using supersonic beams in our apparatus. ${ }^{26}$ We observe strong $\mathrm{NaO}$ signal from decay of long-lived $\mathrm{Na}^{+} \mathrm{NO}_{2}{ }^{-}$ intermediates. Based on this and the past nonreactive and reactive scattering results, there is little doubt that reaction of the heavier alkalis including $\mathrm{Cs}+\mathrm{NO}_{2}$ involve long " lived reaction intermediates. ${ }^{27}$

That alkalis react with $\mathrm{NO}_{2}$ by formation of long-lived complexes is not surprising since the reactions are nearly thermoneutral, $\mathrm{NO}_{2}^{-}$is a stable ion, and the ion pair 
$\mathrm{Cs}^{+} \mathrm{NO}_{2}{ }^{-}$has a deep potential well. The conclusion that alkaline earth atoms react by a direct stripping mechanism, however, also seems very reasonable. The $\mathrm{Ba}^{+} \mathrm{NO}_{2}{ }^{\prime \prime}$ and $\mathrm{Cs}^{+} \mathrm{NO}_{2}{ }^{-}$singly charged ionic intermediates are expected to be similar; both should be bound by about $65 \mathrm{kcal} / \mathrm{mole}$ with respect to reartants. ${ }^{25,28}$ However, the reaction exoergicities are widely different: $\mathrm{Ba}+\mathrm{NO}_{2} \rightarrow \mathrm{BaO}+\mathrm{NO}$ is highly exoergic- $\Delta \mathrm{H}=-61$ $\mathrm{kcal} /$ mole $^{29}$ (Table I), wheras $\mathrm{Cs}+\mathrm{NO}_{2} \rightarrow \mathrm{CsO}+\mathrm{NO}$ is now known to be slightly endoergic $(\Delta \mathrm{H}=+2 \mathrm{kcal} / \mathrm{mole}){ }^{29}$ The large difference is due to the divalent nature of barium: the ground state $\mathrm{BaO}$ molecule, best described as $\mathrm{Ba}^{2+} \mathrm{O}^{2-30}$ is bound by 133 $\mathrm{kcal} / \mathrm{mole}$, whereas the $\mathrm{Cs}^{+} \mathrm{O}^{-}$binding energy is about half this value $(-70 \mathrm{kcai} / \mathrm{mole}){ }^{29}$ Based on thermodynamics alone, the large exoergicity of the Ba reartion is expected to lead to subpicosecond lifetimes for $\mathrm{Ba}^{+} \mathrm{NO}_{2}{ }^{31}$ with the $\mathrm{BaO}$ forward scattered; whereas the slight endoergicity of the reaction of cesium allows the $\mathrm{Cs}^{+} \mathrm{NO}_{2}^{-}$reaction intermediate to survive many rotational periods before decaying to products or back to reactants.

Although velocity distributions were not measured in the previous alkaline earth $+\mathrm{NO}_{2}$ crossed beams experiments, based on the product angular distributions it was concluded that the nascent products were formed with relatively low translational energy. ${ }^{18,19}$ The more recent laser induced fluorescence work ${ }^{17}$ indicated that the dominant ground state $\mathrm{BaO}$ was vibrationally cold. The following question arises: Where has the $61 \mathrm{kcal} / \mathrm{mole}$ reaction exoergicity been disposed? For a reaction apparently involving long range electron transfer with immediate dissociation of $\mathrm{NO}_{2}^{-}$, there is no obvious reason why the reaction exoergicity should be exclusively channeled into vibrational excitation of the NO product. Although it is known that the products are 
rotationally hot, it seems impossible to believe that so much energy could be preferentially funneled into rotation without the accompanying release of some of the excess energy into translation.

The goal of the present work is to probe the dynamics of the reactions of a divalent metal atom with oxygen-containing molecules under single collision coiditions. Barium was deemed to be the most suitable alkaline earth atom for several reasons. Owing to its relatively low second ionization potential (10ev $)^{21}$ it is most likely to exhibit dynamical effects resulting from its divalency. Also, the first optically allowed electronic transition from the ground state $\left({ }^{1} \mathrm{P} \leftarrow^{-1} \mathrm{~S}\right)$ is at a wavelength convenient to $\mathrm{Ar}^{+}$laser pumped ring dye lasers whereas transitions for the lighter alkaline earths are at less accessible, shorter wavelengths. ${ }^{32}$ Here we report ${ }^{33 \mathrm{t}}$ on the reaction $\mathrm{Ba}+\mathrm{NO}_{2}$, and a later chapter will focus on $\mathrm{Ba}+\mathrm{ClO}_{2}$ and $\mathrm{O}_{3}{ }^{33 \mathrm{~b}}$ Although all three triatomic molecules are closely related, the behavior of each provides considerable insight into the reaction dynamics of divalent systems. Unlike all experiments undertaken to date, both the angular and velocity distributions of the products have been measured. Both beams are much better defined than in the past work from other laboratories, having a narrow velocity distribution characteristic of a supersonic expansion. Our results indicate that previous conclusions, that the $\mathrm{Ba}+\mathrm{NO}_{2}$ reaction is analogous to alkali atoms + halogens is not quite correct. We have found that the divalent nature of barium leads to rather interesting and unexpected reaction dynamics.

The primary advantage of the mass spectrometric detection method over chemiluminescence is that all chemical products, including those in the ground electronic 
states are detected simultaneously. In addition to $\mathrm{BaO}+\mathrm{NO}$, a number of other chemical channels are thermodynamically possible from $\mathrm{Ba}+\mathrm{NO}_{2}$ (Table 1). Mass detection provides the opportunity to observe such products that cannot easily be detected by optical techniques either because of experimental complexities or because their electronic spectrum is unknown. We illustrate this by the observation of BaNO in the present experiment. As far as we know, this is the first direct observation of a neutral metal mononitroxide in the gas phase.

\section{EXPERIMENTAL}

The universal crossed molecular beams apparatus is shown in Figure 1. A continuous, seeded supersonic beam of barium atoms was formed in a molybdenum oven source with separately heated barium reservoir and nozzle. Details of this source will be published elsewhere. ${ }^{33 \mathrm{c}}$ The barium reservoir was heated to $-1050^{\circ} \mathrm{C}$, corresponding to a barium pressure of -10 Torr, and pressurized with $300-700$ Torr of an inert gas. The mixture was expanded through a $0.008^{\prime \prime}$ diameter nozzle heated to $13500^{\circ} \mathrm{C}$ to minimize the formation of clusters. The beam was skimmed by a heated $\left(1000^{\circ} \mathrm{C}\right)$ molybdenum skimmer located in the differential pumping region and then collimated to $2^{\circ}$ full width by a set of defining slits.

The electronically excited barium atomic beam was produced by optically pumping the $\mathrm{Ba}\left({ }^{1} \mathrm{P}^{-1} \mathrm{~S}\right)$ resonance either at or upstream of the interaction region using a Coherent 699-21 ring dye laser operating single frequency at $553 \mathrm{~nm}$ with Rhodamine 560 dye. The fluorescence intensity was continuously monitored during the experiment 


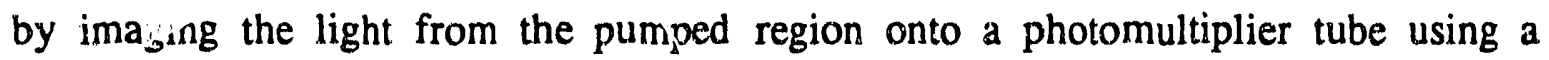
commercial telep oto lens. Once the oven was stabilized, the fluorescence intensity rernained constant to within a few percent over a period of several hours.

The metastable $\mathrm{Ba}\left({ }^{1,3} \mathrm{D}\right)$ population resulted from radiative decay from the ${ }^{1} \mathrm{P}$ state $(r \sim 8.4 \mathrm{~ns}){ }^{34}$ By pumping a $1 \mathrm{~cm}$ length of the beam upstream of the collision zone at $100 \mathrm{~mW}$, it was found that $60 \%$ of the ground state ${ }^{138} \mathrm{Ba}$ population was depleted. This measurement was accomplished by splitting off a small portion $(10 \mathrm{~mW})$ of the laser beam, passing it through an acoustoptic modulator and using the resulting beam to probe the ground state Ba population downstream of the primary pumping region. The $60 \%$ fluorescence depletion represents the fractional decrease in ground state population in the beam due to optical pumping to the long lived $(\sim 1 \mathrm{sec})$ metastable $\left({ }^{1,3} \mathrm{D}\right)$ states. This fraction was relatively insensitive to laser power, indicating that the transition was strongly saturated, as was expected at powers above $50 \mathrm{~mW}$. Our experiment, together with published ${ }^{34} \mathrm{Ba}\left({ }^{1} \mathrm{P}\right)$ branching ratios indicates that by pumping upstream of the crossing region the ${ }^{138} \mathrm{Ba}$ in the beañ consisted of $45 \% \mathrm{Ba}\left({ }^{1} \mathrm{D}\right), 15 \% \mathrm{Ba}\left({ }^{3} \mathrm{D}\right)$ and $40 \%$ $\mathrm{Ba}\left({ }^{1} \mathrm{~S}\right)$, with all other isotopes in the ground $\left({ }^{1} \mathrm{~S}\right)$ state. The reaction of $\mathrm{Ba}\left({ }^{1} \mathrm{P}\right)$ was studied by focussing the laser to $3 \mathrm{~mm}$ diameter and pumping at the interaction region. Under these conditions, the ${ }^{138} \mathrm{Ba}$ consisted of $30 \% \mathrm{Ba}\left({ }^{1,3} \mathrm{D}\right), 35 \% \mathrm{Ba}\left({ }^{1} \mathrm{P}\right)$ and $35 \% \mathrm{Ba}\left({ }^{1} \mathrm{~S}\right)$. Although the $\mathrm{Ba}\left({ }^{1} \mathrm{P}\right)$ atoms are well aligned, we have found no orbital alignment dependence for the neutral product channels from $\mathrm{Ba}+\mathrm{NO}_{2} \cdot{ }^{35}$

The $\mathrm{NO}_{2}$ beam was formed by passing a noble gas through liquid or solid $\mathrm{NO}_{2}$ cooled in a thermostatted temperature bath. The seeded molecular beams were typically 
5-20\% $\mathrm{NO}_{2}$ in $\mathrm{He}$; the lowest collision energy was obtained using neat $\mathrm{NO}_{2}$ vapor. In each case, the $\mathrm{NO}_{2}$ beam nozzle was heated to $200-250^{\circ} \mathrm{C}$ to minimize the formation of $\mathrm{N}_{2} \mathrm{O}_{4}$ and larger clusters. Mass scans with the detector looking directly into the molecular beam indicated that the conicentration of such species were negligible. To be certain, parallel experiments vere run using $100^{\circ} \mathrm{C}$ and $250^{\circ} \mathrm{C}$ nozzle temperatures in He carrier gas. The same beam velocity was attained in each experiment by addition of Ne to the $\mathrm{He}$ in the higher temperature experiment. The $\mathrm{BaO}$ product angular distributions were found to be the same, indicating negligible contribution from reaction of $\mathrm{N}_{2} \mathrm{O}_{4}$. If there was substantial contribution from reaction of $\mathrm{N}_{2} \mathrm{O}_{4}$, its higher concentration in the lower temperature experiment should have led to an increase of product at larger scattering angles since the center-of-mass angle associated with $\mathrm{Ba}+\mathrm{N}_{2} \mathrm{O}_{4}$ scattering is substantially greater than that for $\mathrm{Ba}+\mathrm{NO}_{2} \cdot{ }^{36}$

The $\mathrm{Ba}$ and $\mathrm{NO}_{2}$ beam velocity distributions were measured using the time-offlight method. A $17.8 \mathrm{~cm}$ diameter stainless steel wheel with four $1 \mathrm{~mm}$ slots cut equally spaced around its circumference was mounted to the front of the detector. The wheel was spun at $300 \mathrm{~Hz}$ and the modulated beam was sampled directly through a $0.003^{\prime \prime}$ aperture which could be slid into the entrance of the detector. The distance between the wheel and the effective center of the ionizer was determined experimentally to be $17 . \mathrm{cm}$ by expanding various inert carrier gasses through a room temperature nozzle. The beam velocity distributions were obtained by fitting the time-of-flight profiles using KELVIN $^{37 a}$, a program which convolutes over the known apparatus functions in determining the beam speed $(v)$ and speed ratio $(v / \Delta v)$. Typical beam parameters are 
shown in Table II. It should be noted that a very wide range of Ba beam velocities can be obtained by choosing different inert seed gasses; in all cases the velocity distributions are narrow, characteristic of a supersonic expansion. For reactive scattering studies, the 4-slot wheel was replaced with a $17.8 \mathrm{~cm}$ diameter cross correlation wheel ${ }^{38}$ photoetched by PCM products. The wheel has two 255 channel pseudorandom sequences of open and closed slots providing $50 \%$ transmission and a nominal $5 \mu \mathrm{s}$ time resolution when spun at $392 \mathrm{~Hz}$.

During reactive scattering experiments, the bearn velocities were periodically checked using the cross correlation wheel by moving the detector into the beam, as in the velocity measurements described above. We were especiaily careful to reproduce the Ba oven heating voltages and currents since small changes in Ba vapor pressure can have substantial effects on the average mass of the beam and hence its velocity when light carrier gasses are used.

Angular distributions for $\mathrm{Ba}$ and $\mathrm{BaO}$ were measured in a separate series of experiments with the time of flight wheel removed. The $\mathrm{NO}_{2}$ beam was modulated at $150 \mathrm{~Hz}$ using a tuning fork chopper-- the (beam on) - (beam off) intensities were recorded for each detector angle in separate channels and subtracted to give the reactive scattering signal. In studies of the effects of electronic excitation, the laser beam was chopped at $3 \mathrm{~Hz}$ in synchronization with the $\mathrm{NO}_{2}$ beam modulation and four channels were recorded: 1) Laser on, $\mathrm{NO}_{2}$ on; 2) Laser on, $\mathrm{NO}_{2}$ off; 3) Laser off, $\mathrm{NO}_{2}$ on; 4) Laser off, $\mathrm{NO}_{2}$ off. Further details of this procedure may be found elsewhere. ${ }^{37 b-d}$ The BaNO angular distributions were obtained by integrating the area under the peak in the time of flight 
spectra obtained at appropriate detector angles.

For each species $(\mathrm{Ba}, \mathrm{BaO}$ or $\mathrm{BaNO})$, the data was recorded with the mass spectrometer tuned to the parent ion mass. The dominant $(71 \%){ }^{138} \mathrm{Ba}$ isotope-containing species was monitored in each case. Product velocity distributions were obtained by running parallel experiments at various detector angles with the laser on and off. In all cases, tuning the laser well away from th' barium atomic resonance had the same effect as blocking the laser beam.

\section{RESULTS AND ANALYSIS}

\section{A. $\mathrm{Ba}\left({ }^{1} \mathrm{~S}\right)+\mathrm{NO}_{2} \rightarrow \mathrm{BaO}+\mathrm{NO}$}

Product angular distributions and time-of-flight data were recorded with the mass spectrometer set at $\mathrm{Ba}^{+}(\mathrm{m} / \mathrm{e}=138)$ and $\mathrm{BaO}^{+}(\mathrm{m} / \mathrm{e}=154)$ for the above reaction at 4 collision energies in the range $5-59 \mathrm{kcal} /$ mole. The angular distributions of $\mathrm{BaO}$ exhibited two distinct peaks; at all collision energies the peak near $0^{\circ}$ was larger than the wide angle peak (Fig. 2). The observed signal was very strong; typically only 10 mins. of averaging was required at each angle for each time-of-flight spectrum. The $\mathrm{Ba}^{+}$data at all angles wider than $10^{\circ}$ was very similar to the $\mathrm{BaO}$ data, indicating that the signal obtained for $\mathrm{Ba}^{+}$primarily results from fragmentation of $\mathrm{BaO}$ in the ionizer with a small contribution from nonreactive scattering. Our observations are consistent with a large reaction cross section and the previous conclusions of "reactions at every collision." 13

In the analysis of the $\mathrm{BaO}$ data, an important concern is the internal energy dependence of the fragmentation pattern of $\mathrm{BaO}$ upon $200 \mathrm{~V}$ electron impact ionization. 
This turned out to be an important factor for $\mathrm{NaO}$ in our recent study $\mathrm{y}^{39}$ of the reaction $\mathrm{Na}+\mathrm{O}_{3} \rightarrow \mathrm{NaO}+\mathrm{O}_{2}$. In that case, the fragmentation ratio $\mathrm{Na}^{+} / \mathrm{NaO}^{+}$increased substantially with internal excitation of $\mathrm{NaO}$, and we included the dependence in the analysis. We recorded the $\mathrm{Ba}^{+}$and $\mathrm{BaO}^{+}$time-of-flight data from $\mathrm{Ba}+\mathrm{NO}_{2}$ at the center-of-mass angle, where products with the full range of internal energies contribute to the TOF spectrum. The shape of both spectra were identical, indicating that internal energy of the precursor $\mathrm{BaO}$ is not high enough in the present case to noticeably affect the fragmentation pattern. Similar conclusions have been made by others in the past. ${ }^{19,40}$ It is important to note that our detector is not state specific; we have no way to unambiguously distinguish between different nascent electronic states of $\mathrm{BaO}$ unless their times of arrival are well separated. However, excited states are known to be a minor contribution to the total reaction cross section. 7hey will radiate ${ }^{30}$ during their flight to the ionizer $(\mathrm{T}>100 \mu \mathrm{sec})$, and will be detected with the same efficiency as nascent ground state products. Formation of electronically excited $\mathrm{NO}\left(\mathrm{A}^{2} \Sigma^{+}\right)$is not thermodynamically possible at the collision energies employed in this experiment. ${ }^{29}$

We now consider possible explanations for the observed product angular distribution. Most commonly, the characteristic forward-backward peaking observed here results from decay of long-lived collision intermediates. As was discussed by Miller, et. al. ${ }^{24}$ decay of a prolate complex with a lifetime greater than a few rotational periods ( $>1-2 \mathrm{psec})$ is expected to lead to a forward-backward symmetric center-of-mass product angular distribution, $\mathrm{T}(\theta)$. The degree of peaking at the poles $\left(\theta_{\mathrm{CM}}=0^{\circ}\right.$ and $\left.180^{\circ}\right)$ with respect to $\theta_{\mathrm{CM}}=90^{\circ}$ provides information about the disposal of the total angular 
momentum into product rotation. Upon examining the laboratory angular distributions, one might anticipate that the CM angular distribution was completely forward-backward symmetric with the measured angular distribution distorted in favor of the forward peak due to the transformation Jacobian relating the product intensities in the laboratory to that in the center-of-mass coordinate system: ${ }^{24}$

$$
I_{L}(\theta, v)=I_{C M}(\theta, u) \frac{v^{2}}{u^{2}}
$$

For decay of long-lived complexes, the recoil velocity in the center-of-mass frame of reference $(u)$ is independent of angle. However, as can be seen from the Newion diagram (Fig. 2), the laboratory center-of-mass angle is less than $45^{\circ}$ in this experiment. As a consequence, at small lab angles the lab velocity ( $v)$ associated with a given centerof-mass velocity $(u)$ is greatest in the forward direction, leading to enhancement of $I_{L}(\theta, v)$.

The product angular distributions and time-of-flight spectra were fit using a forward convolution program ${ }^{37 d}$ that assumes a separable form for the center-of-mass product flux distribution:

$$
I_{C M}(\theta, E)=T(\theta) x P(E) \quad(2)
$$

where $T(\theta)$ is the $C M$ product angular distribution, and $P(E)$ is the $C M$ relative product translational energy distribution. Using a trial $T(\theta)$ and $P(E)$, the program generates the lab frame angular distribution and time-of-flight spectra for each lab angle after 
convoluting over the measured beam velocity distributions and known appiaratus functions. The program compares these calculated values with the experimental dala and utilizes the simplex method ${ }^{37 t}$ to optimize the $T(\theta)$ and $P(E)$ iteratively to find a global minimum in the difference between the calculated and experimental angular distriljution and times-of-flights.

We initially attempted to fit the time-of-flight and angular distributions with a single uncoupled CM angular $(\mathrm{T}(\theta))$ and transiational energy $(\mathrm{P}(\mathrm{E}))$ distribution. This approach is expected to be correct for a single channel involving decay of complexes with lifetimes of several rotational and many vibrational periods. An uncoupled $T(\theta)$ and $\mathrm{P}(\mathrm{E})$ is also likely to be a reasonable approximation if 'osculating'41-44 con'plexes were involved with lifetimes on the order of one rotational period. Although the assumption of separability of the angular and energy distribution allowed us to refrroduce the qualitative features of the product time-of-flight and angular distributions, it was not possible to obtain a fit commensurate with the quality of the raw data, which was reproducible and of good signal-to-noise ratio (Fig. 3).

Our data indicates that the average translational entrgy release in the forward direction is smaller than in the backward hemisphere. This leads us to conclude that the assumption of a single uncoupled $T(\theta)$ and $P(E)$ (i.e. a single mechanism involving complexes) is unsatisfactory. The existence of osculating complexes with relatively short lifetimes can be ruled out since it is known that product angular distributions from their decay will be rather sensitive to collision energy. If the complexes lived for $\sim 1$ rotational period at low collision energy, upon increasing the collision energy we should 
observe substantially increased forward scattering as their statistical lifetimes decrease. Such a transition has been observed in other systems. ${ }^{4144}$ In the present case, however, we see no evidence for this effect at a collision energy of $31 \mathrm{kcal} / \mathrm{mole}$. At a collision energy of $59 \mathrm{kcal} / \mathrm{mole}$, although we do see an increased contribution from forward scatteling, the best fit of the angular and time-of-flight distributions indicated that most $\mathrm{BaO}$ resulted from decay of long-lived collision complexes.

The data can only be consistent with two alternative and somewhat more complicated models. The first possibility, which we will subsequently show to be correct, is that two different reaction mechanisms are involved; the dominant channel involves long- lived complexes with large translational energy release, and a second (minor) forward scattered channel with less translational energy imparted to the products. Alternatively, it could be possible that two direct reaction mechanisms are involved; one leading to forward scattering with low product translation and a second leading to backscattering with larger recoil energy. Although a direct reaction with forward scattered $\mathrm{BaO}$ is not at all surprising, the second model also requires direct backscattered $\mathrm{BaO}$ with large translational energy release. Although direct backscattered products are known to result from some bimolecular reactions, most notably $\mathrm{Ba}+\mathrm{N}_{2} \mathrm{O} \rightarrow \mathrm{BaO}+$ $\mathrm{N}_{2}{ }^{45 \mathrm{t}}$, or $\mathrm{Ba}+\mathrm{CH}_{3} \mathrm{I} \rightarrow \mathrm{BaI}+\mathrm{CH}_{3}{ }^{45 b}$, the behavior in those cases is attributable to steric effects. Due to the necessity for attack on sterically hindered atoms such as $O$ in linear $\mathrm{N}_{2} \mathrm{O}$ or $\mathrm{I}$ in $\mathrm{CH}_{3} \mathrm{I}$, successful reaction requires approach of the metal atom from a direction near the symmetry axes $\left(\mathrm{C}_{\infty v}\right.$ or $\mathrm{C}_{3 v}$ for $\mathrm{N}_{2} \mathrm{O}$ or $\mathrm{CH}_{3} \mathrm{I}$, respectively). A direct reaction followed by strong repulsion in the exit channel leads to a "rebound" mechanism 
with the metal atom reversing direction in the CM frame after formation of the chemical bond. Since $\mathrm{NO}_{2}$ is a bent molecule, there appears to be very few collision geometries which could lead to such backscattering; such geometries should be far too rare to be a major source of backscattered $\mathrm{BaO}$.

The reaction $\mathrm{Ba}+\mathrm{NO}_{2} \rightarrow \mathrm{BaO}_{2}+\mathrm{N}$ is thermodynamically possible: based on our measure of $\mathrm{D}_{0}\left(\mathrm{Ba}-\mathrm{O}_{2}\right)^{33, \mathrm{~b}}$, the reaction is calculated to be exoergic by $12 \mathrm{kcal} / \mathrm{mole}$. Such a reaction (if it occurred at all) would most likely result from attack by the $\mathrm{Ba}$ atom near the $C_{2 v}$ axis between the two oxygen atoms, followed by concerted formation of $\mathrm{BaO}_{2}$. Since this might be expected to lead to backscattered $\mathrm{BaO}_{2}$, a possible source of strong signal could be from fragmentation of the peroxide to $\mathrm{BaO}^{+}$upon electron impact ionization. We discount this possibility in the present case since the maximum recoil velocity for $\mathrm{BaO}_{2}$ is restricted to be very low due to the small exoergicity for the $\mathrm{BaO}_{2}$ $+\mathrm{N}$ reaction and the light $\mathrm{N}$ recoil partner. The backscattered $\mathrm{BaO}$ that we observe experimentally has a much larger translational energy than would be possible from the $\mathrm{BaO}_{2}+\mathrm{N}$ reaction. Moreover, we have characterized $\mathrm{BaO}_{2}-$ it yields a parent ion peak from a more exoergic reaction $\left(\mathrm{Ba}+\mathrm{O}_{3}\right) .^{33 \mathrm{a}, \mathrm{b}}$ Yet we cannot detect any $\mathrm{BaO}_{2}{ }^{+}$from $\mathrm{Ba}$ $+\mathrm{NO}_{2}$.

Ruling out a direct reaction leading to backscattered $\mathrm{BaO}$, we now return to the alternative explanation, that a direct forward scattered product is superimposed on a second channel involving long-lived complexes. We have analyzed the data based on this model. As shown in Fig. 4, two independent reaction channels were used in the fits; the first channel (channel 1) was constrained to forward-backward symmetry. This was the 
dominant channel at all collision energies. The second channel (channel 2) is a relatively minur component and is forward scattered. The best fit of the data obtained at a mean collision energy of $12.5 \mathrm{kcal} / \mathrm{mole}$ is shown in Figs. 2 and 3. The first channel, corresponding to the decay of long-lived complexes, leads to larger translational energy release than the second channel. Upon increasing the incident reactant collision energy, the product angular and time-of-flight spectra become more compressed, with somewhat greater uncertainties in the translational energy distributions. However, the backward peak in the product angular distribution can be clearly seen at $\mathrm{E}_{\text {coll }}=31 \mathrm{kcal} / \mathrm{mole}$ (Fig. 5), and the best fit of the angular distribution and TOF data (Fig. 6) even at the highest collision energy ( $59 \mathrm{kcal} / \mathrm{mole}$ ) requires that the dominant channel exhibit forwardbackward symmetry in the CM product angular distribution (Fig. 7). The relative contributions from the two channels remained essentially constant to within experimental uncertainty over the $5-31 \mathrm{kcal} / \mathrm{mole}$ collision energy range. The $\mathrm{BaO}$ product flux contour maps based on the optimized $\mathrm{P}(\mathrm{E})$ and $\mathrm{T}(\theta)$ at $12.5 \mathrm{kcal} / \mathrm{mole}$ are shown in Figs. 8,9. The forward scattered $\mathrm{BaO}$ component (channel 2) accounted for $20 \pm 5 \%$ of the total $\mathrm{BaO}$ cross section at collision energies in the range 5-31 kcal/mole. The forward scattered component increased at $59 \mathrm{kcal} / \mathrm{mole}$ to $40 \pm 10 \%$.

\section{B. $\mathrm{Ba}\left({ }^{1,3} \mathrm{D},{ }^{1} \mathrm{P}\right)+\mathrm{NO}_{2} \rightarrow \mathrm{BaO}+\mathrm{NO}$}

The $\mathrm{BaO}$ angular distributions shown in Fig. 10 show the effect of electronic excitation of the $\mathrm{B} a$ atoms at the interaction region. The beam contained $30 \% \mathrm{Ba}\left({ }^{1,3} \mathrm{D}\right)$, $35 \%\left({ }^{1} \mathrm{P}\right)$ and $35 \%\left({ }^{1} \mathrm{~S}\right)$. Although the effect was rather small, the $\mathrm{BaO}$ intensity was 
found to increase at lab angles smaller than $25^{\circ}$ and greater than $50^{\circ}$. The signal decreased slightly between $25^{\circ}$ and $50^{\circ}$. The Newton diagram (Fig. 10) shows circles for the maximum $\mathrm{BaO} C M$ velocities from reaction of $\mathrm{Ba}\left({ }^{1} \mathrm{P}\right)$ (solid) and $\mathrm{Ba}\left({ }^{\prime} \mathrm{S}\right)$ (dotted). Based on the increased $\mathrm{BaO}$ signal observed near the edges of the Newton sphere, we conclude that electronic excitation of the incident $\mathrm{Ba}$ leads to formation of $\mathrm{BaO}$ with slightly greater average translational energy than reaction of the ground state atom. Because the signal increased the same amount in the forward and backward hemispheres, formation of ground state $\mathrm{BaO}$ from electronically excited $\mathrm{Ba}$ primarily results from decay of long-lived collision complexes, as in the ground state reaction. Excitation of the barium atoms upstream of the collision zone results in $60 \% \mathrm{Ba}\left({ }^{1,3} \mathrm{D}\right)$, and $40 \%{ }^{1} \mathrm{~S}$. The $\mathrm{BaO}$ angular distribution from $\mathrm{Ba}\left({ }^{1,3} \mathrm{D}\right)$ was very similar; however, there was a smaller increase at wide lab angles since less energy was available from reaction of $\mathrm{Ba}\left({ }^{1,3} \mathrm{D}\right)$ than $\mathrm{Ba}\left({ }^{2} \mathrm{P}\right)$.

\section{C. $\mathrm{Ba}+\mathrm{NO}_{2} \rightarrow \mathrm{BaNO}+\mathrm{O}$}

The occurrence of a chemically distinct second channel, BaNO + O was observed from $\mathrm{Ba}\left({ }^{1} \mathrm{~S}\right)+\mathrm{NO}_{2}$ at collision energies above $40 \mathrm{kcal} / \mathrm{mole}$. The observed threshold collision energy from reaction of electronically excited $\mathrm{Ba}\left({ }^{1,3} \mathrm{D}\right)$ was below $25 \mathrm{kcal} / \mathrm{mole}$. Unlike $\mathrm{BaO}$, the energy dependence of the $\mathrm{BaNO}$ fragmentation pattern cannot be easily obtained. Although this species is considerably more weakly bound than $\mathrm{BaO}$, ionization of this radical likely involves removal of a nonbonding electron. This suggests that the internal energy dependence of the BaNO fragmentation pattern is probably not a major 
concern. Indeed, the product time-of-flight for the $\mathrm{NO}^{+}$daughter ion from $\mathrm{BaNO}$ could be observed and appeared to be the same as $\mathrm{BaNO}^{+}$. From the observation of the $\mathrm{NO}^{+}$ daughter ion, the location of the mass peak, and observation that the signal disappeared upon turning off the ionizer, we were able to rule out the possibilities that the signal resulted from $\mathrm{BaO}_{2}{ }^{33 n, b}$ leakage through the mass spectrometer, electronically excited or Rydberg $\mathrm{Ba}$ atoms ${ }^{46}$, or nascent ions. ${ }^{35}$

In the $\mathrm{Ba}\left({ }^{1} \mathrm{~S}\right)+\mathrm{NO}_{2}$ reaction, the $\mathrm{BaNO}$ product intensity was found to be rather weak, increasing with increasing collision energy. Unlike the dominant $\mathrm{BaO}+\mathrm{NO}$ channel, BaNO from reaction of ground state $\mathrm{Ba}$ was only observed over a narrow range of laboratory angles, peaking away from the relative velocity vector. (Fig. 11, filled circles). The $\mathrm{BaNO}+\mathrm{O}$ channel from $\mathrm{Ba}\left({ }^{1} \mathrm{~S}\right)+\mathrm{NO}_{2}$ appears to be completely independent of the $\mathrm{BaO}+\mathrm{NO}$ channel. The BaNO time-of-flight spectra for reaction of $\mathrm{Ba}\left({ }^{\prime} \mathrm{S}\right)$ are shown in Fig. 12. The slower broad peak in the time of flight spectrum remained even when the electron bombardment ionizer was turned off. It results from surface ionization of barium atoms at the back wall of the detector. The product angular and time-of-flight distributions were fit using a single uncoupled $T(\theta)$ and $P(E)$, (Fig. 14). The BaNO product flux contour map from reaction of ground state $\mathrm{Ba}$ is shown in Fig. 15 .

At a collision energy of $59 \mathrm{kcal} /$ mole, electronic excitation of the $\mathrm{Ba}$ atom to the ${ }^{1,3} \mathrm{D}$ states resulted in a twofold increase in BaNO signal, and a larger increase was seen from the 'P state. Unlike the ground state reaction, the best fit of the BaNO angular and velocity distribution from reaction of electronically excited $\mathrm{Ba}\left({ }^{1} \mathrm{P},{ }^{1,3} \mathrm{D}\right.$ ) (Fig. 11- hollow 
squares, Fig. 13) resulted in a forward-backward symmetric center-of-mass angular distribution (Fig. 14). The angular distribution obtained by pumping the $\mathrm{Ba}$ atoms upstream of the collision zone to the metastable ${ }^{1,3} \mathrm{D}$ states was weaker, but qualitatively similar. The forward-backward symmetric angular distributions indicate that unlike the BaNO resulting from reaction of ground state $\mathrm{Ba}\left({ }^{1} \mathrm{~S}\right)$, formation of BaNO from excited state Ba primarily results from decay of long- lived collision complexes.

\section{DISCUSSION}

\section{A. $\mathrm{Ba}+\mathrm{NO}_{2} \rightarrow \mathrm{BaO}+\mathrm{NO}$ \\ i. Comparison to Past Work}

Perhaps the most surprising result of our study is that the reaction $\mathrm{Ba}+\mathrm{NO}_{2} \rightarrow$ $\mathrm{BaO}+\mathrm{NO}$ primarily involves long-lived collision complexes with large releases of translational energy. Since both of these prirnary conclusions disagree with those from the past work of others, ${ }^{18,19}$ we first address this discrepancy. The most obvious difference between this experiment and previous work is the higher collision energy in the present work. The past experiments were conducted using a sirgle mean collision energy of $\sim 2-3 \mathrm{kcal} /$ mole whereas we studied the reaction at four snergies with the lowest at $5 \mathrm{kcal} / \mathrm{mole}$. An explanation for the discrepancy could be that a direct reaction mechanism with forward scattering occurs at the low collision energy of the previous work with the mechanism evolving into one with collision complexes at the higher energies employed here. This appears to be unlikely since the best fit to our data obtained at the west collision energy showed no enhancement of the forward scattering 
component. Moreover, such behavior would be exactly opposite of what is usually observed: ${ }^{4144}$ a decreased statistical lifetime of the complex is normally expected with increasing energy, leading to direct reaction at higher energy.

Another possible explanation for our result is that at higher collision energies, the divalent barium atom preferentially inserts into a covalent bond with formation of $O$ $\mathrm{Ba}^{2+} \mathrm{NO}$. This would be somewhat analogous to the behavior we have recently observed in the reaction $\mathrm{Ba}\left({ }^{1} \mathrm{D}\right)+\mathrm{H}_{2} \mathrm{O} \rightarrow \mathrm{HBaOH}^{*} \rightarrow \mathrm{BaOH}+\mathrm{H}^{47}$, (Chapter 2). In such systems, a forward-backward angular distribution does not necessarily imply that the intermediates survive longer than one rotational period. Since insertion (or more likely, $\mathrm{H}$-atom migration) could involve either of two identical O-H bonds, the symmetric $\mathrm{BaOH}$ angular distribution might simply reflect the $\mathrm{C}_{2 v}$ symmetry of $\mathrm{H}_{2} \mathrm{O}$. Although it might seem that an analogous situation could exist here, we believe that such a situation is unlikely for two reasons. First, symmetry arguments indicate that insertion will be very unfavorable for $\mathrm{Ba}\left({ }^{1} \mathrm{~S}\right)+\mathrm{NO}_{2}$. More importantly, insertion of ground state $\mathrm{Ba}\left({ }^{1} \mathrm{~S}\right)$ into $\mathrm{NO}_{2}$ is likely to involve a large potential energy barrier since the process involves a nearly simultaneous transition from a covalent to a doubly ionic surface. This suggests that a potential energy barrier will exist in the entrance channel. There should be a negligible barrier in the exit channel, however, since decay of the vibrationally activated insertion intermediate to $\mathrm{BaO}+\mathrm{NO}$ should only involve simple bond rupture. Thus, we expect that the products from an insertion mechanism should be vibrationally excited with small translational energy. This is not consistent with the low vibrational excitation measured in the LIF experiments ${ }^{17}$ and large translational energy release that we observe. It 
appears that an OBaNO insertion intermediate does not play an important role in the reaction.

We believe that the conclusions based on the previous crossed beams experiments were incorrect. The danger of making conclusions based on angular distributions alone has been addressed previously. ${ }^{48}$ Without velocity analysis, the transformation from the laboratory to center-of-mass angular distribution is not unique, especially when effusive beams are employed having broad velocity distributions. In particular, for a reaction of fast $\mathrm{Ba}$ atoms + slow $\mathrm{NO}_{2}$ the transformation Jacobian will strongly enhance the forward peak, and the angular distribution alone will be rather insensitive to the actual $T(\theta) P(E)$ combination. Since the metal-oxide bond energies decrease for the lighter alkaline earth atoms, ${ }^{29}$ reactions of those species with $\mathrm{NO}_{2}$ will be less exoergic. It is very likely that reaction of the other alkaline earths (Be is a possible exception) with $\mathrm{NO}_{2}$ will also involve complex intermediates. ${ }^{49}$

\section{ii. Mechanism for $\mathrm{Ba}+\mathrm{NO}_{2} \rightarrow \mathrm{BaO}+\mathrm{NO}$}

There is no question that this reaction is initiated by the well known "harpoon mechanism" 2,3 used to describe reactions such as $\mathrm{K}+\mathrm{Br}_{2} \rightarrow \mathrm{KBr}+\mathrm{Br}$. The energies of the lowest electronic states of $\mathrm{NO}_{2}^{-50}$ are summarized in Table III together with the calculated ionic-covalent curve crossing radii and estimated reaction cross sections. The very large experimental reaction cross section can only be consistent with long range transfer into the half filled $6 \mathrm{a}_{1}$ orbital (Fig. 16), corresponding to formation of ground state $\mathrm{NO}_{2} \cdot\left({ }^{1} A_{1}\right)^{50}$. The analogy between the present reaction and the alkali-halogen 
reaction extends no further, however. In the case of bromine, not only is the process $\mathrm{Br}_{2}$ $+\mathrm{e} \rightarrow \mathrm{Br}_{2}^{-} \rightarrow \mathrm{Br}+\mathrm{Br}^{-}$exoergic, ${ }^{29}$ but vertical electron attachment to $\mathrm{Br}_{2}$ results in formation of $\mathrm{Br}_{2}{ }^{\circ}$ on the inner repulsive wall of the $\mathrm{Br}-\mathrm{Br}$ interaction potential at an energy near the threshold for dissociation. ${ }^{6}$ Electron attachment to $\mathrm{NO}_{2}$, however, results in formation of a strongly bound anion; in fact $D_{0}\left(O^{-}-N O\right)$ actually exceeds $D_{0}(O-$ NO). ${ }^{22,29}$ In low energy electron scattering, it is not surprising that the process $\mathrm{Br}_{2}+$ $\mathrm{e}^{-} \rightarrow \mathrm{Br}+\mathrm{Br}$ is observed at electron energies down to $\mathrm{O} \mathrm{V.}{ }^{51}$ The energy threshold for $\mathrm{NO}_{2}+\mathrm{e}^{\circ} \rightarrow \mathrm{O}^{-}+\mathrm{NO}$, however, is equal to its endoergicity, $1.61 \mathrm{eV}^{52}$

Although there is no information available as to the structure of gaseous $\mathrm{BaNO}_{2}$, it was noted previously that considerable similarity is expected to the analogous alkali nitrites which are known to be stable molecules, even in the gas phase. ${ }^{53}$ We have also noted that an OBaNO structure is unlikely. There appears to be no question that the alkali nitrites are ring shaped $C_{2 v}$ molecules with the metal cation symmetrically located in the plane of $\mathrm{NO}_{2}$. This structure is supported by spectroscopic measurements both in matrix isolation experiments ${ }^{54}$ and in the gas phase. ${ }^{55} \mathrm{Ab}$ initio calculations also indicate that a ring shaped structure is of lowest energy. ${ }^{56}$ Experimental results on the alkaline earth nitrites ${ }^{57}$ in rare gas matrices suggest the same structure or possibly a nonplanar structure with a poorly defined position of the $\mathrm{M}^{+}$above the plane of the anion.

Orbital symmetry considerations (Fig. 16) indicate that interaction of $\mathrm{Ba}^{+}$with $\mathrm{NO}_{2} \cdot 6 \mathrm{a}_{1}^{2}\left({ }^{1} \mathrm{~A}_{1}\right)$ should be particularly favorable in the planar configuration in which the $\mathrm{Ba}^{+}$lies on the $\mathrm{C}_{2 \mathrm{v}}$ axis between the two oxygen atoms. This will maximize the ionic attraction since the electron density on $\mathrm{NO}_{2}^{-}$can be delocalized over the oxygen atoms 
and at the same time interact strongly with $\mathrm{Ba}^{+}$. In addition, a net covalent interaction can be achieved by favorable overlap of the $\mathrm{Ba}^{+}(6 \mathrm{~s})$ orbital and the $\mathrm{NO}_{2}^{-} 6 \mathrm{a}_{1}$ orbital. Other planar geometries (such as $C_{\downarrow}$ ) should be less stable due to poor orbital overlap. The two higher lying excited states of $\mathrm{NO}_{2}{ }^{-}$result from transfer of an electron into the unfilled $2 b_{1}$ orbital leading to the ${ }^{1} B_{1}$ and ${ }^{3} B_{1}$ states. ${ }^{50}$ Not only does this orbital lie $\sim 3 \mathrm{eV}$ higher than the $6 \mathrm{a}_{1}$ (Table III), but based on orbital symmetry it appears that interaction of the excited states of $\mathrm{NO}_{2}^{-}$with $\mathrm{Ba}^{+}$will be weaker than for the ground state since overlap of the orbitals lead to no net covalent attraction.

For nearly all trajectories, long range electron transfer into the $6 a_{1}$ orbital should be very favorable at $\mathrm{r}=4.9 \AA$. Based on the geometries for $\mathrm{NO}_{2}$ and $\mathrm{NO}_{2}^{-}$(Table IV), and the 0-O bonding character of the $6 a_{1}$ orbital, electron transfer will result in symmetric bending of $\mathrm{NO}_{2}{ }^{-}$with only a small amount of $\mathrm{NO}$ vibrational excitation. ${ }^{22}$ We note that the asymmetric stretching mode (formally corresponding to the reaction coordinate) is not expected to be appreciably excited. Approach of Ba directly towards $\mathrm{N}$ along the $\mathrm{C}_{2 \mathrm{v}}$ axis is also expected to lead to efficient electron transfer but the resulting $\mathrm{C}_{2 \mathrm{v}} \mathrm{BaNO}_{2}$ molecule is probably less stable than the bidentate $\mathrm{C}_{2 v}$ structure. However, such a species is still likely to survive for at least several vibrational periods since the departing $\mathrm{O}^{-}$ion will be initially moving along one $\mathrm{N}^{-} \mathrm{O}^{-}$bond axis. For a monodentate $\mathrm{C}_{2 \mathrm{v}} \mathrm{Ba}^{+}-\mathrm{NO}_{2}^{-}$molecule, this motion will oppose the $\mathrm{Ba}^{+}-\mathrm{O}^{-}$coulombic attraction, leading to a longer lifetime for decay of the ionic intermediate.

This reaction is very unusual since it is dominated by a mechanism involving collision complexes despite the fact that a very highly exoergic decay channel $(\mathrm{BaO}+$ 
NO) is known to be accessed with a probability of nearly $100 \%$. Since it is known that the slightly endoergic reaction $\mathrm{Cs}+\mathrm{NO}_{2} \rightarrow \mathrm{CsO}+\mathrm{NO}$ proceeds readily at a collision energy of $3 \mathrm{kcal} / \mathrm{mole}^{25}$ the potential energy barrier for decay of $\mathrm{Cs}^{+} \mathrm{NO}_{2}^{-}$to products must be nearly zero. If the barrier for decay of $\mathrm{Ba}^{+} \mathrm{NO}_{2}^{-}$to $\mathrm{Ba}^{2+} \mathrm{O}^{2-}+\mathrm{NO}$ was also negligible, survival of long-lived complexes for $\tau \geq 1 \mathrm{psec}$ would require a $\mathrm{Ba}-\mathrm{NO}_{2}$ binding energy of $>250 \mathrm{kcal} / \mathrm{mole} .{ }^{58}$ This is far larger than is reasonable. We attribute the existence of complexes and the large amount of product translational energy from their decay to a large exit potential energy barrier for formation of products. This barrier in the exit channel appears to be a consequence of the divalent character of Ba. Decay of the complex to ground state molecules requires a substantial rearrangement of electronic structure, corresponding to transfer of the second valence electron necessary for formation of $\mathrm{Ba}^{2+} \mathrm{O}^{2-}$. The large exit barrier for decay of the complex apparently results from several factors. One factor is related to the most stable geometry for $\mathrm{Ba}^{+} \mathrm{NO}_{2}^{-}$likely being planar. Although the $\mathrm{NO}_{2}^{-}$energy levels will be shifted significantly by the presence of $\mathrm{Ba}^{+}$, it appears that the electronic rearrangement necessary for decay to products requires transfer of electron density into the $2 b_{1}$ lowest unoccupied molecular orbital of $\mathrm{NO}_{2}$. As can be seen from Fig. 14, this is forbidden by orbital symmetry constraints for planar $\mathrm{Ba}^{+} \mathrm{NO}_{2}^{-}$complexes.

The height of the exit barrier for electronic rearrangement can be estimated from this work. It must lie below the energy of the reactants since we know that most complexes decay to products rather than back to reactants. Simple RRKM calculations ${ }^{58}$ using $\mathrm{D}_{\mathrm{o}}\left(\mathrm{Ba}-\mathrm{NO}_{2}\right)=65 \mathrm{kcal} / \mathrm{mole}$ and reasonable estimates of $\mathrm{BaNO}_{2}$ vibrational 
frequencies suggest that at collision energies above $30 \mathrm{kcal} / \mathrm{mole}$, complex lifetimes of $\geq 1$ psec will result only if the barrier for decay of $\mathrm{BaNO}_{2}$ is greater than $\sim 45$ $\mathrm{kcal} / \mathrm{mole}$. Using a $65 \mathrm{kcal} / \mathrm{mole}$ well depth, this implies that the barrier is not lower than $20 \mathrm{kcal} /$ mole below the energy of separated $\mathrm{Ba}+\mathrm{NO}_{2}$. Based on our observation that the observed $\mathrm{Ba}^{+}$signal primarily results from fragmentation of $\mathrm{BaO}$ in the ionizer, (rather than from decay of $\mathrm{BaNO}_{2}$ back to $\mathrm{Ba}+\mathrm{NO}_{2}$ ), we believe that our lower limit of $45 \mathrm{kcal} / \mathrm{mole}$ is likely to be close to the true value. If the barrier were much nearer to the energy of separated $\mathrm{Ba}+\mathrm{NO}_{2}$, nonreactive scattering from decay of $\mathrm{BaNO}_{2}$ back to reactants should lead to an additional component in the Ba time-of-flight spectrum with relatively low translational energy release. Figure 17 shows the energy levels of all relevant chemical species involving ground state Ba-- solid lines denote reaction pathways.

\section{B. Source of the Forward Scattered BaO Channel}

Our experimental data indicates the existence of a second reaction channel leading to forward scattered $\mathrm{BaO}$ with smaller translational energy release than from the dominant channel. This channel results from a direct reaction mechanism; based on the observed product translational energy distribution, by conservation of energy the reaction exoergicity must be primarily channeled into product internal excitation. It might seem plausible that this direct reaction channel corresponds to formation of electronically excited $\mathrm{BaO}$, best described as $\mathrm{Ba}^{+} \mathrm{O}^{-30,59}$ This explanation would appear to be particularly appealing since second electron transfer is not required for this product. 
However, our measurements indicate that the forward scattered channel represents $20 \pm 5 \%$ of the total reaction cross section whereas the single collision chemiluminescence yield is known to be less than $0.2 \% .^{16,17}$ Since there is no reason to believe that electronically excited products should be preferentially formed in dark states, assuming that the chemiluminescence yield is correct, a large fraction of the forward scattered $\mathrm{BaO}$ products must be vibrationally excited ground state molecules.

Since a direct reaction mechanism implies a short lifetime for the ionic intermediate, it might seem at first surprising that the direct reaction mechanism is relatively minor. This indicates that the forward scattered $\mathrm{BaO}$ does not result from kinetic competition with the dominant channel involving collision complexes. Instead, the relatively small yield of direct, forward scattered products must reflect a small probability for avoiding the deep $\mathrm{Ba}^{+} \mathrm{NO}_{2}^{-}$well. There are two possible mechanisms whereby this may be achieved. Some trajectories can remain on the covalent surface by avoiding electron transfer at the first crossing. In this case, electron transfer at the second crossing is nearly certain and the reaction intermediate can be considered to be an excited state of $\mathrm{Ba}^{+} \mathrm{NO}_{2}^{-}$which will have a shorter lifetime due to its weaker bond. This mechanism appears to be dominant in the reaction $\mathrm{Li}+\mathrm{NO}_{2} \rightarrow \mathrm{LiO}+\mathrm{NO}$, which was found to be direct without the involvement of long-lived collision complexes. ${ }^{27}$ This model appears unlikely in the present case, however, since the relative yield of forward scattered products is not very sensitive to collision energy. Since adiabatic behavior at the outer crossing is expected to decrease with increasing collision energies, ${ }^{60}$ if this explanation were correct we should have observed a substantial increase of forward 
scattering with increasing collision energy. Moreover, correlations ${ }^{61}$ between curve crossing distance and electron transfer probability in atom-atom and atom-diatom systems indicate that at $4.9 \AA$, the electron transfer probability will be nearly $100 \%$. The alternative explanation is that the direct reaction results from electron vransfer into the $6 \mathrm{a}_{1}$ orbital from $\mathrm{Ba}-\mathrm{NO}_{2}$ geometries which are unfavorable for formation of long- lived complexes. This situation would be expected to occur in those collisions where the $\mathrm{Ba}^{+}$ can approach very close to one oxygen atom in $\mathrm{NO}_{2}{ }^{-}$. In this case, a very close $\mathrm{Ba}^{+}-\mathrm{O}^{-}$ interaction would be favorable for second electron transfer and formation of grround state products. Good coupling between the incident kinetic energy and the reaction coordinate facilitates second electron transfer and formation of vibrationally hot, forward scattered $\mathrm{BaO}$.

\section{C. $\mathrm{Ba}+\mathrm{NO}_{2} \rightarrow \mathrm{BaNO}+\mathrm{O}$ \\ i) The Ba('S) Reaction Mechanism}

A number of observations allow us to gain considerable insight into the dynamics of this channel. The angular distribution from reaction of ground state $\mathrm{Ba}\left({ }^{\prime} \mathrm{S}\right)$ was found to peak over a very narrow range, well away from the relative velocity vector. Formation of BaNO results from a direct reaction, unlike the dominant ground state $\mathrm{BaO}$ channel. The small cross section and a narrow angular distribution indicates that successful reaction results from a very restricted range of collision geometries.

In the next section, we will argue that $\mathrm{BaNO}$ is best represented as $\mathrm{Ba}^{+}{ }^{+} \mathrm{NO}$. An 
obvious question is whether long range electron transfer into the $6 \mathrm{a}_{1}$ orbital of $\mathrm{NO}_{2}$ precedes formation of BaNO $+\mathrm{O}$. We believe that it does not; rather, BaNO likely results from trajectories which are able to avoid harpooning at the outer crossing point. The probability density maps for electrons in the $6 a_{1}$ and $2 b_{1}$ orbitals (Fig. 16) are useful in determining favorable and unfavorable molecular orientations for electron transfer. Although the shapes of the orbitals will become distorted upon close approach of $\mathrm{Ba}$, they should be reasonable approximations outside the first ionic-covalent curve crossing radius $(4.9 \AA)$. Transfer of an electron from the spherically symmetric $\mathrm{Ba}$ 6s orbital into the $\mathrm{NO}_{2} 6 \mathrm{a}_{1}$ orbital can be best avoided by approach of Ba towards $\mathrm{N}$ just off the $\mathrm{C}_{2 \mathrm{v}}$ axis. This approach geometry will also lead to asymmetric stretching of $\mathrm{NO}_{2}$, an important requisite for reaction. The substantial threshold and narrow product angular spread is consistent with a narrow approach geometry and a need to couple translational energy into the asymmetric stretching of $\mathrm{NO}_{2}$. However, maintaining proper collision geometry alone is not likely to be sufficient to promote this reaction. Since electron transfer into the $6 \mathrm{a}_{1}$ orbital leads to symmetric bending or symmetric stretching, only by remaining on the covalent surface at the outer crossing is it possible to excite the asymmetric $\mathrm{NO}_{2}$ motion. The small product yield $(<2 \%$ that of $\mathrm{BaO})$ is consistent with a very small probability for avoiding electron transfer at the first ionic-covalent crossing.

Based on the translational energy measurements, we calculate $D_{\circ}(\mathrm{Ba}-\mathrm{NO}) \geq 65$ $\mathrm{kcal} / \mathrm{mole}$ (Section iii). Since $\mathrm{D}_{\mathrm{o}}(\mathrm{O}-\mathrm{NO})=72 \mathrm{kcal} /$ mole $^{29}$, the reaction is only slightly endoergic. However, the energy threshold for this reaction from $\mathrm{Ba}\left({ }^{\prime} \mathrm{S}\right)$ appears to be 
much greater than the endoergicity. It appears that the threshold is primarily due to a dynamic rather than thermodynamic requirement. The dynamic requirement is probably the need for nonadiabatic behavior at the outer crossing point and good coupling of the incident kinetic energy into the reaction coordinate, i.e. asymmetric $\mathrm{N}-\mathrm{O}$ stretching. This is supported by our observation that the reaction is strongly promoted by very high collision energy. The probability of long range electron transfer depends on several factors. ${ }^{60,61}$ These include the difference in the gradients for each potential energy surface in the vicinity of the crossing region, impact parameter, orientation of the $\mathrm{NO}_{2}$ molecule, radial velocity, and coupling matrix element. For the reaction of ground state $\mathrm{Ba}\left({ }^{\prime} \mathrm{S}\right)$, formation of BaNO requires small impact parameter collisions. For small impact parameters, the relative velocity is almost entirely radial and an increase in collision energy can lead to substantially decreased adiabatic behavior and asymmetric motion of the $\mathrm{NO}_{2}$ molecule. This should lead to enhancement of BaNO by decreasing the probability for outer harpooning and permitting good coupling of the incident kinetic energy into the reaction coordinate.

\section{ii) The Effect of Electronic Excitation}

Electronic excitation to the ${ }^{1} \mathrm{P}$ state increases the first ionic-covalent curve crossing radius to $\sim 15 \AA$, leading to a substantially decreased probability for electron transfer into the $6 \mathrm{a}_{1}$ orbital. ${ }^{61}$ The next crossings correspond to transfer of the $\mathrm{Ba} 6 \mathrm{~s}$ electron into the $6 \mathrm{a}_{1}$ orbital (retaining the $\mathrm{Ba} 6 \mathrm{p}$ core) or transfer of the $6 \mathrm{p}$ electron into 
the $2 b_{1}$ orbital. Both processes correspond to formation of excited state $\mathrm{Ba}^{+} \mathrm{NO}_{2}$. Based on the $\mathrm{BaO}$ angular distributions, a large fraction of these excited complexes still survive for longer than one rotational yeriod. At least part of this increased energy appears in relative translational motion of the recoiling $\mathrm{BaO} / \mathrm{NO}$ products.

With electronic excitation to the ${ }^{1,3} \mathrm{D}$ states, we observed an approximately twofold enhancement of formation of BaNO +0 . The yield was larger from the ( $\left.{ }^{\mathrm{P}} \mathrm{P}\right)$ state with an enhancement by a factor of 3-4. However, the products appear to result from decay of long-lived complexes, whereas the reaction is direct from the ground state. This unusual behavior likely results from a substantial increase in the energy of the $\mathrm{Ba}^{+} \mathrm{NO}_{2}^{-}$complex due to electronic excitation of the incident $\mathrm{Ba}$ atom. In the case of ground state Ba( $\left.{ }^{1} \mathrm{~S}\right)$, only a very small fraction of collisions could avoid the first electron transfer. With proper collision geometry and good coupling of incident collision energy into the reaction coordinate, $\mathrm{BaNO}+\mathrm{O}$ resulted from a direct reaction mechanism. In the reaction of electronically excited $\mathrm{Ba}$, decay of internally excited $\mathrm{Ba}^{+} \mathrm{NO}_{2}$ complexes leads to the formation of $\mathrm{BaNO}+\mathrm{O}$ products in addition to the dominant $\mathrm{BaO}+\mathrm{NO}$.

\section{iii) The Dissociation Energy of BaNO}

The Ba-NO bin ling energy may be derived from the translational energy distribution for $\mathrm{Ba}\left({ }^{1} \mathrm{~S}\right)+\mathrm{NO}_{2} \rightarrow \mathrm{BaNO}+\mathrm{O}$. The following expression relating the energy of the reactants to that of the products is based on conservation of energy: 
$E_{\text {coll }}+E_{\text {int,NO2 }}-D_{0}\left(O-N_{2}\right)=E_{\text {int, BeNo }}+E_{\text {inh }, 0}+E_{\text {tran, BeNO/0 }}-D_{0}(\mathrm{Ba}-\mathrm{NO})$.

By assuming efficient cooling of rotational but not vibrational energy of $\mathrm{NO}_{2}$ in the supersonic expansion, $\mathrm{E}_{\mathrm{inh}, \mathrm{NO} 2} \approx 2 \mathrm{kcal} / \mathrm{mole}$. The following equation, derived from (2) is actually an equality if the fastest BaNO products correspond to formation of BaNO in its ground rovibrational states and the oxygen atom is $\mathrm{O}\left({ }^{3} \mathrm{P}\right)$ :

$D_{0}(B a-N O) \geq E_{\text {rans, BeNO/O }}+D_{0}\left(\mathrm{O}-\mathrm{NO}_{2}\right)-E_{\text {coll }}-E_{\text {int,No }}$

Using $E_{\text {coll }}=60 \mathrm{kcal} / \mathrm{mole}$ and $\mathrm{D}_{\mathrm{o}}\left(\mathrm{O}-\mathrm{NO}_{2}\right)=72 \mathrm{kcal} / \mathrm{mole}$, we calculate $\mathrm{D}_{\mathrm{o}}(\mathrm{Ba}-\mathrm{NO}) \geq 65$ $\mathrm{kcal} / \mathrm{mole}$, with the uncertainty not greater than $20 \mathrm{kcal} / \mathrm{mole}$. Uncertainties arise in fitting the translational energy distribution and from the spread of the velocity distribution of the $\mathrm{Ba}$ beam. Since it is likely that at least some ground state products are formed in the reaction, we conclude that $\mathrm{D}_{\mathrm{o}}(\mathrm{Ba}-\mathrm{NO})=65 \pm 20 \mathrm{kcal} / \mathrm{mole}$.

There has been no previous direct observation of BaNO in the gas phase. In fact, as far as we know, this is the first direct observation of an isolated gaseous metal mononitroxide. However, infrared spectra of alkali ${ }^{62}$ and alkaline earth ${ }^{57}$ nitroxides have been recorded under matrix isolation conditions. Based on that work, it was concluded that the molecules are ionic: isotope shifts in the IR spectra suggested a bent or linear $\mathrm{M}^{+} \mathrm{NO}^{-}$molecule (rather than $\mathrm{M}^{+} \mathrm{ON}$ ) in all cases except $\mathrm{Li}^{+} \mathrm{ON}^{-}$. Although no binding energies are available for other nitroxides, it is interesting to compare BaNO to known 
metal-dioxygen compounds. As perhaps one might expect, $\mathrm{D}_{0}(\mathrm{Ba}-\mathrm{NO})$ is comparable to singly ionic metal superoxides rather than the alkaline earth-dioxygen molecule which appears to have substantial doubly ionic character: $\mathrm{D}_{0}\left(\mathrm{Na}-\mathrm{O}_{2}\right)=58.1 \pm 2 \mathrm{kcal} / \mathrm{mole} \mathrm{e}^{63}$, $\mathrm{D}_{\mathrm{o}}\left(\mathrm{Ba}-\mathrm{O}_{2}\right)=120 \pm 20 \mathrm{kcal} / \mathrm{mole}^{33 \mathrm{a}, \mathrm{b}}$.

\section{The Absence of $\mathrm{Ba}+\mathrm{NO}_{2} \rightarrow \mathrm{BaO}_{2}+\mathrm{N}$}

Considerable effort was devoted to observing this reaction since there was good reason to believe that it might occur. Electron transfer into the $6 \mathrm{a}_{1}$ orbital strongly enhances bonding between the oxygen atoms with the $\mathrm{O}-\mathrm{N}-\mathrm{O}$ bond angle decreasing from $134.1^{\circ}$ to $115.4^{\circ}$ (Table IV). The reaction $\mathrm{B}+\mathrm{NO}_{2} \rightarrow \mathrm{BO}_{2}+\mathrm{N}$ has been observed by Green and $\mathrm{Gole}^{64}$ and was attributed to rapid scissoring of the $\mathrm{NO}_{2}$ molecule after electron transfer. Other triatomic oxidants such as $\mathrm{O}_{3}$ and $\mathrm{ClO}_{2}$ did not lead to formation of $\mathrm{BO}_{2}$ since the bond angles in those molecuics are not appreciably different from their anions. Dissociative electron attachment to $\mathrm{NO}_{2}$ is known to lead to formation of $\mathrm{O}$, NO and $\mathrm{O}_{2}{ }^{-}$at $1.61 \mathrm{eV}, 3.11 \mathrm{eV}$, and $4.03 \mathrm{eV}$, respectively. ${ }^{52}$ Since these energies are the thermodynamic thresholds for the processes, ${ }^{29,52}$ we postulated that with electronic excitation or at high collision energy, nascent $\mathrm{BaO}_{2}$ might be formed from reaction of $\mathrm{Ba}$ $+\mathrm{NO}_{2}$.

The $\mathrm{BaO}_{2}+\mathrm{N}$ channel either does not occur at all, or is below the sensitivity of the experiment. There was no evidence that electronic excitation promotes this channel. The cross section must be below $1 \AA^{2}$ for formation of $\mathrm{BaO}_{2}+\mathrm{N}$. It appears that the 
contrasting behavior between $\mathrm{B}$ and $\mathrm{Ba}$ arises primarily due to the ionization potential of $\mathrm{B}(8.3 \mathrm{eV})^{21}$ being considerably higher than that of $\mathrm{Ba}(5.2 \mathrm{eV})^{21}$. In the case of $\mathrm{Ba}$, electron transfer occurs at long range $(\sim 4.9 \AA)$ whereas much closer distance is required for $B(\sim 2.4 \AA)$. This difference appears to be critically important to the outcome of the chemical reaction. In thie case of $\mathrm{B}$, electron transfer and symmetric bending of $\mathrm{NO}_{2}$ will only occur when the B atom is essentially within the attractive well of the very strongly bound $\mathrm{B}-\mathrm{O}_{2}$ interaction potential. In the case of $\mathrm{Ba}$, however, the ionic complex will execute many vibrations before the $\mathrm{Ba}^{+}$can approach within the close range required for formation of $\mathrm{BaO}_{2}$. Intramolecular energy redistribution within the complex leads to randomization of the initial symmetric bending motion. This results in long-lived complexes which decay to $\mathrm{BaO}+\mathrm{NO}-$ apparently the potential energy barrier for formation of $\mathrm{BaO}_{2}+\mathrm{N}$ is large. In those collisions where electron transfer into the $6 \mathrm{a}_{1}$ orbital can be avoided, the dominant chemical product is $\mathrm{BaNO}+\mathrm{O}$ rather than $\mathrm{BaO}_{2}$ $+\mathbf{N}$.

\section{CONCLUSIONS}

We have found the chemistry of the $\mathrm{Ba}+\mathrm{NO}_{2}$ reaction to be substantially more complex than previously believed. Our results on $\mathrm{Ba}+\mathrm{NO}_{2}$ disagree with the earlier conclusions, ${ }^{18}$ which were based solely on product angular distributions. We conclude that long-lived $\mathrm{Ba}^{+} \mathrm{NO}_{2}^{-}$intermediates are involved in the majority of all reactive trajectories despite reaction exoergicities that are comparable to complex well depths. 
This rather unusual behavior appears to be a dynamic consequence of the divalent nature of barium: decay of the initially formed complex to ground state molecules involves a substantial potential energy barrier. This barrier is associated with the electronic rearrangement necessary for the initially formed singly ionic $\mathrm{Ba}^{+} \mathrm{NO}_{2}^{-}$complex to decay to ground state doubly ionic $\mathrm{Ba}^{2+} \mathrm{O}^{2-}+\mathrm{NO}$. A very large release of translational energy, the magnitude of which is perhaps unprecedented from decay of collision complexes, results from a barrier to second electron transfer followed by strong repulsion of the stable $\mathrm{BaO}+\mathrm{NO}$ products.

Two additional direct reaction channels were observed. $\mathrm{A}$ minor $\mathrm{BaO}+\mathrm{NO}$ channel led to forward scattering of the metal oxide with a relatively small release of translational energy. Our observation that the yield of forward scattered products is larger than the known chemiluminescent yield indicates that this channel corresponds primarily to formation of vibrationally hot ground state $\mathrm{BaO}$ from direct reaction involving small impact parameter collisions. A previously unknown molecule, BaNO, was observed as a nascent minor product from $\mathrm{Ba}+\mathrm{NO}_{2}$. Unlike the dominant $\mathrm{BaO}$ channels that involve outer harpooning, formation of BaNO from $\mathrm{Ba}\left({ }^{1} \mathrm{~S}\right)$ likely results from the small fraction of collision geometries that avoid long range electron transfer.

Even with electronic excitation of the incident barium atom, reactions involving long-lived collision complexes continued to dominate the neutral product channels. ${ }^{35}$ Electronic excitation results in increased internal excitation of the $\mathrm{Ba}^{+} \mathrm{NO}_{2}^{-}$, leading to a larger average translational energy release in the $\mathrm{BaO}+\mathrm{NO}$ products. Whereas 
complexes resulting from collisions of ground state $\mathrm{Ba}$ only decayed to $\mathrm{BaO}+\mathrm{NO}$, a small fraction of those from electronically excited $\mathrm{Ba}$ also decayed to BaNO $+\mathrm{O}$.

\section{REFERENCES}

1. M. Polanyi, Atomic Reactions (Williams and Norgate, Ltd.), London (1932).

2. M.G. Evans and M. Polanyi, Trans. Faraday Soc., 35, 178 (1939).

3. D.R. Herschbach, Appl. Opt. Supp. 2, 128 (1965).

4. J.L. Magee, J. Chem. Phys., 8, 687, (1940).

5. R.D. Levine, R.B. Bernstein, "Molecular Reaction Dynamics and Chemical Reactivity", Oxford University Press, New York, (1987).

6. R.R. Herm in "Alkali Halide Vapors", P. Davidovits, D.L McFadden, Academic Press, New York, 1979.

7. a) S. Datz and R.E. Minturn, J. Chem. Phys., 41, 1153, (1964). b) R.E. Minturn, S. Datz, R.L. Becker, J. Chem. Phys., 44(3), 1149, (1966). c) K.R. Wilson, G.H. Kwei, J.A. Norris, R.R. Herm, J.H. Birely, and D.R. Herschbach, J. Chem. Phys., 41, 1154, (1964). d) J. H. Birely, R.R. Herm, K.R. Wilson, D.R. Herschbach, J. Chem. Phys., 47(3),993, (1967).

8. a) D.R. Herschbach, G.H. Kwei, J.A. Norris, J. Chem. Phys., 34, 1842, (1961).

b) D.R. Herschbach, Disc. Faraday Soc., 33, 149, 281 (1962).

9. a) E.H. Taylor and S. Datz, J. Chem. Phys., 23, 1711 (1955); 25, 389, 395 (1956). b) T.R. Touw and J.W. Trischka, J. Appl. Phys., 34, 3635 (1963). 
10. Y.T. Lee, J.D. MacDonald, P.R. LeBreton, and D.R. Herschbach, Rev. Sci. Instrum., 40, 1402 (1969).

11. a) A. Schultz, H.W. Cruse and R.N. Zare, J. Chem. Phys., 57(3) 1354 (1972). b) H.W. Cruse, P.J. Dagdigian, R.N. Zare, Faraday Disc. Chem. Soc., 55, 277 (1973).

c) R.N. Zare, P.J. Dagdigian, Science, 185(4153), 739 (1974).

12. a) C.D. Jonah, R.N. Zare, and Ch. Ottinger, J. Chem. Phys. 56, 263, (1972). b) K.G. Anlauf, P.E. Charters, D.S. Horne, R.G. Macdonald, D.H. Maylotte, J. C. Folanyi, W.J. Skrlac, D.C Tardy, and K.B. Woodall, J. Chem. Phys., 53, 4091 (1970) and references therein.

13. Ch. Ottinger and R.N. Zare, Chem. Phys. Lett., 5, 243 (1970).

14. A. Schultz and R.N. Zare, J. Chem Phys. 60, 5120 (1974).

15. C.R. Dickson, S.M. George, and R.N. Zare, J. Chem. Phys. 67, 1024 (1977).

16. For a complete list of papers up to 1982, see J.J. Reuther and H.B. Palmer, J. Chem. Phys. 77(1), 83 (1982).

17. Y.C. Hsu and J.G. Pruett, J. Chem. Phys. 76(12), 5849 (1981).

18. J.A. Haberman, K.G. Anlauf, R.B. Bernstein, F.J. Van Itallie, Chem. Phys. Lett., 16(3), 442 (1972).

19. R.R. Herm, S.M. Lin, C.A. Mims, J. Phys. Chem. 77(25), 2931, 1973.

20. J.H. Birely and D.R. Herschbach, J. Chem. Phys., 44(4) 1690 (1966). 
21. R.C. Weast, Ed., CRC Handbook of Chemistry and Physics, CRC Press, Inc. Boca Raton, Fla. (1987).

22. K.M. Ervin, J. Ho, and W.C. Lineberger, J. Phys. Chem., 92, 5405, (1988).

23. a) D.O. Ham, J.L. Kinsey and F.S. Klein, Disc. Faraday. Soc. 44, 174 (1967). b) D.O. Ham, J.L. Kinsey, J. Chem. Phys, , 48(2), 939 (1968), c) D.O. Ham and J.L. Kinsey, J. Chem. Phys., 53(1), 285 (1970).

24. a) W. B. Miller, S.A. Safron, D.R. Herschbach, Disc. Faraday Soc., 44, 108, (1967). b) W. B. Miller, Thesis, Harvard University, 1969.

25. R.R. Herm and D.R. Herschbach, J. Chem. Phys. $52(11), 5783$ (1970).

26. H.F. Davis, A.G. Suits, Y.T. Lee, to be published.

27. The reaction $\mathrm{Li}+\mathrm{NO}_{2}$ appears to be anomalous since velocity and angular analysis has indicated that the reaction is direct with preferential forward scattering of the $\mathrm{LiO}$ product. It has been argued that the $\mathrm{Li}^{+} \mathrm{NO}_{2}^{-}$intermediate is formed in an electronically excited state which is too weakly bound to survive even one rotational period. See: a) C.M. Sholeen and R.R. Herm, J. Chem. Phys., 64(12), 5261, (1976). b) D.D. Parrish and R.R. Herm, J. Chem. Phys., 54(6), 2518 (1971).

28. The reaction $\mathrm{Cs}+\mathrm{CH}_{3} \mathrm{NO}_{2} \rightarrow \mathrm{CsNO}_{2}+\mathrm{CH}_{3}$ is known to be exothermic (Ref. 25). Thus $\mathrm{D}_{\mathrm{o}}\left(\mathrm{Cs}-\mathrm{NO}_{2}\right)>60 \mathrm{kcal} /$ mole. Based on an empirical correlation between bond energy and electron affinities (Ref. 25), we calculate $\mathrm{D}_{0}\left(\mathrm{Cs}-\mathrm{NO}_{2}\right)$ $=\mathrm{D}_{0}(\mathrm{CsO})+\mathrm{EA}\left(\mathrm{NO}_{2}\right)-\mathrm{EA}(\mathrm{O})=89 \mathrm{kcal} / \mathrm{mole}$. However, this estimate is almost 
certainly too high since it neglects the different interionic distances for $\mathrm{Cs}^{+}-\mathrm{O}$ and $\mathrm{Cs}^{+}-\mathrm{NO}_{2}^{-}$.

29. a) JANAF Thermochemical Tables, 3rd ed. J. Physical and Chemical Ref. Data., Volume 14, (1985) Supplement No.1. (b) J. Phys. Chem. Ref. Data 12(4) 982 (1.783).

30. J.G. Pruett and R.N. Zare, J. Chem. Phys., 62, 2050 (1975).

31. It has generally been assumed that potential energy barriers to decay of the complex would be small.

32. C.E. Moore, Atomic Energy Levels, National Stand. Ref. Data Ser. (National Bureau of Standards, Washington D.C, 1971)

33. a) H. F. Davis, A.G. Suits, H. Hou, and Y.T. Lee, Ber. Bunsenges. Phys. Chem., 94, 11.93 (1990).

b) H. F. Davis, A.G. Suits, and Y.T. Lee, to be submitted to J. Chem. Phys. c) H.F. Davis, A.G. Suits, M.H. Covinsky, and Y.T. Lee, to be submitted to Rev. Sci. Instrum.

34. S. Niggle, M.C.E. Huber, Phys. Rev. A., 35(7), 2908, (1987).

35. The formation of nascent ions is discussed in a separate article. A polarization effect was observed in the ion channels. A.G. Suits, H. Hou, H.F. Davis, and Y.T. Lee, J. Chem. Phys, in press.

36. The reactivity of $\mathrm{Ba}+\mathrm{N}_{2} \mathrm{O}_{4}$ has been investigated. See: D.J. Wren, and $\mathrm{M}$. Menzinger, Chem. Phys., 66, 85 (1982). 
37. a) M.F. Vernon, Ph.D. Thesis, Univ. of California, Berkeley (1983), LBL15855. b) M.F. Vernon, H. Schmidt, P.S. Weiss, M.H. Covinsky, and Y.T. Lee, J. Chem. Phys., 84(10), 5580 (1986). c) P.S. Weiss, Ph.D. Thesis, Univ. of California, Berkeley (1986), LBL-21205. d) R.J. Buss, Ph.D. Thesis, Univ. of California, Berkeley (1979), LBL-9057 e) J.A. Nelder and M. Mead, Computer Journal, 7, 305 (1965).

38. G. Comsa, R. David, B.J. Schumacher, Rev. Sci. Instrum., 52(6), 789 (1981).

39. M.H. Covinsky, A.G. Suits, H.F. Davis, and Y.T. Lee, J. Chem. Phys., submitted for publication.

40. C. Batalli-Cosmovici and K.W. Michel, Chem. Phys. Lett, 11, 245 (1971).

41. Y.T. Lee, J.D. McDonald, P.R. LeBreton and D.R. Herschbach, J. Chem. Phys., 49, 2447, (1968).

42. C. H. Becker, P. Casavecchia, P.W. Tiedmann, J.J. Valentini, and Y.T. Lee, J. Chem. Phys., 73(6), 2833 (1980).

43. R. Wolfgang, Acc. Chem. Res., 3, 48, (1969).

44. G.A. Fisk, J.D. McDonald, D.R. Herschbach, Disc. Faraday. Soc., 44, 228 (1967).

45. a) T. P. Parr, A. Freedman, R. Behrens, Jr., and R.R. Herm, J. Chem. Phys., 67(5), 2181, (1977); b) S.-M. Lin, C.A. Mims, and R.R. Herm, J. Phys. Chem., 77(5), 569 (1973). 
46. We have observed formation of Rydberg sodium atoms in recent experiments. These are formed in the ionizer and subsequently undergo surface ionization at the back surface of the detector. This signal can be easily distinguished from product molecules: The peak is much slower than the reactive signal, it is independent of mass setting, and disappeared upon turning off the ionizer.

47. H.F. Davis, A.G. Suits, Y.T. Lee, C. Alcaraz and J.M. Mestdagh, J. Chem. Phys., to be submitted for publication, and references therein.

48. J.M. Farrar, and Y.T. Lee, Ann. Rev. Phys. Chem., 25, 357, (1974).

49. We found that the reaction $\mathrm{Mg}+\mathrm{NO}_{2} \rightarrow \mathrm{MgO}+\mathrm{NO}$ also involves long-lived collision complexes (work in progress).

50. The energies of the excited states of $\mathrm{NO}_{2}{ }^{-}$are based on the average of several experimental values. See P.A. Benioff, J. Chem. Phys., 68(8), 3405 (1978) and references therein.

51. D.C. Frost, C.A. McDowell, Can. J. Chem., 38, 407 (1960).

52. R. Aboual, R. Paineau and F. Fiquet-Fayard, J. Phys. B., 9(2), 303, (1976).

53. a) C.J. Hardy, B.O Field, J. Chem. Soc., 8, 5130, (1963).

b) A. Büchler and J.L. Stauffer, J. Phys. Chem. 70(12), 4092, (1966).

54. M. Barbeschi, L. Bencivenni, F. Ramondo, Chem. Phys., 112, 387, (1987).

55. a) E.N. Verkhouturov, A.V. Makarov and O.T. Nikitin, Vestn. Mosk. Univ. Khim. 17, 299, (1976). b) A.M. Shapovalov, V.F. Shevelkov and A.A. Maltsev, Vestn. Mosk. Univ. Khim. 14, 151, (1973). 
56. F. Ramondo, Chem. Phys. Lett., 156(4), 346 (1989).

57. a) D.E. Tevault and L. Andrews, Chem. Phys. Lett., 48(1), 103 (1977), b) D.E. Tevault and L. Andrews J. Phys. Chem. 77(13), 1640, (1073).

58. The original version of the RRKM program employed in estimating complex lifetimes was written by W.L. Hase and D.L. Bunker; See P.J. Robinsion and D.A. Holbrook, Unimolecular Reactions, Wiley-Interscience, New York, 1972.

59. S.R. Langhoff, C.W. Bauschlicher, Jr., H. Partridge, J. Chem. Phys., 84(8) 4474 (1986).

60. N.F. Mott, H.S.W. Massey, The Theory of Atomic Collisions, 3rd ed. (Oxford University Press, London, 1965.

61. R.E. Olson, F.T. Smith and E. Bauer, Appl. Optics, 10, 1848 (1971).

62. a) D. E. Tevault and L. Andrews, J. Phys. Chem., 77(13), 1646 (1973). b) W.

L. Andrews, G.C. Pimentel, J. Phys. Chem., 44(6), 2361 (1966).

63. M. Steinberg and K. Schofield, J. Chem. Phys., 94(5), 3901 (1991).

64. G. J. Green and J. L. Gole, Chem. Phys. Lett, 69(1), 45 (1980).

65. G. Herzberg, Spectra of Diatomic Molecules, Van Nostrand, Princeton, N.J. (1950). 
TABLE I. Thermodynamics of Possible $\mathrm{Ba}\left({ }^{1} \mathrm{~S}\right)+\mathrm{NO}_{2}$ Reactions

Reaction

$\Delta \mathrm{H}(\mathrm{kcal} / \mathrm{mole})$

$\mathrm{BaO}\left(\mathbf{X}^{1} \Sigma^{+}\right)+\mathrm{NO}$

$-61^{*}$

$\mathrm{BaO}\left(\mathrm{A}^{1} \Sigma^{+}\right)+\mathrm{NO}$

$-11^{a}$

$\mathrm{BaO}\left(\mathrm{A}^{\prime 1} \mathrm{M}, \mathrm{a}^{3} \mathrm{\Pi}\right)+\mathrm{NO}$

$-11^{4}$

$\mathrm{BaNO}+\mathrm{O}$

$+7^{b}$

$\mathrm{BaO}_{2}+\mathrm{N}$

$-12^{c}$

- Reference 29. ${ }^{b}$ Reference 33a ' References 33a and 33b

TABLE II. Measured Atomic and Molecular Beam Velocities and Speed Ratios

\begin{tabular}{|c|c|c|c|}
\hline Beam & Seed Gas $\left(\mathrm{P}^{n}\right)$ & Beam Velocity $(\mathrm{m} / \mathrm{s})$ & Speed Ratio ${ }^{b}$ \\
\hline $\mathrm{Ba}$ & $\mathrm{Kr}(300)$ & 860 & 12 \\
\hline $\mathrm{Ba}$ & $\operatorname{Ar}(400)$ & 1200 & 14 \\
\hline $\mathrm{Ba}$ & $\mathrm{He}: \mathrm{Ne}^{\mathrm{c}}(550)$ & 1960 & 14 \\
\hline $\mathrm{Ba}$ & $\mathrm{He}(700)$ & 3560 & 16 \\
\hline $\mathrm{NO}_{2} \sim 10 \%$ & $\mathrm{He}(250)$ & 1520 & 14 \\
\hline $\mathrm{NO}_{2} \sim 20 \%$ & $\mathrm{He}(250)$ & 1210 & 12 \\
\hline $\mathrm{NO}_{2}(100 \%)$ & None & 720 & 6 \\
\hline
\end{tabular}


TABLE III. States of $\mathrm{NO}_{2}{ }^{-}$

\begin{tabular}{lllll} 
State & $\mathrm{E}(\mathrm{eV})^{\mathrm{A}}$ & $\mathrm{R}_{\mathrm{x}}(\AA)^{\mathrm{b}}$ & $\sigma_{\text {calc }}\left(\AA^{2}\right)^{\mathrm{c}}$ \\
\hline${ }^{1} \mathrm{~A}_{1}$ & $\ldots .66 \mathrm{a}_{1}{ }^{2}$ & $-2.27^{\mathrm{d}}$ & 4.9 & 75 \\
${ }^{3} \mathrm{~B}_{1}$ & $\ldots .6 \mathrm{a}_{1}{ }^{1}, 2 \mathrm{~b}_{1}{ }^{1}$ & $+0.57^{\mathrm{c}}$ & 2.5 & 20 \\
${ }^{1} \mathrm{~B}_{1}$ & $\ldots .6 \mathrm{a}_{1}{ }^{1}, 2 \mathrm{~b}_{1}{ }^{1}$ & $+1.2^{\mathrm{c}}$ & 2.2 & 15 \\
\hline
\end{tabular}

a. Energy relative to $\mathrm{NO}_{2}+e$.

b. Ionic covalent curve crossing radius calculated using $R_{x}(\AA)=14.4 /\left(I \cdot P_{\cdot B_{n}}-E\right)(e V)$.

c. Estimated harpooning cross section based on $\sigma_{\text {calc }}=\pi \mathrm{R}_{\mathrm{x}}{ }^{2}$

d. Electron affinity of $\mathrm{NO}_{2}$ from Ref 22 .

e. Energies relative to $\mathrm{NO}_{2}+e^{-}$based on $\mathrm{NO}_{2}$ electron affinity and excited state energies tabulated in Ref 50.

TABLE IV: Molecular Parameters

\begin{tabular}{llc} 
Species & $\mathrm{R}_{\mathrm{N} \cdot \mathrm{o}}(\AA)$ & $\alpha$ (degrees) \\
\hline $\mathrm{NO}_{2}\left(\mathrm{X}^{2} \mathrm{~A}_{1}\right)$ & $1.19389(4)^{a}$ & $133.857(3)^{\star}$ \\
$\mathrm{NO}_{2} \cdot\left(\mathrm{X}^{1} \mathrm{~A}_{1}\right)$ & $1.25(2)^{a}$ & $117.5 \pm 2 .^{\star}$ \\
$\mathrm{NO}\left(\mathrm{X}^{2} \mathrm{I}\right)$ & $1.1508^{\mathrm{b}}$ & - \\
\hline
\end{tabular}
a. Ref 22 , and references therein.
b. $\operatorname{Re} f 65$ 


\section{FIGURE CAPTIONS}

1. Top view of the crossed molecular beams apparatus.

2. $\mathrm{BaO}$ laboratory angular distribution for $\mathrm{Ba}+\mathrm{NO}_{2} \rightarrow \mathrm{BaO}+\mathrm{NO}$ at collision energy of $12.5 \mathrm{kcal} / \mathrm{mole}$. O Experimental points. - Total fit to data.

Contribution from channel 1. ...-- Contribution from channel 2. The nominal Newton diagram is shown with a limiting circle indicating the maximum centerof-mass velocity for $\mathrm{BaO}$ based on the known reaction exoergicity for formation of ground state products.

3. $\mathrm{BaO}$ product time-of-flight spectra at indicated laboratory angles for $\mathrm{Ba}+\mathrm{NO}_{2}$ $\rightarrow \mathrm{BaO}+\mathrm{NO}$ at collision energy of $12.5 \mathrm{kcal} / \mathrm{mole}$. o Experimental data.

Total fit to data.

Contribution from channel 1. -.--..- Contribution from channel 2.

4. Best fit translational energy $P(E)$ and center-of-mass angular distribution $T(\theta)$ for the $\mathrm{BaO}+\mathrm{NO}$ products. Collision energy was $12.5 \mathrm{kcal} / \mathrm{mole}$. Channel 1 represents the channel involving long-lived $\mathrm{BaNO}_{2}$ collision complexes and channel 2 is the direct forward scattered channel.

5. $\mathrm{BaO}$ product angular distributions obtained at mean collision energies of 31 and $59 \mathrm{kcal} / \mathrm{mole}$.

6. Same as Fig. 3 but $\mathrm{E}_{\text {coll }}=59 \mathrm{kcal} / \mathrm{mole}$.

7. Same as Fig. 4 but $\mathrm{E}_{\mathrm{coll}}=59 \mathrm{kcal} / \mathrm{mole}$. 
8. BaO product flux contour map at $\mathrm{E}_{\text {coul }}=12.5 \mathrm{kcal} / \mathrm{mole}$. A- Newton diagram BContribution from channel 1. C-Contribution from channel 2. C-Total BaO product flux (Channel $1+$ Channel 2$)$.

9. BaO product flux contour map for channel $1+$ channel 2 superimposed on the nominal Newton diagram. $\mathrm{E}_{\text {coll }}=12.5 \mathrm{kcal} / \mathrm{mole}$.

10. BaO product angular distribution at collision energy of $12.5 \mathrm{kcal} / \mathrm{mole}$ showing effect of electronic excitation of the incident $\mathrm{Ba}$ atoms. Laser excitation was at the collision zone. Beam consists of approx. $30 \%^{1,3} \mathrm{D}, 35 \%{ }^{1} \mathrm{P}, 35 \%{ }^{1} \mathrm{~S}$. Nominal Newton diagram showing circles representing maximum $\mathrm{BaO}$ velocities from reaction of ground state $\mathrm{Ba}\left({ }^{1} \mathrm{~S}\right)$ (dotted line) and electronically excited $\mathrm{Ba}\left({ }^{1} \mathrm{P}\right)$ (solid line).

11. BaNO product angular distribution at collision energy of $59 \mathrm{kcal} / \mathrm{mole}$. Laser off: - Experimental points, --- Fit to data. Laser focussed at interaction region: Experimental points, - Fit to data. Newton diagram is also shown.

12. BaNO product time-of-flight data from reaction of $\mathrm{Ba}\left({ }^{1} \mathrm{~S}\right)$ at indicated laboratory angles for $\mathrm{Ba}+\mathrm{NO}_{2} \rightarrow \mathrm{BaNO}+\mathrm{O}$. Collision energy was $59 \mathrm{kcal} / \mathrm{mole}$. oExperimental points. - Fit to data.

13. Same as Fig. 12 but with laser excitation at interaction region.

14. Best fit translational energy $P(E)$ and center-of-mass angular distribution $T(\theta)$ for the BaNO + O products. Collision energy was $59 \mathrm{kcal} / \mathrm{mole}$. --- Laser off. Laser excitation at interaction region. 
15. Center-of-mass product flux contour map in velocity space for the BaNO product from the $\mathrm{Ba}+\mathrm{NO}_{2}$ reaction. Laser is off, $\mathrm{E}_{\mathrm{coll}}=59 \mathrm{kcal} / \mathrm{mole}$.

16. Electron probability density maps for the half occupied $6 a_{1}$ and unoccupied $2 b_{1}$ orbitals of $\mathrm{NO}_{2}$.

17. Energy level diagram for reaction of $\mathrm{Ba}\left({ }^{1} \mathrm{~S}\right)+\mathrm{NO}_{2}$. Shaded area indicates uncertainties in thermodynamic quantities. 


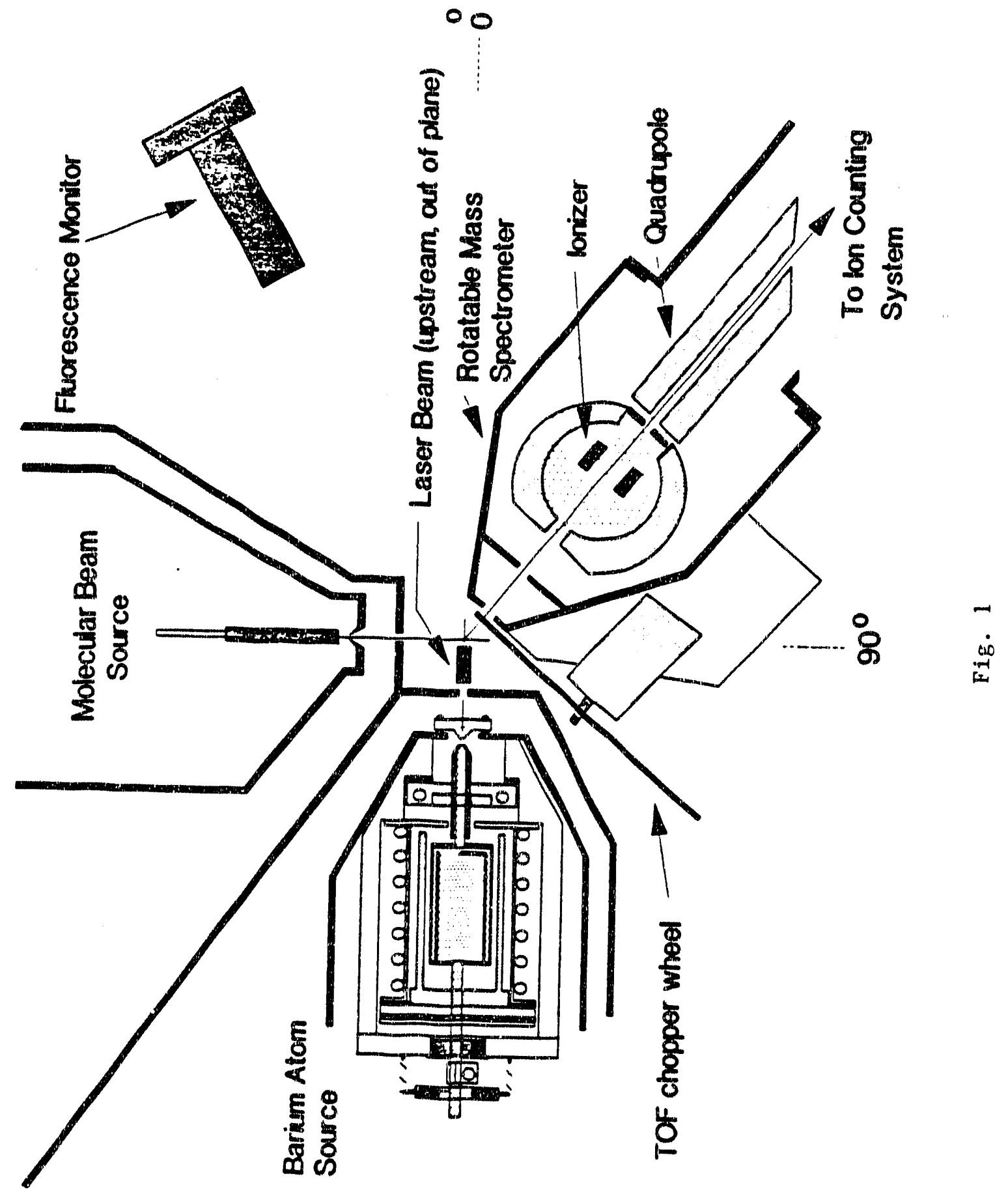



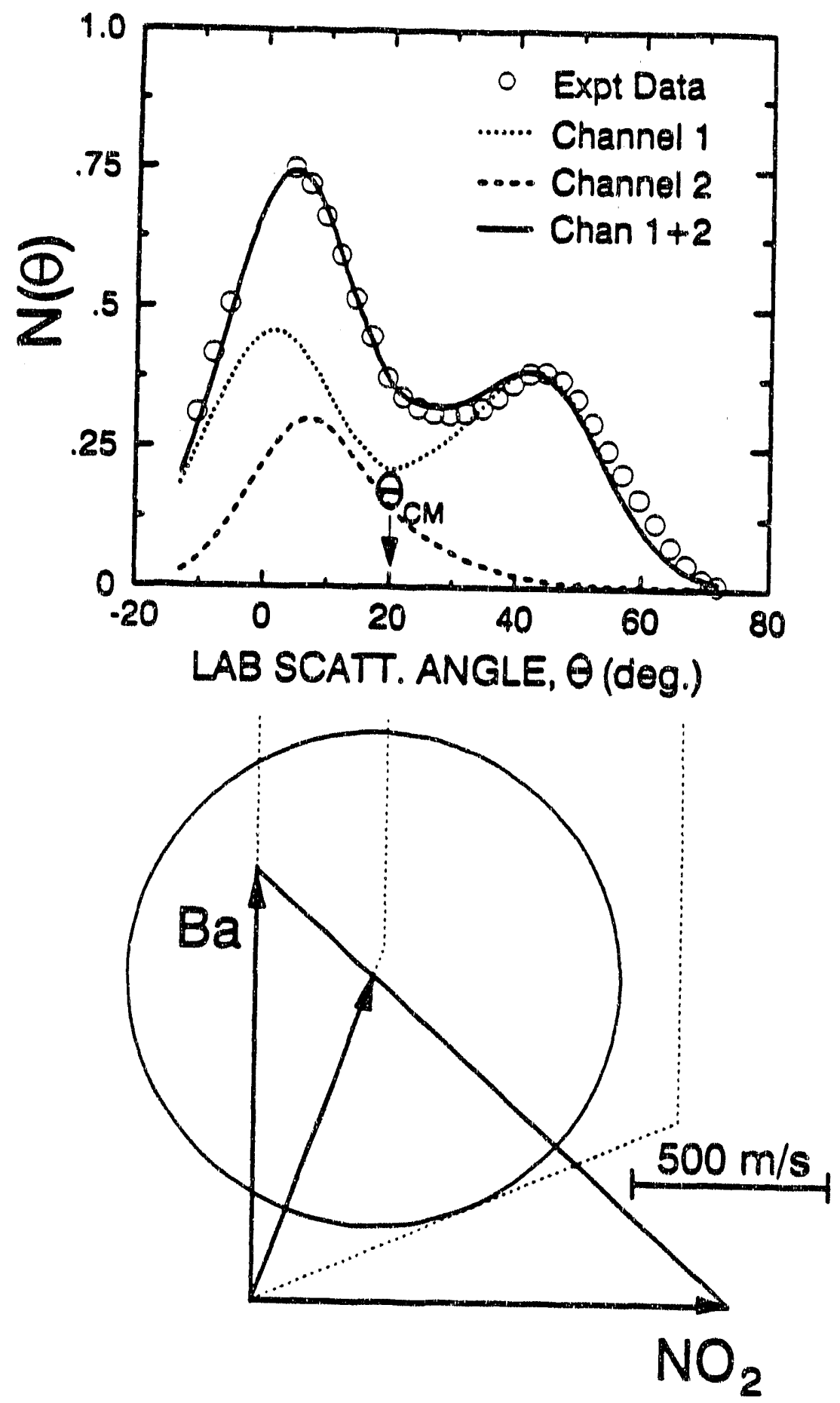

Fig. 2 


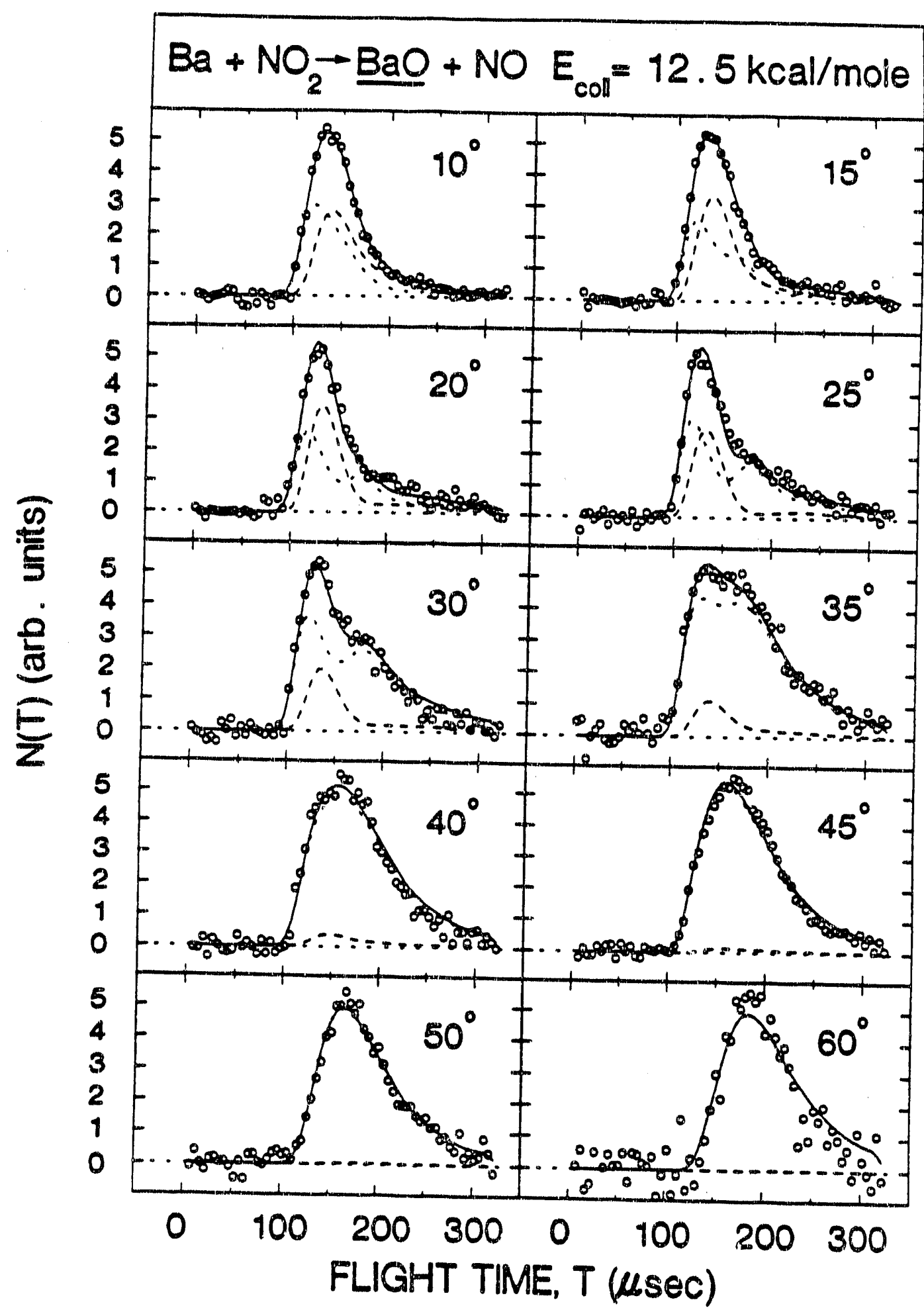

Fig. 3 

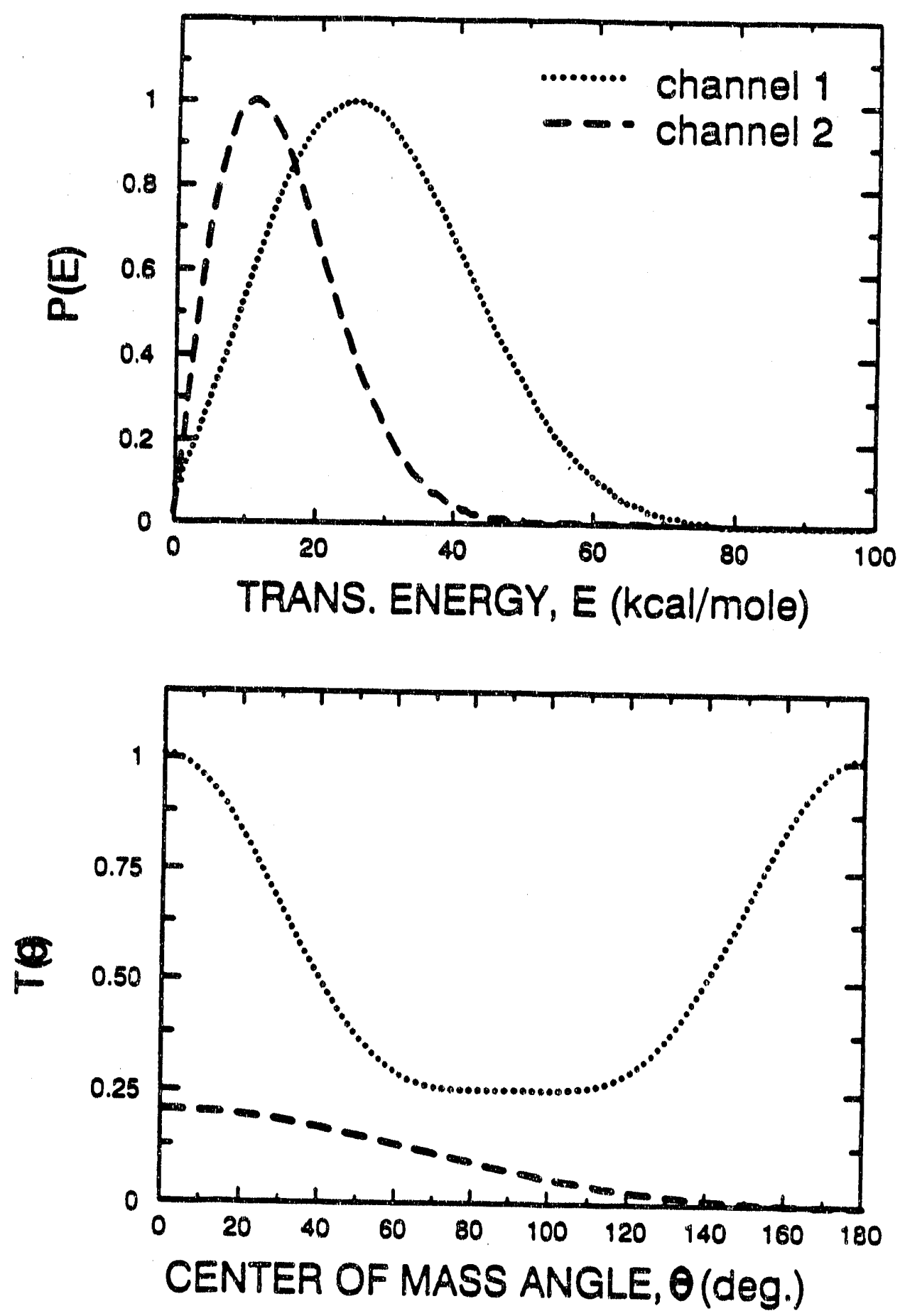

Fig. 4 

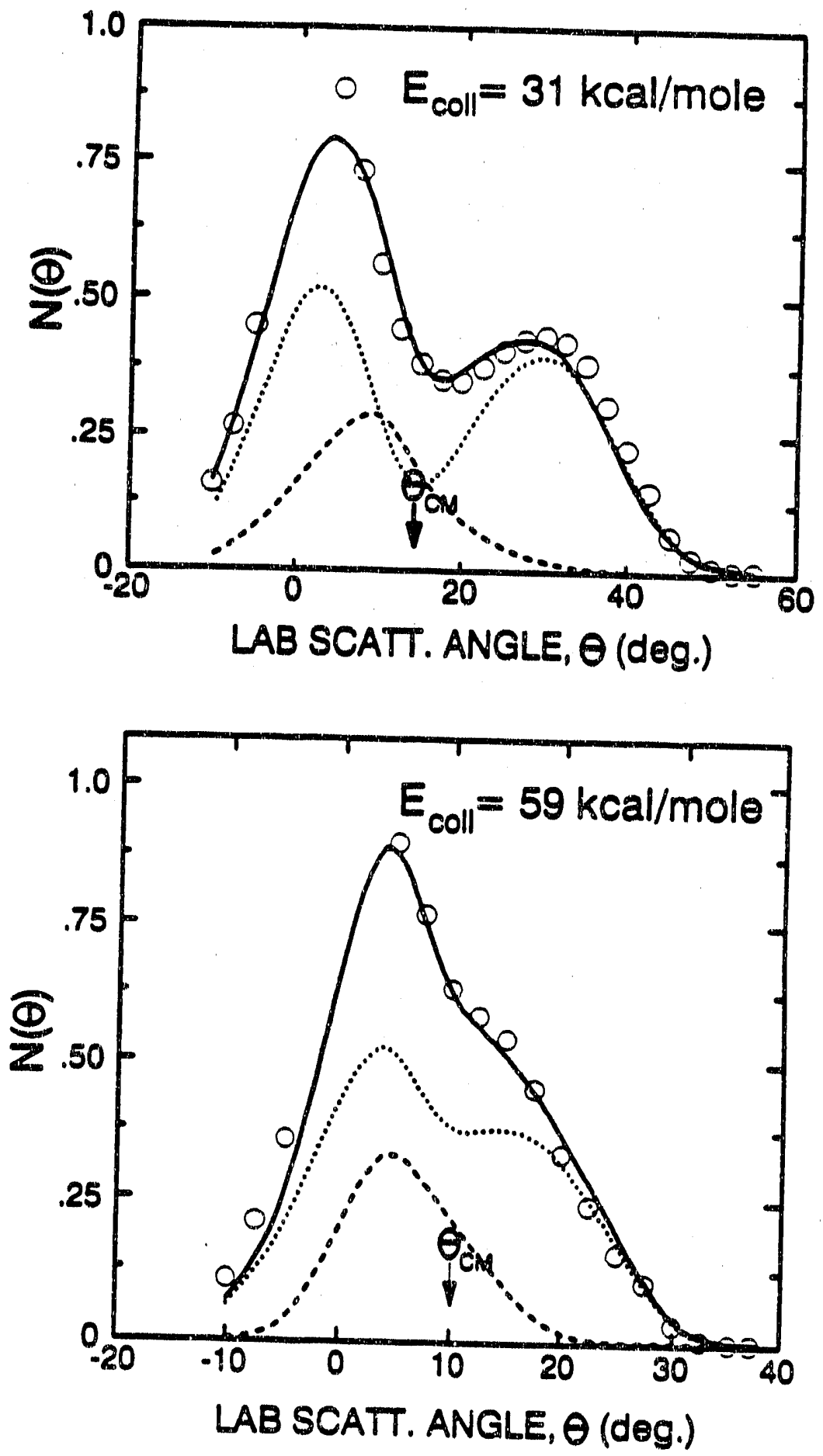

Fig. 5 


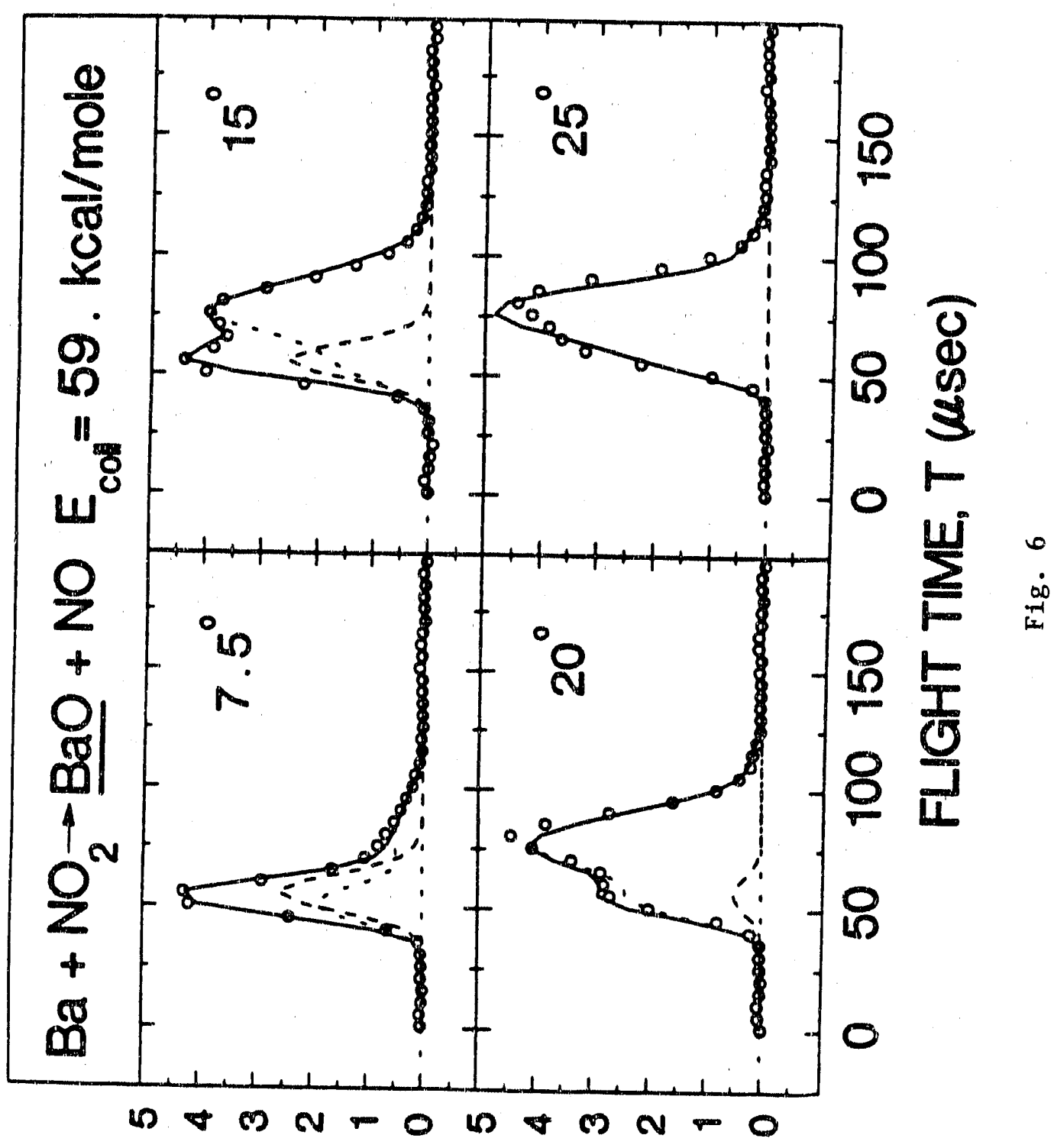



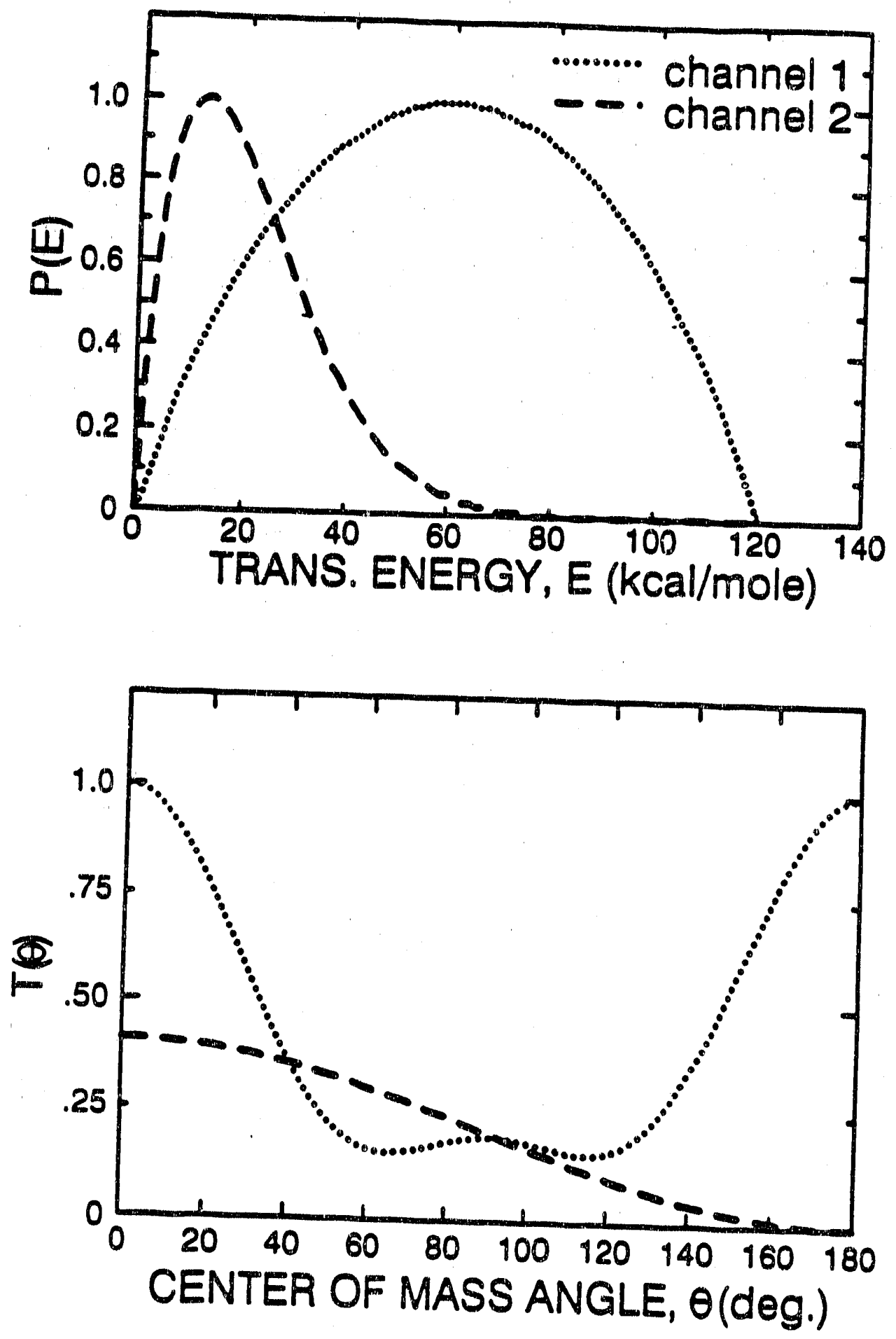

Fig. 7 


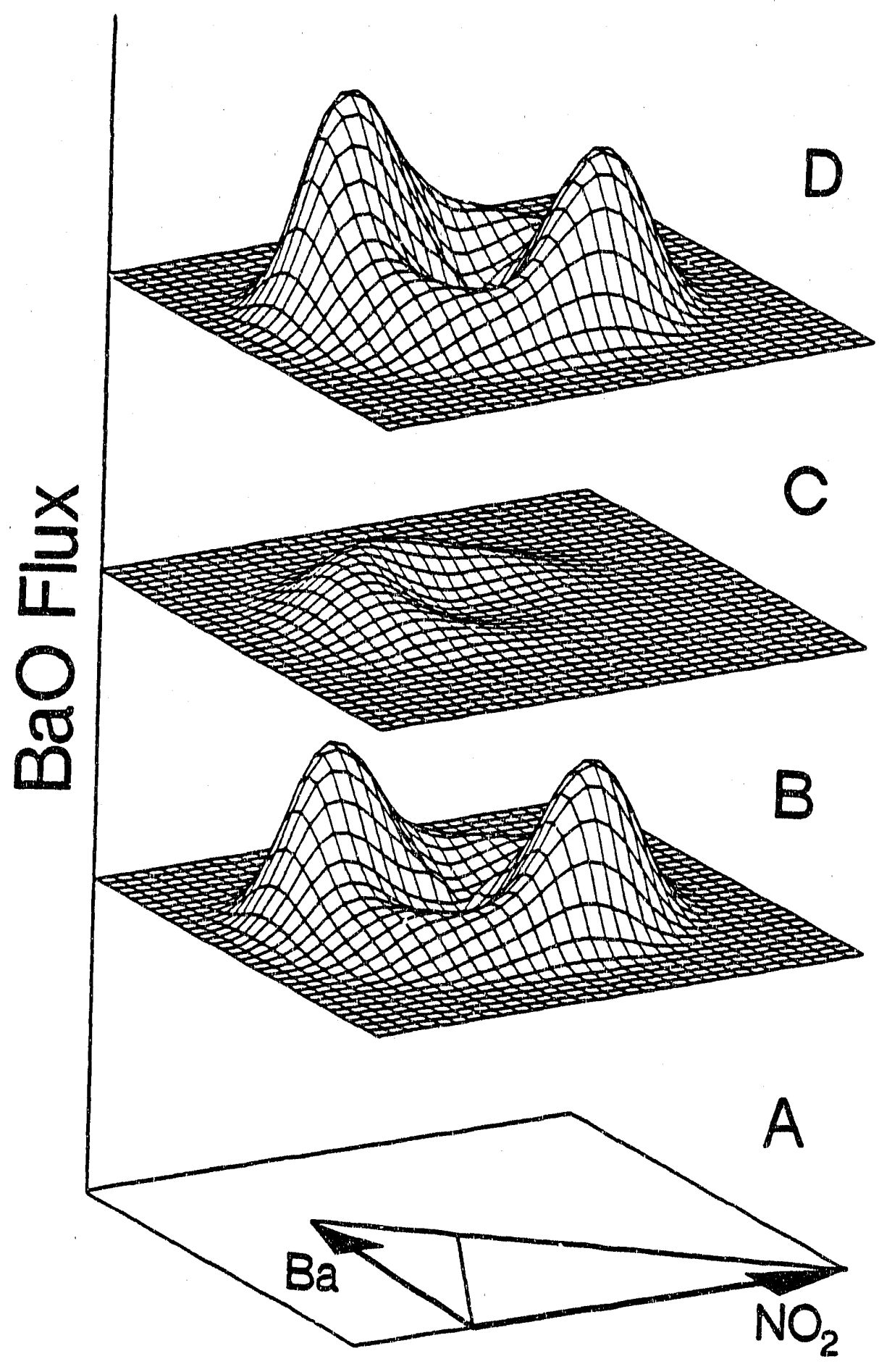

Fig. 8 


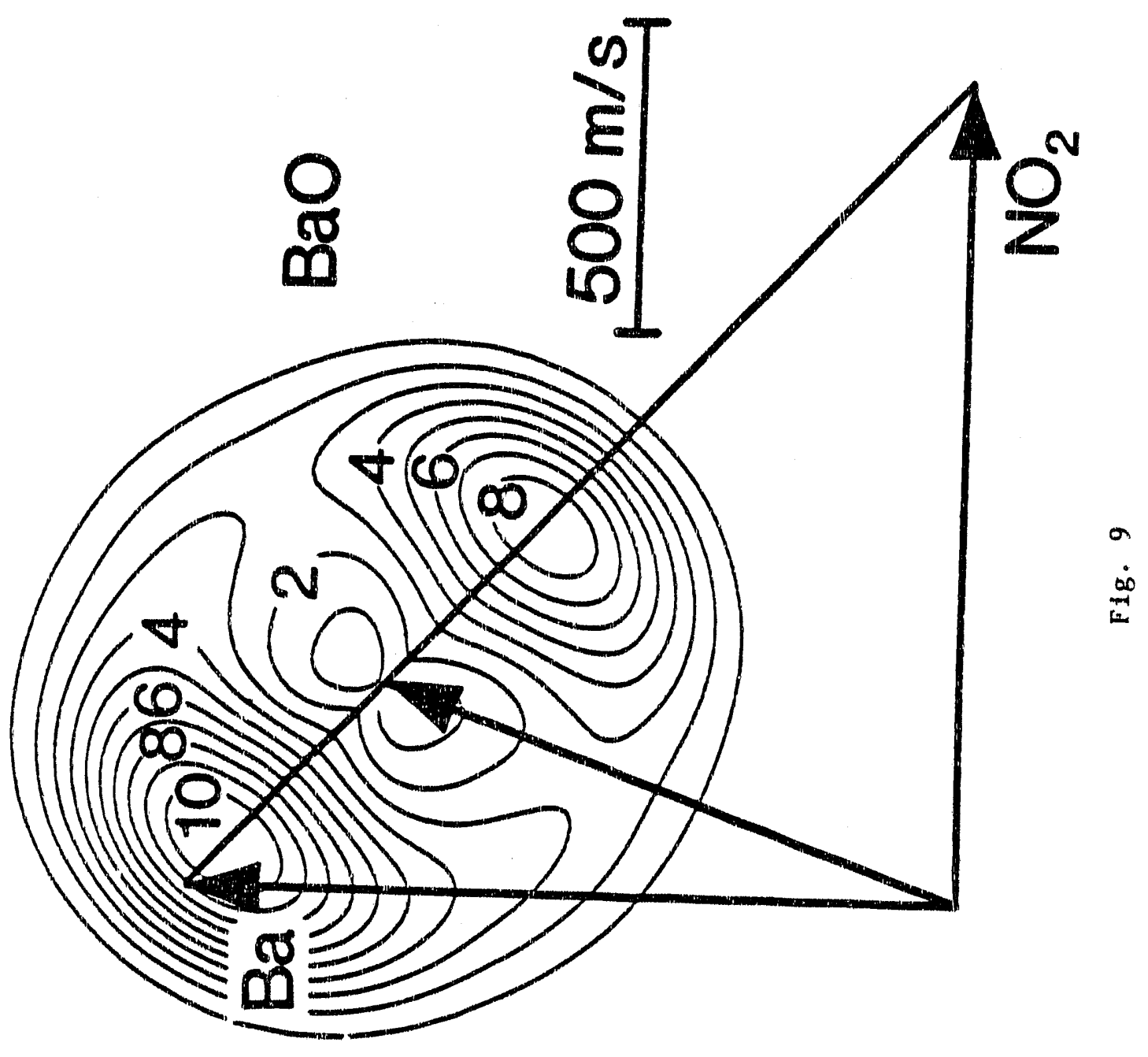




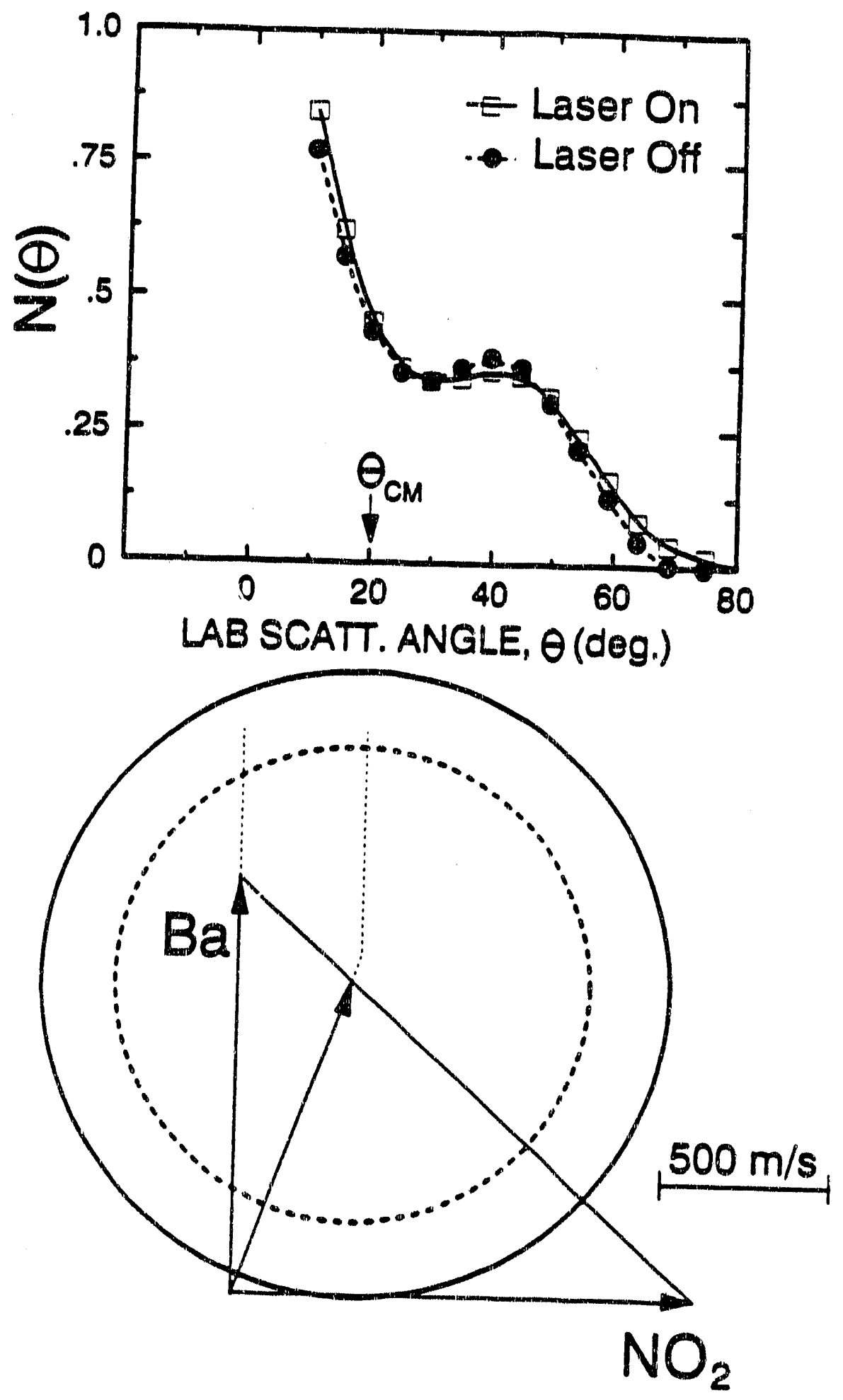

Fig. 10 

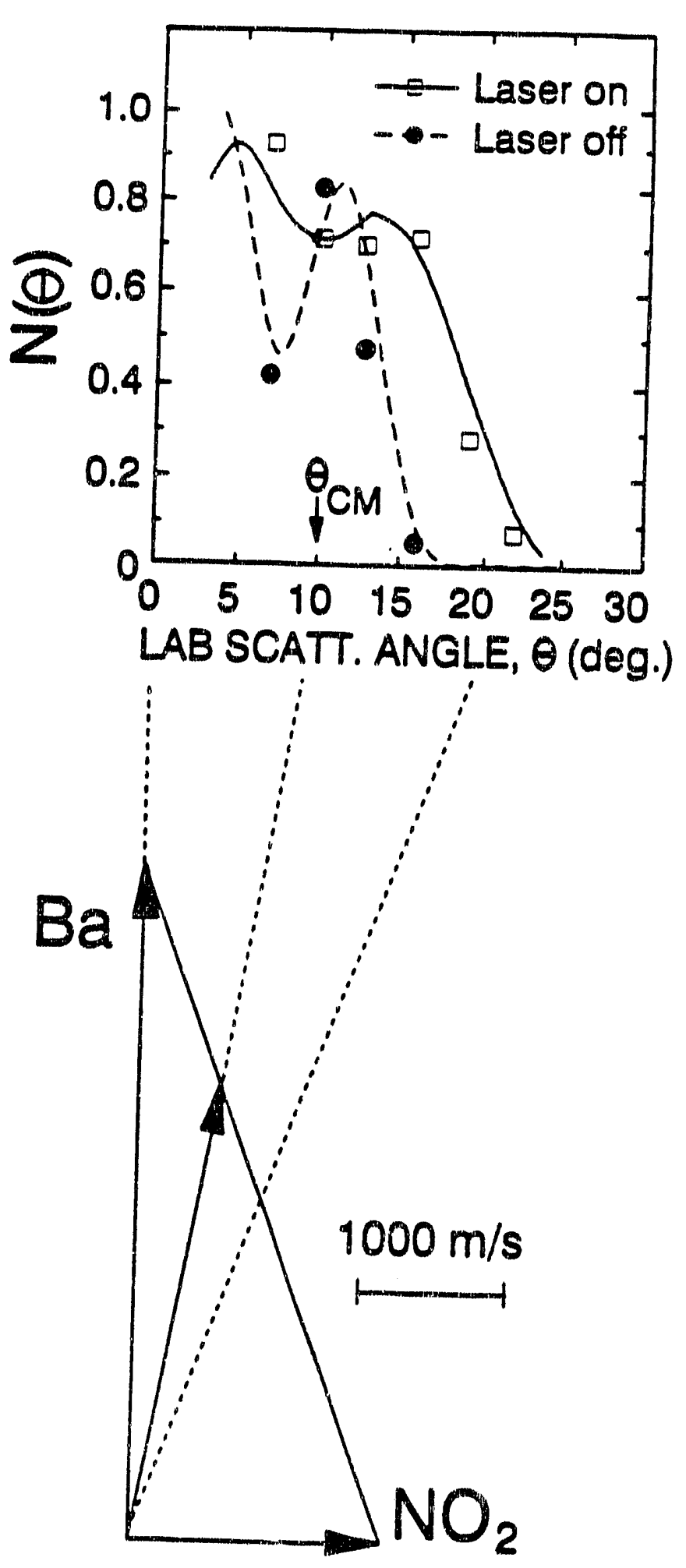

Fig. II 


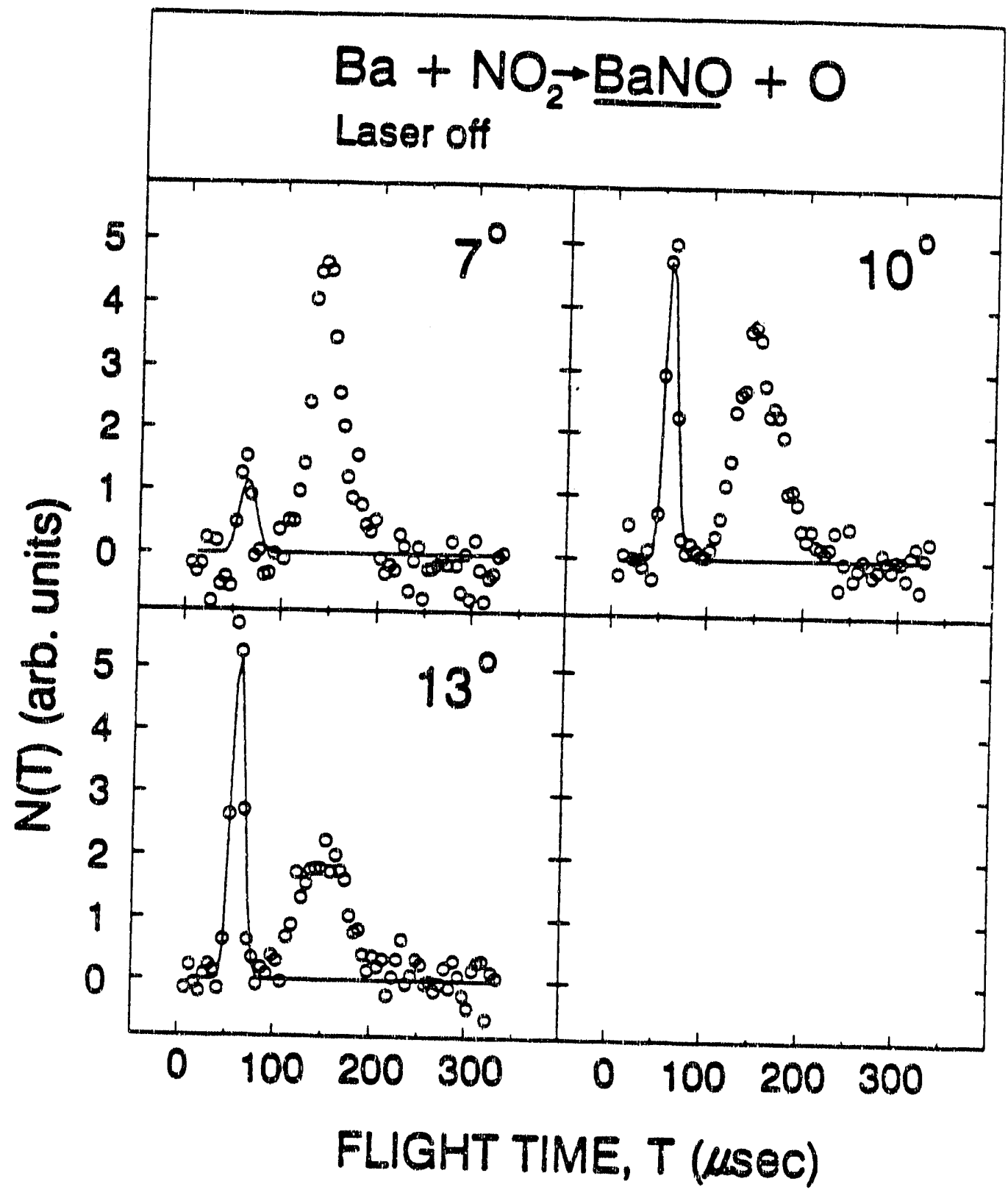

Fig. 12 


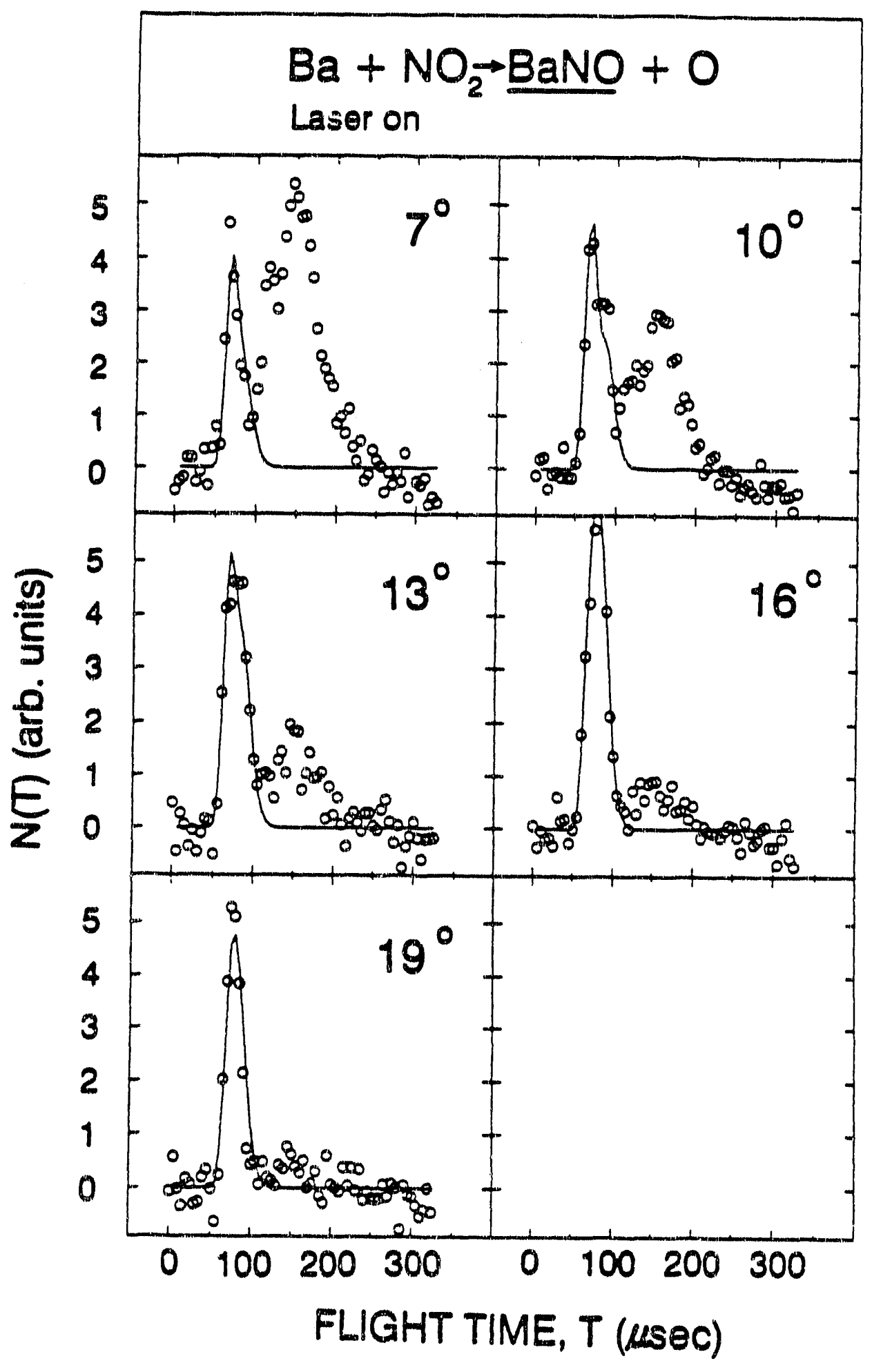

Fig. 13 

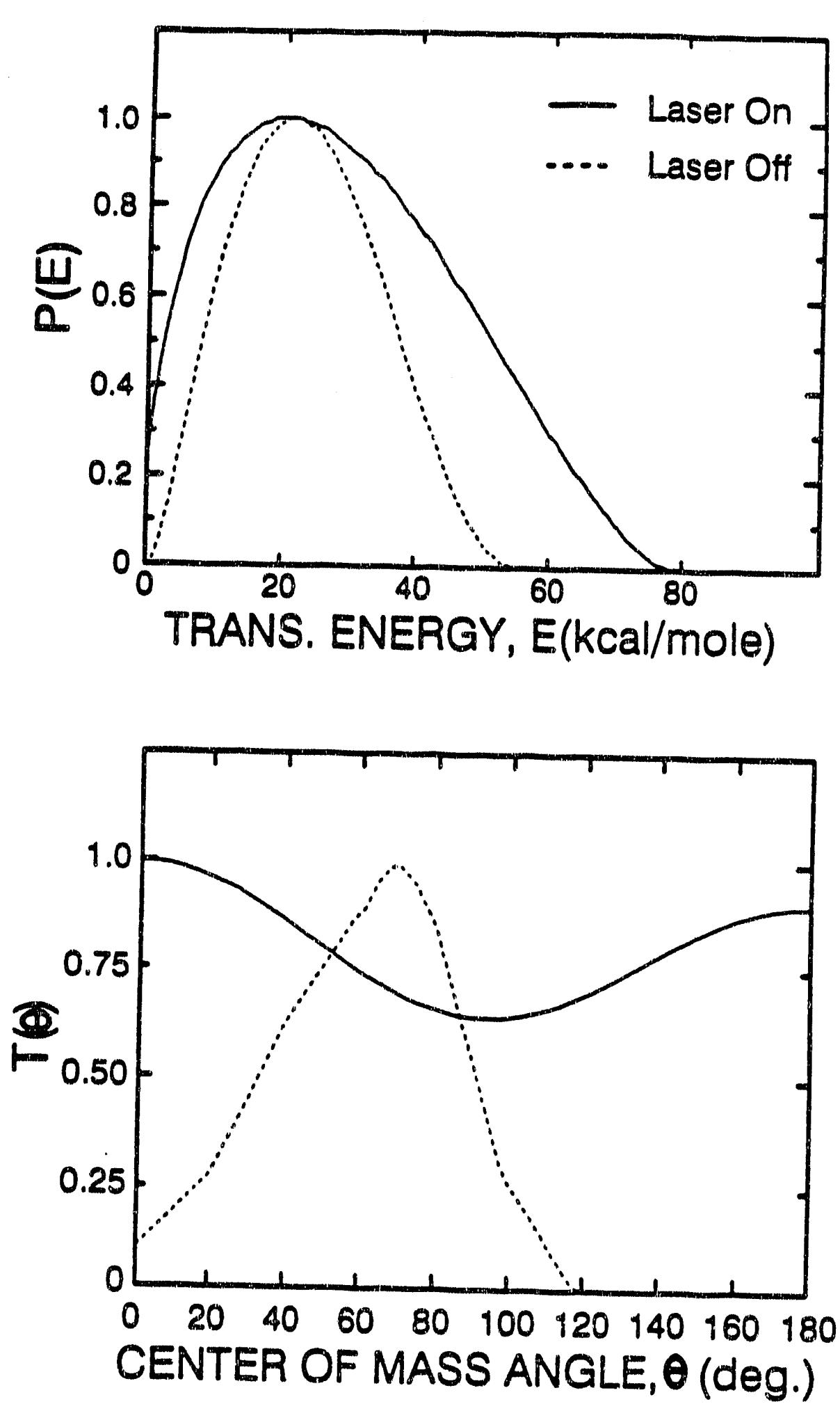

Fig. 14 


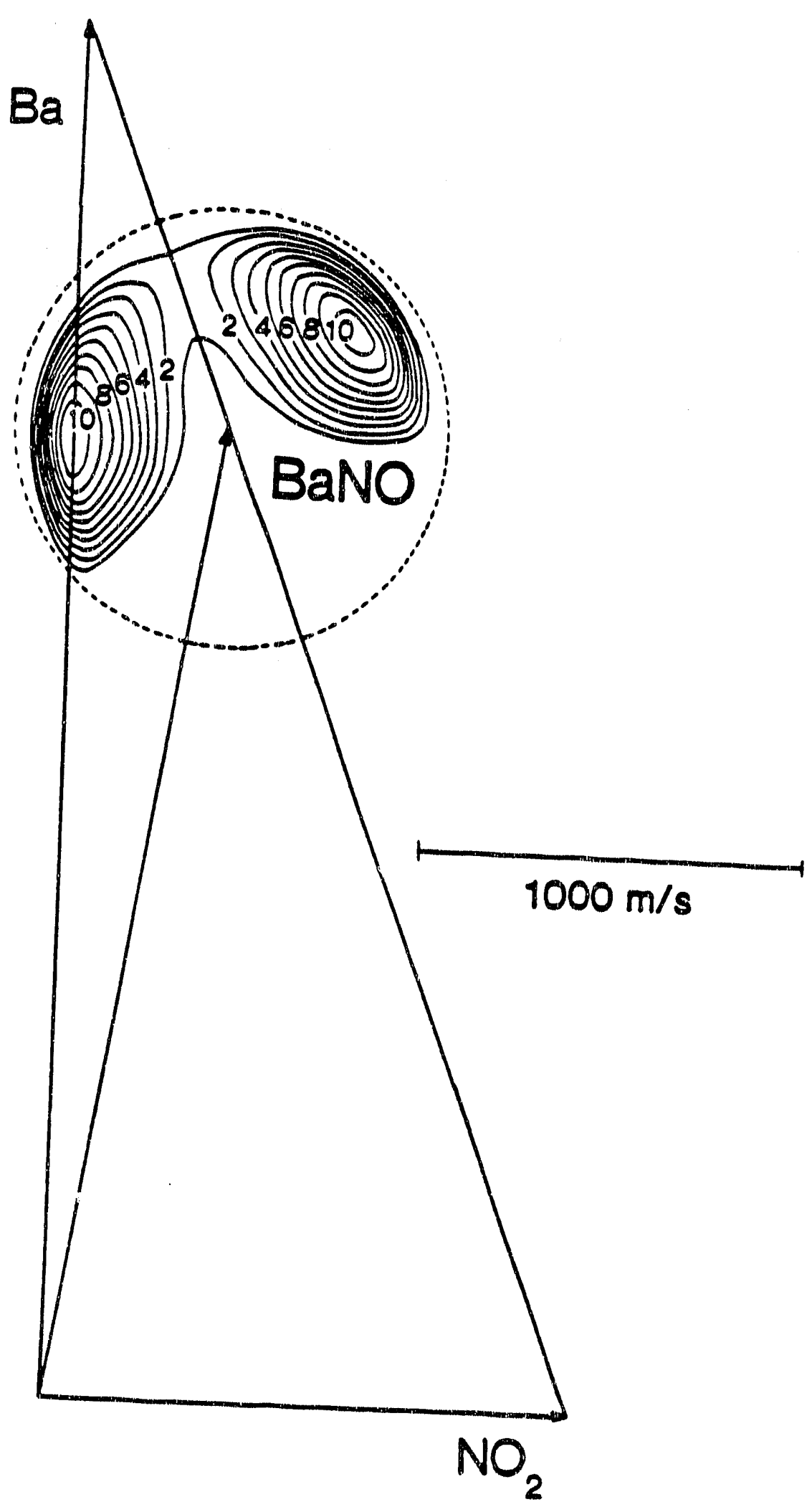

Fig. 15 


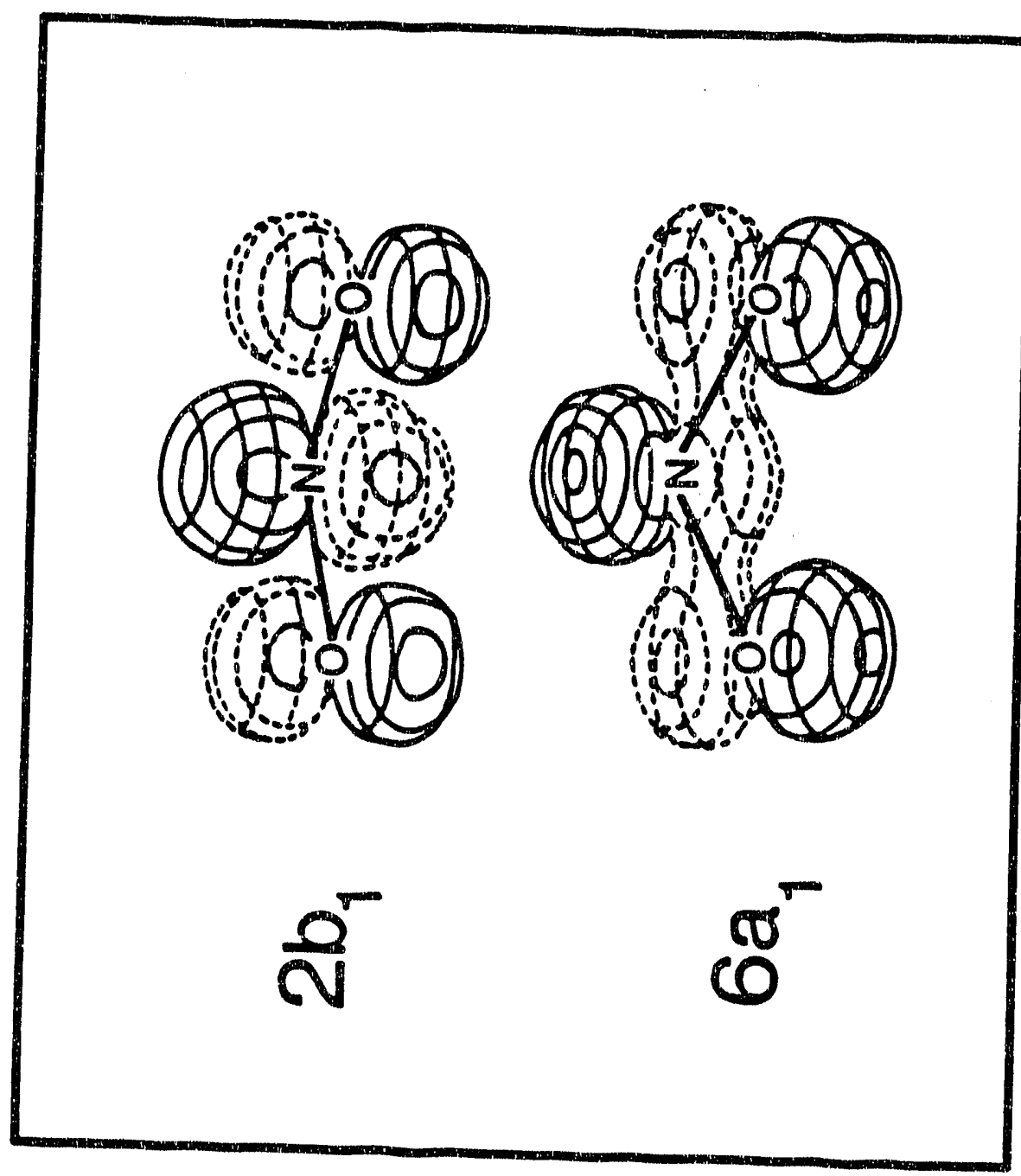

$\underset{\substack{\infty \\ \text { Lid }}}{\infty}$ 


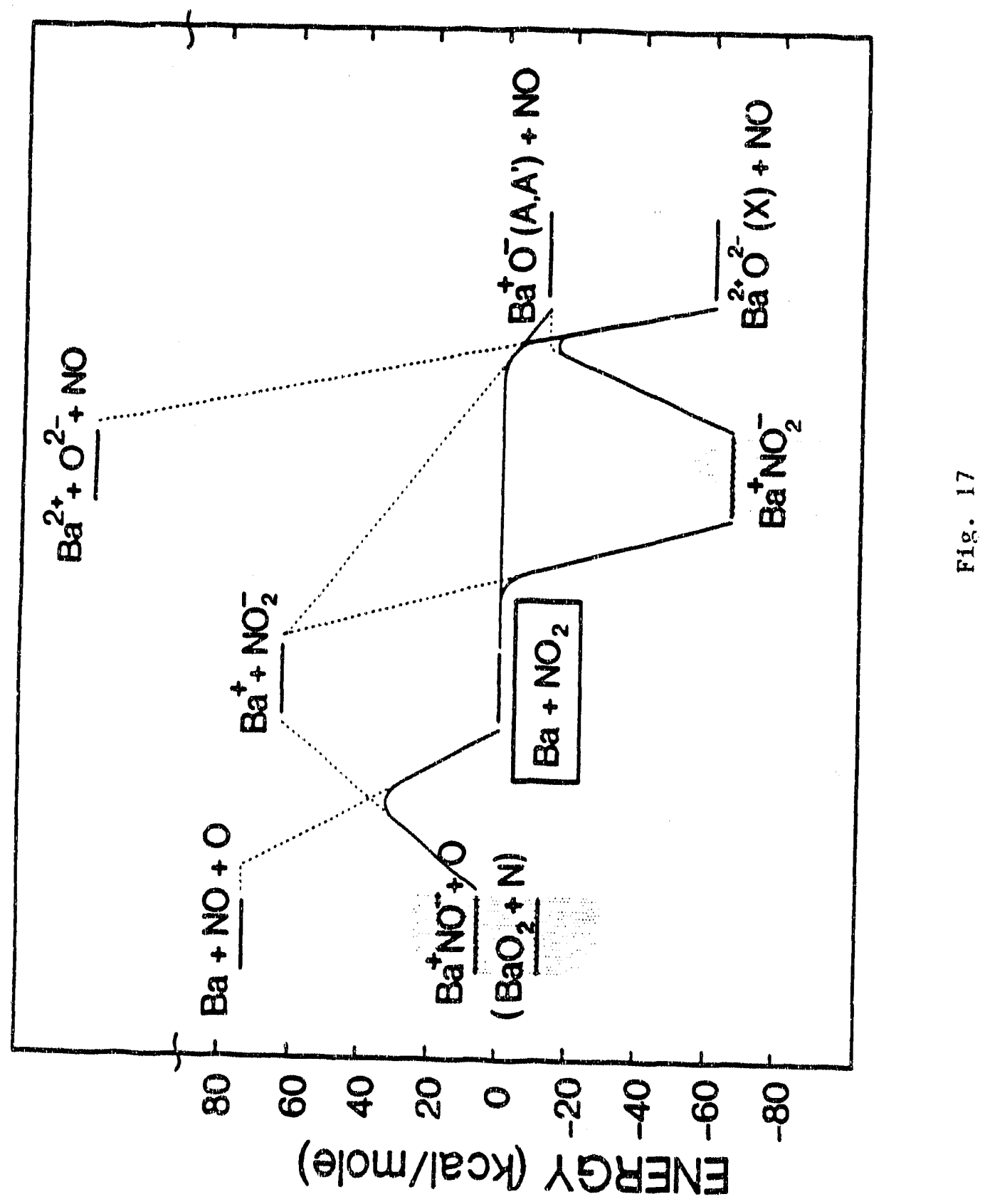




\title{
CHAPTER 2
}

\section{State Specific Reactions of $\mathrm{Ba}\left({ }^{1} \mathrm{~S}_{0}\right)$ and $\mathrm{Ba}\left({ }^{1} \mathrm{D}_{2}\right)$ With Water and its Alkyl Derivatives.}

\begin{abstract}
The reactions of $\mathrm{Ba}\left(6 \mathrm{~s}^{2}-{ }^{1} S_{0}\right)$ and $\mathrm{Ba}\left(6 s 5 \mathrm{~d}-{ }^{-1} \mathrm{D}_{2}\right)$ with water and alcohols were studied under single collision conditions using crossed molecular beams. Reaction of ground state $\mathrm{Ba}\left({ }^{1} \mathrm{~S}\right)+\mathrm{H}_{2} \mathrm{O}$ led to dominant formation of $\mathrm{BaO}\left(\mathrm{X}^{1} \Sigma^{+}\right)+\mathrm{H}_{2}$ at all collision energies studied but the formation of $\mathrm{BaOH}+\mathrm{H}$ could be observed weakly at collision energies above the endoergicity of the reaction $(13 \mathrm{kcal} / \mathrm{mole})$. Electronic excitation of the $\mathrm{Ba}$ atom reactant to the metastable ${ }^{1} \mathrm{D}$ state led to large enhancement in formation of $\mathrm{BaOH}+\mathrm{H}$ but not $\mathrm{BaO}+\mathrm{H}_{2}$. The dominance of $\mathrm{BaO}+\mathrm{H}_{2}$ from ground state $\mathrm{Ba}\left({ }^{1} \mathrm{~S}\right)$ even at collision energies nearly equal to the $\mathrm{Ba}\left({ }^{1} \mathrm{D}\right)$ excitation energy $(32 \mathrm{kcal} / \mathrm{mole}$ ) indicates that the observed reaction state specificity results from participation of different potential energy surfaces for reactions of ground and excited state atoms. Collisions of $\mathrm{Ba}\left({ }^{1} \mathrm{~S}\right)$ and $\mathrm{Ba}\left({ }^{1} \mathrm{D}\right)$ with methanol led only to formation of $\mathrm{BaOCH}_{3}+\mathrm{H}$, whereas reaction with allyl alcohol $\left(\mathrm{H}_{2} \mathrm{C}=\mathrm{CH}-\mathrm{CH}_{2} \mathrm{OH}\right)$ resulted in formation of both $\mathrm{BaOCH}_{2} \mathrm{CH}=\mathrm{CH}_{2}+\mathrm{H}$ and $\mathrm{BaOH}+\mathrm{CH}_{2}=\mathrm{CH}-\mathrm{CH}_{2}$. Large enhancements in reactivity with all alcohols were observed upon electronic excitation but no reaction was observed from $\mathrm{Ba}\left({ }^{1} \mathrm{~S}\right)$ or $\mathrm{Ba}\left({ }^{1} \mathrm{D}\right)+$ dimethyl ether $\left(\mathrm{CH}_{3} \mathrm{OCH}_{3}\right)$. This behavior strongly suggests that the reactions leading to radical formation are dominated by $\mathrm{H}$-atom migration.
\end{abstract}




\section{INTRODUCTION}

By judicious choice of the electronic state of a reactant it is possible to affect or even control the chemical outcome of a bimolecular reaction. Recent work ${ }^{1}$ using guided ion beams has shown that the chemistry of the various electronic states of a transition metal ion can change markedly due to the participation of different potential energy surfaces. In the case of neutral species, early studies showed that $O\left({ }^{\prime} D\right)$ is able to insert into covalent bonds, whereas the ground state $\mathrm{O}\left({ }^{\mathrm{P}} \mathrm{P}\right)$ atom is relatively inert under the same conditions. ${ }^{2}$ More recently, the use of crossed supersonic atomic and molecular beams combined with laser excitation of the atomic reactant has made it possible to study the reaction dynamics of different electronic states of an atom as a function of collision energy under well defined conditions. ${ }^{3-5}$

Electronic excitation does not simply provide energy to drive endoergic reactions. Instead, the differing topologies of the potential energy surfaces will determine the reactivities of different states. This was demonstrated in the reaction $\mathrm{Na}^{*}+\mathrm{O}_{2} \rightarrow \mathrm{NaO}$ $+0 .{ }^{3,4}$ When excited to the $4 \mathrm{~d}$ state, sodium was found to react strongly under single collision conditions, whereas the 5s state (at nearly the same electronic energy) was unreactive.

There has been considerable interest in the interactions between water and isolated metal and main group atoms in the ground and electronically excited states. ${ }^{6-15}$ In addition to being of importance in understanding the mechanisms of hydration, these interactions are intriguing because, unlike most small oxygen-containing molecules, water and its methyl derivatives posses only "Rydberg- like" unfilled molecular orbitals. ${ }^{16,17}$ 
Consequently, reactions are not expected to be initiated by long range electron transfer,

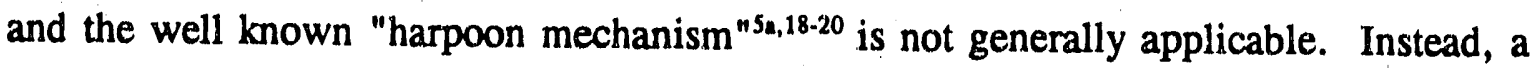
close collision is necessary to initiate a chemical reaction between the atom and molecule. Because $\mathrm{Ba}$ is divalent, the chemistry of these systems is quite rich with several competing channels possible. In the case of water or methanol, insertion of the Ba atom into a covalent bond may occur, possibly forming $\mathrm{HBaOH}, \mathrm{HBaOCH}_{3}$ or $\mathrm{HOBaCH}_{3}{ }^{6,7}$. Decomposition of these intermediates would likely lead to formation of radical products $\mathrm{BaOH}$ or $\mathrm{BaOCH}_{3}$. Alternatively, abstraction of the central oxygen atom resulting in formation of the closed shell molecules $\mathrm{BaO}+\mathrm{H}_{2}$ or $\mathrm{CH}_{4}$ is actually the thermodynamically favored channel. ${ }^{21}$ (Table 1)

The reactions of alkaline earth and a variety of other atoms $(M)$ with water have been studied extensively by Margrave and coworkers 7,8,14,15 using matrix isolation techniques and infrared spectroscopy. They found that codeposition of the reactants in an argon matrix led to formation of a $\mathrm{M}-\mathrm{OH}_{2}$ adduct involving a weak interaction (5-10 $\mathrm{kcal} / \mathrm{mole}$ ) between the metal atom and oxygen in water (Table 1). An increasing red shift in the water bending frequency with the heavier alkaline earth atoms has been taken as evidence that the interaction is strongest for barium ${ }^{7,9}$. For alkaline earth and some transition metal atoms, irradiation of the matrix at wavelengths near the metal atomic resonance line led to formation of $\mathrm{HMOH}$ and $\mathrm{MOH}$. However, in the case of some atoms, the oxygen bonded adduct rearranged spontaneously in the dark to form HMOH. Recent $a b$ initio calculations $s^{9,10}$ for the lighter alkaline earth atoms + water were consistent with these observations. The oxygen bonded adduct was found to represent 
a small but definite well on the potential energy surface; a substantial barrier for insertion explained the need for irradiation to promote the reaction. Based on ab-initio calculations ${ }^{9}$ and empirical bond energy estimates ${ }^{7}, \mathrm{HMOH}$ is expected to be a stable molecule, lying about $30 \mathrm{kcal} /$ mole lower in energy than $\mathrm{M}+\mathrm{H}_{2} \mathrm{O}$.

Very little gas phase work on reactions of water and methanol with neutral atoms using crossed molecular beams has appeared. Due to the absence of long-range electron transfer, the reactions are expected to have small cross sections $\left(<10 \AA^{2}\right)$. This factor, together with the possibility of several competing reaction channels makes it difficult to obtain a full picture of the reaction dynamics. This is because many detection techniques $^{22}$ do not have comparable sensitivities to all possible channels. However, a number of interesting features have been observed in gas phase reactions to date. Alcaraz and coworkers ${ }^{6}$ investigated the luminescent channels from the laser-induced reactions of $\mathrm{Ba}\left(6 s 6 \mathrm{p}^{1} \mathrm{P}_{1}\right)$ and $\mathrm{Ba}\left(6 \mathrm{a}^{2} \mathrm{~d}^{1} \mathrm{D}_{2}\right)$ with $\mathrm{H}_{2} \mathrm{O}$ under single collision conditions. Although no chemiluminescence was observed from reaction of $\mathrm{Ba}\left({ }^{1} \mathrm{D}_{2}\right)$, the $\mathrm{Ba}\left({ }^{1} \mathrm{P}_{1}\right)$ reaction led to $\mathrm{BaOH}\left(\mathrm{B}^{2} \Sigma^{+}{ }_{,} \mathrm{A}^{2} \Pi\right)$. No $\mathrm{BaO}\left(\mathrm{A}^{1} \Sigma^{+}\right.$or $\left.\mathrm{A}^{\prime} \mathrm{I} \Pi\right)$ was observed, even though these channels are more energetically favorable. The lack of the concerted molecular channel was attributed to a large barrier on the potential energy surface. 'The spectroscopy of a number of radicals containing alkaline earth metals has been studied by Bernath ${ }^{23}$ and coworkers. Electronic excitation of the metal atom led to substantial enhancement of reactivity: most notably, $\mathrm{Sr}\left({ }^{1} \mathrm{P}_{1}\right)+\mathrm{CH}_{3} \mathrm{OH}$ led to formation of $\mathrm{SrOCH}_{3}$. However, their focus was on the spectroscopy of the products rather than on the reaction dynamics. A Broida type oven was used in these studies under multiple collision 
conditions, and the reaction mechanisms could not be unambiguously determined.

Although there have been no reports of formation of MO from single collisions of alkaline earth atoms with water or alcohols, such reactions are known to occur for other atomic species. Gole and Pace ${ }^{11}$ observed BO chemiluminescence from $\mathrm{B}+\mathrm{H}_{2} \mathrm{O}$ $\rightarrow \mathrm{BO}^{*}+\mathrm{H}_{2}$. Ab initio calculations ${ }^{12}$ indicated a large potential energy barrier for this reaction which was apparently surmounted by the fast Boltzmann tail of the effusive atomic B beam. Liu and Parson ${ }^{13}$ studied the reactions of $Y$ and Sc with water and alcohols under single collision conditions. Only the MO product was observed; either the hydroxide was not formed or it's LIF spectrum was outside the wavelength range studied.

We have performed crossed molecular beams studies of the reactions of ground state $\left(6 \mathrm{~s}^{2}-{ }^{-1} \mathrm{~S}_{0}\right)$ and metastable $\left(6 s 5 \mathrm{~d}-{ }^{-1} \mathrm{D}_{2}\right)$ barium atoms with water and its alkyl derivatives. Unlike the previous gas phase experiments, products in our study were detected using an electron bombardment ionizer-quadrupole mass spectrometer. ${ }^{24}$ This allowed us to detect all reaction channels, including the dominant ground state products. Our work complements the recent chemiluminescence experiments of Alcaraz et $\mathrm{al}^{6}$; the combined results allow us to gain considerable insight into the dynamics of the reactions.

By changing the kinetic energy of the atomic and molecular beams, we compared the effect of reactant collision energy to reactant electronic energy. We find that the reactions with water are largely state specific; at all collision energies, ground state $\mathrm{Ba}\left({ }^{1} \mathrm{~S}\right)$ reacted primarily to form the molecular products $\mathrm{BaO}+\mathrm{H}_{2}$ by a concerted mechanism, whereas metastable $\mathrm{Ba}\left({ }^{1} \mathrm{D}\right)$ preferentially formed the radical products $\mathrm{BaOH}$ 
$+H$. We show that this behavior results from the participation of different electronic potential ensrgy surfaces. Reactions with $\mathrm{CH}_{3} \mathrm{OH}$, on the other hand, only results in formation of $\mathrm{BaOCH}_{3}+\mathrm{H}$, despite a much larger exoergicity for formation of $\mathrm{BaOH}$ $+\mathrm{CH}_{3}$ or $\mathrm{BaO}+\mathrm{CH}_{4}$ (Table In). Dimethyl ether $\left(\mathrm{CH}_{3} \mathrm{OCH}_{3}\right)$ was found to be unreactive even at the highest collision energies. These observations suggest that the formation of radicals results from hydrogen atom migration, a process strongly enhanced by electronic excitation of the incident barium atom.

\section{U. EXPERIMENTAL}

A continuous, seeded supersonic beam of barium atoms was formed in a molybdenum oven source with separately heated barium reservoir and nozzle. Details of the apparatus ${ }^{5,24}$ and the atomic beam source ${ }^{25}$ are available elsewhere. The molecular beam was formed by bubbling helium or hydrogen carrier gas through the liquid sample held in a refrigerated bath and expanding the mixture through a $0.005^{\prime \prime}$ or $0.010^{\text {" }}$ diameter nozzle. A dilute mixture $(<5 \%)$ and high nozzle temperature $\left(200^{\circ} \mathrm{C}\right)$ was necessary to eliminate dimers and larger clusters. The water was distilled; the alcohols, ether, hydroperoxide and $\mathrm{H}_{2}{ }^{18} \mathrm{O}$ were obtained from Aldrich Chemical Company. Both beams were differentially pumped and crossed at $90^{\circ}$ in a liquid nitrogen cooled chamber maintained at $\sim 1 \times 10^{-7}$ Torr.

Reaction products were detected by a triply differentially pumped electron impact ionizer-quadrupole mass spectrometer that could be rotated in the plane of the atomic and molecular bearns ${ }^{5,24}$. An important goal of the experiment was to measure relative yields 
of $\mathrm{BaOH}(\mathrm{m} / \mathrm{e}=155)$ and $\mathrm{BaO}(\mathrm{m} / \mathrm{e}=154)$. This is inherently difficult due to the close proximity of the mass peaks and fragmentation of $\mathrm{BaOH}$ to $\mathrm{BaO}^{+}$upon electron bombardment ionization. Considerable effort was devoted to characterizing the fragmentation patterns of the product molecules and the transmission of the products through the quadrupole mass filter. Fortunately, resolving these products is aided by the favorable kinematic relationships which confine $\mathrm{BaO}$ and $\mathrm{BaOH}$ to a very narrow scattering angle and lead to rather large signal levels. Also, the background count rate in the detector is nearly zero at these heavy masses. Most importantly, the natural isotopic abundance of $\mathrm{Ba}$ is favorable; the isotopes with masses 138,137 , and $130-136$ are $71.70 \%, 11.23 \%$ and $17.07 \%$ naturally abundant, respectively. ${ }^{26}$ By operating the mass spectrometer at a high resolution setting, it was possible to distinguish between the ${ }^{138} \mathrm{BaOH}(\mathrm{m} / \mathrm{e}=155)$ and ${ }^{138} \mathrm{BaO}(\mathrm{m} / \mathrm{e}=154)$ parent ion peaks with only a minor contribution at $m / e=154$ from ${ }^{137} \mathrm{BaOH}$. Fragmentation of $\mathrm{BaOH}_{2}$ to $\mathrm{BaO}^{+}$upon $200 \mathrm{~V}$ electron bombardment ionization was a factor to consider in the analysis. This fragmentation ratio is difficult to measure with great accuracy since there are few clean sources of $\mathrm{BaOH}$. The reaction of $\mathrm{Ba}\left({ }^{\prime} \mathrm{D}\right)+\mathrm{t}$-butyl hydroperoxide formed both $\mathrm{BaOH}$ + t-butoxy radical and $\mathrm{BaOt}-\mathrm{Butoxide}+\mathrm{OH}$. Due to the similar exoergicities of the reactions (Table III), and the heavier recoil partner for the $\mathrm{BaOH}$ product, it was possible to monitor pure $\mathrm{BaOH}$ far from the $\mathrm{Ba}$ beam outside the angular range for $\mathrm{BaOt}$ Butoxide. This allowed us to measure the fragmentation pattern obtaining a value of $\mathrm{BaOH}^{+} / \mathrm{BaO}^{+}=1.0+1-0.2$. This ratio compares favorably with that observed from the product of the reaction $\mathrm{Ba}\left({ }^{1} \mathrm{D}\right)+\mathrm{H}_{2} \mathrm{O}$, which we estimate to be $90-100 \% \mathrm{BaOH}$. 
We have no way to measure the dependence of this pattern on internal excitation of $\mathrm{BaOH}$, but since ionization involves removal of the non-bonding radical electron ${ }^{26,27}$, it is expected to be small. Adequate discrimination between $\mathrm{m} / \mathrm{e}=154$ and $\mathrm{m} / \mathrm{e}=155$ was checked by monitoring the $\mathrm{BaO}$ product $(\mathrm{m} / \mathrm{e}=154)$ known to result from the $\mathrm{Ba}+\mathrm{O}_{2}$ reaction ${ }^{29,30}$ and increasing the resolution to extinguish signal observed at $m / e=155$. It has been found in other work that fragmentation of $\mathrm{BaO}$ to $\mathrm{Ba}^{+}$is relatively insensitive to internal excitation. ${ }^{50,31}$ Product time of flight distributions were obtained using the cross-correlation method, as described previously ${ }^{5,32}$.

The metastable barium atomic beam was formed by optically pumping the $\mathrm{Ba}\left({ }^{1} \mathrm{P}-\right.$ ${ }^{1}$ S) resonance upstream of the interaction region using a Coherent 699-21 ring dye laser operating single rrequency at $553 \mathrm{~nm}$ with Rhodamine 560 dye, as described previously. ${ }^{5}$ Based on measurements described elsewhere ${ }^{5_{n}}$ and using the published branching ratios ${ }^{33}$ for decay of $\mathrm{Ba}\left({ }^{1} \mathrm{P}\right)$, the ${ }^{138} \mathrm{Ba}$ in the beam consisted of $45 \% \mathrm{Ba}\left({ }^{1} \mathrm{D}\right), 15 \% \mathrm{Ba}\left({ }^{3} \mathrm{D}\right)$ and $40 \% \mathrm{Ba}\left({ }^{\prime} \mathrm{S}\right)$, with all other isotopes in the ground ('S) state. Product angular and velocity distributions were obtained by running parallel experiments at various detector angles with and without the laser. We have not attempted to study the reactivity of $\mathrm{Ba}\left({ }^{\prime} \mathrm{P}\right)$ with water or its alkyl derivatives.

\section{RESULTS}

\section{A. Reaction of $\mathrm{Ba}\left({ }^{1} \mathrm{~S}\right)+\mathrm{H}_{2} \mathrm{O}$ and $\mathrm{D}_{2} \mathrm{O}$}

The reactive and nonreactive scattering of $\mathrm{Ba}\left({ }^{1} \mathrm{~S}_{0}\right)+\mathrm{H}_{2} \mathrm{O}$ and $\mathrm{D}_{2} \mathrm{O}$ was studied at several collision energies in the range $12-30 \mathrm{kcal} / \mathrm{mole}$. The Newton diagram for $\mathrm{Ba}$ 
$+\mathrm{H}_{2} \mathrm{O}$ at a nominal collision energy of $12 \mathrm{kcal} / \mathrm{mole}$ is shown in Fig. 1. This mean collision energy is just below the $13 \mathrm{kcal} /$ mole endoergicity for $\mathrm{Ba}\left({ }^{\prime} \mathrm{S}\right)+\mathrm{H}_{2} \mathrm{O} \rightarrow \mathrm{BaOH}$ $+\mathrm{H}$. Assuming that supersonic expansion of $5 \% \mathrm{H}_{2} \mathrm{O}$ in $\mathrm{He}$ at $200^{\circ} \mathrm{C}$ leads to no vibrational cooling, $<2 \%$ of the $\mathrm{H}_{2} \mathrm{O}$ molecules will have a quantum of symmetric bending excitation $\left(1594 \mathrm{~cm}^{-1}\right){ }^{16}$ At $E_{\text {conl }}=12 \mathrm{kcal} /$ mole, only these molecules and the fast edge of each supersonic beam could react to form $\mathrm{BaOH}+\mathrm{H}$. However, our experiments indicate that the dominant reaction is actually $\mathrm{Ba}\left({ }^{1} \mathrm{~S}\right)+\mathrm{H}_{2} \mathrm{O} \rightarrow \mathrm{BaO}+\mathrm{H}_{2}$. A number of checks were conducted to prove that the $\mathrm{BaO}$ signal was in fact due to bimolecular collisions between $\mathrm{Ba}+\mathrm{H}_{2} \mathrm{O}$. First, the $\mathrm{BaO}$ product angular distribution peaked at the center of mass laboratory angle $\left(20^{\circ}\right)$ consistent with the known masses and velocities of the $\mathrm{Ba}+\mathrm{H}_{2} \mathrm{O}$ colliding pair. Contributions from reactions of possible contaminants, such as $\mathrm{O}_{2}$ or $\left(\mathrm{H}_{2} \mathrm{O}\right)_{2}$ were ruled out since the center-of-mass angle associated with reaction of these species with $\mathrm{Ba}$ is considerably larger. A major concern arose from our observation of trace quantities of $\mathrm{BaO}$ in the $\mathrm{Ba}$ beam itself. Since the vapor pressure of $\mathrm{BaO}$ is extremely low $\mathrm{w}^{34}$ at these temperatures, it must arise from reaction of $\mathrm{Ba}$ atoms in the beam with residual gasses $\left(\mathrm{O}_{2}, \mathrm{H}_{2} \mathrm{O}\right)$ present in the differential pumping region. This $\mathrm{BaO}$ impurity remains primarily within the atonic beam. However, we could also detect some $\mathrm{BaO}$ outside the beam due to elastic and inelastic collisions between the impurity and water in the molecular beam. In order to eliminate this undesirable signal, a series of experiments were conducted using $\mathrm{H}_{2}{ }^{18} \mathrm{O}$ in place of regular water. Figure 2 shows the $\mathrm{Ba}^{18} \mathrm{O}$ time of flight spectra $(\mathrm{m} / \mathrm{e}=156)$ from reaction of ground state $\mathrm{Ba}$ with $\mathrm{H}_{2}{ }^{18} \mathrm{O}$. The quadrupole mass spectrometer was operated 
at unit mass resolution-- as expected, no signal could be observed at $\mathrm{m} / \mathrm{e}=156\left(\mathrm{Ba}^{18} \mathrm{O}\right)$ under the same conditions when ordinary water was used in the molecular beam. At this collision energy, the BaO signal level was weak compared to the Ba signal from nonreactive scattering. Figure 3 shows the time of flight spectra recorded at $\mathrm{Ba}^{+}$ $(m / e=138)$ under the same conditions. The observed signal primarily resulted from nonreactive elastic and inelastic collisions. The maximum velocity for this nonreactively scattered $\mathrm{Ba}$ is shown as a dotted line in the Newton diagram (Fig. 1)-- the forward and backward components of the Newton circle can be clearly seen in the Ba time-of-flight spectra (Fig. 3) at lab angles smaller than 30 degrees.

Figure 4 shows the best fit translational energy distribution $(P(E))$ and center of mass angular distribution $(T(\theta))$ used in the simulation of the data in Figs. 2 and 3 (solid line). A considerable amount of wide angle nonreactive $\mathrm{Ba}^{+}$signal was observed at this collision energy. In figure 3 , the minor component (dotted line) in the Ba signal is the contribution from fragmentation of $\mathrm{BaO}$ product to $\mathrm{Ba}^{+}$in the electron bombardment ionizer. This contribution was calculated using the best fit to the BaO data and a fragmentation ratio of $\mathrm{BaO}^{+}: \mathrm{Ba}^{+}=1.0$. Based on the relative $\mathrm{Ba}$ and $\mathrm{BaO}$ signal level, we estimate that the cross section for the reaction $\mathrm{Ba}\left({ }^{1} \mathrm{~S}\right)+\mathrm{H}_{2} \mathrm{O} \rightarrow \mathrm{BaO}+\mathrm{H}_{2}$ is $<2 \AA^{2}$ at $12 \mathrm{kcal} / \mathrm{mole}$.

Mass scans of the product from the reaction of ground state Ba indicate that formation of $\mathrm{BaO}+\mathrm{H}_{2}$ dominates at all collision energies from reaction of $\mathrm{Ba}\left({ }^{\prime} \mathrm{S}\right)+$ $\mathrm{H}_{2} \mathrm{O}$. Raising the collision energy above the $13 \mathrm{kcal} / \mathrm{mole}$ endoergicity for formation of $\mathrm{BaOH}+\mathrm{H}$ opened up this channel, but the observed signal level remained substantially 
smaller than from $\mathrm{BaO}+\mathrm{H}_{2}$ even at $30 \mathrm{kcal} /$ mole, the highest collision energy studied. Figure 5 shows the angular itistributions for the $\mathrm{BaO}$ and $\mathrm{BaOH}$ from reaction of $\mathrm{Ba}\left({ }^{1} \mathrm{~S}\right)$ $+\mathrm{H}_{2} \mathrm{O}$ at a collision energy $23 \% \mathrm{kcal} / \mathrm{mole}$. Due to the reaction endoergicity and light $\mathrm{H}$-atom recoil partner, the Newton circle for the $\mathrm{BaOH}$ product is very small-- the product is constrained to appear near the center-of-mass angle and a substantial fraction of all reaction products enter the detector. In the case of the dominant $\mathrm{BaO}+\mathrm{H}_{2}$ channel however, a smaller fraction of the $\mathrm{BaO}$ is collected at a given detector angle since the products are scattered over a much larger Newton sphere. By monitoring both channels at the $\mathrm{CM}$ angle $\left(25^{\circ}\right)$, our detection sensitivity is strongly biased towards the $\mathrm{BaOH}+\mathrm{H}$ channel. This differing kinematic relationship and the occurrence of both channels is clearly illustrated (Fig. 5). At a collision energy of $23 \mathrm{kcal} / \mathrm{mole}$, the width of the laboratory angular distribution observed at $\mathrm{BaO}^{+}$is more than 20 degrees, whereas that for $\mathrm{BaOH}^{+}$is $\sim 10$ degrees. Time-of-flight data for the ground state $\mathrm{Ba}$ reaction products are shown in figures 6 and 7; the optimized $P(E)$ and $T(\theta)$ used to fit the data are shown in figure 8. The contribution to the $\mathrm{BaO}$ angular distribution and time-offlights from fragmentation of $\mathrm{BaOH}$ to $\mathrm{BaO}^{+}$in the ionizer is shown in dotted lines in Fig. 7. The laboratory angular distribution for both channels peaked at the center of mass angle (Fig. 5). Based on the fit to the $\mathrm{BaO}$ time of flight profiles, (which are considerably broader than those for $\mathrm{BaOH}$ ) we conclude that there is a substantial release of translational energy in the $\mathrm{BaO}+\mathrm{H}_{2}$ pro fucts (Fig. 8). The best fit to the $\mathrm{BaO}$ lab angular distribution led to a CM angular distribution which was approximately isotropic. It should be pointed out that due to the kinematic limitation, we would not be able to 
resolve a slight forward or backscattering. It is even more difficult to make conclusions about the $\mathrm{BaOH}$ angular and velocity distribution since the data is more compressed due the light $\mathrm{H}$ atom recoil partner. However, our data does indicate that the $\mathrm{CNi}$ angular distribution cannot be strongly forward or backscattered.

Qualitatively similar behavior was observed when $\mathrm{D}_{2} \mathrm{O}$ was used. Again, the $\mathrm{BaO}$ $+D_{2}$ channel dominated, but BaOD $+D$ was clearly seen at collision energies above the reaction endoergicity. Even at the highest collision energy $(30 \mathrm{kcal} / \mathrm{mole})$, nearly that of the $\mathrm{Ba}\left({ }^{1} \mathrm{D}\right)$ excitation energy, formation of $\mathrm{BaO}+\mathrm{H}_{2}$ (or $\mathrm{D}_{2}$ ) remained the dominant channel.

\section{B. Reaction of $\mathrm{Ba}\left({ }^{\mathrm{l}} \mathrm{D}\right)$ ) with $\mathrm{H}_{2} \mathrm{O}$ and $\mathrm{D}_{2} \mathrm{O}$}

Excitation of the incident $\mathrm{Ba}$ atom to the metastable ${ }^{1} \mathrm{D}$ state led to a dramatic increase in the observed signal level at all collision energies studied. Whereas the dominant product in the ground state reaction was $\mathrm{BaO}+\mathrm{H}_{2}$ (or $\mathrm{D}_{2}$ ), eaction of $\mathrm{Ba}\left({ }^{\prime} \mathrm{D}\right)$ leads primarily, and possibly exclusively, to formation of $\mathrm{BaOH}+\mathrm{H}$ (or $\mathrm{BaOD}+\mathrm{D}$ ). Figure 9 shows the time of flight spectra obtained at $m / e=155(\mathrm{BaOH})$. At a collision energy of $12 \mathrm{kcal} / \mathrm{mole}$, the $\mathrm{BaOH}$ signal level at the center-of-mass angle $\left(17.5^{\circ}\right)$ from $\mathrm{Ba}\left({ }^{1} \mathrm{D}\right)$ was $\sim 20 \mathrm{X}$ greater than $\mathrm{BaO}$ signal from $\mathrm{Ba}\left({ }^{1} \mathrm{~S}\right)$. The $\mathrm{BaOH}$ laboratory angular distribution and product translational energy distribution are shown in Fig. 10. The large increase in reactive scattering signal can be seen in the Ba time-of-flight data (Fig 11). The dominant contribution (middle peak) to the Ba signal is now from fragmentation of $\mathrm{BaOH}$ reaction product, rather than from nonreactive scattering. The Ba time-of-flight 
data for collisions of ground and electronically excited $\mathrm{Ba}$ are plotted on absolute scales in figure 12. As already mentioned, the large middle component seen with the laser on results from fragmentation of $\mathrm{BaOH}$. The fast component from wide angle nonreactive scattering also increased with electronic excitation. This component likely arises from quenching of electronic excitation.

The dramatic shift in chemical identity of the reaction product upon electronic excitation of $\mathrm{Ba}$ is best demonstrated in the product mass spectra. Figure 13 shows the mass spectrum of the products from the reaction of $\mathrm{Ba}\left({ }^{1} \mathrm{~S}\right)+\mathrm{D}_{2} \mathrm{O}$ obtained with the detector at the center-of-mass angle. The collision energy was $23 \mathrm{kcal} / \mathrm{mole}$ and the detector was operating at unit mass resolution. A Newton diagrarn showing the expected angular range for the chemical products is also shown. As before, due to the kinematics, we are most sensitive to the $\mathrm{BaOD}$ channel when the detector is at the center of mass angle. Although the observed $\mathrm{BaOD}$ intensity from the $\mathrm{Ba}\left({ }^{1} \mathrm{~S}\right)$ reaction is approx. $1 / 2$ that of $\mathrm{BaO}$ (Fig. 13, dotted line), the true branching ratio after accounting for this Jacobian factor and the fragmentation of $\mathrm{BaOH}$ to $\mathrm{BaO}^{+}$in the ionization process, is $\sim 1: 9 \mathrm{BaOD}: \mathrm{BaO}$ for $\mathrm{Ba}\left({ }^{1} S\right)$ at $23 \mathrm{kcal} / \mathrm{mole}$. However, upon electronic excitation of the incident $\mathrm{Ba}$ atom to the ${ }^{1} \mathrm{D}$ state, a large shift in product branching ratio (Fig. 13, solid line) is observed. At $23 \mathrm{kcal} /$ mole, the BaOD signal from the $\mathrm{Ba}\left({ }^{(} \mathrm{D}\right)$ reaction was approximately 6 times more intense at the center-of-mass angle than the $\mathrm{BaO}$ signal from the ground state reaction. With the mass spectrometer tuned to $\mathrm{m} / \mathrm{e}=154\left(\mathrm{BaO}^{+}\right)$, the product velocity and angular distribution was found to be almost the same as that observed at $\mathrm{BaOD}^{+}$and was attributed to $\mathrm{BaO}^{+}$daughter products from fragmentation 
of $\mathrm{BaOD}$ in the electron bombardment ionizer detector.

From the Newton diagram, the maximum predicted angular range of $\mathrm{BaO}$ from $\mathrm{Ba}\left({ }^{1} \mathrm{~S}\right.$ or $\left.{ }^{1} \mathrm{D}\right)+\mathrm{D}_{2} \mathrm{O} \rightarrow \mathrm{BaO}+\mathrm{D}_{2}$ is substantially greater than from $\mathrm{Ba}\left({ }^{1} \mathrm{D}\right)+\mathrm{D}_{2} \mathrm{O} \rightarrow$ $\mathrm{BaOD}+\mathrm{H}$ due to the greater reaction exoergicity and heavier r'coil partner $\left(\mathrm{D}_{2}\right.$ ins of $\mathrm{D})$. Yet, no $\mathrm{BaO}$ could be observed from the $\mathrm{Ba}\left({ }^{1} \mathrm{D}\right)$ reaction outside the range where $\mathrm{BaOD}$ was seen. Based on this, we conclude that $\mathrm{BaOD}$ results from $90-100 \%$ of all reactive encounters between $\mathrm{Ba}\left({ }^{1} \mathrm{D}\right)$ and $\mathrm{D}_{2} \mathrm{O}$. Comparison of signal levels using $\mathrm{H}_{2} \mathrm{O}$ and $D_{2} O$ under similar beam conditions indicated that $D_{2} O$ is $2.0 \pm 0.4$ times less reactive than $\mathrm{H}_{2} \mathrm{O}$.

\section{Reactions of $\mathrm{Ba}\left({ }^{\prime} \mathrm{S}\right), \mathrm{Ba}\left({ }^{(} \mathrm{D}\right)$ with $\mathrm{CH}_{3} \mathrm{OH}$ and $\mathrm{CH}_{3} \mathrm{OD}$.}

Three chemically distinct reaction channels, producing $\mathrm{BaOH}, \mathrm{BaOCH}_{3}$, and $\mathrm{BaO}$ are thermodynamically possible ${ }^{21,23}$ from reaction of ground state Ba atoms with methanol as shown in Table II. Electronic excitation opens the possibility for formation of electronically excited states of the product molecules ${ }^{23}$. Product angular distributions for reactions of $\mathrm{Ba}$ with methanol, shown in Fig. 14, indicate that formation of $\mathrm{BaOCH}_{3}+$ $\mathrm{H}$ dominates in reactions of ground state and electronically excited $\mathrm{Ba}$. As with water, strong signal enhancement was seen upon electronic excitation, with the most dramatic increase $(20 \mathrm{X})$ at the lowest collision energy studied (15 kcal/mole). At this collision energy, the ground state reaction was only barely detectible. The expected laboratory angular range for the $\mathrm{BaOH}$ product is substantially larger than for $\mathrm{BaOCH}_{3}$ due to its heavier recoil partner $\left(\mathrm{CH}_{3}\right.$ instead of $\left.\mathrm{H}\right)$. However, we were unable to detect $\mathrm{BaOH}^{+}$ 
or $\mathrm{BaOH}$ daughter products $\left(\mathrm{BaO}^{+}, \mathrm{Ba}^{+}, \mathrm{OH}^{+}\right)$at angles outside of that seen for formation of $\mathrm{BaOCH}_{3}+\mathrm{H}$, even upon electronic excitation. The observed $\mathrm{BaO}^{+}$and $\mathrm{Ba}^{+}$signal resulted from fragmentation of $\mathrm{BaOCH}_{3}$ in the electron bombardment ionizer. We conclude that the yield of $\mathrm{BaOCH}_{3}+\mathrm{H}$ is $90-100 \%$ from ground state and electronically excited $\mathrm{Ba}$, in spite of the fact that $\mathrm{AH}$ is more favorable for $\mathrm{BaOH}+\mathrm{CH}_{3}$ production, and formation of $\mathrm{BaO}+\mathrm{CH}_{4}$ is highly exoergic even from the ground state (Table II).

Even at the lowest collision energy studied ( $15 \mathrm{kcal} / \mathrm{mole})$, ground state Ba atoms were found to react weakly, but again, only forming $\mathrm{BaOCH}_{3}+\mathrm{H}$ (Fig. 14, Top Figure). Spurred by the observation of $\mathrm{Ba}\left({ }^{1} \mathrm{~S}\right)+\mathrm{H}_{2} \mathrm{O} \rightarrow \mathrm{BaO}+\mathrm{H}_{2}$, a search was undertaken for $\mathrm{BaO}+\mathrm{CH}_{4}$, but we failed to see any evidence for this channel from ground state or electronically excited barium up to $30 \mathrm{kcal} / \mathrm{mole}$ collision energy. Owing to the large reaction exoergicity and heavier $\mathrm{CH}_{4}$ recoil partner, some BaO should have been observed outside of the angular range for $\mathrm{BaOCH}_{3}$ if its formation accounted for more than $10 \%$ of the total reaction cross section. Angular distributions for $\mathrm{BaOCH}_{3}$ from $\mathrm{Ba}+\mathrm{CH}_{3} \mathrm{OH}$ and $\mathrm{Ba}+\mathrm{CH}_{3} \mathrm{OD}$ are shown in figure 15. A comparison of Figs. 14 and 15 indicates that the reactivity of $\mathrm{Ba}\left({ }^{1} \mathrm{~S}\right)$ does increase with increasing the collision energy from 15 to $30 \mathrm{kcal} / \mathrm{mole}$. However, electronic excitation is far more effective in erhancing the chemical reaction at any collision energy. A similar isotope effect was observed in the methanol reactions with $\mathrm{CH}_{3} \mathrm{OH}$ having a reaction cross section approximately twice that of $\mathrm{CH}_{3} \mathrm{OD}$ at the same collision energy 


\section{Collisions of $\mathrm{Ba}\left({ }^{2} \mathrm{~S}\right)$, ('D) with $\mathrm{CH}_{3} \mathrm{OCH}_{3}$.}

No chemical reaction was observed in collisions of ground state or electronically excited $\mathrm{Ba}$ atoms with dimethyl ether at collision energies up to $25 \mathrm{kcal} / \mathrm{mole}$ despite long averaging for $\mathrm{BaO}^{+}, \mathrm{BaOH}^{+}$, and $\mathrm{BaOCH}_{3}{ }^{+}$. The observed $\mathrm{Ba}^{+}$signal was attributed to elastic and nonreactive inelastic collisions.

\section{E. Collisions with Allyl Alcohol and t-Butyl Hydroperoxide}

In an attempt to observe formation of $\mathrm{BaOH}$ from the single collision of $\mathrm{Ba}+$ an alcohol, allyl alcohol $\left(\mathrm{CH}_{2}=\mathrm{CH}-\mathrm{CH}_{2}-\mathrm{OH}\right)$ appeared promising. As will be discussed below, the electronic structure of allyl alcohol is very different from that of methanol because of the $C=C$ double bond. Moreover, due to the resonance stability of the allyl radical, formation of $\mathrm{BaOH}+\mathrm{CH}_{2}=\mathrm{CH}-\mathrm{CH}_{2}$ is far more exoergic $(\Delta \mathrm{H} \sim-28.5$ $\mathrm{kcal} / \mathrm{mole})$ than is $\mathrm{BaOCH}{ }_{2}-\mathrm{CH}=\mathrm{CH}_{2}+\mathrm{H}(\Delta \mathrm{H} \sim 0 \mathrm{kcal} / \mathrm{mole}) .{ }^{21}$ Indeed, collisions of $\mathrm{Ba}\left({ }^{1} \mathrm{~S},{ }^{\prime} \mathrm{D}\right)$ with allyl alcohol resulted in formation of $\mathrm{Ba}-\mathrm{O}-\mathrm{CH}_{2}-\mathrm{CH}=\mathrm{CH}_{2}+\mathrm{H}$ as well as $\mathrm{BaOH}+\mathrm{CH}_{2}=\mathrm{CH}-\mathrm{CH}_{2}$. Time-of-flight data for the products from the $\mathrm{Ba}\left({ }^{\prime} \mathrm{D}\right)$ reaction are shown in Figs. 16 and 17; the best fit $\mathrm{P}(\mathrm{E})$ and $\mathrm{T}(\theta)$ are shown in Fig. 18. Whereas the $\mathrm{Ba}-\mathrm{O}-\mathrm{CH}_{2}-\mathrm{CH}=\mathrm{CH}_{2}$ signal is localized near the center of mass angel, (30 degrees) the $\mathrm{BaOH}$ product is scattered over a much larger angular range due to its heav er recoil partner $\left(\mathrm{CH}_{2}=\mathrm{CH}-\mathrm{CH}_{2}\right.$ instead of $\left.\mathrm{H}\right)$. This kinematic relationship is better for tl e $\mathrm{BaOH}+\mathrm{CH}_{2}=\mathrm{CH}-\mathrm{CH}_{2}$ channel than for any of the other channels observed in this study. We find that although the $\mathrm{BaOH}$ angular distribution is broad, it is definitely forward peaking, indicating that the reaction occurs on a timescale shorter than $\sim 1$ psec. 
Both channels can be monitored simultaneously at $\mathrm{BaO}^{+}$, since both barium containing products fragment in the electron bombardment ionizer. Collisions between $\mathrm{Ba}$ and tertbutyl hydroperoxide (t-BuOOH) led to formation of $\mathrm{BaO}-\mathrm{t}-\mathrm{Butoxide}+\mathrm{OH}$ and $\mathrm{BaOH}$ + t-Butoxide Radical with an approximately $1: 1$ branching ratio (not shown).

\section{DISCUSSION}

\section{A. Reactions with $\mathrm{H}_{2} \mathrm{O}$.}

The most striking observation in the $\mathrm{Ba}+\mathrm{H}_{2} \mathrm{O}$ study was the strong dependence of product branching ratio on initial electronic state of the reactant $\mathrm{Ba}$ atom. At collision energies below the $13 \mathrm{kcal} /$ mole endoergicity for $\mathrm{Ba}\left({ }^{1} \mathrm{~S}\right)+\mathrm{H}_{2} \mathrm{O} \rightarrow \mathrm{BaOH}+\mathrm{H}$, the ground state reaction led to formation of $\mathrm{BaO}+\mathrm{H}_{2}$. This channel was very weak at 12 $\mathrm{kcal} / \mathrm{mole}$, but increased with increasing collision energy. Although the $\mathrm{BaOH}+\mathrm{H}$ channel did appear at collision energies above its endoergicity, it remained much weaker than the $\mathrm{BaO}+\mathrm{H}_{2}$ channel even at $30 \mathrm{kcal} /$ mole, a collision energy approaching the $\mathrm{Ba}\left({ }^{1} \mathrm{D}\right)$ excitation energy. Electronically excited $\mathrm{Ba}\left({ }^{1} \mathrm{D}\right)$, on the other hand, reacted with water to form $\mathrm{BaOH}+\mathrm{H}$ with a branching ratio of $0.90-1.0$ at all collision energies.

There are two explanations for the observed product specificity. One possibility is that $\mathrm{Ba}\left({ }^{1} \mathrm{D}\right)+\mathrm{H}_{2} \mathrm{O}$ is correlated to $\mathrm{BaOH}+\mathrm{H}$ through an excited state surface, whereas ground state $\mathrm{Ba}\left({ }^{1} \mathrm{~S}\right)+\mathrm{H}_{2} \mathrm{O}$ correlates to $\mathrm{BaO}+\mathrm{H}_{2}$. Alternatively, the effect might be due to energetics alone: electronic excitation may simply drive the endoergic channel. In this case, the collision of $\mathrm{Ba}\left({ }^{1} \mathrm{D}\right)$ might be viewed as quenching of electronic excitation during the encounter of the reagents with the vibrationally hot 
intermediate decaying to form $\mathrm{BaOH}+\mathrm{H}$ on the ground electronic surface. The very large excess energy above threshold provided by the initial electronic excitation would strongly favor simple unimolecular decomposition from a reaction intermediate leading to $\mathrm{BaOH}+\mathrm{H}$ rather than formation of $\mathrm{BaO}+\mathrm{H}_{2}$ through a concerted mechanism. However, we believe that this possibility is unlikely in light of the experimental observations . Although $\mathrm{BaOH}+\mathrm{H}$ was observed from ground state $\mathrm{Ba}+\mathrm{H}_{2} \mathrm{O}$ at collision energies above its endoergicity, the $\mathrm{BaO}+\mathrm{H}_{2}$ cross section increased and remained dominant with increasing collision energy. If the lack of $\mathrm{BaOH}+\mathrm{H}$ from ground state reaction was simply due to energetics alone, the large increase in relative translational energy should have led to a shift toward the radical channel, which, although endoergic, should dominate at high energy since it only involves simple $\mathrm{H}$-atom elimination. Since the $\mathrm{BaOH}+\mathrm{H}$ channel remained weaker than $\mathrm{BaO}+\mathrm{H}_{2}$ even at collision energy near the $\mathrm{Ba}\left({ }^{1} \mathrm{D}\right)$ excitation energy, energetic arguments alone cannot explain the dominance of $\mathrm{BaOH}$ upon electronic excitation.

We now return to the possibility that differing intrinsic features of the ground and excited state surfaces lead to strong preference for different chemical products. Two possible mechanisms can be envisioned for the reaction $\mathrm{Ba}\left({ }^{1} \mathrm{~S}\right)+\mathrm{H}_{2} \mathrm{O} \rightarrow \mathrm{BaO}+\mathrm{H}_{2}$. The reaction could be initiated by insertion of $\mathrm{Ba}\left({ }^{1} \mathrm{~S}\right)$ into one of the $\mathrm{OH}$ bonds in $\mathrm{H}_{2} \mathrm{O}$. Although $\mathrm{HBaOH}$ is expected to be linear or slightly bent, a very low energy bending potential has been calculated for the analogous molecules involving lighter alkaline earth atoms. ${ }^{7,9}$ This low energy bending made could facilitate formation of $\mathrm{BaO}+\mathrm{H}_{2}$ via a four center transition state: 


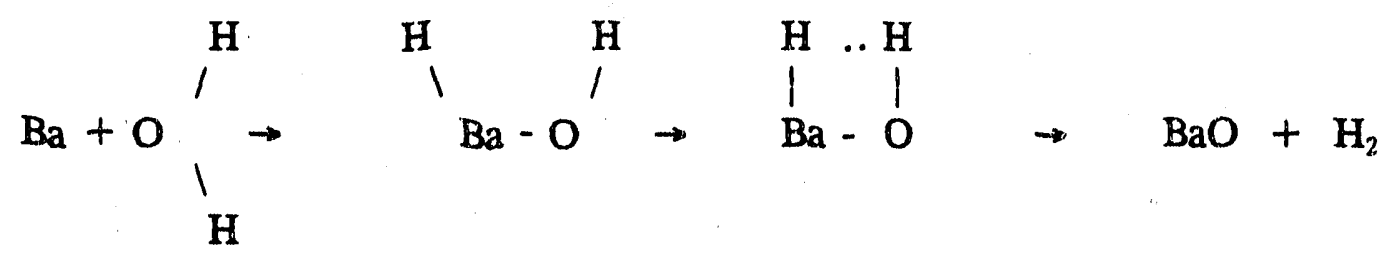

We expect substantial potential energy barriers for this reaction mechanism. The electron configuration for the ground state $\mathrm{Ba}$ atom is $6 \mathrm{~s}^{2}$ - the initial repulsion between this "closed shell" atom and water, as well as the need for sp or sd hybridization for formation of two bonds in the insertion intermediate will likely lead to a substantial potential energy barrier in the entrance channel. Additionally, a second potential energy barrier at the 4-center transition state is expected for $\mathrm{H}_{2}$ elimination from $\mathrm{HBaOH}$. Simple rupture of the very weak $\mathrm{Ba}-\mathrm{H}$ bond in $\mathrm{H}-\mathrm{Ba}-\mathrm{OH}$, on the other hand, should readily lead to $\mathrm{BaOH}+\mathrm{H}$ with no barrier in excess of the $\mathrm{Ba}-\mathrm{H}$ bond energy. For these reasons, we believe that an insertion mechanism will lead to $\mathrm{BaOH}+\mathrm{H}$, rather than $\mathrm{BaO}+\mathrm{H}_{2}$. Since $\mathrm{BaOH}+\mathrm{H}$ was not the dominant ground state product, insertion is not an important mechanism in the ground state $\mathrm{Ba}$ reaction.

Our experimental observations, especially the large exit potential energy barrier manifested in a high translational energy release, indicates that a concerted mechanism is involved in the reaction $\mathrm{Ba}\left({ }^{1} \mathrm{~S}\right)+\mathrm{H}_{2} \mathrm{O} \rightarrow \mathrm{BaO}+\mathrm{H}_{2}$ with abstraction of the central $\mathrm{O}$ atom from $\mathrm{H}_{2} \mathrm{O}$ and simultaneous formation of molecular $\mathrm{H}_{2}$ :

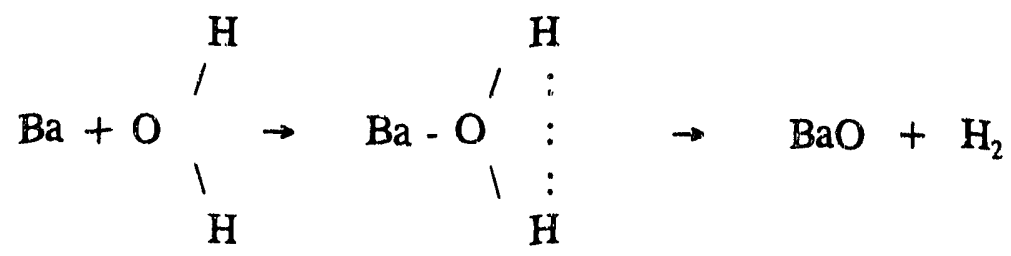


It is well known that concerted reactions are controlled by symmetry constraints. ${ }^{35}$ We first consider coplanar trajectories in $\mathrm{C}_{2 v}$ and $\mathrm{C}_{1}$ symmetry. Approach of $\mathrm{Ba}\left({ }^{\prime} \mathrm{S}\right)$ toward $\mathrm{H}_{2} \mathrm{O}$ along the $C_{2 v}\left(C_{N}\right)$ axis generates a surface of ${ }^{\prime} A_{1}\left({ }^{\prime} A^{\prime}\right)$ symmetry. Similarly, the asymptotic molecular product states with atoms in the same geometry as the reactants generate surfaces of ' $A_{1}$ ('A') symmetry. However, these states do not correlate diabatically, since the ground state of $\mathrm{BaO}$ is best represented as $\mathrm{Ba}^{2+} \mathrm{O}^{2-36}$, the ground state of the product correlates to very high-lying charge transfer states of the reactants. The neutral reactant surface correlates to high- lying non-ionic product states. The avoided crossing of these two ${ }^{1} A_{1}\left({ }^{1} A\right.$ ') surfaces generates a substantial potential energy barrier for the concerted reaction-- the presence of this barrier leads to the small reaction cross section and rather large translational energy release observed for stable closed shell $\mathrm{BaO}+\mathrm{H}_{2}$ products.

In all cases, successful formation of $\mathrm{BaO}+\mathrm{H}_{2}$ requires small impact parameter collisions. This is due to: 1) the very small $\mathrm{Ba}-\mathrm{O}$ approach distance required for transfer of the first valence electron from ground state $\mathrm{Ba}$ to water; and 2) the need to overcome the mechanical barrier associated with sufficient symmetric bending of the water molecule to facilitate concerted formation of $\mathrm{BaO}+\mathrm{H}_{2}$. The covalent-ionic curve crossing radius $\left(\mathrm{R}_{\mathrm{x}}\right)$ is often applied to reactions of alkali and alkaline earth atoms involving long-range electron transfer..$^{5 a, 18-20}$ Although the relation is less applicable in the present case because of the much shorter range for electron transfer due to the negative electron affinity of water, the general conclusions are useful in gaining insight 
into the reaction. In units of Angstroms, the crossing point of the ionic and covalent states is given by:

$$
R_{x}=\frac{14 \cdot 4}{I P_{B a}-E^{\prime} A_{M}}(A)
$$

where $\mathrm{IP}_{\mathrm{Bu}}$ is the ionization potential of $\mathrm{Ba}$, which is $5.2 \mathrm{eV}$ for $\mathrm{Ba}\left({ }^{1} \mathrm{~S}\right)$ and $4.0 \mathrm{eV}$ for $\mathrm{Ba}\left({ }^{1} \mathrm{D}\right)^{18,19}$. $\mathrm{EA}_{\mathrm{M}}$ is the 'effective' electron affinity of the molecule (eV), often taken to be somewhere between the vertical and adiabatic electron affinities. As we will show in detail later (section D), all available data indicates that the adiabatic $\mathrm{EA}_{420} \leq-2 \mathrm{eV}^{37}$; the vertical EA is near $-6 \mathrm{eV} \cdot{ }^{38}$ For $B a\left({ }^{2} S\right)$, electron transfer requires $R_{\text {coll }} \leq 2 A$. The molecular orbit'sls for $\mathrm{H}_{2} \mathrm{O}$ are: ${ }^{16}$

$$
\left(1 a_{1}\right)^{2}\left(2 a_{1}\right)^{2}\left(1 b_{2}\right)^{2}\left(3 a_{1}\right)^{2}\left(1 b_{1}\right)^{2} ; A_{1}
$$

The lowest unoccupied orbital is $4 a_{1}$, which is antibonding with respect to the two $\mathrm{O}-\mathrm{H}$ bonds and bonding with respect to $\mathrm{H} \cdot \mathrm{H}$. Only small impact parameter collisions will lead to the first electron transfer into the $4 \mathrm{a}_{1}$ orbital, at a Ba-O distance of approximately $2 \mathrm{~A}$. This is essentially the bond length of $\mathrm{BaO},{ }^{36}$ and the second electron transfer required for formation of ground state $\mathrm{Ba}^{2+} \mathrm{O}^{2-}$ will occur readily. Electron transfer into the $4 \mathrm{a}_{1}$ orbital at such close range with the $\mathrm{Ba}$ atom near the symmetry axis 
of $\mathrm{H}_{2} \mathrm{O}$ will favor symmetric bending of the water molecule and formation of $\mathrm{BaO}+\mathrm{H}_{2}$. The need for a small impact parameter collision is consistent with the rather small reaction cross section seen for the ground state reaction.

It is expected that approach of $\mathrm{Ba}$ towards the oxygen atom in the plane of the water molecule near the $\mathrm{C}_{2 v}$ axis will most effectively lead to $\mathrm{BaO}+\mathrm{H}_{2}$ since this geimetry will enhance symmetric bencing. Since the water molecules are randomly oriented, however, most of the collisions involve attack of the Ba atom along trajectories that are not in the plane of the water molecule. In this case, the symmetry is $C_{1}$ and all geometries lead to surfaces of A symmetry. However, a substantial barrier is still expected for the same reason as in $C_{1}$ and $C_{2 v}$ symmetries. Of course, small impact parameter collisions will still be required.

Although the light $\mathrm{H}_{2}$ recoil partner results in compression of the $\mathrm{BaO}$ angular distribution, it is either forward-backward symmetric or nearly so. Such forwardbackward symmetry is often taken to be evidence for the existence of a collision intermediate with a lifetime exceeding one rotational period $(1 \mathrm{psec})^{\mathrm{sa}_{\mathrm{a}}, 39-\mathrm{Al}}$. In most cases, such intermediates are associated with deep chemical wells on the potential energy surface. In the present case, the $\mathrm{Ba}_{\mathrm{a}}-\mathrm{H}_{2} \mathrm{O}$ interaction is not much stronger than a typical dispersion interaction with a binding energy not greater than $10 \mathrm{kcal} / \mathrm{mole}^{7}$. It might thus appear surprising that a large fraction of the colliding partners interact long encugh to undergo at least one half of a rotation before product form 'tion. However, a concerted three-center elimination of $\mathrm{H}_{2}$ requires sequential two electron transfer with corisiderable 
deformation of water. This necessitates a closely coupled collision with the $\mathrm{Ba}$ reaching the repulsive inner wall of the $\mathrm{Ba}-\mathrm{H}_{2} \mathrm{O}$ interaction potential before the initiation of electron transfer. Although the $\mathrm{Ba}-\mathrm{H}_{2} \mathrm{O}$ interaction is not very strong, there likely exists entrance and exit potential energy barriers which lead to an effectively deeper well. Also, in the absence of significant steric effects, the CM angular distribution will be broad since non-coplanar trajectories are statistically dominant.

Symmetry arguments may be made for interaction of $\mathrm{Ba}\left({ }^{1} \mathrm{D}\right)+\mathrm{H}_{2} \mathrm{O}$; however, the situation is rather more complicated. In $\mathrm{C}_{2 \mathrm{v}}$, the following surfaces are generated for the reacting pair:' $\mathrm{A}_{1},{ }^{\prime} \mathrm{A}_{1},{ }^{6} \mathrm{~A}_{2},{ }^{\prime} \mathrm{B}_{1},{ }^{1} \mathrm{~B}_{2}$. According to Douglas et al', the lowest lying states are likely to be ' $A_{1}$ and ${ }^{\prime} A_{2}$, the former state having the same symmetry as the ground state molecular products $\mathrm{BaO}+\mathrm{H}_{2}$. But again, a substantial barrier is expected to be generated by the crossing of the excited state reactant and ground (or excited) state product surfaces; the existence of a barrier for formation of $\mathrm{BaO}+\mathrm{H}_{2}$ (or $\mathrm{BaO}^{\circ}+\mathrm{H}_{2}$ ) on the excited surface is consistent with the lack of enhancement of $\mathrm{BaO}$ formation upon electronic excitation in both our experiment and in that of Alcaraz, et. al. ${ }^{6}$

We now tum to the mechanisms expected for formation of the radical products $\mathrm{BaOH}+\mathrm{H}$. Our observation that this channel is promoted by electronic excitation rather than collision energy is good evidence that the reaction occurs much more readily on an excited state surface. This possibility was first suggested by Douglas and Margrave ${ }^{7}$ in discussion of the matrix reactions of alkaline earth atoms with water. In their experiment, irradiation of the $\mathrm{Ba}-\mathrm{OH}_{2}$ adduct, resulting from co-condensation of $\mathrm{Ba}$ 
$+\mathrm{H}_{2} \mathrm{O}$ in a matrix, near the $\mathrm{Ba}$ atomic resonance facilitated "insertion" of the metal atom into the $\mathrm{OH}$ bond with subsequent formation of $\mathrm{BaOH}$. The question naturally arises as to whether the gas phase reaction of electronically excited $\mathrm{Ba}$ is mediated by an insertion mechanism, and if so what is the nature of the motion of the atoms during the process? The results of the alcohol experiments are very helpful in our understanding of this radical channel. We turn to those results before returning to a discussion of the $\mathrm{Ba}\left({ }^{1} \mathrm{D}\right)+\mathrm{H}_{2} \mathrm{O}$ reaction mechanism.

\section{B. Reaction with $\mathrm{CH}_{3} \mathrm{OH}$}

The reaction of ground state and electronically excited $\mathrm{Ba}$ with $\mathrm{CH}_{3} \mathrm{OH}$ shows remarkable preference for formation of $\mathrm{BaOCH}_{3}+\mathrm{H}$. The other product channels $\mathrm{BaOH}+\mathrm{CH}_{3}$ and $\mathrm{BaO}+\mathrm{CH}_{4}$ either do not exist, or are so weak as to be below the sensitivity of our experiment. We conclude that the hydrogen atom elimination channel accounts for between 90 and $100 \%$ of all reactive encounters in the case of ground- and excited state $\mathrm{Ba}+\mathrm{CH}_{3} \mathrm{OH}$.

It is worth noting several important differences between $\mathrm{H}_{2} \mathrm{O}$ and $\mathrm{CH}_{3} \mathrm{OH}$ that pertain to reactions with $\mathrm{Ba}$. The most obvious difference is that formation of $\mathrm{BaOH}+$ $\mathrm{H}$ is endoergic for ground state $\mathrm{Ba}$, whereas formation of $\mathrm{BaOCH}_{3}$ is nearly thermoneutral. We did observe formation of $\mathrm{BaOCH}_{3}$ from reaction of ground state $\mathrm{Ba}$ even at the lowest collision energy obtainable in this experiment, although weakly. Our observation that $\mathrm{BaO}+\mathrm{CH}_{4}$ was not detected from the $\mathrm{Ba}\left({ }^{1} \mathrm{~S}\right.$ or $\left.{ }^{1} \mathrm{D}\right)+$ methanol 
reaction, whereas $\mathrm{BaO}+\mathrm{H}_{2}$ did result from collision of $\mathrm{Ba}\left({ }^{1} \mathrm{~S}\right)$ with water, is not too surprising. Formation of $\mathrm{BaO}+\mathrm{CH}_{4}$ would probably have to be of a concerted nature since insertion would likely favor radical production, as outlined earlier for the $\mathrm{Ba}+$ $\mathrm{H}_{2} \mathrm{O}$ reaction. Such a concerted reaction is less likely in the case for methanol than water since it requires attack by the $\mathrm{H}$ atom from $-\mathrm{OH}$ on an $\mathrm{sp}^{3}$ hybridized carbon atom via a three-center transition state:

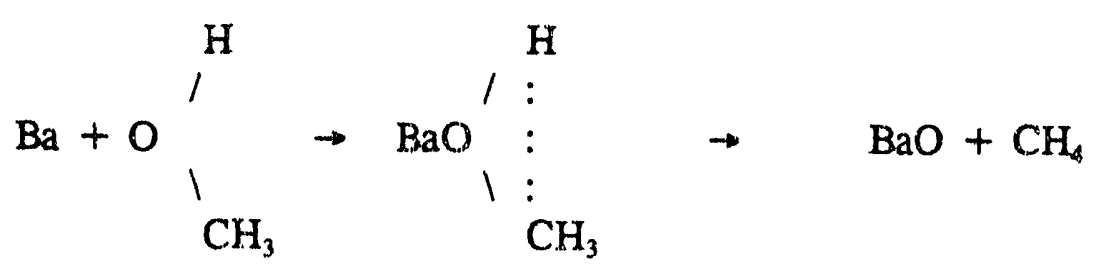

The potential energy bartier for this process will be very high since at the transition state, the strong $\mathrm{O}-\mathrm{CH}_{3}$ bond has to be nearly broken to facilitate bonding between the tetravalent carbon and the attacking $\mathrm{H}$-atom. However, for trivalent group IIIA elements such as $\mathrm{Sc}$ and $\mathrm{Y}$, formation of $\mathrm{MO}+\mathrm{CH}_{4}$ was observed by $\mathrm{Liu}$ and Parson ${ }^{13}$ under single collision conditions. They were unable to observe formation of the metal hydroxides-- either they were not formed or their LIF spectrum was outside the wavelength range studied.

Upon electronic excitation, the large increase in formation of $\mathrm{BaOCH}_{3}+\mathrm{H}$ from methanol is analogous to the increase in $\mathrm{BaOH}+\mathrm{H}$ from water. The most obvious explanation for the formation of $\mathrm{BaOCH}_{3}+\mathrm{H}$ rather than $\mathrm{BaOH}+\mathrm{CH}_{3}$ at all collision energies is that the reaction is dominated by internal migration of the $\mathrm{H}$ atom from $\mathrm{O}$ to 
$\mathrm{Ba}$ within the $\mathrm{Ba}-\mathrm{O}$ bonded intermediate:

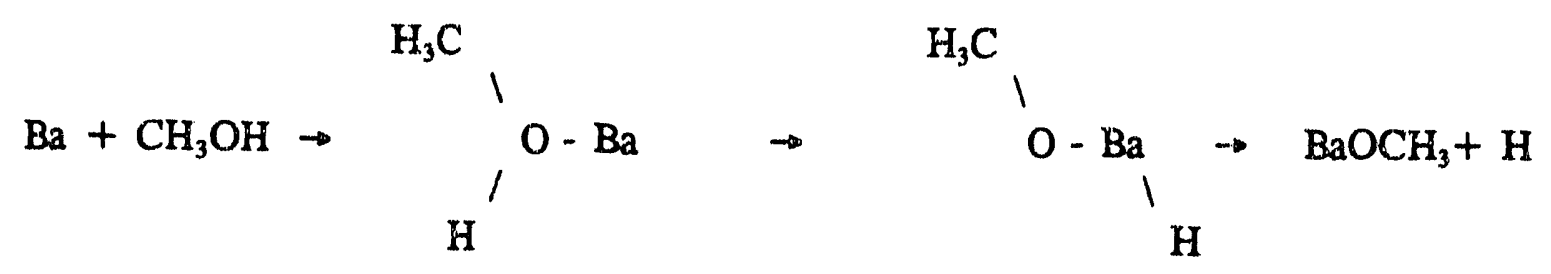

We believe that a mechanism involving $\mathrm{H}$-atom migration will involve substantially smaller potential energy barriers than alternative mechanisms leading to $\mathrm{HOBaCH}$, ie $\mathrm{CH}_{3}$ migration or insertion of $\mathrm{Ba}$ into the $\mathrm{HO}-\mathrm{CH}_{3}$ bond. This is largely due to the spherical shape of the $H$ atom is orbital: good orbital overlap may be maintained with the $\mathrm{O}$ and $\mathrm{Ba}$ atoms simultaneously during the $\mathrm{H}$-atom migration process. This situation contrasts the directional nature of the $\mathrm{sp}^{3}$-hybridized methyl group which necessitates nearly complete rupture of the $\mathrm{O}-\mathrm{CH}_{3}$ bond prior to formation of $\mathrm{HOBaCH}_{3}$.

The present reaction is somewhat analogous $\mathrm{H}_{3} \mathrm{C}-\mathrm{H}$ and $\mathrm{H}-\mathrm{H}$ bond activation by transition metals such as platinum and palladium. ${ }^{42,43}$ It has been fcund that the potential energy barrier is very small for insertion of these metals into $\mathrm{H}_{2}$. However, a substantial barrier exists for formation of $\mathrm{H}-\mathrm{M}-\mathrm{CH}_{3}-$ it is much larger for formation of $\mathrm{CH}_{3}-\mathrm{M}$ $\mathrm{CH}_{3}$. This behavior has been rationalized in terms of the ability for the spherical $\mathrm{H}$-atom to participate in multicenter bonding. ${ }^{42,43}$ Multicenter bonding is less feasible for $-\mathrm{CH}_{3}$ because the tetrahedral $\mathrm{sp}^{3}$ hybrijization leads to highly directional bonding capability. Our observation that dimethyl ether is unreactive under single collision conditions also 
supports our hypothesis that $\mathrm{H}$-atom migration is the dominant mechanism in the radical channels.

This work appears to be the first direct evidence of a metal methoxide in the gas phase under conditions known to involve only a single collision. ${ }^{44}$ As far as we know, only one previous $\mathrm{M}+\mathrm{CH}_{3} \mathrm{OH}$ reaction has been studied in rare gas matrices ${ }^{14}$. Codeposition of $\mathrm{Fe}+\mathrm{CH}_{3} \mathrm{OH}$ led to formation of an $\mathrm{Fe}\left(\mathrm{CH}_{3} \mathrm{OH}\right)$ adduct with the iron atom bonded to the oxygen atom in methanol. Irradiation of the adduct at $400 \mathrm{~nm}<\lambda<500 \mathrm{~nm}$ resulted in formation of $\mathrm{HFeOCH}_{3}$, whereas irradiation at $280 \mathrm{~nm}<\lambda<360 \mathrm{~nm}$ led to $\mathrm{HOFeCH}_{3}$. In other words, a higher photon energy led to 'insertion' into the $\mathrm{C}-\mathrm{O}$ bond. Although the original authors did not draw any conclusions about the reaction mechanism, we suggest that H-atom migration is likely to be the lowest energy process in the iron system. It would not be surprising if this was a general feature in reactions of metal and main group atoms with $\mathrm{H}$-atom containing compounds.

C. The effect of deuterium substitution and collision energy on $\mathrm{Ba}\left({ }^{1} \mathrm{D}\right)$ reactions.

Comparison of $\mathrm{BaOH}$ to $\mathrm{BaOD}$ signal levels indicated that $\mathrm{Ba}\left({ }^{1} \mathrm{D}\right)+\mathrm{D}_{2} \mathrm{O}$ was $2.0 \pm 0.4$ times less reactive than the $\mathrm{H}_{2} \mathrm{O}$ reaction; this ratio was found to remain constant to within the stated uncertainty as the collision energy was varied from 13-30 $\mathrm{kcal} / \mathrm{mole}$. The overall reactive cross section also remained constant to within the experimental uncertainties over this range. 
The observed isotope ratio observed here is not large by comparison to low temperature experiments where the "semiclassical effect" (i.e. without the occurrence of tunneling) is commonly in the range of 3 to $5 .^{45,46}$ Experimental observations ${ }^{15}$ and theoretical calculation $\mathrm{s}^{47}$ on the $\mathrm{Si}+\mathrm{H}_{2} \mathrm{O}$ system have indicated that reaction in rare gas matrices occurs with $\mathrm{H}$-atom migration by quantum mechanical tunneling. Cocondensation of $\mathrm{Si}+\mathrm{H}_{2} \mathrm{O}$ led to rapid formation of $\mathrm{HSiOH}$, whereas visible irradiation of $\mathrm{Si}+\mathrm{D}_{2} \mathrm{O}$ was required for formation of DSiOD. If the barrier for the rate limiting step in the reaction of $\mathrm{Ba}\left({ }^{1} \mathrm{D}\right)+$ water was large, it might be possible to observe a substantially increased isotope effect with decreasing collision energy if tunneling were important. We have found that the isotope effect remains constant over our experimentally obtainable collision energies. Thus, it appears that at these collision energies, quantum mechanical tunneling is not a dominant factor in the deuterium isotope effect that we observe.

\section{D) Product Angular Distributions for the Radical Channels}

Although the $\mathrm{BaOH}$ and $\mathrm{BaOCH}_{3}$ angular distributions are rather compressed due to their light $\mathrm{H}$ or $\mathrm{D}$ atom recoil partner, the best fit of the angular and TOF data was found to employ a forward backward symrnetric, isotropic center-of-mass angular distribution (to within the sensitivity of the fit). The usual explanation for this angular distribution is the existence of an intermediate $\mathrm{HBaOR}$ species with a lifetime exceeding one rotational period. It should be noted, however, that the symmetric product angular 
distribution might also be attributable to the migration process which by its very nature is likely to reflect the symmetry of the water molecule:
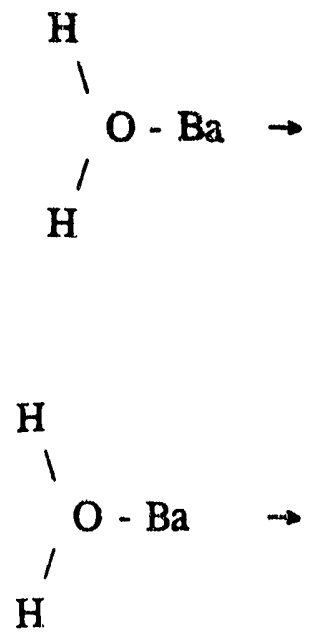

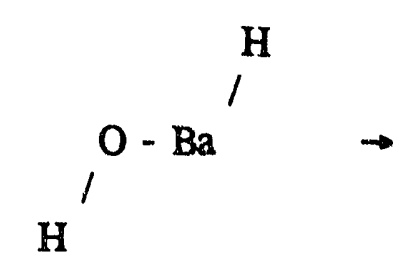

$\mathrm{BaOH}+\mathrm{H}$

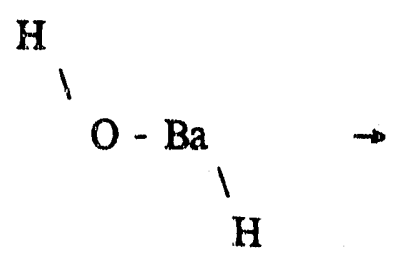

Since both $\mathrm{H}$ atoms are equally likely to migrate, a forward-backward symmetric angular distribution will result even if $\mathrm{HBaOH}$ has a lifetime of less than one rotational period.

\section{E. Comparison with dissociative electron attachment experiments-}

Considerable insight into the similarities and differences between $\mathrm{H}_{2} \mathrm{O}, \mathrm{CH}_{3} \mathrm{OH}$ and $\mathrm{CH}_{2}=\mathrm{CH}-\mathrm{CH}_{2} \mathrm{OH}$ can be gained by examining results of dissociative low energy electron attachment experiments. Electron attachment to water was studied by Melton ${ }^{38}$ in the early '70s; the results on methanol and allyl alcohol are due to Illenberger, et. al. ${ }^{48}$ Briefly, the negative ion fragments resulting from dissociation of the temporary compound ion states are detected as a function of incident electron beam energy. Such experiments provide information on the energies of unoccupied molecular orbitals as well 
as favorable dissociation channels. As we have already mentioned, long range electron transfer cannot occur for this class of reactions, even with electronically excited Ba. However, it is clear that a transition must occur between the covalent surfaces which characterize the reactants and those of the products which are definitely ionic.

When low energy electrons are passed through water vapor, three rather weak resonances are observed at $6.4,8.4$ and $11.2 \mathrm{eV}$; all lead to formation of $\mathrm{H}^{\circ}, \mathrm{OH}^{\circ}$ and O- ${ }^{38}$ The existence of three peaks has been attributed to three electronic states of $\mathrm{H}_{2} \mathrm{O}$, namely ${ }^{2} B_{1},{ }^{2} A_{1}$ and ${ }^{2} B_{2}^{33,49}$; apparently, all dissociate to yield the three ions. In the case of methanol, again signal was observed at three energies- $6.2,7.8$ and $10.2 \mathrm{ev}$, i.e., the energy levels of the unoccupied valence orbitals are comparable for water and methanol. However only $\mathrm{CH}_{3} \mathrm{O}^{-}$was produced at $6.2 \mathrm{eV}$, and $\mathrm{CH}_{3} \mathrm{O}^{-}$dominated at $7.8 \mathrm{eV}$; but all three species $\mathrm{O}^{\circ}, \mathrm{OH}$, and $\mathrm{CH}_{3} \mathrm{O}^{\circ}$ are produced at the highest energy ${ }^{47}$. Allyl alcohol, on the other hand exhibited a much lower energy resonance than water or methanol, at $2 \mathrm{eV}$. Whereas the lowest energy electron attachment to methanol led only to $\mathrm{CH}_{3} \mathrm{O}$, dissociation of the allyl alcohol anion led to both $\mathrm{OH}^{-}$and $\mathrm{CH}_{2}=\mathrm{CH}-\mathrm{CH}_{2} \mathrm{O}$. It appears that a direct analogy may be drawn between the negative ions resulting from decay of the lowest energy resonances in electron scattering with water, methanol, and allyl alcohol, and the negative ions in the radical products resulting from their reactions with $\mathrm{Ba}$ atoms.

The exclusive formation of $\mathrm{CH}_{3} \mathrm{O}^{\circ}$ rather than $\mathrm{OH}^{-}$from electron attachment to methanol at $6.2 \mathrm{eV}$ cannot simply be attributed to thermodynamic effects since the exclusive channel is the most endoergic: ${ }^{47}$ 


$$
\begin{array}{rlrl}
\mathrm{e}+\mathrm{CH}_{3} \mathrm{OH} & \rightarrow \mathrm{CH}_{3}+\mathrm{OH}^{\cdot}, & \Delta \mathrm{H}_{0}=2.1 \mathrm{eV}, \\
& \rightarrow \mathrm{CH}_{4}+\mathrm{O}^{-}, & \Delta \mathrm{H}_{0}=2.4 \mathrm{eV}, \\
& \rightarrow \mathrm{CH}_{3} \mathrm{O}+\mathrm{H}, \quad \Delta \mathrm{H}_{0}=2.9 \mathrm{eV},
\end{array}
$$

When several dissociative channels are available, usually the fragment with the highest electron affinity retains the electron. ${ }^{38}$ This is not true in the present case-- the electron affinity of $\mathrm{CH}_{3} \mathrm{O}(1.57 \pm 0.022 \mathrm{eV})^{50}$ is less than that of $\mathrm{OH}(1.829 \pm 0.010 \mathrm{eV})^{51}$. This suggests that the electron scattering behavior results from dynamic, rather than thermodynamic considerations. Similar behavior is seen in photodissociation of alcohols. The photodissociation of $\mathrm{CH}_{3} \mathrm{OH}$ at $193 \mathrm{~nm}$ is a direct process preferentially resulting in $\mathrm{H}$ atom elimination, whereas formation of vibrationally activated ground state $\mathrm{CH}_{3} \mathrm{OH}$ by insertion of $\mathrm{O}\left({ }^{1} \mathrm{D}\right)$ into $\mathrm{CH}_{4}$ primarily led to the thermodynamically most favored products, $\mathrm{OH}+\mathrm{CH}_{3}{ }^{52}$.

Based on these observations, it would be tempting to suggest that the lowest lying unoccupied molecular orbital of methanol is primarily of $\mathrm{O}-\mathrm{H}$ antibonding character-electron attachment or electronic excitation of methanol leads to preferential $\mathrm{H}$ atom elimination. Since a switch to an ionic surface inevitably occurs in the $\mathrm{Ba}+\mathrm{CH}_{3} \mathrm{OH}$ reaction, this might also explain the dominance of $\mathrm{BaOCH}_{3}+\mathrm{H}$. According to $\mathrm{Ab}$-Initio calculations, ${ }^{53.54}$ the situation actually somewhat more complex. It appears that the first excited state of methanol is repulsive in both the $\mathrm{O}-\mathrm{H}$ and $\mathrm{C}-\mathrm{O}$ coordinates. However, there is a barrier in the adiabatic potential curve for the $\mathrm{C}-\mathrm{O}$ dissociation coordinate 
arising from a sharp Rydberg-valence avoided crossing. ${ }^{33}$. In contrast, the $\mathrm{O}-\mathrm{H}$ dissociation coordinate was found to be completely repulsive.

The very light $\mathrm{H}$ atom product in the $\mathrm{CH}_{3} \mathrm{O}+\mathrm{H}$ (or $\mathrm{CH}_{3} \mathrm{O}+\mathrm{H}$ ) channel leads to an important dynamic effect. ${ }^{33,54}$ For a given recoil energy, the relative velocity of the products $\left(\mathrm{V}_{\mathrm{H}}\right)$ will be five times greater than for $\mathrm{OH}^{+}+\mathrm{CH}_{3}$, (or $\left.\mathrm{OH}+\mathrm{CH}_{3}\right)$. Thus, the dissociation dynarnics primarily derives from the steeper potential in the $\mathrm{O}-\mathrm{H}$ coordinate and the much greater relative velocity for $\mathrm{H}+\mathrm{CH}_{3} \mathrm{O}$. In the $\mathrm{Ba}+\mathrm{CH}_{3} \mathrm{OH}$ reaction, similar eifec: , together with a lowe: potential energy barrier for $\mathrm{H}$-atom migration, lead to preferential formation of $\mathrm{BaOCH}_{3}+\mathrm{H}$ rather than $\mathrm{BaOH}+\mathrm{CH}_{3}$.

The reactivity and low energy electron scattering with allyl alcohol contrasts the $\mathrm{Ba}+\mathrm{H}_{2} \mathrm{O}$ and $\mathrm{CH}_{3} \mathrm{OH}$ systerns. In this case, the low energy resonance is nearly identical to that in ethylene. ${ }^{48}$ Electron attachment to the low lying $\pi_{c c}{ }^{\circ}$ molecular oroital results in rapid randomization of the excitation energy followed by dissociation to $\mathrm{OH}$ or $\mathrm{OCH}_{2}-\mathrm{CH}=\mathrm{CH}_{2} \cdot{ }^{-48}$ We propose that an analogous situation occurs in the reaction of allyl alcohol with $\mathrm{Ba}$; apparently formation of $\mathrm{BaOH}+\mathrm{CH}_{2}-\mathrm{CH}=\mathrm{CH}_{2}$ (favored by thermodynamics) can compete with formation of $\mathrm{BaOCH}_{2}-\mathrm{CH}=\mathrm{CH}_{2}+\mathrm{H}$ (favored by the mobility of the $\mathrm{H}$-atom).

E. The role of the excit:d state in $\mathrm{H}$-atom migration.

As was pointed out by Douglas and coworkers $7, \mathrm{HBaOH}$ can be treated by analogy with the $\mathrm{HAB}$ molecule, with $\mathrm{B}=\mathrm{OH}$. We discuss the particular case of water 
here; a parallel argument should apply to the reaction of methanol since substitution of $\mathrm{H}$ by $\mathrm{CH}_{3}$ should have little effect on the electronic structure of the $\mathrm{Ba}$ core. For $\mathrm{HBaOH}$, the ground state configuration is ${ }^{\prime} \mathrm{A}^{\prime}\left(1 \mathrm{a}^{\circ}\right)^{2}\left(6 \mathrm{a}^{\prime}\right)^{2}$, with an excited state $\left(1 a^{\prime \prime}\right)^{2}\left(6 a^{\prime}\right)\left(7 a^{\prime}\right)$, also of ' $A$ ' symmetry. In the case of the heavier alkaline earth atoms, the ground state 6s-a' orbital of the metal atom probably lies higher than the unoccupied $4 \mathrm{a}_{1}-\mathrm{a}^{\prime}$ orbital of water. The ground state configuration of $\mathrm{Ba}+\mathrm{H}_{2} \mathrm{O}$ in $\mathrm{C}_{1}$ symmetry correlates diabatically with an excited state of $\mathrm{HBaOH}$, whereas the ionic state $\mathrm{Ba}^{+} \mathrm{H}_{2} \mathrm{O}$. (or possibly $\mathrm{Ba}^{2+} \mathrm{H}_{2} \mathrm{O}^{2}$ ) correlates to the $\mathrm{HBaOH}$ ground state. An avoided crossing of these two curves generates a sutstantial barrier for the ground state insertion process. We observed the onset of $\mathrm{Ba}\left({ }^{\prime} \mathrm{S}\right)+\mathrm{H}_{2} \mathrm{O} \rightarrow \mathrm{BaOH}+\mathrm{H}$ at collision energies above 13 $\mathrm{kcal} / \mathrm{mole}$. This might irdicate that the barrier on the ground state surface does not lie much above the reaction endoergicity. Alternatively, the ground state reaction $\mathrm{Ba}\left({ }^{\prime} \mathrm{S}\right)+$ $\mathrm{H}_{2} \mathrm{O} \rightarrow \mathrm{BaOHI}+\mathrm{S}$ might result from a direct abstraction mechanism, rather than from H-atom migration. In any case, it is clear that the potential energy barrier for formation of $\mathrm{BaOH}+\mathrm{H}$ is higher than that for formation of $\mathrm{BaO}+\mathrm{H}_{2}$, which was observed to accur readily even at the lowest collision energy ( $12 \mathrm{kcal} / \mathrm{mole})$.

Our observation that electronic excitation is much more effective than collision energy in enhancing the formation of $\mathrm{BaOH}+\mathrm{H}$ is good evidence that the barrier for formation of $\mathrm{H}-\mathrm{Ba}-\mathrm{OH}$ by $\mathrm{H}$-atom migration is low on the excited state potential energy surface. There his. recently been considerable theoretical work on the activation of covalent bonds by transition metals. ${ }^{42,43}$ The reaction $M+H-R \rightarrow H-M-R(R=a \mid k y l)$ is 
most favorable for those metal atoms with ground state electronic configurations favorable is sd hybridization, since this readily facilitates formation of two covalent bonds. Bond activation is also favored by electronic configurations which minimize longrange electronic repulsion. In the present case, the $6 \mathrm{~s} 5 \mathrm{~d}\left({ }^{\prime} \mathrm{D}\right)$ configuration has the "singlet diradical" character favorable for formation of $\mathrm{H}-\mathrm{Ba}-\mathrm{OR}$. This is clearly not the case for $\mathrm{Ba} 6 s^{2}\left({ }^{1} \mathrm{~S}\right)$ - the paired $6 s^{2}$ electron configuration will have a substantial promotion energy. It will also have a substantially weaker interaction with water due to its closed shell character.

The main difference between $\mathrm{Ba}+\mathrm{H}-\mathrm{OR} \rightarrow \mathrm{H}-\mathrm{Bd}-\mathrm{OR}$ and transition metal reactions such as $\mathrm{M}+\mathrm{H}-\mathrm{R} \rightarrow \mathrm{H}-\mathrm{M}-\mathrm{R}\left(\mathrm{R}=\mathrm{H}, \mathrm{CH}_{3}\right)$ is that the $\mathrm{Ba}$ intermediato has substantial ionic character, whereas the transition metal intermediate is primarily covalently bonded. Thus, some additional insight into the reaction dynamics may be gained by considering the factors which favor the transition from the covalent to ionic surface which must ultimately occur for formation of $\mathrm{Ba}^{+} \mathrm{OR}^{-}+\mathrm{H}$. Vertical electron transfer to $\mathrm{H}_{2} \mathrm{O}$ (especially from $\mathrm{Ba}\left({ }^{\prime} \mathrm{S}\right)$ ) is thermodynamically unfavorable, with the lowest vertical electron attachment resonance at $6.4 \mathrm{eV} .{ }^{38}$ Interestingly, the literature reveals one experimental observation ${ }^{37}$ of $\mathrm{H}_{2} \mathrm{O}^{-}$in ion cyclotron resonance experiments. It has been determined that this molecule, probably best described ${ }^{37}$ as $\mathrm{OH}^{-} \ldots \mathrm{H}$ is stable anct lies about $2.1 \mathrm{eV}$ above $\mathrm{H}_{2} \mathrm{O}+\mathrm{e}^{-*}$. This is below the energy of separated $\mathrm{OH}^{-}+\mathrm{H}$ $(3.28 \mathrm{eV})^{21}$. The Ba-water collision timescale is long compared with the vibrational frequency of water. Electron transfer from $\mathrm{Ba}$ to $\mathrm{H}_{2} \mathrm{O}$ will be most favorable for 
collision geometries resulting in asymmetric stretching of the water molecule. For those molecules, the "effective electron affinity" will be near $-2.1 \mathrm{eV}$, and the curve crossing radius for $\mathrm{Ba}\left({ }^{\prime} \mathrm{D}\right)$ is $\sim 2.5 \AA$. Note that the crossing radius based on eq. 1 for $\mathrm{Ba}\left({ }^{\prime} \mathrm{S}\right)$ will still be belop' $2 \AA$ even with this "most favorable" value of $-2.1 \mathrm{eV}$ for the EA of $\mathrm{H}_{2} \mathrm{O}$. This difference between the curve crossing radii in these two cases will play a role in determining the identity of the final product. In the case of electronically excited ba, transfer of the more easily ionized d-electron to the symmetry-allowed orbitals in $\mathrm{H}_{2} \mathrm{O}$ will preferentially occur at $\sim 2.5 \AA$ in collisions leading to asymmetric stretching of the water molecule. The weakly bound $\mathrm{H}$ atom in the newly formed $\mathrm{H}_{2} \mathrm{O}$ molecule will readily migrate away from the oxygen before the $\mathrm{Ba}$ can approach to within the close range required for second electron transfer that is required for formation of $\mathrm{BaO}\left({ }^{1} \Sigma\right)+$ $\mathrm{H}_{2}$.

\section{CONCLUSIONS}

The reaction of $\mathrm{Ba}$ with water illustrates that under appropriate conditions, it is indeed possible to control the chemical outcome of a reaction by proper selection of the initial electronic state of a reactant. The observation that reaction of ground state $\mathrm{Ba}$ results in $\mathrm{BaO}+\mathrm{H}_{2}$, whereas $\mathrm{Ba}$ electronic excitation leads to $\mathrm{BaOH}+\mathrm{H}$, is a consequence of the different dynamic and electronic requirements for each channel. Due to the existence of a large mechanical barrier, and the need for close approar $h$ of the reactants, the molecular products are favored by the ground state barium atoms. For 
only in the ground state can $\mathrm{Ba}$ approach to within $-2 \AA$ before the first electron transfer. Concerted molecular rearrangement with second electron transfer can occur near the inner turning point of the collision, resulting in production of $\mathrm{BaO}+\mathrm{H}_{2}$. Formation of radical products, on the other hand, results from $\mathrm{H}$ - atom migration. Initial excitation of one valence electron to the 5d-orbital strongly promotes this process. Two main factors contribute to this effect. The "singlet diradical" character of the 6s5d configuration is more favorable to formation of two bonds required for $\mathrm{H}-\mathrm{Ba}-\mathrm{OR}$. Electronic excitation also increases the electron transfer radius. Electron transfer at longer range is favored by asymmetric stretching of the water molecule, leading to $\mathrm{H}$ atom migration and radical formation. This precludes the second electron transfer required for the molecular channel.

The observation of only $\mathrm{BaOCH}_{3}$ from reaction with methanol, and lack of reaction of dimethyl ether has provided additional evidence for the importance of $\mathrm{H}$-atom migration in the radical channels. The parallels drawn between reactions involving electror. transfer, and the products from dissociative electron attachment, suggests that analogies between the processes may provide a solid basis for future predictions of the most probable outcomes of other chemical reactions, which in principal might posses more than one possible ionic product. 


\section{V1. REFERENCES}

1. (a) P.B. Armentrout, Science 251, 175, (1991)., (b) J.L. Elkind and P.B. Armentrout, J. Chem. Phys., 86(4), 1868 (1987). (c) R. Georgiadis and P.B. Armentrout, J. Phys. Chem. 92, 7067 (1988).

2. (a) H. Yamazaki and R.J. Cvetanovic, J. Chem. Phys., 41, 3703 (1964). (b) G. Paraskevopoulos and R.J. Cvetanovic, J. Chem. Phys., 50, 590 (1969); 52, 5821 (1970). c) C.L. Lin and W.B. DeMore, J. Phys. Chem. 76, 1375 (1972). d) R.J. Buss, P. Casavecchia, T.Hirooka, S.J. Sibener, and Y.T. Lee, J. Chem. Phys., 73, 6351 (1980).

3. (a) P.S. Weiss, J.M. Mestdagh, M.H. Covinsky, B.A. Balko, and Y.T. Lee, Chem. Phys., 126, 93, (1988); (b) M.F. Vemon, H. Schmidt, P.S. Weiss, M.H. Covinsky, and Y.T. Lee, J. Chem. Phys., 84(10) 5580, 1986; (c) H. Schmidt, P.S. Weiss, J.M. Mestdagh, M.H. Covinsky, and Y.T. Lee, Chem. Phys. Lett. 118, 6, 539 (1985); (d) J.M. Mestdagh, B.A. Balko, M.H. Covinsky, P.S. Weiss, M.F. Vernon, H. Schmidt, and Y.T. Lee, Faraday Disc., 84, 145 (1987).

4. Y.T. Lee, Science 236, 793 (1987).

5. (a) H.F. Davis, A.G. Suits, and Y.T. Lee, J. Chem. Phys., in press. (b) H.F. Davis, A.G. Suits, H. Hou, and Y.T. Lee, Ber. Bunsenges. Phys. Chem., 94, 1193 (1990). (b) A.G. Suits, H. Hou, H.F. Davis, and Y.T. Lee, J. Chem. Phys., 95, 8207 (1992). (c) A.G. Suits, H. Hou, H.F. Davis, and Y.T. Lee, J. M. Mestdagh, J. Chem. Phys., 95, 8178 (1991). (d) A.G. Suits, H. Hou, and 
Y.T. Lee, J. Phys. Chem., 94, 5672, (1990).

6. C. Alcaraz, J.M. Mestdagh, P. Meyadier, P. de Pujo, J.P. Visticot, A. Binet, and J. Cuvellier, Chem. Phys. Lett. 156, 191 (1989) .

7. a) M.A. Douglas, R.H. Hauge and J.L. Margrave, High Temp. Sci., 18, 97 (1984). b) J.W. Kauffman, R.H. Hauge, J.L. Margrave, High Temp. Sci., 18, 201, (1984). c) R.H. Hauge, J.W. Kauffman, and J.L. Margrave, J. Am. Chem. Soc., 102, 6005 (1980), d) P.F. Meier, R. H. Hauge, and J.L. Margrave, J. Am. Chem. Soc., 100, 2108 (1978).

8. J. W. Kauffman, R.H. Hauge, and J.L. Margrave, (a) J. Phys. Chem, 89, 3541,(1985)., (b) J. Phys., Chem, 89, 3547 (1985).

9. L. A. Curtiss, D.J. Frurip, Chem. Phys. Lett., 75,1,69(1980).

10. S. Sakai, K.D. Jordan, Chem. Phys. Lett., 130, 1,2, 103 (1986).

11. J.L. Gole, S.A. Pace, J. Phys. Chem, 85, 2651 (1981).

12. S. Sakai, K.D. Jordan, J. Phys. Chem, 87, 2293 (1983).

13. K. Liu, J.M. Parson, J. Chem. Phys., 68(4) 1794 (1978)

14. M. Park, R. H. Hauge, Z.H. Kafafi, and J. L. Margrave, J. Chem. Soc. Chem. Comm., 1570 (1985).

15. Z.K. Ismail, R.H. Hauge, L. Fredin, J.W. Kauffman, and J.L. Margrave, J. Chem. Phys., 77(4), 1617, (1982).

16. G. Herzberg, "Molecular Spectra and Molecular Structure, "Vol. III, "Electronic Spectra and Electronic Structure of Polyatomic Molecules." Van Nostrand Reinhold, Princeton, New Jersey, 1966. 
17. M.B. Robin, Higer Excited States of Polyatomic Molecules, Vol III., Academic Press, New York, 1985, pg. 165.

18. D. Herschbach, Appl. Opt. Supp., 2, 128,(1965)

19. Magee, J. Chem. Phys., 8, 687, (1940).

20. a) Ronald R. Herm, in: Alkali Halide Vapors, edited by. P. Davidovits and D.L. MicFadden (Academic Press, 1979) p. 189.

b) R.D. Levine and R.B. Bernstein, Molecular Reaction Dynamics and Chemical Reactivity, (Oxford University, New York, 1987).

21. JANAF Thermochemical Tables, 3rd ed., J. Physical and Chemical Ref. Data., 14, (1985), Supp. No. 1.

22. For a discussion of various detection methods, see G. Scoles, ed. "Atomic and Molecular Beam Methods, Vol. 1 Oxford University Press, New York, 1988.

23. a) C.R.Brazier, L.C. Ellingboe, S. Kinsey-Nielsen, and P.F. Bernath, J. Am. Chem. Soc., 108, 2126 (1986). b) C. R.Brazier, L.C. Ellingboe, S. KinseyNielsen, and P.F. Bernath, J.Am.Chem.Soc., 108, 2126 (1986). c) C.R. Brazier, P.F. Bernath, S. Kinsey-Nielsen, L.C. Ellingboe, J. Chem. Phys., 82, 1043 (1985). đ) S. Kinsey-Nielsen, C.R. Brazier, P.F. Bernath, J. Chem. Phys., 84, 698 (1986). e) P.F. Bernath, S. Kinsey-Nielsen, Chem.Phys.Lett., 105, 663, (1984).

24. Y.T. Lee, J.D. McDonald, P.R. LeBreton, and D.R. Herschbach, Rev. Sci. Instrum., 40, 1402 (1969).

25. H.F. Davis, A.G. Suits, M.H. Covinsky, and Y.T. Lee, in preparation. 
26. CRC Handbook of Chemistry and Physics, edited by R.C. Weast (CRC, Boca Raton, Florida, 1987).

27. The elf stronic structures of $\mathrm{BaOH}$ and $\mathrm{BaOCH}_{3}$ are analogous to the alkaline earth halides: For a discussion of the insensitivity of fragmentation of the alkaline earth halides with internal excitation upon electron impact see Ref. 28.

28. C.A. Mims, S-M Lin, R.R. Herm, J. Chem. Phys. 58(5), 1983 (1973).

29. T.P. Parr, A. Freedman, R.Behrens, Jr., R.R. Herm, J. Chem. Phys, 72(9), 5163 (1980).

30. R.R. Herm, S.M. Lin, C.A. Mims, J. Phys. Chem. 77(25),2931 (1973).

31. C. Batalli-Cosmovici and K.W. Michel, Chem. Phys. Lett, 11, 245 (1971).

32. G. Comsa, R. David, B.J. Schumacher, Rev. Sci. Instrum., 52 (6) 789 (1981).

33. (a) S. Niggli and M.C.E. Huber, Phys. Rev. A, 35, 7, 2908, (1987); (b) A.F. Bernhardt, Appl. Phys., 9,19 (1976).

34. R.S. Newbury, G.W. Barton, A.W. Searcy, J. Chem. Phys., 48(2), 793 (1968).

35. R. B. Woodward and R. Hoffmann, "The Conservation of Orbital Symmetry", Academic Press, New York (1969)

36. J.G. Pruett, R.N. Zare, J. Chem. Phys. 62, 2050,(1975)

37. L.J. deKoning, N.M.M. Nibbering, J. Am. Chem. Soc., 106, 7971, (1984).

38. C.E. Melton, J. Chern. Phys., 57,(10),4218,(1972).

39. Miller, S.A. Safron, and D.R. Herschbach, Discuss. Faraday Soc. 44, 108 (1967).

40. W.B. Miller, Thesis, Harvard University, (1969). 
41. a) D.O. Ham, J.L. Kinsey and F.S. Klein, Disc. Faraday. Soc. 44, 174 (1967). b) D.O. Ham, J.L. Kinsey, J. Chem. Phys., 48(2), 939 (1968). c) D.O. Ham and J.L. Kinsey, J. Chem. Phys., 53(1), 285 (1970).

42. (a) J.J. Low, W.A. Goddard III, J. Am. Chem. Soc., 106, 8321, (1984). (b) J.J. Low, W.A. Goddard III, J. Am. Chem. Soc., 106, 6928, (1984) c) J.J. Low, W.A. Goddard, Organmometallics, 5, 609 (1986). d) J.J. Low, W.A. Goddard III, J. Am. Chem. Soc., 108, 6115 (1986).

43. a) M. Blomberg, U. Brandemark, P. Siegbahn, J. Am. Chem.Soc., 105, 5557 (1983). b) M. Blomberg, U. Brandemark, L. Pettersson, P. Siegbahn, P. Int. J. Quantum Chem., 23, 855 (1983). c) M.R.A. Blomberg, P.E.M. Siegbahn and M. Svensson, J. Phys. Chem., 95, 4313 (1991).

44. Bernath and coworkers (Ref 23) postulated that the large increase in signal with electronic excitation resulted from the onset of a direct mechanism.

45. W.D. Forst, "Theory of Unimolecular Reactions (Academic, New York, 1973).

46. S.E. Barlow, J.M. Van Doren, C.H. DePuy, V.M. BierBaum, I. Dotan, E.E. Ferguson, N.G. Adams, D. Smith, B.R. Rowe, J.B. Marquette, G.Depeyrat, M. Durup-Ferguson, J. Chem. Phys, 85(7) 3851, (1986).

47. A. Tachibana, M. Koizumi, H. Teramae, and T. Yamabe, J. Am. Chem. Soc., $109,1383,(1987)$

48. A. Kühn, H-P Fenzlaff, and E. Illenberger, J. Chem. Phys. 88 (12), 7453, (1988).

49. D.S. Belic, M. Landau, R.I. Hall, J. Phys. B: At. Mol. Phys. 14, 175 (1981). 
50. P.C. Engelking, G.B. Ellison, and W.C. Lineberger, J. Chem. Phys, 69(5), 1826 (1978)

51. R.L. Celotta, R.A. Bennett and J.L. Hall, J. Chem. Phys., 60, 1740 (1974).

52. S. Satapal, J. Park, R. Bersohn and B. Katz, J. Chem. Phys., 9 (11), 6873 (1989).

53. R. J. Buenker, G. Olbrich, H.-P. Schuchmann, B.L. Sch'rmann, and C. von Sonntag, J. Am. Chem. Soc., 106, 4362 (1984).

54. E. Kassab, J.T. Gleghorn, E.M. Evleth, J. Am. Chem. Soc., 105, 1746 (1983). 


\section{LIST OF FIGURES}

Fig 1. Newton Diagram for $\mathrm{Ba}\left({ }^{1} \mathrm{~S}\right)+\mathrm{H}_{2} \mathrm{O}$ at $\mathrm{E}_{\mathrm{coll}}=12 \mathrm{kcal} /$ mole. Inner circle shows maximum center of mass velocities for $\mathrm{BaO}$ from $\mathrm{Ba}+\mathrm{H}_{2} \mathrm{O} \rightarrow \mathrm{BaO}+\mathrm{H}_{2}$. Larger circle shows Ba velocity from elastic scattering from $\mathrm{H}_{2} \mathrm{O}$.

Fig 2. $\mathrm{BaO}^{18}$ time-of-flight spectra from $\mathrm{Ba}\left({ }^{1} \mathrm{~S}\right)+\mathrm{H}_{2} \mathrm{O}^{18} \rightarrow \mathrm{BaO}^{18}+\mathrm{H}_{2}$ at $\mathrm{E}_{\mathrm{coll}}=$ 12kcal $/$ mole. ono0o- experimenta' data. — Fit to data using $\mathrm{P}(\mathrm{E})$ anf $\mathrm{T}(\theta)$ from figure 4.

Fig 3. Ba time-of-flight spectra from $\mathrm{Ba}\left({ }^{1} \mathrm{~S}\right)+\mathrm{H}_{2} \mathrm{O}$ collisions at $\mathrm{E}_{\text {coll }}=12 \mathrm{kcal} / \mathrm{mole}$. The fastest and slowest peaks are due to the forward and backward components of the Newton circle. The small middle component is the contribution from fragmentation of $\mathrm{BaO}$ to $\mathrm{Ba}^{+}$in the ionizer.

Fig 4. Best fit product translational energy distribution $(P(E))$ and center of mass angular distribution $(T(\theta))$ for $\mathrm{BaO}+\mathrm{H}_{2}$ reaction channel and nonreactive inelastic $\mathrm{Ba}+$ $\mathrm{H}_{2} \mathrm{O}$ channel.

Fig $5 \mathrm{BaO}$ and $\mathrm{BaOH}$ angular distributions from reaction of $\mathrm{Ba}\left({ }^{1} \mathrm{~S}\right)+\mathrm{H}_{2} \mathrm{O}$ at $\mathrm{E}_{\text {coll }}=$ $23 \mathrm{kcal} / \mathrm{mole}$ showing relative signal intensities for both channels. Nominal Newton diagram for two reartion channels is also shown.

Fig 6. $\mathrm{Ba}^{18} \mathrm{OH}$ time-of-flight spectra from $\mathrm{Ba}\left({ }^{1} \mathrm{~S}\right)+\mathrm{H}_{2}{ }^{18} \mathrm{O}$ at $\mathrm{E}_{\text {coll }}=23 \mathrm{kcal} / \mathrm{mole}$.

Fig 7. Same as Fig. 6 but mass spectrometer set at $\mathrm{BaO}^{18}$. Small dotted line denotes contribution from $\mathrm{Ba}^{18} \mathrm{OH}$ fragmentation in electron bombardment ionizer. 
Fig 8. Product translational energy distribution $\mathrm{P}(\mathrm{E})$ for $\mathrm{BaO}$ and $\mathrm{BaOH}$ from reaction of $\mathrm{Ba}\left({ }^{1} \mathrm{~S}\right)+\mathrm{H}_{2} \mathrm{O}$ at $\mathrm{E}_{\text {coil }}=23 \mathrm{kcal} / \mathrm{mole}$.

Fig 9. $\mathrm{BaOH}$ time-of-flight spectra from $\mathrm{Ba}\left({ }^{\prime} \mathrm{D}\right)+\mathrm{H}_{2} \mathrm{O}$ collisions at $\mathrm{E}_{\text {coll }}=12$ $\mathrm{kcal} / \mathrm{mole}$. Solid line shows best fit to data.

Fig10 Upper Figure: $\mathrm{BaOH}$ Angular Distribution from $\mathrm{Ba}\left({ }^{\prime} \mathrm{D}\right)+\mathrm{H}_{2} \mathrm{O}$ at $\mathrm{E}_{\text {call }}=12$ $\mathrm{kcal} / \mathrm{mole}$. Lower Figure: Translational energy distribution for $\mathrm{BaOH}$ from $\mathrm{Ba}\left({ }^{\prime} \mathrm{D}\right)+\mathrm{H}_{2} \mathrm{O}$ at $\mathrm{E}_{\text {coll }}=12 \mathrm{kcal} /$ mole.

Fig11 Ba time-of-flight spectra from $\mathrm{Ba}\left({ }^{1} \mathrm{D}\right)+\mathrm{H}_{2} \mathrm{O}$ colisions at $\mathrm{E}_{\mathrm{coll}}=12 \mathrm{kcal} / \mathrm{mole}$. The fastest and slowest peaks are due to the forward and backward components of the Newton circle. The large middle component is calculated contribution from fragmentation of $\mathrm{BaOH}$ to $\mathrm{Ba}^{+}$in the ionizer.

Fig12 Ba time-of-flight spectra at $12 \mathrm{kcal} /$ mole showing effect of electronic excitation on reactive component (middle peak) and nonreactive component (fast and slow components).

Fig13 Product mass spectra obtained with detector at center of mass from reaction $\mathrm{Ba}$ $+\mathrm{D}_{2} \mathrm{O}$ at collision energy of $31 \mathrm{kcal} / \mathrm{mole}$. Squares and dotted line: Laser offDominant product is $\mathrm{BaO}$ but small contribution is seen from BaOD. Circles and solid line: Laser on- Product results from formation of $\mathrm{BaOD}+\mathrm{D}$. $\mathrm{BaO}$ is from fragmentation of $\mathrm{BaOD}$ and residual ground state reaction. Figure also shows Newton diagram for $\mathrm{Ba}+\mathrm{D}_{2} \mathrm{O}$. Circles represent maximum center of mass velocities for the chemical products. Solid circles correspond to major 
channels, dotted circles were minor channels or not observed.

Fig14 Angular distributions for $\mathrm{BaOCH}_{3}, \mathrm{BaO}$, and $\mathrm{Ba}$ resulting from $\mathrm{Ba}+\mathrm{CH}_{3} \mathrm{OH}$ at $15 \mathrm{kcal} / \mathrm{mole}$, showing effect of laser excitation on the incident $\mathrm{Ba}$ atcm. $\mathrm{BaO}$ and $\mathrm{Ba}$ signal at wide angle $\left(>15^{\circ}\right)$ results from fragmentation of $\mathrm{BaOCH}_{3}$ product in the electron bombardment ionizer.

Fig15 $\mathrm{BaOCH}_{3}$ angular distributions from $\mathrm{Ba}+\mathrm{CH}_{3} \mathrm{OH}$ (upper figure) and $\mathrm{Ba}+$ $\mathrm{CH}_{3} \mathrm{OD}$ (lower figure) at collision energy of $30 \mathrm{kcal} / \mathrm{mole}$, showing effect of laser excitation of $\mathrm{Ba}$ atom. Although $\mathrm{BaOCH}_{3}$ signal increased with collision energy, electronic excitation was far more effective in promoting reaction.

Fig16 TOF spectra for $\mathrm{BaOCH}_{2}-\mathrm{CH}=\mathrm{CH}_{2}$ from $\mathrm{Ba}\left({ }^{\prime} \mathrm{D}\right)+\mathrm{CH}_{2}=\mathrm{CH}-\mathrm{CH}_{2} \mathrm{OH}$ at $E_{\text {coll }}=28 \mathrm{kcal} / \mathrm{mole}$.

Fig17 TOF spectra for $\mathrm{BaO}$ daughter ion from fragmentation of $\mathrm{BaOH}$ and $\mathrm{BaOCH}_{2}$ $\mathrm{CH}=\mathrm{CH}_{2}$ from Ba('D) $+\mathrm{CH}_{2}=\mathrm{CH}-\mathrm{CH}_{2} \mathrm{OH}$ at $\mathrm{E}_{\text {coll }}=28 \mathrm{kcal} / \mathrm{mole}$.

Fig18 Upper Figure: CM Angular distribution for products from $\mathrm{Ba}\left({ }^{1} \mathrm{D}\right)+\mathrm{CH}_{2}=\mathrm{CH}$ $\mathrm{CH}_{2} \mathrm{OH}$ at $\mathrm{E}_{\text {coll }}=28 \mathrm{kcal} /$ mole. Lower Figure: Best Fit translational energy distribution for reaction.

Fig19 Energy level diagram for $\mathrm{Ba}+\mathrm{H}_{2} \mathrm{O}$. The energy levels indicate the known or most probable values. Shaded regions indicate maximum uncertainties in energies of reaction intermediates or transition states. Reaction paths observed in this study are indicated by lines connecting reactants to products. Solid lines indicate primary reaction channels; dotted line indicates minor channels. Producis and 
intermediates not connected to lines were not observed in this work or in chemiluminescence experiments described in Ref 6 .

Fig20 Same as Fig. 2, but reaction is $\mathrm{Ba}+\mathrm{CH}_{3} \mathrm{OH}$.

Table 1. Thermodynamics of the $\mathrm{Ba}+\mathrm{H}_{2} \mathrm{O}$ System $^{6,7,18}$

\begin{tabular}{rlr} 
Reaction & & $\Delta \mathrm{H}(\mathrm{kcal} /$ mole $)$ \\
\hline $\mathrm{Ba}\left({ }^{\prime} \mathrm{S}\right)+\mathrm{H}_{2} \mathrm{O}$ & $\rightarrow \mathrm{Ba}-\mathrm{OH}_{2}$ & -5 \\
& $\rightarrow \mathrm{HBaOH}$ & -29 \\
& $\rightarrow \mathrm{BaOH}(\mathrm{X})+\mathrm{H}$ & +13 \\
& $\rightarrow \mathrm{BaO}(\mathrm{X})+\mathrm{H}_{2}$ & -17 \\
$\mathrm{Ba}\left({ }^{\prime} \mathrm{D}\right)+\mathrm{H}_{2} \mathrm{O}$ & $\rightarrow \mathrm{BaOH}(\mathrm{X})+\mathrm{H}$ & -20 \\
& $\rightarrow \mathrm{BaO}(\mathrm{X})+\mathrm{H}_{2}$ & -49 \\
& $\rightarrow \mathrm{BaO}\left(\mathrm{A}, \mathrm{A}^{\prime}\right)+\mathrm{H}_{2}$ & $\approx 0$ \\
\hline
\end{tabular}


Table 2. Thermodynamics of the $\mathrm{Br},+\mathrm{CH}_{3} \mathrm{OH}$ System ${ }^{6,7,18}$ Reaction $\Delta \mathrm{H}(\mathrm{kcal} / \mathrm{mole})$

\begin{tabular}{rlr}
\hline $\mathrm{Ba}\left({ }^{1} \mathrm{~S}\right)+\mathrm{CH}_{3} \mathrm{OH}$ & $\rightarrow \mathrm{Ba}-\mathrm{OH}\left(\mathrm{CH}_{3}\right)$ & -5 \\
& $\rightarrow \mathrm{HBaOCH}_{3}$ & -29 \\
& $\rightarrow \mathrm{HOBaCH}$ & -29 \\
& $\rightarrow \mathrm{BaOH}(\mathrm{X})+\mathrm{CH}_{3}$ & +13 \\
& $\rightarrow \mathrm{BaO}(\mathrm{X})+\mathrm{CH}_{4}$ & -17 \\
$\mathrm{Ba}\left({ }^{\prime} \mathrm{D}\right)+\mathrm{H}_{2} \mathrm{O}$ & $\rightarrow \mathrm{BaOH}(\mathrm{X})+\mathrm{H}$ & -20 \\
& $\rightarrow \mathrm{BaO}(\mathrm{X})+\mathrm{H}_{2}$ & -49 \\
& $\rightarrow \mathrm{BaO}\left(\mathrm{A}, \mathrm{A}^{\prime}\right)+\mathrm{H}_{2}$ & -0 \\
\hline
\end{tabular}

Table 3. Thermodynamics of Other Systems Studied ${ }^{6,7,28}$

$$
\begin{aligned}
& \text { Reaction } \\
& \Delta \mathrm{H}(\mathrm{kcal} / \mathrm{mole}) \\
& \begin{aligned}
\mathrm{Ba}\left({ }^{\prime} \mathrm{S}\right)+\mathrm{CH}_{3} \mathrm{OCH}_{3} & \rightarrow \mathrm{BaOCH}(\mathrm{X})+\mathrm{CH}_{3} & +13 \\
& \rightarrow \mathrm{BaO}(\mathrm{X})+\mathrm{C}_{2} \mathrm{H}_{6} & -17
\end{aligned} \\
& \mathrm{Ba}\left({ }^{1} \mathrm{~S}\right)+\mathrm{CH}_{2}=\mathrm{CHCH}_{2} \mathrm{OH} \rightarrow \mathrm{Ba} \mathrm{OH}(\mathrm{X})+\mathrm{CH}_{2}=\mathrm{CHCH}_{2} \quad-20 \\
& \rightarrow \mathrm{BaOCH}_{2} \mathrm{CH}_{2} \mathrm{CH}_{3}+\mathrm{H} \quad-49 \\
& \mathrm{Ba}\left({ }^{1} \mathrm{~S}\right)+\left(\mathrm{CH}_{3}\right)_{3} \mathrm{COOH} \rightarrow \mathrm{BaOH}+\left(\mathrm{CH}_{3}\right)_{3} \mathrm{CO} \\
& \rightarrow \mathrm{BaO}\left(\mathrm{CH}_{3}\right)_{3}+\mathrm{OH}
\end{aligned}
$$




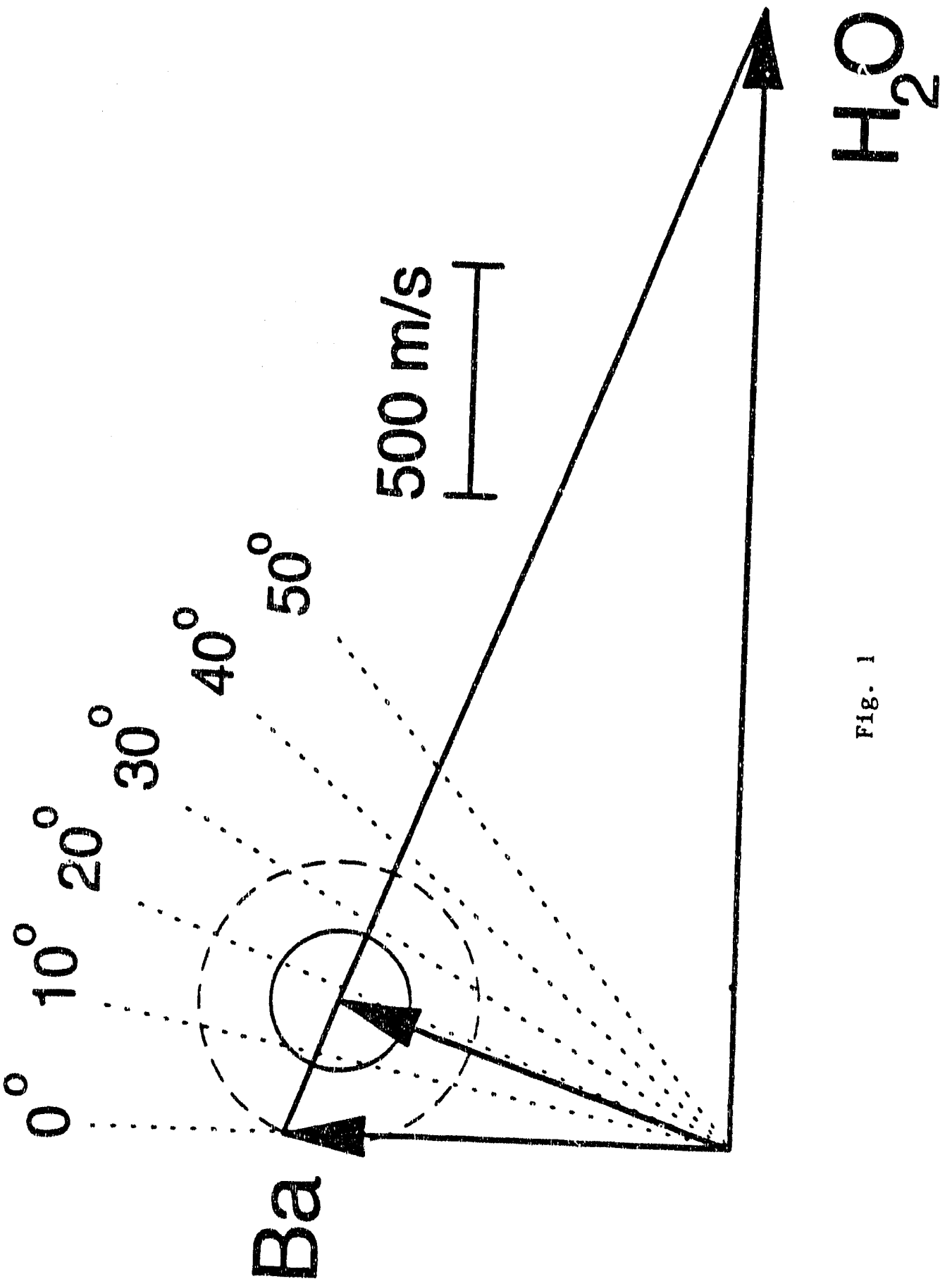




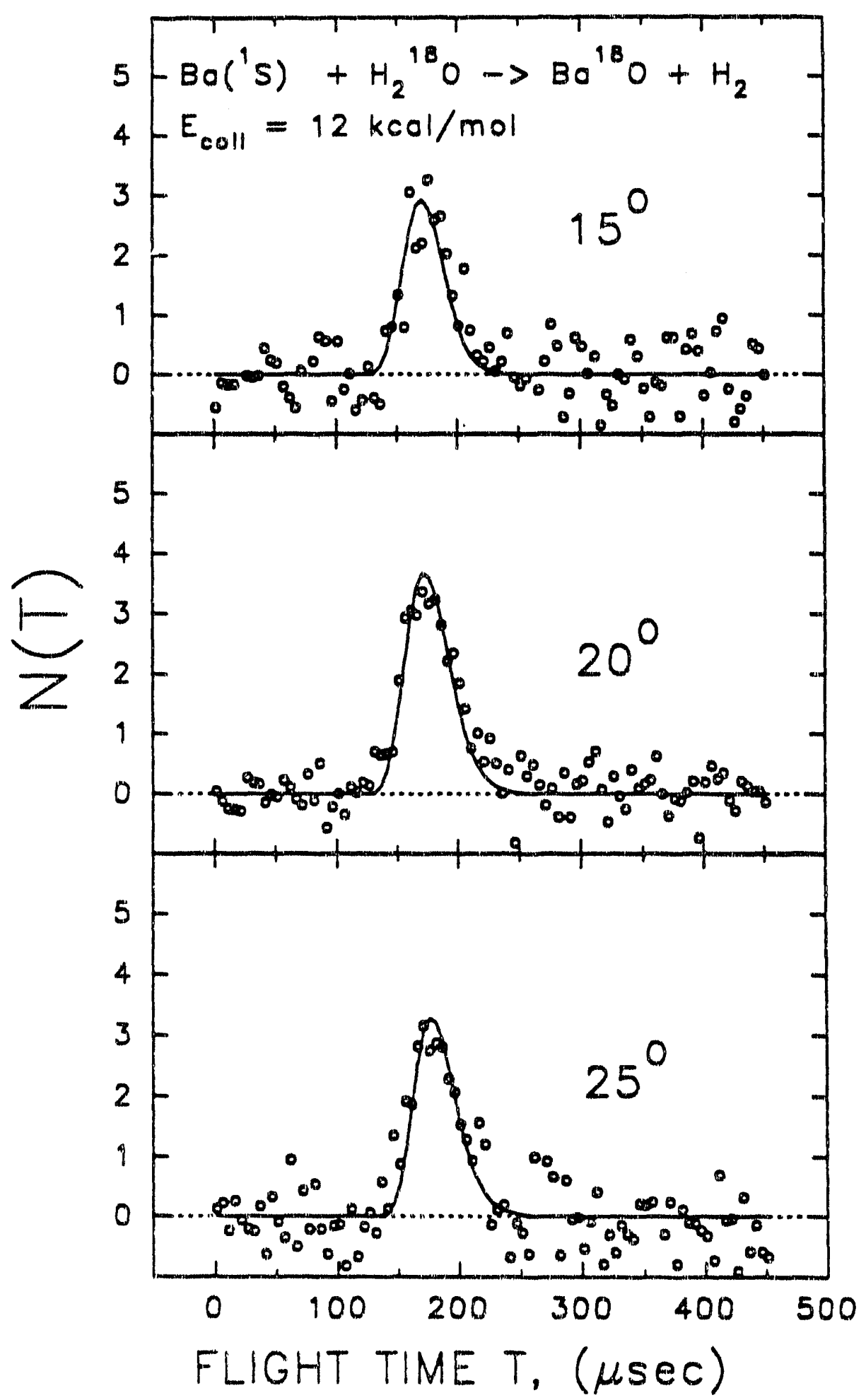

Fig. 2 


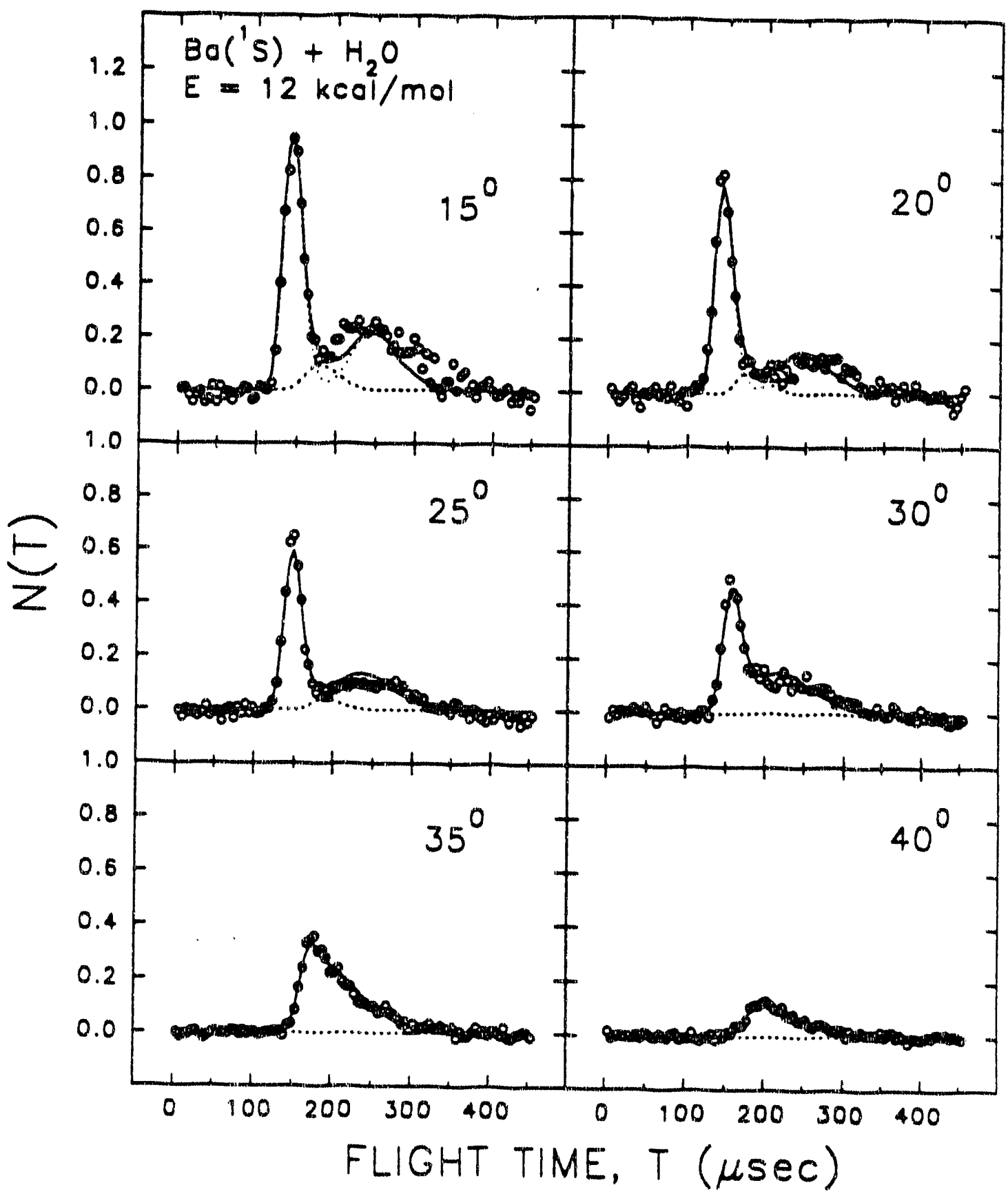

Fig. 3 

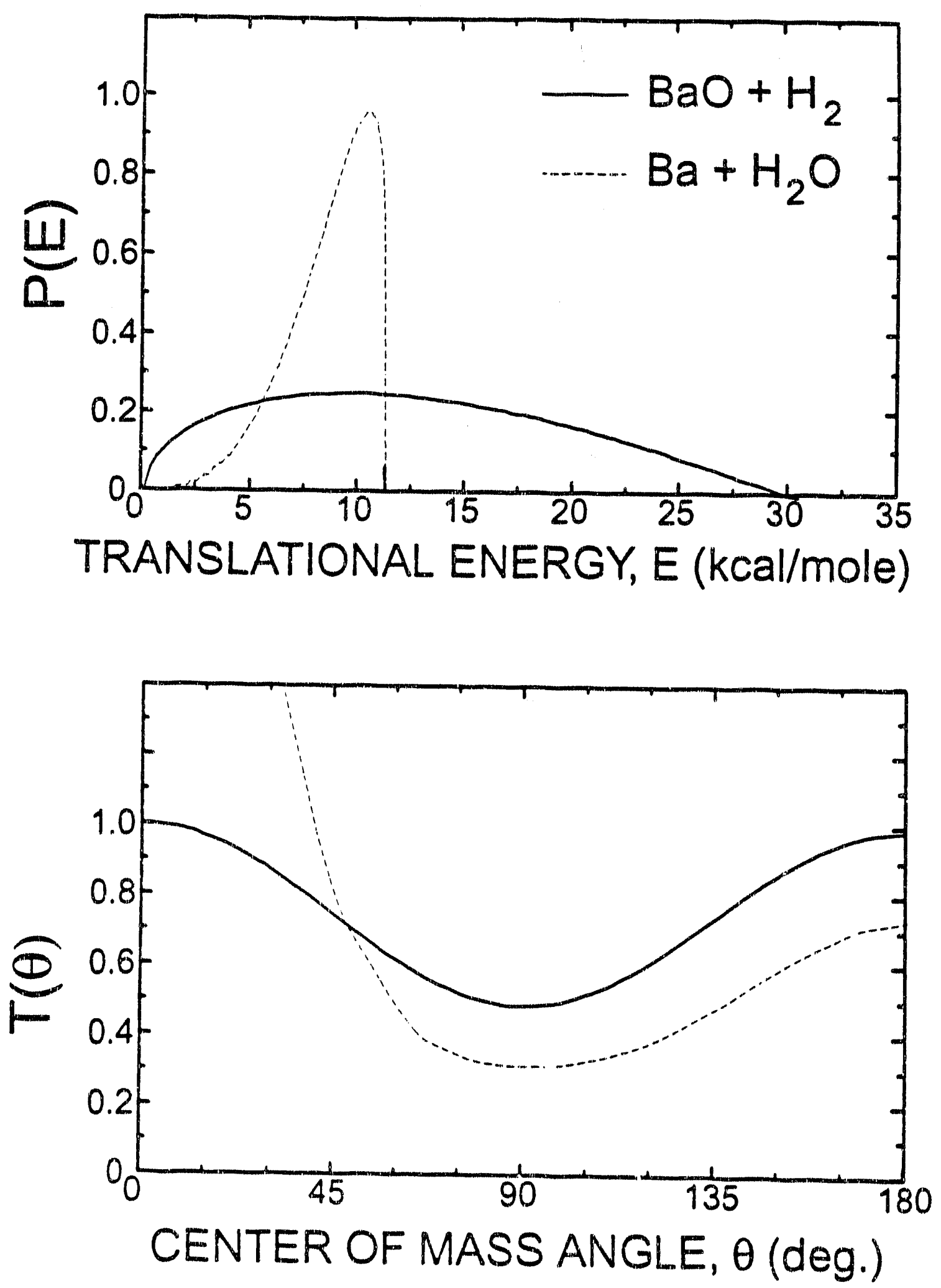

Fig. 4 

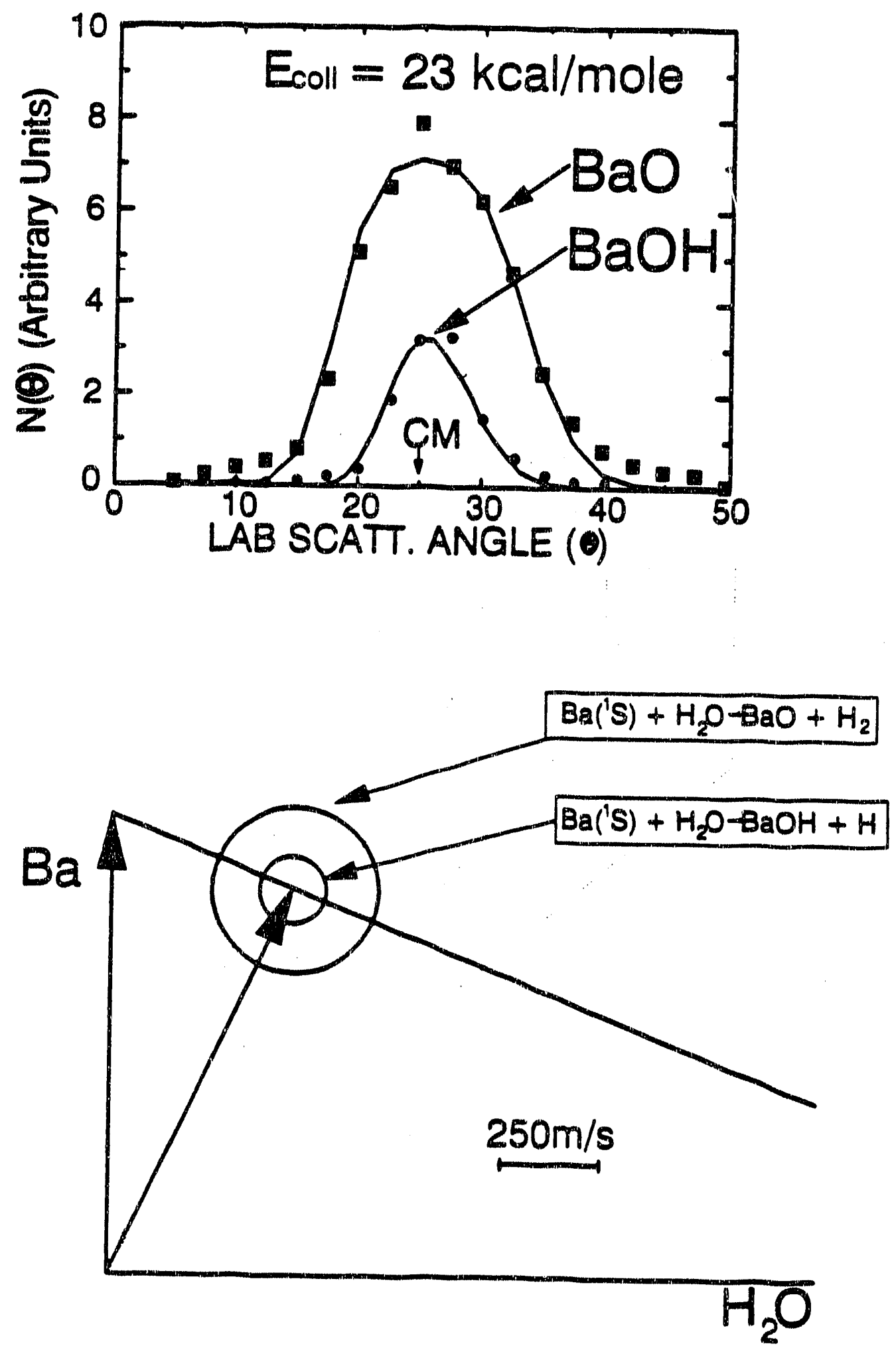

Fig. 5 


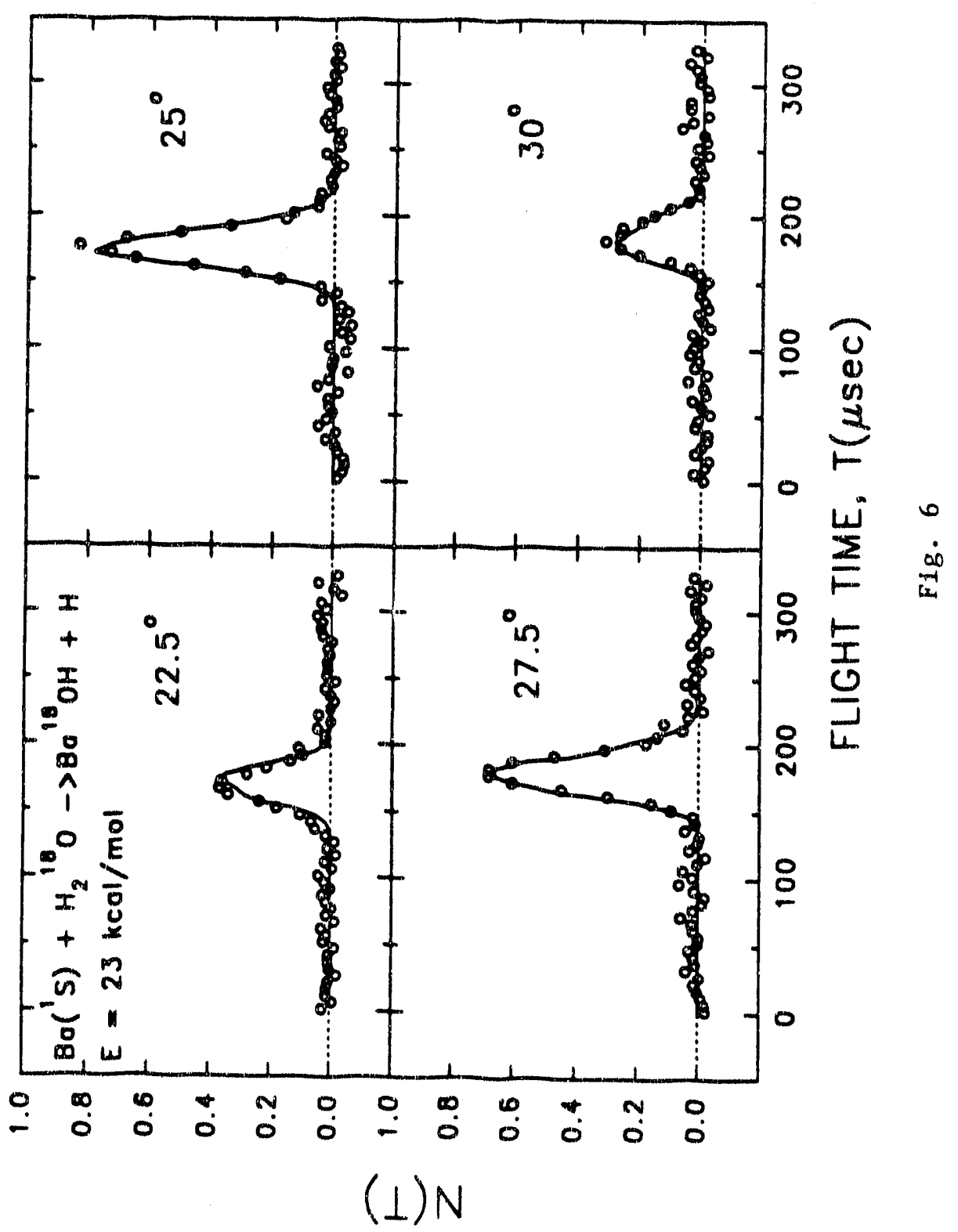




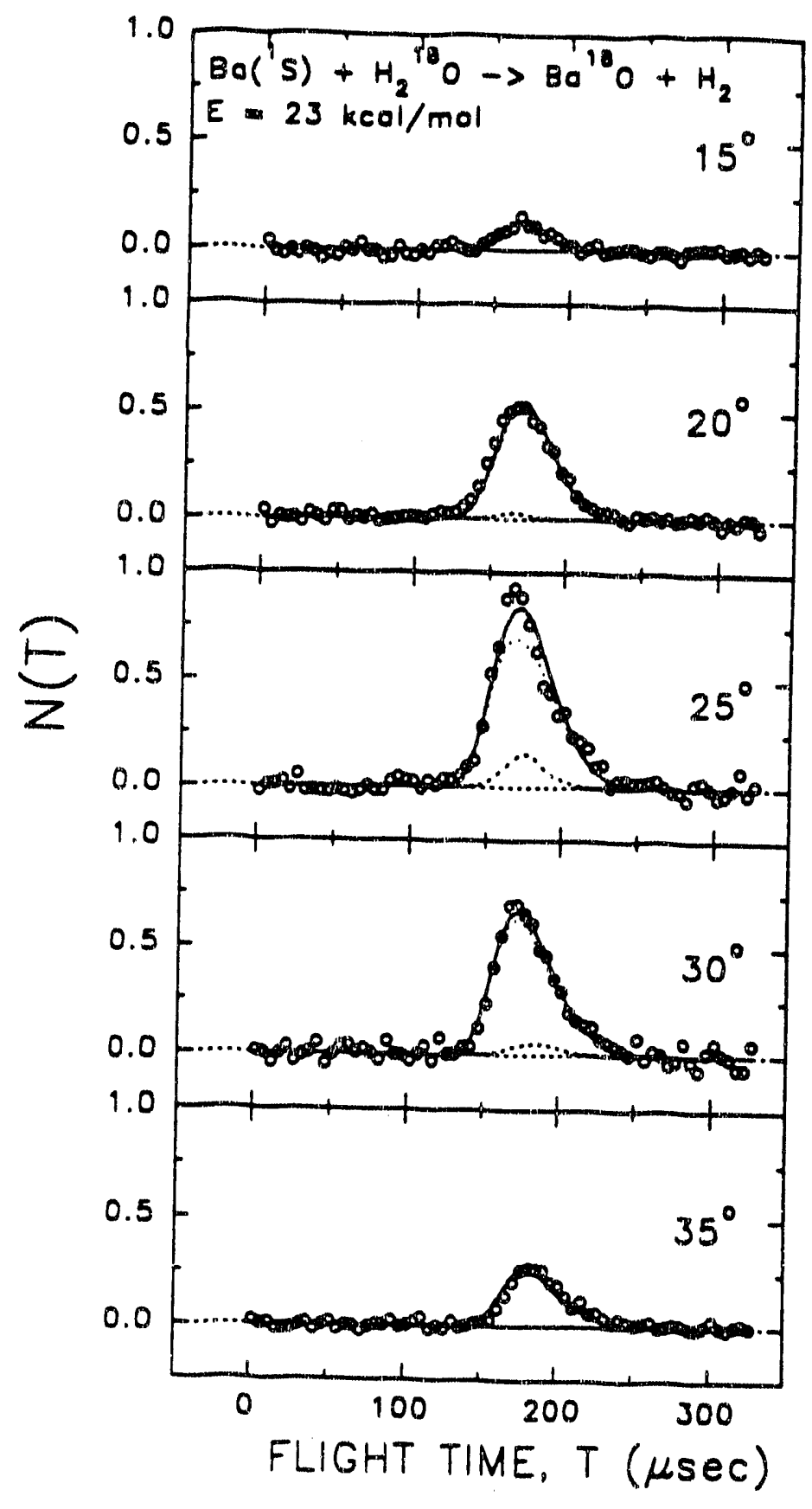

Fig. 7 


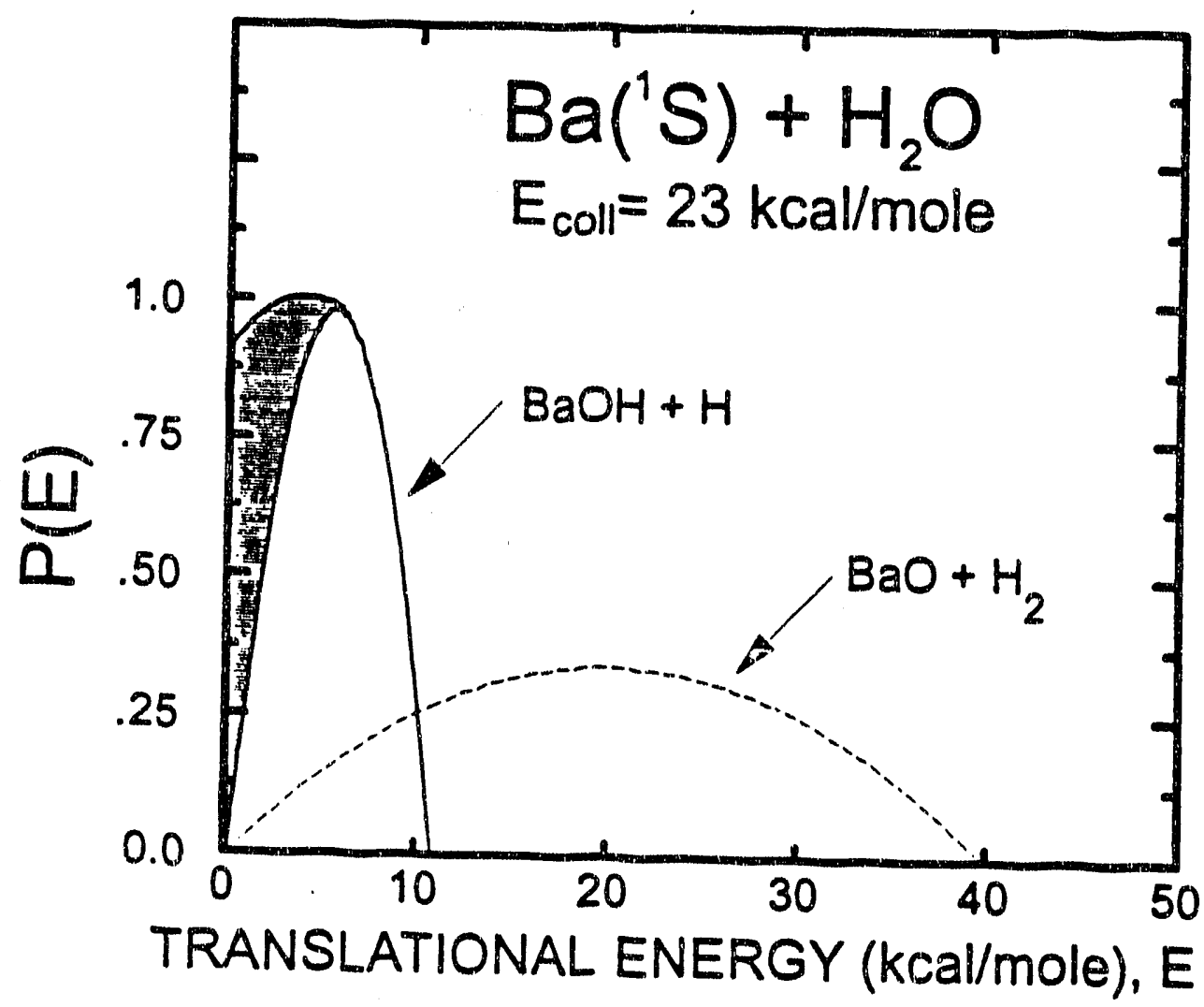

Fig. 8 


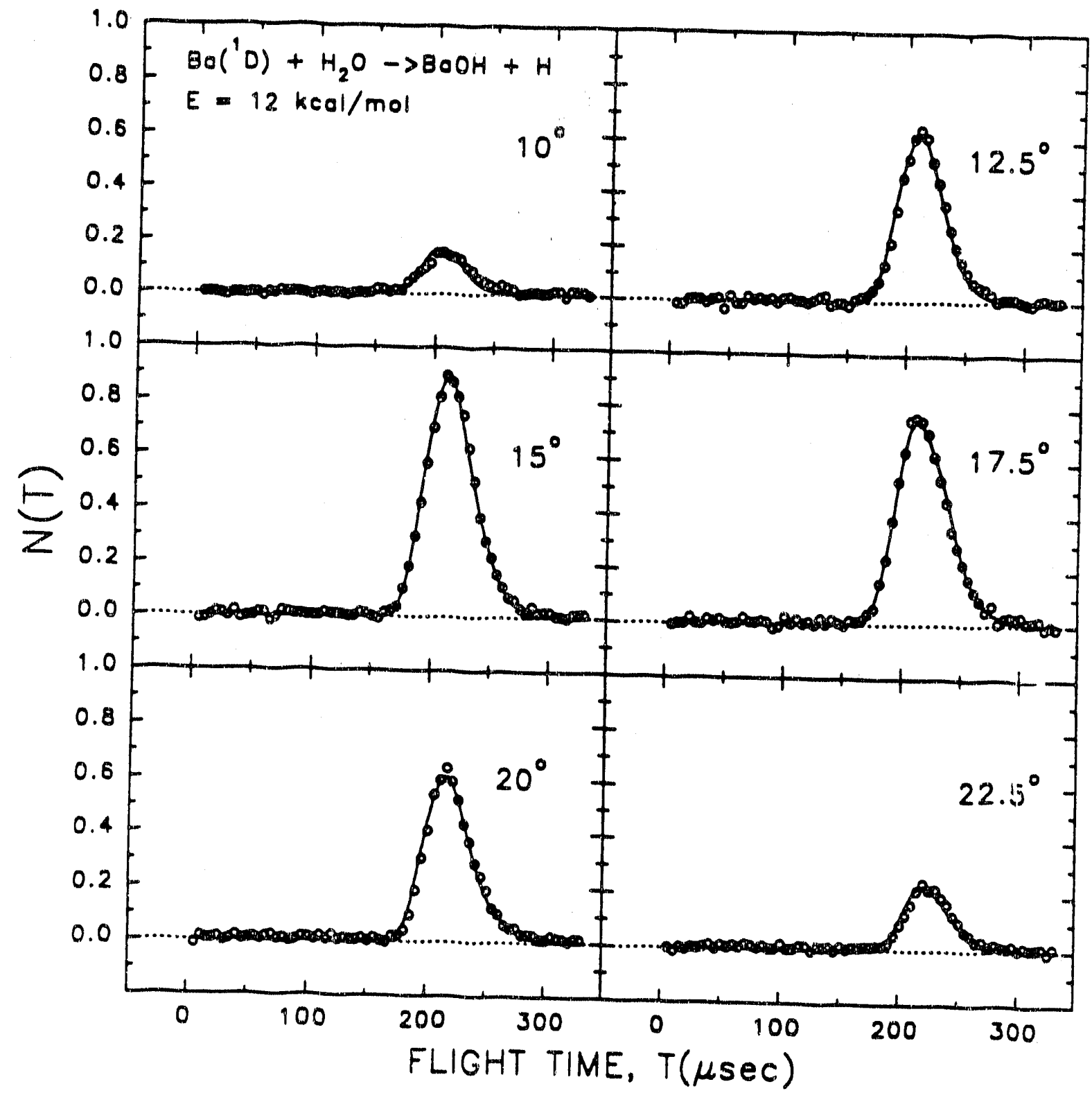

Fig. 9 

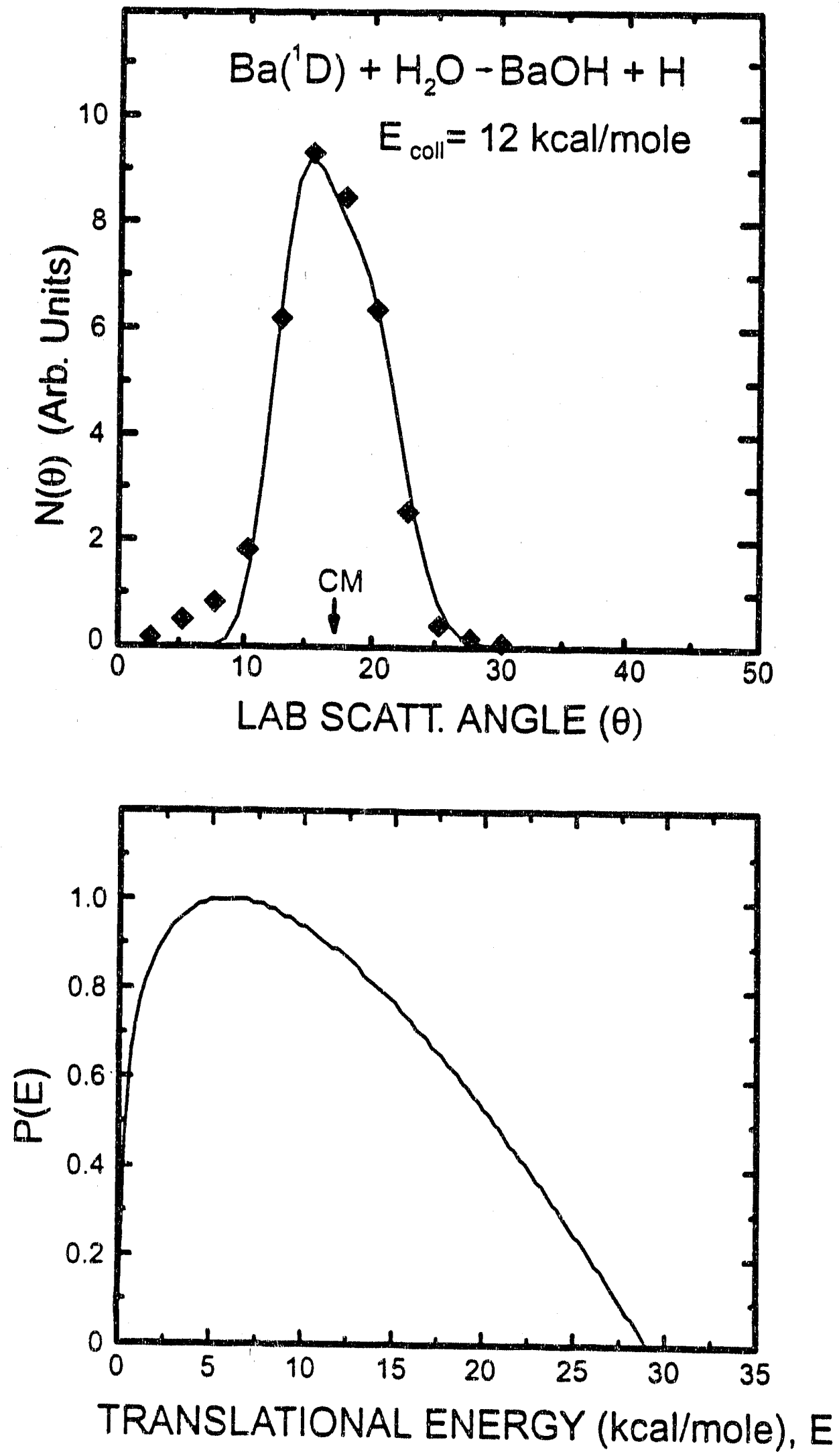


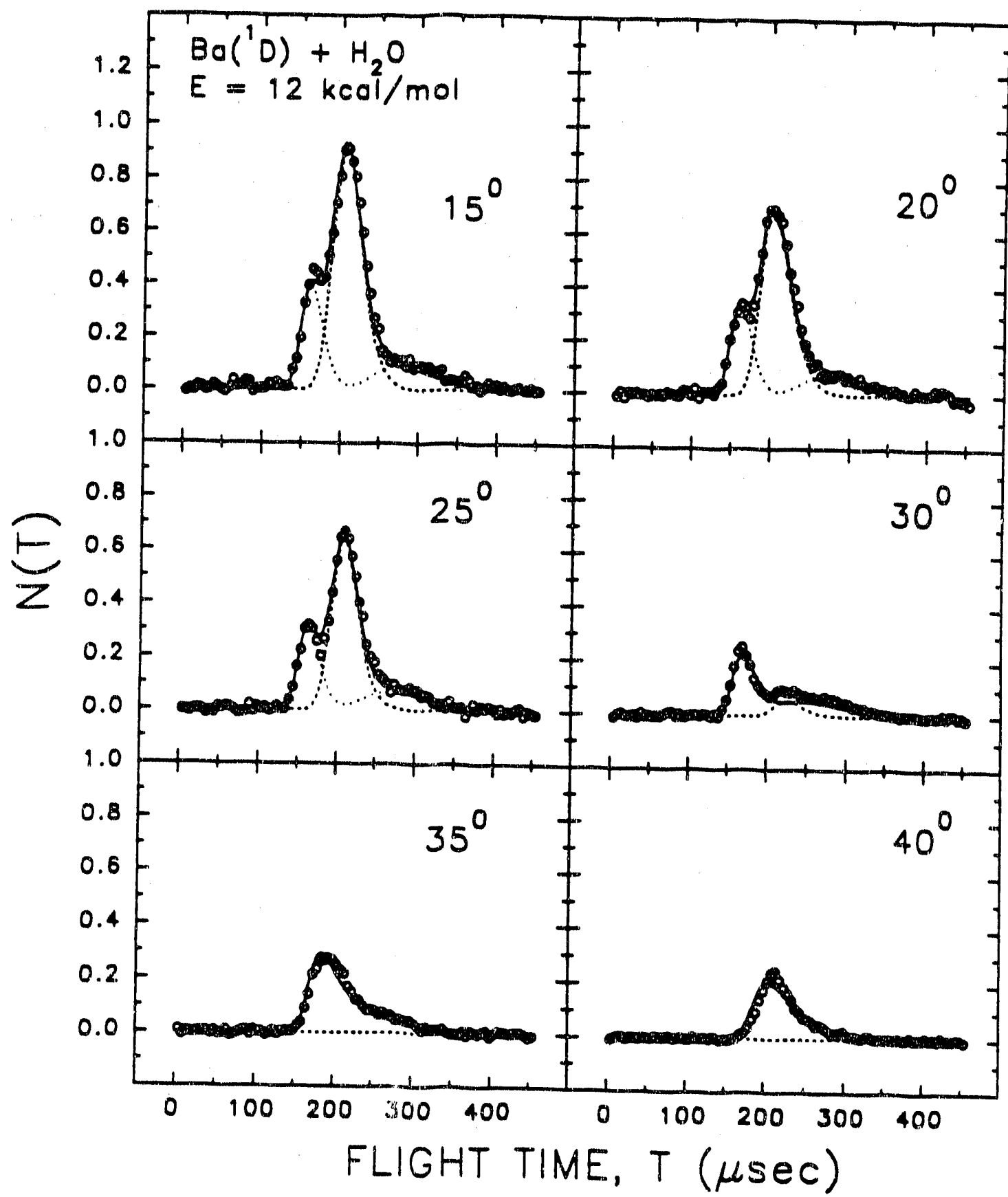

Fig. 11 


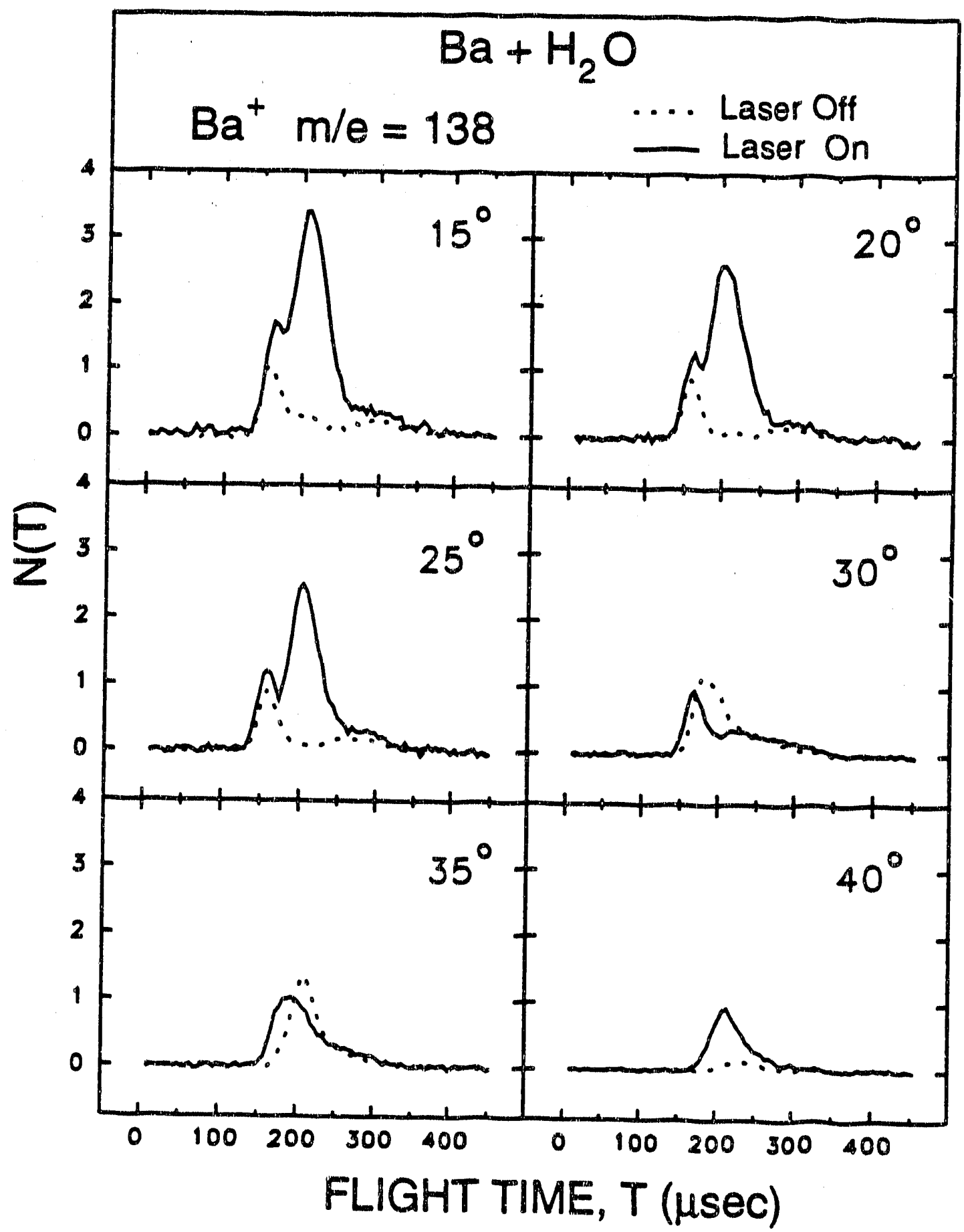

Fig. 12 

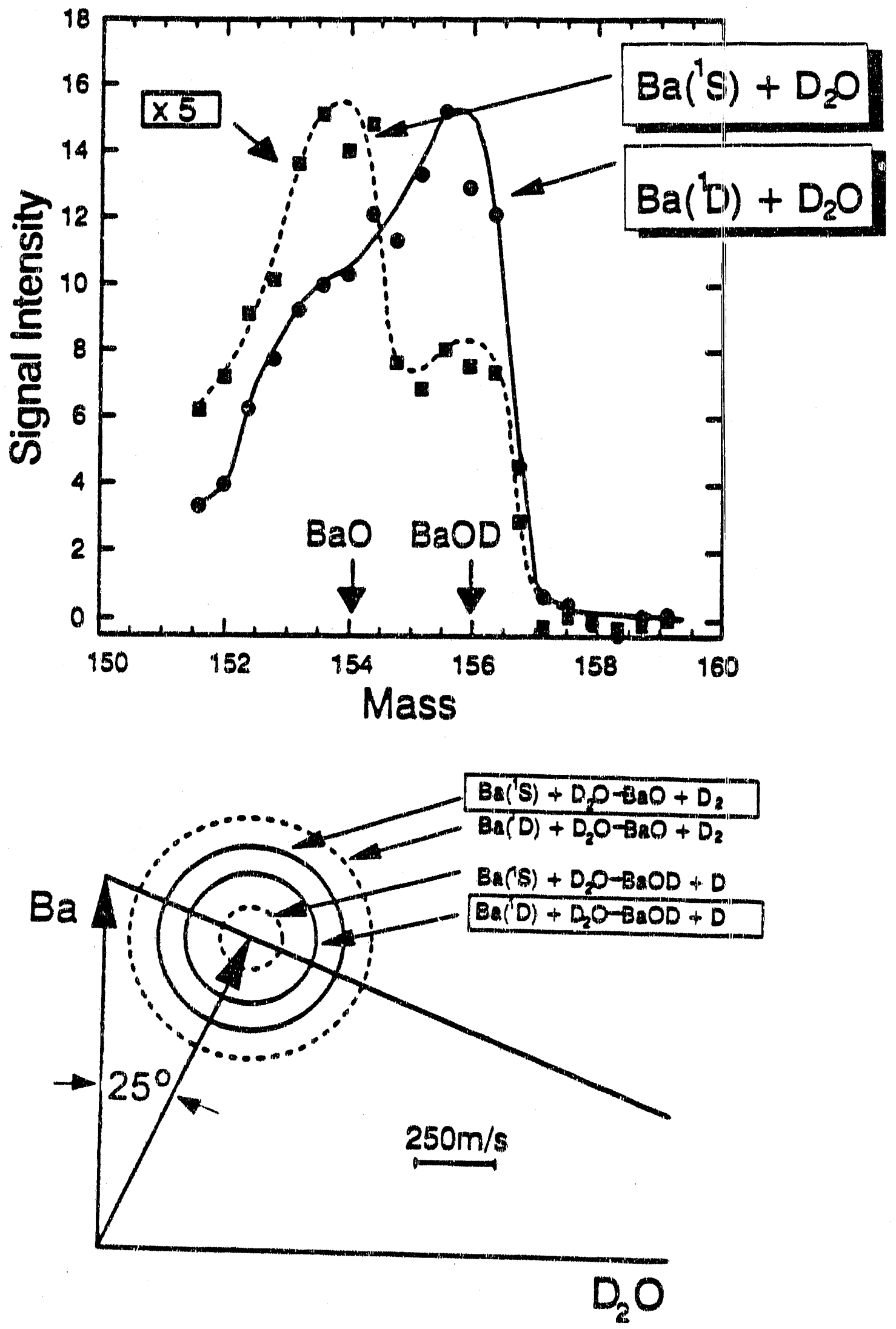

F18. 13 


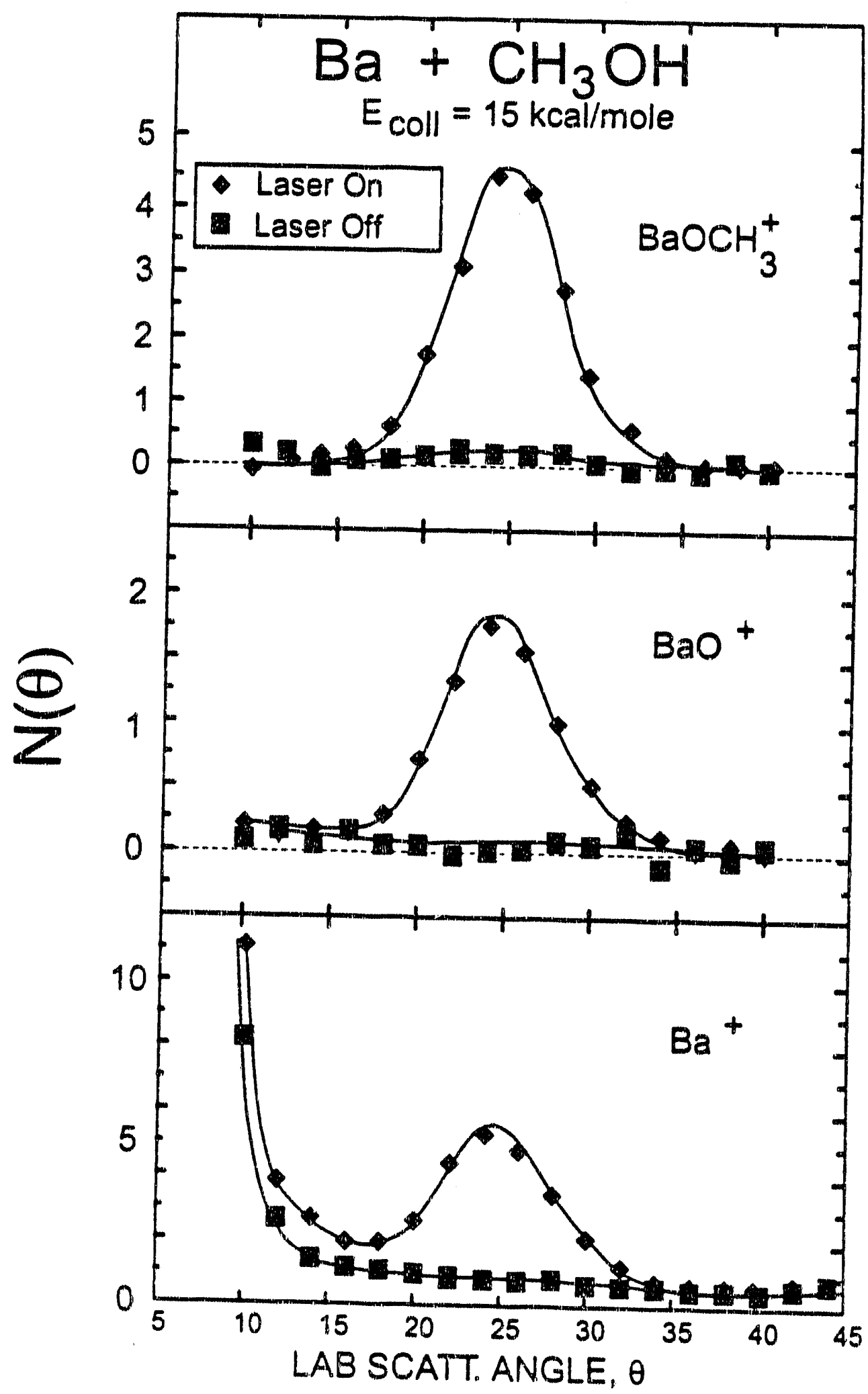

Fig. 14 


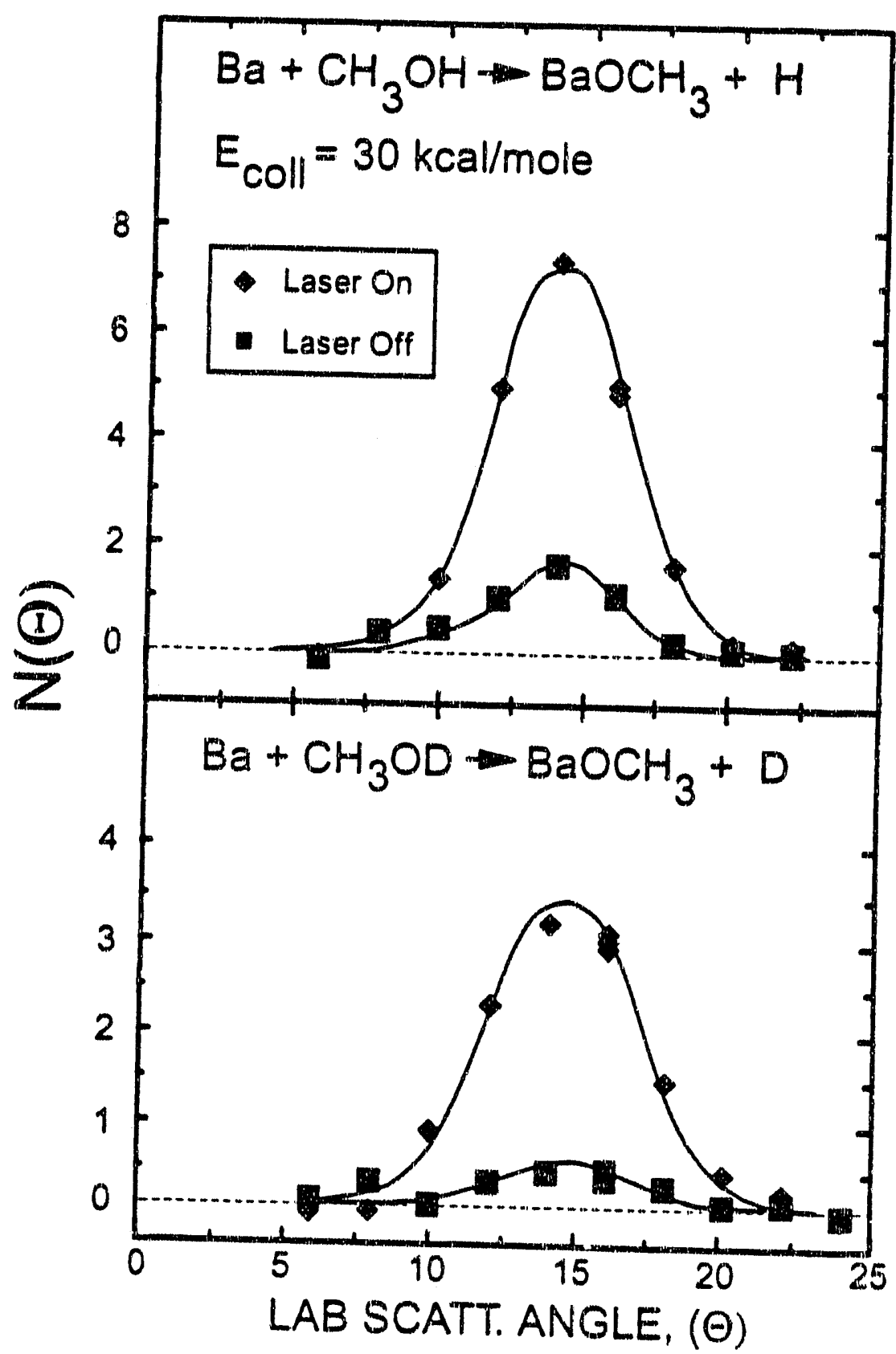

F18. 15 


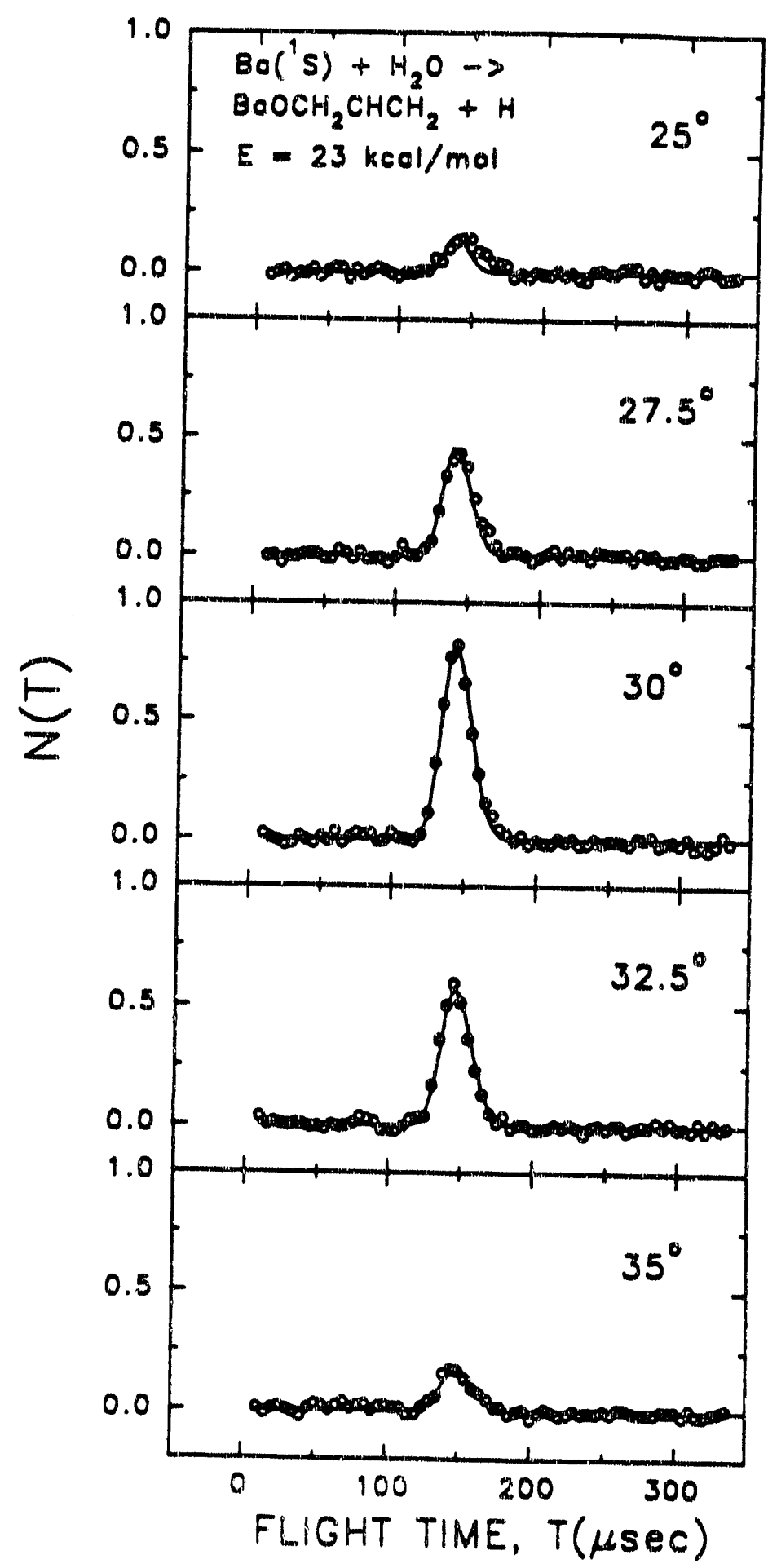

Fig. 16 


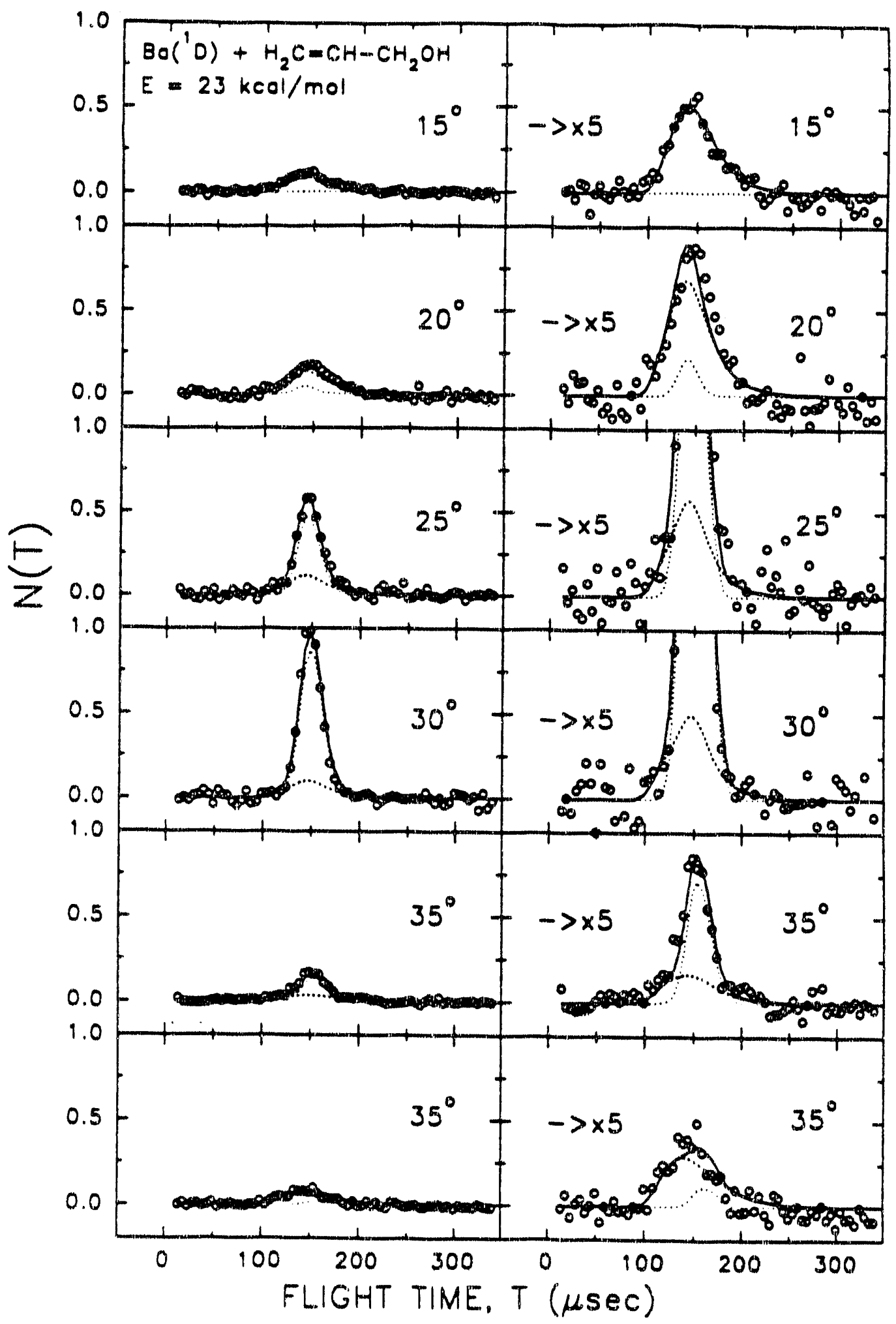

F1g. 17 

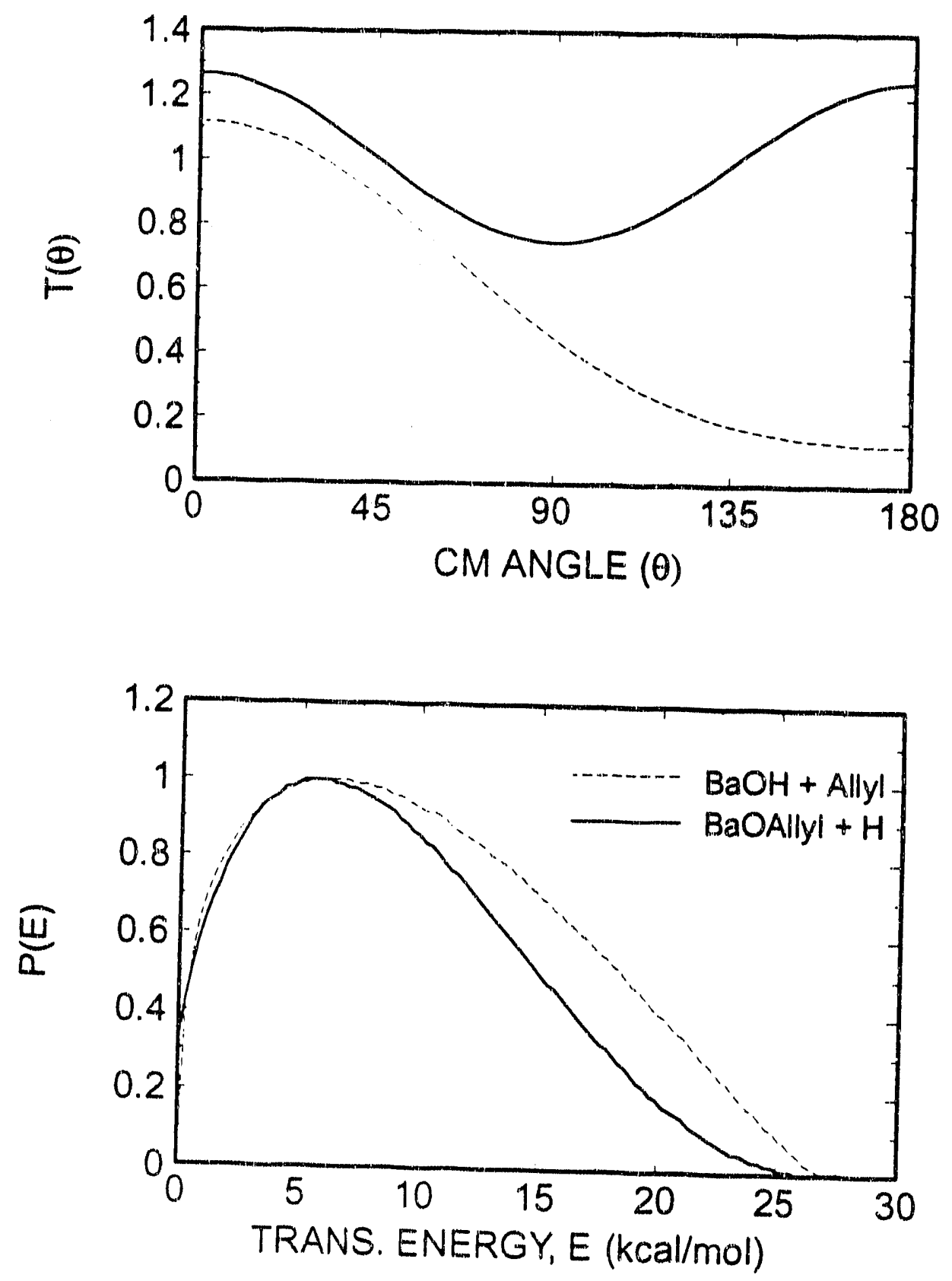

Fig. 18 


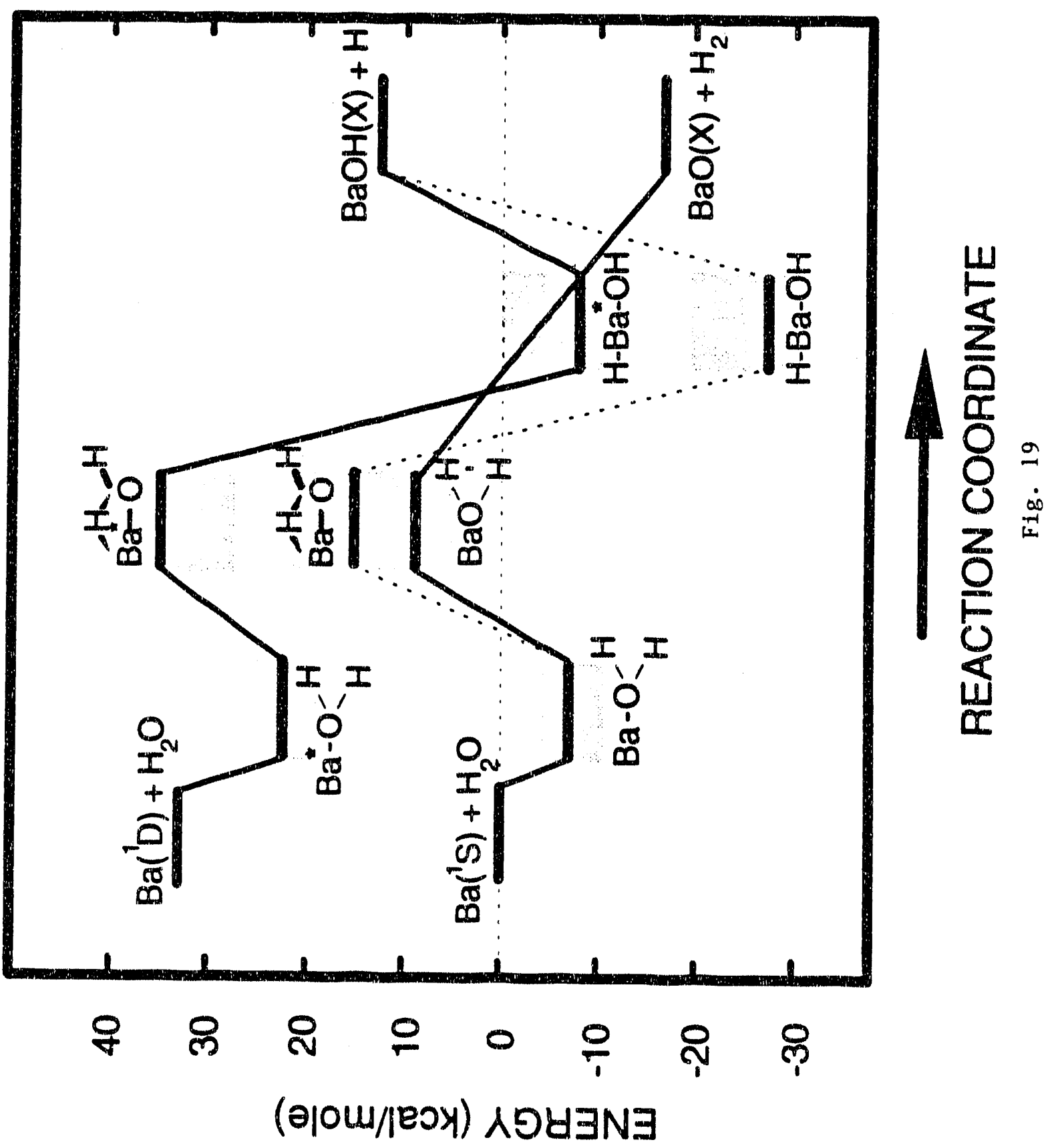




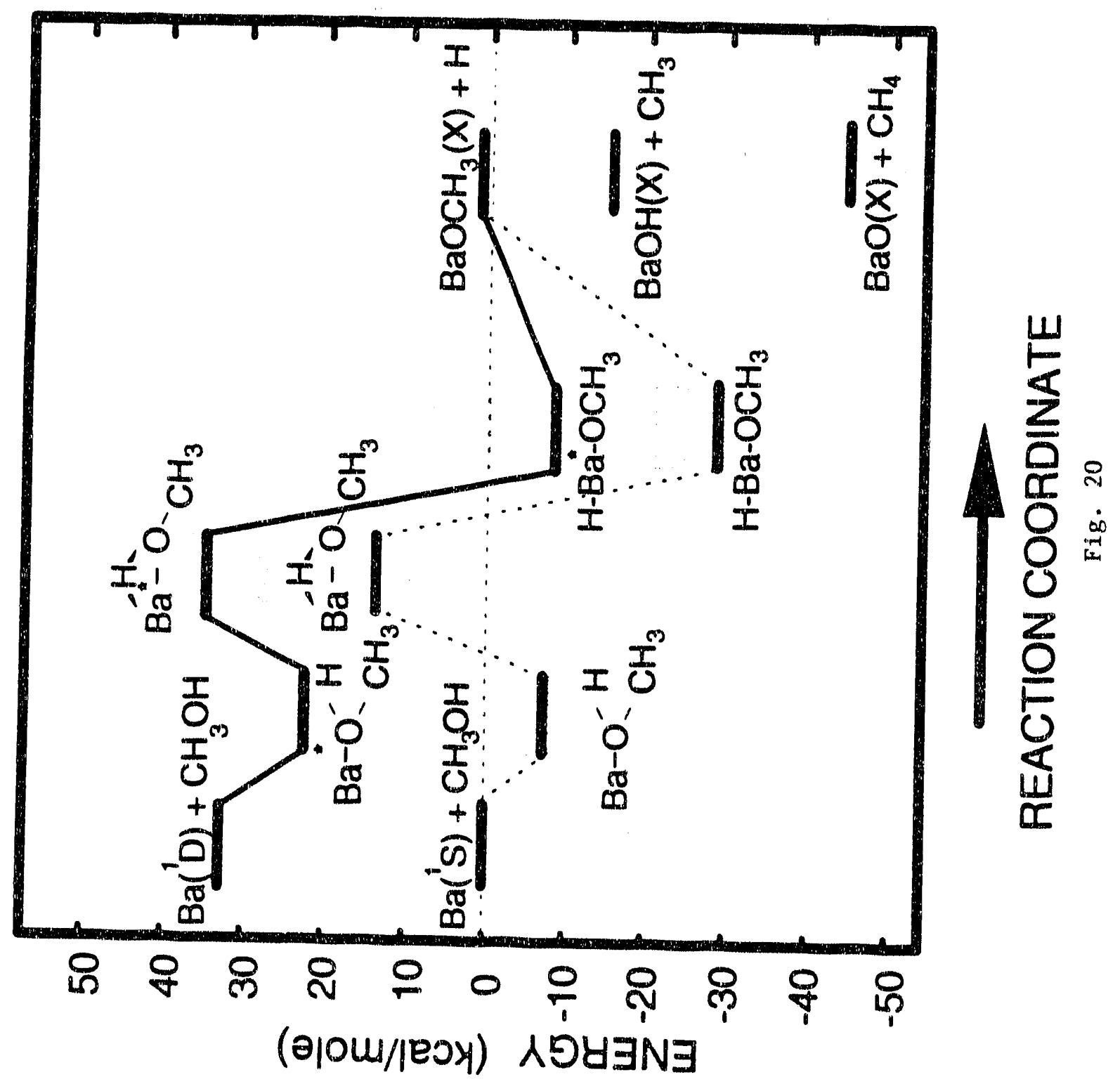




\section{CHAPTER 3}

Reactions of $\mathrm{Ba}$ atoms with Triatomic Oxidants: $\mathrm{Ba}+\mathrm{ClO}_{2}$ and $\mathrm{O}_{3}$

\section{ABSTRACT}

This chapter presents the results of a study of the reactions of Ba atoms with symmetrical chlorine dioxide $\left(\mathrm{ClO}_{2}\right)$ and ozone $\left(\mathrm{O}_{3}\right)$ using the crossed molecular beams method. As was the case in $\mathrm{Ba}+\mathrm{NO}_{2}$ (Chapter 1), chemical products result from direct reaction mechanisms, and by decay of long-lived collision complexes. Single collisions between $\mathrm{Ba}+\mathrm{ClO}_{2}$ led primarily $(-90 \%)$ to formation of $\mathrm{BaO}+\mathrm{ClO}$. The dominant mechanism involved an ionic $\mathrm{Ba}^{+} \mathrm{ClO}_{2}{ }^{-}$intermediate that survived longer than one rotational period. Formation of $\mathrm{BaCl}+\mathrm{O}_{2}$ by abstraction of the central chlorine atom of $\mathrm{ClO}_{2}$ involving a concerted mechanism accounted for $\sim 10 \%$ of the total reaction cross section. The $\mathrm{BaCl}$ angular distribution indicated that the $\mathrm{Ba}+\mathrm{ClO}_{2}$ collision partners survive for at least several rotational periods before concerted decomposition to $\mathrm{BaCl}+\mathrm{O}_{2}$. We observe no evidence for formation of $\mathrm{BaO}_{2}+\mathrm{Cl}$, the most thermodynamically favorable channel.

Two chemically distinct reaction channels, $\mathrm{BaO}+\mathrm{O}_{2}$ and $\mathrm{BaO}_{2}+\mathrm{O}$, resulted from $\mathrm{Ba}+\mathrm{O}_{3}$. This reaction led to a much larger fraction of forward scattered $\mathrm{BaO}$ than was seen in the $\mathrm{NO}_{2}$ and $\mathrm{ClO}_{2}$ cases, indicating a greater contribution from direct reactions. This is consistent with the decreased thermodynamic stability of $\mathrm{O}_{3}^{-}$relative to $\mathrm{NO}_{2}^{-}$and $\mathrm{ClO}_{2}^{-}$upon electron attachment to the neutral molecule. This work represents the first direct observation of nascent $\mathrm{BaO}_{2}$ in the gas phase. Based on the 
maximum $\mathrm{BaO}_{2}+\mathrm{O}$ translational energy release, we calculate $\mathrm{D}_{\mathrm{o}}\left(\mathrm{Ba}-\mathrm{O}_{2}\right)=120 \pm 20$ $\mathrm{kcal} /$ mole. This is nearly twice that of comparable alkali superoxides, (e.g. $\mathrm{Cs}^{+} \mathrm{O}_{2}{ }^{-}$), suggesting that $\mathrm{BaO}_{2}$ possesses considerable peroxide (doubly ionic) character. Despite the very large reaction exoergicity $(-98 \mathrm{kcal} / \mathrm{mole})$ for $\mathrm{Ba}+\mathrm{O}_{3} \rightarrow \mathrm{BaO}_{2}+\mathrm{O}$, the reaction results exclusively from decay of long-lived $\mathrm{Ba}^{+} \mathrm{O}_{3}$ collision complexes. This is attributed to the existence of a large exit potential energy barrier associated with the electronic rearrangement required for decay of the initially formed singly ionic $\mathrm{Ba}^{+} \mathrm{O}_{3}{ }^{-}$ to doubly ionic $\mathrm{Ba}^{2+} \mathrm{O}_{2}{ }^{2-}$. The $\mathrm{Ba}+\mathrm{O}_{2}$ reaction is discussed in light of these new results.

\section{INTRODUCTION}

Walsh's rules ${ }^{3}$ and molecular orbital theory ${ }^{4}$ allow us to predict trends in the geometries of triatomic $\mathrm{AB}_{2}$ species as well as changes in bond angles and bond lengths upon electronic excitation or electron attachment. Based on the success of these ideas, it seems natural that systematic trends in the dynamics of reactions initiated by longrange electron transfer are likely to exist in the series of bent triatomic molecules: $\mathrm{NO}_{2}$, $\mathrm{O}_{3}$ and $\mathrm{ClO}_{2}$. With this in mind, we have conducted a systematic study of the reactions of $\mathrm{Ba}$ with these oxidants using crossed molecular beams. The $\mathrm{NO}_{2}$ reaction was discussed in Chapter 1: we now focus on reactions with $\mathrm{O}_{3}$ and $\mathrm{ClO}_{2}$. The ultimate goal of our work is to further our understanding of the general principles important in the reactions of divalent atoms with triatomic oxidants.

Several studies on the gas phase reactions of barium atoms with ozone ${ }^{5 \cdot 8}$ and 
chlorine dioxide have appeared in the literature over the past twenty years. In all cases, only the chemiluminescent or ionic products were studied although it was known that under single collision conditions, these channels represent no more than $20 \%$ of the total reaction cross section. ${ }^{6-8} \quad \mathrm{~A}$ review of the literature to date regarding the $\mathrm{Ba}+\mathrm{O}_{3}$ reaction mechanism indicates that it is initiated by long-range electron transfer, that the reaction cross section is $\sim 70 \mathrm{~A}^{2}$, and that the nascent chemiluminescent products are primarily $\mathrm{BaO}\left(\mathrm{A}, \mathrm{A}^{\prime}\right)$. The reactions of alkaline earth atoms with $\mathrm{ClO}_{2}$ were studied by Engelke and Zare in crossed beams chemiluminescence experiments. A particularly fascinating result was the observation of $\mathrm{BaCl}$ chemiluminescence from abstraction of the central $\mathrm{Cl}$ atom, with formation of $\mathrm{O}_{2}$ from the outer oxygen atoms of $\mathrm{ClO}_{2}$ by a concerted mechanism. An additional feature in that system was preference for formation of $\mathrm{BaO}\left(\mathrm{A}^{\prime}\right)$ rather that $\mathrm{BaO}\left(\mathrm{A}^{\prime \prime}\right)$, even though the exoergicities of both channels were comparable.

In chapter 1 , we concluded that the reaction $\mathrm{Ba}+\mathrm{NO}_{2} \rightarrow \mathrm{BaO}+\mathrm{NO}$ primarily involved long-lived $\mathrm{Ba}^{+} \mathrm{NO}_{2}^{-}$collision intermediates even at high collision energies or with electronic excitation of the $\mathrm{Ba}$ atom, despite a large reaction exoergicity and relatively few vibrational degrees of freedom in the complex. This behavior was attributed to the thermodynamic stability of the planar $\mathrm{Ba}^{+} \mathrm{NO}_{2}{ }^{-}$intermediate and a large exit potential energy barrier for its decay to chemical products. This barrier results from the unfavorable symmetry of the $\mathrm{NO}_{2} 2 \mathrm{~b}_{1}$ orbital involved in the electronic rearrangement necessary for decay of $\mathrm{Ba}^{+} \mathrm{NO}_{2}^{-}$to doubly ionic $\mathrm{Ba}^{2+} \mathrm{O}^{2-}+\mathrm{NO}{ }^{2,10}$ Like $\mathrm{NO}_{2}$ (E.A. $=2.3 \mathrm{eV})^{11}$, the electron affinities of $\mathrm{O}_{3}(2.10 \mathrm{eV})^{12}$ and $\mathrm{ClO}_{2}(2.37 \mathrm{eV})^{13}$ are 
appreciable, and the possibility of long-range electron transfer will again lead to large reaction cross sections. In the $\mathrm{ClO}_{2}$ reaction, formation of ground state $\mathrm{BaO}+\mathrm{ClO}$ products $(\Delta \mathrm{H}=-73 \mathrm{kcal} / \mathrm{mole})^{14}$ is of comparable exoergicity to $\mathrm{BaO}+$ NO production from the $\mathrm{NO}_{2}$ reaction $(\Delta \mathrm{H}=-61 \mathrm{kcal} / \mathrm{mole})^{14}($ Fig. 1). In the case of ozone, however, formation of $\mathrm{BaO}+\mathrm{O}_{2}$ is substantially more exoergic $(\Delta \mathrm{H}=-110 \mathrm{kcal} / \mathrm{mole}) . .^{14,15}$ In all cases, however, the thermodynamic stabilities of the singly ionic reaction intermediates $\mathrm{Ba}^{+} \mathrm{ClO}_{2}{ }^{-}, \mathrm{Ba}^{+} \mathrm{O}_{3}{ }^{-}$, and $\mathrm{Ba}^{+} \mathrm{NO}_{2}{ }^{-}$are expected to be comparable, ${ }^{16}$ lying $\sim 65 \mathrm{kcal} / \mathrm{mole}$ lower in energy than the separated neutral reactants (Fig. 2).

Although the chemistry and thermochemistry of ozone $e^{17}$ and the ozonide anion $\left(\mathrm{O}_{3}^{-}\right)^{18}$ have been studied extensively using a variety of techniques, there have been very few experimental investigations of the dynamics of their chemical reactions under isolated single collision conditions. ${ }^{19}$ Analogous studies of $\mathrm{ClO}_{2}{ }^{20}$ and $\mathrm{ClO}_{2}{ }^{21}$ have been rare, with substantial uncertainty in the electron affinity only recently resolved. ${ }^{13}$ In this chapter, we present angular and velocity distributions of the products resulting from the reactions of $\mathrm{Ba}$ with the 18 electron triatomic ozone and 19 electron chlorine dioxide. A comparison of these reactions with the closely related 17 electron $\mathrm{NO}_{2}$ will allow us to gain some insight into the general behavior of these molecules.

Although chemiluminescent $\mathrm{BaO}$ was the only nascent product observed in previous studies of the gas phase $\mathrm{Ba}+\mathrm{O}_{3}$ reaction, extensive work using matrix isolation techniques with IR or Raman spectroscopy by several groups ${ }^{22-25}$ has revealed considerably richer chemistry. Andrews and coworkers found that codeposition of Ba and other alkaline earth atoms with $\mathrm{O}_{3}{ }^{22}$ and $\mathrm{O}_{2}{ }^{23}$ in rare gas matrices led to formation 
of $\mathrm{BaO}$ and $\mathrm{BaO}_{2}$. In the ozone experiments, $\mathrm{BaO}_{3}$ was also observed. Similar reactions have also been seen in reactions of alkali atoms ${ }^{25}$ with $\mathrm{O}_{2}$ and $\mathrm{O}_{3}$. As expected, all species were found to be highly ionic owing to the low ionization potentials of the metals and appreciable electron affinities of $\mathrm{O}, \mathrm{O}_{2}$, and $\mathrm{O}_{3}$. The $\mathrm{BaO}_{2}$ resulted from several different reaction mechanisms $\mathrm{s}^{22 \mathrm{a}}$ due to multiple collisions in the matrix:

$$
\mathrm{Ba}+\mathrm{O}_{3} \rightarrow \mathrm{BaO}_{2}+\mathrm{O}
$$

or

$$
\begin{aligned}
& \mathrm{Ba}+\mathrm{O}_{3} \rightarrow \mathrm{BaO}+\mathrm{O}_{2} \\
& \mathrm{BaO}+\mathrm{O}_{3} \rightarrow \mathrm{BaO}_{2}+\mathrm{O}_{2}
\end{aligned}
$$

or

$$
\mathrm{Ba}+\mathrm{O}_{2}+\mathrm{M} \rightarrow \mathrm{BaO}_{2}+\mathrm{M}
$$

Apparently, all three processes were operative, but the relative importance of processes 1 and $2 a$ could not be ascertained. By studying the reactions under single collision conditions in the gas phase, it should be possible to unravel the reaction mechanisms.

The nature of the $\mathrm{Ba}-\mathrm{O}_{2}$ interaction in the gas phase has remained uncertain for many years. ${ }^{26-30}$ By analogy with the ground state $\mathrm{BaO}$ molecule, which is best described in terms of a doubly ionic bond $\mathrm{d}^{10}\left(\mathrm{Ba}^{2+} \mathrm{O}^{2}\right)$, we might expect the barium-dioxygen molecule to be considerably more peroxide-like (i.e. $\mathrm{Ba}^{2+} \mathrm{O}_{2}{ }^{2-}$ ) than its alkali counterparts which are superoxides (eg. $\mathrm{Cs}^{+} \mathrm{O}_{2}{ }^{-}$). Although this is certainly true ${ }^{31}$ in the case of solid $\mathrm{BaO}_{2}$, it has been concluded that $\mathrm{BaO}_{2}$ formed under matrix isolation conditions is a 
superoxide..$^{22,23}$ This conclusion was based on the intraionic 0-O vibrational frequency observed for $\mathrm{BaO}_{2}$ formed in matrix isolation experiments. The observed $1120 \mathrm{~cm}^{-1}$ frequency is substantially higher than that expected for a peroxide $\left(\sim 840 \mathrm{~cm}^{-1}\right)$. Based on the matrix isolation work, it was concluded that in the case of the Ba dioxygen molecule, the potential divalency of barium is only seen in the solid. A number of our experimental results on $\mathrm{Ba}+\mathrm{O}_{3}$ provide new insight into the $\mathrm{BaO}_{2}$ molecule. Based on the recoil velocity of the $\mathrm{BaO}_{2}$ product, we deduce a lower limit to $\mathrm{D}_{0}\left(\mathrm{Ba}-\mathrm{O}_{2}\right)$ of 120 $\mathrm{kcal} / \mathrm{mole}$. The large binding energy strongly suggests that the molecule does have considerable peroxide character (i.e. $\mathrm{Ba}^{2+} \mathrm{O}_{2}{ }^{2-}$ ), in contrast to the much more weakly bound alkali superoxides such as $\mathrm{Na}^{+} \mathrm{O}_{2}^{-}\left(D_{0} \approx 40 \mathrm{kcal} / \mathrm{mole}\right)$. Some of the relevant features of the much studied $\mathrm{Ba}+\mathrm{O}_{2}$ reaction, ${ }^{26-30}$ and the apparent disagreement with the conclusions from the matrix isolation experiments are discussed in this chapter.

Based on the similarities in the molecules $\mathrm{NO}_{2}, \mathrm{O}_{3}$, and $\mathrm{ClO}_{2}$ (Table 1), we might expect to see many of the same features in the $\mathrm{Ba}+\mathrm{ClO}_{2}$ and $\mathrm{O}_{3}$ dynamics that were observed in the $\mathrm{Ba}+\mathrm{NO}_{2}$ system. Although at first glance this anpears to be true, with direct and long-lived mechanisms contributing to the overall reaction cross section, a considerably larger contribution from a direct mechanism is seen in the $\mathrm{O}_{3}$ reaction. Whereas the secondary chemically distinct reaction channel $\mathrm{Ba}\left({ }^{\prime} \mathrm{S}\right)+\mathrm{NO}_{2} \rightarrow \mathrm{BaNO}+$ $O$ resulted from a direct mechanism (Chapter 1), in the present reactions both secondary chemical channels, $\mathrm{Ea}+\mathrm{ClO}_{2} \rightarrow \mathrm{BaCl}+\mathrm{O}_{2}$ and $\mathrm{Ba}+\mathrm{O}_{3} \rightarrow \mathrm{BaO}_{2}+\mathrm{O}$, result from mechanisms involving long-lived complexes.

Based on the experimental data from the $\mathrm{Ba}+\mathrm{O}_{3}$ experiments alone, a number 
of important questions regarding the reaction dynamics could not be answered unambiguously. This complication arose because there was no way to tell for certain which oxygen atoms (apical or terminal) in ozone are responsible for formation of $\mathrm{BaO}$ and $\mathrm{BaO}_{2}$. This was one motivation for the $\mathrm{ClO}_{2}$ studies since chlorine dioxicle possesses many similarities to ozone but the chemically distinct central atom (which leads to chemically distinct products) provides clearer insight into the reaction mecllanisms.

\section{EXPERIMENTAL}

The experimental apparatus employed in this study is identical to that used in the work described in Chapters 1 and 2. The handling of ozone in the contexl of molecular beams deserves particular mention. Since liquid $\mathrm{O}_{3}$ is unstable and decomposes to $\mathrm{O}_{2}$ with possible explosion, condensation of $\mathrm{O}_{3}\left(\mathrm{bp}=-111.9^{\circ} \mathrm{C}\right)^{33}$ is generally avoided. ${ }^{34-36}$ In our early experiments, the effluent from a commercial ozonizer ${ }^{37}\left(\begin{array}{lll}10 \% & \mathrm{O}_{3}, 90 \% & \mathrm{O}_{2}\end{array}\right)$ was passed through a pyrex trap containing coarse silica gel cooled to $-78^{\circ} \mathrm{C}$ in a dry ice/acetone mixture. After $\sim 1$ hour of running time, approximately $10 \mathrm{~g}$ of deep blue $\mathrm{O}_{3}$ with a small amount of $\mathrm{O}_{2}$ was adsorbed on the $\mathrm{Si}$ gel. The trap was transported to the molecular beams laboratory and a slow flow of He used to carry the desorbing ozone out of the trap and through the molecular beam nozzle. A thermostatically controlled variable temperature bath was used to slowly warm the $\mathrm{O}_{3}$ trap in order to maintain a constant concentration as the $\mathrm{O}_{3}$ was depleted. The $\mathrm{O}_{3}$ concentration was continuously monitored by its absorption at $280 \mathrm{~nm}^{38}$ in a $1 \mathrm{~cm} \times 1 \mathrm{~cm}$ quartz flow cuvette just prior to entry into the molecular beams apparatus. The beam was continuous and contained $10 \% \mathrm{O}_{3},-1 \%$ 
$\mathrm{O}_{2}$, and $89 \%$ He at a total pressure of $\sim 300$ Torr, after the system was allowed to stabilize for at least 1 hour. With some practice, it was possible to obtain ozone beams of reproducible intensity and velocity over a period of -6 hrs. In our experience, this method is quite safe when several precautions are taken. Pumping undiluted $\mathrm{O}_{3}$ through rotary pumps is to be avoided, and sealed Si gel traps containing ozone must never be warmed up or pressurized. With daily oil changes, the dilute $\mathrm{O}_{3} / \mathrm{He}$ mixture does not seem to seriously harm mechanical pumps. Condensing $\mathrm{O}_{3}$ in $\mathrm{LN}_{2}$ foreline traps is not recommended due to the explosive nature of the liquid, especially in the presence of pump oil. It is also important that clean stainless steel, glass, or teflon tubing be used throughout the system since decomposition of $\mathrm{O}_{3}$ is enhanced by other metals and impurities. Also, ozone rapidly decomposes rubber o-rings. The nozzle tip was heated to $\sim 100^{\circ} \mathrm{C}$ to minimize the formation of dimers. Without heating the nozzle, considerable $\mathrm{O}_{5}{ }^{+}$signal could be observed upon sampling the beam directly with the mass spectrometer. This signal was attributed to fragmentation of $\left(\mathrm{O}_{3}\right)_{2}$ upon electron impact ionization.

In the ozone experiments, the $\mathrm{BaO}$ measurements were greatly hampered by the presence of $\mathrm{O}_{2}$ in the beam since the reaction cross section for $\mathrm{Ba}+\mathrm{O}_{2} \rightarrow \mathrm{BaO}+\mathrm{O}$ is known to be large. ${ }^{26-30}$ We found that the quantity of $\mathrm{O}_{2}$ impurity decreased substantially as the beam was run over a period of several hours, making it nearly impossible to unambiguously distinguish between $\mathrm{BaO}$ signal arising from reaction of $\mathrm{Ba}$ with $\mathrm{O}_{3}$ from that with $\mathrm{O}_{2}$. With the current apparatus geometry, it is not possible to accurately monitor the fraction of $\mathrm{O}_{2}$ in the $\mathrm{O}_{3}$ beam during reactive scattering experiments. A 
considerable effort was devoted to finding conditions that would minimize the concentration of $\mathrm{O}_{2}$ impurity in the $\mathrm{O}_{3}$ sample. The $\mathrm{O}_{2}$ impurity could be easily monitored by elastic scattering experiments off Ne. By choosing an appropriate detector angle, it is possible to resolve the separate peaks in the $\mathrm{O}_{2}{ }^{+}$TOF due to contributions from both $\mathrm{O}_{2}$ and $\mathrm{O}_{3}$ elastic scattering. After a considerable amount of experimentation, we concluded that the silica gel itself slowly decomposes $\mathrm{O}_{3}$, making it impossible to obtain pure $\mathrm{O}_{3}$ using the silica trap method. We found that the only certain way to obtain a pure $\mathrm{O}_{3} / \mathrm{He}$ beam was to employ liquid $\mathrm{O}_{3}$. Due to the possible explosive nature of $\mathrm{O}_{3(\mathfrak{l})}$, the sample delivery system and valves were set up to permit remote operation, and the reservoir was clamped behind a safety shield before any $\mathrm{O}_{3}$ was introduced to the system. As before, approximately $10 \mathrm{~g}$ of $\mathrm{O}_{3}$ was deposited on the $\mathrm{Si}$ gel trap at $-78 \mathrm{C}$. After transporting the trap to the laboratory, the $\mathrm{O}_{3}$ was condensed into a standard glass bubbler cooled to $77 \mathrm{~K}$ using $\mathrm{He}$ as the carrier gas while slowly warming the trap from $78 \rightarrow-40 \mathrm{C}$ over a period of $\sim 20 \mathrm{mins}$. In this way, it was possible to trap $5-10 \mathrm{~g}$ of the deep blue $\mathrm{O}_{3} / \mathrm{O}_{2}$ mixture. The bubbler used to trap the liquid $\mathrm{O}_{3}$ was constructed using a short internal tube so the $\mathrm{O}_{3}$ level was always below the gas outlet. Great care was exercised to avoid any vibration, shock, or organic impurities, all of which are known to promote explosive decomposition. ${ }^{34-36}$ After the ozone transfer was completed, a slow stream of He was passed into the trap with the effluent directed into the nozzle. The $\mathrm{LN}_{2}$ trap was carefully replaced with an isopentane slush $\left(-155^{\circ} \mathrm{C}\right)$ using remote manipulators, giving an $\mathrm{O}_{3}$ vapor pressure of $\sim 20 \mathrm{Torr}^{33}$ At $-155^{\circ} \mathrm{C}$, the more volatile ${ }^{33} \mathrm{O}_{2}$ impurity is depleted within several minutes leaving pure $\mathrm{O}_{3}$. Elastic scattering experiments off $\mathrm{He}$ 
showed a negligible presence of $\mathrm{O}_{2}$ contamination in the beam when using this method. We found $\mathrm{O}_{3}{ }^{+}: \mathrm{O}_{2}{ }^{+}: \mathrm{O}^{+}=4.7: 3.0: 1.0$, in excellent agreement with the published mass spectral data on pure $\mathrm{O}_{3}$ sampled from a molecular beam. ${ }^{39}$ It should be emphasized that this procedure was undertaken with considerable planning and very carefully adopted procedures which could be implemented remotely. In general, the use of liquid ozone is to be avoided due to the hazards associated with its use.

Chlorine dioxide was prepared by the heterogeneous reaction $\mathrm{Cl}_{2(\mathrm{~g})}+2 \mathrm{NaClO}_{2(s)} \rightarrow$ $2 \mathrm{NaCl}+2 \mathrm{ClO}_{2}$ using an adaption of the method of Derby and Hutchinson. ${ }^{40}$ A $10 \%$ $\mathrm{Cl}_{2} / \mathrm{He}$ mixture was produced by bubbling $1 \mathrm{~atm} \mathrm{He}$ through liquid $\mathrm{Cl}_{2}$ in a cooled trap. $\left(-78^{\circ} \mathrm{C}\right)$ The mixture was directed through a $1^{\prime \prime}$ dia. pyrex tube (2' long, wrapped with duct tape) loosely packed with technical grade $\mathrm{NaClO}_{2}$ (MCB). The effluent, which is nearly pure ${ }^{41} \mathrm{ClO}_{2}$, passed through a $\mathrm{U}$-tube containing $\mathrm{P}_{2} \mathrm{O}_{5}$ to remove water ${ }^{42}$ and into a trap cooled to $-196^{\circ} \mathrm{C}$. The $\mathrm{Cl}_{2}$ impurity was subsequently removed by pumping periodically on the sample while it was warmed slowly to $-78^{\circ} \mathrm{C}$. The sample was stored in the dark at $-196^{\circ} \mathrm{C}$. A beam of $\mathrm{ClO}_{2}$ was formed by bubbling He carrier gas through the trap maintained at $-40^{\circ} \mathrm{C}$. Our experience is consistent with past reports of spontaneous $\mathrm{ClO}_{2}$ detonation ${ }^{9,43,44}$ when its vapor pressure exceeds $\sim 80 \mathrm{Torr}$. Extreme care is required when handling $\mathrm{ClO}_{2}$; toward the end of these experiments explosion of an inline $\mathrm{LN}_{2}$ cooled trap containing several grams of $\mathrm{ClO}_{2}$ pointed out the dangers associated with this thermodynamically unstable molecule. No injury or serious damage resulted since extensive precautions had been observed throughout. A recent report ${ }^{13}$ that $\mathrm{ClO}_{2}$ is "safe" should be taken with caution. An alternative procedure involving in situ 
production of $\mathrm{ClO}_{2}{ }^{45}$ has been described in the literature. However, in our experience, the method as described always led to the presence of considerable $\mathrm{Cl}_{2} \mathrm{impurity}$, with the concentration varying from batch to batch. Since the level of this impurity could not be ascertained, an unknown $\mathrm{BaCl}$ contribution from $\mathrm{Ba}+\mathrm{Cl}_{2}$ would inevitably result. Thus, the liquid $\mathrm{ClO}_{2}$ method was found to be preferable-- upon starting the beam, the more volatile $\mathrm{Cl}_{2}$ was depleted rapidly, leaving pure $\mathrm{ClO}_{2}$. Mass analysis of the beam produced using liquid $\mathrm{ClO}_{2}$ indicated that it was composed of pure $\mathrm{ClO}_{2}$ with no indications of impurities such as $\mathrm{Cl}_{2}$ or $\mathrm{Cl}_{2} \mathrm{O}$. It should be noted that in more recent experiments (Chapter 5), we have found that conversion of $\mathrm{Cl}_{2}$ to $\mathrm{OClO}$ can be nearly quantitative, but only when some moisture is present in the $\mathrm{NaClO}_{2}$. In that work, the presence of a small quantity of $\mathrm{Cl}_{2}$ impurity is inconsequential; this was not the case in the present experiment. The nozzle was heated to $150^{\circ} \mathrm{C}$ to inhibit formation of clusters. We found no evidence for gradual thermal decomposition of $\mathrm{ClO}_{2}$, even when the nozzle was heated to $150^{\circ} \mathrm{C}$, in agreement with the findings of others. ${ }^{41}$

\section{RESULTS AND ANALYSIS}

\section{$\mathrm{A} . \mathrm{Ba}+\mathrm{ClO}_{2} \rightarrow \mathrm{BaO}+\mathrm{ClO}$}

The product angular and velocity distributions for the above reaction were recorded at collision energies of 6,14 , and $30 \mathrm{kcal} / \mathrm{mole}$. The Newton diagram for $\mathrm{Ba}\left({ }^{1} \mathrm{~S}\right)+\mathrm{ClO}_{2} \rightarrow \mathrm{BaO}+\mathrm{ClO}$ is shown in Fig. 3 for a nominal collision energy of 14 $\mathrm{kcal} / \mathrm{mole}$. The $\mathrm{BaO}$ angular distribution (Fig 3.) is forward peaking, indicating the 
occurrence of direct reaction mechanisms. However, there is also a wide angle component which we attribute to decay of long lived complexes. Time-of-flight spectra for the $\mathrm{BaO}$ product at a collision energy of $14 \mathrm{kcal} / \mathrm{mol}$ is shown in Fig. 4. The most notable feature of the data is its similarity to the $\mathrm{BaO}$ resulting from the $\mathrm{Ba}+\mathrm{NO}_{2}$ reaction. ${ }^{2}$ We have obtained a reasonably good fit to the data by assuming a single uncoupled $T(\theta)$ and $P(E)$, (Fig. 5). However, the fit is expected to be improved somewhat through the use of two uncoupled $\mathrm{T}(\theta)$ and $\mathrm{P}(\mathrm{E})$ combinations, as employed in the $\mathrm{Ba}+\mathrm{NO}_{2}$ study. This procedure is currently in progress.

\section{B. $\mathrm{Ba}+\mathrm{ClO}_{2} \rightarrow \mathrm{BaCl}+\mathrm{O}_{2}$}

Nascent $\mathrm{BaCl}$ was observed at the parent ion mass and was attributed to the central atom abstraction reaction shown above. The most conclusive evidence for formation of $\mathrm{BaCl}+\mathrm{O}_{2}$ would be observation of the momentum matched $\mathrm{O}_{2}$ fragment at $\mathrm{m} / \mathrm{e}=32\left(\mathrm{O}_{2}{ }^{+}\right)$. Although we did look for the $\mathrm{O}_{2}$ fragment, the search was unsuccessful. This was expected, based on earlier signal-to-noise calculations. This situation primarily results from high background countrate in the detector at $m / e=32$ $\left(\mathrm{O}_{2}^{+}\right)$due to the presence of residual $\mathrm{O}_{2}$. A second reason for our inability to detect $\mathrm{O}_{2}$ results from the kinematic relationship. Due to the heavy $\mathrm{BaCl}$ partner, the recoil velocity of the light $\mathrm{O}_{2}$ is very large. Due to the large center of mass velocity of $\mathrm{O}_{2}$ (i.e. a large Newton sphere), the signal intensity at the detector is relatively small.

Consequently, we were concerned about the possibility that the signal observed as $\mathrm{BaCl}^{+}$might be attributable to fragmentation of $\mathrm{BaClO}$ from the possible $\mathrm{BaClO}+$ 
$\mathrm{O}$ channel, rather than from $\mathrm{BaCl}+\mathrm{O}_{2}$. This reaction would be analogous to $\mathrm{Ba}+\mathrm{NO}_{2}$ $\rightarrow$ BaNO +0 , discussed in Chapter 1 . We ruled out this reaction based on the following arguments: 1) $\mathrm{BaClO}$ is an unlikely product since it is expected to be thermodynamically unstable ${ }^{46}$ with respect to $\mathrm{BaO}+\mathrm{Cl}$; 2) If nascent $\mathrm{BaClO}$ had been formed, it is likely to be observable (weakly) at the parent mass or $\mathrm{ClO}^{+}$, as was the case for $\mathrm{BaNO}$ in $\mathrm{Ba}+\mathrm{NO}_{2}{ }^{2}$. Yet no such signal was found; 3) The $\mathrm{BaCl}$ product translational energy distribution peaked well away from zero energy as would be expected for a concerted reaction involving central atom abstraction followed by repulsion of $\mathrm{BaCl}+\mathrm{O}_{2}$;4) Nascent $\mathrm{BaCl}$ has been observed in past chemiluminescence work. ${ }^{9}$

Zare and coworkers were able to detect nascent $\mathrm{BaCl}^{+9 b}$ (in addition to neutral chemiluminescent $\mathrm{BaCl}^{\circ}$ ), apparently due to reaction 4 :

$$
\mathrm{Ba}+\mathrm{ClO}_{2} \rightarrow \mathrm{BaCl}^{+}+\mathrm{O}_{2}+\mathrm{e}^{-}
$$

This channel is expected to have an even smaller cross section than the chemiluminescent $\mathrm{BaCl}$ channel. ${ }^{9}$ We can rule out contribution of nascent ions to our observed signal since our ionizer was floated at $+70 \mathrm{~V}$. This prevents any positive ions produced in the scattering region from entering the mass spectrometric detector. We also found that the $\mathrm{BaCl}$ signal disappeared upon turning off the electron bombardment ionizer, indicating that it does not result from surface ionization of metastable species in the detector.

The angular distribution for the $\mathrm{BaCl}$ product from the $\mathrm{Ba}+\mathrm{ClO}_{2}$ reaction at 
14kcal/mole is shown in Fig. 6. A good fit of this data and the $\mathrm{BaCl}$ TOF (shown in Fig. 7), was obtained using a single uncoupled $P(E)$ and $T(\theta)$ combination. The best fit to this data at $14 \mathrm{kcal} / \mathrm{mole}$ is shown in Fig. 8. The angular distribution was found to exhibit forward-backward symmetry in the center-of-mass frame of reference at all collision energies.

The yield for the $\mathrm{BaCl}+\mathrm{O}_{2}$ channel was found to be approximately $10 \%$ that of the $\mathrm{BaO}+\mathrm{ClO}$ channel at all collision energies studied. This quantity was calculated from the optimized $P(E)$ and $T(\theta)$, after normalization of the observed signal intensities. In the calculation, we assumed equal detection efficiencies for $\mathrm{BaO}$ and $\mathrm{BaCl}$ at their parent ion masses. This is a reasonable assumption in the present case since it is known that the parent ion peaks for both $\mathrm{BaO}$ and $\mathrm{BaCl}$ are comparable to the daughter ion peak at $\mathrm{Ba}^{+}$. The fragmentation patterns are also known to be relatively insensitive to internal excitation of the parent neutral molecule. ${ }^{2}$ The ionization cross sections for both species are calculated to be nearly identical..$^{47}$

\section{C. $\mathrm{Ba}+\mathrm{O}_{3} \rightarrow \mathrm{BaO}+\mathrm{O}_{2}$}

The product angular and velocity distributions were recorded at three collision energies between 6 and $40 \mathrm{kcal} /$ mole using liquid ozone. The $\mathrm{BaO}$ angular distribution obtained at a collision energy of $14 \mathrm{kcal} / \mathrm{mole}$ was more forward peaking than in the case of $\mathrm{Ba}+\mathrm{NO}_{2}$ or $\mathrm{Ba}+\mathrm{ClO}_{2}$. Although the $\mathrm{BaO}$ angular distributions clearly indicate a substantially larger yield of forward scattered products than in the $\mathrm{Ba}+\mathrm{NO}_{2}$ and $\mathrm{ClO}_{2}$ systems, a wide angle component is seen. The time of flight data at this collision energy 
is shown in Fig. 9; the translational energy and CM angular distribution resulting from the data is presented in Fig. 10. A BaO product flux contour diagram, superimposed on the nominal Newton diagram is depicted in Fig. 13. By analogy with the $\mathrm{NO}_{2}$ system, the involvement of long-lived $\mathrm{Ba}^{+} \mathrm{O}_{3}{ }^{-}$collision complexes is a logical explanation for backscattered $\mathrm{BaO}$. However, an alternative mechanism that was impossible for $\mathrm{Ba}+$ $\mathrm{NO}_{2}$, involving abstraction of the central $\mathrm{O}$ atom from $\mathrm{O}_{3}$ resulting in $\mathrm{O}_{2}$ by formation of a chemical bond between the outer oxygen atoms in ozone, is possible in principle. It is likely to be dominated by small impact parameter collisions with near $\mathrm{C}_{2 v}$ approach of the $\mathrm{Ba}$ atom towards the apical oxygen atom in ozone, possibly leading to backscattering of the $\mathrm{BaO}$ molecule. An analogous process has been postulated by van den Ende and coworkers ${ }^{19 \mathrm{a}}$ to account for a sharply backscattered $\mathrm{NO}_{2}$ peak in the reaction $\mathrm{NO}+\mathrm{O}_{3} \rightarrow \mathrm{NO}_{2}+\mathrm{O}_{2}$. If such a reaction were operative in the present reaction, analysis of our scattering data using an iterative forward convolution approach might best involve two separable $T(\theta)$ and $P(E)$ combinations-- one involving a forward scattered "stripping" channel and the other due to abstraction of the central $\mathrm{O}$ atom with $\mathrm{BaO}$ backscattering. However, we have chosen not to use this approach. Although the data presented here was analyzed using a single $P(E)$ and $T(\theta)$ combination, further analysis in progress employs the same model used in the analysis of the $\mathrm{BaO}$ from the $\mathrm{Ba}+\mathrm{NO}_{2}$ data, with one forward-backward symmetric channel and a second forward scattered angular distribution. This approach is largely inspired by our observations in the analogous system $\mathrm{Ba}+\mathrm{ClO}_{2}$ where a substantial yield of $\mathrm{BaCl}+\mathrm{O}_{2}$ was observed, but the best fit $\mathrm{BaCl}$ angular distribution was forward-backward symmetric rather than 
backscattered. We believe that central atom abstraction from ozone, if it were to occur at all, will likely show a forward-backward symmetric $\mathrm{BaO}$ angular distribution. (This will be discussed in detail in section IV-A.) The fact that the $\mathrm{BaO}_{2}$ product angular distribution exhibited forward-backward symmetry clearly indicates the existence of a stable $\mathrm{Ba}^{+} \mathrm{O}_{3}$ intermediate which will likely branch into both $\mathrm{BaO}+\mathrm{O}_{2}$ and $\mathrm{BaO}_{2}+\mathrm{O}$. We cannot envision any physically realistic mechanism requiring us to incorporate a separate reaction channel involving $\mathrm{BaO}$ backscattering.

\section{D. $\mathrm{Ba}+\mathrm{O}_{3} \rightarrow \mathrm{BaO}_{2}+\mathrm{O}$}

The formation of nascent $\mathrm{BaO}_{2}$ from a single encounter between $\mathrm{Ba}+\mathrm{O}_{3}$ was clearly observed. Product velocity and angular distributions were recorded at three collision energies. Since it is not possible that $\mathrm{O}_{2}$ contamination can lead to observation of $\mathrm{BaO}_{2}$ at the detector, as was verified in experiments using pure $\mathrm{O}_{2}^{48}$, extensive experiments using liquid ozone were deemed to be unnecessary and the data presented here employed $\mathrm{O}_{3}$ directly from the silica gel trap. However, an experiment was carried out using liquid $\mathrm{O}_{3}$ to verify that the $\mathrm{BaO}_{2}$ signal resulted exclusively from reaction with $\mathrm{O}_{3}$, and was not affected by the presence of $\mathrm{O}_{2}$ impurity in the $\mathrm{O}_{3}$ beam.

There is no way to precisely determine the $\mathrm{BaO}_{2}$ fragmentation patterns upon electron bombardment ionization since the signal observed at $\mathrm{BaO}^{+}$is strongly dominated by nascent $\mathrm{BaO}$ from the $\mathrm{BaO}+\mathrm{O}_{2}$ channel. Analysis of the $\mathrm{Ba}^{+}$data is complicated by the fact that it results from fragmentation of both $\mathrm{BaO}_{2}$ and $\mathrm{BaO}$ upon electron bombardment ionization, as well as from nonreactive scattering events (although this is 
probably minor). The data presented here were recorded with the mass spectrometer tuned to $\mathrm{BaO}_{2}{ }^{+}(\mathrm{m} / \mathrm{e}=170)$. We believe that the internal energy dependence of the $\mathrm{BaO}_{2}$ fragmentation pattern is likely to be small. This is based on the large $\mathrm{BaO}_{2}$ binding energy (this work), as well as a large binding energy for $\mathrm{BaO}_{2}{ }^{+}{ }^{32 \mathrm{~b}}$ Good fits to the $\mathrm{BaO}_{2}$ product TOF (Fig 11) and angular distributions were obtained using a single uncoupled $P(E)$ and $T(\theta)$ combination (Fig 12). The center of mass angular distribution exhibited forward-backward symmetry at all collision energies. The $\mathrm{BaO}_{2}$ product flux contour map, superimposed on a nominal Newton diagram at $14 \mathrm{kcal} / \mathrm{mol}$ is shown in Fig. 13.

\section{DISCUSSION}

\section{A. $\mathrm{Ba}+\mathrm{ClO}_{2}$}

There is remarkable similarity between the $\mathrm{BaO}$ resulting from reaction of barium with $\mathrm{ClO}_{2}$ with that from $\mathrm{NO}_{2}$. Again, one mechanism involves long-lived complexes and a second involves direct reactions. Perhaps the only substantial difference is that the average translational release for the present reaction is somewhat less, despite a slightly larger reaction exoergicity. Although we have not attempted to measure relative reaction cross sections for $\mathrm{Ba}+\mathrm{NO}_{2}$ and $\mathrm{ClO}_{2}$, they are expected to be comparable since the electron affinities of the molecules are nearly identical. ${ }^{11,13}$ The $\mathrm{BaO}+\mathrm{ClO}$ channel is dominant and accounts for $\sim 90 \%$ of the total reaction cross section at all collision energies.

As was the case for $\mathrm{NO}_{2}$, formation of the negative ion fragments from $\mathrm{ClO}_{2}+$ $\mathrm{e}^{\cdot}$ is generally endoergic with the notable exceptions of the three-center rearrangements 
forming $\mathrm{Cl}^{-}+\mathrm{O}_{2}$ or $\mathrm{Cl}+\mathrm{O}_{2} \cdot:^{\cdot 50}$

$$
\begin{aligned}
\mathrm{ClO}_{2}+\mathrm{e}^{-} & \rightarrow \mathrm{ClO}_{2}^{-} & \Delta \mathrm{H} & =-54.6 \mathrm{kcal} / \mathrm{mole} \\
\mathrm{ClO}_{2}+\mathrm{e}^{-} & \rightarrow \mathrm{ClO}+\mathrm{O} & & (5) \\
& \rightarrow \mathrm{ClO}+\mathrm{O}^{-} & & =+11.5 \mathrm{kcal} / \mathrm{mole}(6) \\
& \rightarrow \mathrm{Cl}^{-}+2 \mathrm{O} & & =+38.7 \mathrm{kcal} / \mathrm{mole}(8) \\
& \rightarrow \mathrm{Cl}+\mathrm{O}_{2}^{-} & & =-5 \mathrm{kcal} / \mathrm{mole}
\end{aligned}
$$

There appears to be no information regarding cross sections for these processes. However, electron attachment to $\mathrm{ClO}_{2}$ at low energy should lead to formation of a longlived anion, ${ }^{30}$ due to a large potential energy barrier for the concerted molecular rearrangements (processes 9,10 ). ${ }^{536}$ The energetics of $\mathrm{ClO}_{2}{ }^{-}$decomposition are shown in Fig. 14. Based on the thermodynamics, the situation is completely analogous to $\mathrm{NO}_{2}$ and its anion: the neutrals have large electron affinities, and the anion is thermodynamically stable with respect to fragmentation..$^{2,50,51}$ For most collision trajcctories, long-range electron transfer results in formation of a long-lived collision intermediate. The highest unoccupied molecular orbital of $\mathrm{ClO}_{2}$ is ${ }^{52}\left(2 b_{1}\right)^{1}$. Long-range electron transfer into the half-occupied $2 \mathrm{~b}_{1}$ orbital leads to $\left.\mathrm{ClO}_{2} \cdot\left({ }^{1} \mathrm{~A}_{1}\right)\right)^{9,49}$ Whereas electron attachment to $\mathrm{NO}_{2}$ results in considerable decrease in bond angle, (from $133.9^{\circ}$ to $117.5^{\circ}$ ), a much smaller change from $117^{\circ}$ to $111^{\circ}$ (Ref. $58 \mathrm{~b}$, Table 1) occurs in the case of $\mathrm{ClO}_{2}$. However, the $\mathrm{O}-\mathrm{O}$ bonding character of the $2 \mathrm{~b}_{1}$ orbital and the large exoergicities for the $\mathrm{BaO}_{2}+\mathrm{Cl}$ and $\mathrm{BaCl}+\mathrm{O}_{2}$ channels suggest that concerted 
decomposition might occur. Although little information is available regarding the next unoccupied orbitals of $\mathrm{ClO}_{2}$, there is good evidence that the next higher orbital is of Rydberg character. ${ }^{52}$ Like the $\mathrm{Ba}+\mathrm{NO}_{2}$ reaction, electron transfer leads to symmetric stretching and bending in the $\mathrm{ClO}_{2}^{-}$ion. Since the reaction coordinate for formation of $\mathrm{BaO}+\mathrm{ClO}$ involves asymmetric stretching, a substantial fraction of the collisions result in formation of long-lived complexes. The potential energy barrier associated with orbital rearrangement required for formation of ground state doubly ionic $\mathrm{BaO}+\mathrm{ClO}$ products, and the barrier for the concerted process favor formation of long-lived complexes.

The $\mathrm{BaCl}+\mathrm{O}_{2}$ reaction is of particular interest since the reaction has been found to involve concerted central atom abstraction. ${ }^{9}$ Although such reactions are extremely rare under single collision conditions, we find that the yield of $\mathrm{BaCl}+\mathrm{O}_{2}$ is appreciable $(\sim 10 \%)$. Engelke and Zare ${ }^{9}$ concluded that long-range electron transfer into the $2 b_{1}$ orbital led to a decrease in $\mathrm{ClO}_{2}$ bond angle with enhanced bonding between the oxygen atoms resulting in formation of $\mathrm{BaCl}+\mathrm{O}_{2}$. Based on the observation that the internal energy distribution was nonstatistical, they concluded that formation of chemiluminescent $\mathrm{BaCl}$ resulted from a direct reaction mechanism, rather than from one involving longlived intermediates. Although the large $\mathrm{BaCl}$ signal level observed in our experiment is consistent with a mechanism initiated by long-range electron transfer into the $2 b_{1}$ orbital, the nearly perfect forward-backward symmetry observed in the product angular distribution is very strong evidence that the $\mathrm{Ba}^{+} \mathrm{ClO}_{2}{ }^{-}$intermediate undergoes at least several rotations before formation of most $\mathrm{BaCl}$ product molecules. The existence of an 
osculating complex with lifetime of about one rotational period is ruled out based on the insensitivity of the angular distribution to collision energy. The nonstatistical internal energy distribution observed by Zare and coworkers thus might be indicative of different reaction mechanisms for formation of chemiluminescent and ground state $\mathrm{BaCl}$. Alternatively, the internal energy distribution that they observed might result from the effects of a large potential energy barrier in the $\mathrm{BaCl}+\mathrm{O}_{2}$ exit channel.

We find that the yield of $\mathrm{BaCl}$ relative to $\mathrm{BaO}$ is insensitive to collision energy. One possible reaction mechanism would involve a common $\mathrm{Ba}^{+} \mathrm{ClO}_{2}{ }^{-}$intermediate with kinetic competition for its decay to $\mathrm{BaO}+\mathrm{ClO}$ or $\mathrm{BaCl}+\mathrm{O}_{2}$. The lack of a collision energy dependence could be taken as evidence that the potential energy barriers for the two processes are comparable. Alternatively, the observations might be interpreted in terms of two different reaction mechanisms arising from different reactant approach geometries. Since both apparently involve long-lived intermediates, this would suggest the participation of two different geometric isumers of $\mathrm{Ba}^{+} \mathrm{ClO}_{2}{ }^{-}$with formation of $\mathrm{BaCl}$ $+\mathrm{O}_{2}$ resulting from a $\mathrm{Ba}-\mathrm{Cl}$ bonded complex and $\mathrm{BaO}+\mathrm{ClO}$ from decay of a bidentate structure analogous to that postulated in the $\mathrm{Ba}+\mathrm{NO}_{2}$ reaction (Chapter 1). Matrix isolation experiments have indicated that the $\mathrm{Cs}^{+} \mathrm{ClO}_{2}{ }^{-}$complex has $\mathrm{C}_{2 \mathrm{v}}$ symmetry. ${ }^{53,54}$ Although the authors mentioned a bidentate structure, it appears that this assignment was based only on the apparent analogy with similar molecules such as $\mathrm{Cs}^{+} \mathrm{NO}_{2}^{-}, \mathrm{Cs}^{+} \mathrm{CO}_{2}$, or $\mathrm{Cs}^{+} \mathrm{SO}_{2}{ }^{-}$, all of which are believed to be bidentate. However, in the case of $\mathrm{Cs}^{+} \mathrm{ClO}_{2}{ }^{-}$ or $\mathrm{Ba}^{+} \mathrm{ClO}_{2}{ }^{-}$, a monodentate $\mathrm{C}_{2 \mathrm{v}}$ structure should be substantially more favorable than in the case of $\mathrm{NO}_{2}$ or $\mathrm{CO}_{2}$. This is due to the stronger interaction between the metal cation 
and the central atom in $\mathrm{ClO}_{2}$ than in $\mathrm{NO}_{2}$ or $\mathrm{SO}_{2}$, because of the greater electronegativity of the $\mathrm{Cl}$ atom.

It is interesting to note that the most exoergic reaction channel, $\mathrm{Ba}+\mathrm{ClO}_{2} \rightarrow$ $\mathrm{BaO}_{2}+\mathrm{Cl}$ is not observed. Based on Fig. 14, formation of $\mathrm{Cl}+\mathrm{O}_{2}$ from decay of $\mathrm{ClO}_{2}$ is nearly thermoneutral, whereas formation of $\mathrm{Cl}^{-}+\mathrm{O}_{2}$ is highly exoergic. Of course, this is due to the much greater electron affinity of $\mathrm{Cl}$. Although both concerted channels will have substantial potential energy barriers, based on the simple energetics of the anions we would expect that formation of $\mathrm{BaCl}$ will be more energetically favorable than $\mathrm{BaO}_{2}$. It should also be noted that the ground state of $\mathrm{BaO}_{2}$ correlates to a doubly ionic (excited state) of $\mathrm{BaClO}_{2}$, whereas the $\mathrm{BaCl}$ molecule is only singly ionic. Consequently, formation of $\mathrm{BaCl}$ from concerted cecomposition of a monodentate complex is expected to involve substantially less electronic rearrangement than a hypothetical $\mathrm{BaO}_{2}$ product from a bidentate intermediate. Also, formation of $\mathrm{BaCl}$ or $\mathrm{BaO}_{2}$ necessitates considerable deformation of the $\mathrm{BaClO}_{2}$, likely requiring large amplitude symmetric bending of $\mathrm{ClO}_{2}$. As mentioned previously, electronic excitation into the $2 b_{1}$ orbital will lead to "scissoring", i.e. excitation of the reaction coordinate. Although this is very favorable in the $\mathrm{Ba}-\mathrm{Cl}$ bonded inlermediate, in a bidentate $\mathrm{BaClO}_{2}$ molecule, it is likely that such motion will be "damped" considerably by the presence of the $\mathrm{Ba}^{+}$. In light of these considerations, we are not surprised by the absence of the $\mathrm{BaO}_{2}$ channel in the $\mathrm{Ba}+\mathrm{ClO}_{2}$ reaction.

There has been extensive discussion in the literature ${ }^{44,55.59}$ regarding photochemical 
isomerization of the symmetric $\mathrm{ClO}_{2}$ molecule (i.e. $\mathrm{OClO}$ ) to $\mathrm{Cl}-\mathrm{OO}$. Electronic excitation of $\mathrm{ClO}_{2}$ corresponds to excitation of an electron into the $2 \mathrm{~b}_{1}$ orbital; the same orbital populated by long range electron transfer from $\mathrm{Ba}$ in the $\mathrm{Ba}+\mathrm{ClO}_{2}$ reaction. Thus, it might be argued that the gas phase $\mathrm{Ba}+\mathrm{ClO}_{2}$ reaction could involve a mechanism involving isomerization of the $\mathrm{ClO}_{2}{ }^{-}$in $\mathrm{BaClO}_{2}$ to the peroxy form, followed by simple bond rupture resulting in $\mathrm{BaCl}+\mathrm{O}_{2}$. However, this mechanism would not be consistent with the measured $\mathrm{BaCl}$ translational energy distribution. The $\mathrm{P}(\mathrm{E})$ clearly peaks well away from zero, as expected for a reaction having a substantial potential energy barrier in the exit channel. An isomerization mechanism followed by simple bond rupture forming $\mathrm{BaCl}$ should not have an appreciable exit potential energy barrier, and should result in a $P(E)$ peaking near zero energy. Indeed, as will be pointed out in Chapter 5, the hypothesized gas phase isomerization mechanism is in fact not correct for an isolated electronically excited $\mathrm{ClO}_{2}$ molecule.

\section{B. $\mathrm{Ba}+\mathrm{O}_{3} \rightarrow \mathrm{BaO}+\mathrm{O}_{2}$}

As was the case for simple bond rupture of nitrite $\left(\mathrm{NO}_{2}{ }^{-}\right)$and chlorite $\left(\mathrm{ClO}_{2}{ }^{-}\right)$, dissociation of the ozonide ion $\left(\mathrm{O}_{3}{ }^{-}\right)$to $\mathrm{O}^{-}+\mathrm{O}_{2}$ is more endoergic than is formation of $\mathrm{O}+\mathrm{O}_{2}$ from the neutral molecule. However, it is important to note an important feature of the energetics that is unique to $\mathrm{O}_{3}$. We postulate that this one feature of ozonide has a substantial effect on the reaction dynarnics. Whereas $\mathrm{O}$ production from dissociative electron attachment to $\mathrm{NO}_{2}$ and $\mathrm{ClO}_{2}$ is endoergic, the process $\mathrm{O}_{3}+\mathrm{e} \rightarrow \mathrm{O}_{2}$ $+O^{\circ}$ is appreciably exoergic ${ }^{14,60,61}$ (Fig. 14). This is reminiscent of the behavior seen 
in the halogens. ${ }^{62}$ Indeed, in low energy attachment experiments, both $\mathrm{O}_{3}{ }^{60}$ and $\mathrm{Br}_{2}{ }^{62}$ possess finite cross sections for dissociation even at zero electron kinetic energy. This suggests that the $\mathrm{Ba}+\mathrm{O}_{3}$ reaction might show features which are more analogous to the alkali + halogen system which has been interpreted using the spectator stripping mechanism. ${ }^{63,64}$ In spectator stripping, long-range electron attachment leads to immediate dissociation of the anion with forward scattering of the metal containing molecule. This hypothesis appears to be supported by the angular and velocity distributions that we have obtained for the $\mathrm{BaO}$ product.

In the spectator stripping limit, the atom (X) not involved in formation of the chemical bond in the reaction $M+X_{2} \rightarrow M^{+} X^{-}+X$ is assumed to remain unperturbed throughout the encounter. The magnitude and direction of its final velocity vector is identical to that of the incident $\mathrm{X}_{2}$ molecule. It might appear inappropriate to extend such a simple mechanism to a reaction of a triatomic molecule, since the molecular fragment $\left(\mathrm{O}_{2}\right)$ possesses vibrational and rotational degrees of freedom. However, this limiting case is likely to be approached for a substantial fraction of all reaction trajectories in the present reaction for several reasons: The ozone molecule and ozonide anion are extremely weakly bound; dissociation of the anion is likely to be facile in the field of $\mathrm{Ba}^{+}$. Even more importantly, the resulting molecular fragment $\left(\mathrm{O}_{2}\right)$ is sirongly bound, but has a bondlength only $0.07 \AA^{65}$ shorter than that of the neutral ozone molecule.

The calculated $\mathrm{BaO}-\mathrm{O}_{2}$ recoil velocity based on the spectator stripping model leads to a mean product translational energy of $10 \mathrm{kcal} / \mathrm{mole}$, and the spectator stripping 
laboratory angle for the $\mathrm{BaO}$ product is 15 degrees. The small release of translational energy with large internal excitation of the product molecules, and forward peaking angular distribution, is consistent with a substantial contribution from a spectator stripping mechanism.

Formation of electronically excited $\mathrm{BaO}$ will most likely result from long-range electron transfer followed by immediate formation of $\mathrm{Ba}^{+} \mathrm{O}^{-}+\mathrm{O}_{2}$. The singly ionic structure of $\mathrm{BaO}$ is electronically excited. ${ }^{10}$ Although the angular distribution of the chemiluminescence has not been measured precisely, it was relatively easy for us to observe this emission by eye after turning off the lights and becoming accustomed to the dark. A long $(\sim 30 \mathrm{~cm})$ chemiluminescent streak could be observed inside our apparatus; apparently this resulted from emission by the relatively long-lived $\mathrm{BaO}\left(\mathrm{A}^{\prime}\right)$ state. ${ }^{10} \mathrm{~A}$ particularly interesting feature of the chemiluminescence is that it appeared to be very nearly confined to the Ba beam axis. This indicates that it came from a direct mechanism with forward scattering of the electronically excited $\mathrm{BaO}$ molecule with low recoil energy. This appears to be consistent with the spectator stripping mechanism leading to electronically excited products.

Despite the fact that formation of ground state products is $\sim 50 \mathrm{kcal} / \mathrm{mole}$ more exoergic than the $\mathrm{Ba}+\mathrm{NO}_{2}$ reaction, we observe smaller release of translational energy in the present reaction, indicating that the products are highly internally excited. Since the single collision yield of electronically excited $\mathrm{BaO}$ is known to not exceed $20 \%{ }^{6}$, it is certain that a large fraction of products are $\mathrm{O}_{2}\left({ }^{1} \Delta\right)$ or $\mathrm{O}_{2}\left({ }^{1} \Sigma\right)$. Indeed, formation of ground state $\mathrm{BaO}\left({ }^{1} \Sigma\right)$ from the singlet reactants requires formation of electronically 
excited singlet $\mathrm{O}_{2}$ to conserve spin. The requirement of spin conservation in the context of barium atom reactions has received considerable attention in the past. $\mathrm{Zare}^{66}$ and Herm ${ }^{67}$ have both studied the reaction

$$
\left.\mathrm{Ba}\left({ }^{1} \mathrm{~S}\right)+\mathrm{SO}_{2}\left({ }^{\mathrm{A}} \mathrm{A}_{1}\right) \rightarrow \mathrm{BaO}\left({ }^{1} \Sigma^{+}\right)+\mathrm{SO}^{3} \Sigma^{3}\right)
$$

At low collision energies, the only thermodynamically possible reaction is spin forbidden since the spin allowed process:

$$
\left.\mathrm{Ba}\left({ }^{1} \mathrm{~S}\right)+\mathrm{SO}_{2}\left({ }^{1} \mathrm{~A}_{1}\right) \rightarrow \mathrm{BaO}\left({ }^{1} \Sigma^{+}\right)+\mathrm{SO}^{\mathrm{d}} \Delta\right)
$$

is endoergic by $14.1 \mathrm{kcal} / \mathrm{mole}$. However, strong $\mathrm{BaO}$ signal was observed and resulted from decay of long-lived $\mathrm{Ba}^{+} \mathrm{SO}_{2}^{-}$collision complexes. The existence of collision complexes in that reaction was not surprising in view of the small reaction exoergicity, and earlier indications ${ }^{68}$ that long-lived $\mathrm{Cs}^{+} \mathrm{SO}_{2} \cdot$ complexes were involved in nonreactive scattering of $\mathrm{Cs}+\mathrm{SO}_{2}$. The very large cross section for the spin forbidden process

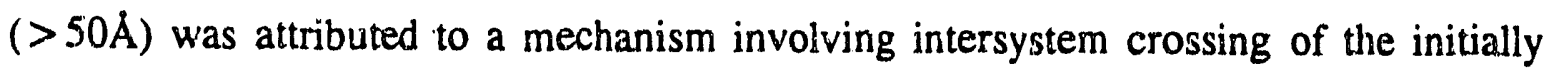
formed singlet intermediate: 66,67

$$
\mathrm{Ba}\left({ }^{1} \mathrm{~S}\right)+\mathrm{SO}_{2}\left({ }^{1} \mathrm{~A}_{1}\right) \rightarrow{ }^{1}\left(\mathrm{Ba}^{+} \mathrm{SO}_{2}{ }^{-}\right) \rightarrow{ }^{3}\left(\mathrm{Ba}^{+} \mathrm{SO}_{2}{ }^{-}\right) \rightarrow \mathrm{BaO}\left(\mathrm{X}^{1} \Sigma^{+}\right)+\mathrm{SO}\left({ }^{3} \Sigma\right)
$$

Enhanced spin-orbit coupling due to the presence of the heavy Ba and S atoms apparently 
leads to an appreciable rate of intersystem crossing in this system. Since the lifetime of the intermediate complex is greater than several picoseconds, with the only alternative process being decay back to reactants, the probability for the spin forbidden process in collision complexes can be large. A similar behavior in the analogous ozone reaction, with formation of spin forbidden ground state $\mathrm{BaO}\left({ }^{1} \Sigma^{+}\right)+\mathrm{O}_{2}\left({ }^{3} \Sigma^{-}\right)$, also appears feasible due to the effect of the heavy $\mathrm{Ba}$ atom. However, in the present case, our product angular distributions indicate that the dominant reaction mechanism involves a direct process, with forward scattering dominating at all collision energies. This implies that most products are formed on a much shorter average timescale in this reaction. In reactions of light atoms, a short lifetime would suppress spin forbidden processes. For an atom such as $\mathrm{Ba}$, however, this is probably not a major consideration. It is worth noting, however, that based on the low average translational energy we observe in the $\mathrm{BaO}$ products, a large fraction of the product $\mathrm{O}_{2}$ molecules must be electronically excited. Since the dominant $\mathrm{BaO}$ is $\mathrm{X}^{1} \Sigma^{+}$, a large fraction of the $\mathrm{BaO}+\mathrm{O}_{2}$ products do result from reactions which conserve spin.

We have already mentioned that the backscattered $\mathrm{BaO}$ molecules could result from direct abstraction of the central oxygen atom with formation of $\mathrm{O}_{2}$ from the outer oxygen atoms in ozone. Unfortunately, we see no unique features in our data that can be associated with this process. Based on our observations for $\mathrm{Ba}+\mathrm{ClO}_{2} \rightarrow \mathrm{BaCl}+\mathrm{O}_{2}$, even if such an abstraction were to occur in the $\mathrm{Ba}+\mathrm{O}_{3}$ reaction, it would likely lead to a forward-backward symmetric angular distribution. Although we do find that the $\mathrm{BaCl}$ product from the concerted channel peaks well away from zero energy, the maximum 
energy remains very low. Clearly, most of the energy is channeled into internal excitation of the products. If central atom abstraction were to occur in the $\mathrm{Ba}+\mathrm{O}_{3}$ reaction, the product is likely to be hidden under the $\mathrm{BaO}$ from reaction of the outer oxygen atoms resulting from decay of $\mathrm{Ba}^{+} \mathrm{O}_{3}{ }^{-}$intermediates.

\section{C. $\mathrm{Ba}+\mathrm{O}_{3} \rightarrow \mathrm{BaO}_{2}+\mathrm{O}$}

One of the most intriguing observations in the rather extensive history of $\mathrm{Ba}$ oxidation studies ${ }^{26-30}$ was that $\mathrm{BaO}\left(\mathrm{A}^{1} \Sigma^{+} \rightarrow \mathrm{X}^{1} \Sigma^{+}\right)$emission above $17588 \mathrm{~cm}^{-1}$ can be seen from the $\mathrm{Ba}+\mathrm{O}_{2}$ reaction despite a reaction exoergicity for $\mathrm{Ba}+\mathrm{O}_{2} \rightarrow \mathrm{BaO}+\mathrm{O}$ of only $4547 \mathrm{~cm}^{-1}$. Beginning with the earliest experiments, there was considerable discussion and speculation regarding a likely multi-step mechanism consistent with sufficient energy pooling to permit a high pressure chemiluminescence yield approaching $10 \%{ }^{26-30}$ Although the common denominator in all mechanisms has been the participation of $\mathrm{BaO}_{2}$, this species has proven to be particularly elusive to direct observation. The clearest evidence for its transient existence was obtained by Herm and coworkers in the forwardbackward symmetric $\mathrm{BaO}$ angular distribution observed in crossed beams studies of the $\mathrm{Ba}+\mathrm{O}_{2}$ reaction. ${ }^{28}$ Their work indicated that the lifetime of the $\mathrm{BaO}_{2}$ intermediate exceeded several rotational periods (several psecs).

Edelstein and coworkers ${ }^{30 n}$ found a series of bands in diffusion flame experiments that they attributed to emission from electronically excited $\mathrm{BaO}_{2}$ produced in three-body recombination reactions. These so called "Y-bands" appeared near 700nm. Although more recent experiments by Reuther and $\mathrm{Palmer}{ }^{296}$ provided additional support for their 
hypothesis, the actual nature of the transitions leading to the emission remains unknown, and no thermodynamic or structural information exists on gas phase $\mathrm{BaO}_{2}$ to date. Although the existence of long-lived $\mathrm{BaO}_{2}$ collision complexes even at collision energies of $40 \mathrm{kcal} / \mathrm{mole}$ suggests that $\mathrm{D}_{0}\left(\mathrm{Ba}-\mathrm{O}_{2}\right)$ is likely to be substantial, Herschbach ${ }^{270}$ has suggested that a long intermediate lifetime might be attributable to hopping between singlet and triplet surfaces rather than from thermodynamic stability alone. Other comments that $\mathrm{D}_{0}\left(\mathrm{Ba}-\mathrm{O}_{2}\right)$ is likely to be substantial are scattered throughout the literature, ${ }^{26-30}$ but a definitive measurement does not exist.

The $\mathrm{Ba}-\mathrm{O}_{2}$ bond dissociation energy was obtained from the maximum translational energy release in the reaction $\mathrm{Ba}+\mathrm{O}_{3} \rightarrow \mathrm{BaO}_{2}+\mathrm{O}$. Using the same arguments presented in the determination of $\mathrm{D}_{0}(\mathrm{Ba}-\mathrm{NO})$ in the chapter 1 , the following relation may be derived:

$D_{0}\left(B a-O_{2}\right) \geq E_{\text {rans max }, \text { Bro } 02 / 0}+D_{0}\left(O-O_{2}\right)-E_{\text {coll }}-E_{\text {int }, 03}$

Based on the results of the lowest collision energy experiment: $E_{\text {tran max, BaO2/o }}=110$ $\mathrm{kcal} / \mathrm{mole}, \mathrm{E}_{\text {coll }}=16 \mathrm{kcal} / \mathrm{mole}$ and $\mathrm{E}_{\text {int, } 03}=1 \mathrm{kcal} / \mathrm{mole}$ we obtain $\mathrm{D}_{\mathrm{o}}\left(\mathrm{Ba}-\mathrm{O}_{2}\right) \geq$ $120 \mathrm{kcal} / \mathrm{mole}$. Since both reactants are singlets, spin conservation requires formation of triplet $\mathrm{BaO}_{2}$ if the $\mathrm{O}$ atom is in the ground state $\left({ }^{3} \mathrm{P}\right)$. Although we will argue that the ground state of $\mathrm{BaO}_{2}$ is a singlet, by analogy with the $\mathrm{Ba}+\mathrm{SO}_{2}$ reaction, the involvement of long-lived complexes in formation of $\mathrm{BaO}_{2}$ is expected to lead to relaxation of the requirement of spin conservation. Thus at least some $\mathrm{BaO}_{2}+\mathrm{O}$ 
products will be formed in their ground electronic states and equation 14 will an equality to within the expected error limits of $\pm 20 \mathrm{kcal} / \mathrm{mole}$.

Although there are no experimental or theoretical values available for alkaline earth-dioxygen bond strengths, considerable insight into the nature of the interaction can be obtained by comparison with the analogous quantity for the alkali superoxides which are at most singly ionic due to those metals' monovalent nature:

$\begin{array}{lc}\text { Molecule } & \underline{\mathrm{D}}_{\mathrm{a}}\left(\mathrm{M}-\mathrm{O}_{2}\right) \mathrm{kcal} / \mathrm{mole}^{70-72} \\ \mathrm{Li}-\mathrm{O}_{2} & 52 \pm 5 \\ \mathrm{Na}-\mathrm{O}_{2} & 39 \pm 5 \\ \mathrm{~K}-\mathrm{O}_{2} & 41.5 \pm 5 \\ \mathrm{Rb}-\mathrm{O}_{2} & 43 \pm 5 \\ \mathrm{Cs}_{2}-\mathrm{O}_{2} & 44.5 \pm 5\end{array}$

These values are in very good agreement with bond strengths predicted based on a simple Hess cycle ${ }^{72}$ for singly ionic molecules:

$$
\mathrm{D}_{\mathrm{o}}\left(\mathrm{M}-\mathrm{O}_{2}\right)=\mathrm{D}_{\mathrm{o}}(\mathrm{MO}-\mathrm{O})+\mathrm{D}_{\mathrm{o}}(\mathrm{MO})-\mathrm{D}_{\mathrm{o}}\left(\mathrm{O}_{2}\right)
$$

Since the oxygen-oxygen vibrational frequency in the alkali superoxides is nearly identical to that of the free superoxide ion, it is customary ${ }^{72}$ in these calculations to take $D_{0}(M O-O) \approx D_{0}\left(O-O^{-}\right)=4.09 \mathrm{eV}$. Since $D_{0}\left(O_{2}\right)=5.114 \mathrm{eV}$, the dissociation of the 
singly ionic metal superoxide is related to that of the monoxide by:

$$
\mathrm{D}_{\mathrm{o}}\left(\mathrm{M}-\mathrm{O}_{2}\right)=\mathrm{D}_{\mathrm{o}}(\mathrm{MO})-1.02 \mathrm{eV}
$$

If $\mathrm{BaO}_{2}$ is a superoxide (singly ionic), we expect that its bond dissociation energy would be well approximated by the above relationships. Failure to observe good agreement with a value based on a singly ionic structure could be taken as evidence for substantial doubly ionic character. The ground state $\mathrm{BaO}\left(\mathrm{X}^{1} \Sigma^{+}\right)$molecule $\left(\mathrm{D}_{0}=5.77 \mathrm{eV}\right)$ is best described as $\mathrm{Ba}^{2+} \mathrm{O}^{2-}(\operatorname{Ref} 10)$, whereas the first excited state $\mathrm{A}\left({ }^{1} \Pi\right)$ at $2.17 \mathrm{eV}^{73,74}$ is well represented as $\mathrm{Ba}^{+} \mathrm{O} \cdot .^{10,74}$ Indeed, Langhoff and Bauschlicher ${ }^{74}$ have pointed out that $D_{0}\left(M O^{\circ}\right)-D_{0}(M F)$ for the excited state $A\left({ }^{1} I I\right)$ alkaline earth oxides and the ground state alkaline earth fluorides is nearly constant at $2.4 \mathrm{eV}$. This is good support of a singly ionic interaction for both species. Thus, for singly ionic $\mathrm{BaO}, \mathrm{D}_{\mathrm{o}}(\mathrm{Ba}-\mathrm{O})=5.77-2.17=$ $3.6 \mathrm{eV}$. Assuming a superoxide structure, we should expect that $\mathrm{D}_{\mathrm{o}}\left(\mathrm{Ba}-\mathrm{O}_{2}\right)$ should lie 1.02 less than this, at about $2.6 \mathrm{eV}(60 \mathrm{kcal} / \mathrm{mole})$.

The experimental $\mathrm{Ba}-\mathrm{O}_{2}$ binding energy obtained from this experiment is twice that predicted assuming a superoxide structure. This is good evidence that the $\mathrm{BaO}_{2}$ resulting from the $\mathrm{Ba}+\mathrm{O}_{3}$ reaction does have substantial peroxide-like character. It is interesting to note that $\mathrm{D}_{\mathrm{o}}(\mathrm{Ba}-\mathrm{NO})=65 \mathrm{kcal} /$ mole $($ Chapter 1$)$ is very close to the value calculated for singly ionic $\mathrm{BaO}_{2}$. This is not surprising since all available evidence indicates that alkaline earth nitroxides are well represented as $\mathrm{M}^{+} \mathrm{NO}$ (Chapter 1). By analogy with the alkaline earth monoxides, we expect electronic excitation of ground 
state barium peroxide to be largely charge-transfer in nature, with the excited state well represented by $\mathrm{Ba}^{+} \mathrm{O}_{2}^{-}$. The emission attributed to $\mathrm{BaO}_{2}$ by Edelstein ${ }^{304}$ and coworkers at $650 \mathrm{~nm}$ suggests the existence of two $\mathrm{BaO}_{2}$ electronic states separated by approximately $1.9 \mathrm{eV}$. This is somewhat less than the $2.6 \mathrm{eV}(60 \mathrm{kcal} / \mathrm{mole})$ gap we have calculated between our experimental bond energy for the peroxide and that estimated for the superoxide. However, this difference is perhaps not too surprising based on the crude approximations involved here. If we take $\mathrm{Ba}+\mathrm{O}_{3}$ to be at zero energy, it appears very reasonable that the ground state of $\mathrm{BaO}_{2}$, represented as $\mathrm{Ba}^{2+} \mathrm{O}_{2}^{2-}$ lies at approximately $120 \mathrm{kcal} / \mathrm{mole}$, and the excited charge transfer state $\left(\mathrm{Ba}^{+} \mathrm{O}_{2}{ }^{-}\right)$at an energy $1.9 \mathrm{eV}$ higher than this, near $-75 \mathrm{kcal} / \mathrm{mole}$.

Our finding that the ground state of gaseous $\mathrm{BaO}_{2}$ has substantial peroxide character is consistent with the known electronic structure of the solid ${ }^{31}$ but is somewhat contradictory to the results of matrix isolation experiments. The matrix conclusions ${ }^{23 n}$ were based on the observation of a $\mathrm{BaO}_{2}$ intraionic $\mathrm{O}-\mathrm{O}$ stretching frequency of $1120 \mathrm{~cm}^{-1}$, as expected for a superoxide molecule. It appears that the discrepancy may be reconciled in light of our work on the reaction dynamics of $\mathrm{Ba}$ with oxygen containing species. The singly ionic (electronically excited) species is likely to be metastable in the matrix due to the presence of a large potential energy barrier between singly and doubly ionic states. However, collisional processes should induce internal relaxation of at least some of the $\mathrm{BaO}_{2}$ molecules to the ground electronic state. Thus, at least some ground state $\mathrm{BaO}_{2}$ should have been observable. Unfortunately, no mention is made in the original papers as to the absence or presence of $\mathrm{BaO}_{2}$ absorptions in the peroxide 
stretching region. Presumably this is because a $\mathrm{BaO}_{2}$ molecule possessing a $1120 \mathrm{~cm}^{-1}$ frequency had been identified, and appeared quite analogous to earlier observations of other molecules such as $\mathrm{Cs}^{+} \mathrm{O}_{2}^{-}$. Apparently, the possibility for other $\mathrm{BaO}_{2}$ frequencies was not considered. However, one IR absorption in the peroxide stretching region at $752 \mathrm{~cm}^{-1}$ remained unassigned and in principal might be consistent with $\mathrm{Ba}^{2+} \mathrm{O}_{2}{ }^{2}$. The difference between this value and that in solid $\mathrm{BaO}_{2}$ is perhaps not unreasonable due to the effects of their different environments. The $752 \mathrm{~cm}^{-1}$ absorption was postulated to be due to a hypothetical $\mathrm{Ba}_{2}{ }^{2+} \mathrm{O}_{2}{ }^{2-}$ species with a $\mathrm{C}_{2 \mathrm{v}}$ nonplanar structure. However, in view of the known strength of the $\mathrm{BaO}$ bond, electronic rearrangement with formation of two $\mathrm{BaO}$ molecules (even electronically excited) or a $(\mathrm{BaO})_{2}$ dimer structure (having a $\mathrm{BaO}-\mathrm{BaO}$ binding energy of $\sim 80 \mathrm{kcal} / \mathrm{mole}^{22,23}$ ) should be highly exoergic. Unless some extremely large potential barrier existed for decomposition of $\mathrm{Ba}_{2}{ }^{2+} \mathrm{O}_{2}{ }^{2-}$, its existence seems unlikely. It is also interesting to note that concentration dependence studies described in the original work actually supported a $1: 1 \mathrm{Ba}: \mathrm{O}_{2}$ stoichiometry for the unassigned line, again consistent with $\mathrm{Ba}^{2+} \mathrm{O}_{2}{ }^{2-}$ rather than $\mathrm{Ba}_{2}{ }^{2+} \mathrm{O}_{2}{ }^{2-}$.

An alternative explanation for the failure to observe $\mathrm{Ba}^{2+} \mathrm{O}_{2}{ }^{2-}$ in the matrix is that its infrared absorption is very weak. This is quite likely in view of the small change in dipole moment expected for $\mathrm{O}-\mathrm{O}$ stretching in a triangular $\mathrm{BaO}_{2}$ molecule. Raman spectroscopy was used in the study $y^{31}$ of solid $\mathrm{BaO}_{2}$, and might also be a sensitive probe in the matrix.

Gas phase and matrix environments can lead to vastly different chemistry in the same systems. Indeed, one of the powers of the matrix isolation technique is the ability 
to observe weakly bound molecules, which in the matrix remain trapped in local potential energy minima. In the gas phase, most thermodynamically unstable species undergo unimolecular decomposition or reaction within several rotational periods or less. The gas phase $\mathrm{Ba}+\mathrm{O}_{2}$ reaction is initiated by formation of the singly ionic $\mathrm{Ba}^{+} \mathrm{O}_{2}^{-}$intermediate. Under collision free conditions, it must decay within several picoseconds, either back to reactants or to the only thermodynamically accessible products, $\mathrm{BaO}\left({ }^{1} \Sigma\right)+\mathrm{O}\left({ }^{3} \mathrm{P}\right)$. Radiative processes are far to slow to stabilize the intermediate. However, in the matrix, some of the $\mathrm{Ba}^{+} \mathrm{O}_{2}^{-}$species can become stabilized as their vibrational energy is transferred to the host matrix molecules which have an effective temperature of only a few Kelvin. Subsequently, there will be insufficient energy available for decay back to $\mathrm{Ba}+\mathrm{O}_{2}$ or to the more thermodynamically stable $\mathrm{Ba}^{2+} \mathrm{O}_{2}{ }^{2}$. In the matrix reaction, the product of the initial "harpooning step" may become trapped, and can be observed in the infrared spectrum.

Many of the other observations made over the last 20 years related to $\mathrm{BaO}_{2}$ can be rationa'ized in terms of a substantial potential energy barrier between superoxide and peroxide electronic structures. However, in the gas phase $\mathrm{Ba}+\mathrm{O}_{2}$ reaction, the situation is even more complex. The reaction is known to result from harpooning, with formation of a long-lived complex. However, because the $\mathrm{Ba}\left({ }^{1} S\right)+\mathrm{O}_{2}\left({ }^{3} \Sigma\right)$ reactants approach on a triplet surface; the initially formed complex is expected to be a singly ionic triplet molecule. ${ }^{27 c}$ This reaction is known to involve a complex even at collision energies approaching $50 \mathrm{kcal} / \mathrm{mole}$. Some authors have taken this to indicate the existence of a very strong $\mathrm{BaO}_{2}$ intermediate, which is confirmed in the present work. However, 
the strongly bound intermediate is a peroxide. Based on the molecular orbitals of $\mathrm{O}_{2}$, the strongly bound barium peroxide molecule will be a singlet. Thus, the long lifetime in the $\mathrm{Ba}+\mathrm{O}_{2}$ reaction does not derive from the thermodynamic stability of the initially formed $\mathrm{Ba}^{+} \mathrm{O}_{2}{ }^{-}$intermediate, since its bond energy does not greatly exceed $75 \mathrm{kcal} / \mathrm{mole}$. The potential energy barriers that lie along the reaction path will play an important role. The reaction path involves hopping from the singly ionic triplet surface to the strongly bound doubly ionic surface. This facilitates the electronic rearrangement necessary for formation of the doubly ionic ground state $\mathrm{BaO}\left({ }^{1} \Sigma\right)$, the only thermodynamically accessible product. However, thermodynamics also dictates formation of $\mathrm{O}\left({ }^{3} \mathrm{P}\right)$. Thus, a final hop back to the triplet surface will be required for exit. Although the ground state of $\mathrm{BaO}_{2}$ does represent a very deep minima, it is not accessed in the initial harpooning step but is ultimately accessed in the reaction, since no other channels (other than decay back to reactants) exist. We conclude that the long reaction timescale in the $\mathrm{Ba}+\mathrm{O}_{2}$ reaction results from both facturs-- multiple surface hopping and a strong $\mathrm{BaO}_{2}$ intermediate.

\section{CONCLUSIONS:}

We have found that although the gas phase chemistry of $\mathrm{Ba}+\mathrm{O}_{3}$ and $\mathrm{Ba}+\mathrm{ClO}_{2}$ is highly complex, most of our observations can be rationalized in terms of rather fundamental principles. These principles derive from the chemistry and thermochemistry of the anions, and from the same molecular orbital concepts which have proven so useful in understanding general trends in triatomic molecules. As we saw in the $\mathrm{NO}_{2}$ reaction, 
the initial features in reactions involving divalent $\mathrm{Ba}$ are similar to those of monovalent species. However, the participation of the second valence electron does lead to additional features in the reaction dynamics when doubly ionic products are formed. Since this divalent character, which leads to the large reaction excergicities is not seen in the initially formed singly ionic intermediate, the reaction dynamics are often controlled by the dynamics of the unimolecular decomposition of a long lived complex. The participation of reaction complexes in general leads to product angular distributions exhibiting forward-backward symmetry, which unfortunately reduces the potential insight into favorable reaction geometries, often afforded in direct reactions. However, the present technique is uniquely powerful in many respects. Not only can we identify all hemical products without the handicap of having to know their spectral, but we can gain insight into the dominant features of the potential energy surface which will control the breakup of singly ionic species into their more stable divalent products. 


\section{REFERENCES:}

1. H.F. Davis, A.G. Suits, H. Hou and Y.T. Lee, Ber. Bunsenges. Phys. Chem., 94, 1193 (1990).

2. H. F. Davis, A. G. Suits, and Y. T. Lee, J. Chem. Phys., in press.

3. A.D. Walsh, J. Chem. Soc., 2260 (1953), and following papers.

4. R.J. Buenker and S.D. Peyerimhoff, Chem. Rev. 74(2), 127 (1974).

5. A. Schultz and R.N. Zare, J. Chem. Phys., 60(12), 5120 (1974).

6. J.W. Cox, P.J. Dagdigian, J. Chem. Phys., 79(11), 5351 (1983).

7. J.J. Reuther and H.B. Palmer, J. Chem. Phys., $77(1) .83$ (1982).

8. D.J. Eckstrom, S.A. Edelstein, D.L. Huestis, B.E. Perry, and S.W. Benson, J. Chern. Phys., 63(9), 3828 (1975).

9. a) F. Engelke, R.K. Sander, and R.N. Zare. J. Chem. Phys., 65(3), 1146 (1976).

b) G.J. Dieboid, F. Engelke, H.U. Lee, J.C. Whitehead, and R.N. Zare, Chem. Phys.,30, 265 (1977).

10. J.G. Pruett and R.N. Zare, J. Chem. Phys., 62, 2050 (1975).

11. K.M. Ervin, J. Ho, and W.C. Lineberger, J. Phys. Chem., 92(19), 5405 (1988).

12. a) S. E. Novick, P.C. Engelking, P.L. Jones, J.H. Futrell, and W.C. Lineberger, J. Chem. Phys., 70(6), 2652 (1978).

b) L.J. Wang, S.B. Boo, and E.M. Helmy, Phys. Rev. A., 35 (2), 759 (1987).

c) T. Tanka and Y. Morina, J. Mol. Spectr. 33, 552 (1970).

13. L.M. Babcock, T. Pentecost, and W.H. Koppenol, J. Phys. Chem. 93(25), 8126 
(1989).

14. JANAF Thermochemical Tables, 3rd. ed., J. Phys. Chem. Ref. Data., 14(1985), Supplement No 1. (b) 12, 982, (1983).

15. We used the currently accepted value for $\mathrm{D}_{0}\left(\mathrm{O}-\mathrm{O}_{2}\right)=1.05 \mathrm{eV}$ from Ref. 14 in our calculations. Surprisingly, according to Ref. 18(a,b), use of this value leads to inconsistencies in thermodynamic cycles involving $\mathrm{O}_{3}{ }^{-}, \mathrm{O}_{3}$, and $\mathrm{O}_{3}{ }^{+}$. Although they suggested that this can be reconciled using $\mathrm{D}_{0}\left(\mathrm{O}-\mathrm{O}_{2}\right) \leq 0.797 \mathrm{eV}$, we have employed the larger value.

16. All of the $\mathrm{BaXO}_{2}$ molecules $(\mathrm{X}=\mathrm{N}, \mathrm{Cl}, \mathrm{O})$ are expected to be singly ionic. Doubly ionic structures likely correspond to insertion intermediates (OBaXO) which are likely to be unstable with respect to doubly ionic $\mathrm{Ba}^{2+} \mathrm{O}^{2-}+\mathrm{XO}$.

17. a) R. Atkinson, W.P.L. Carter, Chem. Rev., 84, 437 (1984).

b) J. Banichevich, S.D. Peyerimhoff, F. Grein, Chem. Phys. Lett., 173(1), 1 (1990).

18. a) I.F. Hiller, and M.L. Vestal, J. Chem. Phys., 74(11) 6096 (1981).

b) C. Lifshitz, R.L.C. Wu, T.O. Tiernan, and D.T. Terwilliger, J. Chem. Phys., 68(1) 247, (1978).

c) R.L.C. Wu, T.O. Tieman, C. Lifshitz, Chem. Phys. Lett, , 51(2), 211 (1977).

d) P.C. Cosby, J.T. Moseley, J.R. Peterson, J.H. Ling, J. Chem. Phys., 69(6), 2771 (1978).

e) I. Dotan, J.A. Davidson, G.E. Streit, D.L. Albritton, F.C. Fehsenfeld, J. Chem. Phys., 67(6), 2874 (1977). 
f) D.L. Albritton, I. Dotan, G.E. Streit, D.W. Fahey, F.C. Fehsenfeld, E.E. Ferguson, J. Chem. Phys., 70(11), 6614 (1983).

19. a) D. van den Ende, S. Stolte, J.B. Cross, G.H. Kwei, J.J. Valentini, J. Chem. Phys., 77(4) 2206 (1982).

b) J.L. Gole, and R.N. Zare, J. Chem. Phys., 57(12), 5331 (1972).

20. J.W. Birks, B. Shoemaker, T.J. Leck, R.A. Borders, L.J. Hart, J. Chem. Phys., 66(10), 4591 (1977).

21. B.L. Henke, R.C.C. Perera, D.S. Urch, J. Chem. Phys., 68(8), 3692 (1978).

22. a) D.M. Thomas and L. Andrews, J. Mol. Spect., 50, 220 (1974).

b) B.S. Ault and L. Andrews, J. Chem. Phys., 62(6), 2320 (1975).

c) B.S. Ault, and L. Andrews, J. Mol. Spect., 65, 437 (1977).

23. B.S. Ault, and L. Andrews, J. Chem. Phys., 62(6), 2312 (1975).

24. a) S. Abramowitz and N. Acquista, J. Res. Nat. Bur. Stand, 75A(1), 23, (1971).

b) S.R. Long, Y-P. Lee, O.D. Krogh, and G.C. Pimentel, J. Chem. Phys., 77(1), 226 (1982).

c) J.B. Bates, M.H. Brooker, G.E. Boyd, Chem. Phys. Lett., 16(2) 391 (1972).

d) M.E. Jacox and D.E. Milligan, J. Mol. Spect. 43, 148 (1972).

e) G. Steffen, W. Hesse, M. Jansen, D. Reinen, Inorg. Chem., 30(8) 1923 (1991).

25. a) L. Andrews, J. Chem. Phys., 63(10) 4464 (1975).

b) L. Andrews, J. Chem. Phys., 50(10) 4288 (1969).;

c) R.R. Smardzewski and L. Andrews, J. Phys. Chem. 77(6) 801 (1973).; 
d) L. Andrews, J. Am. Chem. Soc., 95(14) 4487 (1973).

e) L. Andrews and D.E. Tevault, J. Mol. Spect., 55, 452, (1975).

f) R. Spiker Jr. and L. Andrews, J. Chem. Phys., 59(4) 1851 (1973).

g) L. Andrews and R.C. Spiker, Jr., J. Chem. Phys., 59(4) 1863 (1973).

h) L. Andrews, and R. Smardzewski, J. Chem. Phys., 58(6) 2258 (1973).

26. a) K. Sakurai, S.E. Johnson, H.P. Broida, J. Chem. Phys., 52(4) 1625 (1970).

27. a) P.J. Dagdigian, H.W. Cruse, A. Schultz, and R.N. Zare, J. Chem. Phys., 61(11) 4450 (1974).

b) A. Schultz, H.W. Cruse, and R.N. Zare, J. Chein. Phys., 57(3), 1354 (1972).

c) H.J. Loesch and D.R. Herschbach, Faraday Disc. Chem. Soc., 55, 385 (1973).

28. T.P. Parr, A. Freedman, R. Behrens, Jr., and R.R. Herm, J. Chem. Phys., 72(9) 5163 (1980).

29. a) R.H. Obenauf, C.J. Hsu and H.B. Palmer, Chem. Phys. Lett., 17(3) 455 (1972).

b) J.J. Reuther and H.B. Palmer, Chem. Phys. Lett., 84(3) 523 (1981).

30. a) S.A. Edelstein, B.E. Perry., D.J. Eckstrom and T.F. Gallagher, Chem. Phys. Lett. 49(2) 293 (1977).

b) J.P. Visticot, C. Alcaraz, J. Berlande, J. Cuvellier, T. Gustavsson, J.M. Mestdagh, P. Meynadier, P. de Pugo, O. Sublemontier, J. Chem. Phys. 94(7), 4913 (1991).

c) C.F. Nien, J.M.C. Plane, J. Chem. Phys., 94(11), 7193 (1991).

31. a) H.H. Eyse. and S. Thym, Z. Anorg. Allg. Chemie, 411, 97 (1975). 
b) G.E. Walrafen, P.N. Krishnan, M. Hokmabadi, D.L. Griscom, R.G. Munro, J. Chem. Phys., 77(7) 3840 (1982).

32. a) H.F. Davis, A.w. Suits, Y.T. Lee, C. Alcaraz and J.M. Mestdagh, J. Chem. Phys., to be submitied.

b) A.G. Suits, H. Hou, H.F. Davis, and Y.T. Lee, J. Chem. Phys., in press.

33. CRC Handbook of Chemistry and Physics, Edited by R.C. Weast (CRC, Boca Raton, Florida, 1987).

34. Ozone Chemistry and Technology, Advances in Chemistry, Series 21, American Chemical Society (1959).

35. Ozone and its Reactions with Organic Compounds, S.D. Raxumouskii and G.E. Zaikov, Studies in Organic Chemistry, Vol. 15, Elsevier (1984).

36. G. M. Platz and C.K. Hersh, Ind. and Eng. Chem., 48(4), 742 (1956).

37. An Orec ozonizer was employed using standard in-house $\mathrm{O}_{2}$.

38. Photochemistry of Small Molecules, H. Okabe, J. Wiley and Sons, Inc. (1978).

39. M.W. Siegel, Int. J. Mass. Spec. Ion Phys., 44, 19 (1982).

40. R.I. Derby, W.S. Hutchinson, Inorg. Synth. 4, 152 (1953).

41. A. Wahner, G.S. Tyndall, A.R. Ravishankara, J. Phys. Chem. 91(11), 2734 (1987).

42. Note that solid $\mathrm{NaClO}_{2}$ should never be brought into contact with solid $\mathrm{P}_{2} \mathrm{O}_{\text {: }}$

43. E.T. McHale and G. von Elbe, J Phys. Chem. $72(6) 1849$ (1968).

44. J.L. Gole, J. Phy'. Chem. 84(11) 1333 (1980).

45. E.C. Richard, C. Tom Wickham-Jones and V. Vaida, J. Phys. Chem. 93(17) 
6346 (1989).

46. We expect $\mathrm{D}_{0}(\mathrm{Ba}-\mathrm{ClO}) \leq 65 \mathrm{kcal} / \mathrm{mole}$. Since $\mathrm{D}_{0}(\mathrm{Cl}-\mathrm{O})=60 \mathrm{kcal} / \mathrm{mole}$ and $\mathrm{D}_{0}(\mathrm{Ba}-$ $0)=133 \mathrm{kcal} / \mathrm{mole}$, we calculate that $\Delta \mathrm{H}=-8 \mathrm{kcal} / \mathrm{mole}$ for $\mathrm{BaClO} \rightarrow \mathrm{BaO}+\mathrm{Cl}$.

47. The calculation of ionization cross sections based on tabulated polarizabilities is discussed in detail in chapter 4.

48. The cross section for the three body radiative association process $\mathrm{Ba}+\mathrm{O}_{2} \rightarrow$ $\mathrm{BaO}_{2}+\mathrm{h} v$ is expected to be negligible at these collision energies under single collision conditions.

49. G.J. Green and J.L. Gole, Chem. Phys. Lett. 69(1), 45 (1980).

50. a) D. Wecker, A.A. Christodoulides and R.N. Schindler, Int. J. Mass. Spect. and Ion. Phys., 38, 391 (1981).

b) E.L Wagner, J. Chem. Phys., 37, 751 (1962).

51. R. Aboual, R. Paineau, and F. Fiquet-Fayard, J. Phys. B., B9, 303 (1976).

52. G. Herzberg, Electronic Spectra of Polyatomic Molecules, (Van Nostrand, Princeton, N.J., 1950)

53. R. Teghil, B. Janis and L. Bencivenni, Inorg. Chim. Acta, 88, 115 (1984).

54. D.E. Tevault, F.F. Chi, L. Andrews, T. Mol. Spect., 51, 450 (1974).

55. Richard, E.C.; Vaida,V. J. Chem. Phys., 1991, 94(1), 153, and Refs. therein.

56. Richard, E.C.; Vaida, V. J. Chem. Phys., 1991, 94(1), 163.

57. Ruhl, E.; Jefferson, A.; Vaida, V.; J. Phys. Chem., 1990, 94, 2990.

58. Vaida, V.; Solomon, S.; Richard, E.C.; Ruhl, E.; Jefferson, A. Nature, 1989, 342,405 . 
59. Bishenden, E.; Haddock, J.; Donaldson, D.J. J. Phys. Chem., 1991, 95, 2113.

60. R.K. Curran, J. Chem. Phys., 35(5), 1849 (1961).

61. D. Stelman, J.L. Moruzzi and A.V. Phelps, J. Chem. Phys., 56(8) 4183 (1972).

62. D.C. Frost and C.A. McDowell, Can. J. Chem. 38, 407 (1968).

63. R.R. Herm, in Alkali Halide Vapors, edited by P. Davidovits and D.L. McFadden (Academic, New York, 1979.)

64. a) S. Datz and R.E. Minturn, j. Chem. Phys., 41, 1153, (1964).

b) R.E. Minturn, S. Datz, R.L. Becker, J. Chem. Phys., 44(3), 1149, (1966).

c) K.R. Wilson, G.H. Kwei, J.A. Norris, R.R. Herm, J.H. Birely, and D.R. Herschbach, J. Chem. Phys., 41, 1154, (1964).

d) J. H. Birely, R.R. Herm, K.R. Wilson, D.R. Herschbach, J. Chem. Phys., 47(3),993, (1967).

65. K.P. Huber and G. Herzberg, Molecular Spectra and Molecular Structure IV. Constants of Diatomic Molecules, Van Nostrand Reinhold Co. (1979).

66. G.P. Smith and R.N. Zare, J. Am. Chem. Soc., 97(7) 1985 (1975).

67. A. Freedman, T.P. Parr, R. Behrens, Jr., and R.R. Herm, J. Chem. Phys., $70(11) 5251$ (1979).

68. a) D.O. Ham, J.L. Kinsey and F.S. Klein, Disc. Faraday. Soc. 44, 174 (1967).

b) D.O. Ham, J.L. Kinsey, J. Chem. Phys., 48(2), 939 (1968).

69. D.O. Ham and J.L. Kinsey, J. Chem. Phys., 53(1), 285 (1970).

70. A.J. Hynes, M. Steinberg and K. Schofield, J. Chem. Phys., 80(6) 2585 (1984).

71. M. Steinberg and K. Schofield, J. Chem. Phys., 94, 3910 (1991). 
72. M.H. Alexander, J. Chem. Phys., 69(8) 3502(1978).

73. R.W. Field, J. Chem. Phys., 60(6) 2400 (1974).

74. S.R.Langhoff, C.W.Bauschlicher,Jr., H.Partridge, J.Chem.Phys., 84(8), 4474 (1986). 
Table I: Molecular Parameters for $\mathrm{NO}_{2}, \mathrm{O}_{3}, \mathrm{ClO}_{2}$ and Their Anions.

\begin{tabular}{|c|c|c|c|c|c|}
\hline Neutral & $\begin{array}{c}\mathrm{R}(\mathrm{X}-\mathrm{O}) \\
(\mathrm{A})\end{array}$ & $\begin{array}{l}\theta_{\text {oxo }} \\
\text { (deg) }\end{array}$ & Anion & $\begin{array}{c}\mathrm{R}(\mathrm{X}-\mathrm{O}) \\
(\mathrm{A})\end{array}$ & $\begin{array}{l}\theta_{\text {oxor }} \\
\text { (deg) }\end{array}$ \\
\hline $\mathrm{NO}_{2}$ & $1.1938^{\circ}$ & $133.857^{\circ}$ & $\mathrm{NO}_{2}^{\circ}$ & $1.252^{\mathrm{a}}$ & $117.5^{a}$ \\
\hline $\mathrm{O}_{3}$ & $1.2717^{\circ}$ & $116.78^{c}$ & $\mathrm{O}_{3}^{-}$ & $1.3415^{b}$ & $112.6 \pm 2^{b}$ \\
\hline $\mathrm{ClO}_{2}$ & $1.47^{\mathrm{c}}$ & $117^{\circ}$ & $\mathrm{ClO}_{2}^{-}$ & $1.70^{c}$ & $110^{\circ}$ \\
\hline
\end{tabular}

Ref 11

'Ref $12 b$

${ }^{\mathrm{C}}$ Ref $12 \mathrm{c}$

${ }^{\mathrm{d}} \operatorname{Ref} 44$

${ }^{\mathrm{e}} \operatorname{Ref} 50 \mathrm{~b}$ 


\section{FIGURE CAPTIONS}

1. Energetics of the $\mathrm{Ba}+\mathrm{ClO}_{2}$ reactions. Energy levels for the thermodynamically allowed reaction channels are shown. The $\mathrm{Ba}^{+} \mathrm{ClO}_{2}^{-}$is estimated to lie at approximately $-65 \mathrm{kcal} /$ mole with respect to $\mathrm{Ba}+\mathrm{ClO}_{2}$. See text for details.

2. Energetics of the $\mathrm{Ba}+\mathrm{O}_{3}$ reactions. Energy levels for the thermodynamically allowed reaction channels are shown. The $\mathrm{Ba}^{+} \mathrm{O}_{3}^{-}$is estimated to lie at approximately $-65 \mathrm{kcal} / \mathrm{mole}$ with respect to $\mathrm{Ba}+\mathrm{O}_{3}$. See text for details.

3. $\mathrm{BaO}$ laboratory angular distributionfor $\mathrm{Ba}+\mathrm{ClO}_{2} \rightarrow \mathrm{BaO}+\mathrm{ClO}$ at nominal collision energy of $14 \mathrm{kcal} /$ mole. Angular distribution is very similar to that seen from $\mathrm{Ba}+\mathrm{NO}_{2}$. Effect of laser excitation on reaction dynamics will be discussed in full paper.

4. $\mathrm{BaO}$ TOF spectra from $\mathrm{Ba}+\mathrm{ClO}_{2}$ reaction at $\mathrm{E}_{\text {coll }}=14 \mathrm{kcal} / \mathrm{mole}$.

5. Relative product translational energy distribution $P(E)$ and center of mass angular distribution $\mathrm{T}(\theta)$ for the $\mathrm{BaO}$ channel from $\mathrm{Ba}+\mathrm{ClO}_{2}$ reaction. A single uncoupled $T(\theta)$ and $P(E)$ was used in the analysis.

6. $\mathrm{BaCl}$ laboratory angular distribution from $\mathrm{Ba}+\mathrm{ClO}_{2}$ at $\mathrm{E}_{\text {coll }}=14 \mathrm{kcal} / \mathrm{mole}$. Effect of laser excitation on reaction dynamics will be discussed in full paper.

7. $\mathrm{BaCl}$ TOF spectra from $\mathrm{Ba}+\mathrm{ClO}_{2}$ reaction at $\mathrm{E}_{\text {coll }}=14 \mathrm{kcal} / \mathrm{mole}$. A single uncoupled $P(E)$ and $T(\theta)$ combination vas employed.

8. $\mathrm{P}(\mathrm{E})$ and $\mathrm{T}(\theta)$ for the $\mathrm{BaCl}$ channel from $\mathrm{Ba}+\mathrm{ClO}_{2}$ reaction.

9. $\mathrm{BaO}$ TOF spectra from $\mathrm{Ba}+\mathrm{O}_{3}$ reaction at $\mathrm{E}_{\mathrm{coll}}=14 \mathrm{kcal} / \mathrm{mole}$. 
10. $\quad P(E)$ and $\mathrm{T}(\theta)$ for the $\mathrm{BaO}$ channel from $\mathrm{Ba}+\mathrm{O}_{3}$ reaction.

11. $\mathrm{BaO}_{2}$ TOF spectra from $\mathrm{Ba}+\mathrm{O}_{3}$ reaction at $14 \mathrm{kcal} / \mathrm{mole}$.

12. $\mathrm{BaO}_{2}$ Product translational energy distribution and center of mass angular distribution from reaction at $14 \mathrm{kcal} / \mathrm{mole}$

13. $\mathrm{BaO}_{2}$ and $\mathrm{BaO}$ product flux contour maps superimposed on nominal Newton diagrams for $\mathrm{Ba}+\mathrm{O}_{3}$ reaction.

14. Energetics of $\mathrm{ClO}_{2}, \mathrm{O}_{3} \cdot$ and its decay products. See text for details. 


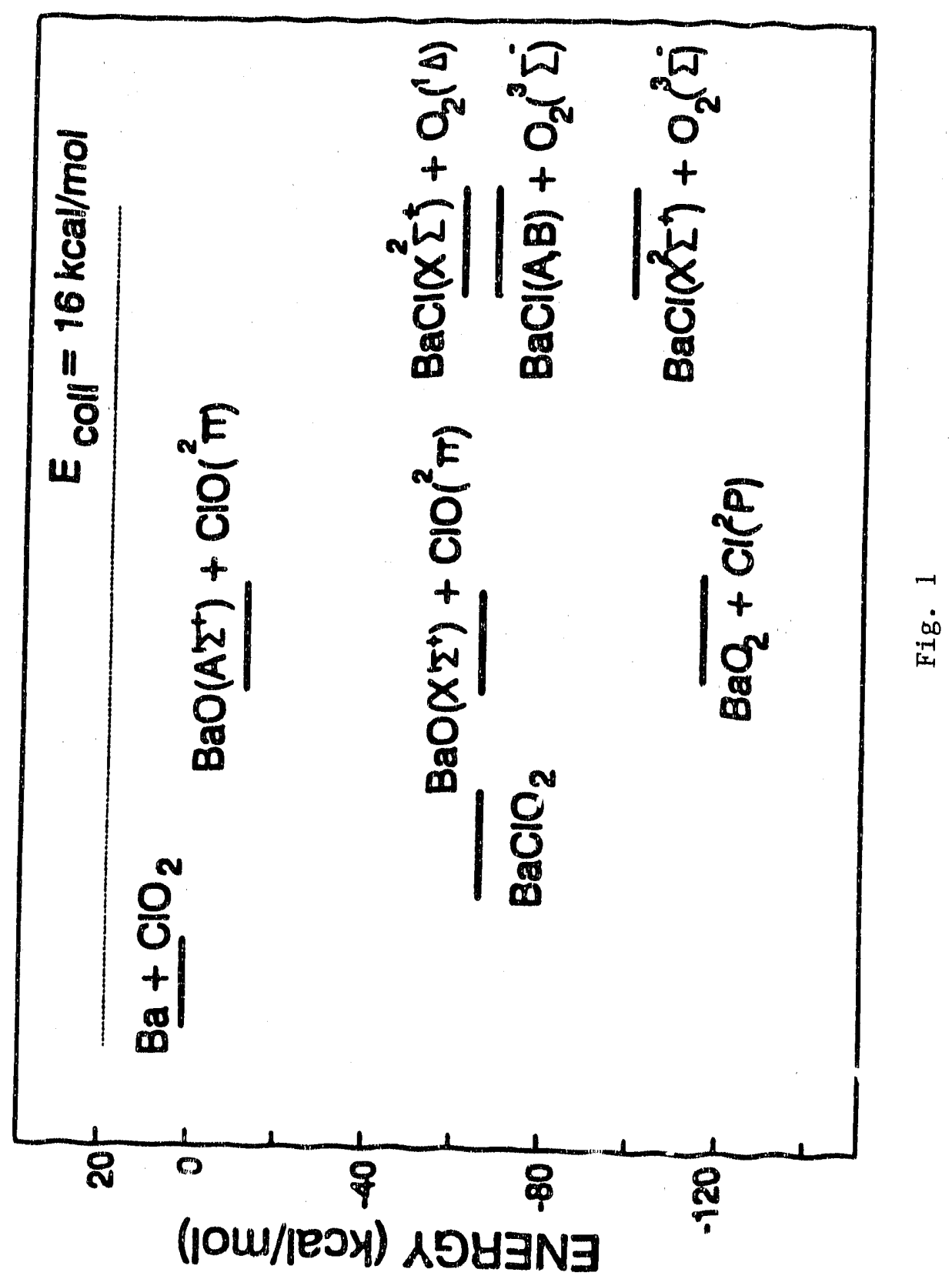




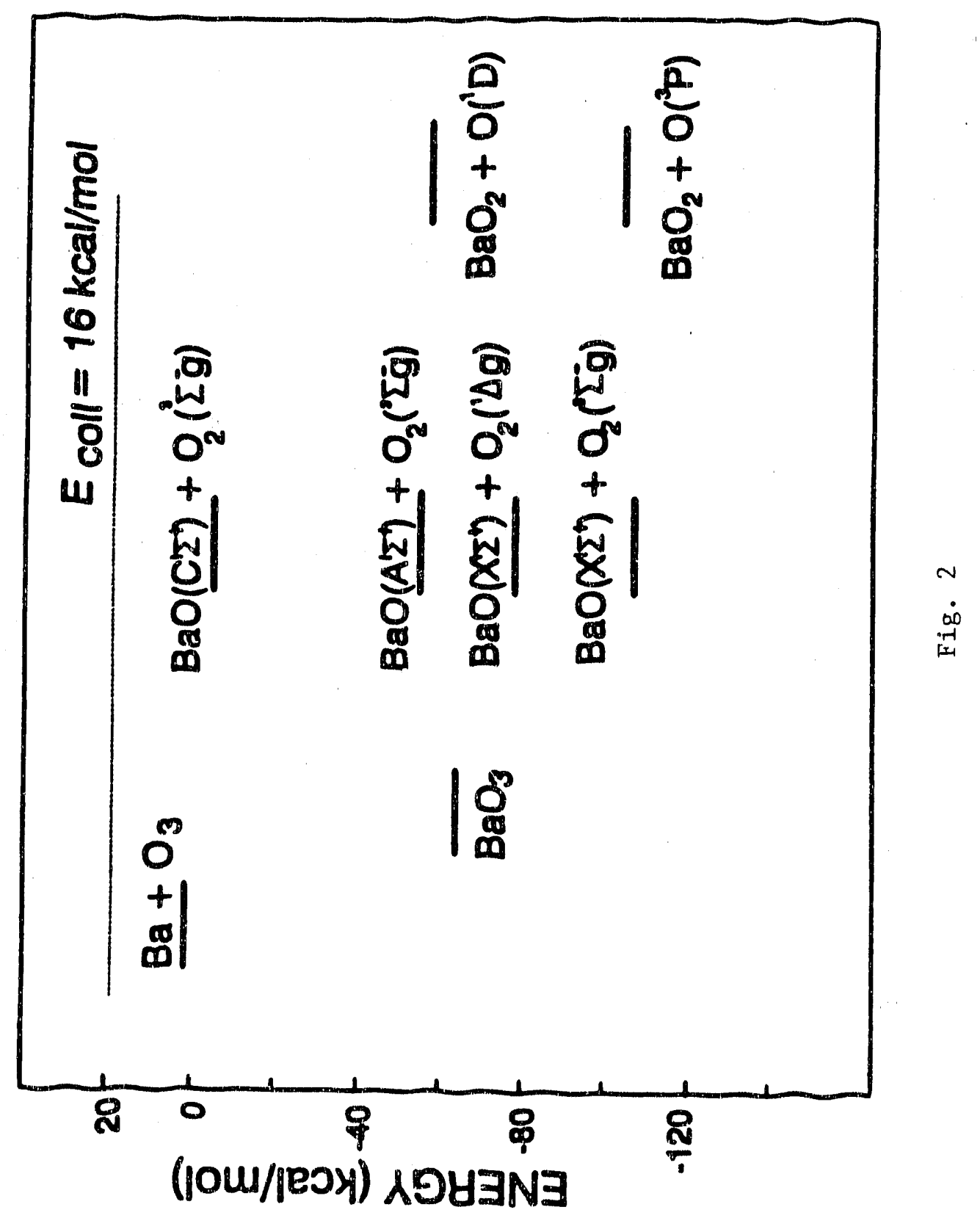




\section{$\mathrm{Ba}+\mathrm{ClO}_{2} \rightarrow \mathrm{BaO}+\mathrm{ClO}$}

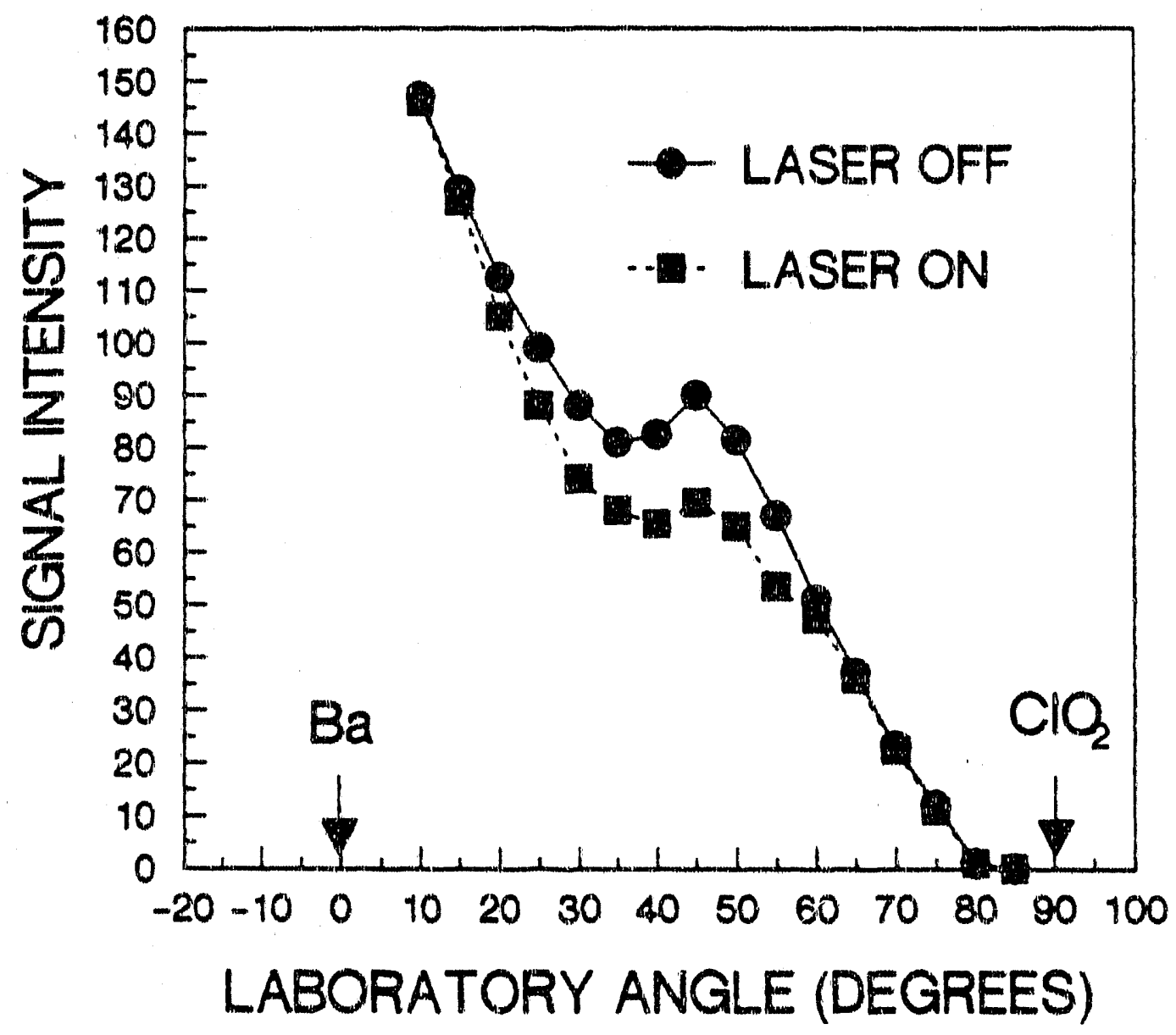

Fig. 3 


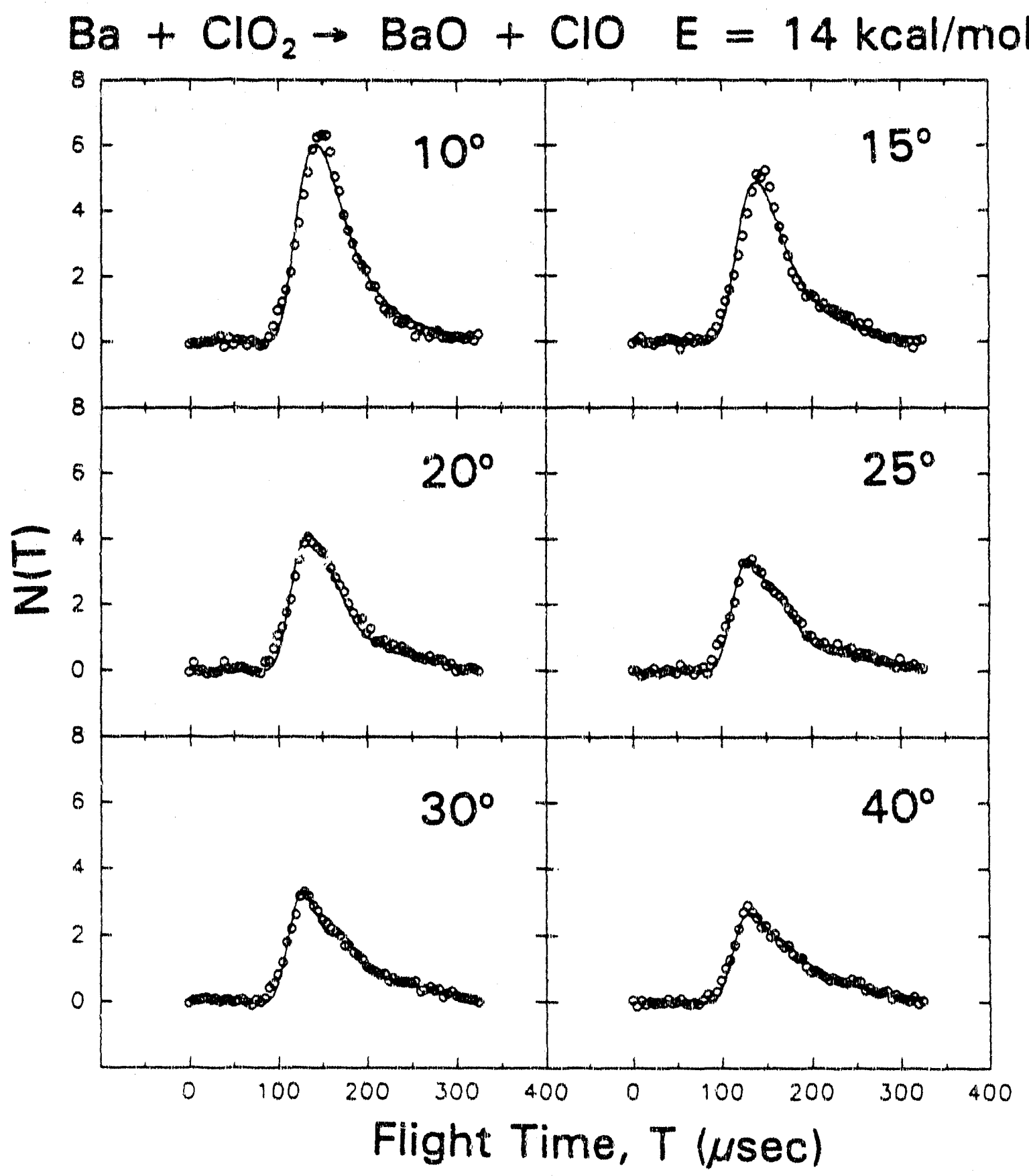

Fig. 4 

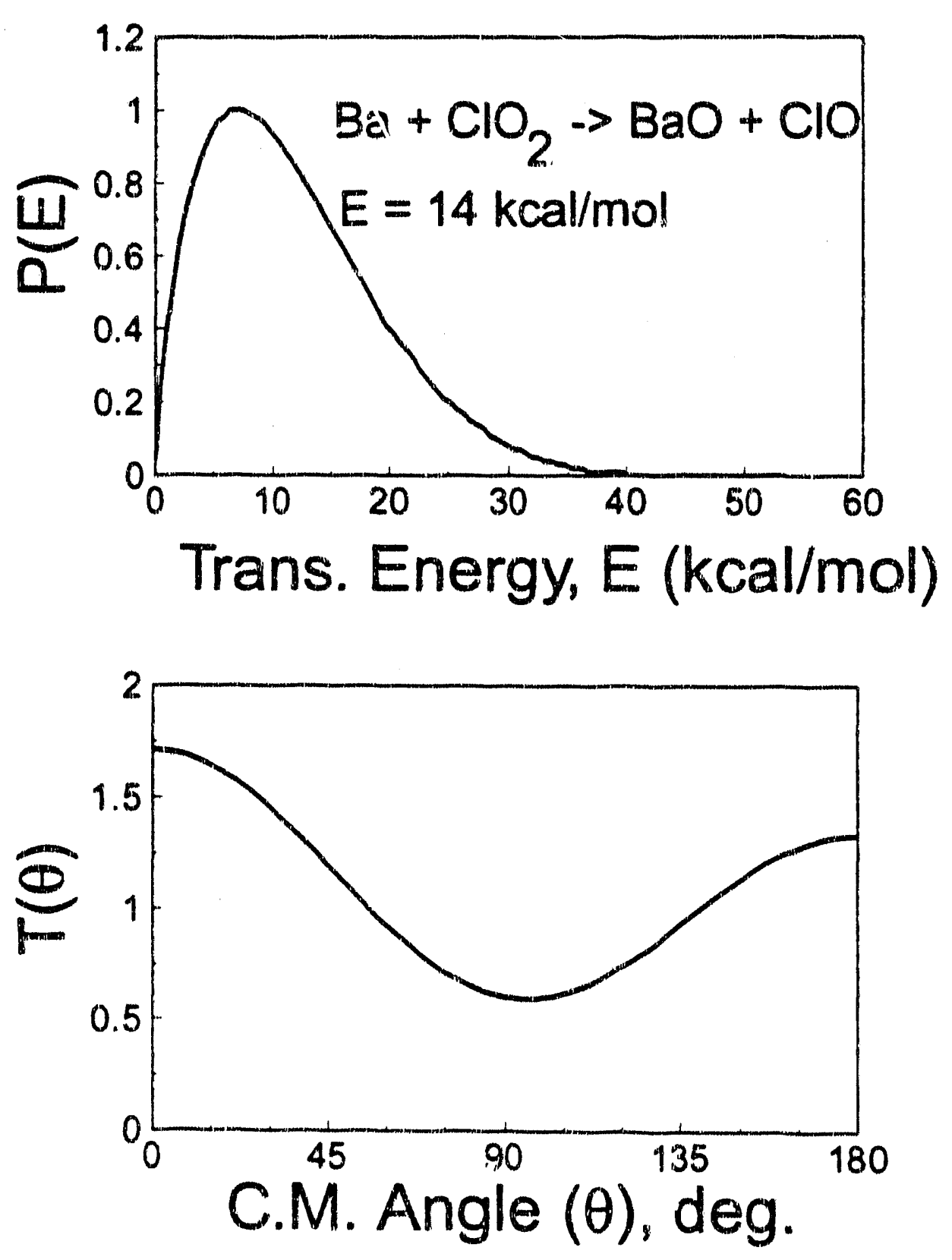

Fig. 5 


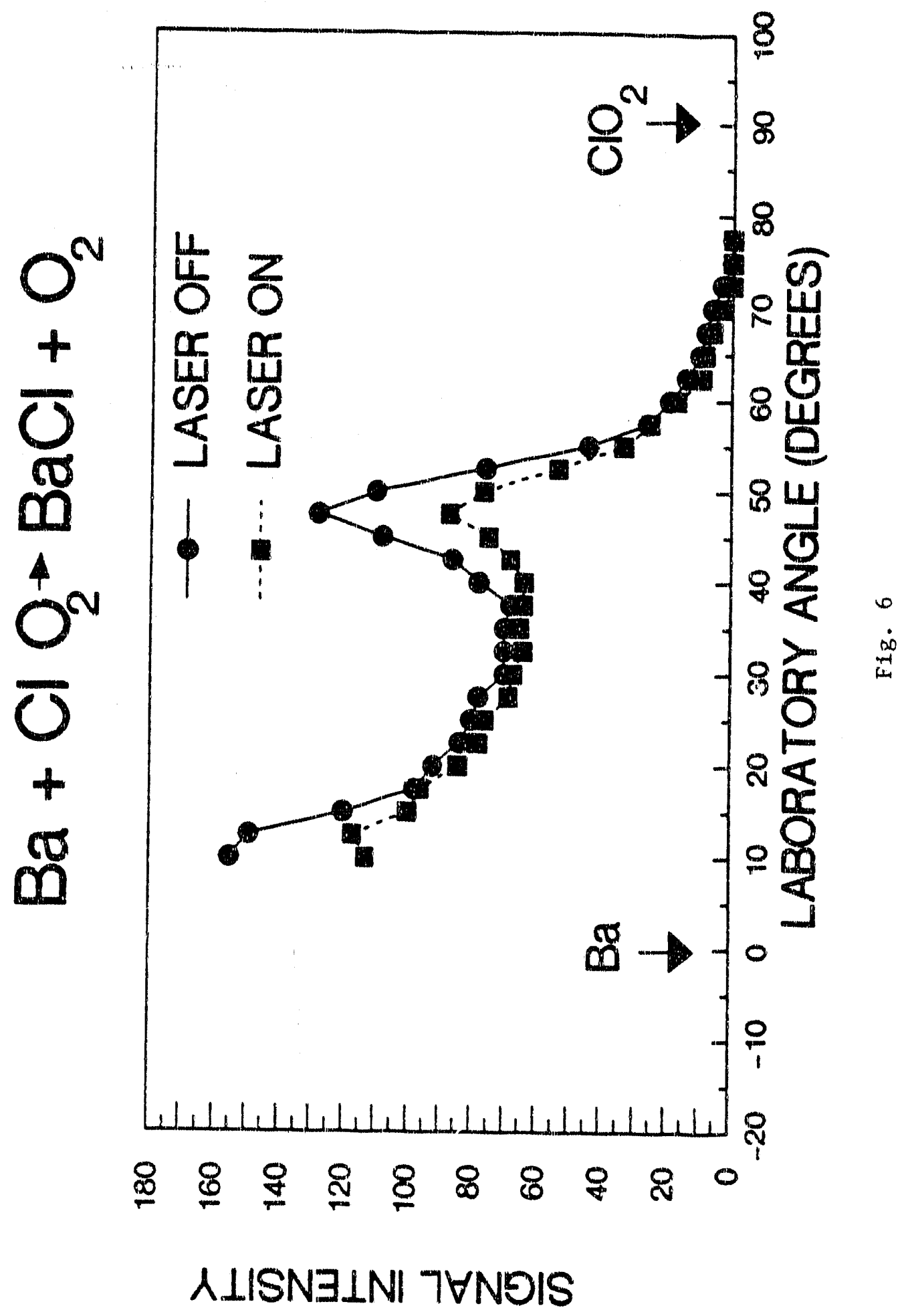




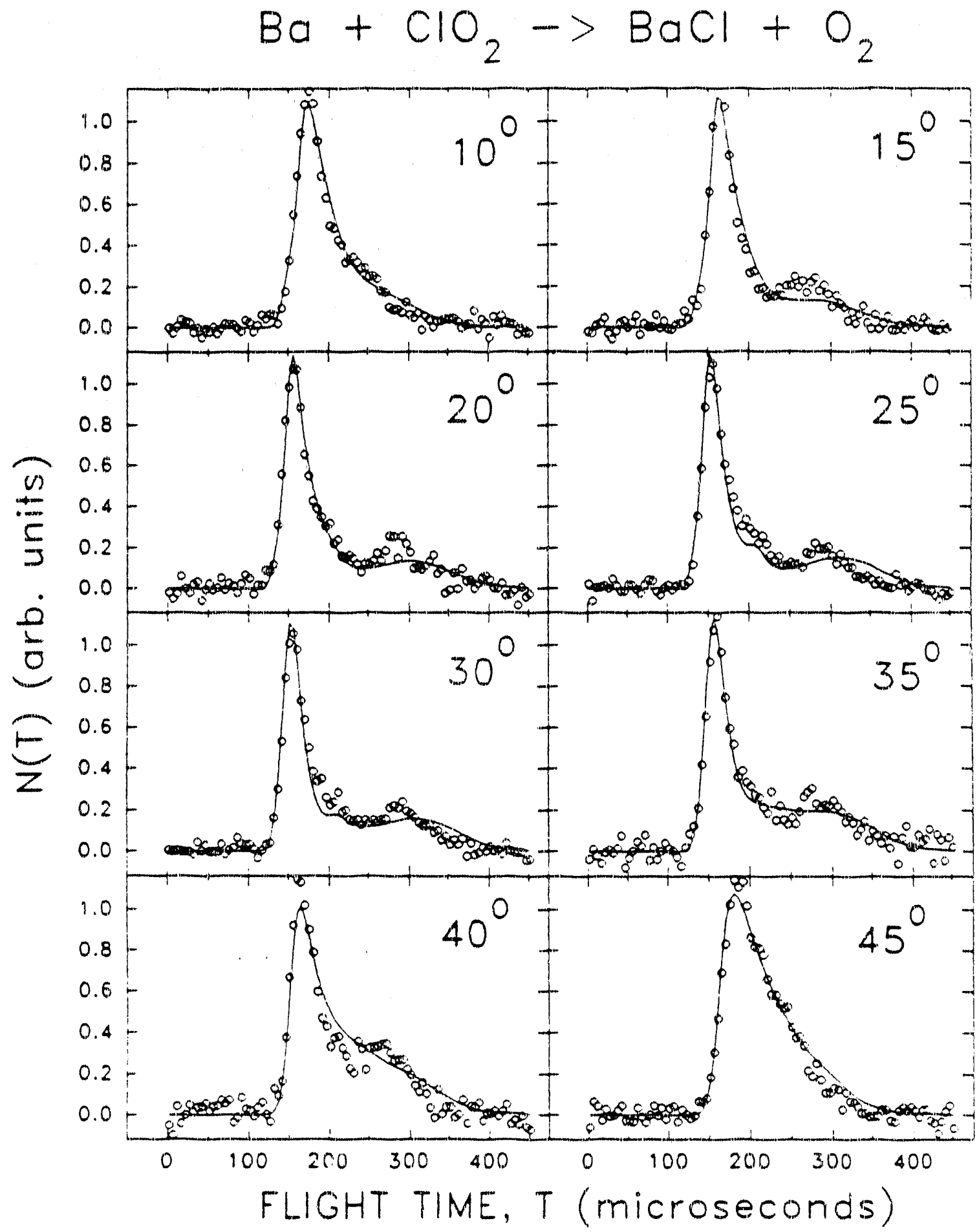

Fig. 7 

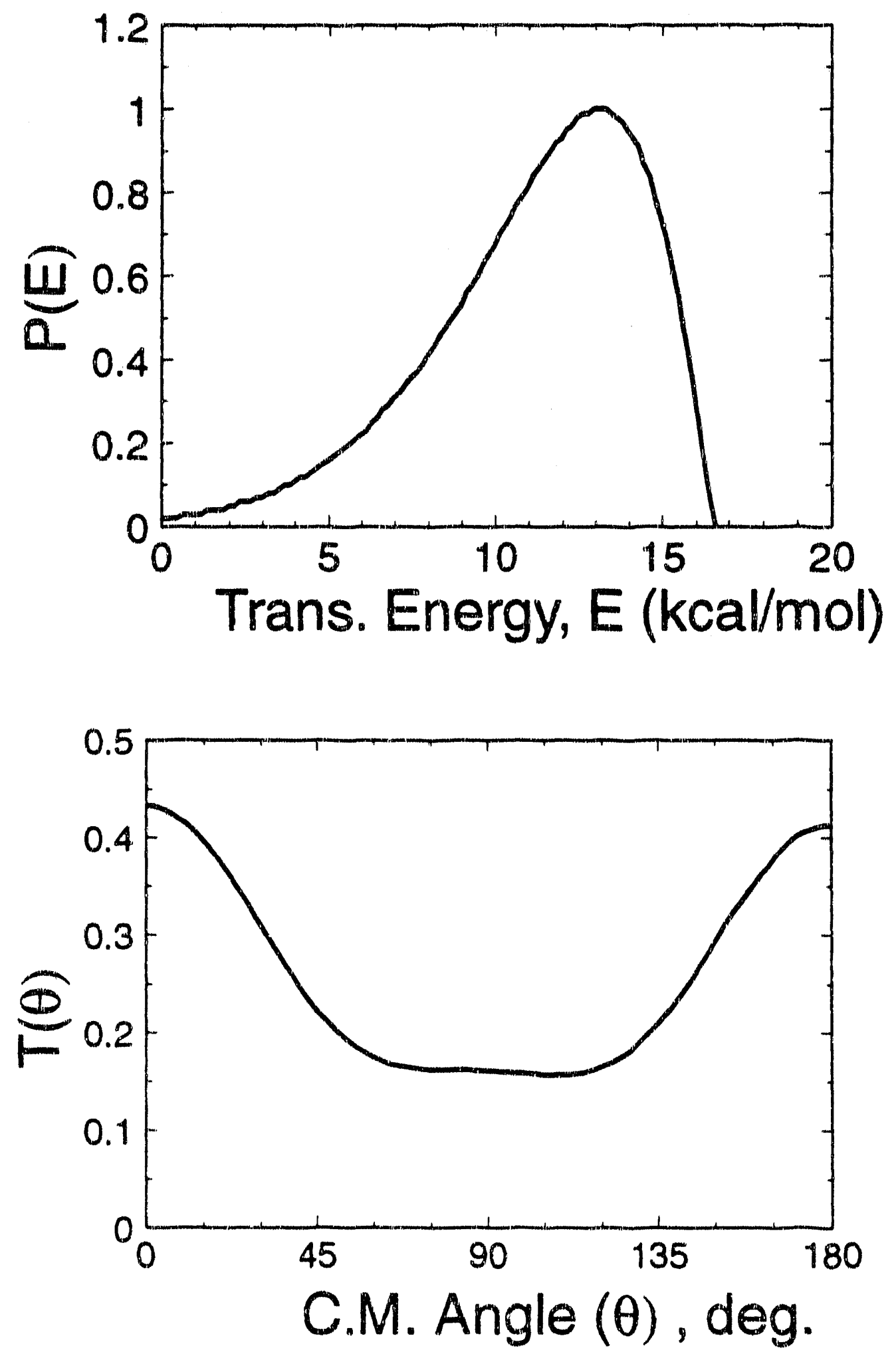

Fig. 8 


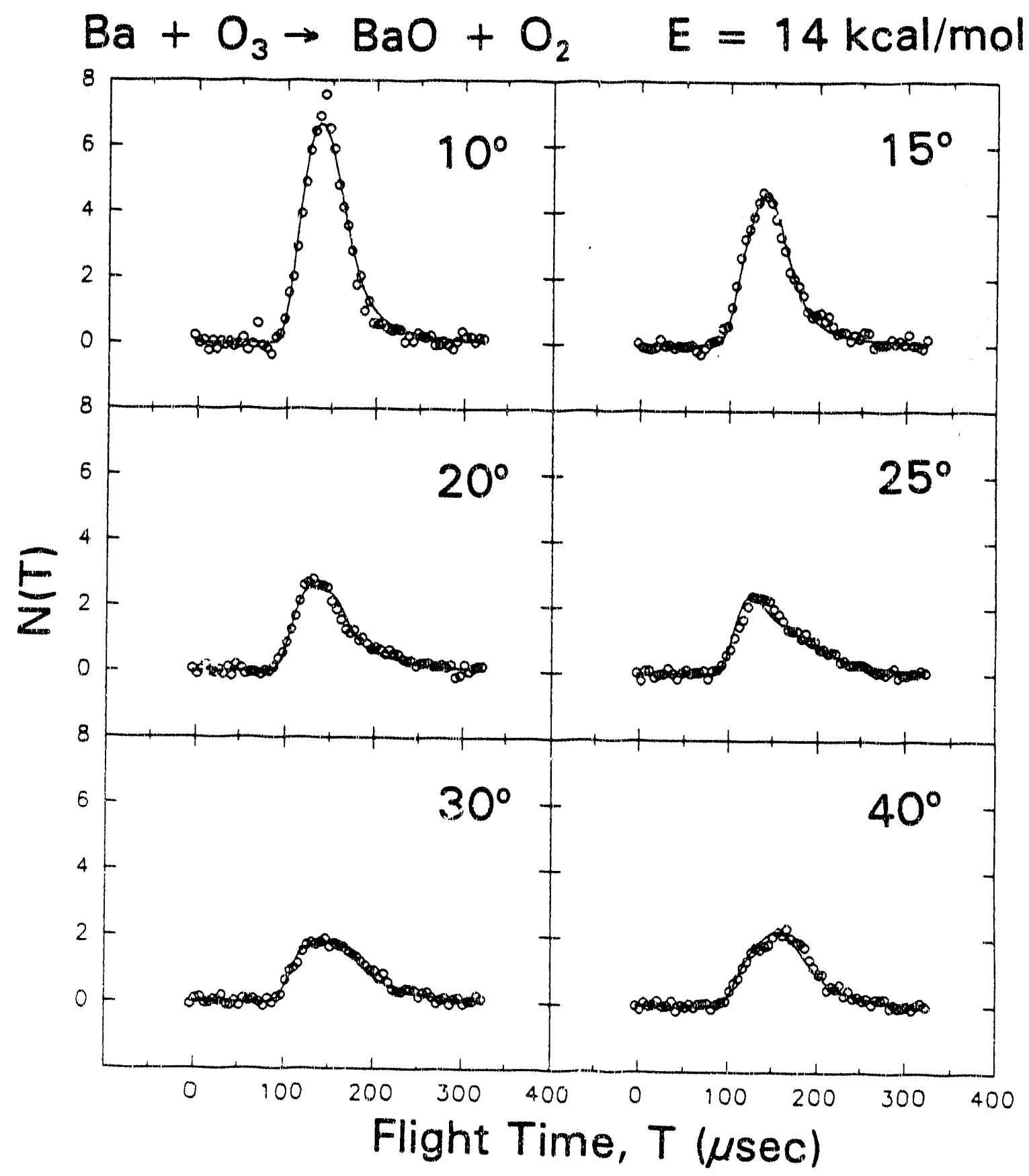

Fig. 9 

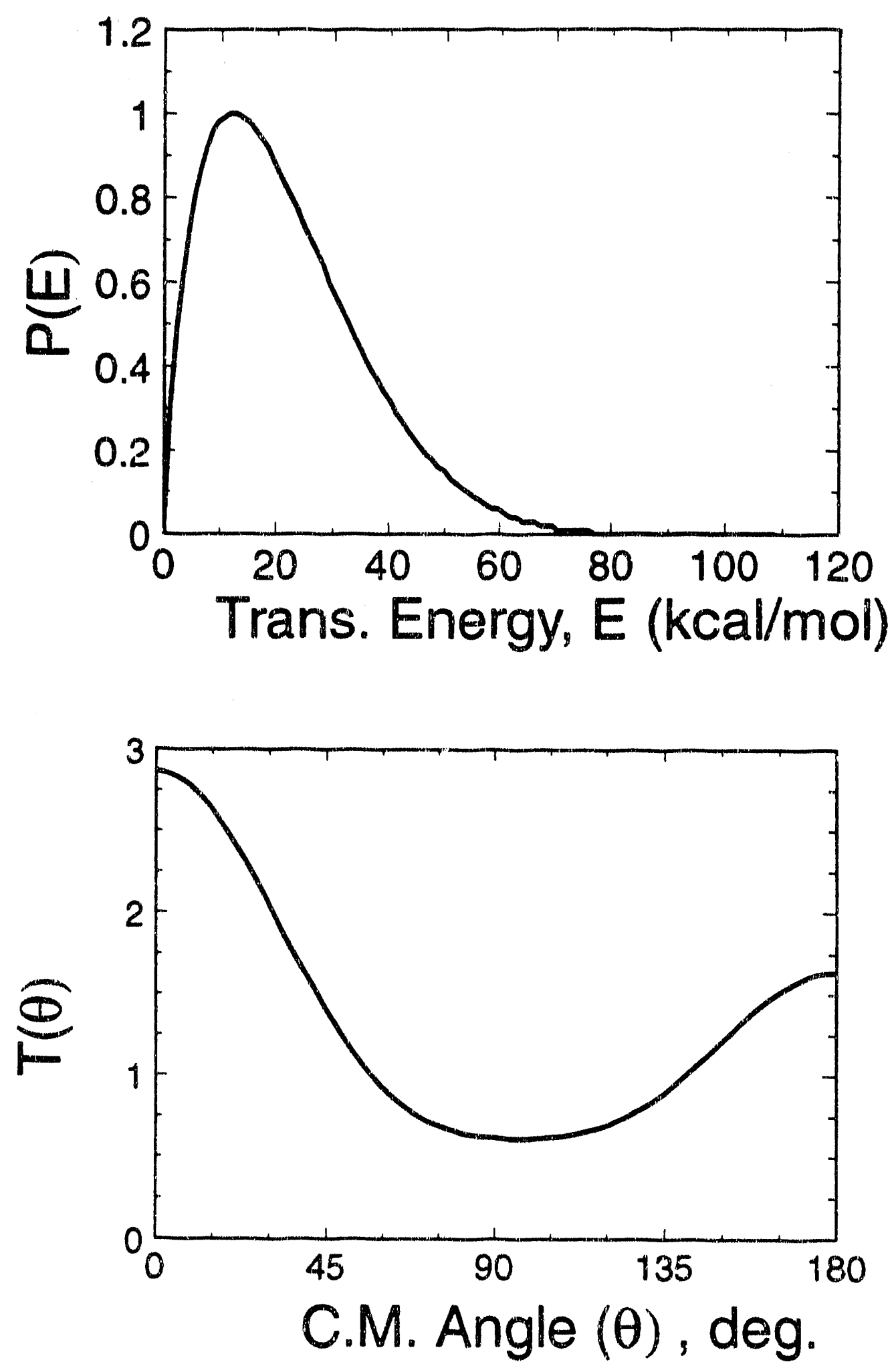

Fig. 10 


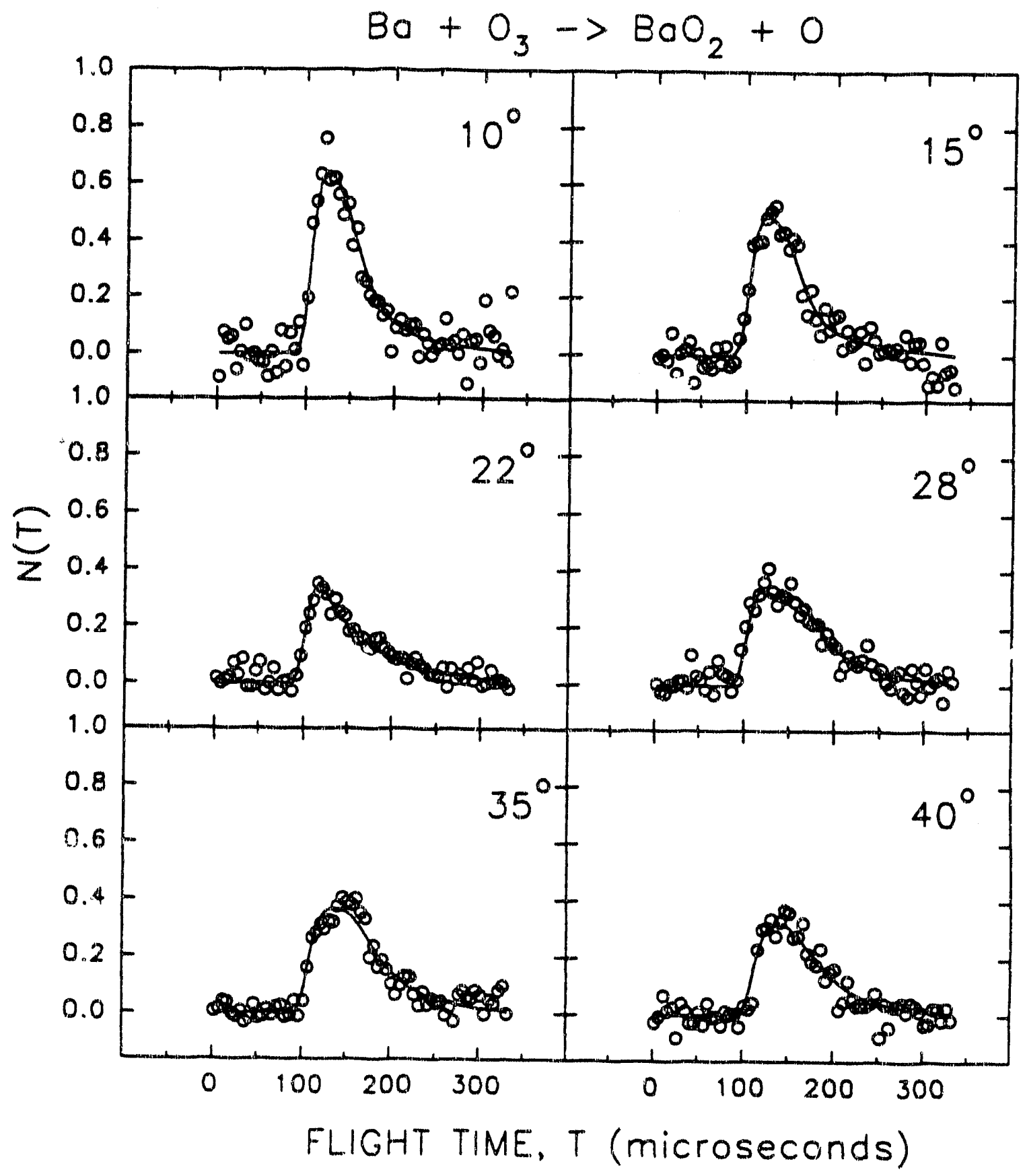

Fig. 11 

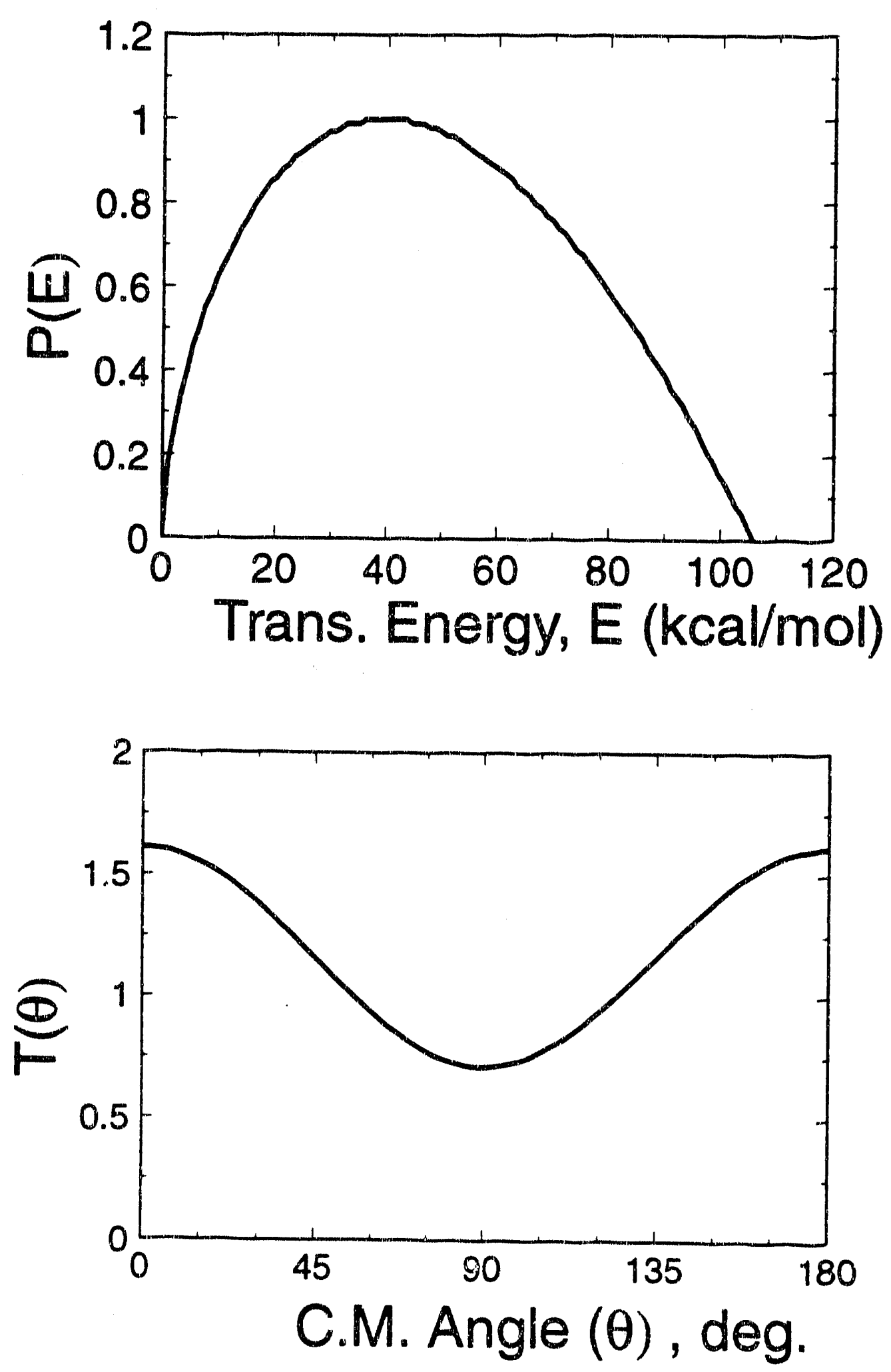

Fig. 12 

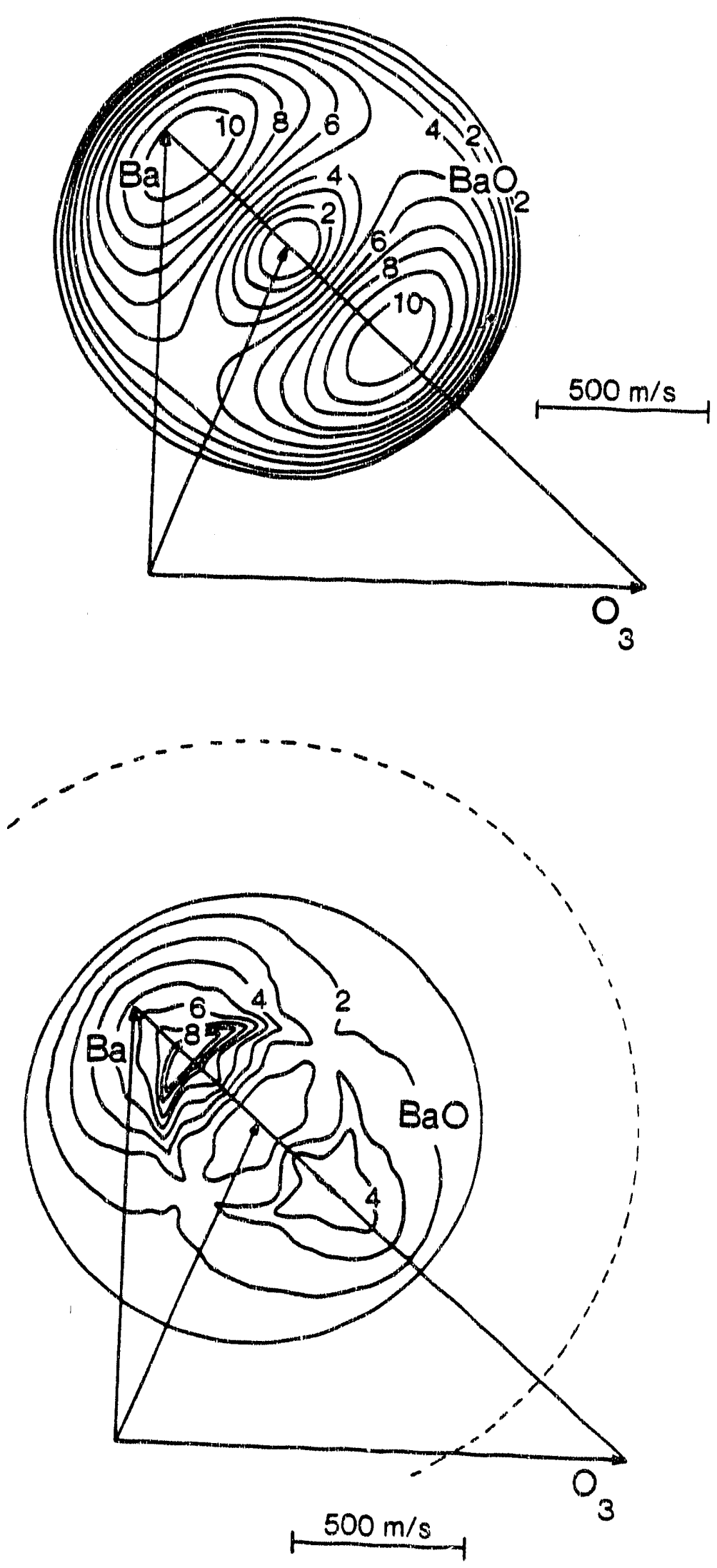

Fig. 13 

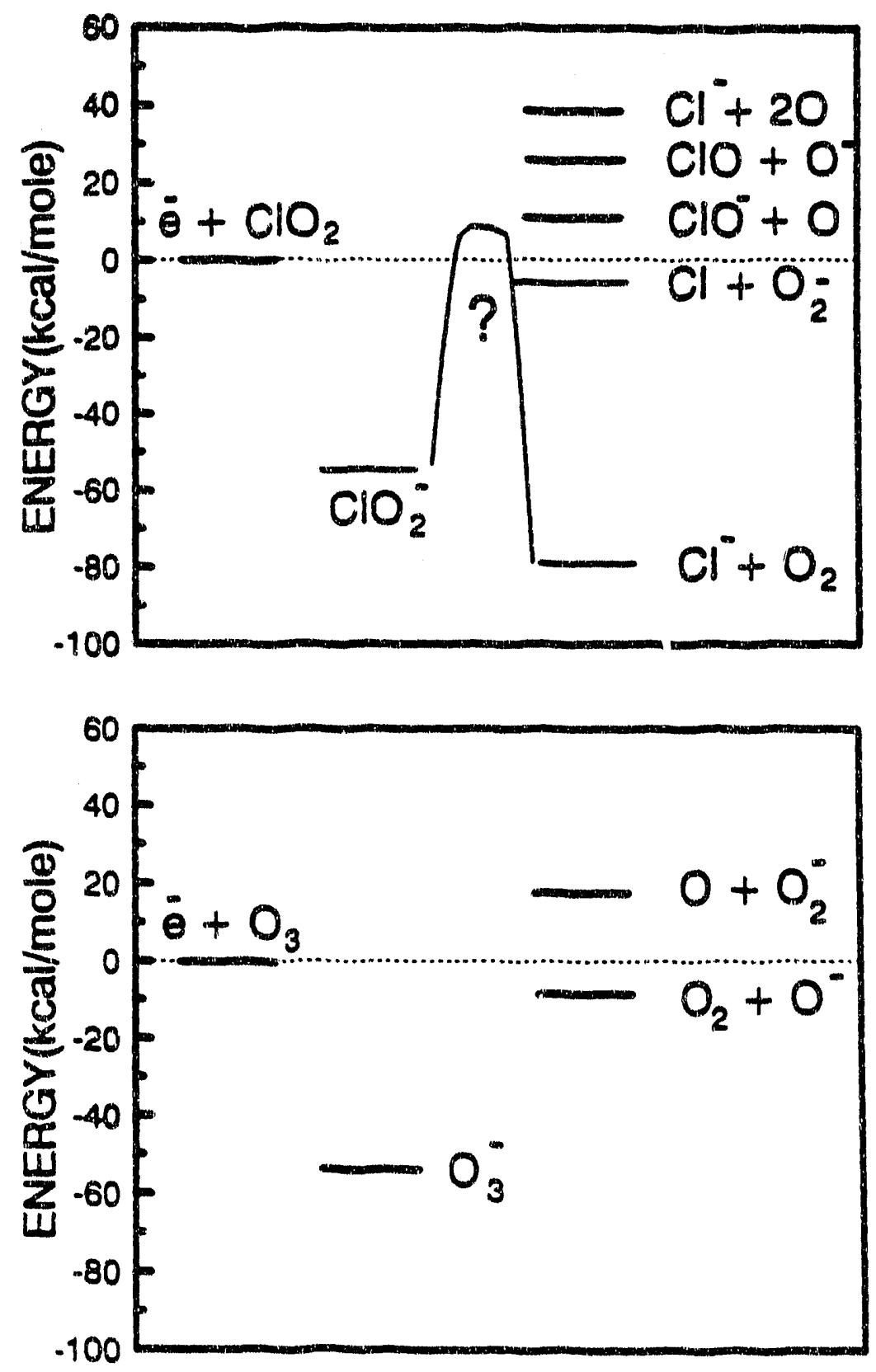

Fig. 14 


\section{CHAPTER 4}

Photodissociation Dynamics of the $\mathrm{NO}_{3}$ Radical.

\section{ABSTRACT}

The photodissociation of $\mathrm{NO}_{3}$ was studied using the crossed laser-molecular beam technique at excitation wavelengths between $532 \mathrm{~nm}$ and $662 \mathrm{~nm}$. Within this wavelength rarge, we observe formation of $\mathrm{NO}_{2}\left(\mathrm{X}^{2} \mathrm{~A}_{1}\right)+\mathrm{O}(\mathrm{P})$ and $\mathrm{NO}\left({ }^{2} \mathrm{M}\right)+\mathrm{O}_{2}\left({ }^{3} \Sigma_{8}\right)$. There is good evidence for substantial production of NO $+\mathrm{O}_{2}\left({ }^{1} \Delta_{q}\right)$. The branching ratios for the two chemically distinat channels, $\mathrm{NO}_{2}+\mathrm{O}$ and $\mathrm{NO}+\mathrm{O}_{2}$ are strongly wavelength dependent. The observed yisld of NO $+\mathrm{O}_{2}$ reaches a maximum of $50 \pm 10 \%$ near $590 \mathrm{~nm}$, falling to $<0.02 \%$ below $584 \mathrm{~nm}$. Our observations indicate that strong vibronic coupling between the ' $\mathrm{E}$ ' state and high lying vibrational levels of the ${ }^{2} \mathrm{~A}$ ' state of $\mathrm{NO}_{3}$ leads to formation of a vibrationally hot $\mathrm{NO}_{3}$ molecule that decays with kinetic competition between concerted unimolecular decomposition to $\mathrm{NO}+\mathrm{O}_{2}$ and simple $\mathrm{O}$ $\mathrm{NO}_{2}$ bond rupture. Product time of flight spectra indicate that most of the excess energy in the molecular product channel is funneled into $\mathrm{O}_{2}$ vibrational and electronic excitation, and $\mathrm{NO}+\mathrm{O}_{2}$ translational energy. From our experiments, we obtain a wavelength threshold for $\mathrm{NO}_{3}\left({ }^{2} \mathrm{~A}_{2}{ }^{\prime}\right)+\mathrm{h} v \rightarrow \mathrm{NO}_{2}\left(\mathrm{X}^{2} \mathrm{~A}_{1}\right)+\mathrm{O}\left({ }^{3} \mathrm{P}\right)$ of $589 \pm 2 \mathrm{~nm}$, indicating that $\mathrm{D}_{0}\left(\mathrm{O}-\mathrm{NO}_{2}\right)=48.55 \pm 0.16 \mathrm{kcal} / \mathrm{mole}$. By combining this with the known values for $\Delta \mathrm{H}_{\mathrm{r}}\left(\mathrm{NO}_{2}\right)$, and $\Delta \mathrm{H}_{\mathrm{r}}\left(\mathrm{O}^{3} \mathrm{P}\right)$, we calculate $\Delta \mathrm{H}_{\mathrm{f}}\left(\mathrm{NO}_{3}\right)=19.01 \pm 0.24 \mathrm{kcc} / \mathrm{mole}(\mathrm{OK})$. Using heat capacity corrections, this corresponds to $\Delta \mathrm{H}_{\mathrm{f}}\left(\mathrm{NO}_{3}\right)=17.75 \pm 0.24$ $\mathrm{kcal} /$ mole $(298 \mathrm{~K})$. We clearly observe structure in the NO $+\mathrm{O}_{2}$ TOF at 588 and 594 $\mathrm{nm}$ due to vibrational excitation of the $\mathrm{O}_{3}$ product. Our observations indicate that the 
potential energy barrier for $\mathrm{NO}_{3} \rightarrow \mathrm{NO}+\mathrm{O}_{2}\left({ }^{2} \Sigma_{z},{ }^{1} \Delta\right)$ is below $\mathrm{D}_{0}\left(\mathrm{O}-\mathrm{NO}_{2}\right)$, i.e. $<48.55 \mathrm{kcal} / \mathrm{mol}$. Our results are compared to those of Magnotta and Johnston.

\section{INTRODUCTION}

Owing to its importance in the atmosphere ${ }^{1}$, the nitrate free radical $\left(\mathrm{NO}_{3}\right)$ has received considerable attention experimentally ${ }^{1-6}$ and theoretically. ${ }^{7 \cdot 12}$ Walsh ${ }^{13}$ predicted that $\mathrm{NO}_{3}$ would have $\mathrm{D}_{3 \mathrm{~b}}$ symmetry with a ground state configuration of ${ }^{2} \mathrm{~A}_{2}{ }^{\prime}$. Its excited electronic states are denoted by ${ }^{2} \mathrm{E}$ ' and ${ }^{2} \mathrm{E}$ ". The blue color observed upon mixing $\mathrm{NO}_{2}$ with $\mathrm{O}_{3}$ has been attributed to strong $\mathrm{NO}_{3}$ visible absorption resulting from the ${ }^{2} \mathrm{E}$ ' $-{ }^{2} \mathrm{~A}_{2}$ ' transition. ${ }^{14}$ This absorption spectrum was first recorded in 1937 by Jones and Wulf, ${ }^{15}$ and reinvestigated by Ramsey ${ }^{14}$ in 1962 , with several of the peaks assigned. The spectruri shown in Fig. 1 was recorded by Sander. ${ }^{16}$ The longest wavelength transition at $662 \mathrm{~nm}$ was attributed by Ramsey ${ }^{12}$ as due to the $(0,0)$ band; the peaks at $623 \mathrm{~nm}$ and $590 \mathrm{~nm}$ result from a short progression in the symmetric stretching vibration, $v_{1}$. Similar, relatively low resolution spectra have been recorded in a number of laboratories ${ }^{17-20}$ using various chemical methods for generation of $\mathrm{NO}_{3}$. These methods include:
Chemical Reaction:
a) $\mathrm{F}+\mathrm{HNO}_{3} \rightarrow \mathrm{HF}+\mathrm{NO}_{3}$
b) $\mathrm{NO}_{2}+\mathrm{O}_{3} \rightarrow \mathrm{NO}_{3}+\mathrm{O}_{2}$

Photochemical Decomposition: $\quad \mathrm{ClONO}_{2}+\mathrm{h} v \rightarrow \mathrm{Cl}+\mathrm{NO}_{3}$

Thermal Decomposition: $\quad \mathrm{N}_{2} \mathrm{O}_{5} \rightarrow \mathrm{NO}_{2}+\mathrm{NO}_{3}$ 
All evidence points towards the existence of a planar $\mathrm{NO}_{3}$ molecule with a centrally located $\mathrm{N}$ atom. However, there has been considerable discussion ${ }^{3-12}$ regarding the ground state symmetry of $\mathrm{NO}_{3}$. It now appears that most inconsistencies which have arisen from assigning a rigid $\mathrm{C}_{2 \mathrm{v}}(\mathrm{Y} \text {-shaped })^{3}$ or $\mathrm{D}_{3 \mathrm{k}}$ (3-fold symmetric) structure, ${ }^{60}$ can be reconciled in terms of an $\mathrm{NO}_{3}$ molecule possessing a triple minimum with only a small potential energy barrier for interconversion between three $\mathrm{C}_{2 v}$ structures. ${ }^{21.22}$ On the rotational timescale $\left(10^{-12} \mathrm{~s}\right)$, molecular vibrations tend to average out the $C_{2 v}$ structure, and most features of $\mathrm{NO}_{3}$ are consistent with an "average" $D_{3 b}$ structure. ${ }^{21,22}$ If theory or experiment is sufficiently detailed, however, the underlying $\mathrm{C}_{2 \mathrm{v}}$ structure may become apparent. ${ }^{21,22}$

Sander observed a substantial temperature dependence for the $\mathrm{NO}_{3}$ absorption cross section. ${ }^{16}$ This has been supported by independent measurements by Ravishankara and Mauldin. ${ }^{19}$ At nearly all wavelengths, the absorption cross section increases upon decreasing the cell temperature. ${ }^{16}$ Such behavior suggests that the absorptions arise primarily from transitions from the ground vibrational state of $\mathrm{NO}_{3}$, since the ground state population increases with decreasing temperature. Two peaks, at 678.4 and $637 \mathrm{~nm}$ were found to show the opposite temperature dependence, ${ }^{16}$ indicating that they are hot bands of the $6 i^{-}, \mathrm{nm}$ and $623 \mathrm{~nm}$ transitions, respectively. Subsequently, Cantrell and coworkers ${ }^{20}$ have conducted a more limited study at the $662 \mathrm{~nm}(0,0)$ band only. They concluded that the $662 \mathrm{~nm}$ absorption cross section is temperature independent. Such behavior, if real, could be taken as evidence for overlapping $(0,0)$ and $(1,1)$ transitions, possibly indicating a very small geometry change for the ${ }^{2} \mathrm{E}^{\prime} \leftarrow{ }^{2} \mathrm{~A}_{2}$ transition. The 
nature of the $\mathrm{NO}_{3}$ absorption spectrum, asd its temperature dependence is of considerable importance in the present study and will be addressed in detail below.

The ritrate radical is one of the most poorly understood atmospheric molecules. Although the wavelengths of the peaks in the visible absorption spectrum are now well established, the identity of the transitions are only now becoming understood. ${ }^{21}$ However, there remains considerable uncertainty in the excited state dynamics of $\mathrm{NO}_{3} .{ }^{1,2,3}$ There is general agreement that in the absence of collisions, excitation at $662 \mathrm{~nm}$ leads to fluorescence emission with a quantum yield of 1.0., ${ }^{3,54}$ Based on the JANAF values for $\Delta \mathrm{H}_{\mathrm{r}}\left(\mathrm{NO}_{3}\right), \Delta \mathrm{H}_{\mathrm{r}}\left(\mathrm{NO}_{2}\right)$, and $\Delta \mathrm{H}_{\mathrm{r}}(\mathrm{O}),{ }^{23}$ a wavelength threshold of $583 \mathrm{~nm}$ is calculated for the simplest possible photodissociation process in $\mathrm{NO}_{3}$ :

$$
\mathrm{NO}_{3}\left({ }^{2} \mathrm{~A}_{2}{ }^{\prime}\right)+\mathrm{h} v \rightarrow \mathrm{NO}_{3}\left({ }^{2} \mathrm{E}^{\prime}\right) \rightarrow \mathrm{NO}_{2}\left(\mathrm{X}^{2} \mathrm{~A}_{1}\right)+\mathrm{O}\left({ }^{3} \mathrm{P}\right)
$$

This channel involves simple bond rupture, and no appreciable potential energy barrier if expected above the endothermicity. ${ }^{3}$ Consequently, this channel is expected to dominate at energies only slightly above threshold. Because of the substantial uncertainty $( \pm 5 \mathrm{kcal} / \mathrm{mol})$ in the JANAF value for $\Delta \mathrm{I} \mathrm{r}_{\mathrm{r}}\left(\mathrm{NO}_{3}, \mathrm{OK}\right)^{23}$ however, the wavelength threshold for process (4) is quite uncertain, lying between $528 \mathrm{~nm}$ and $649 \mathrm{~nm}$.

Although the concentration of $\mathrm{NO}_{3}$ in the atmosphere has been found to be substantial at night, it is photolyzed rapidly at sunrise. ${ }^{5}$ If the quantum yield for reaction 4 is urity under the strong peaks in the absorption spectrum, then the formation and photolysis of $\mathrm{NO}_{3}$ will lead to a null cycle in the balance of atmospheric $\mathrm{O}_{3}: 1.2$ 


$$
\begin{aligned}
& \mathrm{NO}_{2}+\mathrm{O}_{3} \rightarrow \mathrm{NO}_{3}+\mathrm{O}_{2} \\
& \mathrm{NO}_{3}+\mathrm{h} \nu \rightarrow \mathrm{NO}_{2}+\mathrm{O} \\
& \mathrm{O}+\mathrm{O}_{2}+\mathrm{M} \rightarrow \mathrm{O}_{3}+\mathrm{M}
\end{aligned}
$$

Net: Null Cycle

However, several molecular channels are thermodynamically possible at all visible wavelengths: $: 1,2,23,25$

$$
\begin{aligned}
\mathrm{NO}_{3}\left({ }^{2} \mathrm{~A}_{2}{ }^{\prime}\right)+\mathrm{hv} \rightarrow \quad \mathrm{NO}_{3}\left({ }^{2} \mathrm{E}^{\prime}\right) & \rightarrow \mathrm{NO}(\mathrm{II})+\mathrm{O}_{2}\left({ }^{3} \Sigma_{\mathrm{g}}\right) \\
& \rightarrow \mathrm{NO}(\mathrm{II})+\mathrm{O}_{2}\left({ }^{1} \Delta_{\mathrm{g}}\right) \\
& \rightarrow \mathrm{NO}\left({ }^{2} \mathrm{II}\right)+\mathrm{O}_{2}\left({ }^{1} \Sigma_{\mathrm{g}}\right)
\end{aligned}
$$

The energetics of $\mathrm{NO}_{3}$ photodissociation and an approximate correlation diagram, as postulated by Nelson, et al. ${ }^{3}$ are presented in Fig. 2. If the production of molecular $\mathrm{NO}+\mathrm{O}_{2}$ contributes significantly to the $\mathrm{NO}_{3}$ integrated absorption cross section, then photodissociation of $\mathrm{NO}_{3}$ in the atmosphere leads to catalytic destruction of $\mathrm{O}_{3}$ by visible light:

$$
\begin{aligned}
& \mathrm{NO}+\mathrm{O}_{3} \rightarrow \mathrm{NO}_{2}+\mathrm{O}_{2} \\
& \mathrm{NO}_{2}+\mathrm{O}_{3} \rightarrow \mathrm{NO}_{3}+\mathrm{O}_{2} \\
& \mathrm{NO}_{3}+\mathrm{h} v \rightarrow \mathrm{NO}+\mathrm{O}_{2}
\end{aligned}
$$

Net: $\quad 2 \mathrm{O}_{3} \rightarrow 3 \mathrm{O}_{2}$

The only previous experimental investigations of $\mathrm{NO}_{3}$ photochemistry were by Graham and Johnston ${ }^{1}$ and later by Magnotta and Johnston. ${ }^{2}$ Magnotta's study employed tunable laser flash photolysis of $\mathrm{NO}_{3}$ generated by thermal decomposition of $\mathrm{N}_{2} \mathrm{O}_{5}$ in a 
flow cell. Resonance fluorescence detection of the $\mathrm{O}(\mathrm{P})$ and $\mathrm{NO}(\textrm{ } \mathrm{II})$ photoproducts indicated the occurrence of both $\mathrm{NO}_{2}+\mathrm{O}$ and $\mathrm{NO}+\mathrm{O}_{2}$ as primary photodissociation channels. Their results are summarized in Fig. 3. The quantum yield for $\mathrm{NO}_{2}+\mathrm{O}$ was unity at $580 \mathrm{~nm}$, remained constant at 0.8 below $560 \mathrm{~nm}$ and dropped to zero at $635 \mathrm{~nm}$. The NO $+\mathrm{O}_{2}$ quantum yield peaked at 0.34 near $590 \mathrm{~nm}$, also dropped to zero to the red at $630 \mathrm{~nm}$, and fell to zero to the blue at $584 \mathrm{~nm} .^{2}$

A number of Magnotta's observations are particularly relevant to the present study. Formation of $\mathrm{NO}_{2}+\mathrm{O}$ was observed at wavelengths considerably to the red of ine nominal $583 \mathrm{~nm}$ threshold implied by the JANAF values for $\Delta \mathrm{H}_{\mathrm{f}}\left(\mathrm{NO}_{3}, \mathrm{OK}\right)$. Although they did not attempt to explain this, more recent interpretations of their data by others ${ }^{3}$ suggest that it was collisionally induced. It is important to note that Magnotta's work was conducted before the first observation of fluorescence from $\mathrm{NO}_{3}{ }^{3,64}$ Their measurements were "absolute"-- knowledge of possible radiative processes was not required in the analysis. There was concern that the total measured photodissociation cross section $\boldsymbol{\Phi}_{\text {dias }}=$ $\phi_{N o}+\phi_{O}$ exceeded unity at $590 \mathrm{~nm},{ }^{2}$ indicating the presence of some systematic error. This is now velieved to have resulted from minor heating of the flowcell by the resonance lamps used in detection of the photoproducts. ${ }^{26}$ However, the mechanism of the dissociation, ie: direct or via internal conversion, collisional or collision free, was in question, as was the possible electronic state(s) of the $\mathrm{O}_{2}$ photoproduct.

Recent work on the heat of formation of $\mathrm{NO}_{3}$ has considerably complicated the interpretation of Magnotta's results. McDaniel ${ }^{4}$ and coworkers have reevaluated the heat of formation of $\mathrm{N}_{2} \mathrm{O}_{5}$ and $\mathrm{NO}_{3}$ by vapor pressure and chemical equilibrium 
measurements. Their value of $\Delta \mathrm{H}_{\mathrm{r}}\left(\mathrm{NO}_{3}\right)=15.39 \pm 0.75 \mathrm{kcal} / \mathrm{mol}(298 \mathrm{~K})$ indicates that $\mathrm{NO}_{3}$ is more stable than suggested by the JANAF value. ${ }^{23}$ Combined with the well known values for heats of formation of $\mathrm{NO}_{2}\left(\mathrm{X}^{2} \mathrm{~A}_{1}\right)$ and $O\left({ }^{3} \mathrm{P}\right),{ }^{23}$ these results lead to a calculated endothermicity of $51.17 \mathrm{kcal} / \mathrm{mole}$ for $\mathrm{NO}_{3} \rightarrow \mathrm{NO}_{2}+\mathrm{O}\left({ }^{3} \mathrm{P}\right)$, corresponding to a wavelength threshold of $554 \mathrm{~nm}$. This is even further to the blue of Magnotta's observed maximum in the $\mathrm{NO}_{2}$ quantum yield. ${ }^{2}$ If correct, McDaniel's value would indicate that a very large fraction of the photodissociation products observed by Magnotta and Johnston could not have resulted from photodissociation of ground state $\mathrm{NO}_{3}$ under collision free conditions.

Quite recently, Weaver and Neumark ${ }^{24}$ obtained photodetachmen'i spectra of $\mathrm{NO}_{3}$, and directly observed the "dark." $2 \mathrm{E}$ " state of $\mathrm{NO}_{3}$ near $8000 \mathrm{~cm}^{-1}$. 'They also obtained a value of $3.937 \pm 0.018 \mathrm{eV}$ for the electron affinity of $\mathrm{NO}_{3}$. By combining this with the previously measured ${ }^{27}$ value for $\Delta \mathrm{H}_{\mathrm{f}}\left(\mathrm{NO}_{3}{ }^{-}\right)$, they calculated $\Delta \mathrm{H}_{\mathrm{f}}\left(\mathrm{NO}_{3}\right)=17.9 \pm 0.8$ $\mathrm{kcal} / \mathrm{mol}$, in disagreement with McDaniel's result, but in good agreement with the less precise JANAF value of $17.0 \pm 5 \mathrm{kcal} / \mathrm{mol}$

There are a number of possible explanations for Magnotta's observation of $O$ atoms at wavelengths substantially longer than calculated using the JANAF tables, ${ }^{23}$ or from the results of McDaniel ${ }^{4}$ or Weaver ${ }^{24}$. The first possibility is that Magnotta's signal did result from photodissociation of a thermal population of $\mathrm{NO}_{3}$ molecules, and all published heats of formation for $\mathrm{NO}_{3}$ are simply far too low. This would have very important effects on calculated reaction rate constants for a number of atmospheric processes. ${ }^{4}$ If the stability of $\mathrm{NO}_{3}$ was in fact much lower that previously believed, it 
would also raise many questions in a number of systems involving $\mathrm{NO}_{3} ; \mathrm{N}_{2} \mathrm{O}_{5}$, and $\mathrm{HNO}_{3}$. Another possibility is that Magnotta's $\mathrm{O}$ atom signal in the red resulted from two photon dissociation of $\mathrm{NO}_{3}$ :

$\mathrm{NO}_{3}\left({ }^{2} \mathrm{~A}_{2}\right) \quad \stackrel{\text { hv }}{\rightarrow} \quad \mathrm{NO}_{3}\left({ }^{(} \mathrm{E}^{\prime}\right) \quad \stackrel{\mathrm{h} v}{\rightarrow} \quad \mathrm{NO}_{3}{ }^{* *} \quad \rightarrow \quad \mathrm{NO}_{2}{ }^{*}+\mathrm{O}\left({ }^{3} \mathrm{P}\right)$,

In equation (10), $\mathrm{NO}_{3}{ }^{-*}$ is an excited electronic state of $\mathrm{NO}_{3}$ lying near $31,000 \mathrm{~cm}^{-1}$. The ionization potential of $\mathrm{NO}_{3}$ is expected ${ }^{29,30}$ to exceed $80,000 \mathrm{~cm}^{-1}$. Excited states of $\mathrm{NO}_{3}$ are likely to exist at energies accessible by a two photon transition through the $\left({ }^{2} E\right.$ ') state. The $\mathrm{NO}_{2}$ product could be vibrationally or electronically excited. Since the $\mathrm{NO}_{3}$ fluorescence lifetime is known to be very long $(30-300 \mu \mathrm{sec}),{ }^{3,64}$ a sequential two photon process through the ${ }^{2} \mathrm{E}^{\prime}$ state is quite possible, since a substantial population of $\mathrm{NO}_{3}{ }^{\circ}$ will accumulate during the laser pulse. If the second absorption step has a large cross section, it could easily be saturated. Two photon processes were identified by Magnotta ${ }^{2}$ and explicitly taken into account in the analysis. However, if the second photon absorption was saturated, power dependence measurements could be misleading.

It is expected that a considerable fraction of the $\mathrm{NO}_{3}$ molecules in the flowcell are vibrationally excited at room temperature. These species could be dissociated with light of lower energy than those in the ground state. The calculated vibrational populations for $\mathrm{NO}_{3}$ at two temperatures are summarized in Table I. The large discrepancy between Magnotta's observed threshold $(640 \mathrm{~nm})$ and that predicted from McDaniel's heat of formation $(555 \mathrm{~nm})$ cannot be reconciled by arguing that internally hot molecules absorb 
strongly. In Magnotia's experiment, it should be possible to characterize the $\mathrm{NO}_{3}$ radicals by a Boltzmann dir ribution with a well defined temperature. Assuming McDaniel's value to be correct, an effective temperature of $>1000 \mathrm{~K}$ would be required to provide sufficient internal excitation to lead to the observed wavelength dependence.

The participation of collisional effects, as suggested by Nelson, et $a l .^{3}$ is not easily dismissed. Magnotta's experiment was conducted at a pressure of several Torr. At this pressure, the excited $\mathrm{NO}_{3}$ molecule could undergo many collisions within the fluorescence timescale. Our work was conducted under collision free conditions in a mciecular beam. Thus, some additional insight into the possibility of collisional effects might be gained by comparison of Magnotta's observations with the present results.

Insight into the excited state dynamics of $\mathrm{NO}_{3}$ may be obtained from past laser induced fluorescence (LIF) work. ${ }^{3,64,21}$ Independently, and at nearly the same time, the groups of Nelson ${ }^{3}$, and Ishiwata ${ }^{6_{4}}$ reported similar $\mathrm{NO}_{3}$ fluorescence excitation spectra. These spectra were nearly identical to the $\mathrm{NO}_{3}$ absorption spectrum (Fig. 1) at wavelengths above $615 \mathrm{~nm} .{ }^{3}$ This has been taken to indicate that the fluorescence quantum yield likely reaches 1.0 at a wavelength somewhere above $615 \mathrm{~nm} .{ }^{3}$ Upon tuning to the blue, however, the fluorescence intensity was found to decrease sharply, dropping to zero below $605 \mathrm{~nm} .{ }^{3,68}$ This behavior clearly indicates the onset of efficient photodissociation below $605 \mathrm{~nm}$. Assuming that $\mathrm{McDaniel}$ ' $\mathrm{s}^{4}$ reported value of $\Delta \mathrm{H}_{\mathrm{f}}\left(\mathrm{NO}_{3}\right)$ is correct, the LIF measurements would imply that the quantum yield for formation of NO $+\mathrm{O}_{2}$ must be 1.0 in the wavelength range $555-605 \mathrm{~nm} .{ }^{2,3}$ This would conflict with Magnotta's results. ${ }^{2}$ 
Recently, the $\mathrm{NO}_{3}$ system has attracted a considerable amount of theoretical work. ${ }^{9 \cdot 12,18}$ Although most studies have focussed on the question of the ground state geomeliy of $\mathrm{NO}_{3}$, two groups have addressed the question of the height of the potential energy barrier between $\mathrm{NO}_{3}$ and $\mathrm{NO}(\mathrm{m})+\mathrm{O}_{2}\left({ }^{5} \Sigma\right) .{ }^{9.28}$ The barrier height is of considerable importance in understanding the mechanism for oxidation of NO in the atmosphere, since it must involve an intermediate species, either $\mathrm{NO}_{3}$ or $\mathrm{N}_{2} \mathrm{O}_{2} \cdot{ }^{9}$ Using CASSCF and contracted $\mathrm{CI}$ methods, Siegbahn? found that the $\mathrm{C}_{2 v}$ constrained barrier height for $\mathrm{NO}(\mathrm{II})+\mathrm{O}_{2}\left({ }^{3} \Sigma\right) \rightarrow \mathrm{NO}_{3}$ was as high as $191 \mathrm{kcal} / \mathrm{mole}$, and concluded that $\mathrm{NO}_{3}$ was not an important intermediate in the atmospheric oxidation of $\mathrm{NO}$ to $\mathrm{NO}_{2}$. Since the reaction NO $+\mathrm{O}_{2} \rightarrow \mathrm{NO}_{3}$ is nearly thermoneutral (Fig. 3), Siegbahn's result implies that the reverse reaction will also have a very high potential energy barrier, at least when the reaction path maintains $C_{2 v}$ symmetry. Subsequently, Boehm and Lohr ${ }^{28}$ used $a b$ initio methods to calculate the NO $+\mathrm{O}_{2}$ potential energy surface. Their results were also consistent with a very high potential energy barrier for the $\mathrm{C}_{2 v}$ constrained reaction. They did find a considerably lower barrier for the $\mathrm{NO}+\mathrm{O}_{2}$ reaction when the path was nonplanar, and when the NO bond length was allowed to vary with $\mathrm{O}_{2}$ bond distance. ${ }^{28}$ However, in summarizing their work, it was stated that they would be surprised if it were determined that the transition state for $\mathrm{NO}+\mathrm{O}_{2} \rightarrow \mathrm{NO}_{3}$ had an energy outside $68 \pm 17 \mathrm{kcal} / \mathrm{mole} .^{28}$ Their lowest limit $(51 \mathrm{kcal} / \mathrm{mole})$ would imply a wavelength threshold for $\mathrm{NO}_{3} \rightarrow \mathrm{NO}(\pi)+\mathrm{O}_{2}\left({ }^{3} \Sigma\right)$ of $560 \mathrm{~nm}$. If the $\mathrm{LIF}^{3,64}$ and $\mathrm{NO}_{3}$ enthalpy data ${ }^{4}$ is correct, and the quantum yield for $\mathrm{NO}_{3} \rightarrow \mathrm{NO}+\mathrm{O}_{2}$ is 1.0 for $555 \mathrm{~nm}<\lambda<605 \mathrm{~nm}$, the calculations might suggest that the $\mathrm{O}_{2}$ is formed exclusively in 
an electronically excited state.

Many observations regarding $\mathrm{NO}_{3}$ indicate that strong vibronic coupling exists between the first optically allowed ${ }^{2} \mathrm{E}$ ' state and high lying levels of the ground ${ }^{2} \mathrm{~A}$ ' state. ${ }^{21,24}$. This coupling, also known as the Douglas effect ${ }^{30}$ is well known in $\mathrm{NO}_{2}$ and $\mathrm{SO}_{2}$, and leads to a number of important properties. In the case of $\mathrm{NO}_{3}$, the absorption spectra are found to be diffuse, ${ }^{14,31}$ even at relatively high resolution, at wavelet.; ths where dissociation cannot occur. This results from a very high level density, on the order of $1000 / \mathrm{cm}^{-1},{ }^{3,32}$ leading to a very congested spectrum. This results in a very long fluorescence lifetime of $30-300 \mu \mathrm{sec}^{3}{ }^{3}$ In the "zero order" picture, this can be explained in terms of strong "dilution" of the initially prepared state due to strong vibronic coupling to nearby high lying levels of the ground state. More precisely, the wavefunctions describing the $\mathrm{NO}_{3}$ eigenstates accessed by absorption of a visible photon are superpositions of the ${ }^{2} \mathrm{~A}$ ' and ' $\mathrm{E}$ ' states. This effect will be shown to be of considerable importance in the present work.

Most of the uncertainties in $\mathrm{NO}_{3}$ largely stem from its reactivity, the resulting need for complex reaction mixtures for its generation, and the possible role of collisional processes under bulk analysis. A number of these complicating factors have been eliminated in the present study. The results of Magnotta, ${ }^{2}$ combined with the questions regarding $\Delta \mathrm{H}_{\mathrm{f}}\left(\mathrm{NO}_{3}\right),{ }^{4,23,24}$ prompted this experimental effort. We have used the crossed laser-molecular beam method to study the photodissociation of $\mathrm{NO}_{3}$ under "isolated" collision free conditions. Our goal was to identify the chemical products and their electronic state(s) and to determine barrier heights and possible mechanisms for the 
dissociation as a function of wavelength. Here we report the angular and velocity distributions for both product channels resulting from excitation of $\mathrm{NO}_{3}$ between 532 and $662 \mathrm{~nm}$. Based on the $\mathrm{NO}_{2}+\mathrm{O}$ translational energy distributions, and the wavelength threshold for this product channel, we conclucie that $\mathrm{NO}_{3}$ is substantially less stable than is implied by the recent thermochemical measurements. ${ }^{4}$ Our result is in excellent agreement, but somewhat more precise, than the recent calculated value based on $\mathrm{EA}_{\mathrm{NO} 3}{ }^{24}$ and $\Delta \mathrm{H}_{f}\left(\mathrm{NO}_{3}{ }^{-}\right){ }^{27}$ This system has proven to be rather complex. Consequently, the project has evolved over a period of time, with the necessity of several experimental approaches. Some of the early conclusions from this work were presented in the thesis of Bongsoo Kim. ${ }^{33}$ As will be shown, although many conclusions were correct, the early work did suffer from several shortcomings. As a result of our recent experimental efforts, the deficiencies in our earlier work have been identified, and a clear picture regarding the photodissociation dynamics of $\mathrm{NO}_{3}$ has emerged.

\section{EXPERIMENTAL}

The original experiments were conducted using the A-machine, which is the same apparatus used for the $\mathrm{Ba}$ atom experiments described in Chapters 1-3. The experimental arrangement for photodissociation experiments is shown in Fig 4. The most recent experimental results were obtained using a second apparatus specifically designed for studies of photodissociation dynamics. ${ }^{35}$ Unlike the A-machine, it has a fixed detector and rotatable molecular beam source (Fig. 5). This "Rotating Source Machine" (RSM) is capable of achieving considerably better translational energy resolution. This is due 
to a longer neutral flight length $(36.7 \mathrm{~cm}$ vs. $20.8 \mathrm{~cm})$, but similar effective ionizer length $(\sim 1 \mathrm{~cm})$. An additional feature of the RSM is that it is possible to extend the neutral flight lengih to $\sim 85 \mathrm{~cm}$, providing exceptionally high resolution. Of course, this is only possible if the signal levels are high enough to withstand a decrease in signal intensity by a factor of $\sim 5$. Perhaps the only disadvantage of the RSM is a nore constricted source chamber, requiring a more compact molecular beam source, and a more limited pumping capacity.

A continuous $\mathrm{NO}_{3}$ radical beam was formed by pyrolysis of a $1-5 \% \mathrm{~N}_{2} \mathrm{O}_{5} / \mathrm{He}$ mixture in the nozzle tip at $\sim 600 \mathrm{~K}$. Nitrogen pentoxide $\left(\mathrm{N}_{2} \mathrm{O}_{5}\right)$ was prepared by reaction of $\mathrm{NO}_{2}$ with $\mathrm{O}_{3}$ as described by Schott and Davidson. ${ }^{36}$ The $\mathrm{N}_{2} \mathrm{O}_{5} / \mathrm{He}$ mixture was formed by passing He through a large glass trap containing crystalline $\mathrm{N}_{2} \mathrm{O}_{5}$, held at $\sim-20 \mathrm{C}$ in a thermostatically controlled bath. The trap was identical to the Si gel traps normally used to trap $\mathrm{O}_{3}$ (Chapter 3). In the present application, the Si gel was removed. A number of nozzle designs were used in this study. The first nozzle (Nozzle 1-Fig. 6a) was made by drilling a $0.020^{\prime \prime}$ dia. hole in a $0.020^{\prime \prime}$ thick plate, 0.25 " in diameter, and welding it to the end of a $0.25 "$ OD, $0.15^{\prime \prime}$ ID stainless steel tube. Calculations, ${ }^{33}$ summarized in Fig. 7 , indicated that high $\mathrm{NO}_{3}$ concentrations $(>0.1$ Torr before expansion) may be achieved, but only using pyrolysis times shorter than $1 \mathrm{msec}$ at temperatures near $600 \mathrm{~K}$. By heating only the final $2 \mathrm{~mm}$ tip of the nozzle, the heating time for the $\mathrm{N}_{2} \mathrm{O}_{5}$ molecules could be kept short. The newly formed $\mathrm{NO}_{3}$ radicals are rotationally cooled by supersonic expansion into the vacuum chamber before being destroyed by therma reactions which would normally lead to formation of $\mathrm{NO}$ and $\mathrm{NO}_{2}$. 
The heater was fabricated by soldering to the end of the nozzle a small copper sleeve $\left(0.25^{\prime \prime} \mathrm{ID}, 0.35^{\prime \prime} \mathrm{OD}, 0.15^{\prime \prime}\right.$ long); wrapped and soldered to the sleeve was one turn of

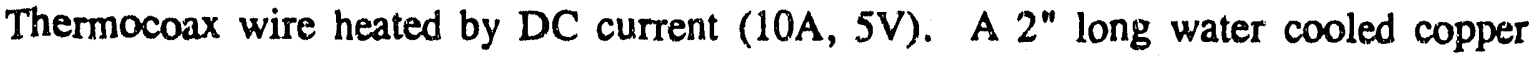
block was soldered to the tube $1 \mathrm{~mm}$ behind the heating zone to keep the remainder of the nozzle at room temperature. A slot was machined into the circumference of the nozzle tube to decrease the heat loss from the hot nozzle tip to the water cooled region (Fig. 6)

In the early stages of this project, the only known method for monitoring the $\mathrm{NO}_{3}$ concentration was by its LIF intensity at $662 \mathrm{~nm} \cdot{ }^{3,60,33}$ The nozzle temperature, total stagnation pressure, (typically 150 Torr), and $\mathrm{N}_{2} \mathrm{O}_{3}$ concentration were adjusted to maximize the $\mathrm{NO}_{3}$ fluorescence. Once these conditions were found, the beam was sampled directly by the mass spectrometer through a $0.003^{\prime \prime}$ dia. pinhole. It was found that the parent $\mathrm{N}_{2} \mathrm{O}_{5}$ molecule yielded essentially no $\mathrm{NO}_{3}{ }^{+}$fragment upon $200 \mathrm{~V}$ electron impact ionization. However, the $\mathrm{NO}_{3}$ molecule resulting from its thermal dissociation showed a strong parent ion peak. This remarkable behavior allowed us to optimize the nozzle conditions by simply maximizing the $\mathrm{m} / \mathrm{e}=62\left(\mathrm{NO}_{3}{ }^{+}\right)$countrate while monitoring the beam directly. This was found to be extremely useful since $\mathrm{NO}_{3}$ does not fluoresce at most wavelengths used in this work. ${ }^{3,64}$ Based on the magnitude of the photodissociation signal that we observe, we estimate the $\mathrm{NO}_{3}$ concentration in the nozzle before expansion to be in the range 0.1 to 0.5 Torr. This is extremely high for an unstable radical and made it possible to obtain very high signal to noise ratios in the photofragment time-of-flight spectra. 
In this experiment, beam collimation was especially important. This is because the beam is actually dominated ${ }^{33}$ by $\mathrm{NO}_{2}$. Other species, namely $\mathrm{NO}, \mathrm{O}_{2}$, and $\mathrm{N}_{2} \mathrm{O}_{5}$ are also present to a lesser extent (Fig. 7). All of these impurities will contribute to a large, constant background at product masses. Only $\mathrm{NO}_{3}$ and $\mathrm{NO}_{2}$ absorb at the wavelengths studied. ${ }^{1,2,6 e}$ However, $\mathrm{NO}_{2}$ remains bound upon single photon absorption. ${ }^{23}$ Consequently, these contaminant molecules cannot contribute to the photodissociation signal because they are constrained to the beam. The detector only observes those lasercorrelated particles scattered out of the beam due to photodissociation. In order to gauge the possible role of two photon absorption by $\mathrm{NO}_{2}$, parallel experiments were nun using $5 \% \mathrm{NO}_{2} / \mathrm{He}$ mixtures. Formation of $\mathrm{NO}+\mathrm{O}$ was observed at $532 \mathrm{~nm}$ only when the laser was tightly focussed and very high pulse energies ( $>50 \mathrm{~mJ} /$ pulse) were used. Multiphoton effects its $\mathrm{NO}_{2}$ could not be seen at longer wavelengths. In the experiments reported here, the laser was unfocussed with a $2 \mathrm{~mm}$ spot size at the interaction region, and the pulse energies were in the range $0.5-15 \mathrm{~mJ} / \mathrm{pulse}$.

In early experiments using Nozkle 1 , we estimated the $\mathrm{NO}_{3}$ vibrational temperature. ${ }^{33}$ This invoived measurements of hotband intensities at $678.4 \mathrm{~nm}$ relative to the $(0,0)$ band at $662 \mathrm{~nm}$. This hotband corresponds to excitation of $\mathrm{NO}_{3}$ molecules having $360 \mathrm{~cm}^{-1}$ of vibrational excitation. The hotband intensity ratios measured by Sander, et. al., ${ }^{16}$ at two well defined temperatures were employed in the calculation of the beam temperature. Our measurements indicated that essentially no vibrational cooling results from supersonic expansion through the $600 \mathrm{~K}$ nozzle with 0.020 " channel length (i.e. $T_{\text {vib }} \approx 600 \mathrm{~K}$ ). ${ }^{33}$ This is consistent with the general expectation that vibrational 
cooling in supersonic expansions is relatively inefficient.

As can be seen in table $\mathrm{I}$, due to the very low vibrational frequencies of $\mathrm{NO}_{3}$, even at $600 \mathrm{~K}$ a very significant fraction of the molecules in the beam are vibrationally excited. This is of considerable importance in our determinatiun of the $\mathrm{O}-\mathrm{NO}_{2}$ bond dissociation energy since internally hot molecules will be dissociated with redder light than those in the ground state. For a given laser wavelength above threshold, these hot molecules could lead to photofragments with larger translational energy than would be found from dissociation oi ground state molecules. In an effort to cool vibrations, the front plate and nozzle orifice was cooled to $\sim 300 \mathrm{~K}$ by spot welding six nickel wires, 0.030 " dia, 1 " long to the plate surface, without constricting the orifice. The wires were soldered to a water cooled $0.125^{\prime \prime}$ dia. copper tube. This arrangement did result in some vibrational cooling, based on the observation of decreased hotband intensities, as described elsewhere. ${ }^{33}$ However, the use of $\mathrm{Ni}$ wires as described is not a very efficient, nor elegant way to provide a heat sink. In the final experimental effort on the RSM, a somewhat more sophisticated nozzle was designed (Fig 6b). One advantage of the newest design was that it provided an even shurter pyrolysis time. This is clearly desirable since calculations indicate that this will increase the $\mathrm{NO}_{3}$ concentration ${ }^{33}$ (Fig7). Of course, the chief goal of this design was to reduce the vibrational temperature of the $\mathrm{NO}_{3}$. As can be seen in Fig. 6, the region around the nozzle orifice is cooled by the water cooled front electrode to a temperature near $300 \mathrm{~K}$. In principle, this should result in some cooling of the $\mathrm{NO}_{3}$ radicals during expansion through the nozzle. This expectation is based on the earlier measurements using the older nozzle designs in which 
the hot band intensity near $675 \mathrm{~nm}$ was probed using LIF, and found to decrease if the aperture was cooled..$^{33}$ In general, we found that the vibrational temperatures of the particles in the beam are reasonably close to the ambient temperatures of the nozzle orifice. To date, quantitative LIF measurements have not been conducted using the present nozzle. However, we are able to distinguish between signal resulting from photodissociation of ground state and vibrationally hot $\mathrm{NO}_{3}$, as will be shown conclusively in the discussion section.

Nozzle 2 (Fig 6B) was heated by passing AC current $(1 \mathrm{~V}, 60 \mathrm{~A})$ from the front electrode to the back electrode. Both electrodes are copper, and are water cooled. The $0.25 "$ OD copper tubes used for the cooling water also facilitated transmission of the electric current. The front wall of the stainless steel nozzle tube was tumed down to $0.010^{\prime \prime}$ thickness. The flow of current through this region preferentially heats this thin walled section of the tube. The length of this region was $2 \mathrm{~mm}$. The end of the tube was capped, and the nozzle orifice $\left(0.020^{\mathrm{N}}\right.$ dia.) centrally located. Soldered to the front of the tube, near the orifice, was the water cooled front electrode. Due to the large heat capacity of this electrode and efficient cooling due to the flow of water, the region near the nozzle orifice is expected to be near $300 \mathrm{~K}$. Since the heated portion of the tube was very thin, it had little mechanical strength. Consequentiy, the front electrode is actually supported by a ceramic insulating sieeve. This provided strength, while at the same time provided a "slip fit" to allow for expansion of the thin walled portion of the tube upon heating. We have found that this nozzle is very reliable and provides a stable $\mathrm{NO}_{3}$ beam with reproducible velocity and intensity. 
The velocity of the molecular beam was determined by modulating the molecular beam with a spinning slotted disk in front of the detector. The beam velocity could also be checked without using the whell, in holeburning experiments. Due to the large absorption cross section of $\mathrm{NO}_{3},{ }^{1,2,16}$ at high laser powers it was relatively easy to observe depletion of $\mathrm{NO}_{3}$ parent molecules in the beam by simply monitoring the $\mathrm{NO}_{3}{ }^{+}$ parent ion signal while sampling the beam directly through the $0.003^{n}$ aperture. The time profile of this depletion could be used to determine the beam velocity. This was particularly convenient in the early experiments using the A-machine since the wheel had to be removed from the apparatus during the photodissociation experiments.

A number of different laser systems have been employed in this project. For most experiments, a XeCl excimer pumped Lambda Physik FL2002 pulsed dye laser was used to excite the $\mathrm{NO}_{3}$ radicals. The laser polarization could be rotated using a double fresnel rhomb. In the earliest work, a Quanta-Ray Yag pumped pulsed dye laser was employed. Although this laser was capable of achieving very high pulse energies, the repetition rate was only $20 \mathrm{~Hz}$. Owing to the very large $\mathrm{NO}_{3}$ absorption cross section, the laser power had to be attenuated to minimize multiphoton effects. Thus, the excimer pumped laser, which could be operated at $50 \mathrm{~Hz}$, but with a considerably lower pulse energy, was preferable. A series of experiments were also conducted on the RSM using a continuous wave Coherent 699 ring dye laser pumped by a $6 \mathrm{~W} \mathrm{Ar}^{+}$laser. The dye laser was operated in "broadband" mode (ie. like a 699-05), and the typical output was $\sim 1$ Watt. The laser bearn was modulated using the cross correlation technique ${ }^{37}$ by sending the beam t'irough a small vacuum chamber in which a double sequence cross 
correlation wheel was spun at $392 \mathrm{~Hz}$. The cross correlation wheel provided $50 \%$ duty cycle with a nominal $5 \mu \mathrm{sec}$ time resolution. In all $\mathrm{CW}$ experiments, the laser wavelength was monitored by sending a very small portion of the beam through a $0.5 \mathrm{~m}$ monochromator and the transmission was measured using a visible PMT. The monochromator was calibrated using a standard neon resonance lamp.

In the RSM, a small fraction of the photodissociation products fly $36.7 \mathrm{~cm}$ into an electron bombardment ionizer. ${ }^{35}$ The distance on the A-machine is only $20.8 \mathrm{~cm}$. However, the detectors are similar in both machines. ${ }^{34,35}$ The resulting ions are extracted into a quadrupole mass filter and detected by a Daly ion detector. The geometry of the detector defining slits ensures that only the $2 \times 2 \mathrm{~mm}$ zone centered at the interaction region is viewed by the detector. Consequently, only those dissociation events which occur within $-2 \mu$ s are detected. A 1024 channel scaler with $1 \mu \mathrm{s}$ dwelltime, triggered by the laser pulse, was used Cor product TOF measurements. In all experiments, the detector was operated at unit mass resolution.

The translational energy distribution $\mathrm{P}(\mathrm{E})$ for each product channel is obtained by the forward convolution method. ${ }^{35}$ The experimental time of flight data is compared to a calculated spectrum based on a trial $P(E)$. The trial $P(E)$ is iteratively adjusted until good agreement is observed between the calculated and observed TOF data. The computer program used in this procedure convolutes over the spread in beam velocity and the known detector parameters, and calculates the required laboratory to center of mass Jacobian transformations needed for the simulation. 


\section{RESULTS AND ANALYSIS}

In most experiments, the laser was vertically polarized, perpendicular to the detector axis. However, if the dissociation lifetime is less than one parent rotational period, an anisotropic product angular distribution is possible, and must be considered in the data analysis. We have found that the product angular distributions are isotropic at all wavelengths studied-- i.e. the anisotropy parameter ( $\beta$-parameter) is zero. This measurement was accomplished by conducting a series of polarization experiments at a number of wavelengths down to $532 \mathrm{~nm}$. Using a reduced laser intensity to minimize possible saturation effects, product time-of-flight spectra were recorded using a number of polarizations. The polarization was rotated using a double Fresnel rhomb. The isotropic product angular distribution that we observe is consistent with a dissociation timescale considerably longer than one $\mathrm{NO}_{3}$ rotational period ( $\sim$ lpsec).

Experiments were conducted at a wide range of laser wavelengths, primarily at the peak $\mathrm{NO}_{3}$ absorbances in the range 532-662nm. Photodissociation product signal was observed at $\mathrm{m} / \mathrm{e}=46\left(\mathrm{NO}_{2}{ }^{+}\right), \mathrm{m} / \mathrm{e}=32\left(\mathrm{O}_{2}{ }^{+}\right), \mathrm{m} / \mathrm{e}=30\left(\mathrm{NO}^{+}\right)$, and $\mathrm{m} / \mathrm{e}=16\left(\mathrm{O}^{+}\right)$. The earliest work obtained using the A-machine and nozzle 1 will be discussed in section 3.1. The purpose of this section is to present a number of the important observations. In the earliest work, we focused our attention on the peak near $590 \mathrm{~nm}$, as photolysis at this wavelength led to the maximum observed $\mathrm{NO}+\mathrm{O}_{2}$ signal level. The effect of tuning the laser above and below 590nm (still using nozzle 1 on the A-machine) is explored in detail in section 3.2. We clearly observed multiphoton effects at wavelengths above $590 \mathrm{~nm}$. Although this effect could be minimized by running experiments at very low 
power, the signal to noise ratio was very poor when the laser output was reduced to these low levels. This observation laid the groundwork for the more recent experiments, which were conducted using the RSM. In addition to eliminating a substantial contribution from dissociation of hot $\mathrm{NO}_{3}$ radicals, the RSM experiments provided much higher resolution, making it possible to resolve vibrational structure in the $\mathrm{NO}+\mathrm{O}_{2}$ TOF. This data, obtained using the excimer pumped dye laser will be presented in section 3.3. The focus of section 3.4 is on measurements pertaining to the determination of $\mathrm{D}_{0}\left(\mathrm{O}-\mathrm{NO}_{2}\right)$. This quantity was obtained from two separate kinds of measurements. The first method involves observation of the wavelength dependence of the $\mathrm{NO}_{2}+\mathrm{O}$ channels. This data was obtained under single photon conditions using the ring laser. The second method involved careful measurements of the maximum translational energy release for the $\mathrm{NO}_{2}+\mathrm{O}$ channel at wavelengths considerably above threshold. These two complimentary measurements, as well as a number of other observations, lead to an accurate determination of $\mathrm{D}_{0}\left(\mathrm{O}-\mathrm{NO}_{2}\right)$, allowing us to calculate $\Delta \mathrm{H}_{\mathrm{r}}\left(\mathrm{NO}_{3}\right)$ directly.

\section{A. Photodissociation of $\mathrm{NO}_{3}$ at $590 \mathrm{~nm}$ using A-machine and Nozzle 1 .}

The Newton diagram for the $\mathrm{NO}$ channels from photodissaciation of $\mathrm{NO}_{3}$ at $590 \mathrm{~nm}$ is shown in Figure 8. The radius of the Newton circle for the $\mathrm{NO}_{2}$ product from the $\mathrm{NO}_{2}+\mathrm{O}$ channel will be very sensitive to the actual value of $\mathrm{D}_{\mathrm{o}}\left(\mathrm{O}-\mathrm{NO}_{2}\right)$ and the vibrational energy of the $\mathrm{NO}_{3}$ molecules in the beam. The radius must be small, however, because of the close proximity to the wavelength threshold for $\mathrm{NO}_{2}+\mathrm{O}$. In addition, the heavy $\mathrm{NO}_{2}$ particle is constrained to appear near the beam because of its 
light $\mathrm{O}$ atom recoil partner. The simultaneous existence of the $\mathrm{NO}_{2}+\mathrm{O}$ and $\mathrm{NO}+\mathrm{O}_{2}$ product channels at $590 \mathrm{~nm}$ is demonstrated in the 590nm data shown in Fig 9. The observed $\mathrm{NO}_{2}{ }^{+}$signal results from the $\mathrm{NO}_{2}+\mathrm{O}$ channel. A similar slow peak is also seen in the NO+ TOF. This is the daughter ion from fragmentation of $\mathrm{NO}_{2}$ to $\mathrm{NO}^{+}$upon electron impact ionization. The fast peak in the $\mathrm{NO}^{+} \mathrm{TOF}$ is due to NO parent ion from the NO $+\mathrm{O}_{2}$ channel. This conclusion is confirmed by the existence of a similar peak in the $\mathrm{m} / \mathrm{e}=32\left(\mathrm{O}_{2}^{+}\right)$TOF spectrum corresponding to the momentum matched $\mathrm{O}_{2}$ fragment (Fig 9). Signal from both dissociation channels was found to disappear if the nozzle heater was switched off. It also decreases upon heating above $600 \mathrm{~K}$ due to decrease in $\mathrm{NO}_{3}$ concentration. In the early experiments, we did not have any means to rotate the laser polarization without realignment of the laser beam. However, based on the comparable signal levels in experiments using vertical and horizontal laser polarization, we believed the effect was near zero, and this was confirmed in more recent work using the RSM. The NO TOF spectra at other detector angles are shown in Figs. 10 and 11. An additional feature, observed between 10 and 20 degrees at $\sim 100-170 \mu \mathrm{s}$ results from sequential 2 photon absorption by $\mathrm{NO}_{3}$ yielding $\mathrm{NO}_{2}+\mathrm{O}$ (Fig 10). This contribution to the observed TOF was not fitted in the analysis. The two photon effect will be discussed below. As expected from the kinematics, the $\mathrm{NO}_{2}$ product channel is only observed at angles less than or equal to 12.5 degrees, whereas $\mathrm{NO}+\mathrm{O}_{2}$ products can be seen at all detector angles. (Figs. 10,11)

The product translational energy distributions that resulted from the fit of the 590nm data (solid line in Figs. 10,11) are shown in Fig 12. Very little structure could 
be resolved in this data. However, upon closely examining the NO $+\mathrm{O}_{2} \mathrm{TOF}$, a small but reproducible shoulder can be observed on the fast edge of the NO time of flight spectra at all angles. This fast shoulder must result from formation of $\mathrm{NO}(\mathrm{II})+\mathrm{O}_{2}\left({ }^{3} \Sigma_{z}\right)$ (the ground electronic states of $\mathrm{O}_{2}$ ). This conclusion is based on energy conservation-product translational energies higher than $25 \mathrm{kcal} / \mathrm{mol}$ leave insufficient energy for excitation to the $\mathrm{O}_{2}\left({ }^{1} \Delta_{\mathrm{g}}\right)$ state. Interestingly, the dominant, slower component in the TOF spectrum fell completely within the translational energy range dictated (by conservation of energy) for the NO $+\mathrm{O}_{2}\left({ }^{1} \Delta_{8}\right)$ channel. These observations prompted the use of two separate contributions in fitting the $\mathrm{NO}+\mathrm{O}_{2}$ translational energy distributions. The two components were fitted by requiring that the slower peak fall completely within the energy boundaries consistent with NO $+\mathrm{O}_{2}\left({ }^{1} \Delta_{\mathrm{g}}\right)$ (i.e.; $\left.\mathrm{E}_{\text {rana, } \max }-25 \mathrm{kcal} / \mathrm{mol}\right)$. These early observations strongly suggested that ${ }^{1} \Delta_{g}$ is in fact the dominant electronic state of $\mathrm{O}_{2}$ resulting from the photodissociation of $\mathrm{NO}_{3}$ at $590 \mathrm{~nm}$.

The branching ratio for the $\mathrm{NO}_{2}+\mathrm{O}$ to the $\mathrm{NO}+\mathrm{O}_{2}$ channel at $590 \mathrm{~nm}$, based on measurements using the relatively hot $\mathrm{NO}_{3}$ radicals formed in nozzle 1 , was obtained from the $\mathrm{m} / \mathrm{e}=30\left(\mathrm{NO}^{+}\right)$TOF data. The optimized fit of the entire data set (Figs. 912) acquired at all detector angles yields an "apparent" branching ratio $\mathbf{R}_{\text {spp }}$ defined by equation 1 :

$$
R_{\mathrm{app}}=\frac{\chi\left(\mathrm{NO}+\mathrm{O}_{2}\right)}{\chi\left(\mathrm{NO}_{2}+\mathrm{O}\right)}=1.10
$$


where the $\chi$ 's are the integrated areas under the product $P(E)$ distributions for the two different chemical product channels, normalized for the differing Jacobian factors calculated by the computer program in carrying out the $\mathrm{LAB} \rightarrow \mathrm{CM}$ coordinate transformations. The actual branching ratio $\mathrm{R}$ is related to the "apparent" ratio by the following expression:

$$
R=R_{\text {app }} \times \frac{\sigma_{\text {ion }}\left(\mathrm{NO}_{2}\right)}{\sigma_{\text {ion }}(\mathrm{NO})} \times \frac{F\left(\mathrm{NO}^{+} / \mathrm{NO}_{2}\right)}{F\left(\mathrm{NO}^{+} / \mathrm{NO}\right)}
$$

In equation $12, \sigma_{\text {ien }}\left(\mathrm{NO}_{2}\right)$ and $\sigma_{\text {ion }}(\mathrm{NO})$ are the ionization cross sections for $\mathrm{NO}_{2}$ and $\mathrm{NO}$, respectively. They were calculated using the following empirical relationship ${ }^{38}$ relating the peak ionization cross section $\left(\sigma_{\text {ioo }}\right)$ to molecular polarizability $(\alpha)$ :

$$
\sigma_{i o n}=36 \sqrt{\alpha}-18
$$

The molecular polarizabilities are taken to be the sum of the atomic polarizabilities. ${ }^{39}$ $\mathrm{F}\left(\mathrm{NO}^{+} / \mathrm{NO}_{2}\right)$ is the fraction of $\mathrm{NO}_{2}$ product molecules that fragment to $\mathrm{NO}^{+}$, a quantity directly measurable in this experiment. Although the fragmentation pattern of $\mathrm{NO}_{2}$ is expected to strongly depend on its level of internal excitation, our fragmentation ratios agree quite closely to published values for room temperature $\mathrm{NO}_{2}{ }^{40}$ This similarity is a result of our close proximity to the wavelength threshold for $\mathrm{NO}_{3} \rightarrow \mathrm{NO}_{2}+\mathrm{O}$ at $590 \mathrm{~nm}$. By inserting the appropriate values into equation 2 we find that $R=1.01$, 
indicating that yields of the two chemical products are equal at $590 \mathrm{~nm}$ to within the errors associated with the calculation, estimated to be $\pm 20 \%$. The largest source of error stems from uncertainty in the $P(E)$ for $E_{\text {tras }}<1 \mathrm{kcal} / \mathrm{mol}$ due to our inability to detect photodissociation products within 5 degrees of the beam. Thus we conclude that at $590 \mathrm{~nm}$ :

$$
\begin{aligned}
\mathrm{NO}_{3} \rightarrow \quad \mathrm{NO}_{2}+\mathrm{O} & \Phi_{1}=0.5 \pm 0.1 \\
& \rightarrow \quad \mathrm{NO}+\mathrm{O}_{2} \quad \Phi_{2}=0.5 \pm 0.1
\end{aligned}
$$

This calculation is based on several assumptions. First, we assume that photodissociation occurs within $2 \mu \mathrm{sec}$; i.e., before the excited $\mathrm{NO}_{3}$ molecules fly out of the viewing range of the detector. We have also assumed that $\Phi_{1}+\Phi_{2}=1.0$ at $590 \mathrm{~nm}$. This appears to be a reasonable assumption based on the absence of fluorescence under collision free conditions below $600 \mathrm{~nm}$. We also assume that multiphoton processes are negligible at $590 \mathrm{~nm}$. Although this will be discussed in detail below, this appears to be be reasonable.

\section{B. Wavelength Dependence Studies on the A-machine}

A dramatic decrease in the $\mathrm{NO}+\mathrm{O}_{2}$ quantum yield is observed upon tuning the laser from 590 to $584 \mathrm{~nm}$ as evidenced by the NO TOF data recorded at 10 degrees (Fig 13). As expected, the same behavior is observed in the $\mathrm{O}_{2}{ }^{+}$data. The integrated signal 
intensity for the $\mathrm{NO}_{2}+\mathrm{O}$ channel (measured at $\mathrm{m} / \mathrm{e}=30$ or 46 ) was found to increase upon tuning from 590 to $584 \mathrm{~nm}$. Figure 14 shows the $\mathrm{NO}^{+}$time of flight data taken at 10 degrees as the photolysis wavelength is set above $590 \mathrm{~nm}$. The laser pulse energy was $10 \mathrm{~mJ} /$ pulse. Two major effects may be noted. First, the yield of NO $+\mathrm{O}_{2}$ (faster peak) decreases somewhat with respect of the $\mathrm{NO}_{2}+\mathrm{O}$ peak. This decrease in $\mathrm{NO}+\mathrm{O}_{2}$ was also apparent from the $\mathrm{O}_{2}{ }^{+}$TOF data. The second observation is that another component grows in, between the two peaks. On reaching $596 \mathrm{~nm}$, the three components have nearly merged together. We attribute this third component, which was also observed at $\mathrm{NO}_{2}{ }^{+}$ (but not $\mathrm{O}_{2}{ }^{+}$), as sequential two photon absorption of $\mathrm{NO}_{3}$ resulting in formation of $\mathrm{NO}_{2}$ +0 . All available evidence indicates that two photon absorption does not lead to formation of $\mathrm{NO}+\mathrm{O}_{2}$. Because the two photon process leads to $\mathrm{NO}_{2}$ with substantially larger translational energy than the one photon process, we at first believed that they could be distinguished from one another. However, it is impossible to rule out the possibility of formation of internally excited $\mathrm{NO}_{2}$ from two photon photodissociation of $\mathrm{NO}_{3}$. This makes it very difficult to unambiguously separate the two contributions, particularly since the signal to noise ratio declines considerably at lower pulse energies. However, it is certain that the contribution from two photon effects increases substantially upon tuning the laser above $590 \mathrm{~nm}$, even at the lowest laser power. It should be noted that power dependence measurements showed linear behavior, suggesting that the second photon absorption cross section is very large, and was saturated at these laser powers.

Prolonged averaging at $\mathrm{m} / \mathrm{e}=32\left(\mathrm{O}_{2}{ }^{+}\right)$with the laser at $605 \mathrm{~nm}$ revealed weak 
signal indicating the existence of the $\mathrm{NO}+\mathrm{O}_{2}$ channel. $\mathrm{No}_{2}{ }^{+}$signal was observed at $613,623,637$, or $662 \mathrm{~nm}$ (local maxima in the room temperature $\mathrm{NO}_{3}$ absorption spectrum), but the $\mathrm{NO}_{2}+\mathrm{O}$ channel could be seen with decreasing intensity at wavelengths up to $637 \mathrm{~nm}$, using the pulsed laser. It should be noted that it was impossible to rule out possible contributions from some multiphoton effects in the long wavelength regime. There was also considerable concern about the role of vibrationally hot molecules, which might be dissociated considerably to the red of true $\mathrm{NO}_{2}+\mathrm{O}$ wavelength threshold. Figure 15 shows the observed wavelength dependence for the two chemically distinct channels, measured using Nozzle 1. Because the absorption spectrum is not known for rotationally cold $\mathrm{NO}_{3}$, the data in Fig. 15 is not normalized for the absorption cross sections. While the data in Fig. 15 was reproducible, and was obtained under the lowest possible laser fluence $\left(<1 \mathrm{~mJ} /\right.$ pulse), there was concern that the $\mathrm{NO}_{2}$ + O signal at wavelengths above $590 \mathrm{~nm}$ could still result from multiphoton effects or from photodissociation of internally hot $\mathrm{NO}_{3}$. Power dependence studies showed that the intensity was linear in power at these pulse energies, but this could also be due to saturation of the second photon transition. It is interesting to note that the wavelength dependence for the NO $+\mathrm{O}_{2}$ signal level (Fig. 15) shows many similarities to that obtained by Magnotta (Fig. 3). In particular, the sharp drop of the $\mathrm{NO}+\mathrm{O}_{2}$ channel below $590 \mathrm{~nm}$ that we observe is essentially identical to their earlier result. Our quantum yield of $0.5 \pm 0.1$ at $590 \mathrm{~nm}$ is slightly higher, but in reasonable agreement with Magnotta's value. The main difference is that the $\mathrm{NO}_{2}$ yield in our experiment is smaller than that obtained in Magnotta's experiment in the red region of the spectrum. The 
question of the $\mathrm{NO}_{2}$ quantum yields near threshold will be addressed in section 3.4.2.

\section{C. High resolution studies on the RSM using Nozzle 2.}

As already mentioned, the longer neutral flightlength of the RSM provides the opportunity to achieve increased resolution in the translational energy distributions. Structure observable in the $\mathrm{NO}+\mathrm{O}_{2}$ data obtained on the A-machine suggested that it might in fact be possible to resolve features resulting from vibrational excitation of the product molecules. Resolving such structure could provide useful insight into the dynamics of the $\mathrm{NO}+\mathrm{O}_{2}$ channel, particularly if this structure is wavelength dependent. A series of experiments were conducted at two excitation wavelengths, $588 \mathrm{~nm}$ and $594 \mathrm{~nm}$. These wavelengths were chosen because the $\mathrm{NO}+\mathrm{O}_{2}$ channel is appreciable, yet they fall near the edges of the range where $\mathrm{NO}+\mathrm{O}_{2}$ is observed (Fig 15). Earlier experiments suggested that the structure in the TOF changed somewhat, upon tuning across this wavelength region.

The $\mathrm{NO}^{+}$fragment was monitored at a number of angles for each wavelength. For each time of flight, the data was accuinulated for a period of 1 hour. The data is shown in Figs. 16 and 17, and the resulting translational energy distributions are shown if Figs. 18 and 19. A considerable amount of structure is observed in the time-of-flight spectra obtained at high resolution. The resulting translational energy distributions reflect this structure. The $\mathrm{P}^{\prime} \mathrm{s}(\mathrm{E})$ shown in Figs. 18 and 19 result from the best fit to the data at all angles for each wavelength. 
III. D. $\mathrm{NO}_{2}+\mathrm{O}$ Transiational energy distributions at wavelengths above threshold An accurate determination of the enthalpy of formation of the nitrate free radical $\left(\mathrm{NO}_{3}\right)$ is of considerable importance in properly thodelling reactions involving nitrogen oxides and ozone. The currently accepted literature values, ${ }^{4,23}$ of $\left.\Delta \mathrm{H}^{\circ} \times \mathrm{NO}_{3}\right)$ rely on the combined results of several separate thermochemical measurements involving dinitrogen pentoxide $\left(\mathrm{N}_{2} \mathrm{O}_{5}\right)$, a relatively unstable molecule that is extremely difficult to prepare in pure form.

In addition to providing considerable information on the dynamics of the photodissociation process, this technique is a particularly attractive method for thermochemical measurements involving unstable species. ${ }^{35}$ In the photodissociation of an isolated $\mathrm{NO}_{3}$ molecule, conservation of energy dictates that:

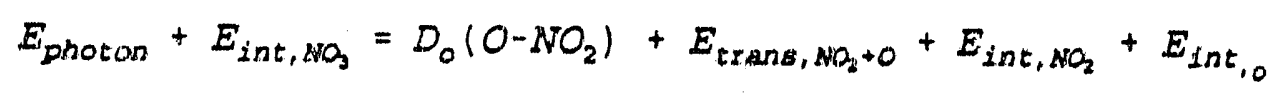

In a simple bond rupture, such as $\mathrm{NO}_{3} \rightarrow \mathrm{NO}_{2}+\mathrm{O}\left({ }^{3} \mathrm{P}\right)$, the maximum transiationlal energy release corresponds to the production of ground state fragments. Thus, by measuring the maximum translational energy for the $\mathrm{NO}_{2}+\mathrm{O}$ products, we obtain $\mathrm{D}_{0}(\mathrm{D}$ $\mathrm{NO}_{2}$ ) directly:

$$
\left.E_{\text {photon }}+E_{\text {int, NO }}=D_{C}(1)-\mathrm{NO}_{2}\right)+E_{\text {trans, max }, \mathrm{NO}_{2}+\mathrm{O}}(17)
$$

or

$$
D_{0}\left(0-\mathrm{NO}_{2}\right)-E_{\text {int, HO }}=E_{\text {photon }}-E_{t \text { tans, max, NO }}+0(28)
$$




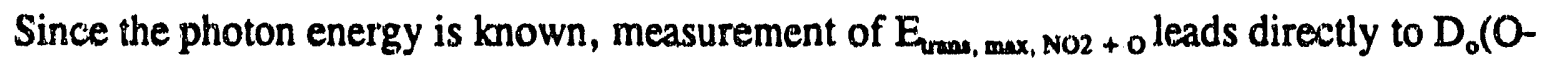
$\left.\mathrm{NO}_{2}\right)-\mathrm{E}_{\text {int,NO3 }}$. Usualiy, $\mathrm{E}_{\text {nut }}$ is assumed to be zero. However, in the present case, this could be a bad assumption, particularly because the molecules are formed by pyrolysis. It is also important to note that because $\mathrm{NO}_{3}$ has low vibrational frequencies, a substantial fraction of the beam will be vibrationally hot (Table I). Consequently, in the present experiment we have conducted measurements at several wavelengths. Based on the maximum translational energies at different excitation wavelengths, we should be able to address the possible role of vibrationally excited $\mathrm{NO}_{3}$ in the beam.

In the earlier experiments on the A-machine, we focussed our attention primarily on wavelengths above $580 \mathrm{~nm}$ since this is the wavelength region where the $\mathrm{NO}+\mathrm{O}_{2}$ channel was seen. It also seemed reasonable to measure the maximurn translational energy for the $\mathrm{NO}_{2}+\mathrm{O}$ channel near threshold, since the $v^{2} / \mathrm{u}^{2}$ Jacobian factor in the $\mathrm{CM} \rightarrow \mathrm{LAB}$ transformation leads to large signal levels for slow particles. This appeared to be a logical approach because we were very concerned with the contribution from multiphoton processes. However, the maximum translational energies that we obtained at $590 \mathrm{~nm}$ were near $4 \mathrm{kcal} / \mathrm{mole}$ (Fig. 12). The majority of the signal, however fell at energies below $2 \mathrm{kcal} /$ mole. Unfortunately, it was impossible to tell for certain whether the fast edge resulted from hot molecules in the beam, from multiphoton effects, or from dissociation of "cold" $\mathrm{NO}_{3}$.

In planning the final experimental effort on the RSM, we considered the possibility of multiphoton effects and photodissociation of hot molecules in the molecular beam. It appears that multiphoton effects can be largely attributable to the long 
dissociation timescale for $\mathrm{NO}_{3}$ at $\lambda>590 \mathrm{~nm}$. Thus, it appeared that the best approach on the RSM would be to measure the maximum translational energy release at a number of wavelengths considerably above threshold, where the dissociation timescale is expected to be much faster. Since it is clear that the quantum yield for $\mathrm{NO}_{2}+\mathrm{O}$ is 1.0 below $580 \mathrm{~nm}$, any structure in the translational energy distribution observed at higher excitation energies might reflect the vibrational distribution of the parent $\mathrm{NO}_{3}$ molecules. A "cold" nozzle (Fig. 6B) was designed in hopes of cooling the radicals-- if a substantially different result was seen using this nozzle, we would have evidence for dissociation of hot $\mathrm{NO}_{3}$.

The TOF data taken at $\mathrm{m} / \mathrm{e}=16\left(\mathrm{O}^{+}\right)$at an excitation wavelength of $560 \mathrm{~nm}$ is shown in Fig. 20. Three translational energy distributions are shown in Fig. 20. As shown in Fig. 20b, the best fit was obtained with the maximum recoil energy of 3.5 $\mathrm{kcal} / \mathrm{mol}$. Note that most products have an energy of $\leq 2.5 \mathrm{kcal} / \mathrm{mole}$. Figures $20 \mathrm{a}$ and $20 \mathrm{c}$ show the sensitivity of the fit. It is clear that $E_{\text {rans, } \max }=3.5 \pm 0.5 \mathrm{kcal} / \mathrm{mol}$ at $560 \mathrm{~nm}$. Figures 21 and 22 show the TOF and $\mathrm{P}(\mathrm{E})$ for the $\mathrm{NO}_{2}+\mathrm{O}$ channel at $548 \mathrm{~nm}$. The maximum translational energy release was $4.3 \mathrm{kcal} / \mathrm{mole}$ at $548 \mathrm{~nm}$. The fast edge of the translational energy distributions at both wavelengths were assumed to correspond to formation of $\mathrm{NO}_{2}$ in the ground vibrational and rotational state. This assumption is reasonable in view of the proximity to the wavelength threshold and the nature of the process: simple $\mathrm{O}-\mathrm{NO}_{2}$ bond rupture. The calibration of the laser is known to be within $5 \mathrm{~cm}^{-1}(0.014 \mathrm{kcal} / \mathrm{mol})$ based on the experiments described in Chapter 5 .

Based on these measurements, we obtain the following relationships: 
548nm:

$$
\mathrm{D}_{\mathrm{o}}\left(\mathrm{O}-\mathrm{NO}_{2}\right)-\mathrm{E}_{\mathrm{ath}, \mathrm{NO} 3}=\mathrm{E}_{\mathrm{b}}, \mathrm{E}_{\mathrm{rrans}, \max }=(52.15-4.3)=47.8 \pm 0.5 \mathrm{kcal} / \mathrm{mol}
$$

560nm:

$\mathrm{D}_{0}\left(\mathrm{O}-\mathrm{NO}_{2}\right)-\mathrm{E}_{\text {tat } \mathrm{NO} O 3}=\mathrm{E}_{\mathrm{h},}-\mathrm{E}_{\mathrm{ranas}, \max }=(51.03-3.5)=47.5 \pm 0.5 \mathrm{kcal} / \mathrm{mol}$

We are encouraged by the fact that the maximum recoil energy follows the laser photon energy.

If all of the $\mathrm{NO}_{3}$ molecules in the beam were in their ground vibrational state, then the maximum product translational energies would give an upper limit to the bond dissociation energy. Because the beam was formed at $600 \mathrm{~K}$, however, low frequency vibrational modes of $\mathrm{NO}_{3}$ are expected to have appreciable populations. We must consider possible contributions from these hot molecules. The vibrational frequencies ${ }^{10}$ for $\mathrm{NO}_{3}$ (assuming $\mathrm{D}_{3 \mathrm{k}}$ symmetry) and expected equilibrium populations relative to the ground vibrational state are listed in Table 1. Based on the earlier measurements of hotband intensities, we have found that the vibrational temperature of the $\mathrm{NO}_{3}$ beam is very close to the nozzle temperature. Using the first nozzle, we obtained a temperature of $600 \mathrm{~K}$, in close agreement with the expected nozzle temperature. In nozzle 2 , the orifice is water cooled, and is expected to be nearer to room temperature. Unfortunately, it is not clear that the vibrational temperature of the $\mathrm{NO}_{3}$ will be as cool as this. However, we can confidently exclude the possibility that the $\mathrm{NO}_{3}$ is hotter than $600 \mathrm{~K}$ since it is formed by thermal dissociation of $\mathrm{N}_{2} \mathrm{O}_{5}$. Since the $\mathrm{NO}_{3}$ molecules are formed 
by an endothermic process (simple bond rupture), it is extremely unlikely that they will be hotter than the ambient nozzle temperature, particularly since they subsequently undergo collisions before and during the supersonic expansion.

The temperature dependence of the $\mathrm{NO}_{3}$ absorption spectrum (Fig. 1) indicates that the transitions at 548 and 560nin do not result exclusively from hotband activity. Although Cantrell ${ }^{20}$ has found the absorption at $662 \mathrm{~nm}$ to be temperature independent, there is no evidence that the earlier temperature dependence measurements of Sander ${ }^{16}$ suffer from wavelength dependent artifacts. Thus, the molecules absorbing at 560 and $548 \mathrm{~nm}$ exhibit behavior similar to that seen across nearly the entire spectrum. It is also worth noting that the observation that the maximum translational energy release tracks with the photon energy gives us confidence that we have not accidentally selected 'hotband' transitions at these two wavelengths.

\section{E. Wavelength dependence for the $\mathrm{NO}_{2}+\mathrm{O}$ Channel}

A second approach exists for determining the $\mathrm{O}-\mathrm{NO}_{2}$ bond dissociation energy. It involves measuring the $\mathrm{NO}_{2}+\mathrm{O}$ yields as a function of wavelength near threshold. Based on our earlier experiments on the A-machine, and the results presented in section 3.4.1, it appeared that the wavelength threshold for formation of $\mathrm{O}+\mathrm{NO}_{2}$ was near $600 \mathrm{~nm}$. As already mentioned, very strong multiphoton effects are seen in this region, as discussed in Section 3.1.

The pulsed dye laser is typically operated at $50 \mathrm{~Hz}$, and the pulse duration is $\sim 20$ ns. This transiates into a duty cycle of $1 \times 10^{-6} \ldots$ i.e. the laser is only on for one- 
millionth of the time. With a total output power of up to $1 \mathrm{~W}$, it is not surprising that multiphoton effects are observed in the $\mathrm{NO}_{3}$ photodissociation experiments at wavelengths where the excited state lifetime likely exceeds many picoseconds. The Coherent 699 ring dye laser provides comparable output power (1W), but it is continuous, rather than pulsed. Using the cross correlation technique, we can obtain a $50 \%$ duty cycle and still obtain product TOF information. With the ring laser, the effective peak power is $10^{6}$ times lower than in the pulsed experiment, ruling out the possibility of multiphoton effects.

The Newton diagram for the $\mathrm{O}$ atom product from photodissociation of $\mathrm{NO}_{3}$ at various energies above threshold is shown in Fig. 23. By monitoring the light $\mathrm{O}$ atom fragment at 10 degrees, we can observe the $\mathrm{NO}_{2}+\mathrm{O}$ reaction channel provided that the photon energy is at least $0.25 \mathrm{kcal} / \mathrm{mol}$ above threshold. The $\mathrm{O}^{+}$time of flight spectrum obtained at an excitation wavelength of 592nm using the ring laser is shown in Fig. 24. The data was accumulated for a period of 1 hour. Due to the inherently stable output of the ring laser, it was very easy to maintain a constant output power for many hours throughout the duration of the experiment. The integrated area under the $\mathrm{O}^{+}$TOF peak is plotted as a function of wavelength in Fig. 25. The signal was undetectable at wavelengths above $599 \mathrm{~nm}$. The signal level increased steadily at wavelengths below $599 \mathrm{~nm}$, teaching a plateau near $592 \mathrm{~nm}$. The signal level increased sharply below $584 \mathrm{~nm}$. Similar experiments were conducted while monitoring $\mathrm{NO}$ from the $\mathrm{NO}+\mathrm{O}_{2}$ channel at 40 degrees. The shape of the TOF was found to be very similar to that obtained using the pulsed laser, indicating that multiphoton processes do not contribute 
significantly to the observed $\mathrm{NO}+\mathrm{O}_{2}$ TOF (Fig. 26). Of course, it multiphoton activity is competing with the NO $+\mathrm{O}_{2}$ yield, this will lead to an artificially low value for the $\mathrm{NO}+\mathrm{O}_{2}$ quantum yield. The integrated intensity for NO at 40 degrees is plotted as a function of wavelength in Fig. 27. It is interesting to note that the signal drops to zero below $586 \mathrm{~nm}$, in excellent agreement with the behavior seen earlier by $\mathrm{us}^{33}$ using the pulsed laser, and by Magnotta. ${ }^{3}$

Based on the $\mathrm{O}^{+}$wavelength dependence plotted in Fig. 25, The "observed" wavelength threshold for the $\mathrm{NO}_{2}+\mathrm{O}$ channel was $599 \pm 2 \mathrm{~nm}\left(\mathrm{E}_{\mathrm{h} \nu}=47.71 \pm 0.15\right.$ $\mathrm{kcal} / \mathrm{mol}$ ) under single photon conditions using the ring laser. However, it is important to note that at an angle of 10 degrees, the minimum recoil energy detectable is 0.25 $\mathrm{kcal} / \mathrm{mol}$. Thus the threshold for formation of $\mathrm{NO}_{2}+\mathrm{O}$ with zero recoil energy is $47.71 \pm 0.25-0.25=47.46 \pm 0.16 \mathrm{kcal} / \mathrm{mol}$. Assuming that at least some of the $\mathrm{NO}_{2}$ products are formed in their ground rotational and vibrational states near threshold (a good assumption for simple bond rupture), we obtain the following relationship:

$\mathrm{D}_{0}\left(\mathrm{O}-\mathrm{NO}_{2}\right)-\mathrm{E}_{\text {int,NO3 }}=\mathrm{E}_{\mathrm{hresh}}=47.46 \pm 0.16 \mathrm{kcal} / \mathrm{mol}$

This value is slightly lower, but in reasonable agreement with the values obtained from the maximum translational energy release at energies well above threshold.

In order to establish a value for $\mathrm{D}_{\mathrm{o}}\left(\mathrm{O}-\mathrm{NO}_{2}\right)$, we must evaluate $\mathrm{E}_{\text {int,No3 }}$. Based on the data presented in Table 1, it is clear that a large fraction of $\mathrm{NO}_{3}$ molecules will possess one quantum of excitation in the doubly degenerate $v_{4}$ mode at $363 \mathrm{~cm}^{-1}$. 
Depending on the actual temperature of the beam, this population could even be $84 \%$ of that having $v_{4}=0$. The population of $\mathrm{NO}_{3}$ molecules having two quanta of doubly degenerate $v_{4}$ excitation $\left(2 \times 363 \mathrm{~cm}^{-1}=726 \mathrm{~cm}^{-1}\right)$ will not be negligible if the beam temperature is near $600 \mathrm{~K}$. It is important to note that $363 \mathrm{~cm}^{-1}$ translates to $1.03 \mathrm{kcal} / \mathrm{mole}$, and $726 \mathrm{~cm}^{-1}=2.07 \mathrm{kcal} / \mathrm{mole}$. Thus, the potential error in our value of $\mathrm{D}_{\mathrm{o}}\left(\mathrm{O}-\mathrm{NO}_{2}\right)$ will be large if we do not correctly evaluate $\mathrm{E}_{\mathrm{inh}, \mathrm{No3}}$. Further discussion will be deferred to section 4.1 .

\section{DISCUSSION}

\section{A. $\mathrm{NO}_{3}$ Photodissociation Wavelength Dependence.}

Perhaps the most striking result of this work is the narrow wavelength range over which NO $+\mathrm{O}_{2}$ is observed, corresponding to a range of less than $1.75 \mathrm{kcal} / \mathrm{mole}$ of excitation energy. In contrast, $\mathrm{NO}_{2}+\mathrm{O}$ is observed with a quantum yield of 1.0 at all wavelengths below $584 \mathrm{~nm}$. At $590 \mathrm{~nm}, \mathrm{NO}_{3}$ is excited only $5.3 \mathrm{kcal} / \mathrm{mole}$ above the ${ }^{2} \mathrm{E}$ ' band origin. Formation of NO $+\mathrm{O}_{2}$ involves substantial bond rearrangement requiring bond distortion far greater than that provided by only $5.3 \mathrm{kcal} / \mathrm{mole}$ of vibrational excitation. As suggested by Nelson, ${ }^{3}$ this, together with the strong vibronic coupling known to exist ${ }^{21,22,24}$ between the ' $E$ ' excited state and high lying levels of the ${ }^{2} \mathrm{~A}$ ' ground state, strongly suggests that formation of $\mathrm{NO}+\mathrm{O}_{2}$ involves internal conversion of $\mathrm{NO}_{3}$. Siegbahn has calculated a barrier height of $145 \mathrm{kcal} /$ mole for the $C_{2 v}$ constrained dissociation process. Our results clearly indicate that the barrier actually lies below $48.11 \mathrm{kcal} /$ mole $(\lambda>594 \mathrm{~nm})$ above $\mathrm{NO}_{3}$. This could suggest that the symmetry of $\mathrm{NO}_{3}$ 
may not be near $\mathrm{C}_{2 \mathrm{v}}$ at the transition state, since the potential barriers for transition states of lower symmetry are expected to be substantially less than $145 \mathrm{kcal} / \mathrm{mole}^{28}$ We will address this point in detail in discussing the NO $+\mathrm{O}_{2}$ TOF spectra in section 4.3. It is worthwhile noting that our experimental barrier height is slightly below the lowest limit of $51 \mathrm{kcal} / \mathrm{mol}$ calculated by Boehm and Lohr. ${ }^{28}$

The sharply decreasing signal level for $\mathrm{NO}_{3} \rightarrow \mathrm{NO}+\mathrm{O}_{2}$ below $590 \mathrm{~nm}$ is a very dramatic effect. Our observations are in very good agreement with those of Magnotta. ${ }^{2}$ Since this falloff was reproduced using both the pulsed and ring laser, it cannot result from participation of multiphoton effects. Using the first nozzle, we found that the quantum yield for the channel decreases from $0.5 \pm 0.1$ to $<0.01$ over a $6 \mathrm{~nm}$ range, corresponding to a change in photon energy of only $0.50 \mathrm{kcal} / \mathrm{mol}$. In order to explain this behavior, we must also consider the $\mathrm{NO}_{2}+\mathrm{O}$ signal level in this wavelength interval. The only reliable $\mathrm{NO}_{2}+\mathrm{O}$ data above $590 \mathrm{~nm}$ is that obtained using the ring laser under strict one photon conditions. We find that the $\mathrm{NO}_{2}+\mathrm{O}$ yield increases rapidly at photon energies above the $599 \mathrm{~nm}$ threshold, reaching a plateau near $590 \mathrm{~nm}$. This behavior is quite different than that seen earlier using the pulsed laser. The large difference indicates that a substantial fraction of the $\mathrm{NO}_{2}$ signal we saw earlier at wavelengths above $590 \mathrm{~nm}$ resulted from multiphoton effects. Although we expect that the $\mathrm{NO}_{3}$ will be cooler in the present experiment due to the cooling of the nozzle orifice, based on Table I, the large shift in the $\mathrm{NO}_{2}+\mathrm{O}$ threshold cannot be simply attributed to a cooler $\mathrm{NO}_{3}$ beam. We also observe a very sharp increase in observed $\mathrm{NO}_{2}+\mathrm{O}$ signal level (at 10 degrees) at a wavelength below $584 \mathrm{~nm}$. Since no other processes are 
possible in this wavelength range, our observations indicate that kinetic competition is occurring between the two photodissociation channeis.

According to eq. $21, \mathrm{D}_{\mathrm{o}}\left(\mathrm{O}-\mathrm{NO}_{2}\right)-\mathrm{E}_{\mathrm{im}, \mathrm{NO} 3}=47.46 \pm 0.16 \mathrm{kcal} / \mathrm{mol}$. We might be tempted to postulate that the energy threshold for dissociation of ground state $\mathrm{NO}_{3}$ is $47.46 \mathrm{kcal} / \mathrm{mol}$, i.e. $\mathrm{E}_{\mathrm{iut}, \mathrm{NO} 3}=0$ for absorption near $599 \mathrm{~nm}$. However, this conclusion is incorrect. This "threshold" in fact corresponds to dissociation of $\mathrm{NO}_{3}$ radicals which posses 1 quantum of $v_{4}$ excitation at $363 \mathrm{~cm}^{-1}(1.03 \mathrm{kcal} / \mathrm{mol})$. Based on this, we calculate that the $\mathrm{NO}_{3}$ bond dissociation energy is $\mathrm{D}_{0}\left(\mathrm{O}-\mathrm{NO}_{2}\right)=47.46+1.03=48.49 \mathrm{kcal} / \mathrm{mol}$. This corresponds to a wavelength threshold of $\sim 589 \mathrm{~nm}$. A $589 \mathrm{~nm}$ threshold for dissociation of ground state $\mathrm{NO}_{3}$ to $\mathrm{NO}_{2}+\mathrm{O}$ explains the sharp decrease in $\mathrm{NO}+\mathrm{O}_{2}$ yield seen in our experiments and in the experiments of Magnotta. Upon tuning the laser through the $\mathrm{NO}_{2}+\mathrm{O}$ threshold at $589 \mathrm{~nm}$, that channel will quickly dominate since the rate of simple bond rupture, even near threshold, will be much greater than that for concerted formation of $\mathrm{NO}+\mathrm{O}_{2}$. In Fig. 25, a sharp increase in $\mathrm{m} / \mathrm{e}=16\left(\mathrm{O}^{+}\right)$signal was seen below $584 \mathrm{~nm}$. This sharp increase results from dissociation of ground state $\mathrm{NO}_{3}$ to $\mathrm{NO}_{2}+\mathrm{O}$. It must be remembered, however, that we are able to detect the $\mathrm{O}^{+}$ product at 10 degrees only if $E_{\text {rans }} \geq 0.25 \mathrm{kcal} / \mathrm{mol}$. By drawing a smooth line through the data to the wavelength axis, the threshold for this process is found to be near $585 \mathrm{~nm}$ $\left(E_{\mathrm{hu}}=48.85 \mathrm{kcal} / \mathrm{mol}\right)$. The energy threshold for formation of "zero kinetic energy" $\mathrm{NO}_{2}$ $+\mathrm{O}$ is $48.85-0.25=48.6 \mathrm{kcal} / \mathrm{mol}$. This corresponds to a wavelength of $588 \mathrm{~nm}$, which is $1 \mathrm{~nm}$ to the blue of the $589 \mathrm{~nm}$ threshold stated above. However, the slight deviation from $589 \mathrm{~nm}$ is not unreasonable since an extrapolation is required in a region 
where there is an overlapping contribution from dissociation of vibrationally hot $\mathrm{NO}_{3}$.

All of our observations using the ring laser provide evidence that the wavelength threshold for dissociation of ground state $\mathrm{NO}_{3}$ to $\mathrm{NO}_{2}+\mathrm{O}$ is $589 \pm 2 \mathrm{~nm}$ and that $\mathrm{D}_{0}$ $\left(\mathrm{O}-\mathrm{NO}_{2}\right)=48.55 \pm 0.16 \mathrm{kcal} / \mathrm{mol}$. However, these measurements are based on threshold behavior, and will be incorrect if any appreciable potential energy barrier exists for $\mathrm{NO}_{3} \rightarrow \mathrm{NO}_{2}+\mathrm{O}$. Calculations of $\mathrm{D}_{0}\left(\mathrm{O}-\mathrm{NO}_{2}\right)$ from the translational energy distributions well above threshold at 560 and $548 \mathrm{~nm}$ do not suffer from this possible source of error. Based on our $560 \mathrm{~nm}$ data, we calculated that $\mathrm{D}_{0}\left(\mathrm{O}-\mathrm{NO}_{2}\right)-\mathrm{E}_{\mathrm{ma}, \mathrm{NO3}}=$ $47.5 \pm 0.5 \mathrm{kcal} / \mathrm{mol}$. This is in excellent agreement with the threshold measurements if the fast component in the $\mathrm{P}(\mathrm{E})$ (Fig. 20b) results from photodissociation of $\mathrm{NO}_{3}$ with one quantum of $363 \mathrm{~cm}^{-1}$ excitation, i.e. $E_{\text {ia }, N O 3}=1.03 \mathrm{kcal} / \mathrm{mole}$. At $548 \mathrm{~nm}$, we found that $\mathrm{D}_{\mathrm{o}}\left(\mathrm{O}-\mathrm{NO}_{2}\right)-\mathrm{E}_{\text {ine } \mathrm{NO3}}=47.8 \pm 0.5 \mathrm{kcal} / \mathrm{mol}$. This is also in good agreement with the $589 \mathrm{~nm}$ threshold, provided that $\mathrm{E}_{\mathrm{inh}, \mathrm{NO} O 3}$ is $1.03 \mathrm{kcal} / \mathrm{mole}$.

It is perhaps ironic that by measuring the $\mathrm{NO}+\mathrm{O}_{2}$ quantum yield at $590 \mathrm{~nm}$, we have in fact simply measured the population of $\mathrm{NO}_{3}$ in the ground vibrational state. At $590 \mathrm{~nm}$, the photon energy is just below threshold for the $\mathrm{NO}_{2}+\mathrm{O}$ channel. Since fluorescence is known to be zero, our measurement that $\phi_{\mathrm{NO}+\mathrm{O} 2}=0.5 \pm 0.1$ at $590 \mathrm{~nm}$ simply reflects the ground state population, all of which is dissociating to $\mathrm{NO}+\mathrm{O}_{2}$. Of course, the other half of the $\mathrm{NO}_{3}$ molecules in the beam are internally excited, and are dissociated to $\mathrm{NO}_{2}+\mathrm{O}$, since $\mathrm{E}_{\text {phowos }}+\mathrm{E}_{\mathrm{imL} \text { NO3 }}$ exceeds $\mathrm{D}_{0}\left(\mathrm{O}-\mathrm{NO}_{2}\right)$. Because the potential energy barrier for $\mathrm{NO}+\mathrm{O}_{2}$ is just below the endothermicity for $\mathrm{NO}_{2}+\mathrm{O}$, the concerted NO $+\mathrm{O}_{2}$ channel occurs readily, but only within a very narrow wavelength 
range.

It is rather straightforward to show that the $589 \pm 2 \mathrm{~nm}$ "threshold" corresponds to the threshold for dissociation of ground state $\mathrm{NO}_{3}$. If the threshold for dissociation of ground state $\mathrm{NO}_{3}$ was actually at $599 \mathrm{~nm}$, it would be very difficult to rationalize a number of our observations. First, we know that there must be internally hot $\mathrm{NO}_{3}$ molecules in the beam. This conclusion is based on our earlier hotband intensity measurements ${ }^{33}$ and the calculated data in Table 1 . If we attributed the observed threshold for $\mathrm{NO}_{2}+\mathrm{O}$ at $599 \mathrm{~nm}$ to be due to ground state $\mathrm{NO}_{3}$, we imply that internally excited $\mathrm{NO}_{3}$ molecules make no contribution here. However, we have found that the $599 \mathrm{~nm}$ "threshold" and the maximum translational energy release at $560 \mathrm{~nm}$ and $548 \mathrm{~nm}$ are mutually self- consistent. This would lead us to the conclusion that the absorptions at 560 and 548 also do not result from contributions from hot $\mathrm{NO}_{3}$. This would be surprising since vibrationally hot molecules must contribute to the $\mathrm{NO}_{3}$ absorption spectrum, and the temperature dependence at 560 and 548 is similar to that seen at nearly all other wavelengths. It also seems very unlikely that absorption at both 560 and 548 have no contribution from vibrationally excited $\mathrm{NO}_{3}$ since the photon energies for these two transitions lie $390 \mathrm{~cm}^{-1}$ apart. If the $548 \mathrm{~nm}$ transition resulted from excitation from the ground state, then that at $560 \mathrm{~nm}$ should show some contribution from excitation of those $\mathrm{NO}_{3}$ molecules having one quantum of $363 \mathrm{~cm}^{-1}$ excitation to the same upper state. Based on these arguments, it appears to be nearly impossible that hot molecules can make no contribution at 560,548 , and $600 \mathrm{~nm}$. Secondly, this scenario would imply that the $\mathrm{NO}+\mathrm{O}_{2}$ and the $\mathrm{NO}_{2}+\mathrm{O}$ channel both have wavelength thresholds near $600 \mathrm{~nm}$, and 
quantum yields rising in tandem to -0.5 at $590 \mathrm{~nm}$. Such behavior could not arise from simple kinetic competition between the two channels, since the Arrhenius preexponential factor for the simple bond rupture will be much greater than for the NO $+\mathrm{O}_{2}$ channel. Thus, if both channels had the same wavelength threshold, the $\mathrm{NO}_{2}+\mathrm{O}$ channel should have been dominant at $590 \mathrm{~nm}$.

It might seem possible that the $599 \mathrm{~nm}$ threshold corresponds to threshold for dissociation of $\mathrm{NO}_{3}$ molecules possessing two quanta of $363 \mathrm{~cm}^{-1}$ vibrational excitation, i.e. $\mathrm{E}_{\mathrm{itt}}=2.07 \mathrm{kcal} / \mathrm{mol}$. In this case, we would calculate a value for the $\mathrm{O}-\mathrm{NO}_{2}$ bond energy of $47.46+2.07=49.53 \mathrm{kcal} / \mathrm{mol}$. This corresponds to a wave length threshold of $577 \mathrm{~nm}$. This is clearly impossible since we find that the quantum yield for $\mathrm{NO}_{3} \rightarrow \mathrm{NO}_{2}$ $+O$ has already reached -1.0 at wavelengths $7 \mathrm{~nm}$ to the red at $584 \mathrm{~nm}$.

Using the ring laser, the NO $+\mathrm{O}_{2}$ channel showed the same behavior as was seen earlier using the pulsed laser. This indicates that multiphoton effects do not have a significant effect on the $\mathrm{NO}+\mathrm{O}_{2}$ wavelength dependence. However, multiphoton effects can effect the $\mathrm{NO}+\mathrm{O}_{2}$ quantum yield. For example, at $594 \mathrm{~nm}$, we predict that a ground State $\mathrm{NO}_{3}$ molecule will dissociate exclusively to $\mathrm{NO}+\mathrm{O}_{2}$. However, if the excited $\mathrm{NO}_{3}$ absorbs a second photon it will dissociate to $\mathrm{NO}_{2}+\mathrm{O}$. Thus, multiphoton effects could artificially lead to a lower observed $\mathrm{NO}+\mathrm{O}_{2}$ quantum yield.

In earlier pulsed experiments, although we did see some $\mathrm{O}_{2}$ at $605 \mathrm{~nm}$, it was very weak. In Magnotta's experiment, however, $\mathrm{NO}+\mathrm{O}_{2}$ was observed with a significant quantum yield up to $620 \mathrm{~nm}$, with a small tail out to $630 \mathrm{~nm}$. Since we obtained very similar wavelength behavior using both the pulsed laser and the dye laser, it appears that 
sequential absorption by $\mathrm{NO}_{3}$ does not lead to formation of $\mathrm{NO}+\mathrm{O}_{2}$. There are several possible explanations for the differences between our $\mathrm{NO}+\mathrm{O}_{2}$ yield above $595 \mathrm{~nm}$ and that of Magnotta. We do not expect Magnotta's $\mathrm{NO}_{3}$ vibrational temperatures to be much different than ours. 'Thus, it is very unlikely that the difference can be attributed to a larger contribution from vibrationally hot $\mathrm{NO}_{3}$ in Magnotta's experiment. However, due to efficient rotational cooling in the beam, we do expect a considerable difference in rotational temperature in the two experiments. In our experiment, a rotational temperature well below $50 \mathrm{~K}$ would be expected, whereas that in the flow cell should be near room temperature. The rotational constants of $\mathrm{NO}_{3}$ are on the order of $1 \mathrm{~cm}^{-1}$. At room temperature, there will be a substantial population of $\mathrm{NO}_{3}$ with $J=20-30$. These rotational levels correspond to rotational energies of approximately $1.5-3 \mathrm{kcal} / \mathrm{mole}$, which at this energy is in fact a $15-30 \mathrm{~nm}$ wavelength range. Thus, it appears that a considerable fraction of the NO $+\mathrm{O}_{2}$ seen by Magnotta to the red of $600 \mathrm{~nm}$ (Fig. 28) could arise from dissociation of rotationally hot $\mathrm{NO}_{3}$. Unfortunately, since the dependence of the $\mathrm{NO}_{3}$ absorption spectrum on rotational temperature is not known, it is difficult to be more quantitative in addressing this possibility. Of course, collisional effects could also play a role in the $\mathrm{NO}+\mathrm{O}_{2}$ signal at wavelengths above $605 \mathrm{~nm}$ in Magnotta's experiment.

Our experiment is only sensitive to those dissociation processes which occur within $\sim 2 \mu \mathrm{sec}$ of the laser pulse. Under normal circumstances, this is not a significant consideration since the dissociation timescales of even very large molecules seldomly exceeds several hundred picoseconds. However, in the present case, it is possible that 
the $\mathrm{NO}_{3} \rightarrow \mathrm{NO}+\mathrm{O}_{2}$ dissociation timescale could become very long above $600 \mathrm{~nm}$. If it is on the order of microseconds, the $\mathrm{NO}_{3}$ molecules will "fly out" of the viewing region before dissociation. We attempted to observe this in the present experiment using two approaches. First, we attempted to monitor $\mathrm{NO}_{3}$ depletion in the beam with the detector at 0 degrees using the ring laser. We also attempted experiments with the laser moved upstream of the interaction region. These experiments have been inconclusive to date. Although a microsecond dissociation timescale might seem surprising for a 4 atom molecule, it is in fact quite reasonable in view of the fact that the onset of fluorescence emission is seen at $605 \mathrm{~nm}$ and the fluorescence lifetime is known to exceed $30 \mu$ secs at $613 \mathrm{~nm}$. However, since fluorescence is seen at $605 \mathrm{~nm}$, it appears that the wavelength range in question is very small. This conclusion is also supported by RRKM calculations which indicate that for a 4-atom molecule, the range of internal energies corresponding to microsecond $\mathrm{NO}+\mathrm{O}_{2}$ dissociation timescales will be very limited.

Perhaps the most important conclusion regarding the observed wavelength dependence of the two photodissociation channels is that the measured quantum yields will be very sensitive to the vibrational population of the $\mathrm{NO}_{3}$ molecules. Based on our results, we predict that the $\mathrm{NO}+\mathrm{O}_{2}$ quantum yield for a pure sample of "cold" $\mathrm{NO}_{3}$ would be unity at $590 \mathrm{~nm}$. A real sample of $\mathrm{NO}_{3}$ at finite temperature will have some vibrationally excited molecules, and so the $\mathrm{NO}+\mathrm{O}_{2}$ yield will always be smaller than this. Multiphoton effects will also serve to diminish the observed $\mathrm{NO}+\mathrm{O}_{2}$ quantum yields at wavelengths above $590 \mathrm{~nm}$. 


\section{B. Calculation of $\Delta \mathrm{H}_{r}^{\circ}\left(\mathrm{NO}_{3}\right)$}

All of our experimental data indicates that the wavelength threshold for $\mathrm{O}-\mathrm{NO}_{2}$ bond rupture of ground state $\mathrm{NO}_{3}$ is $589 \pm 2 \mathrm{~nm}$. Based on the dramatic decrease in NO $+\mathrm{O}_{2}$ below $590 \mathrm{~nm}$, it is nearly impossible to rationalize a value below the energy corresponding to $589 \mathrm{~nm}$. In the case of $\mathrm{NO}_{20}$ it is known $\mathrm{n}^{41,42}$ that the fluorescence quantum yield drops sharply to zero near $397.92 \mathrm{~nm}$. Apparently, the quantum yield for NO $+\mathrm{O}$ becomes substantial within only a few $\mathrm{cm}^{-1}$ of the dissociation threshold. In the case of $\mathrm{NO}_{3}$, the $\mathrm{NO}_{2}+\mathrm{O}$ channel should also become dominant near threshold, in the absence of a significant potential energy barrier in the exit channel.

It should be noted that our translational energy distributions at $560 \mathrm{~nm}$ and $548 \mathrm{~nm}$ peak away from zero. This might be taken as evidence for a potential energy barrier in the exit channel, invalidating our measurements of the threshold wavelength for $\mathrm{NO}_{2}$ $+O$. However, it is extremely unlikely that the observed $P(E)$ indicates the existence of an exit barrier based on the fact that we did get reasonable agreement in the threshold measurement and the measurements of $E_{\text {trass,nex }}$ above threshold. Thus one might wonder why the $P(E)$ peaks away from zero when we are so close to threshold for a reaction without a barrier. The most probable answer is that at energies this close to threshold, the range of accessible product internal energies is not "continuous" on our energy scale since, of course, the $\mathrm{NO}_{2}$ vibrational energy is quantized. Only a few vibrational levels of $\mathrm{NO}_{2}$ are available at these energies. Consequently, the peaking away from zero likely reflects the small number of $\mathrm{NO}_{2}$ quantum states available in this energy range. For a given $\mathrm{NO}_{2}$ vibrational level, excess energy can only be channeled into relative 
translational motion or $\mathrm{NO}_{2}$ rotation. Thus, even though the excitation energy will be rapidly randomized in $\mathrm{NO}_{3}$ due to strong vibronic coupling effects, the $\mathrm{P}(\mathrm{E})$ peaks away from zero. This suggests that a very limited amount of energy appears in rotation. This is not at all surprising for simple $\mathrm{O}-\mathrm{NO}_{2}$ bond rupture since the impact parameter for the ensuing $\mathrm{O}+\mathrm{NO}_{2}$ "half collision" will be near zero due to the $\mathrm{D}_{3 \mathrm{~h}}$ symmetry of $\mathrm{NO}_{3}$. In the photodissociation of $\mathrm{NO}_{2}$, on the other hand, the $\mathrm{O}+\mathrm{NO}$ impact parameter is large and a substantial fraction of the available energy can appear as rotational motion in the NO fragment.

We have concluded that the $\mathrm{O}-\mathrm{NO}_{2}$ wavelength threshold for ground state $\mathrm{NO}_{3}$ is $589 \pm 2 \mathrm{~nm}$. This indicates that $\mathrm{D}_{0}\left(\mathrm{O}-\mathrm{NO}_{2}\right)=48.55 \pm 0.16 \mathrm{kcal} / \mathrm{mol}$. This result is more precise than the values we obtained from measuring the maximum translational energy release at 560 and $548 \mathrm{~nm}$. However, our value of $589 \pm 2 \mathrm{~nm}$ as the threshold for $\mathrm{O}+\mathrm{NO}_{2}$ is solidly supported by our observed wavelength behavior using both the pulsed and ring laser. It is also supported by the earlier results of Magnotta. In order to calculate $\Delta \mathrm{H}_{\mathrm{r}}^{\circ}\left(\mathrm{NO}_{3}\right), 0 \mathrm{~K}$, we require values for $\Delta \mathrm{H}_{\mathrm{r}}^{\circ}\left(\mathrm{O}^{3} \mathrm{P}\right), 0 \mathrm{~K}$ and $\Delta \mathrm{H}_{\mathrm{r}}^{\circ}\left(\mathrm{NO}_{2}\right), 0 \mathrm{~K}$. According to the JANAF tables, $\left.\Delta \mathrm{H}_{\mathrm{K}}^{\circ} \mathrm{O}^{3} \mathrm{P}\right)=59.98 \pm 0.02 \mathrm{kcal} / \mathrm{mol}(0 \mathrm{~K})$ and $\Delta \mathrm{H}_{\mathrm{r}}^{\circ}\left(\mathrm{NO}_{2}\right)=8.59 \pm 0.19 \mathrm{kcal} / \mathrm{mol}(0 \mathrm{~K})$. The uncertainty in the latter quantity will considerably increase the uncertainty in our calculated value of $\Delta \mathrm{H}_{\mathrm{r}}^{\circ}\left(\mathrm{NO}_{3}\right),(0 \mathrm{~K})$.

In a beautiful series of experiments, Robra and Welge ${ }^{41}$ studied the photodissociation of $\mathrm{NO}_{2}$ near threshold in a molecular beam. They monitored $\mathrm{NO}_{2}$ fluorescence and NO photodissociation product intensity simultaneously while scanning their photolysis laser through the $\mathrm{NO}_{2}$ dissociation threshold. They found that 
fluorescence dropped to near zero abruptly near $397.93 \mathrm{~nm}$. Based on their observations, they concluded that the energy threshold for dissociation of ground state $\mathrm{NO}_{2}$ to $\mathrm{NO}+$ $O$ is $25130.6 \pm 0.6 \mathrm{~cm}^{-1}$. This corresponds to a value for $D_{0}(\mathrm{O}-\mathrm{NO})$ of $71.8604 \pm$ $0.0002 \mathrm{kcal} / \mathrm{mol}$. Based on the JANAF values for $\Delta \mathrm{H}_{\mathrm{f}}^{\circ}\left(\mathrm{O}^{3} \mathrm{P}\right)=58.98 \pm 0.02 \mathrm{kcal} / \mathrm{mol}$ $(0 \mathrm{~K})$ and $\Delta \mathrm{H}_{\mathrm{r}}^{\circ}(\mathrm{NO})=21.46 \pm 0.04 \mathrm{kcal} / \mathrm{mol}(\mathrm{OK})$, we calculate $\Delta \mathrm{H}_{\mathrm{f}}^{\circ}\left(\mathrm{NO}_{2}\right)=8.58 \pm$ $0.06 \mathrm{kcal} / \mathrm{mol}(0 \mathrm{~K})$. This is nearly identical to the JANAF value, but the error limits are considerably smaller. Based on this, we can use our value for $\mathrm{D}_{0}\left(\mathrm{O}-\mathrm{NO}_{2}\right)$ to calculate $\Delta \mathrm{H}_{\mathrm{r}}^{\circ}\left(\mathrm{NO}_{3}\right)=19.01 \pm 0.24 \mathrm{kcal} / \mathrm{mole}$ at $\mathrm{OK}$. Based on published heat capacity corrections $^{43}$ which agree with those we calculate according to Herzberg, ${ }^{44}$ our value corresponds to a room temperature value of $\Delta \mathrm{H}_{\mathrm{f}}^{\circ}\left(\mathrm{NO}_{3}\right)=17.75 \pm 0.24 \mathrm{kcal} / \mathrm{mole}$ (298K).

The value for $\Delta \mathrm{H}_{\mathrm{r}}^{\circ}\left(\mathrm{NO}_{3}\right), 298 \mathrm{~K}$ obtained in this experiment is in excellent agreement with the calculated value employing the $\mathrm{NO}_{3}$ electron affinity of Weaver ${ }^{24}$ and the previously measured value of $\Delta_{\mathrm{f}} \mathrm{H}^{\circ}\left(\mathrm{NO}_{3}{ }^{\circ}\right)$. They calculated $\Delta_{\mathrm{f}} \mathrm{H}^{\circ}\left(\mathrm{NO}_{3}\right)=17.9 \pm$ $0.8 \mathrm{kcal} / \mathrm{mole}(298 \mathrm{~K})$. However, our finding is not consistent with the thermochemical measurements of Cantrell. Their value for $\Delta_{\mathrm{f}} \mathrm{H}^{\circ}\left(\mathrm{NO}_{3}\right)$ would imply that the threshold for formation of $\mathrm{NO}_{2}+\mathrm{O}$ from ground state $\mathrm{NO}_{3}$ lies near $556 \mathrm{~nm}$. If this were the case, we should have observed the onset of a significant low energy component in the $548 \mathrm{~nm}$ product time of flight spectra due to the onset of dissociation of ground state molecules. This was not observed. Moreover, since $\mathrm{NO}_{3}$ fluorescence is known to drop to zero below $605 \mathrm{~nm}$, their result could only indicate that the quantum yield for $\mathrm{NO}+\mathrm{O}_{2}$ is unity for $560<\lambda<605 \mathrm{~nm}$, which is ruled out by this work, and that of Magnotta. 
The enthalpy of formation that we have obtained is $2.36 \mathrm{kcal} / \mathrm{mol}$ higher than the recent thermochemical values. Unfortunately, these values, which are clearly incorrect, have been incorporated by JANAF in the most recent thermochemical tables. ${ }^{43}$ The consequences of using our results, rather than those newly adopted, will be very substantial in certain cases. The effect will be particularly dramatic in calculations pertaining to processes that are nearly thermoneutral. For example, by using our value, the equilibrium constant for $\mathrm{NO}_{3}+\mathrm{HCl} \rightleftarrows \mathrm{HNO}_{3}+\mathrm{Cl}$ is calculated to be approximately 1000 times larger than the value based on Cantrell's thermodynamic data. ${ }^{4}$

It is important to point out that based on Magnotta's earlier results, and our observation of $\mathrm{NO}_{2}+\mathrm{O}$ considerably to the red of $600 \mathrm{~nm}$ in the pulsed experiments, we believed for a long time ${ }^{33}$ that the true threshold was above $600 \mathrm{~nm}$, and that even the value obtained by Weaver ${ }^{24}$ for $\Delta \mathrm{H}_{\mathrm{r}}^{\circ}\left(\mathrm{NO}_{3}\right)$ was near the lower edge of our error bar. It was only after completing the "single photon" experiments using the ring laser that we realized that multiphoton effects were in fact dominating our measurements of the $\mathrm{NO}_{2}$ $+O$ channel above $590 \mathrm{~nm}$. We had been somewhat "deceived" by the earlier experiments. It appears unlikely that the vibrational energy of the $\mathrm{NO}_{3}$ observed in the flowcell could be much hotter than that we derive from thermal decomposition of $\mathrm{N}_{2} \mathrm{O}_{5}$. However, in Magnotta's experiment, we do expect considerable contribution from photodissociation of higher rotational levels from the thermal distribution of $\mathrm{NO}_{3}$ molecules, and this will increase the contribution to the $\mathrm{NO}_{2}+\mathrm{O}$ signal to the red of $589 \mathrm{~nm}$. In retrospect, it is perhaps not too surprising that $\mathrm{NO}_{3}$ does suffer from multiphoton activity above $590 \mathrm{~nm}$, since the groundstate molecules are below the $\mathrm{O}-\mathrm{NO}_{2}$ 
bond energy and are likely to be dissociating on an extremely long timescale. Our work indicates that an electronic state of $\mathrm{NO}_{3}$ exists near $31000 \mathrm{~cm}^{-1}$, and this state dissociates readily to $\mathrm{NO}_{2}+\mathrm{O}$, with the $\mathrm{NO}_{2}$ internally excited. It should be noted that $31000 \mathrm{~cm}^{-1}$ is an energy range considerably above that currently known for $\mathrm{NO}_{3}$. In addition, because the selection rules for one and two photon absorption processes are different, it is very likely that this state will not be accessed by one $320 \mathrm{~nm}$ photon.

\section{C. The Structure in the NO $+\mathrm{O}_{2}$ TOF.}

Our high resolution spectra show considerable vibrational structure. Since we have established that the NO signal results primarily from photodissociation of $\mathrm{NO}_{3}$ in its ground state, the observed structure must result from internal excitation of the product molecules. This reaction channel involves formation of two diatomics, each with vibrational and rotational degrees of freedom. In view of this, it is somewhat surprising that this amount of structure is observed at all. Intuitively, we would expect that $\mathrm{NO}_{3}$ $\rightarrow \mathrm{NO}+\mathrm{O}_{2}$ will lead to a significant yield of vibrationally excited $\mathrm{O}_{2}$, since no $0-\mathrm{O}$ bond exists in $\mathrm{NO}_{3}$, but a very strong $\mathrm{O}=\mathrm{O}$ bond is produced in the reaction. This hypothesis is clearly supported by the data. We first examine the $588 \mathrm{~nm}$ data. As summarized in Table II, the substantially larger vibrational frequency for NO allows us to rule out the possibility that the structure in the $P(E)$ is attributable to a progression in NO vibrations. The spacing that we observe clearly corresponds to progressions in $\mathrm{O}_{2}$ vibrational motion. Figure 29 shows the expected maximum translational energy release for various internal states of the $\mathrm{O}_{2}$ product if we assume that the NO partner is internally cold $(\mathrm{v}=0)$. Our value for $\Delta \mathrm{H}_{\mathrm{f}}\left(\mathrm{NO}_{3}\right)$ was used in the calculations. The $\mathrm{O}_{2}$ vibrational 
energies compiled in Huber and Herzberg ${ }^{45}$ were also employed, as this appears to be the most reliable data on $\mathrm{O}_{2}$ available. Of course, our detector is not state specific, and we must be very careful when drawing conclusions about the internal states of the products. It is worthwhile mentioning that if we had higher resolution, we would likely be able to resolve more structure in the high translational energy range. The TOF becomes very compressed at energies above $25 \mathrm{kcal} / \mathrm{mol}$ and possible structure in the TOF is not resolvable under the present conditions. However, since we do see significant $\mathrm{NO}+\mathrm{O}_{2}$ with translational energy above $25 \mathrm{kcal} / \mathrm{mole}$, we are able to state with certainty that at least some $\mathrm{O}_{2}\left({ }^{3} \Sigma\right)$ is formed in the dissociation process. Based on the integrated $P(E)$, we conclude that the yield of ground state $\mathrm{O}_{2}$ exceeds $20 \%$ at $588 \mathrm{~nm}$. It is very interesting to note that the dominant products are formed with translational energy consistent with formation of $\mathrm{O}_{2}\left({ }^{1} \Delta\right)$. In fact, if the data in Figs. 29 and 30 are examined carefully, we are very tempted to postulate that the observed structure results from a progression in $\mathrm{O}_{2}\left({ }^{1} \Delta\right)$, with the most probable vibrational level being $\mathrm{v}=3$, if most NO is produced in $v=0$. Alternatively the data might be interpreted to indicate that in fact the $\mathrm{O}_{2}$ is entirely formed in its ground vibrational state, with the most probable vibrational level being 8 . Based on the data alone, it is impossible to state with certainty which interpretation is correct. However, if the symmetries of the appropriate orbitals are considered, formation of ground state $\mathrm{O}_{2}$ is strongly forbidden for dissociation constrained to $\mathrm{C}_{2 \mathrm{v}}{ }^{9,28}$ Of course, we do clearly observe this channel, which will be favored by departure from $C_{2 v}$ symmetry in the transition state. ${ }^{9.28}$ However, it is expected that the potential energy barrier for formation of $\mathrm{O}_{2}\left({ }^{1} \Delta\right)$ will be smaller than 
for the ground state, based on correlation of the symmetry species involved. ${ }^{3}$ In light of this, and our data, it would be tempting to say that $\mathrm{O}_{2}\left({ }^{1} \Delta\right)$ is dominant. We are currently considering this question in detail, based on the appropriate symmetry arguments.

The possibility that the NO is primarily in $v=1$ can be explored based on the observed data in Fig. 30. If $\mathrm{O}_{2}$ is in the ${ }^{1} \Delta$ state, then the predicted maximum translational energy for $v^{\prime}=3-4$ appears to differ considerably from the data. Thus, it appears that NO $v^{\prime}=0$ is likely to be dominant. Of course, we expect that NO will appear in a range of vibrational levels, particularly in view of the fact that the $\mathrm{N}-\mathrm{O}$ bond length decreases somewhat from $1.24 \AA$ in $\mathrm{NO}_{3}$ to $1.15 \AA$ in the NO product. However, our data does indicate that it is mostly formed in low vibrational levels. Usually, the resolution of our experiments is not sufficient to provide information on the disposal of energy into rotational degrees of freedom of the products. However, in the present case, it is clear that rotational energy of the products must be small. Otherwise, the $P(E)$ could not show the structure reported here. A small amount of rotational energy in the two product molecules is very reasonable in this process. Since $\mathrm{NO}_{3}$ has $\mathrm{D}_{3 \mathrm{~h}}$ symmetry, the impact parameter for the recoiling $\mathrm{O}_{2}+$ NO products must be nearly zero in the dissociation process. Consequently, we expect to see very little rotational energy since there are no strong forces to provide the rotational excitation. The transition state requires considerable symmetric bending to bring the two oxygen atoms within close enough proximity to form an $\mathrm{O}=\mathrm{O}$ bond. Even if the transition state is nonplanar, we do expect that nearly all of the energy will appear in $\mathrm{O}_{2}$ excitation. Due to the small 
impact parameter in the half collision process, the NO will be formed with nearly zero rotational energy. Since total angular momentum must be conserved in the dissociation process, the $\mathrm{O}_{2}$ molecule is "constrained" to also having very small angular momentum, but in the opposite direction. This explains why we are able to see structure in a process where so many product degrees of freedom would normally be expected to wash out the structure entirely.

There is a noticeable difference between our observations near the $\mathrm{O}-\mathrm{NO}_{2}$ dissociation threshold and the observations of Welge ${ }^{41}$ near threshold for formation of $\mathrm{NO}+\mathrm{O}$ in photodissociation of $\mathrm{NO}_{2}$. We find that the yield of $\mathrm{NO}_{2}+\mathrm{O}$ from ground state $\mathrm{NO}_{3}$ increases rather gradually from 0 to $100 \%$ over the wavelength range 590 $584 \mathrm{~nm}$, an energy range of $-175 \mathrm{~cm}^{-1}$. The quantum yield for NO +0 in photodissociation of $\mathrm{NO}_{2}$, on the other hand, apparently undergoes the same increase over an energy range of only $1-2 \mathrm{~cm}^{-1}$. This behavior appears to be mostly attributable to the expectation that the $\mathrm{NO}_{3}$ density of states near threshold will be far higher than in $\mathrm{NO}_{2}$, leading to a much smaller rate for dissociation at energies near threshold.

The $594 \mathrm{~nm}$ data is plotted in the same manner in Figs 31 and 32 . Of course the $0.5 \mathrm{kcal} /$ mole decrease in photon energy produces the corresponding shifts in the observed peaks. All of the arguments stated above also apply to the $594 \mathrm{~nm}$ data. Perhaps the most important observation is that the relative contribution from ground state $\mathrm{O}_{2}$ is clearly smaller at the lower photon energy, i.e. the fast component shows a smaller contribution. At first glance, it might seem strange that less ground state $\mathrm{O}_{2}$ is formed with the lower energy photon. However, based on the calculations of Siegbahn, ${ }^{9}$ and by 
Boehm and Lohr, ${ }^{28}$ we expect that the yield of ground state $\mathrm{O}_{2}$ will be very sensitive to the degree to which $\mathrm{C}_{2 v}$ symmetry is broken. At the lower photon energy, there is slightly less internal energy available. However, the probability that the molecule will achieve a configuration below the ground state potential energy barrier will be critically dependent on its vibrational excitation. It appears that this is the dominant reason why only $0.5 \mathrm{kcal} / \mathrm{mole}$ more energy leads to nearly a factor of 2 greater yield of ground state $\mathrm{O}_{2}$. As expected, we see a larger yield of more internally excited $\mathrm{O}_{2}$ at the longer wavelength. These considerations will be explored in detail in a forthcoming publication. ${ }^{45}$

\section{CONCLUSIONS}

We have demonstrated that $\mathrm{NO}_{3}$ undergoes some very interesting photodissociation dynamics upon electronic excitation in the visible. The observed wavelength dependence is easily explained in terms of kinetic competition between the possible dissociation mechanisms. At an excitation energy just below threshold for dissociation of ground state $\mathrm{NO}_{3}$ to $\mathrm{NO}_{2}+\mathrm{O}$, all the ground state molecules dissociate to $\mathrm{NO}+\mathrm{O}_{2}$. This situation is seen at $590 \mathrm{~nm}$. At this wavelength, those $\mathrm{NO}_{3}$ molecules in the beam having any vibrational excitation $(-50 \%)$ dissociate by the dynamically more favorable route to $\mathrm{NO}_{2}+\mathrm{O}$. Although at least $10-20 \%$ of the $\mathrm{O}_{2}$ is in its ground state, (depending upon wavelength), there is good evidence that a substantial fraction is actually formed in the ' $\Delta$ state. Based on the observed wavelength dependence for the channels, and measurements of the $\mathrm{NO}_{2}+\mathrm{O}$ translational energy release, we conclude that $\mathrm{D}_{0}\left(\mathrm{O}-\mathrm{NO}_{2}\right)=48.55 \pm 0.16 \mathrm{kcal} / \mathrm{mole}$. By combining this with the known values 
for $\Delta \mathrm{H}_{\mathrm{f}}\left(\mathrm{NO}_{2}\right)$, and $\Delta \mathrm{H}_{\mathrm{f}}\left(\mathrm{O}^{3} \mathrm{P}\right)$, we calculate $\Delta \mathrm{H}_{\mathrm{f}}\left(\mathrm{NO}_{3}\right)=19.01 \pm 0.24 \mathrm{kcal} / \mathrm{mole}(\mathrm{OK})$, and $\Delta \mathrm{H}_{r}\left(\mathrm{NO}_{3}\right)=17.75 \pm 0.24 \mathrm{kcal} / \mathrm{mole}(298 \mathrm{~K})$. Although this result does not agree with recent thermochemical measurements, it is in excellent agreement with a calculated value based on the most recent values for $\mathrm{EA}\left(\mathrm{NO}_{3}\right)$ and $\Delta \mathrm{H}_{\mathrm{r}}\left(\mathrm{NO}_{3}{ }^{-}\right)$.

\section{REFERENCES}

1. a) R.A. Graham, H.S. Johnston, J. Phys. Chem, 82, 3, 254, (1978).

b) R.A. Graham, Ph.D. Thesis, University of California, Berkeley, (1978).

c) H.S. Johnston, and R.A. Graham, Can. J. Chem., 52, 1415, (1974).

2. a) F. Magnotta, H.S. Johnston, Geophys. Res. Lett., 7, 769, (1980).

b) F. Magnotta, Ph.D. Thesis, University of California, Berkeley and Lawrence Berkeley Laboratory Report LBL-9981 (1979).

3. a) H.H. Nelson, Louise Pasternack, J.R. McDonald, J. Chem. Phys., 79, 19, 4279, (1983).

b) Nelson, H.H.; Pasternack, L.; McDonald, J.R. J. Phys. Chem. 1983, 87, 1286.

4. a) A.H. McDaniel, J.A. Davidson, C.A. Cantrell, R.E. Shetter, J.G. Calvert. J. Phys. Chem, 92,4172, (1988).

b) C.A. Cantrell, J.A. Davidson, A.H. McDaniel, R.E. Shetter, J.G. Calvert, J. Chem. Phys., 88, 8, 4997, (1988).

5. J. P. Smith, and S. Solomon, J. Geophys. Res., 95, D9, 13,819 (1990)

6. a) Ishiwata, T.; Fujiwara, I. Naruge, Y.; Obi, K.; Tanaka, I. J. Phys. Chem. 87, 1349 (1983). 
b) T. Ishiwata, I. Tanaka, K. Kawaguchi, and E. Hirota, J. Chem. Phys., 82, 2196, (1985).

c) K. Kawaguchi, E. Hirota, T. Ishiwata, and I. Tanaka, J. Chem. Phys.,J. Chem. Phys., 1990.

7. R.R. Friedl and S.P. Sander, J. Phys. Chem. 91, 2721, (1987).

8. Bongsoo Kim. H.S. Johnston, D.A. Clabo, Jr., H.F. Schaefer III, J. Chem. Phys., 88 (5),3204 (1988).

9. Per E.M. Siegbahn, J. Compt. Chem., 6,3,182, (1985).

10. J.F. Olsen and L. Burnell, J. Am. Chem. Soc., 92, 12 3659, (1970)

11. R.C. Boehm and L. L. Lohr, J. Phys. Chem., 93, 3430 (1989).

12. E. Hirota, K. Kawaguchi, T. Ishiwata, and I. Tanaka, J. Chem. Phys., 95(2), $771(1991)$

13. A.D. Walsh, J. Chem. Soc. 2301 (1953).

14. D.A. Ramsey, Proc. Colloq. Spect. Int. 10, 583 (1962).

15 E.J. Jones, and O.R. Wulf, J. Chem. Phys., 5, 873, (1937).

16. S.P. Sander J. Phys. Chem.,90,4135, (1986)

17. A.R. Ravishankara and P.H. Wine, Chem. Phys. Lett., 101, 73, (1983).

18. J. P. Burrows, G.S. Tyndall, G.K. Moortgat, J. Phys. Chem., 89, 4848, (1985).

19. A.R. Ravishankara and R.L. Mauldin, J. Geophys. Res., 91, 8709, (1986).

20. C.A. Cantrell, J.A. Davidson, R.E. Shetter, B.A. Anderson, and J.G. Calvert, J. Phys. Chem., 91, 5858, (1987).

21. B. Kim, P.L. Hunter, and H.S. Johnston, J. Chem. Phys., 96(6), 4057 (1992), 
and references therein.

22. J.F. Stanton, J. Gauss and R.J. Bartlett, J. Chem. Phys., 94, 4084 (1991).

23. M.N. Chase Jr., C.A. Davies, J.R. Downey, D.J. Frurip, R.A. McDonald, A.N. Syrerud, J. Phys. Chem. Ref. Data, 14,1537,(1985) (JANAF Thermochemical Tables, 3rd. Ed., 1985, Supplement.

24. A. Weaver, D.W. Arnold, S.E. Bradforth, and D.M. Neumark, J. Chem. Phys., 94, 1740 (1991).

25. K.P. Huber and G. Herzberg, Molecular Spectra and Moiecular Structure IV. Constants of Diatomic Molecules, Van Nostrand Reinhold Co. (1979).

26. H.S. Johnston, Personal Communication.

27. J. A. Davidson, F.C. Fehsenfeld, and C.J. Howard, Int. J. Chem. Kinetics 9, 17 (1977).

28. R.C. Boehm, and L. L. Lohr, J. Comp. Chem., 1990.

29. Gas Phase Ion and Neutral Thermochemistry, J. Phys. Chem. Ref. Data, (1991).

30. A.E. Douglas, J. Chem. Phys., 45, 1007 (1966).

31. W.J.Marinelli, D.M. Swanson, H.S. Johnston, J. Chem. Phys., 76, 2864 (1982).

32. Bongsoo Kim, Personal Communication.

33. B. Kim, Ph.D. Thesis, University of California, Berkeley, 1991.

34. Y.T. Lee, J.D. McDonald, P.R. LeBreton, D.R. Herschbach, Rev. Sci. Instrum., 40,1402, (1969).

35. Wodtke, A.M.; Lee, Y.T. J. Phys. Chem.1985, 89, 4744.

36. Schott, G.; Davidson, N. J. Am. Chem. Soc. 1958, 80, 1841. 
37. G. Comsa, R.David, and B.J. Schumacher, Rev. Sci. Instrum., 52, 789, (1981).

38. R.E. Center and A. Mandl, J. Chem. Phys., 57, 4104, (1972).

39. R.C. Weast, Ed., CRC Handbook of Chemistry and Physics, CRC Press, Inc. Boca Raton, Fla. (1987).

40. Atlas of Mass Spectral Data.

41. U. Robra, H. Zacharias, and K.H. Welge, Z. Phys. D, 16, 175 (1990).

42. C.H. Chen, D.W. Clark, M.G. Payne, S.D. Kramer, Opt. Comm. 32, 391 (1980).

43. S. Abramowitz and M.W. Chase,Jr.,Pure and Appl. Chem., 63(10). 1449 (1991).

44. G. Herzberg, Spectra of Polyatomic Molecules (Van Nostrand, Princeton, N.J., 1950)

45. H.F. Davis, B. Kim, H.S. Johnston, and Y.T. Lee, manuscript in preparation. Table 1: Calculated $\mathrm{NO}_{3}$ Vibrational Populations Assuming $\mathrm{D}_{3 \mathrm{~h}}$
Symmetry

\begin{tabular}{|c|c|c|c|}
\hline \multirow[t]{2}{*}{ Mode } & \multirow{2}{*}{$\begin{array}{l}\text { Vibrational Frequency }{ }^{12} \\
\qquad\left(\mathrm{~cm}^{-1}\right)\end{array}$} & \multicolumn{2}{|c|}{$\mathrm{N}\left(\nu_{\mathrm{j}}\right) / \mathrm{N}(\nu=0)$} \\
\hline & & $(600 \mathrm{~K})$ & $(300 \mathrm{~K})$ \\
\hline$\nu_{1}$ & 1050 & 0.08 & 0.0066 \\
\hline$\nu_{2}$ & 762 & 0.16 & 0.026 \\
\hline$\nu_{3}$ & $1492(2)$ & 0.056 & 0.0016 \\
\hline$\nu_{4}$ & $363(2)$ & 0.84 & 0.35 \\
\hline
\end{tabular}


Table II: Vibrational energies of $\mathrm{NO}$ and various electronic states of $\mathrm{O}_{2}{ }^{25}$

\begin{tabular}{lll} 
Molecule & $\varpi_{\mathrm{e}}\left(\mathrm{cm}^{-1}\right)$ & $\varpi_{\mathrm{e}} \mathrm{x}_{\mathrm{e}}\left(\mathrm{cm}^{-1}\right)$ \\
\hline NO $(\mathrm{m})$ & 1904.04 & 14.1 \\
$\mathrm{O}_{2}\left(\Sigma_{\mathrm{z}}\right)$ & 1580.19 & 11.98 \\
$\mathrm{O}_{2}\left({ }^{1} \Delta_{\mathrm{g}}\right)$ & 1483.5 & 12.9 \\
$\mathrm{O}_{2}\left({ }^{1} \Sigma^{+}\right)$ & 1432.77 & $(11)$ \\
\hline
\end{tabular}

\section{LIST OF FIGURES:}

Fig. $1 \mathrm{NO}_{3}$ Absorption Spectrum at 230 and $298 \mathrm{~K}$, obtained from Ref. 16.

Fig. 2 Approximate Correlation and energy diagram for $\mathrm{NO}_{3}$ photodisscciation, obtained from Ref. 3.

Fig. 3 NO and $\mathrm{O}$ quantum yields for $\mathrm{NO}_{3}$ photolysis, as obtained by Magnotta and Johnston. Data reproduced from Ref $2 b$.

Fig. 4 Experimental arrangement for photodissociation experiments on the Amachine.

Fig. 5 Schematic diagram for the Rotating Source Machine. See Ref. 35 for details.

Fig 6 A) Schematic of the original nozzle design used on A-machine.

B) Schematic of the improved nozzle design used on RSM

Fig. 7 Relative abundances of $\mathrm{N}_{2} \mathrm{O}_{5}$ and its decomposition products upon 
pyrolysis at 600K. See Ref. 33 for details.

Fig. 8 Newton Diagram for the NO containing fragments from photodissociation of $\mathrm{NO}_{3}$ at $590 \mathrm{~nm}$.

Fig. 9 TOF spectra obtained for $\mathrm{NO}_{2}{ }^{+}, \mathrm{NO}^{+}$, and $\mathrm{O}_{2}{ }^{+}$products from $590 \mathrm{~nm}$ photolysis of $\mathrm{NO}_{3}$.

Fig. $10 \mathrm{NO}^{+}$TOF spectra obtained at several detector angles from $590 \mathrm{~nm}$ photolysis of $\mathrm{NO}_{3}$.

Fig.11 $\mathrm{NO}^{+}$TOF spectra obtained at several detector angles from $590 \mathrm{~nm}$ photolysis of $\mathrm{NO}_{3}$.

Fig 12 Product translational energy distributions for the two possible channels from $\mathrm{NO}_{3}$ photodissociation at $590 \mathrm{~nm}$.

Fig 13 Wavelength dependence for two channels upon tuning laser below $590 \mathrm{~nm}$.

Fig 14 Wavelength dependence for two channels upon tuning laser above $590 \mathrm{~nm}$.

Fig 15 Wavelength dependence for two channels.

Fig 16 NO TOF spectra obtained at 588nm using RSM and Nozzle 2

Fig17 NO TOF spectra obtained at $594 \mathrm{~nm}$ using RSM and Nozzle 2

Fig $18 \mathrm{NO}+\mathrm{O}_{2}$ transiational energy distribution $(\mathrm{P}(\mathrm{E}))$ for $588 \mathrm{~nm}$ photolysis.

Fig $19 \mathrm{NO}+\mathrm{O}_{2}$ translational energy distribution $(\mathrm{P}(\mathrm{E}))$ for $594 \mathrm{~nm}$ photolysis.

Fig $20 \mathrm{O}^{+}(\mathrm{m} / \mathrm{e}=16)$ TOF data obtained at $20^{\circ}$ from dissociation of $\mathrm{NO}_{3}$ at $560 \mathrm{~nm}$ showing sensitivity to $P(E)$. A) $\left.E_{\text {rras, max }}=3.0 \mathrm{kcal} / \mathrm{mol} \mathrm{B}\right) E_{\text {rans, } \max }$ $=3.0 \mathrm{kcal} / \mathrm{mol} \mathrm{C}$ ) $\mathrm{E}_{\mathrm{vans,max}}=3.5 \mathrm{kcal} /$ mole. Best fit is B).

Fig 21 TOF data obtained at $\mathrm{O}^{+}(\mathrm{M} / \mathrm{E}=16)$ and $\mathrm{NO}^{+}(\mathrm{m} / \mathrm{e}=30)$ from $\mathrm{NO}_{2}+$ 
O channel at $560 \mathrm{~nm}$.

Fig $22 \quad \mathrm{P}(\mathrm{E})$ for $\mathrm{NO}_{2}+\mathrm{O}$ channel for $\mathrm{NO}_{3}$ photolysis at $548 \mathrm{~nm}$.

Fig 23 Newton diagram for $\mathrm{O}$ atom signal from photodissociation of $\mathrm{NO}_{3}$

Fig $24 \quad \mathrm{O}^{+}$TOF obtained using ring laser. Angle between beam and detector was 10 degrees. Background is included.

Fig 25 Wavelength dependence of oxygen atom product observed at 10 degrees. Ring laser was used as the excitation source.

Fig 26 Time-of-Flight spectrum for NO from NO $+\mathrm{O}_{2}$ at $590 \mathrm{~nm}$ using ring laser. Spectrum is superimposed on TOF obtained using pulsed laser at the same wavelength.

Fig 27 NO signal intensity as a function of laser wavelength using ring laser.

Fig 28 NO intensity data $\left(\phi_{\mathrm{NO}} \sigma_{\mathrm{NO}}\right)$ of Magnotta (Ref $\left.2 \mathrm{~b}\right)$.

Fig $29 \quad \mathrm{P}(\mathrm{E})$ for $\mathrm{NO}+\mathrm{O}_{2}$ products from $588 \mathrm{~nm}$ excitation of $\mathrm{NO}_{3}$. Maximum translational energies are indicated for various $\mathrm{O}_{2}$ internal states, assuming $\mathrm{NO}(v=0)$.

Fig 30 Same as Fig. 29, but assuming $\mathrm{NO}(v=1)$.

Fig $31 \quad \mathrm{P}(\mathrm{E})$ for $\mathrm{NO}+\mathrm{O}_{2}$ products from $594 \mathrm{~nm}$ excitation of $\mathrm{NO}_{3}$. Maximum translational energies are indicated for various $\mathrm{O}_{2}$ internal states, assuming NO $(v=0)$.

Fig 32 Same as Fig. 31, but assuming $N O(v=1)$. 


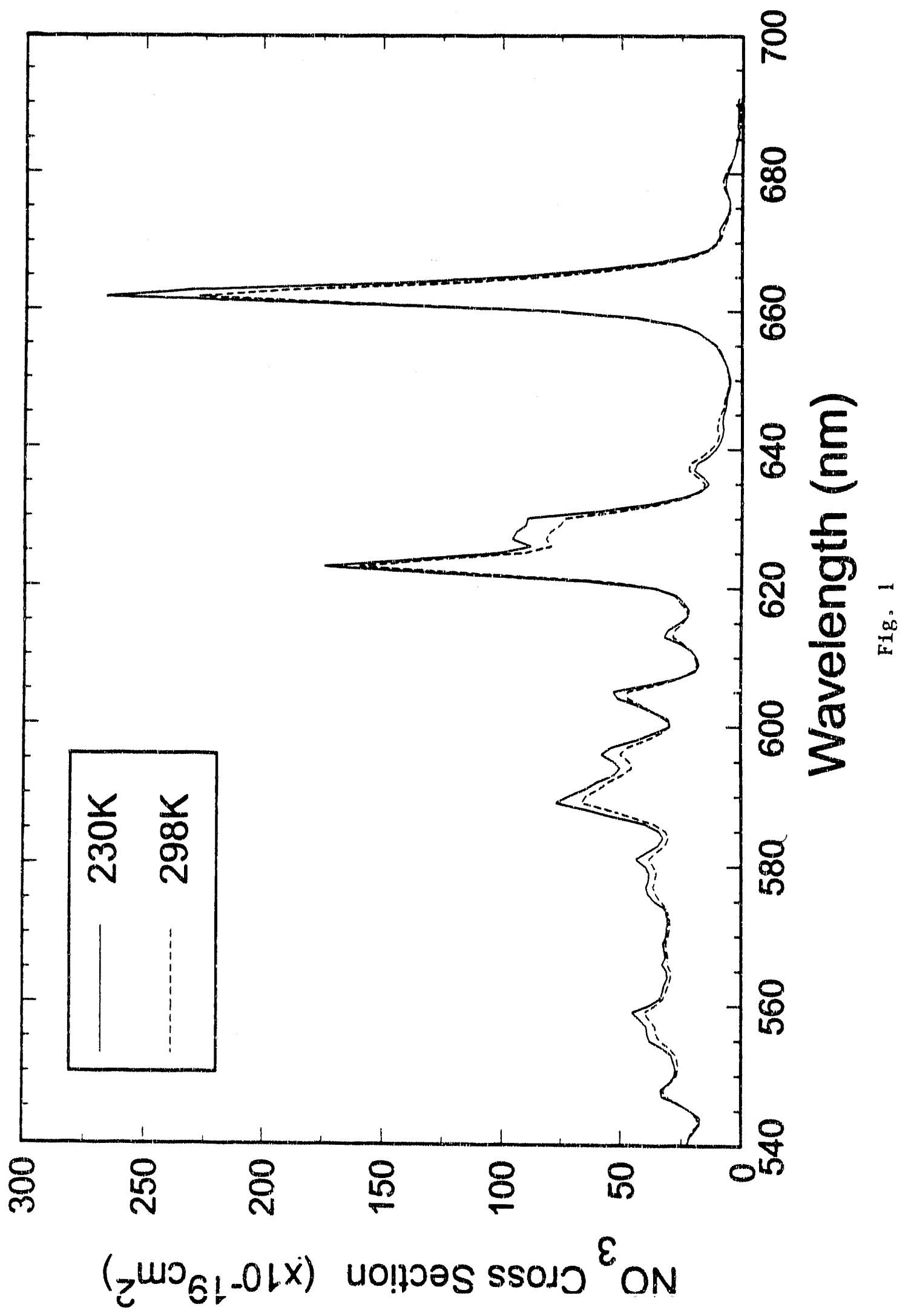




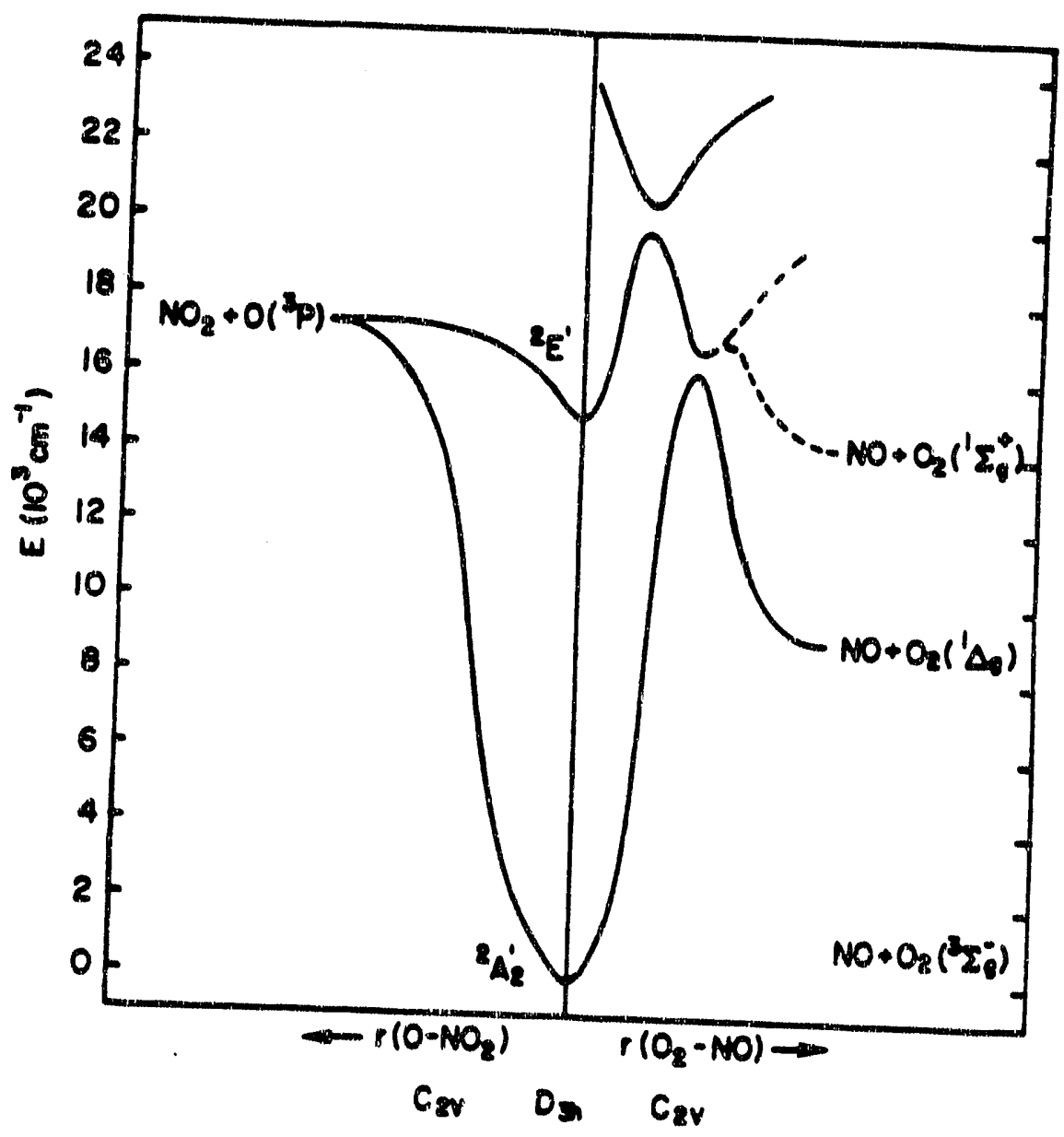

Fig. 2 


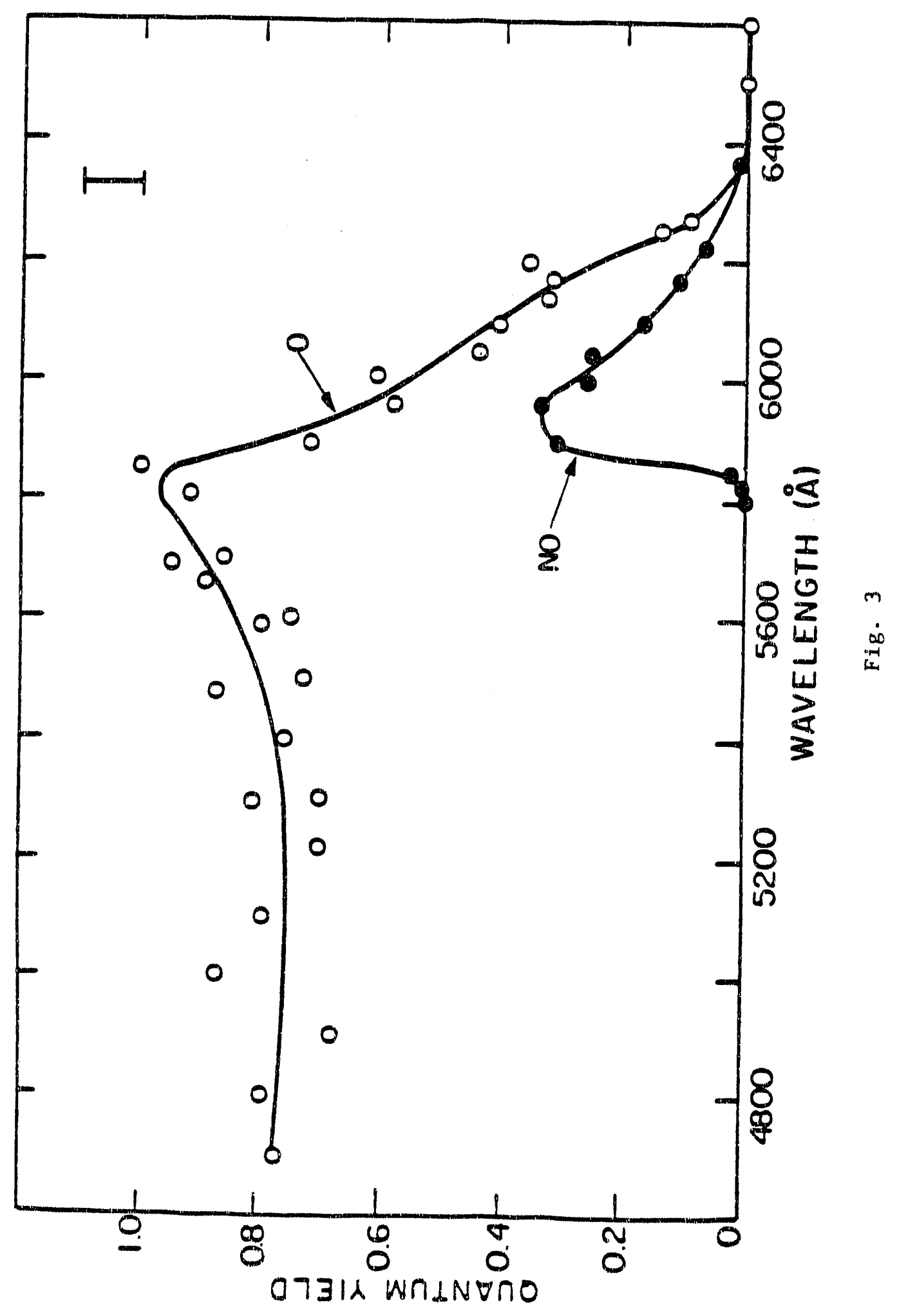




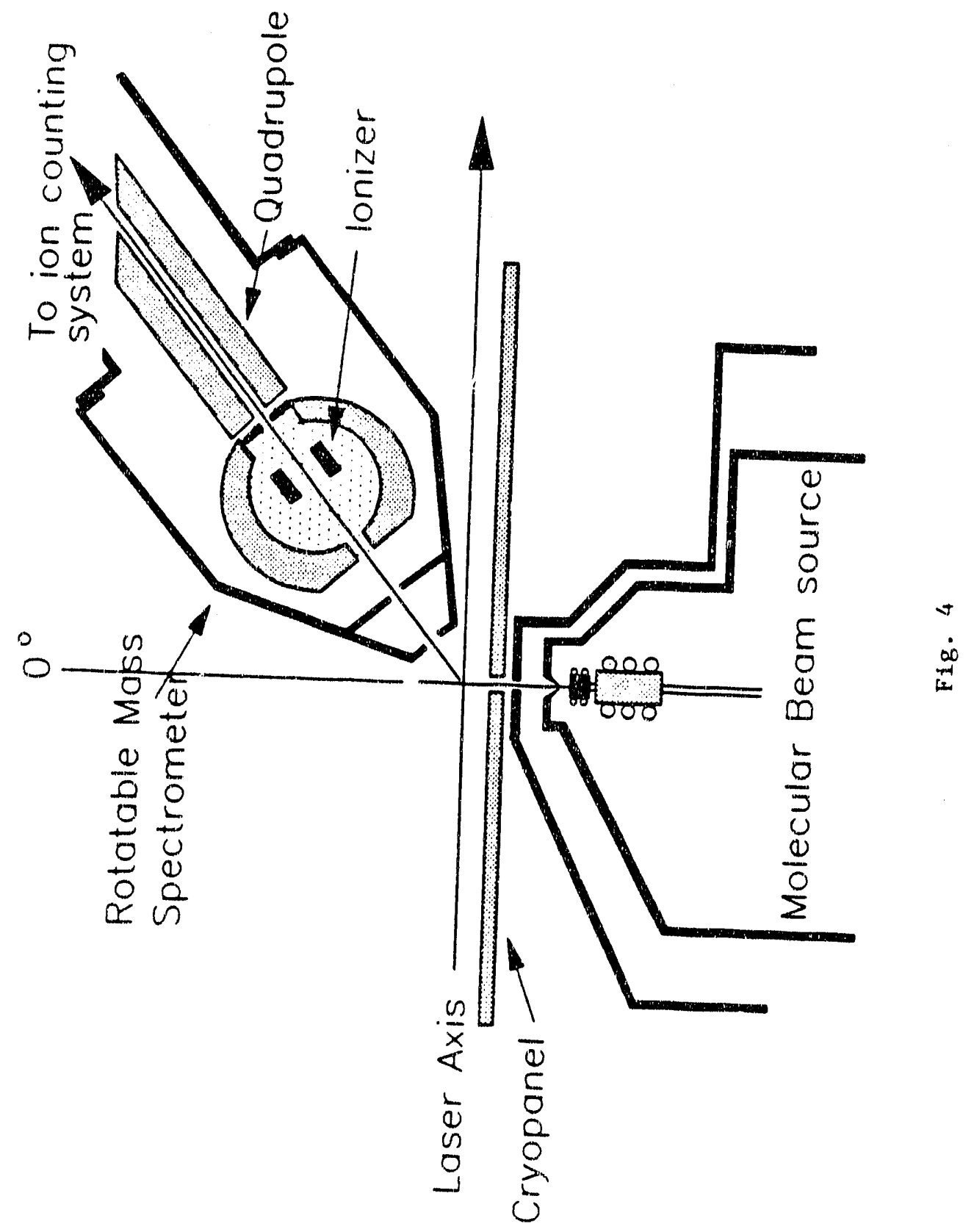




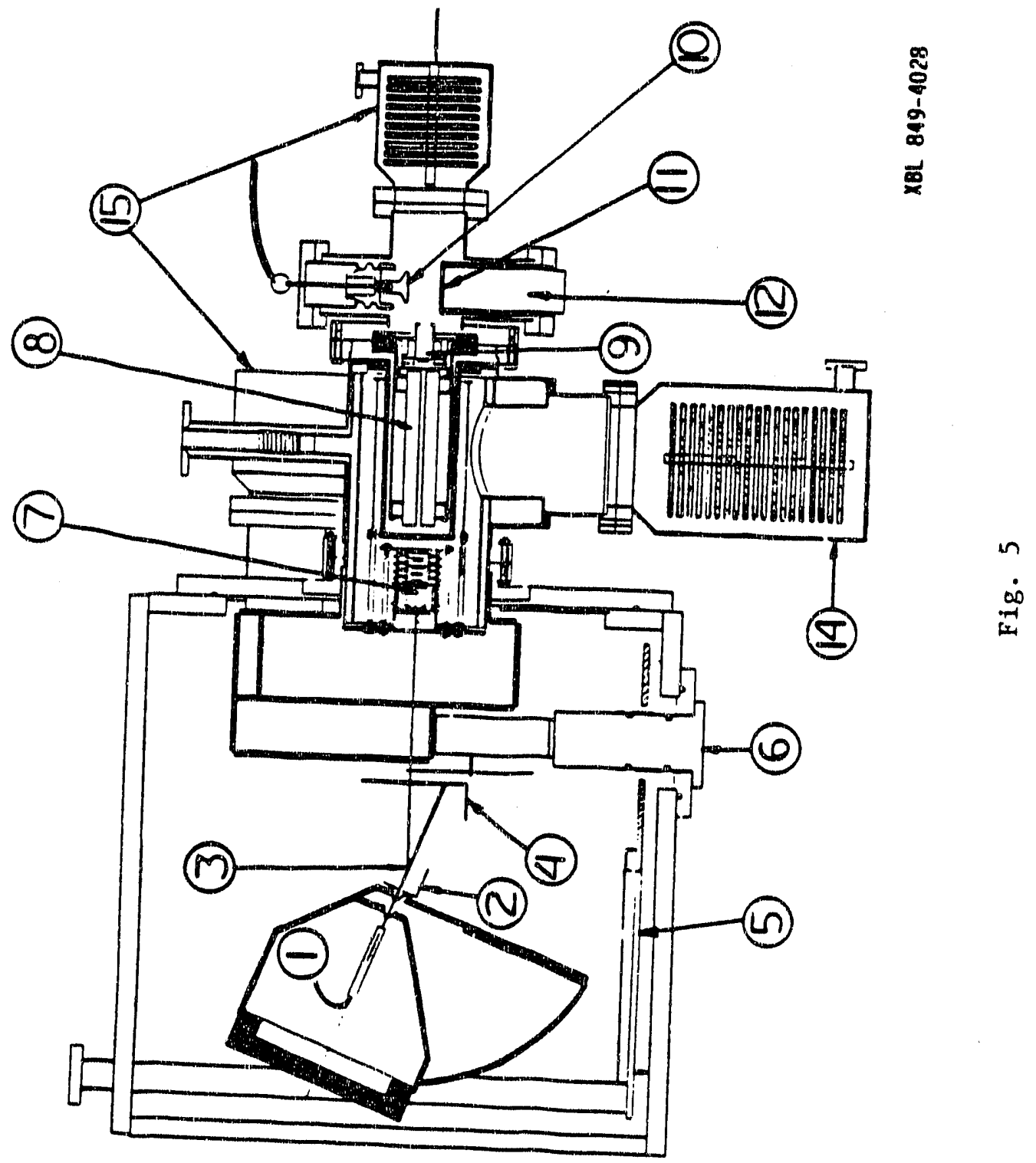



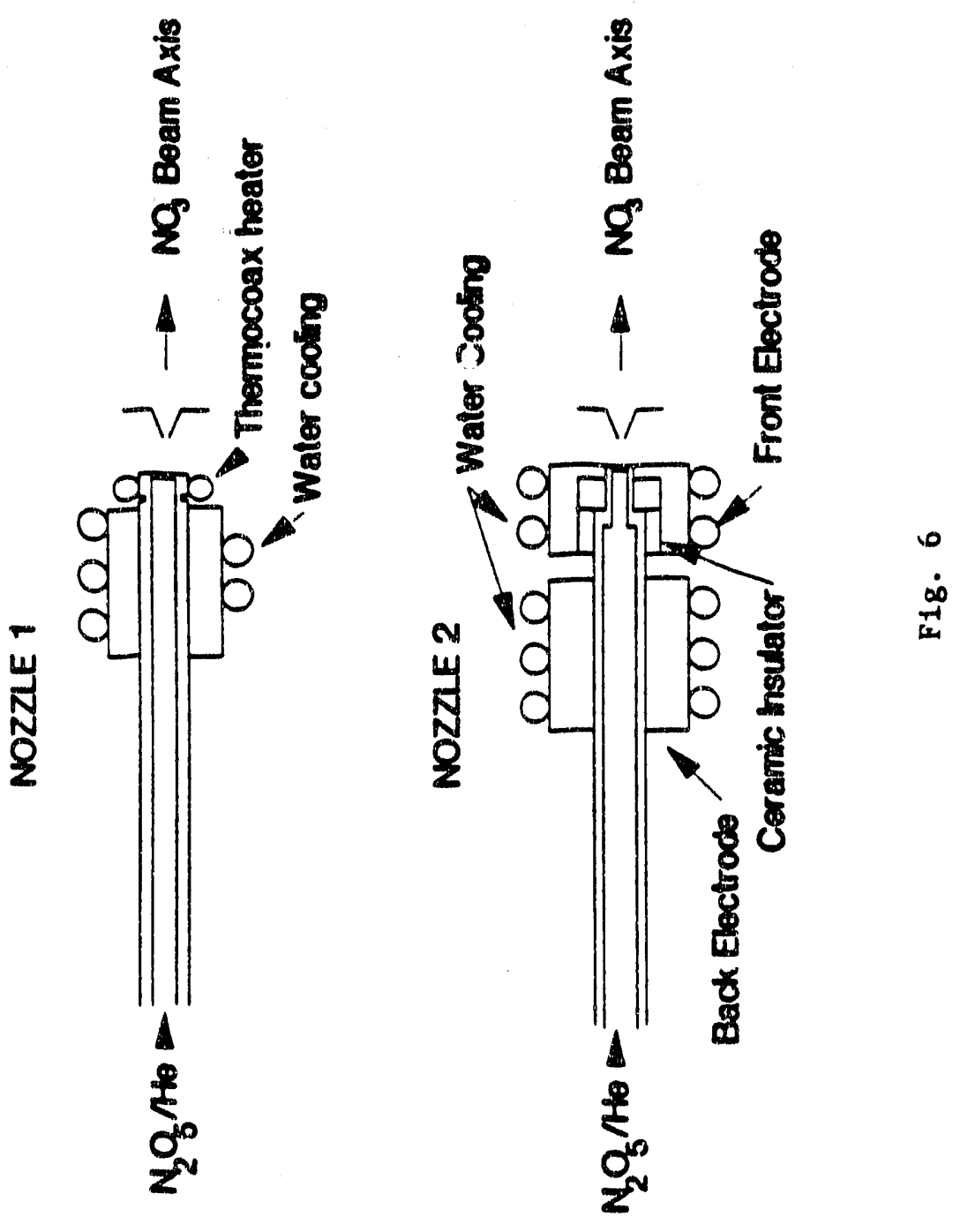


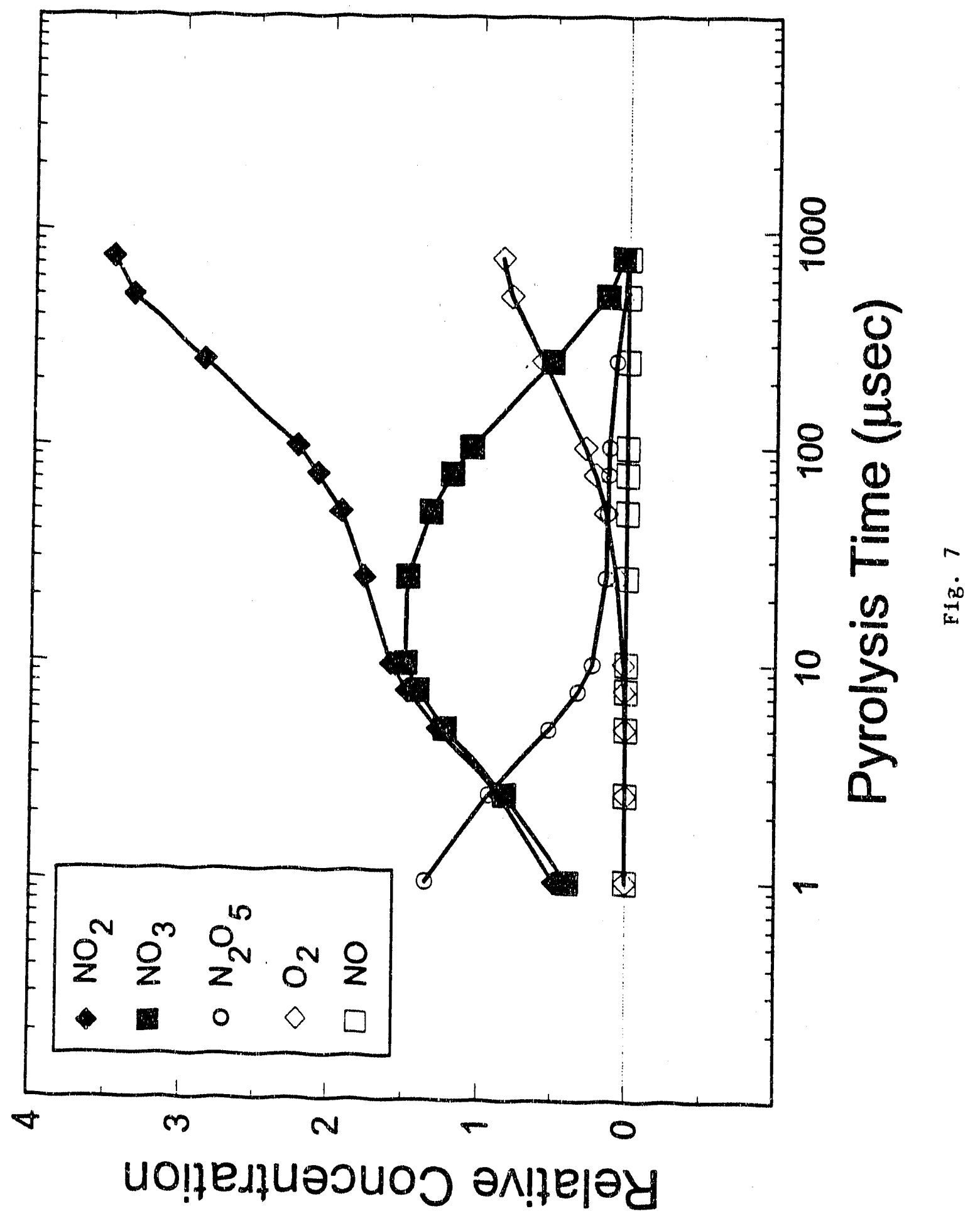




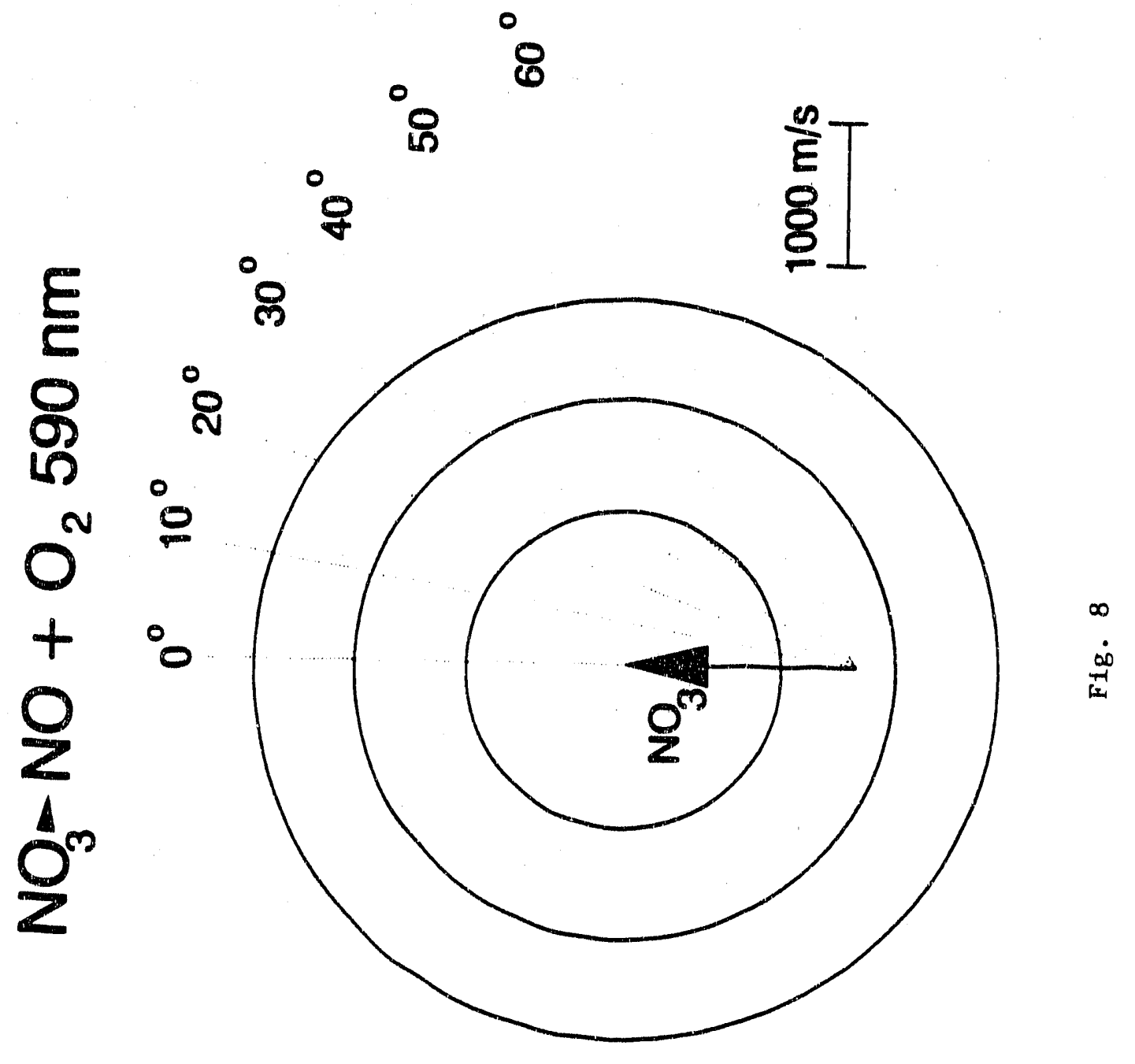



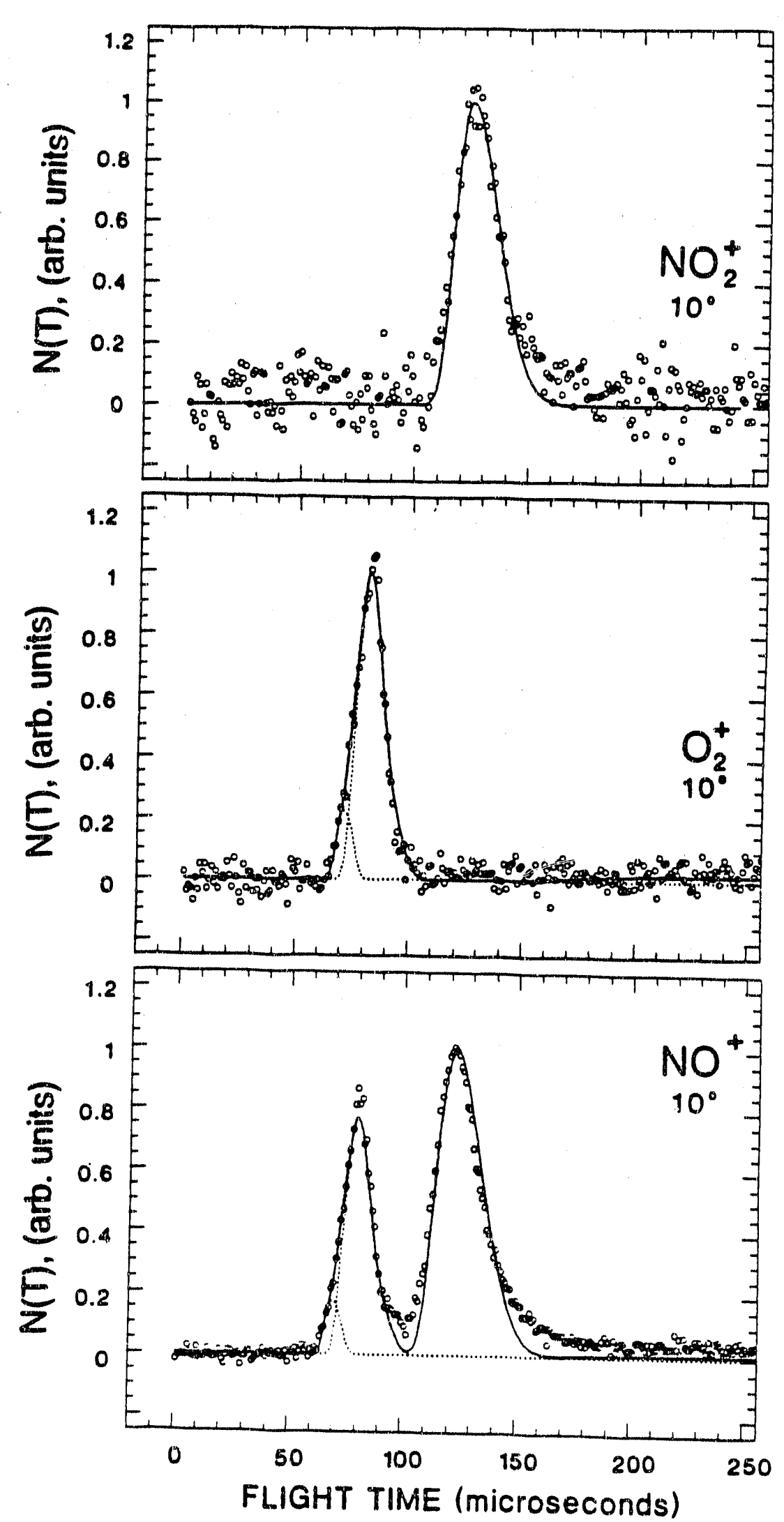

Fig. 9 


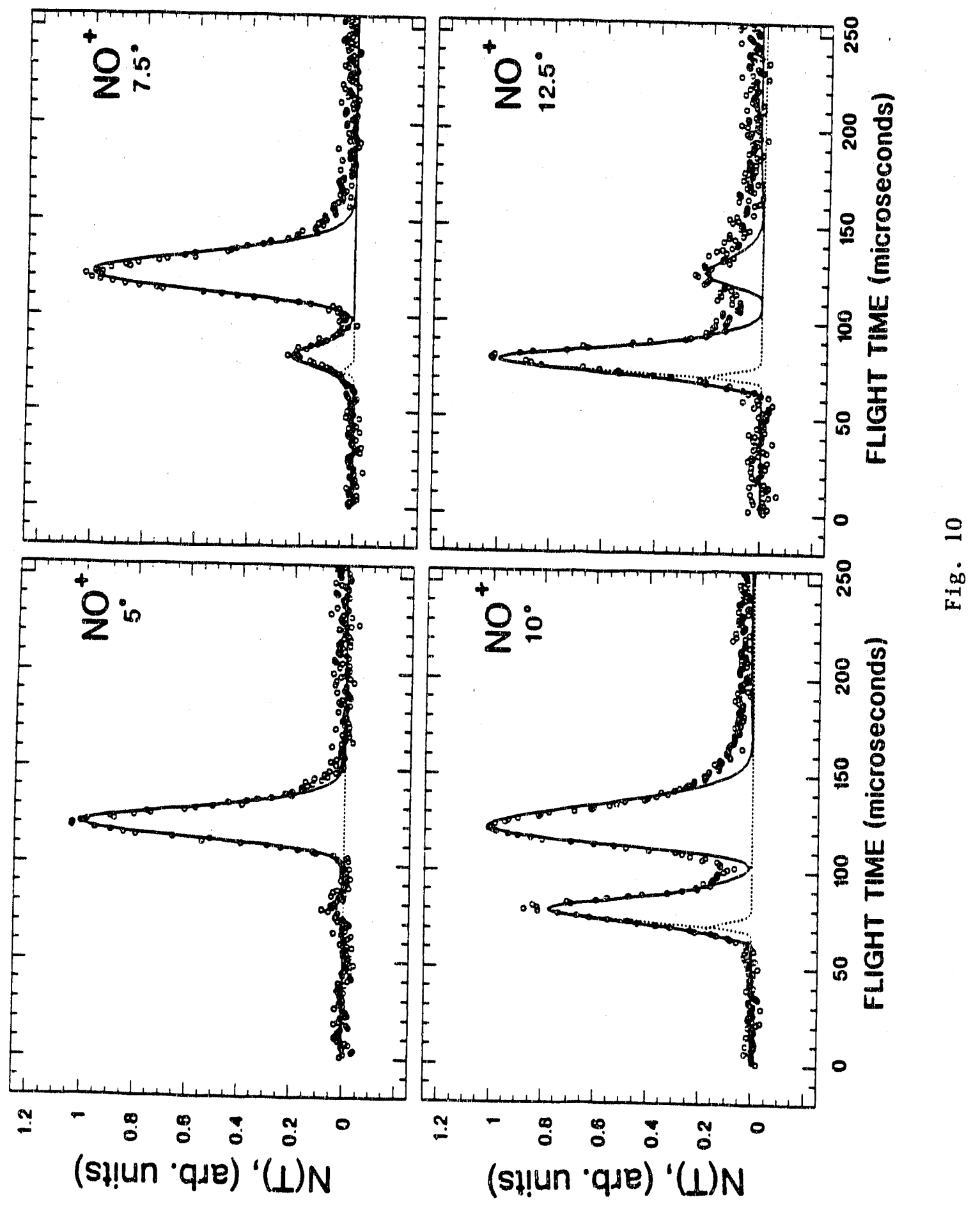



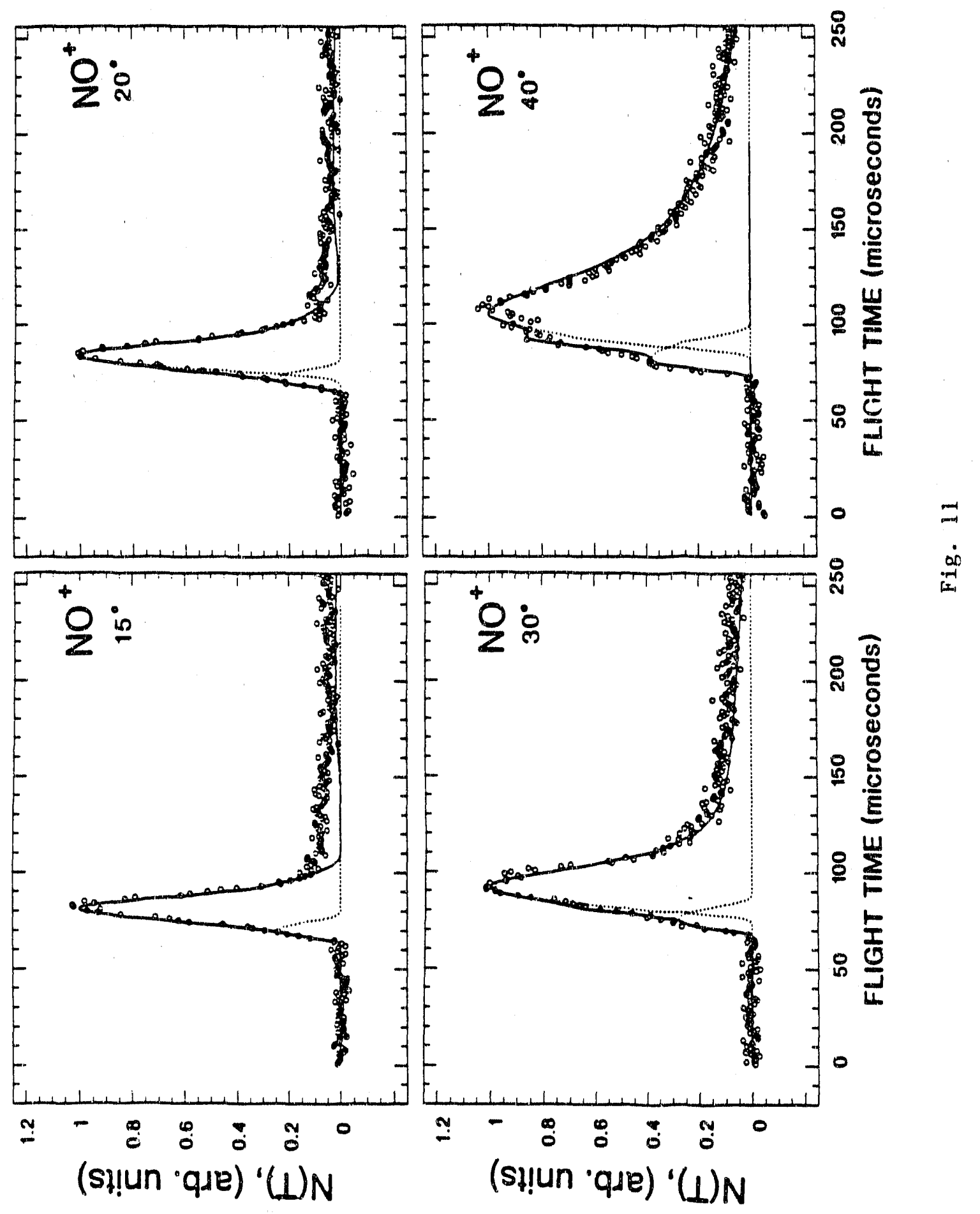


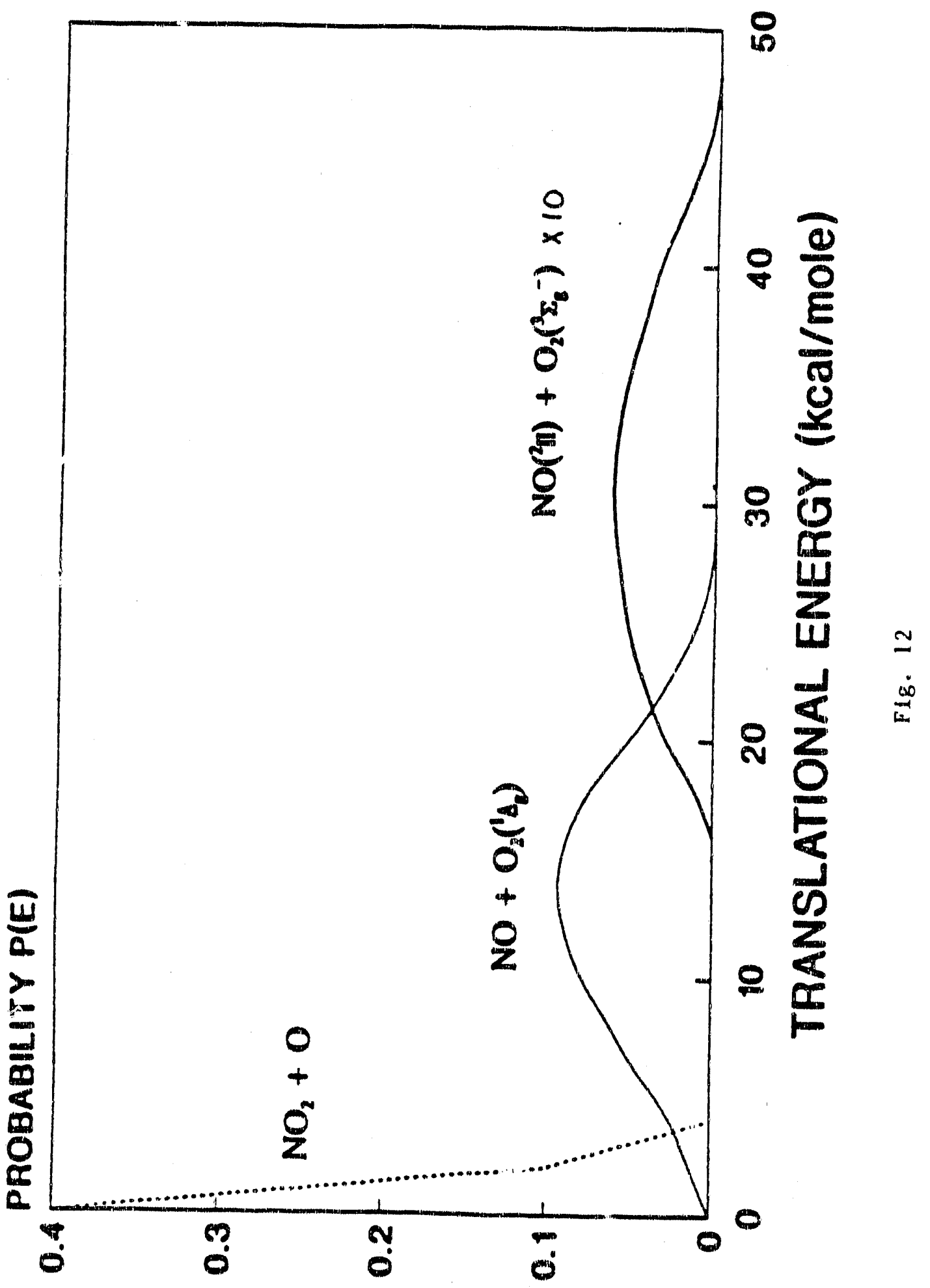



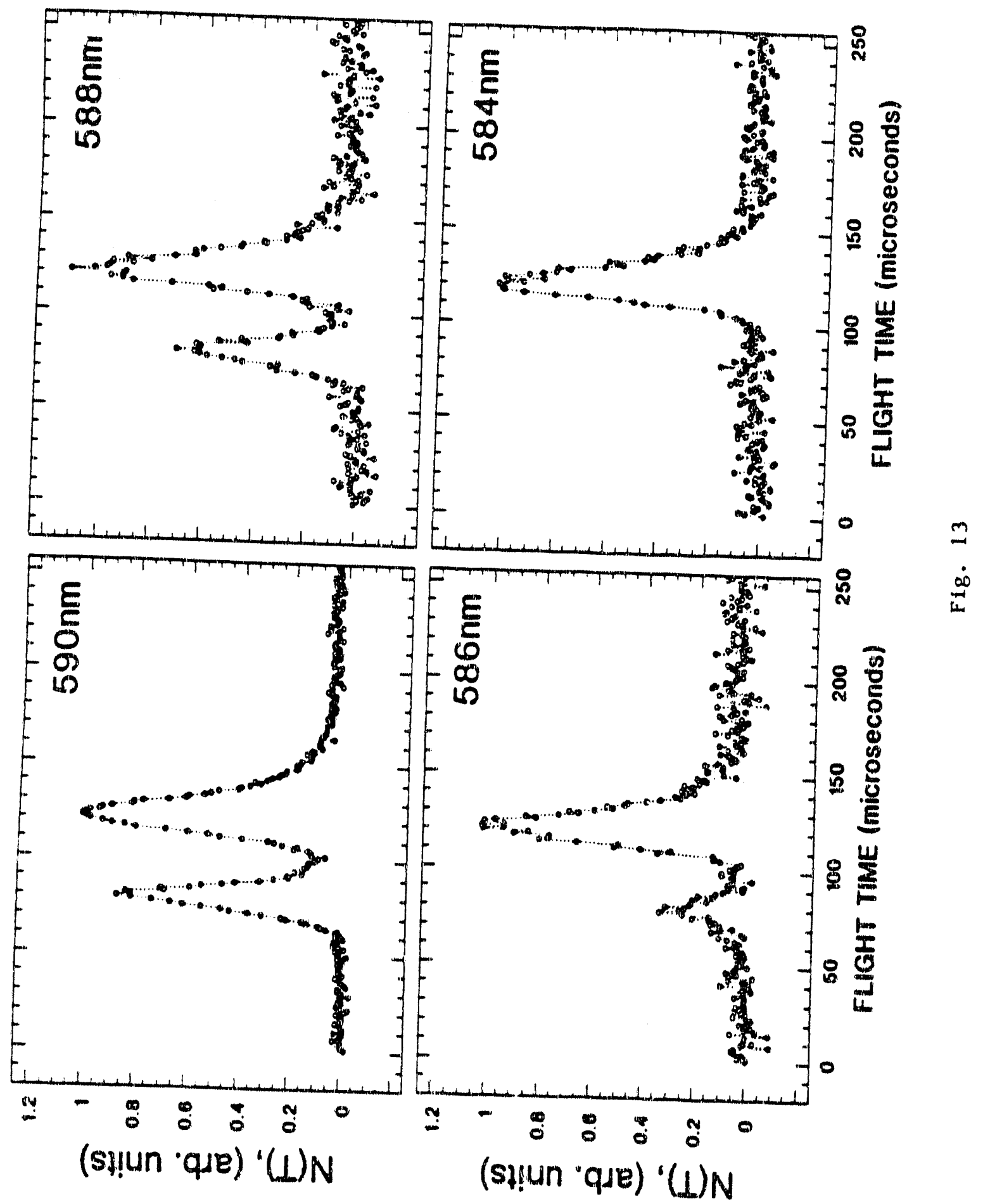

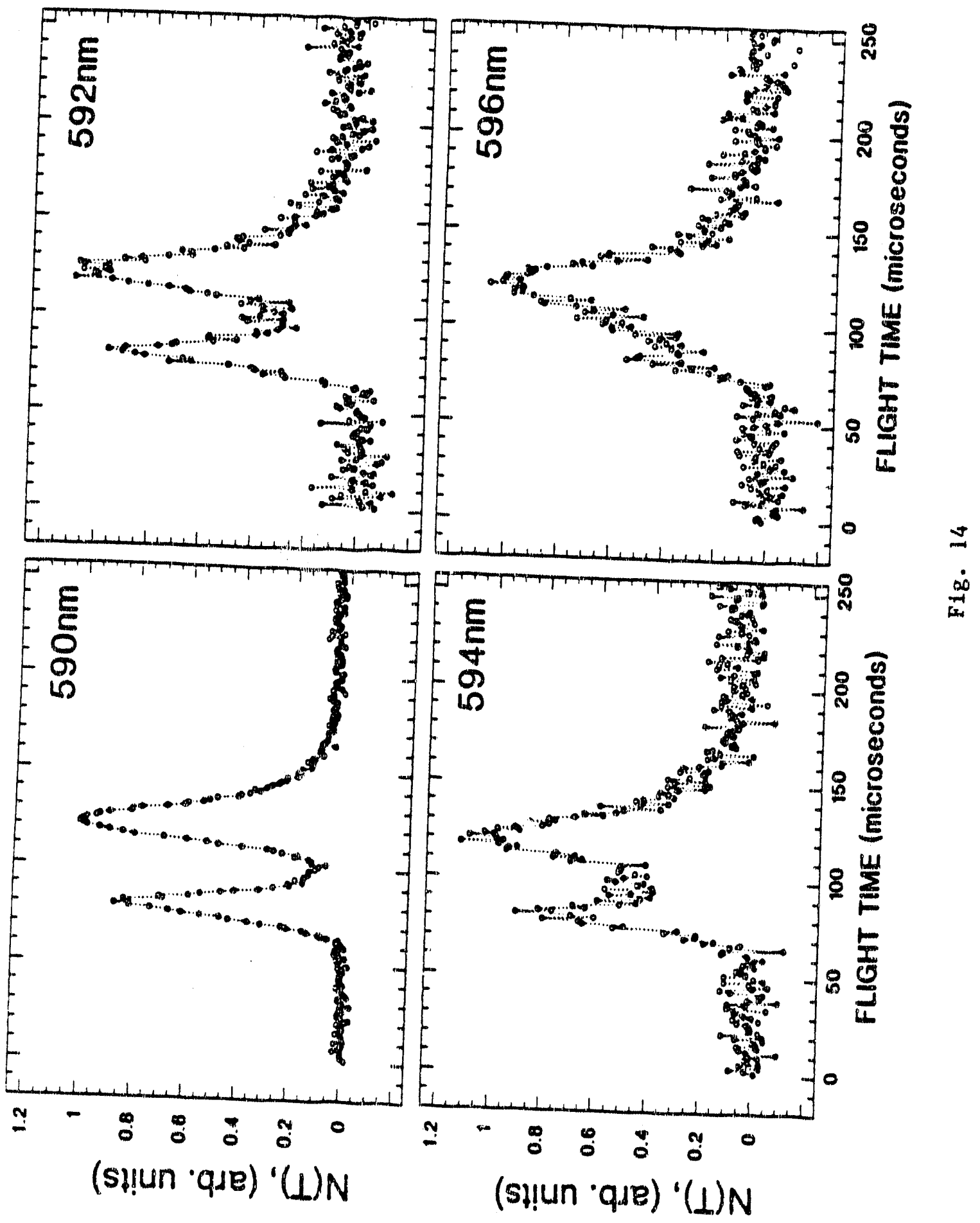


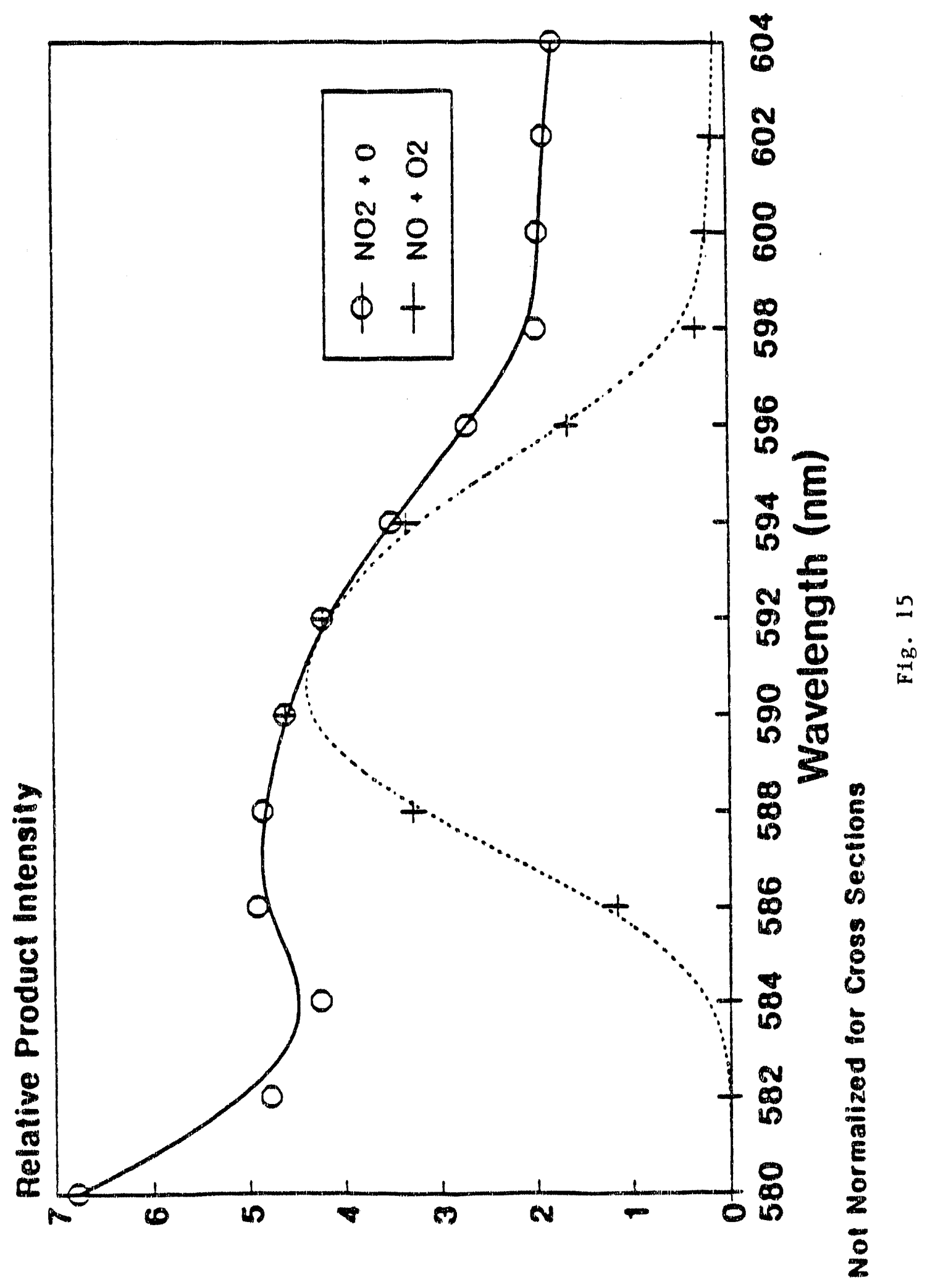




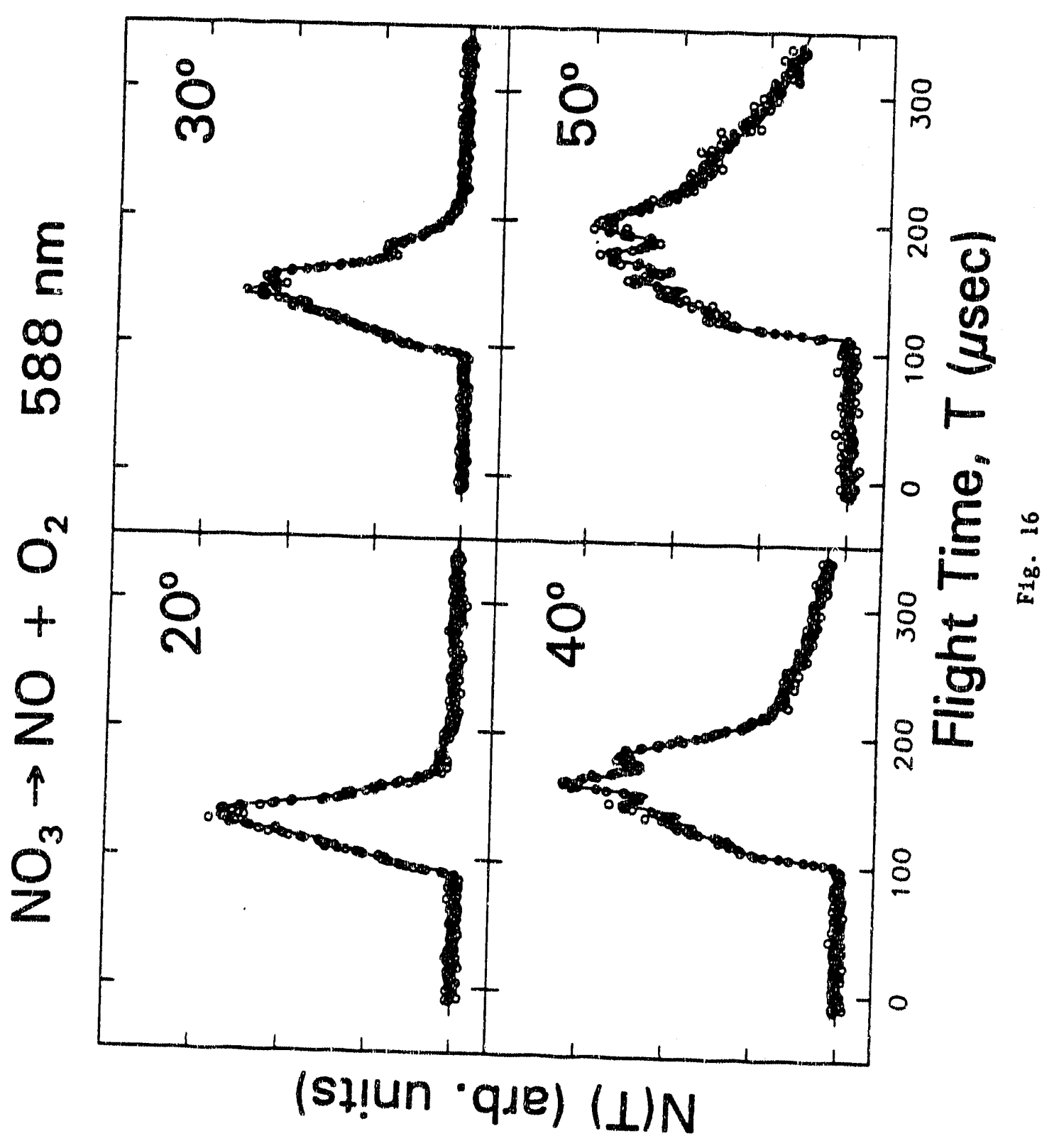




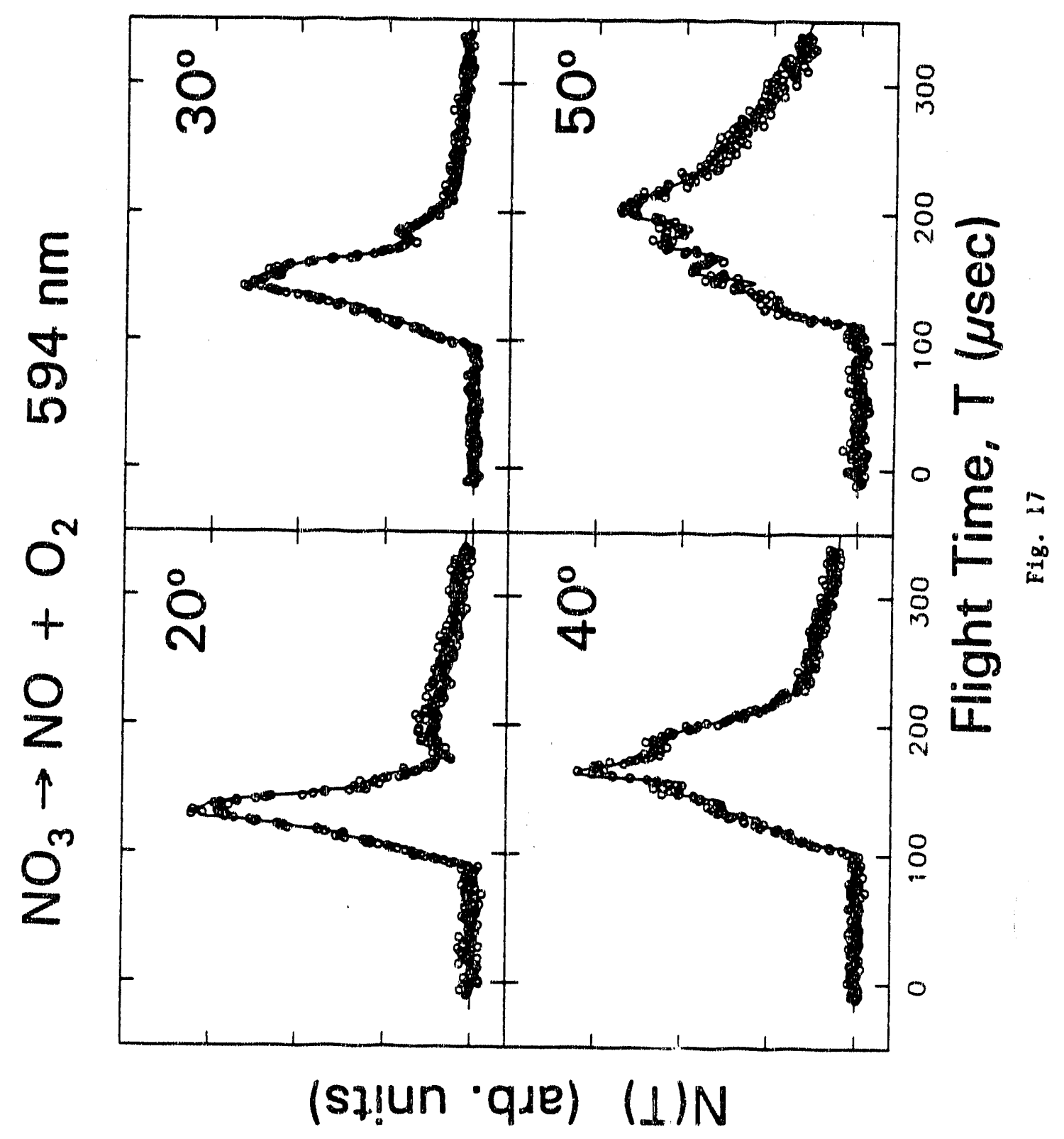




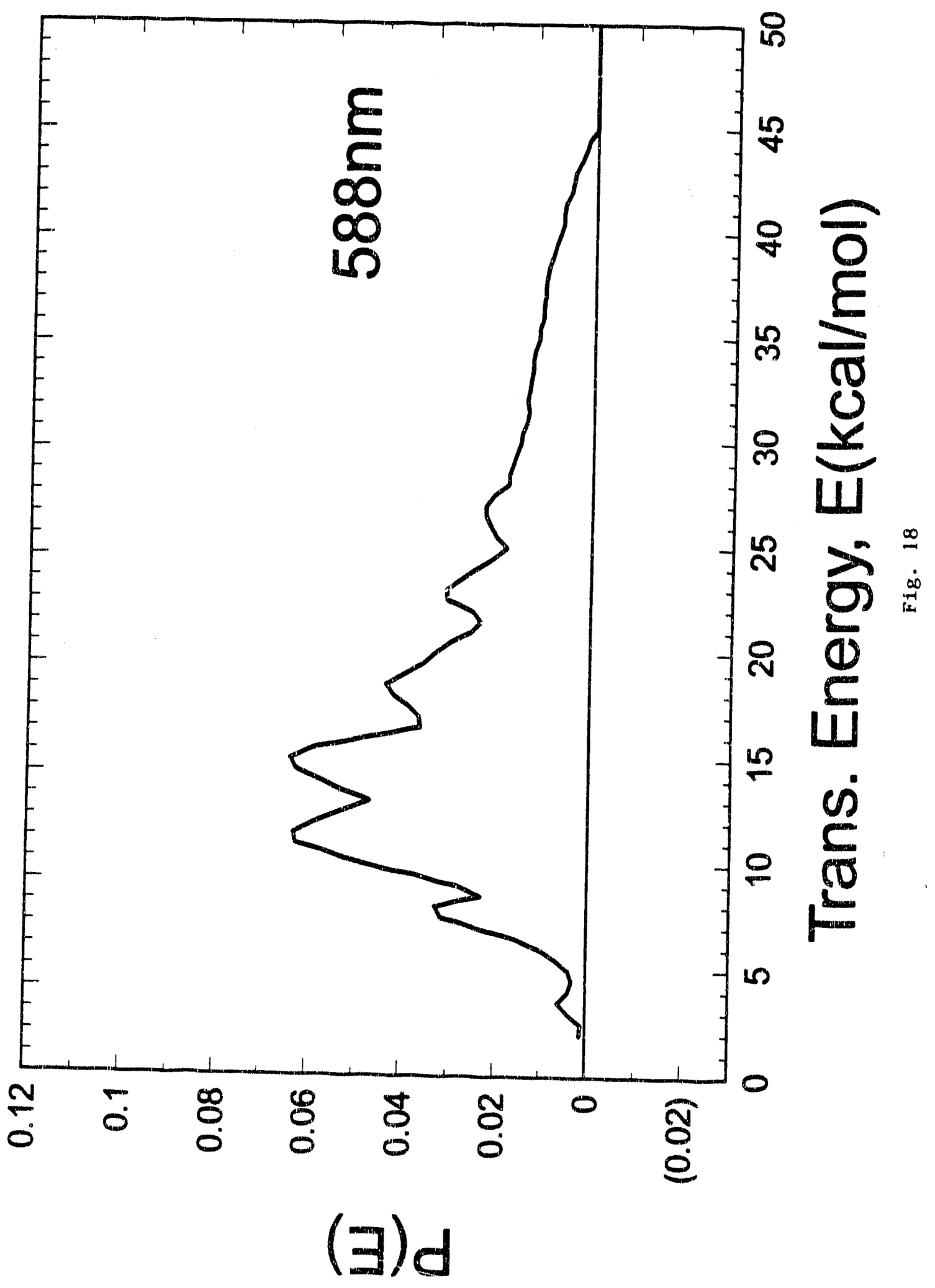




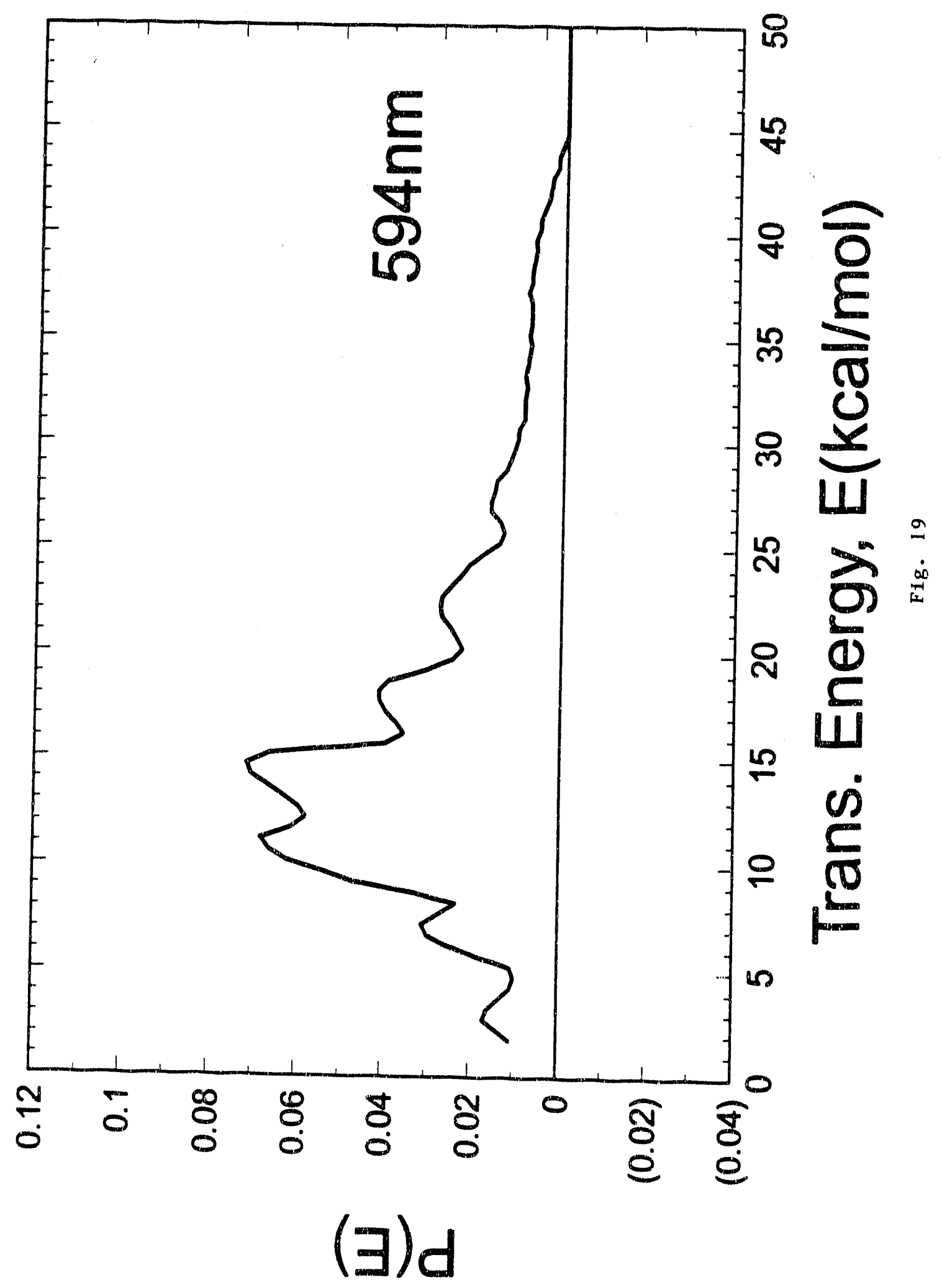




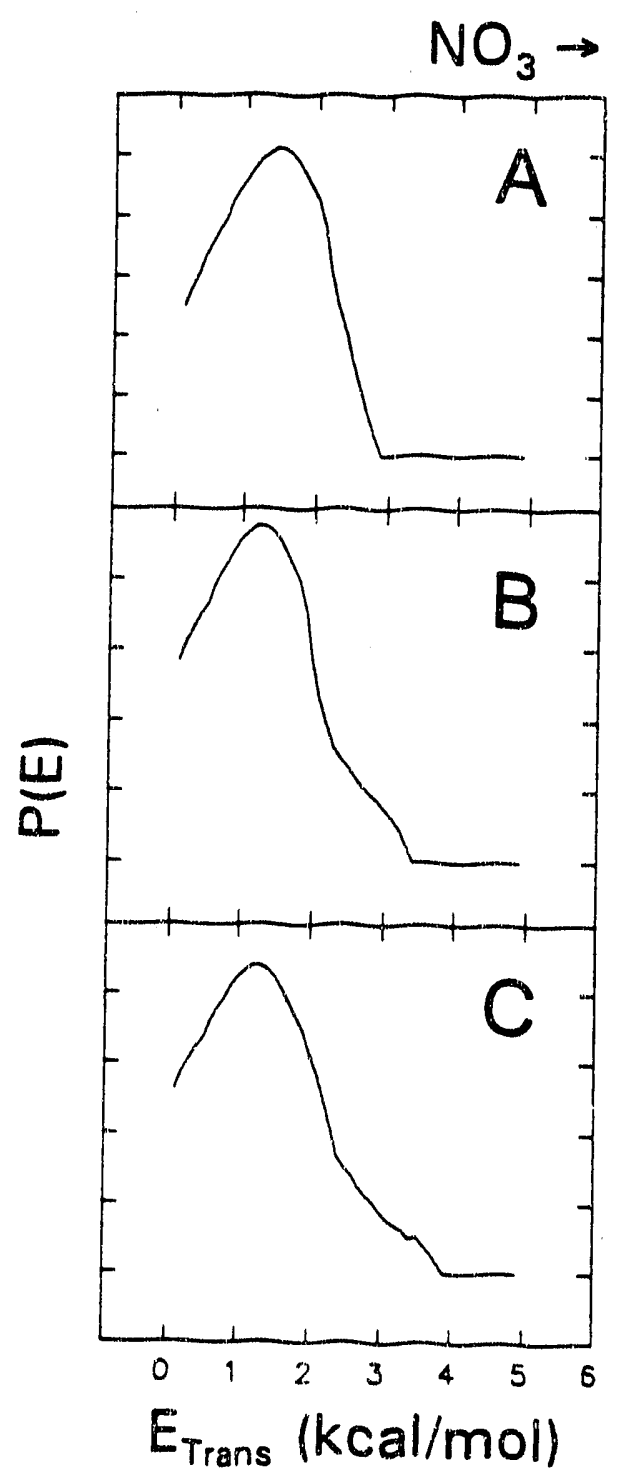

$\mathrm{NO}_{2}+\mathrm{Q} 20^{\circ} \quad 560 \mathrm{~nm}$

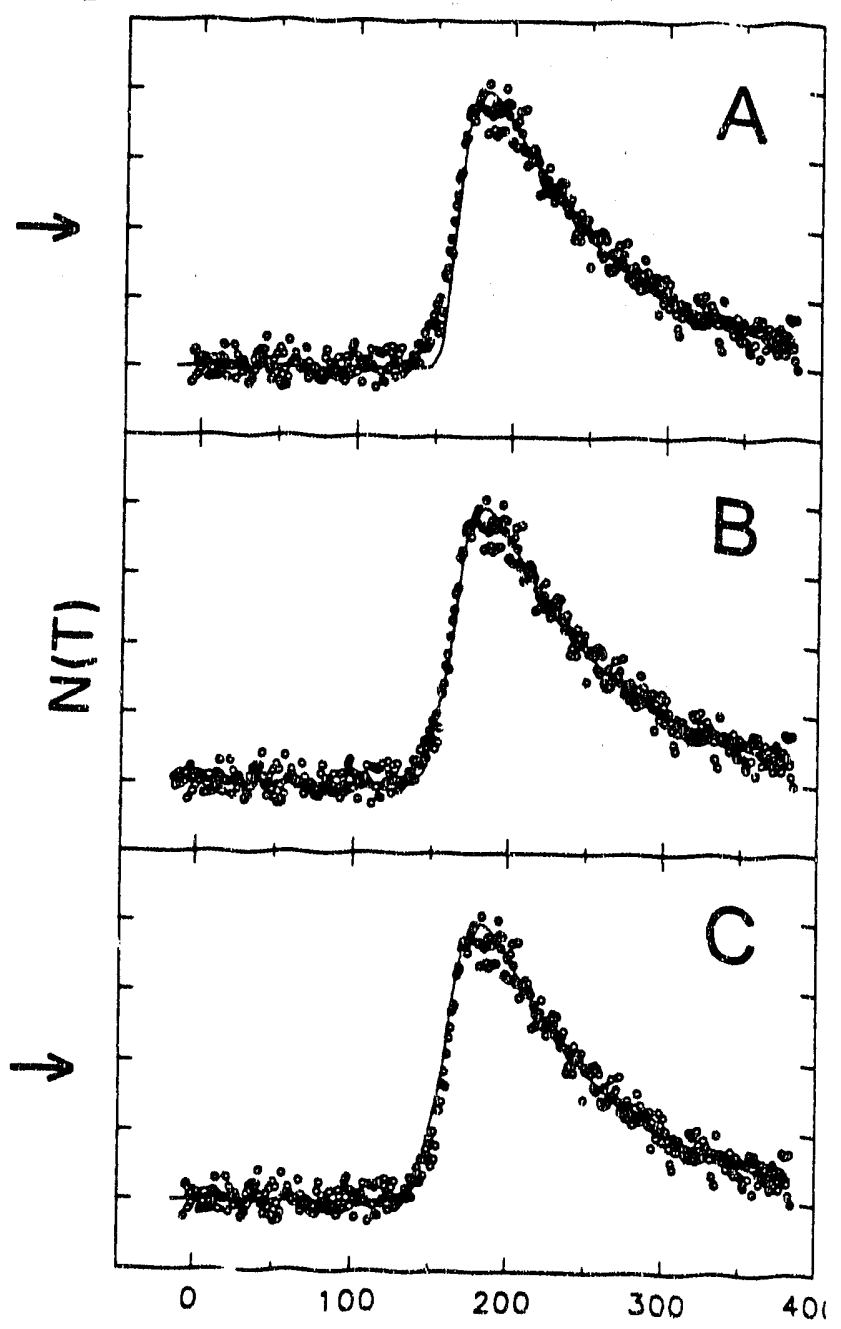

Flight Time, $T$ ( $\mu$ sec)

Fig. 20 


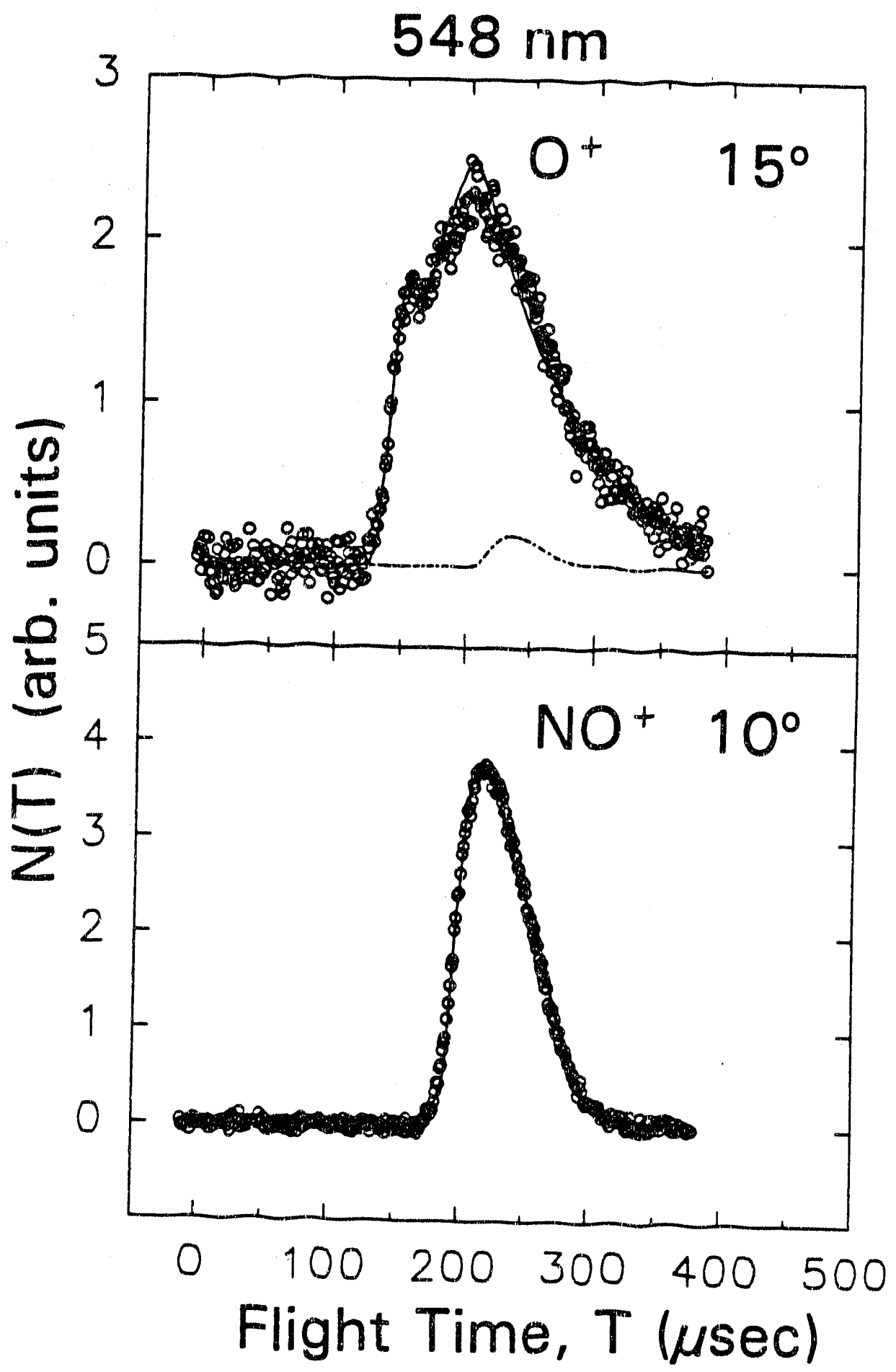

Fig. 21 


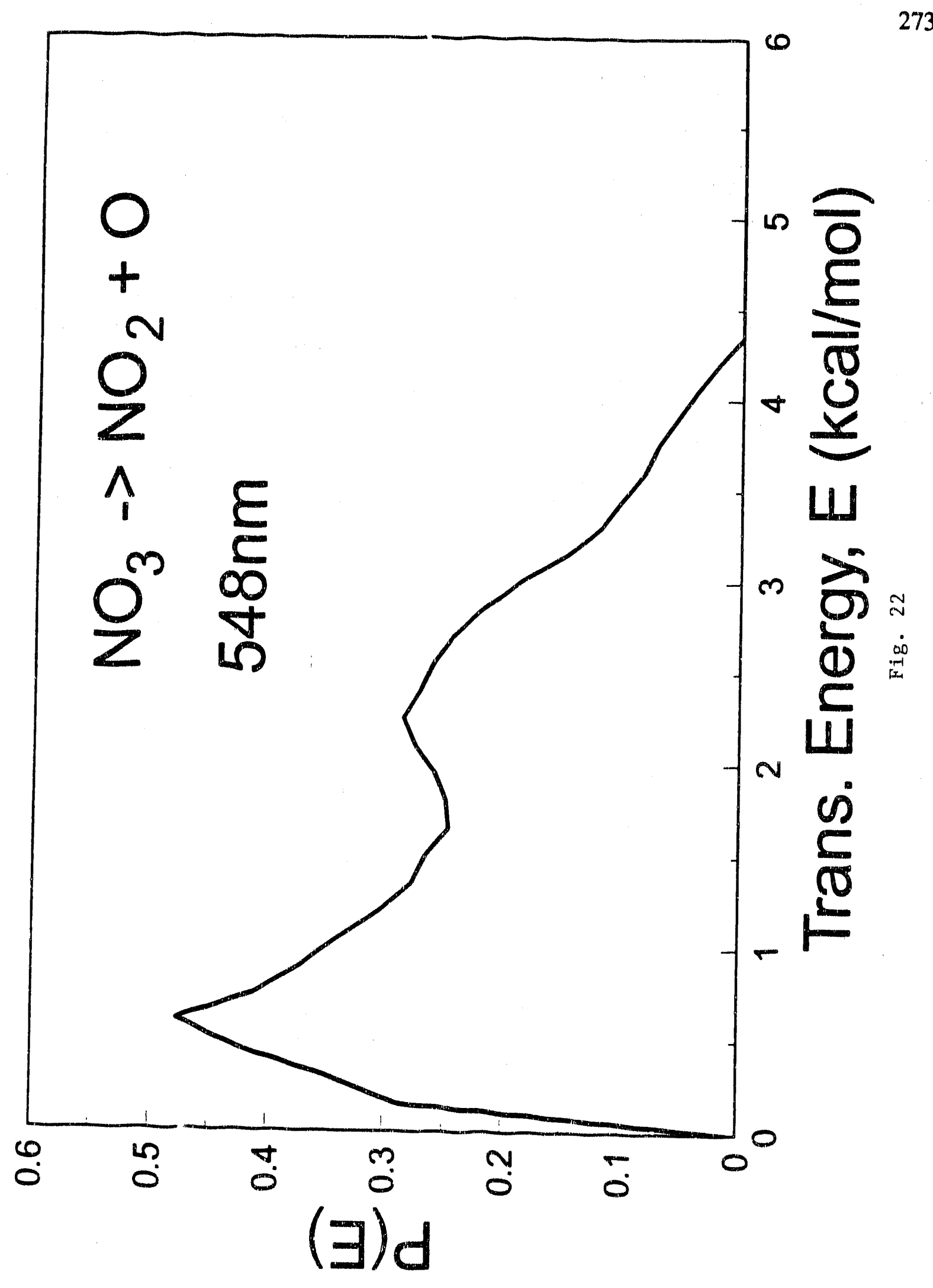




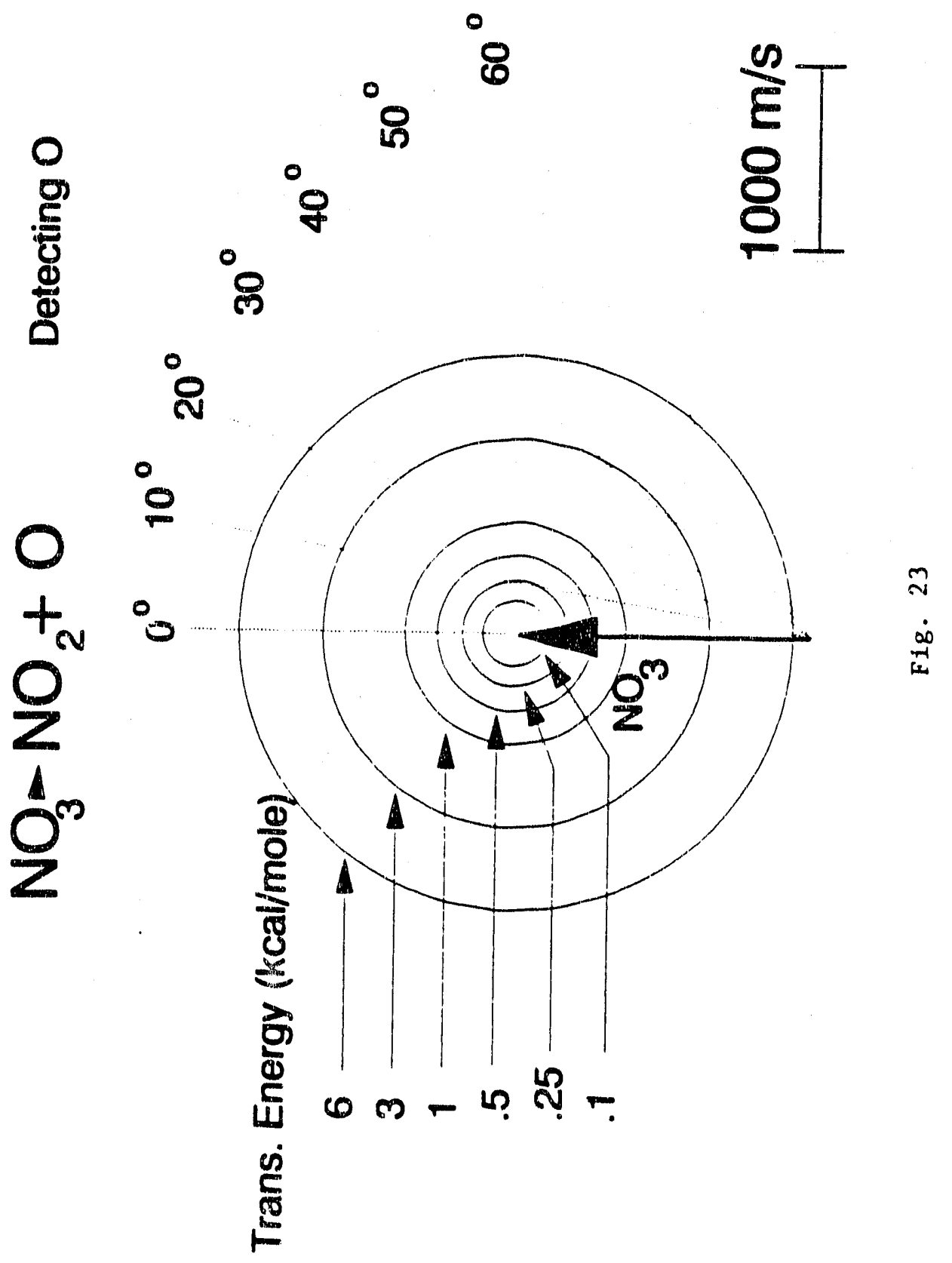




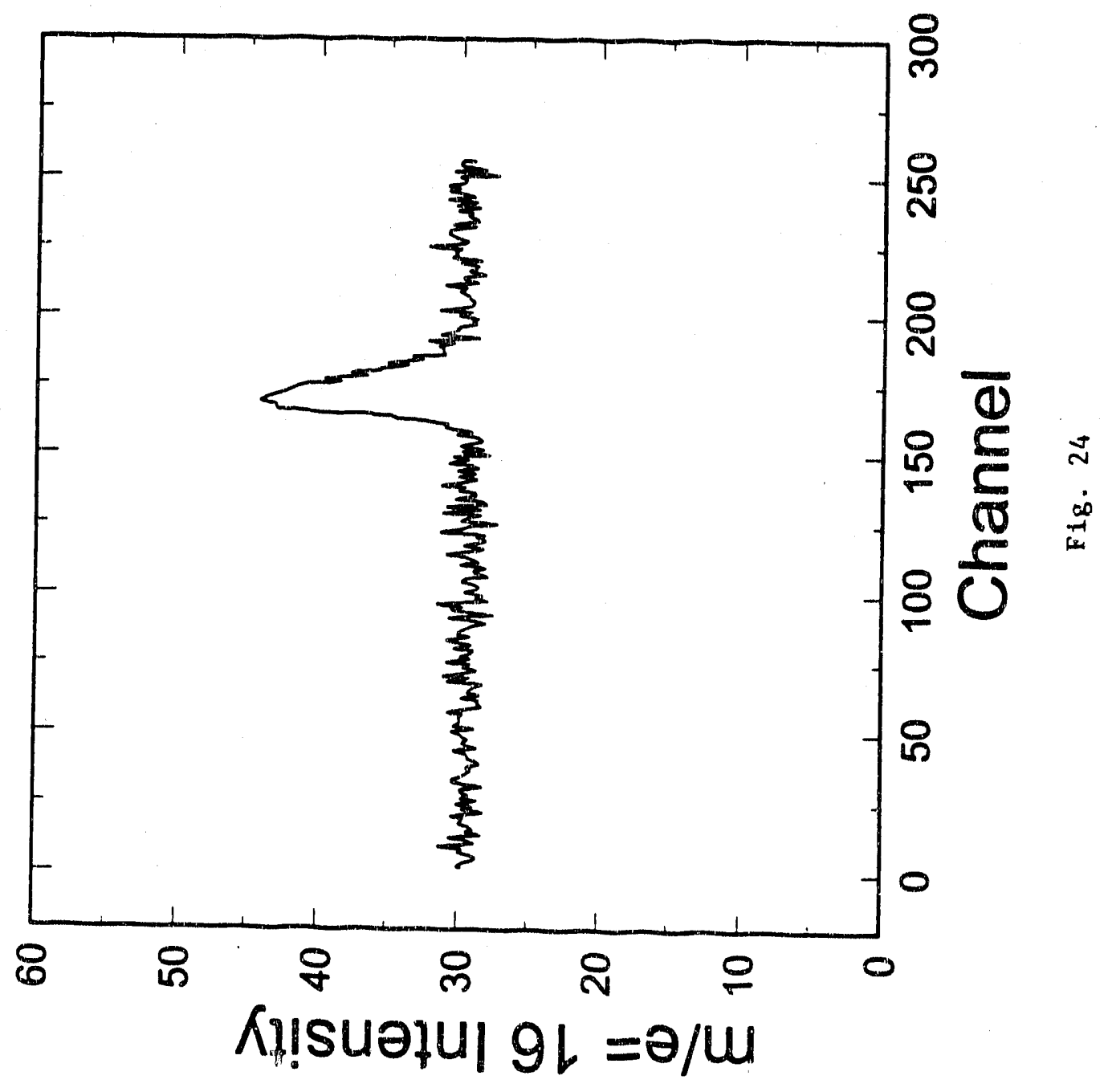




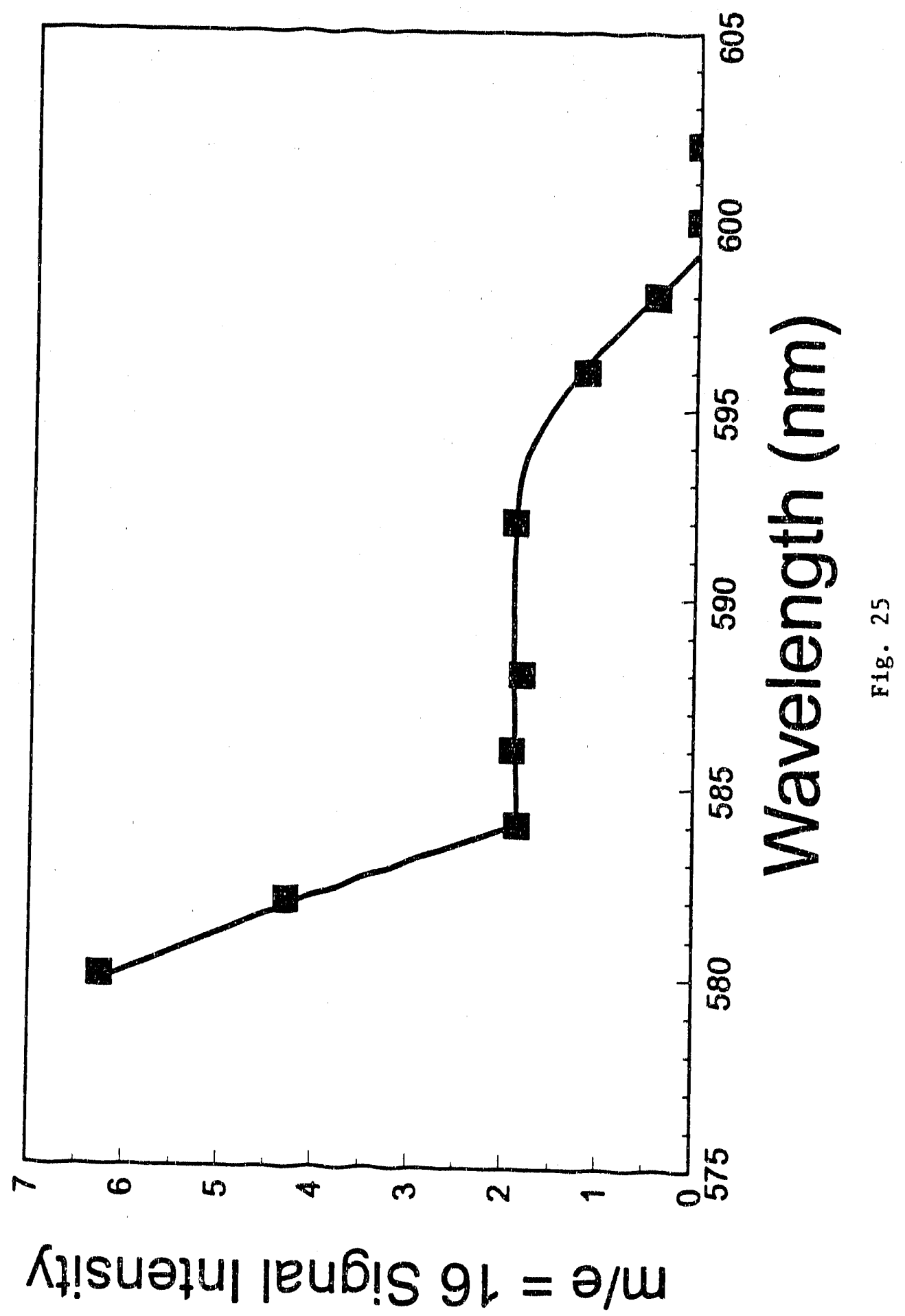




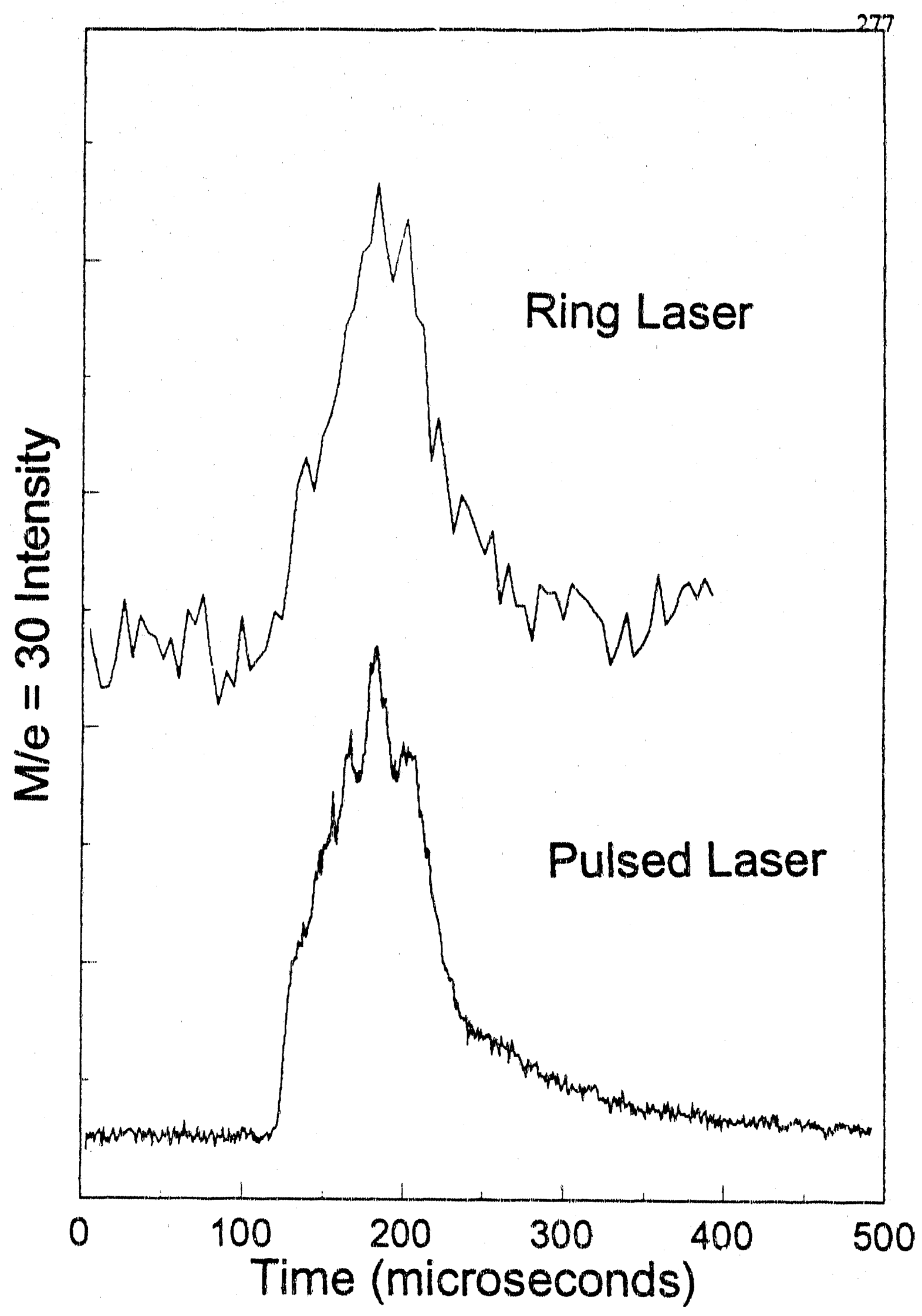




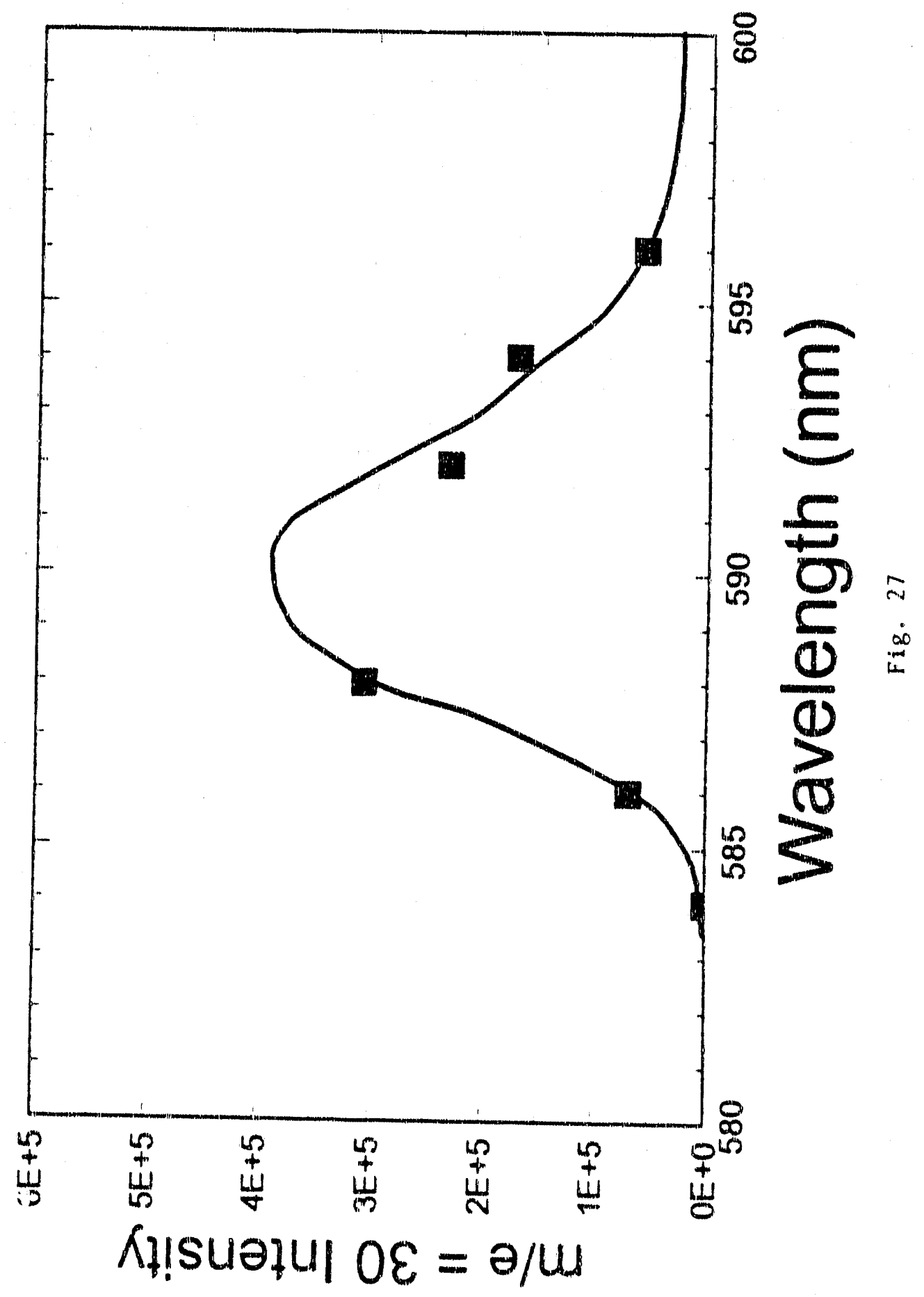




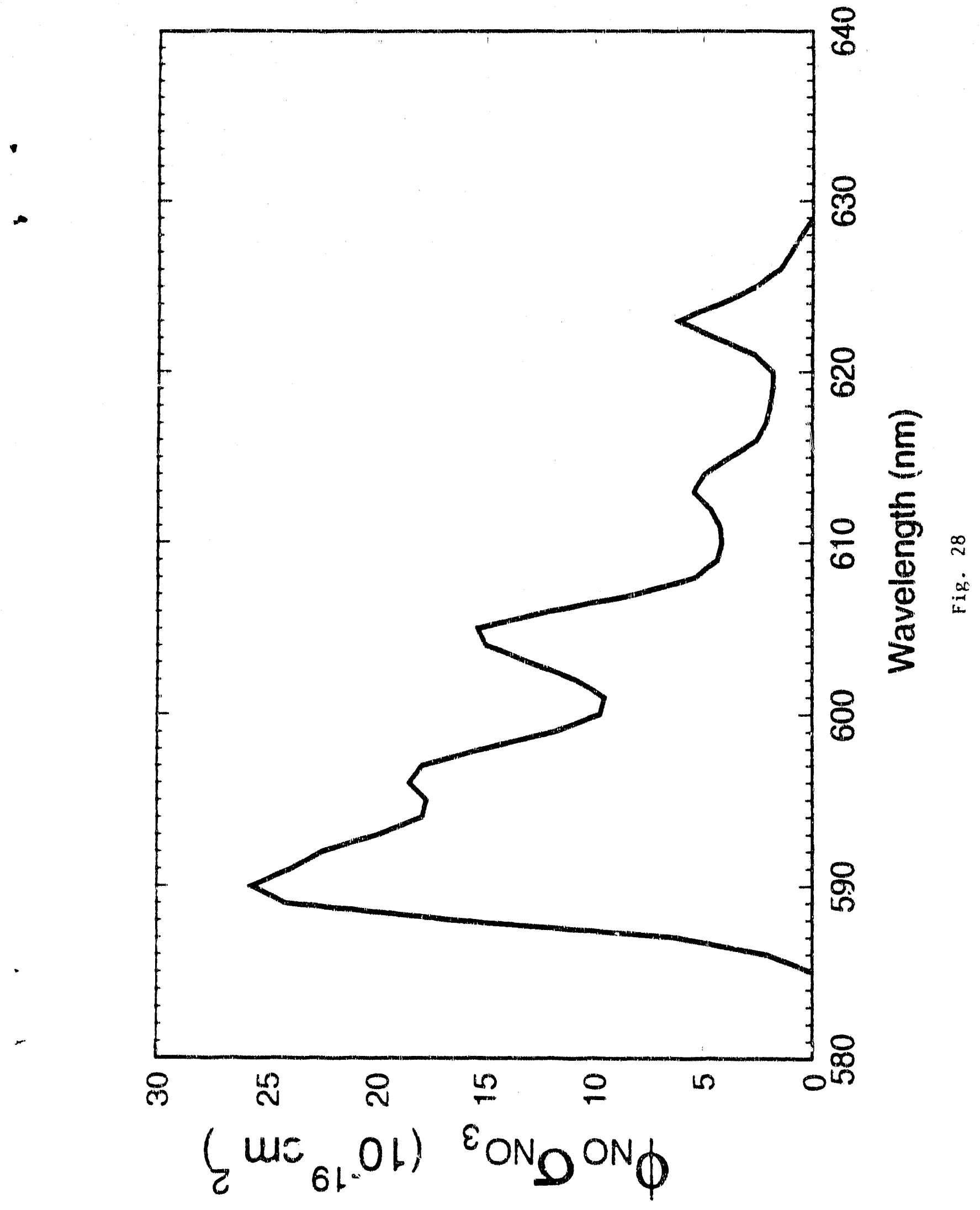




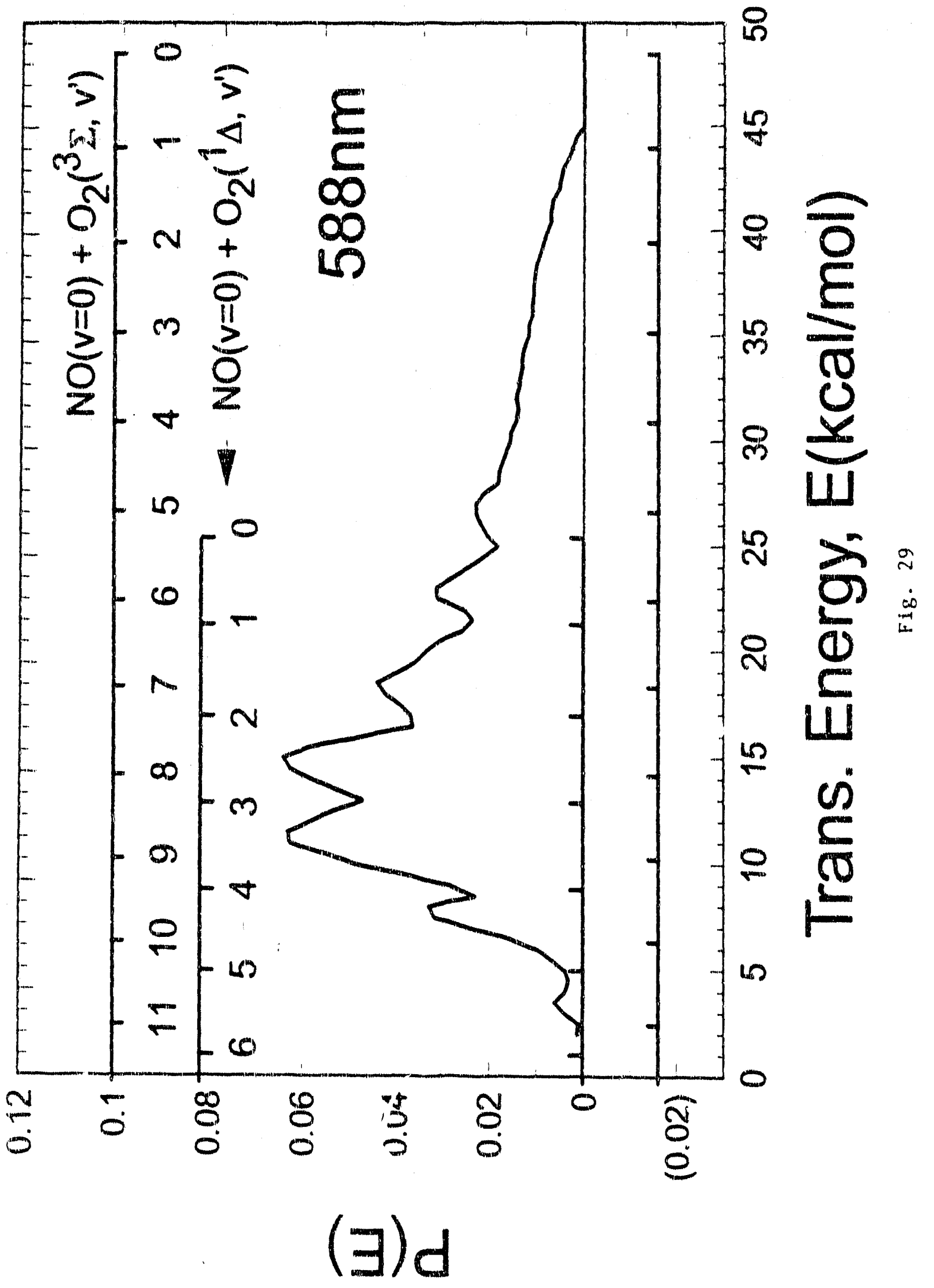




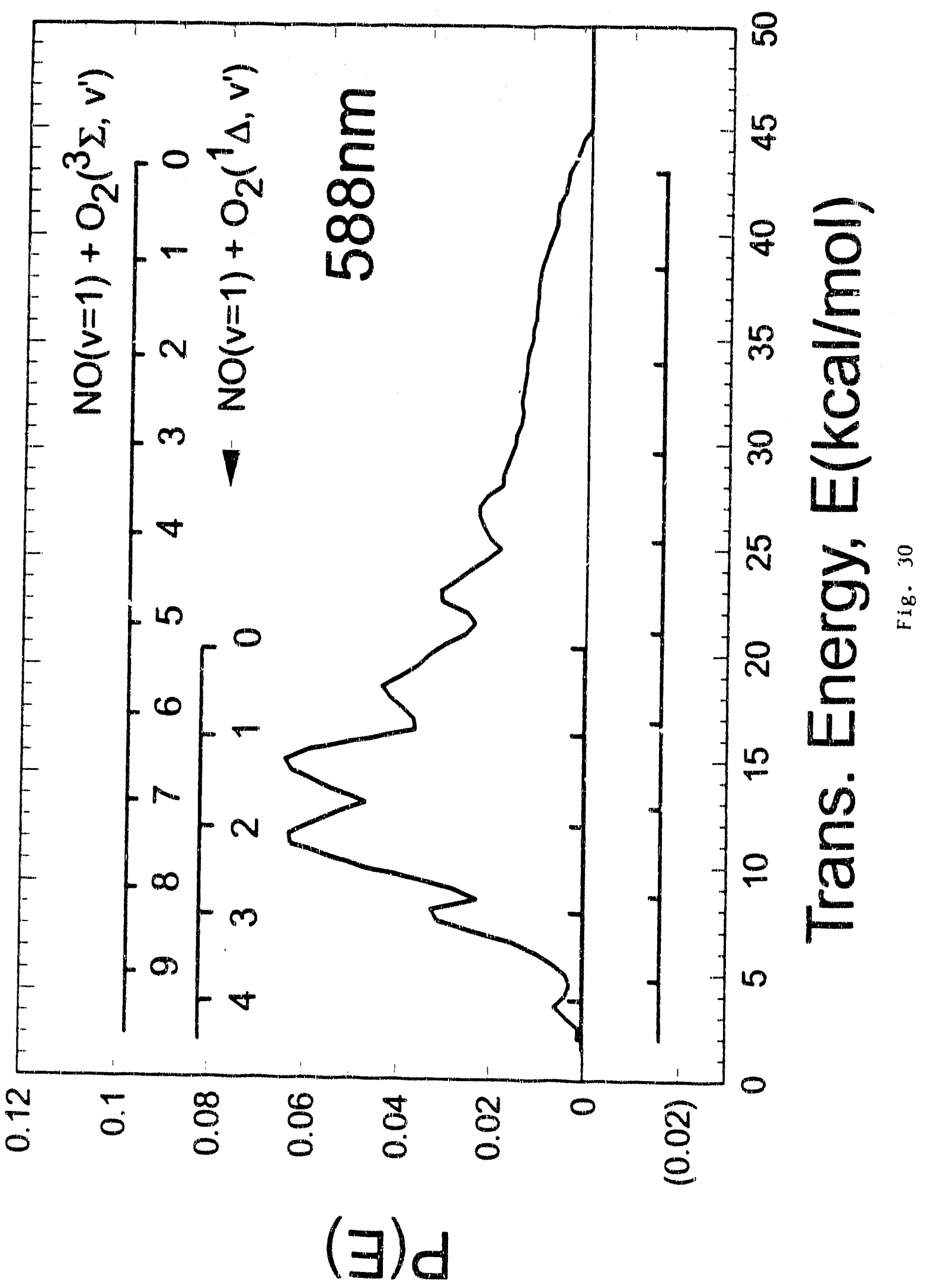




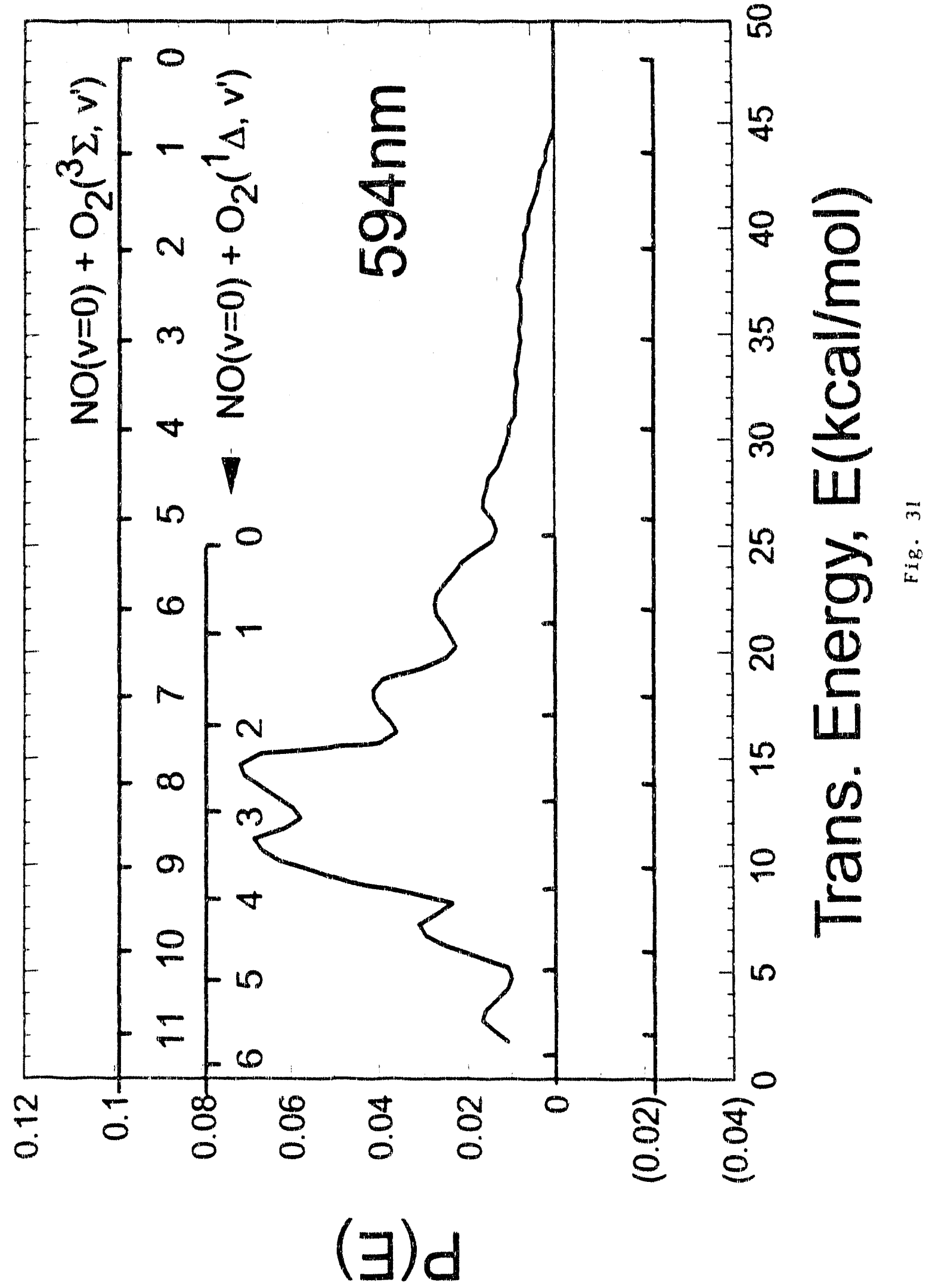




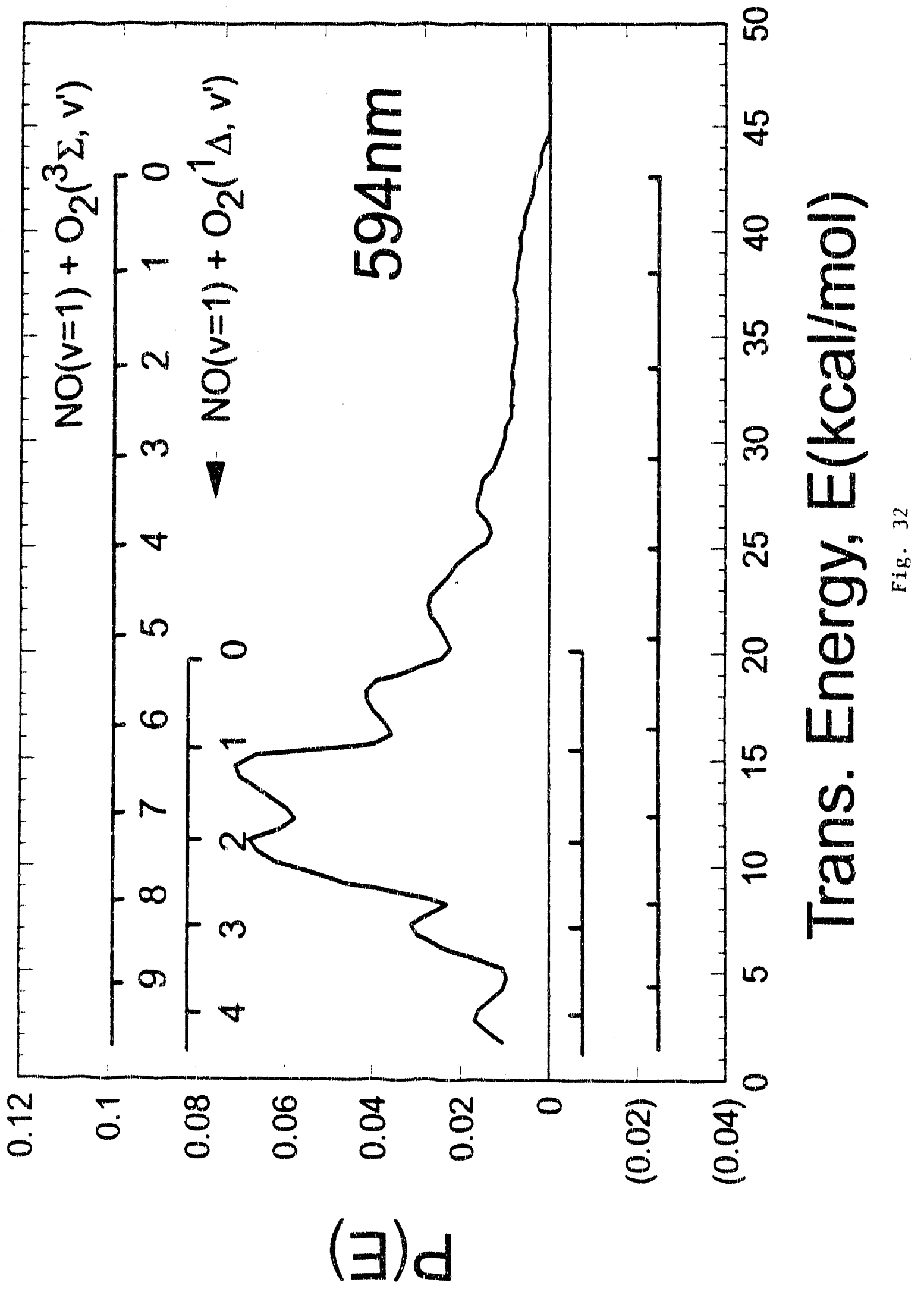




\section{CHAPTER 5}

\section{Dynamics and Mode Specificity in OClO Photodissociation}

\section{ABSTRACT}

The photodissociation of $\mathrm{OClO}$ in a molecular beam was studied using photofragment translational energy spectroscopy at wavelengths between 350 and $475 \mathrm{~nm}$. Although the dominant products are $\mathrm{ClO}\left({ }^{2} \mathrm{M}\right)+\mathrm{O}\left({ }^{3} \mathrm{P}\right)$, we observe formation of $\mathrm{Cl}\left({ }^{2} \mathrm{P}\right)$ $+\mathrm{O}_{2}\left({ }^{3} \Sigma_{\mathrm{g}}\right)$, and find strong evidence for $\mathrm{Cl}\left({ }^{2} \mathrm{P}\right)+\mathrm{O}_{2}\left({ }^{1} \Delta_{8}\right)$. The total yield reaches a maximum of $3.9 \pm 0.8 \%$ near $404 \mathrm{~nm}$ and decreases to $<0.2 \%$ under the absorption peaks below $370 \mathrm{~nm}$. It is known that the $\mathrm{OClO}\left(\mathrm{A}^{2} A_{2} \leftarrow \mathrm{X}^{2} \mathrm{~B}_{1}\right)$ absorption spectrum has a well defined vibrational progression resulting from excitation to the $\left(\nu_{1}, 0,0\right),\left(\nu_{1}, 1,0\right),\left(\nu_{1}, 0,2\right)$, and $\left(\nu_{1}, 1,2\right)$ levels of the excited state. We find that the branching ratios for the two chemically distinct channels display mode specificity. Although the yield of $\mathrm{Cl}+\mathrm{O}_{2}$ from $\mathrm{OClO}$ with symmetric stretching $\left(\nu_{1}, 0,0\right)$ excitation is substantial $(3.2 \%)$, a modest enhancement (to $3.9 \%$ ) is seen under neighboring peaks associated with symmetric stretching + symmetric bending $\left(\nu_{1}, 1,0\right)$. However, the $\mathrm{Cl}+\mathrm{O}_{2}$ yield is suppressed by a factor of $\sim 10$ (to $0.4 \%$ ) from states at nearly the same energy with asymmetric stretching excitation. The $\mathrm{Cl}+\mathrm{O}_{2}$ results from concerted unimolecular decomposition with release of up to $\sim 68 \mathrm{kcal} / \mathrm{mol}$ in relative translational energy. 


\section{INTRODUCTION}

Nearly two decades have passed since Molina and Rowland ${ }^{1}$ first pointed out the possibility that reactions of photogenerated $\mathrm{Cl}$ atoms in the atmosphere could lead to catalytic destruction of global ozone. In 1985, Farman and coworkers ${ }^{2}$ noted a considerable decline in the abundance of Antarctic ozone, with a decrease in total column Ozone of up to $50 \%$ in the month of September. These observations have been substantiated in more recent years, ${ }^{3}$ and have led to a considerable increase in experimental activity; both in the field, as well as in the laboratory. It has been found that the concentration of $\mathrm{ClO}$ and $\mathrm{OClO}$ in the Antarctic stratosphere reach levels nearly two orders of magnitude higher than normal, and these levels strongly anticorrelate with $\mathrm{O}_{3}$ abundance. ${ }^{4}$ Although a number of catalytic cycles have been implicated in ozone depletion, ${ }^{5.7}$ it appears that the two major mechanisms are:

$$
\begin{aligned}
& 2\left(\mathrm{Cl}+\mathrm{O}_{3} \rightarrow \mathrm{ClO}+\mathrm{O}_{2}\right) \\
& \mathrm{ClO}+\mathrm{ClO}+\mathrm{M} \rightarrow(\mathrm{ClO})_{2}+\mathrm{M} \\
& (\mathrm{ClO})_{2}+\mathrm{h} v \rightarrow \mathrm{ClOO}+\mathrm{Cl} \\
& \mathrm{ClOO}+\mathrm{M} \rightarrow \mathrm{Cl}+\mathrm{O}_{2}+\mathrm{M}
\end{aligned}
$$

Net : $2 \mathrm{O}_{3}+\mathrm{h} v \rightarrow 3 \mathrm{O}_{2} \quad($ Cycle 1$)$

and, 


$$
\begin{aligned}
& \mathrm{Cl}+\mathrm{O}_{3} \rightarrow \mathrm{ClO}+\mathrm{O}_{2} \\
& \mathrm{Br}+\mathrm{O}_{3} \rightarrow \mathrm{BrO}+\mathrm{O}_{2} \\
& \mathrm{ClO}+\mathrm{BrO} \rightarrow \mathrm{Br}+\mathrm{ClOO} \\
& \mathrm{ClOO}+\mathrm{M} \rightarrow \mathrm{Cl}+\mathrm{O}_{2}+\mathrm{M}
\end{aligned}
$$

Net : $2 \mathrm{O}_{3}+\mathrm{h} v \rightarrow 3 \mathrm{O}_{2} \quad($ Cycle 2)

However, an alternative chemical product in reaction of $\mathrm{ClO}+\mathrm{BrO}$ (cycle 2) is possible: ${ }^{8-10}$

$\mathrm{ClO}+\mathrm{BrO} \rightarrow \mathrm{OClO}+\mathrm{Br}$

Although the branching ratio for channel 3 is known to be greater than $50 \%,{ }^{8,9}$ $\mathrm{OClO}$ in the atmosphere had not been considered important in cycles involving catalytic ozone destruction because it is rapidly photolyzed in sunlight:

$\mathrm{OClO}\left(\mathrm{X}^{2} \mathrm{~B}_{1}\right) \rightarrow \mathrm{OClO}\left(\mathrm{A}^{2} \mathrm{~A}_{2}\right) \rightarrow \mathrm{ClO}(\mathrm{I})+\mathrm{O}\left({ }^{3} \mathrm{P}\right)$.

There have been no experimental measurements of the quantum yield for reaction (4) in the gas phase. However, it has been taken as unity in atmospheric modelling calculations. ${ }^{6}$ If this quanturn yield is correct, the formation of $\mathrm{OClO}$ and its subsequent photolysis regenerates free $\mathrm{O}$ atorns. Since they rapidly recombine with $\mathrm{O}_{2}$ to regenerate 
$\mathrm{O}_{3}$, the $\mathrm{OClO}$ cycle would have no effect on ozone concentration in the atmosphere. In 1990, Vaida and coworkers ${ }^{11}$ reported experimental evidence for the following reaction under collision free conditions:

$\operatorname{OClO}\left(\mathrm{X}^{2} \mathrm{~B}_{1}\right) \rightarrow \mathrm{OClO}\left(\mathrm{A}^{2} \mathrm{~A}_{2}\right) \rightarrow \mathrm{OClO}\left(\mathrm{B}_{2}\right) \rightarrow \mathrm{ClOO} \rightarrow \mathrm{Cl}+\mathrm{O}_{2}^{\circ}$

In their experiment, a molecular beam containing $\mathrm{OClO}$ was crossed with the output of a focussed dye laser operating at wavelengths near $362 \mathrm{~nm}$. The $0 \mathrm{ClO}$ was photolyzed and the products were subsequently ionized by nonresonant absorption of additional photons. These ions were extracted into a time-of-flight mass spectrometer, and their intensities monitored as a function of laser wavelength. They observed a feature in the $\mathrm{Cl}$ atom REMPI spectrum at $362 \mathrm{~nm}$ that they attributed to isomerization of OClO to $\mathrm{ClOO}$, fsllowed by dissnciation to $\mathrm{Cl}+\mathrm{O}_{2}$. In a subsequent report to Nature, ${ }^{12}$ they estimated that if the quantum yield for $\mathrm{Cl}+\mathrm{O}_{2}$ is $100 \%$ over its entire absorption spectrum, the gas phase photoisomerization mechanism could lead to up to $30 \%$ of the $\mathrm{O}_{3}$ depletion seen in Antarctica. If the quantum yield was only $10 \%$, then it would still have an appreciable effect on the overall budget of $\mathrm{O}_{3}$ in the Antarctic atmosphere, and should be included in atmospheric modelling. The notion of a gas phase isomerization mechanism was largely inspired by an early observation of $\mathrm{COO}$ in matrix isolation experiments by Arkell and Schwager. ${ }^{13}$ They found that $\mathrm{ClOO}$ was readily formed in the matrix by photolysis of $\mathrm{OClO}$ at wavelengths near $365 \mathrm{~nm}$. Apparently, photolysis at other wavelengths led to a smaller yield of $\mathrm{ClOO}$. Matrix assisted photoisomerization of 
OClO seemed to provide a much more efficient source of $\mathrm{ClOO}$ than other methods, such as photolysis of $\mathrm{Cl}_{2}+\mathrm{O}_{2}$ mixtures. Gole has performed calculations on the ground and electronically excited states of $\mathrm{OClO}$ and $\mathrm{ClOO} \cdot{ }^{14} \mathrm{He}$ postulated that coupling between these electronically excited states of the two species provides a likely mechanism for photoassisted rearrangement of $\mathrm{OClO}$ to $\mathrm{ClOO}$ in the matrix.

The ideas derived from the matrix isolation work have been extended to the gas phase in recent years, ${ }^{11,12,16,19}$ with some controversy regarding the quantum yields for $\mathrm{Cl}$ $+\mathrm{O}_{2}{ }^{11,15,16}$ The quantum yield of $\mathrm{Cl}$ atoms was not determined in the original work of Vaida, and coworkers. ${ }^{11}$ However, Lawrence, et. al. ${ }^{15}$ reported that the quantum yield of $\mathrm{Cl}$ was below $5 \times 10^{-4}$ between 359 and $368 \mathrm{~nm}$, and that the $\mathrm{Cl}+\mathrm{O}_{2}$ channel had a negligible impact on the balance of atmospheric ozone. Quite recently, Bishenden and coworkers ${ }^{16}$ disagreed, concluding that $\mathrm{Cl}$ atoms are formed upon single photon excitation of $\mathrm{OClO}$ near $362 \mathrm{~nm}$ with a quantum yield of $0.15 \pm 0.1$. The $\mathrm{Cl}$ atom yield at other wavelengths was not explicitly reported, but a structured Cl REMPI action spectrum was presented ${ }^{16}$ for the wavelength range $355 \mathrm{~nm}-367 \mathrm{~nm}$. Although it is now apparent that heterogeneous processes contribute to the depletion of ozone, ${ }^{5}$ a clear understanding of the photochemistry of atmospheric molecules under collision free conditions is required before addressing other complicating factors, such as perturbations by solvent molecules or adsorption on ice crystals.

A number of factors inspired the present experiment. First, the $\mathrm{NO}_{3}$ experimental work (Chapter 4) had already been completed and the analysis was in progress. The observation of a significant yield of $\mathrm{NO}+\mathrm{O}_{2}$ in that system prompted a search in the 
literature for other previously studied molecules exhibiting similar behavior. It was hoped that comparisons with $\mathrm{NO}_{3}$ might lead to additional insight into this highly complex molecule. Indeed, OCIO appeared to be such a system, "but the experimental evidence for the formation of $\mathrm{Cl}+\mathrm{O}_{2}$ in the gas phase was not compelling, as will be discussed below. The second motivation was that the reaction cross section for $\mathrm{Ba}+\mathrm{OClO} \rightarrow \mathrm{BaCl}$ $+\mathrm{O}_{2}$ was found to appreciable (Chapter 3). This reaction involves concerted central atom abstraction, and is initiated by long range electron transfer from $\mathrm{Ba}$ to the $\mathrm{OClO}$ $2 b_{1}$ orbital, leading to a decreas - in $\mathrm{OClO}$ bond angle and increase in $\mathrm{ClO}$ bond length. ${ }^{14}$ The situation is quite analogous to $\mathrm{OClO}\left(\mathrm{A}^{2} \mathrm{~A}_{2}-X^{2} \mathrm{~B}_{1}\right)$ excitation, since it aiso involves promotion of an electron to the $2 b_{1}$ orbital, leading to similar changes in molecular geometry favorable to formation of $\mathrm{O}_{2}{ }^{14}$

The photodissociation dynamics of the bent triatomic molecules $\mathrm{O}_{3}$ and $\mathrm{NO}_{2}$ has been studied extensively over the past 20 years using a wide range of techniques. Triatomics are particularly amenable to detailed study because the parent molecule: possess only three vibrational degrees of freedorn and their atom + diatom products are easily detected experimentally, and modelled theoretically. However, the apparent simplicity of $\mathrm{O}_{3}$ and $\mathrm{NO}_{2}$ is belied by a complex electronic structure and fast: predissociation processes, leading to poorly understood features in their electronic absorption spectra. The recent work of Vaida and coworkers ${ }^{17.19}$, on the absorption spectroscopy of OCIO has led to a reinterpretation and considerable clarification of the OClO $\left(A^{2} A_{2} \leftarrow X^{2} B_{1}\right)$ absorption spectrum. Their work led to accurate assignments of this line positions, making it possible to use a tunable dye laser to prepare the OClO molecule 
in well defined vibrational levels of the electronically excited $\left(A^{2} A_{2}\right)$ state.

Figure 1 shows the energetics of $\mathrm{OClO}$ decomposition..$^{20}$ At all wavelengths, three electronic states of $\mathrm{O}_{2}$ are thermodynamically possible. In none of the experiments reported to date ${ }^{11,16}$ was the electronic state of the $\mathrm{O}_{2}$ determined. In fact, in no case was $\mathrm{O}_{2}$ directly observed-- all experimental evidence has been based on observation of the $\mathrm{Cl}$ atom alone. This leaves open the possible involvement of other sources of $\mathrm{Cl}$ signal, such as photodissociation of the dominant $\mathrm{ClO}$ product.

Using the technique of pliotofragment translational energy spectroscopy,,$^{23}$ we find that $\mathrm{Cl}+\mathrm{O}_{2}$ is formed from single photon absorption by $\mathrm{OClO}$, but the yield is only appreciable $(>1 \%)$ at wavelengths longer than $390 \mathrm{~nm}$. Unlike the previous measurements, ${ }^{11,16}$ we have observed both momentum matched $\mathrm{Cl}+\mathrm{O}_{2}$ products, and the quantum yields are based on direct measurements under well defined single photon conditions. Translational energy measurements show that $\mathrm{O}_{2}$ is definitely formed in the ground $\left({ }^{3} \Sigma_{z}\right)$ state and there is very strong evidence for a substantial fraction in the first excited $\left({ }^{1} \Delta_{k}\right)$ state.

Spectroscopic work by a number of groups ${ }^{17,18,21}$ has clearly shown that the OClO absorption linewidths increase upon tuning the excitation source to the blue. This is a clear signature of a decreasing excited state lifetime, possibly by faster predissociation via the "dark" ${ }^{2} \mathrm{~B}_{2}$ state. ${ }^{17,18,21}$ Since the ${ }^{2} \mathrm{~B}_{2}$ state cannot be accessed by a single photon transition from the ground state, it has not been observed experimentally. ${ }^{17}$ However, $a b$ initio calculations ${ }^{14}$ indicate that it probably lies at energies lower that the ${ }^{2} \mathrm{~A}_{2}$ state, which is the only excited state to be observed experimentally. The linewidths associated 
with excitation of asymmetric stretching + symmetric stretching $\left(\nu_{1}, 1,0\right)$, or symmetric bending + symmetric stretching $\left(\nu_{1}, 0,2\right)$, are known to be considerably broader than those due to symmetric stretching excitation $\left(\nu_{1}, 0,0\right)$ alone. . $^{17,18,21}$

The OClO molecule has a structured absorption spectrum ${ }^{17,22}$ corresponding to progressions in $\left(v_{1}, 0,0\right),\left(v_{1}, 1,0\right),\left(v_{1}, 0,2\right)$, and $\left(v_{1}, 1,2\right)$ of the excited ${ }^{2} A_{2}$ state (Fig. 2). Despite a dissociation lifetime of many vibrational periods, ${ }^{17,88,21}$ we do observe mode specificity in the branching ratios for the two channels. The yield for $\mathrm{Cl}+\mathrm{O}_{2}$ is always greatest (up to 3.9\%) under $\mathrm{OClO}$ absorption peaks associated with combinations of symmetric stretching with symmetric bending $\left(v_{1}, 1,0\right)$ motion. Although the yield is only slightly smaller from pure symmetric stretining modes $\left(v_{1}, 0,0\right)$, excitation at nearly the same energy to a symmetric stretching + asymmetric stretching mode $\left(v_{1}, 0,2\right)$ leads to a tenfold decrease in the $\mathrm{Cl}+\mathrm{O}_{2}$ yield. Mode specific behavior is also seen in the ClO vibrational energy distributions which are strongly dependent on the initial vibrational state of the OClO molecule.

\section{EXPERIMENTAL}

The experiments were conducted using a molecular beam apparatus equipped with a rotatable molecular beam source and fixed detector. ${ }^{23}$ The unfocussed output from an excimer-i umped Lambda-Physik FL2002 dye laser was crossed at 90 degrees with a seeded supersonic molecular beam containing 10-20\% OClO in helium or argon. In some experiments, a continuous beam was formed by expanding -150 Torr of the mixture through a $0.007^{\prime \prime}$ dia. nozzle heated to $\sim 80^{\circ} \mathrm{C}$. Experiments were also conducted using 
a room temperature pulsed nozzle $\left(0.020^{\prime \prime}\right.$ dia.) and a pressure of $1 \mathrm{~atm}$. The $\mathrm{OClO}$ was generated in-situ by flowing a $5-10 \% \mathrm{Cl}_{2} /$ inert gas mixture through a U-tube packed with glass beads and $\mathrm{NaClO}_{2}$, as described elsewhere. ${ }^{22} \mathrm{The}^{\mathrm{Cl}_{2}}$ impurity in the beam, measured using a mass spectrometer, was found to be negligible provided that the $\mathrm{NaClO}_{2}$ is not ton dry-- apparently the reaction $\mathrm{Cl}_{2}(\mathrm{~g})+2 \mathrm{NaClO}_{2}(\mathrm{~s}) \rightarrow 2 \mathrm{NaCl}(\mathrm{s})+$ $2 \mathrm{ClO}_{2}(\mathrm{~g})$ requires the presence of some moisture.

A small fraction of the photodissociation products recoiled away from the molecular beam axis into an electron bombardment ionizer located $36.7 \mathrm{~cm}$ away from the interaction region. ${ }^{23}$ Ions were cxtracted into a quadrupole mass filter and detected by a Daly ion detector. A multichannel scaler, triggered by the laser puise, was used to record the product time of flight spectra at various angles between the molecular beam and detector. The product time of flight spectra were analyzed using an updated version of the forward convolution program CMLAB2, as described previously. ${ }^{23}$

\section{RESULTS AND DISCUSSION}

Under all absorption peaks between $350 \mathrm{~nm}$ and $475 \mathrm{~nm}$, the dominant products (>96\%) from dissoriation of $\mathrm{OClO}$ are $\mathrm{ClO}(2 \mathrm{M})+\mathrm{O}\left({ }^{3} \mathrm{P}\right)$. Product time of flight (TOF) spectra were recorded at $\mathrm{Cl}^{+}, \mathrm{ClC}^{+}, \mathrm{O}^{+}$, and $\mathrm{O}_{2}^{+}$. We observed $\mathrm{Cl}^{+}$daughter ions from fragmentation of $\mathrm{ClO}$ (from $\mathrm{ClO}+0$ ) in the electron bombardment ionizer, and $\mathrm{Cl}^{+}$ parent ions from the $\mathrm{Cl}+\mathrm{O}_{2}$ channel. As predicted from the Newton diagram (Fig. 3), both photodissociation channels can be seen by monitoring $\mathrm{Cl}^{+}$and can be distinguished by their TOF spectra. Even if the $\mathrm{O}_{2}$ fragment is formed in $\mathrm{v}=5$ of the ${ }^{\prime} \mathrm{L}_{\mathrm{g}}^{+}$state (the 
second electronically excited state), the recoil velocity of its $\mathrm{Cl}$ atom partner will be greater than the velocity of $\mathrm{ClO}(\mathrm{v}=0)$ from the $\mathrm{ClO}+\mathrm{O}$ channel.

Time of flight spectra recorded at $\mathrm{Cl}^{+}(\mathrm{m} / \mathrm{e}=35)$ are shown in Figure 4 for three neighboring excitation wavelengths, corresponding to the $(5,1,0),(4,0,2)$, and $(5,0,0)$ vibrational leveis of $\mathrm{OClO}\left(\mathrm{A}^{2} \mathrm{~A}_{2}\right)$. The angle between the molecular beam and detector was $20^{\circ}$, and a $20 \% \mathrm{OClO} / \mathrm{He}$ mixture was expanded through a room temperature pulsed nozzle. The slower peak in the TOF spectrum was identical to that seen in the $\mathrm{ClO}^{+} \mathrm{TOF}$ and results from $\mathrm{ClO}$ fragmentation in the ionizer. The fast peak is due to $\mathrm{Cl}$ from the $\mathrm{Cl}+\mathrm{O}_{2}$ channel. Our assignments are confirmed by observation of the respective momentum matched $O$ and $O_{2}$ fragments (Fig. 5). Based on linewidth measurernents ${ }^{17,18}$, it is known that the $\mathrm{OClO}$ dissociation lifetime is many picoseconds at these wavelengths. Thus, unless the laser was tuned very close to the origin ${ }^{17}$ of a vibrational band, we found that rotating the laser polarization using a double fresnel rhomb had no effect on product intensities, since the parent molecule rotated at least several times before dissociating. A.l data reported here was obtained with the dye laser tuned $4-5 \mathrm{~cm}^{-1}$ to the red of the bandhead positions reported in Ref. 17. Although our laser does not provide rotational resolution, $\left(\Delta \mathrm{E}-0.2 \mathrm{~cm}^{-2}\right)$, we see only minor effects on the shapes of the TOF or $\mathrm{Cl}+\mathrm{O}_{2}$ yields upon tuning across the rotational envelopes of given vibrational levels of OClO.

The translational energy distributions for both channels from excitation of the $(5,1,0)$ band are shown in Figure 6. They are based on data shown in Figures 4 and 5 , as well as other data (not shown) obtained at other angles between the molecular beam 
and detector. ${ }^{24}$ The fastest component of the $\mathrm{Cl}+\mathrm{O}_{2}$ channel, with $\mathrm{E}_{\text {rnss }}$ up to $\sim 68$ $\mathrm{kcal} / \mathrm{mole}$, must correspond to formation of ground state $\mathrm{O}_{2}\left({ }^{3} \Sigma_{\mathrm{g}}\right)$. The additional feature peaking at $\sim 33 \mathrm{kcal} / \mathrm{mole}$ is very strongly suggestive of formation of excited $\mathrm{O}_{2}\left({ }^{\prime \prime} \Delta_{\mathfrak{\imath}}\right)$. As shown in Fig. 4, the shapes of the $\mathrm{Cl}+\mathrm{O}_{2}$ times of flight (anc $\mathrm{O}_{2}$ internal state distributions) are not strongly dependent on the initial OClO vibrational level. The ClO internal state distribution, on the other hand, is very sensitive to the initially prepared OClO state. Structure due to vibrational excitation of the $\mathrm{ClO}(\mathrm{N})$ product is quite well resolved, particularly when its $O$ atom recoil partner was monitored (Fig. 5). Analysis is currently under way to extract approximate vibrational energy distributions as a function of OClO vibrational state. ${ }^{24}$

The branching ratios for formation of $\mathrm{Cl}+\mathrm{O}_{2}$ relative to $\mathrm{ClO}+\mathrm{O}$ were calculated from the fits to the experimental data at $\mathrm{m} / \mathrm{e}=35\left(\mathrm{Cl}^{+}\right)$, accounting for the different Jacobian factors for the $\mathrm{LAB} \rightarrow \mathrm{CM}$ transformation for each channel. One additional factor that is required in the analysis is the relative detection sensitivity for $\mathrm{ClO}$ and $\mathrm{Cl}$ at $m / e=35\left(\mathrm{Cl}^{+}\right)$. This quantity was determined experimentally in a separate experiment. We monitored the equal yields of $\mathrm{Cl}$ and $\mathrm{ClO}$ from $\mathrm{ClOCl}$ photodissociation at $423 \mathrm{um} .{ }^{24,25}$ The fast peak in the $\mathrm{m} / \mathrm{e}=35$ TOF resulted from $\mathrm{Cl}$ and the slower peak was from fragmentation of ClO-- their contributions led to a very accurate measure of the relative detection sensitivity for the two fragments. ${ }^{26}$ The measured branching ratios were converted to absolute yields by assuming that $\Phi_{\mathrm{dis}}=\phi_{\mathrm{C} 1+02}+\phi_{\mathrm{C} 10+\mathrm{O}}=1.0 .{ }^{27}$ Our absolute $\mathrm{Cl}+\mathrm{O}_{2}$ yields should be accurate to $\pm 20 \%$. 
Our results indicate that the yield for $\mathrm{Cl}+\mathrm{O}_{2}$ has a maximum of $3.9 \pm 0.8 \%$ under the peak near $404 \mathrm{~nm}$ dropping to $<0.2 \%$ under peaks at wavelengths below $370 \mathrm{~nm}$. The $\mathrm{Cl}+\mathrm{O}_{2}$ channel is observed at longer wavelengths, but is weaker-- the yield under the $(4,0,0)$ band at $-423 \mathrm{~nm}$ is $\sim 1.2 \%$. Our conclusion that the yield is negligible below $370 \mathrm{~nm}$ is in qualitative agreement with Lawrence, ${ }^{15}$ who could not actually see $\mathrm{Cl}+\mathrm{O}_{2}$, but placed an upper limit of $0.05 \%$ below $368 \mathrm{~nm}$. Extensive averaging would be required in our experiment to further reduce our upper limit of $0.2 \%$ for $\lambda<370 \mathrm{~nm}$. All previous experimental efforts ${ }^{11,15,16}$ have focussed on a wavelength range near $365 \mathrm{~nm}$, apparently because early matrix isolation experiments ${ }^{13}$ found that the formation of $\mathrm{ClOO}$ by irradiation of $\mathrm{OClO}$ was favored using filters transmitting at that wavelength. We have not been able to observe any $\mathrm{Cl}+\mathrm{C}_{2}$ in this region in our molecular beam experiment.

Bishenden, et al, ${ }^{16}$ reported a REMPI spectrum with the peak $\mathrm{Cl}$ intensity near $362 \mathrm{~nm}$. This appeared surprising since the OCIO molecule has an absorption minimum at this wavelength. However, these authors have recently explained this behavior in terms of an accidental laser calibration problem. The spectrum should be shifted by $2 \mathrm{~nm}$ to the blue, so that it resembles the OClO absorption spectrum. However, their shifted data would still indicate a $\mathrm{Cl}+\mathrm{O}_{2}$ quantum yield in excess of $10 \%$, which is at least $50 \mathrm{X}$ higher than our upper limit of $0.2 \%$ in this wavelength region. It seems quite possible that the observed $\mathrm{Cl}$ signal results from a multiphoton process involving dissociation of $\mathrm{OCl}$ by the REMPI laser. This would not be surprising since the focussed laser at $235 \mathrm{~nm}$ will be absorbed strongly by the nascent $\mathrm{ClO}$ molecule, and their laser 
power dependences could be misleading due to saturation. The $\mathrm{Cl}$ atom product is then ionized by the $2+1$ REMPI process.

It is important to note that our measurement of the $\mathrm{Cl}+\mathrm{O}_{2}$ quantum yields do not require knowledge of the OClO absorption cross section. This is one significant advantage to the present technique--. virtually all other methods require that this quantity be known. In the case of $\mathrm{OClO}$, there is considerable rotational structure under its vibrational envelopes. This structure will be resolved to some extent if dye lasers having linewidths less than $1 \mathrm{~cm}^{-1}$ are used, and this will lead to considerable uncertainty in the measurement. Our calibration is only based on the relative sensitivity of our detector to $\mathrm{Cl}$ and $\mathrm{ClO}$. This was accurately determined by measuring the signal levels from equal numbers of these products from photodissociation of $\mathrm{ClOCl}$.

It is interesting to compare our gas phase results with the matrix results of Arkell, et al. ${ }^{13}$ We observe a significant yield $(>1 \%)$ of $\mathrm{Cl}+\mathrm{O}_{2}$ only at wavelengths longer than $390 \mathrm{~nm}$, whereas they found that $\mathrm{ClOO}$ is favored in the matrix by irradiation at $\sim 365 \mathrm{~nm} .{ }^{13}$ This could suggest that our observation of the $\mathrm{Cl}+\mathrm{O}_{2}$ channel under isolated gas phase conditions might be unrelated to observation of $\mathrm{ClOO}$ in the matrix experiments. Photodissociation near $365 \mathrm{~nm}$ could lead to formation of $\mathrm{ClO}+\mathrm{O}$ in the matrix, but due to the matrix cage effect, back reaction of the nascent $\mathrm{O}$ atom leads to ClOO. Back reaction in the matrix cage will be facile because the $\mathrm{ClO}\left({ }^{2} \Pi\right)+\mathrm{O}\left({ }^{3} \mathrm{P}\right)$ electronic states correlate directly with $\mathrm{ClOO}\left(\mathrm{A}^{\prime}, \mathrm{A}^{\prime}\right) .{ }^{14}$ "The "enhanceinent" in yield of $\mathrm{ClOO}$ in the matrix by irradiation near $365 \mathrm{~nm},{ }^{13}$ (rather than at $220 \mathrm{~nm}<\lambda<350 \mathrm{~nm}$ or $450 \mathrm{~nm}<\lambda<590 \mathrm{~nm}$ ) could simply result from the OClO absorbing most strongly in 
that region. ${ }^{17,22,31}$

It is also possible that the $3000 \mathrm{~cm}^{-1}$ shift between the wavelength maxima for the gas phase $\mathrm{Cl}+\mathrm{O}_{2}$ ch anel and the matrix. $\mathrm{ClOO}$ channels is real. Although $3000 \mathrm{~cm}^{-1}$ is a very large shift, it may not be unreasonable since the $\mathrm{OClO}\left(\mathrm{A}^{2} \mathrm{~A}_{2} \leftarrow \mathrm{X}^{2} \mathrm{~B}_{1}\right)$ transition does have considerable charge transfer character, and the crossings of the relevant potential energy surfaces could be shifted significantly in the presence of a matrix hosi. While it is likely that a fraction of the $\mathrm{ClOO}$ in the matrix does result from recombination of $\mathrm{ClO}+\mathrm{O}$ due to the cage effect, Gole has noted a number of interesting features in the matrix work which have been taken to result from "matrix assisted photoisomerization."14 Our results indicate that comparisons between gas phase and condensed phase behavior will be complex in the case of OClO photochemistry.

Previous discussion regarding $\mathrm{OClO} \rightarrow \mathrm{Cl}+\mathrm{O}_{2}$ in the gas phase has centered on a photoisomerization mechanism involving an intermediate ClOO radical. ${ }^{11,12,16-18}$ However, a mechanism formally involving isomerization of $\mathrm{OClO}$ to $\mathrm{ClOO}$ in the gas phase, followed by simple bond ruptur: does not appear to be consistent with our observations. The large translational energy release that we observe in the recoiling $\mathrm{Cl}$ $+\mathrm{O}_{2}$ is characteristic of a concerted unimolecular decomposition from a highly constrained transition state, followed by strong repulsion between the products. This transition state is probably best considered to be an $\mathrm{OClO}$ molecule with a strongly compressed bond angle and only some distortion from $C_{2 v}$ symmetry. This is consistent with the $\mathrm{Cl}-\mathrm{O}$ antibonding and $\mathrm{O}-\mathrm{O}$ bonding nature of the $2 \mathrm{~b}_{1}$ orbital into which the electron is excited, resulting in a decrease in OClO bond angle from 117 to $\sim 107^{\circ}$, and 
increase in $\mathrm{Cl}-\mathrm{O}$ bond length from 1.47 to $1.62 \AA . .^{14}$ Our observation that symratric stretching + symmetric bending excitation promotes the $\mathrm{Cl}+\mathrm{O}_{2}$ channel strongly supports a mechanism involving concerted decomposition from a transition state geometry close to $\mathrm{C}_{2 \mathrm{v}}$. The region of the $\mathrm{Cl}+\mathrm{O}_{2}$ potential energy surface corresponding to the $\mathrm{Cl}$ $O O$ isomer represents a very shallow minimum with $D_{0}(\mathrm{Cl}-O O)=4.76 \pm 0.49 \mathrm{kcal} / \mathrm{mol}^{32}$ and $\theta_{c-\infty}-110^{\circ} .13,14$ In the absence of a large torque on the $\mathrm{O}=\mathrm{O}$ molecule, the newly born $\mathrm{Cl}$ atom will be near the $\mathrm{C}_{2 v}$ axis of $\mathrm{OClO}$, perpendicular to the $\mathrm{O}=0$ bond axis. Since the $\mathrm{Cl}-\mathrm{O}_{2}$ interaction at this angle is repulsive, ${ }^{14}$ the $\mathrm{Cl}-\mathrm{O}_{2}$ "isomer" will not exist for much more than one vibrational period. Instead, strong product repulsion leads to a large $\mathrm{Cl}+\mathrm{O}_{2}$ recoil energy of up to $\sim 68 \mathrm{kcal} / \mathrm{mol}$.

The dissociation to $\mathrm{ClO}+\mathrm{O}$ is thought to occur by coupling between the prepared ${ }^{2} A_{2}$ and "dark" ${ }^{2} B_{2}$ state. The observation that the OClO absorption linewidths are independent of rotational energy has been interpreted in terms of a mechanism involving spin-orbit coupling between these states. ${ }^{21}$ The coupling is expected to be enhanced considerably by asymmetric stretching and bending motion of the $\mathrm{OClO}$ molecule. ${ }^{18}$ The importance of asymmetric stretching in promoting the $\mathrm{ClO}+\mathrm{O}$ channel is certainly not surprising in view of the fact that it is the reaction coordinate for the process. Indeed, for a given excitation energy, the OClO absorption lines are known to be a factor of $\sim 7-8$ times broader (i.e. $\sim 7-8$ times faster dissociation) when excitation is accompanied by 2 quanta of asymmetric stretching. ${ }^{17,18}$ Interestingly, excitation of asymmetric stretching decreases both the excited state lifetime, and the $\mathrm{Cl}$ $+\mathrm{O}_{2}$ yield by roughly the same factor. Based on the known linewidths, ${ }^{17,18}$ the $\mathrm{OClO}$ 
dissociation lifetime is extraordinarily long for a triatomic molecule ( $>10 \mathrm{ps})$, even at these energies which are $>10 \mathrm{kcal} / \mathrm{mol}$ above the $\mathrm{ClO}+\mathrm{O}$ threshold. This is indicative of very weak coupling between the initially prepared ${ }^{2} \mathrm{~A}_{2}$ state and that responsible for production of $\mathrm{O}+\mathrm{ClO}$. Although electronic excitation leads to strong symmetric motion, a sparse excited state level density with widely different frequencies for the three vibrational modes leads to very inefficient redistribution of energy into the reaction coordinate, asymmetric stretching. Consequently, only two quanta of asymmetric OClO vibration leads to a tenfold decrease in excited state lifetime. Our observation that the $\mathrm{Cl}+\mathrm{O}_{2}$ channel decreases with asymmetric stretching by a factor of 10 is most easily explained by faster decomposition to $\mathrm{ClO}+\mathrm{O}$, at the expense of the $\mathrm{Cl}+\mathrm{O}_{2}$ channel.

Based on the results presented in Fig. 7, and the measured OClO absorption linewidths, we can make several conclusions regarding the role of symmetric bending in promoting the $\mathrm{O}+\mathrm{ClO}$ channel. At all wavelengths where we observe $\mathrm{Cl}+\mathrm{O}_{2}$, ( $380 \mathrm{~nm}<\lambda<430 \mathrm{~nm})$, the quantum yield is enhanced only slightly when excitation is accompanied by symmetric bending, whereas the yield decreases dramatically $(\sim 10 \mathrm{X})$ when accompanied by asymmetric stretching (Fig. 4). Since electronic excitation already results in a large decrease in OClO bond angle, one additional quantum of symmetric bending apparently has a relatively minor additional effect on the $\mathrm{Cl}+\mathrm{O}_{2}$ quantum yield. However, it is known that the $\mathrm{OClO}$ absorption linewidths are $\sim 4-5$ times broader when symmetric stretching is accompanied by one quantum of symmetric bending. Taking this observation with our finding that symmetric bending only leads to a modest enhancement of the $\mathrm{Cl}+\mathrm{O}_{2}$ yield, we conclude that symmetric bending leads to a substantially 
increased rate of predissociation to $\mathrm{OCl}+\mathrm{O}$. This appears to be consistent with previous assertions ${ }^{14,17,18,21}$ that it is the dark ${ }^{2} \mathrm{~B}_{2}$ state that is involved in the $\mathrm{OCl}+\mathrm{O}$ channel. The prepared ${ }^{2} \mathrm{~A}_{2}$ and the dark ${ }^{2} \mathrm{~B}_{2}$ states represent a Renner-Teller pair, becoming orbitally degenerate ${ }^{2} \Pi$ states in the linear configuration. ${ }^{17,18}$ Consequently, the coupling between these states wil! be very sensitive to the bending coordinate. This appears to be born out by our experimental results. Analysis of $\mathrm{OCl}$ vibrational energy distributions from a range of initially prepared OClO vibrational states is currently under way. We hope that this data will provide detailed insight into the nature of the interaction between the ${ }^{2} \mathrm{~A}_{2}$ and ${ }^{2} \mathrm{~B}_{2}$ electronic states.

As already stated, our observations strongly suggest that the transition state for the $\mathrm{Cl}+\mathrm{O}_{2}$ channel is likely to be near $\mathrm{C}_{2 v}$. The region of the $\mathrm{Cl}+\mathrm{O}_{2}$ interaction potential corresponding to the weakly bound $\mathrm{Cl}-\mathrm{OO}$ isomer will not likely be accessed to a great extent in the gas phase dynamics. Of course, the dissociation process does involve coupling between the excited states of $\mathrm{OClO}$ and the $\mathrm{A}^{\prime}$ and $\mathrm{A}^{\prime \prime}$ states of the $\mathrm{Cl}$ $+\mathrm{O}_{2}$ interaction potential. As calculated by Gole, the $\mathrm{A}^{\prime}$ and $\mathrm{A}^{\prime \prime}$ states are strongly repulsive at small $\mathrm{Cl}-\mathrm{OO}$ angles. This is consistent with the large translational energy release that we observe in the $\mathrm{Cl}+\mathrm{O}_{2}$ products. It has already been noted that the ${ }^{2} \mathrm{~A}_{2}$ $\leftarrow{ }^{2} B_{1}$ transition does lead to considerable decrease in $\mathrm{OClO}$ bond angle. However, due to the increased bond length of the ${ }^{2} \mathrm{~A}_{2}$ state, the expected O-O distance at the inner turning point for $\mathrm{OClO}^{2} \mathrm{~A}_{2}$ bending is far too large to facilitate formation of an $\mathrm{O}=\mathrm{O}$ bond. This suggests that the $\mathrm{Cl}+\mathrm{O}_{2}$ dissociation process must also involve strong coupling with one of the excited states of OClO. Two states are possible-- the dark ${ }^{2} \mathrm{~B}_{2}$ 
and the, as yet unobserved, ${ }^{2} \mathrm{~A}_{1}$. Gole's calculations indicate equilibrium bond angles of $\sim 90^{\circ}$ for the ${ }^{2} B_{2}$; that of the ${ }^{2} A_{1}$ is near 120 degrees. Thus, coupling with the ${ }^{2} B_{2}$ is also likely to play an important role in the $\mathrm{Cl}+\mathrm{O}_{2}$ dissociation mechanism.

We believe that more analysis of the present datz combined the linewidth measurements will provide further insight into the photodissociation dynamics of OClO. We also hope that this work will inspire more detailed calculations on the $\mathrm{ClO}_{2}$ and $\mathrm{Cl}$ $+\mathrm{O}_{2}$ potential energy surfaces.

\section{CONCLUSIONS}

We have clarified a number of questions regarding the formation of $\mathrm{Cl}+\mathrm{O}_{2}$ in the collision free photodissociation of OClO. Our results indicate that the yield is only appreciable ( $>1 \%$ ) above $390 \mathrm{~nm}$. For a given energy, the yield of $\mathrm{Cl}+\mathrm{O}_{2}$ is always slightly greater under those lines corresponding to excitation of the symmetric bending motion, but is much smaller when exciting an asymmetric mode. The decrease in yield at shorter wavelengths or with asymmetric vibrational excitation likely results from faster predissociation to $\mathrm{ClO}+\mathrm{O}$. Suggested gas phase isomerization of $\mathrm{OClO}$ to $\mathrm{ClOO}$, based on the earlier matrix isolation results of Arkell, et al.,$^{13}$ appears to be inappropriate. Although a substantial amount of $\mathrm{O}_{2}$ is formed in the ground electronic state, there is strong evidence for a comparable yield for $\mathrm{O}_{2}\left({ }^{1} \Delta\right)$, the total reaching a maximum of $3.9 \pm 0.8 \%$ near $404 \mathrm{~nm}$.

According to Solomon, et al., ${ }^{4,12}$ a $100 \%$ quantum yield for $\mathrm{Cl}+\mathrm{O}_{2}$ across the entire $\mathrm{OClO}$ absorption spectrum could lead to up to $30 \%$ of the observed Antarctic 
ozone hole. Since we find that the quantum yield for $\mathrm{Cl}+\mathrm{O}_{2}$ in the collision free photodissociation of $\mathrm{OClO}$ is not only small, but only extends over a relatively narrow portion of the absorption spectrum, we conclude that $\mathrm{OClO}$ photodissociation in the gas phase plays a very minor role in the depletion of ozone currently seen in Antarctica. Further details regarding the mode specificity in the dynamics, complete yields of $\mathrm{Cl}+$ $\mathrm{O}_{2}$ as a function of wavelength, and approximate $\mathrm{ClO}$ vibrational energy distributions will be presented in a forthcoming article. ${ }^{24}$

\section{REFERENCES}

1. Molina, M.J.; Rowland, F.S., Nature, 1974, 249, 810.

2. Farman, J.C.; Gardiner, B.G.; Shanklin, J.D., Nature, 1981, 294, 733.

3. Stolarski, R.S.; Kreuger, A.J. Schoeberl, M.R., McPeters, R.D., Newman, P.A., Alpert, J.C., Nature, 1986, 322, 808.

4. a) Solomon, S., Sanders, R.W., Miller, H.L.,Jr., J. Geophys. Res. 1990, 95,D9, 13,807 , and Refs. therein.

b) Solomon, S., Sanders, R.W., Carroll, M.A., Schmeltekopf, A.L., J. Geophys. Res., 1989, 94, 11,393.

c) Solomon, S. Mount, G.H., Sanders, R.W., Schmeltekopf, A. L., J. Geophys., Res., 1987, 92, D7, 8329.

5. Hamill, P.; O.B. Toon, Physics Today, 1991, 44(12), 34., and Refs. therein.

6. Anderson, J.G., Toohey, D.W., Brune, W.H., Science, 1991, 251, 39., and 
Refs. therein.

7. Brune, W.H., Anderson, J.G., Toohey, D.W., Fahey, D.W., Kawa, S.R., Jones, R.L., McKenna, D.S., Poole, L.R., Science, 1991, 252, 1260.

8. Sander, S.P., Friedl, R.R., J. Phys. Chem., 1989, 93, 4764.

9. Turnipseed, A.A., Birks, J.W., Calvert, J.G., J. Phys. Chem., 1991, 954356.

10. Hills, A.J., Cicerone, R.J., Calvert, J.G., Birks, J.W., Nature, 1987, 328, 405.

11. Ruhl, E.; Jefferson, A.; Vaida, V.; J. Phys. Chem., 1990, 94, 2990.

12. Vaida, V.; Solomon, S.; Richard, E.C.; Ruhl, E.; Jefferson, A. Nature, 1989, 342,405 .

13. Arkell, A.; Schwager, I.; J. Am. Chem. Soc., 1967, 89(24), 5999.

14. Gole, J.L.; J. Phys. Chem. 1980, 84, 1333, and references therein.

15. Lawrence, W.G.; Clemitshaw, K.C.; Apkarian, V.A. J. Geophys. Res., 1990, 95(Di1) 18,591 .

16. Bishenden, E.; Haddock, J.; Donaldson, D.J. J. Phys. Chem., 1991, 95, 2113.

17. Richard, E.C.; Vaida,V. J. Chem. Phys, 1991, 94(1), 153, and Refs. therein.

18. Richard, E.C.; Vaida, V. J. Chem. Phys., 1991, 94(1), 163.

19. Richard,E.C.; Wickham-Jones, C.T. ;Vaida, V. J. Phys. Chem., 1989, 93, 6346.

20. JANAF thermochemical Tables, 3rd ed, J. Phys. Chem. Ref. Data, 1985i, Supp. 1,14 .

21. Michielsen, S. Merer, A.J., Rice, S.A., Novak, F.A., Freed, K.F., Klamada, Y., J. Chem. Phys., 1981, 74, 3089. 
22. Wahner, A.; Tyndall, G.S.; Ravishankara, A.R.; J. Phys. Chem. 1987, 91, 2734.

23. a) Wodtke, A.M.; Lee, Y.T; J. Phys. Chem. 1985, 89, 4744.

b) Minton, T.K.; Nathanson, G.M.; Lee, Y.T.; J. Chem. Phys. 1987, 86(4), 1991.

24. Davis, H.F.; Lee, Y.T., to be published.

25. Renard, J.J.; Bolker, H.I.; Chemical Reviews, 1976, 76(4), 487.

26. In the OClO experiments, we found that the $\mathrm{ClO}$ fragment TOF spectra measured at both $\mathrm{ClO}^{+}$and $\mathrm{Cl}^{+}$had identical shapes. This indicates that the $\mathrm{ClO}$ fragmentaticn pattern to $\mathrm{Cl}^{+}$is not sensitive to its vibrational level for $\mathrm{v}^{\prime}=1-5$.

27. Fluorescence observed at longer wavelengths (Ref. 28) should be negligible at these energies.

28. Curl, R.F. Jr.; Abe, K.; Bissinger, J; Bennett, C.; Tittel, F.K.; J. Mol. Spect., $1973,48,72$.

29. We used the following room temperature values from Refs. 16, 22, and 30: $362 \mathrm{~nm}-\mathrm{I}_{C V O C 10}: \mathrm{I}_{\mathrm{CVCL}}-10 ., \sigma_{\mathrm{OClO}}=2.4 \times 10^{-18} \mathrm{~cm}^{2} ; \sigma_{\mathrm{cL}}=1.2 \times 10^{-19} \mathrm{~cm}^{2}, \phi_{\mathrm{CUCL}}=2.0$

30. Watson, R.R. J. Phys. Chem. Ref. Data, 1977, 6, 871.

31. Dunn, R.C.; Richard, E.C.; Vaida, V.; Simon, J.D. J. Phys. Chem. 1991, 95, 6060.

32. Nicovich,J.M.; Kreutter,K.D.; Shackelford,C.J.; Wine, P.H.; Chem.Phys. Lett., 1991, 179(4), 367.

33. Harris, A., Berg, M. Harris, C., J. Chem. Phys., 1986, 84, 788. 


\section{FIGURE CAPTIONS:}

Fig.1: Energy level diagram for $\mathrm{OClO}$ and possible photodissociation products.

Fig.2: OClO absorption spcctrum (204K), from Ref. 12. Vibrational assignments from Ref. 1.

Fig.3: Newton diagram in velocity space for Cl-containing fragments from OClO photodissociation at $404 \mathrm{~nm}$. Arrow denotes initial OClO beam velocity, and circles are calculated recoil velocities for formation of ground vibrational state fragments.

Fig.4: Product time-of-flight spectra $\left(20^{\circ}\right)$ recorded at $\mathrm{m} / \mathrm{e}=35\left(\mathrm{Cl}^{+}\right)$from indicated OClO vibrational levels. Inset shows expanded vertical scale $(x 15)$ to reveal structure in $\mathrm{Cl}+\mathrm{O}_{2}$ channel. $\mathrm{Cl}+\mathrm{O}_{2}$ yields are also indicated. ... Experimental Data. - - Optimized fit.

Fig.5: Time-of-flight spectra $\left(40^{\circ}\right)$ for the $\mathrm{O}_{2}$ and $\mathrm{O}$ atom channels recorded at $\mathrm{m} / \mathrm{e}=32$ $\left(\mathrm{O}_{2}{ }^{+}\right)$, and $\mathrm{m} / \mathrm{e}=16\left(\mathrm{O}^{+}\right)$, from $(5,1,0)$ level. Contribution to $\mathrm{O}^{+}$from fragmentation of $\mathrm{O}_{2}$ is negligible and contribution from $\mathrm{ClO}$ is broad peak at $\mathrm{T}=350-600 \mu \mathrm{sec}$.

-.. - Experimental Data. - - Optimized fits based on Fig. 6.

Fig.6: Translational energy distributions for $\mathrm{Cl}\left({ }^{2} \mathrm{P}\right)+\mathrm{O}_{2}$ and $\mathrm{O}(\mathrm{P})+\mathrm{ClO}$ channels from $(5,1,0)$ level. The calculated maximum relative transiational energies for production of internally excited diatomics are indicated.

Fig.7: OClO Absorption Spectrum, taken from Ref. 22. Also indicated are quantum yields for the $\mathrm{Cl}+\mathrm{O}_{2}$ channel from preliminary analysis of the data. 


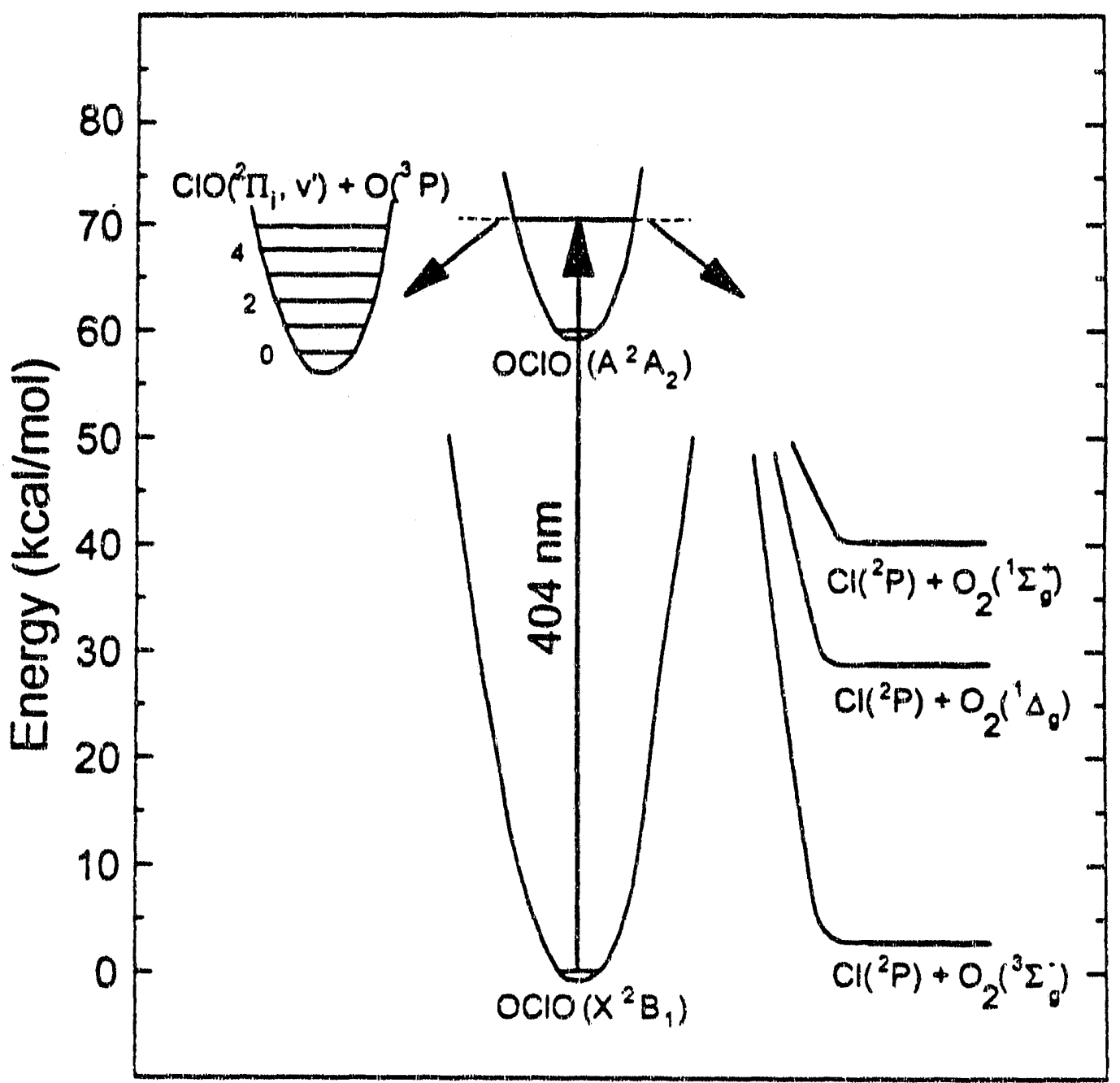

Fig. 1 

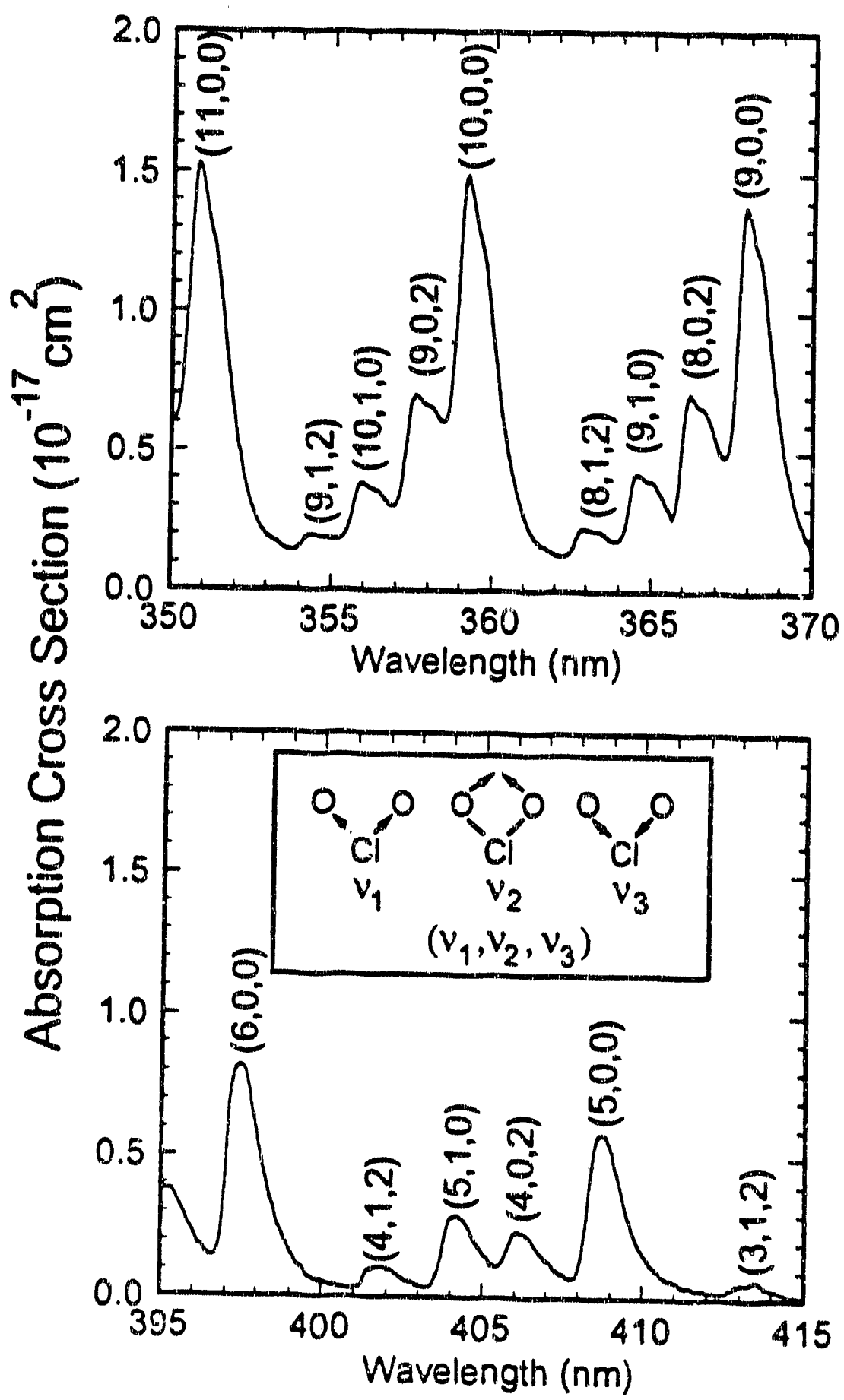

Fig. 2 


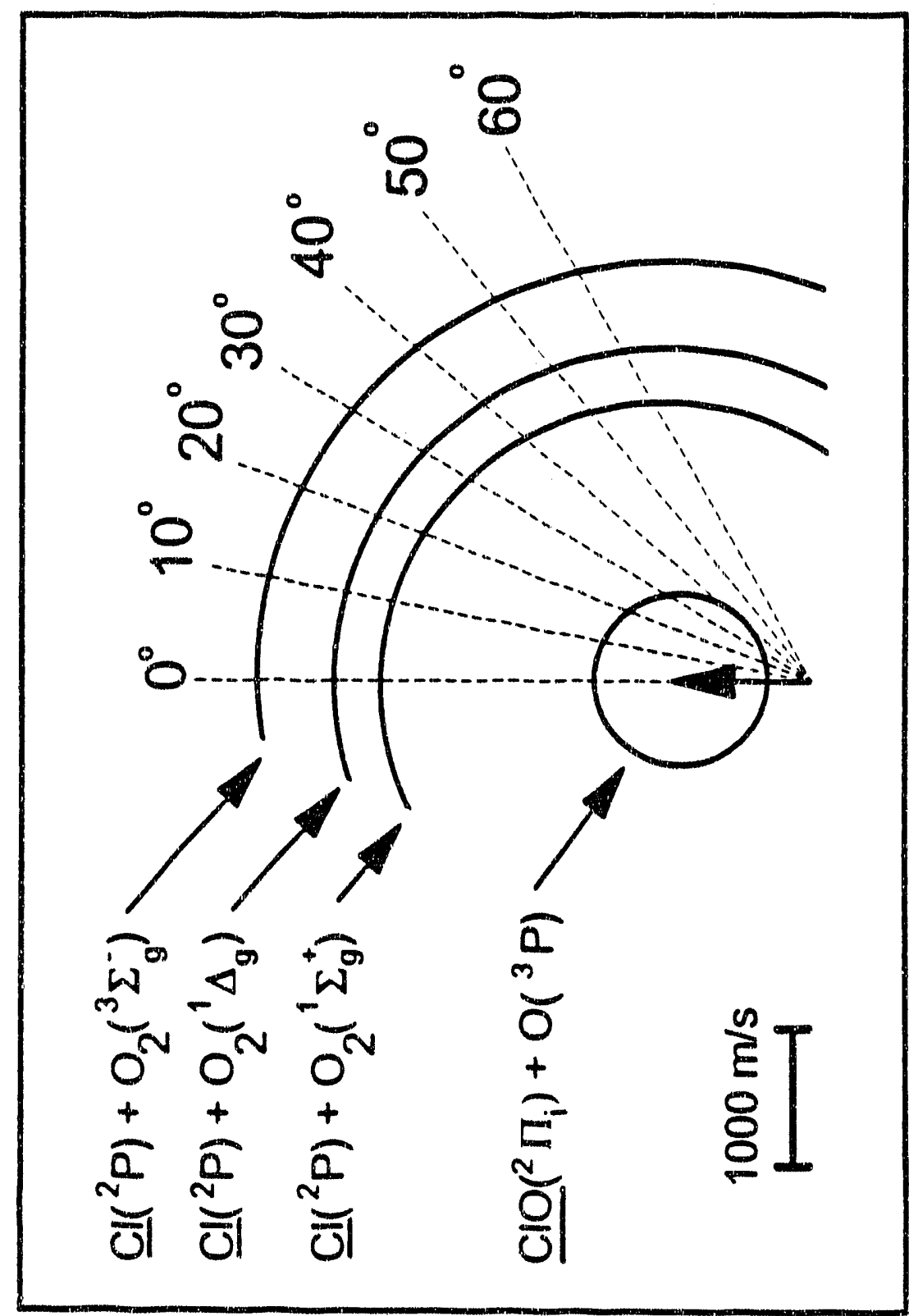

$\underset{m}{m}$ 


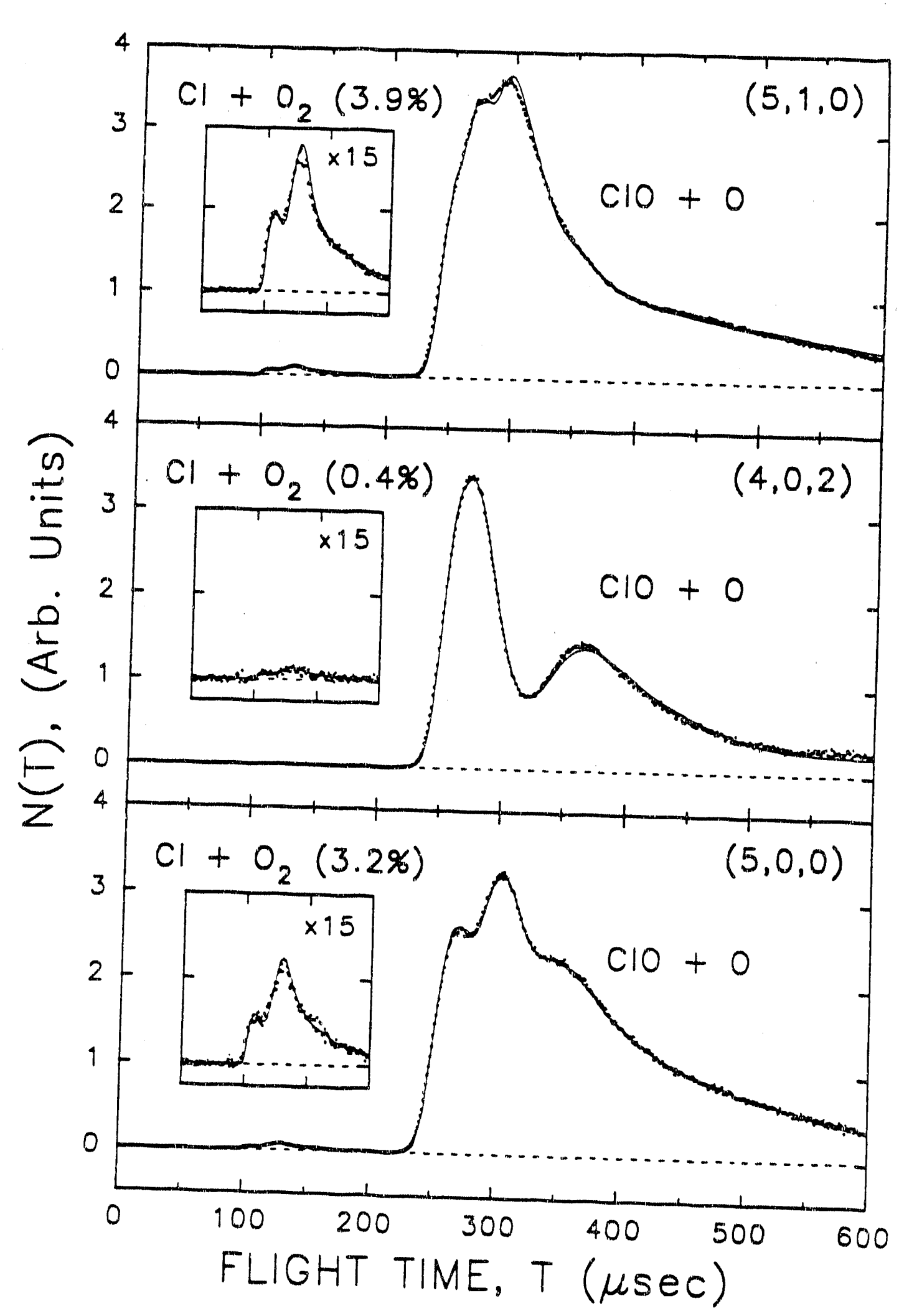

309

Fig. 4 


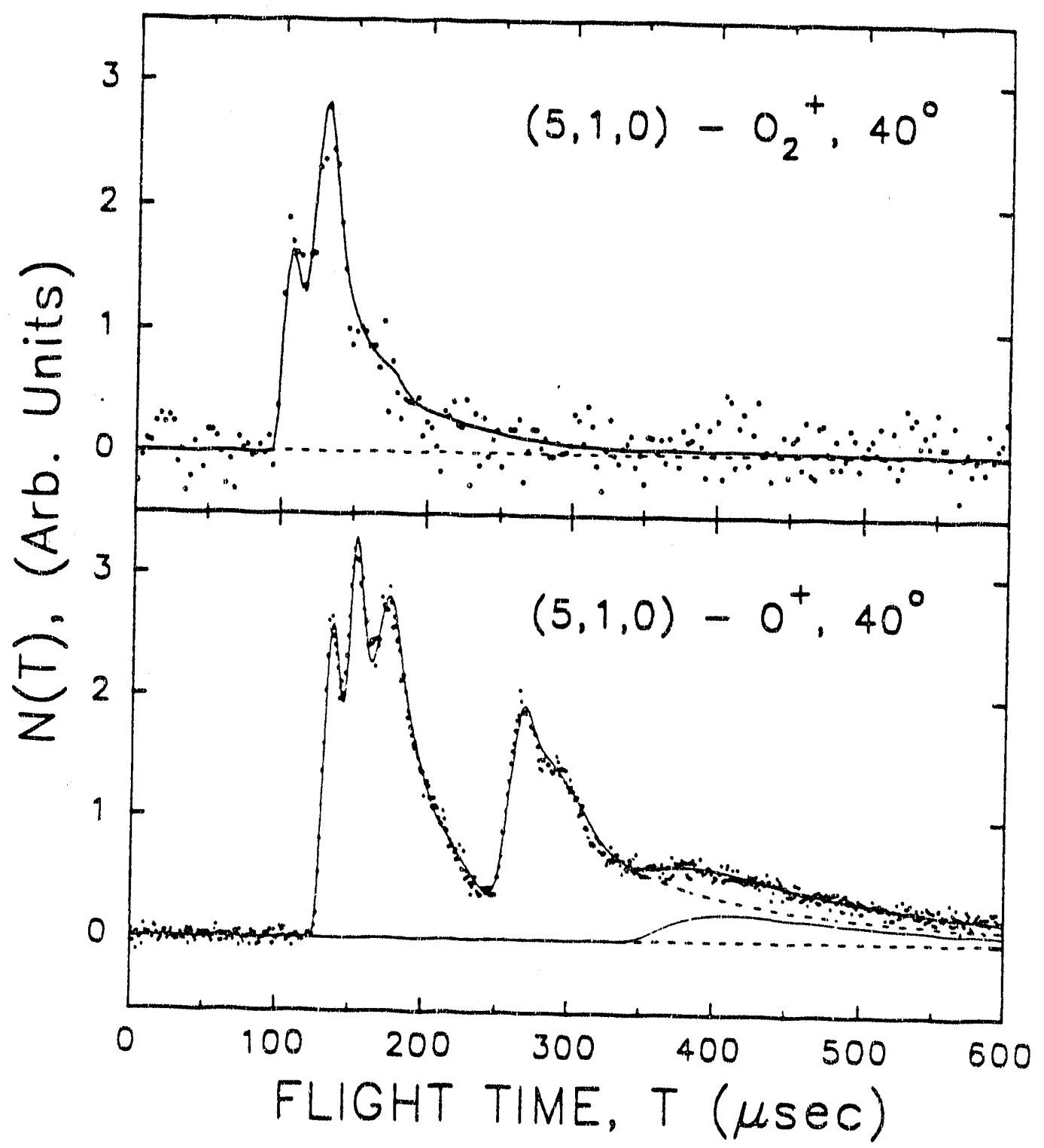

Fig. 5 

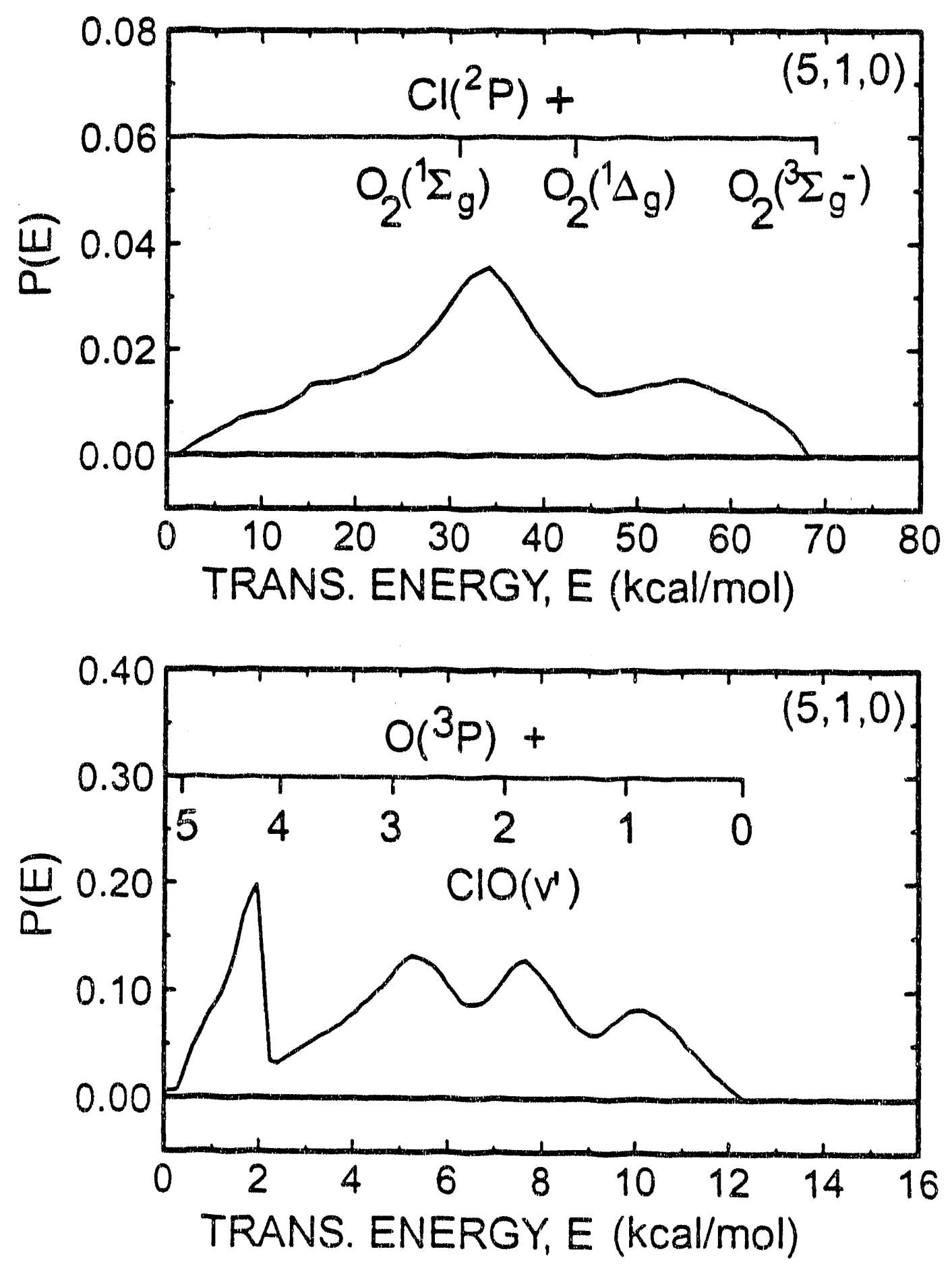

Fig. 6 


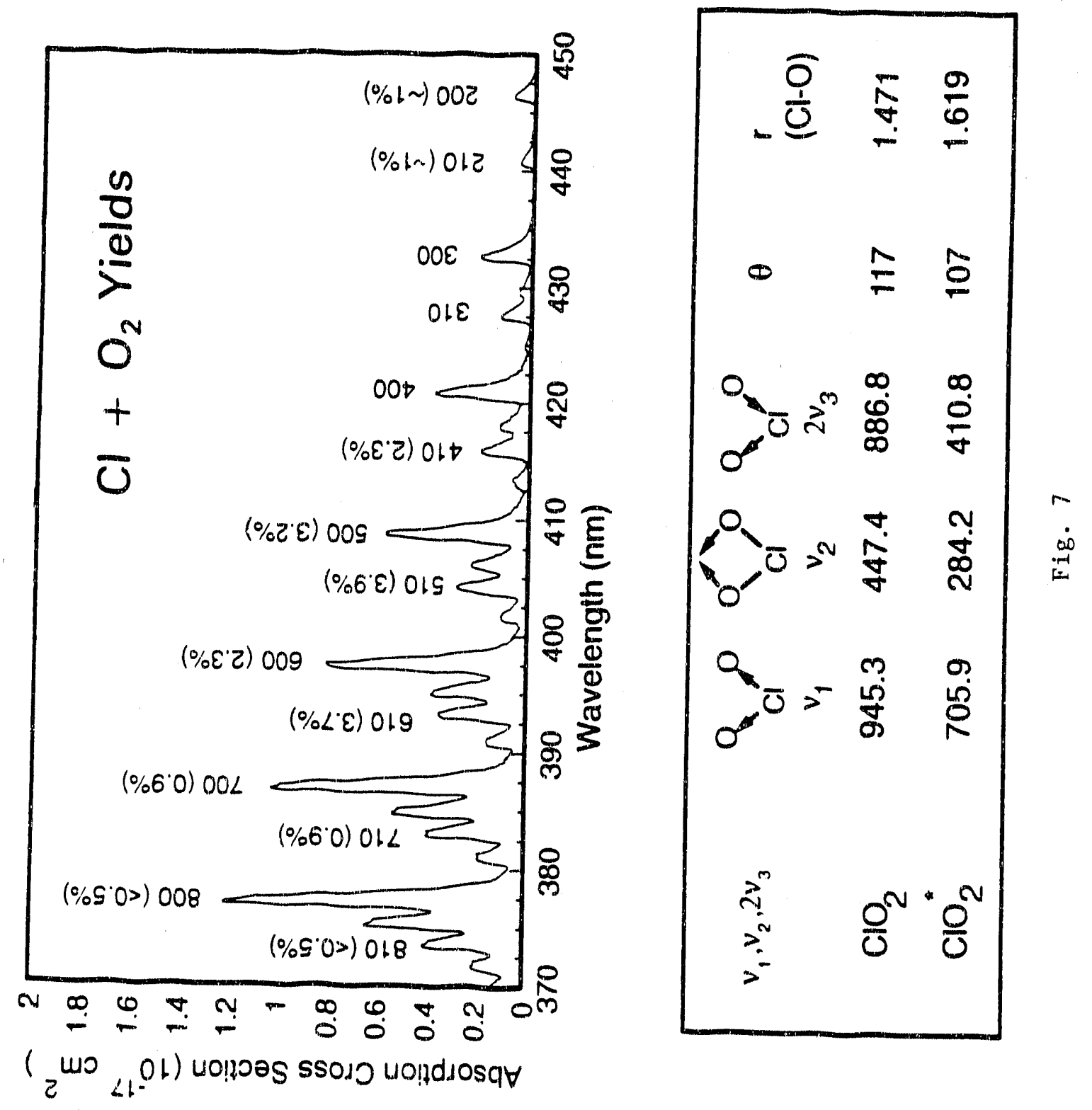



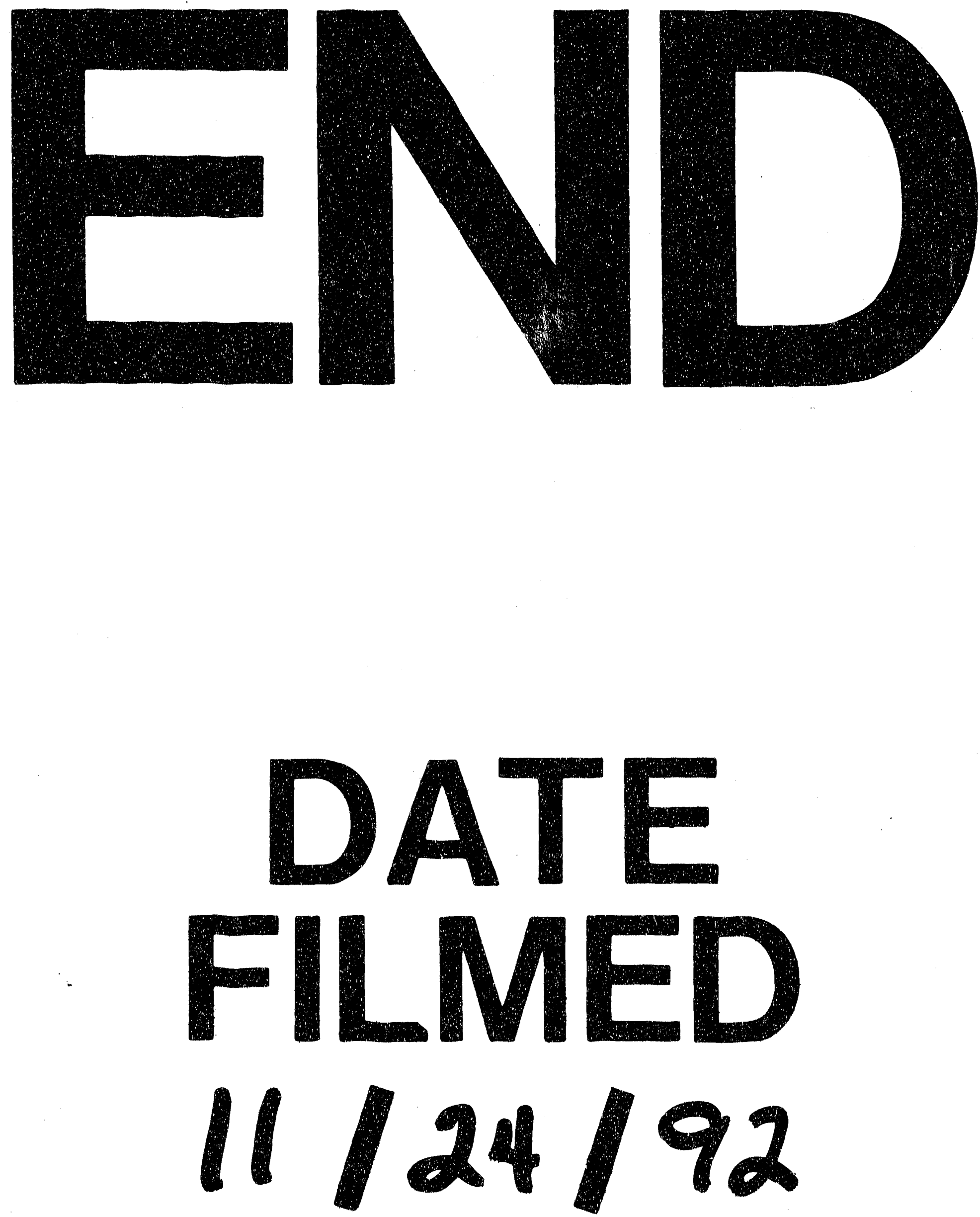
